Para citar o enlazar este recurso, use: https://doi.org/10.24275/uama.6735.7459

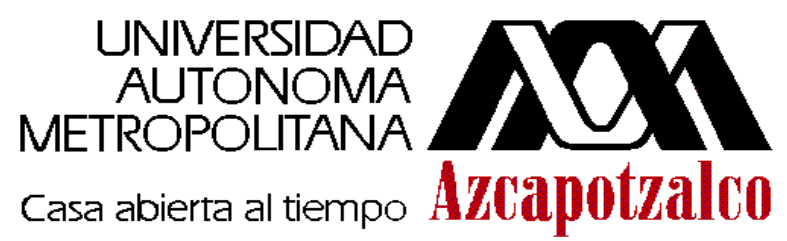

DIVISIÓN DE CIENCIAS BÁSICAS E INGENIERÍA DOCTORADO EN CIENCIAS E INGENIERÍA AMBIENTALES

\title{
DEGRADACIÓN DEL 2,5-DCP EN AGUA DESTILADA Y EN AGUA RESIDUAL POR LOS PROCESOS DE OXIDACIÓN AVANZADA CON OZONO Y OZONO-UV COMBINADOS CON UN TRATAMIENTO BIOLÓGICO.
}

\section{TESIS DE DOCTORADO}

\author{
PRESENTA:
}

M. en C.I.A. JACQUELINE CATHERINE ALEXANDER

ASESORA

DRA. CLEMENTINA RITA RAMÍREZ CORTINA 


\section{CONTENIDO}

\begin{tabular}{lr}
\hline AGRADECIMIENTOS & $\mathrm{VII}$ \\
DEDICATORIA & $\mathrm{IX}$ \\
RESUMEN & $\mathrm{X}$ \\
ABSTRACT & $\mathrm{XI}$ \\
ÍNDICE DE TABLAS & $\mathrm{XII}$ \\
ÍNDICE DE FIGURAS & $\mathrm{XV}$ \\
ÍNDICE DE GRÁFICAS & $\mathrm{XVIII}$ \\
CAPÍTULO 1. INTRODUCCIÓN & 1 \\
REFERENCIAS & 7
\end{tabular}

CAPÍTULO 2. MARCO TEÓRICO 11

2.1. Antecedentes de la Investigación 11

2.2. El Diclorofenol Estudiado 12

2.2.1. Toxicidad en animales 13

2.2.2. Toxicidad y efectos en la salud humana 14

2.3. Los Procesos de Oxidación Avanzada 15

2.3.1. Oxidación en agua supercrítica 18

2.3.2. Irradiación ultrasónica 21

2.3.3. La oxidación por vía húmeda 24

2.3.4. Procesos del reactivo Fenton y Foto-Fenton 29

2.3.5. Ultravioleta con peróxido de hidrógeno 32

2.3.6. Ozonización con peróxido de hidrógeno 33

2.3.7. Oxidación fotocatalítica 34

2.3.8. Procesos de fotólisis 36

2.3.9. Proceso de oxidación con ozono

2.3.10. Fotólisis de ozono $\left(\mathrm{O}_{3}-\mathrm{UV}\right) \quad 47$

2.4. Cinética y Mecanismos de Reacción de los Diclorofenoles 51

2.5. Transferencia de Masa $\quad 56$

2.5.1. Transferencia de gas-líquido aplicada a ozono en agua 56

2.5.2. Tipos de reactores para el tratamiento de aguas residuales $\quad 59$

2.5.3. Determinación de coeficiente de la transferencia de masa de ozono indirectamente 60

$\begin{array}{ll}\text { 2.6. Tratamientos Biológicos } & 64\end{array}$

2.6.1. Procesos aerobios $\quad 64$

2.6.2. Tipos de biorreactores 65

Los biorreactores pueden operar de tres formas $\quad 65$

Jacqueline C. Alexander I 
2.6.3. Velocidad de utilización de oxígeno en los microorganismos 66

2.6.4. Rol de los microorganismos

2.6.5. Tipo de microorganismos presentes en los lodos activados 67

2.6.6. Identificación de los microorganismos 68

2.6.7. Microorganismos importantes en la degradación de compuestos fenólicos 70

$\begin{array}{ll}\text { 2.7. Pruebas de Toxicidad } & 76\end{array}$

$\begin{array}{ll}\text { REFERENCIAS } & 79\end{array}$

CAPÍTULO 3. HIPÓTESIS Y OBJETIVOS

\begin{tabular}{lr}
3.1. & Hipótesis \\
\hline
\end{tabular}

$\begin{array}{lr}\text { 3.2. Objetivos } & 97\end{array}$

3.2.1. Objetivo General $\quad 97$

3.2.2. Objetivos Específicos $\quad 98$

$\begin{array}{ll}\text { REFERENCIAS } & 99\end{array}$

CAPÍTULO 4. METODOLOGÍA 100

4.1. Desarrollo experimental 100

4.2. Procesos de Oxidación con ozono y ozono-UV 102

4.2.1.1. Preparación de la solución tóxica de 2,5-diclorofenol 102

4.2.1.2. Solución de 2,5-DCP en agua destilada (S1) 102

4.2.1.3. Solución de 2,5-DCP en agua residual (S2) 102

4.2.2. Descripción del proceso de oxidación 103

$\begin{array}{ll}\text { 4.3. Métodos Analíticos } & 104\end{array}$

4.3.1. Determinación de la Demanda Química de Oxígeno 104

4.3.2. Determinación de Carbono Orgánico Total 105

4.3.3. Determinación de Demanda Bioquímica de Oxígeno 105

4.3.4. DBO Método Respirométrico 105

4.3.4.1. Principio del método 105

4.3.4.2. Preparación del Inóculo de microorganismos 106

4.3.5. Cromatografía Líquida de Alta Precisión 106

4.3.6. Cromatografía de Gases acoplado a Espectrometría de masas 106

$\begin{array}{ll}\text { 4.3.6.1. Preparación de muestras de GC-MS } & 107\end{array}$

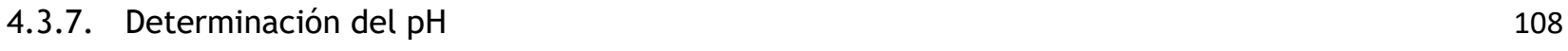

$\begin{array}{lll}\text { 4.3.8. } & \text { Espectrofotometría } & 108\end{array}$

$\begin{array}{ll}\text { 4.3.9. Conductividad eléctrica } & 108\end{array}$

$\begin{array}{ll}\text { 4.4. Método de las Pruebas de Toxicidad } & 108\end{array}$

4.4.1. Método de las pruebas de respirometría $\quad 109$

4.4.1.1. Preparación de la solución nutritiva para alimentar los biorreactores 110

Jacqueline C. Alexander II 
4.4.2. Centrifugado de los lodos

4.5. Tratamiento y análisis de las soluciones acuosas

4.5.1. Identificación de los microorganismos

4.5.1.1. Métodos basados en Criterios Morfológicos

4.5.1.2. Métodos basados en Tinción Diferencial

4.5.2. Cuantificación de los Microorganismos

4.5.3. Determinación de aniones

4.5.6. Determinación de sólidos suspendidos totales

4.5.7. Determinación de oxígeno disuelto

4.5.8. Determinación de la velocidad de utilización de oxígeno

4.5.9. Cálculo de la Velocidad específica de utilización de oxígeno

4.5.10. Determinación del Índice Volumétrico de Lodos

4.5.11. Coeficiente de transferencia gas/líquido en el reactor $\quad 124$

4.5.12. Reactor Biológico semi-continuo 125

4.5.12.1. FASE I de los experimentos de los biorreactores 126

4.5.12.2. Reactores de lodos adaptados 127

4.5.12.3. Procedimiento de Bioensayo en soluciones preozonizadas 130

4.5.12.4. Pruebas de Biodegradabilidad - Fase II 132

4.5.12.5. Prueba de Biodegradabilidad con Unidad Husmann 134

$\begin{array}{ll}\text { 4.6. Reactivos } & 137\end{array}$

$\begin{array}{ll}\text { 4.7. Diseño de Experimentos } & 138\end{array}$

$\begin{array}{ll}\text { REFERENCIAS } & 139\end{array}$

CAPÍTULO 5. RESULTADOS Y DISCUSIÓN 141

5.1. Transferencia de Masa en el Reactor 142

5.1.1. Determinación indirecta del coeficiente volumétrico de transferencia de ozono 142

5.1.2. Cálculos del coeficiente de transferencia gas/líquido 144

5.1.3. Discusión sobre la transferencia gas/líquido 148

\subsection{Procesos de Oxidación Avanzada con Ozono y Radiación UV 149}

5.2.1. Análisis del agua residual 151

5.2.2. Discusión sobre el cambio de pH durante la ozonación de agua residual 152

5.2.3. Resultados de las pruebas de oxidación con agua residual 153

5.2.4. Discusión sobre la remoción de la DQO durante la ozonación del agua residual 153 
5.2.5. Pruebas de oxidación del 2,5-DCP

5.2.5.1. Variación del color durante las pruebas de oxidación del 2,5-DCP 154

5.2.6. Discusión sobre la variación del color durante los procesos de oxidación 156

5.2.7. Cambios del pH durante la oxidación del 2,5-DCP 157

5.2.8. Discusión sobre los cambios del pH durante los tratamientos de oxidación 158

5.2.9. Eficiencia de la oxidación del 2,5-DC medida como DQO 159

5.2.10. Discusión sobre la eficiencia de la eliminación de DQO 161

5.2.11. Relación entre el consumo de ozono y la remoción de DQO 161

5.2.12. Discusión sobre el consumo de ozono y la remoción de DQO 163

5.2.13. Resultados del espectro de absorción (UV-Vis) 165

5.2.14. Discusión sobre los resultados del espectro de absorción (UV-Vis) 167

5.2.15. Evolución de la DBO en la degradación del 2,5-DCP en los POA 168

5.2.16. Biodegradabilidad del 2,5-DCP 170

5.2.17. Discusión sobre la biodegradación del 2,5-DCP 171

5.2.18. Eficiencia de los POAs en la eliminación de Carbono Orgánico Total 172

5.2.19. Discusión sobre la eficiencia de los POAs en la eliminación de Carbono Orgánico Total 172

5.2.20. Cambio en estado de Oxidación del DCP 173

5.2.21. Discusión sobre el Cambio en el estado de Oxidación 174

5.2.22. Degradación del 2,5-DCP 175

5.2.23. Discusión de la degradación del 2,5-DCP 177

5.2.24. Decloración del 2,5-DCP y sus productos intermedios 178

5.2.25. Discusión sobre la degradación del DCP y la Decloración 180

\subsection{Cinética y Mecanismos de Reacción de la Oxidación del 2,5-DCP 182}

5.3.1. Estudio de la cinética de la oxidación del 2,5-DCP 182

5.3.1.1. Constantes de la velocidad de reacción de la DQO 182

5.3.2. Discusión sobre los resultados de la cinética de la DQO 184

5.3.2.1. Constantes de la velocidad de reacción del COT 184

5.3.3. Discusión sobre la constante cinética del COT 185

5.3.3.1. Constantes de la velocidad de reacción del 2,5-DCP 185

5.3.4. Discusión sobre la constante cinética de la oxidación del 2,5-DCP 186

5.3.5. Determinación de la constante de disociación del 2,5-DCP 187

5.3.6. Discusión sobre la constante de disociación del 2,5-DCP 189

5.3.7. Discusión sobre los productos intermedios de la degradación de 2,5,DCP por reacción con ozono y ozono-UV 195

5.3.8. Mecanismo de reacción del 2,5-DCP 196

$\begin{array}{ll}\text { 5.4. Pruebas de Toxicdad } & 196\end{array}$

Jacqueline C. Alexander IV 
5.4.1. Los cambios en Toxicidad durante los Tratamientos con $\mathrm{O}_{3}$ y $\mathrm{O}_{3}$-UV 196

$\begin{array}{ll}\text { 5.4.1.1. Pruebas de toxicidad del 2,5-DCP sin tratamiento } & 197\end{array}$

5.4.1.2. Pruebas de toxicidad después de la ozonación 198

5.4.1.3. Pruebas de toxicidad después de la ozonación -UV 198

5.4.2. Discusión sobre las Pruebas de Toxicidad 199

5.5. Evaluación de los Procesos Biológicos 200

5.5.1. FASE 1: Evaluación de la eficiencia de los biorreactores de agitación SBR 201

5.5.1.1. Observación Microscópica de los microorganismos 201

5.5.1.2. Discusión de la observación microscópica 204

5.5.1.3. Observaciones macroscópicas $\quad 204$

5.5.1.4. Recuento de microorganismos 204

5.5.2. Discusión sobre el recuento de colonias 205

5.5.2.1. Crecimiento en agar cetrimida: 206

5.5.2.2. Discusión sobre del crecimiento en agar cetrimida 206

5.5.2.3. Pruebas Bioquímicas 206

5.5.2.4. Discusión sobre las Pruebas bioquímicas 207

5.5.2.5. Comportamiento físico-químico de los reactores. 208

5.5.2.6. Discusión sobre la Demanda Química de Oxígeno 217

5.5.2.7. Demanda Química de Oxígeno de los reactores con solución pre-ozonizada. 217

5.5.2.8. Análisis del comportamiento de la DQO en los biorreactores con solución pretratada 218

5.5.3. FASE 2: Evaluación de los biorreactores de agitación para biodegradar solución pretratada con ozono y ozono-UV 219

5.5.3.1. Observación Microscópica de los microorganismos 219

5.5.3.2. Observación macroscópica y cuenta de colonias 220

5.5.3.3. Discusión sobre la concentración de bacterias en los reactores 220

5.5.3.4. Identificación de bacterias 221

5.5.3.5. Discusión sobre los resultados obtenidos en la Fase II: de los biorreactores. 222

5.5.4. FASE 3: Evaluación de los biorreactores Husman adaptados (BHA) para degradar las soluciones pretradas con ozono y ozono-UV. 223

5.5.4.1. Demanda química de oxígeno de los biorreactores Husman adaptados (BHA) 223

5.5.4.2. Caracterización y aislación de Pseudomonas sp. 226

5.5.5. Discusión sobre los resultados de FASE 3: de los biorreactores Husmann 228

5.6. Análisis estadístico de los resultados $\quad 229$

5.6.1. Análisis de varianza de un factor - Biodegradabilidad del 2,5-DCP en S1: con agua destilada con tratamientos de POA (ozono y ozono-UV) 
5.6.2. Análisis de varianza de un factor - Biodegradabilidad de 2,5-DCP en S2: con agua residual con tratamientos de POA

5.6.3. Análisis de varianza de dos factores con una sola muestra por grupo -Biodegradabilidad de 2,5DCP con tratamientos de POA ( $\mathrm{O}_{3}$ y $\mathrm{O}_{3}$-UV) en las soluciones ( $\mathrm{S} 1$ y $\mathrm{S} 2$ )

5.6.4. Prueba t para medias de dos muestras emparejadas -Biodegradabilidad de 2,5-DCP con tratamientos de POAs $\left(\mathrm{O}_{3}\right.$ y UV) en las soluciones ( $\left.\mathrm{S} 1\right)$

ANEXOS

ANEXO A. 


\section{AGRADECIMIENTOS}

En primer lugar quiero dar gracias a Dios por darme el conocimiento y la fuerza para terminar mi tesis.

Mi profundo gratitud a la Dra. Clementina R. Ramírez Cortina por el asesoramiento, apoyo, orientación y por siempre estar disponible para ayudarme. Mil gracias, sin su ayuda hubiera sido difícil realizar satisfactoriamente este trabajo.

Al Dr. Isaías Hernández, le doy las gracias por su apoyo en todas las fases de esta investigación y por facilitarme el uso de sus equipos.

También agradezco al Dr. Victor luna Pabello, al M. en C. Luciano Hernández Gómez, a la Técnica Laura y a las demás personas del Laboratorio de Microbiología Experimental de la UNAM, por su apoyo durante la fase de los estudios de microbiología e identificación de los compuestos intermediarios.

Al Dr. Luis Carlos Fernandez Linares de UPIBI- Instituto Politécnico Nacional por prestarme sus equipos, muchísimas gracias.

A la M. en C. Sandra García de UPIBI- Instituto Politécnico Nacional, por estar siempre dispuesta a apoyarme en todo, eres una buena amiga, mil gracias.

Al Técnico Mario A. Rocha Pérez y al Departamento de Sistemas por su apoyo en la construcción de las unidades de Husman.

A Departamento de Energía por prestarme los recursos necesarios para terminar mis experimentos y a los técnicos de laboratorio de Docencia y a mis colegas por su apoyo.

A los coordinadores y a Xochitl del Laboratorio de Tecnologías Sustentables por prestarme su equipo.

A la Dra. Icela Baceló por prestarnos su equipo de laboratorio. 
Al Dr. Mario Romero Romo, Dra. Violeta Mugica y miembros del Comité de Posgrado en Ciencias e Ingeniería Ambientales y a todos los demás que me ayudaron en esta investigación con sus valiosos comentarios.

A los miembros del Jurado evaluador, quienes revisaron mi tesis, muchísimas gracias por sus valiosos comentarios.

A mis compañeros de laboratorio: Alma, Araceli, Gerardo y Maritza, gracias por la convivencia.

Un agradecimiento especial al personal encargado de la Planta de Tratamiento de Aguas Residuales (El Rosario) por su donación de agua residual y los lodos activados para hacer las pruebas de toxicidad.

Mi sincero agradecimiento al Consejo Nacional de Ciencia y Tecnología CONACYT por la beca que me otorgó y por darme la oportunidad de estudiar mi doctorado en la Universidad Autónoma Metropolitana, Muchas Gracias. 


\section{DEDICATORIA}

To my Mom lona Alexander, my first teacher, my loving family and my husband, Jesse for his patience, love and support.

In memory of my dad, Charles Alexander

Thanks for always believing in me.

(Feb1938 - Jan 2012).

"Timendi causa est nescire" - Seneca

"Ignorancia es la causa del miedo." 
En los últimos años la contaminación de los suministros de agua se ha incrementado debido a la descarga continua de las aguas residuales de las industrias químicas y farmacéuticas, sin tratamiento adecuado que eliminan los compuestos orgánicos recalcitrantes que contienen. Estos contaminantes ponen en peligro la calidad de las aguas superficiales y subterráneas, la salud de la población y dañan los ecosistemas.

En vista de estos problemas, en el presente trabajo se estudió la efectividad de la combinación de los procesos de ozono y ozono-UV con un proceso biológico para aumentar la biodegradabilidad y reducir los niveles de la toxicidad del 2,5-diclorofenol (2,5-DCP) y los compuestos intermedios generados durante la oxidación.

Se hizo un estudio comparativo en un reactor de columna equipado con un difusor de vidrio poroso de burbuja fina para aplicar el ozono con una transferencia de masa volumétrica kıa de 1.58 min- $^{1}$. En cada experimento se utilizó un volumen de $1.5 \mathrm{~L}$ con concentración de $3.07 \mathrm{mM}$ de 2,5-DCP en solución acuosa con agua destilada y con agua residual municipal, a un pH inicial de 7. Se usó una dosis de ozono aplicado de $22 \mathrm{mg} \mathrm{min}^{-1}$ con un flujo de gas de oxígeno-ozono de $0.7 \mathrm{~L} \mathrm{~min}^{-1}$. Además, se utilizó una lámpara de UV con longitud de onda de $254 \mathrm{~nm}$ para llevar a cabo los tratamientos con ozono-UV.

Los resultados obtenidos, mostraron que el 2,5-DCP se degrada completamente con una dosis de ozono de aproximadamente $1.2 \mathrm{~g} \mathrm{~h}^{-1}$ en las dos soluciones estudiados tratadas con ozono y ozonoUV. Los mejores resultado se obtuvieron con el proceso de ozono-UV después de 60 min en la solución acuosa de 2,5-DCP con agua residual, lo que muestra que la adición de fotólisis (intensidad

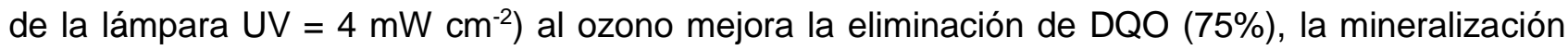
(53\%) y la biodegradabilidad (DBO5 / DQO) de 2,5-DCP de 0.2 a 0.85 .

La toxicidad del 2,5-DCP y sus productos intermedios se analizó para diferentes intervalos de tiempo con la prueba de inhibición de la respiración de lodos activados. Los análisis de la prueba de toxicidad mostraron que los tratamientos $\mathrm{O}_{3}$ y $\mathrm{O}_{3}-U V$ fueron eficaces en disminuir la toxicidad del 2,5-DCP y de sus productos intermedios, que fueron menos tóxicos para los microorganismos en el lodo activado $\left(\mathrm{IC}_{25}=125 \mathrm{mg} / \mathrm{L}\right)$, que el 2,5-DCP $\sin$ tratamiento $\left(\mathrm{IC}_{50}=50 \mathrm{mg} / \mathrm{L}\right)$. Los resultados de este trabajo muestran que la materia orgánica y la materia inorgánica presentes en el agua residual, tuvieron un efecto positivo sobre la oxidación del 2,5-DCP, lo que apoya el uso potencial de los procesos de ozono y ozono-UV para tratar efluentes contaminados con alta concentración de compuestos clorofenólicos. 


\section{ABSTRACT}

In recent years, there have been increases in contamination of water supplies, due to the continuous discharge of wastewater from chemical and pharmaceutical industries, without them being properly treated to remove the refractory organic compound they may contain. These contaminants endanger the quality of surface and groundwater, the ecosystems, and the health of the world's population.

In view of these problems, the present work examined the effectiveness of combining ozone and ozone-UV processes with a biological treatment to increase biodegradability and reduce toxicity levels of the chlorophenolic compound, 2,5-dichlorophenol (2,5-DCP) and its oxidative intermediates.

A comparative study was carried out in a glass bubble column reactor equipped with a fine-pore glass diffuser with a volumetric mass transfer $\mathrm{k}$ a of $1.58 \mathrm{~min}^{-1}$. Each experiment was done using a $1.5 \mathrm{~L}$ volume of 2,5-DCP (3.07 mM) aqueous solution of distilled water and municipal wastewater, at $\mathrm{pH} 7$ with an applied ozone dose of $22 \mathrm{mg} \mathrm{min}^{-1}$ and an oxygen-ozone flow rate of $0.7 \mathrm{~L} \mathrm{~min}^{-1}$. Additionally, a low mercury UV lamp with wavelength of $254 \mathrm{~nm}$ was used during ozone-UV treatments.

The results obtained, showed that 2,5-DCP was completed degraded with an ozone dose of approximately $1.2 \mathrm{~g} \mathrm{~h}^{-1}$ in both solutions, treated with ozone and ozone-UV processes. The best results were obtained with the ozone-UV processes after $60 \mathrm{~min}$ of oxidation, showing that the addition of photolysis treatment (UV lamp intensity $=4 \mathrm{~mW} \mathrm{~cm}^{-2}$ ) to ozone, accelerated COD removal (75\%), mineralization (53\%) and biodegradability (BOD $/ \mathrm{COD})$ of $2,5-\mathrm{DCP}$ from 0.2 to 0.85 in the wastewater.

The toxicity of 2,5-DCP and its oxidation by-products were monitored at different time intervals using activated sludge respiration inhibition tests. The test analyses showed that ozone and ozone-UV treatments were effective in reducing the toxicity of 2,5-DCP and its by-products, which were less toxic to the microorganisms in activated sludge $\left(\mathrm{IC}_{25}=135 \mathrm{mg} / \mathrm{L}\right)$, than the untreated $2,5-\mathrm{DCP}$ solutions $\left(\mathrm{EC}_{50}=50 \mathrm{mg} / \mathrm{L}\right)$.

The results achieved in this work, showed that the presence of organic and inorganic matters in the wastewater, had a positive effect on the oxidation of 2,5-DCP, which support the potential use of ozone and ozone-UV processes for the treatment of effluent with high concentration of chlorophenols. 


\section{ÍNDICE DE TABLAS}

Tabla 2-1 Principales tecnologías de los Procesos de Oxidación Avanzada. .....................17

Tabla 2-2 Radiación UV de diferentes Clorofenoles. (Benitez y col. [40]) ........................37

Tabla 2-3 Potenciales redox estandares de algunos oxidantes en medio ácido

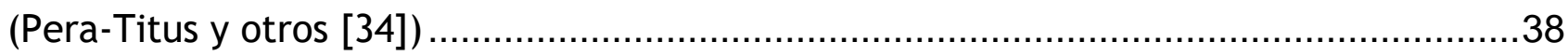

Tabla 2-4 Constantes de velocidad de reacción con $\mathrm{O}_{3}$ de ...............................................41

Tabla 2-5 Organismos indicadores que se encuentran en Lodos Activados [143, 144] ....69

Tabla 2-6 Lista de varios M.O. involucrados en la degradación de Fenol (Basha y col. [148]).

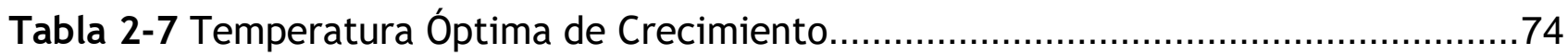

Tabla 2-8 Características Fenotípicas de especies de Pseudomonas [160-162] ................75

Tabla 2-9 Los valores de $\mathrm{EC}_{50}$ de algunos compuestos orgánicos usando diferentes pruebas

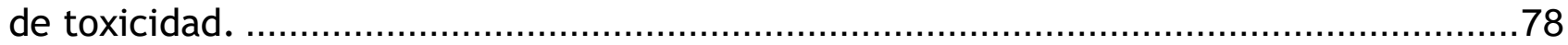

Tabla 4-1 Descripción de las Pruebas Bioquímicas de API 20 E y API 20 NE $[13,14] \ldots . . .121$

Tabla 4-2 Volumen a purgar y alimentar en cada ciclo durante la aclimatación.............129

Tabla 4-3 Fase I: Volumen a purgar y reemplazar durante cada ciclo $(\mathrm{mL})$..................131

Tabla 4-4 Fase 2: Volumen a remover durante cada ciclo $(\mathrm{mL})$..................................133

Tabla 5-1 Resultados de la transferencia de oxígeno y de ozono en el reactor..............147

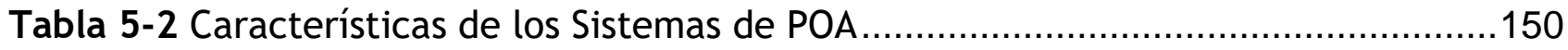

Tabla 5-3 Características Fisicoquímicas del Agua residual ........................................151

Tabla 5-4 Resultados de Agua residual tratada con ozonización con $0.5 \mathrm{~L} / \mathrm{min}$.............151

Tabla 5-5 Resultados de Agua residual tratada con ozonización con $0.7 \mathrm{~L} / \mathrm{min}$..............151

Tabla 5-6 Resultados de la DQO del agua residual con tratamiento de oxidación de

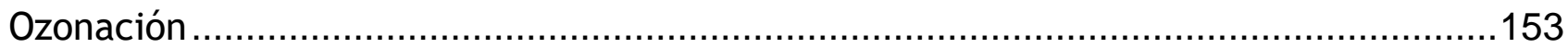

Tabla 5-7 Tratamiento con ozono. Valores de DQO y Desviación estándar en las soluciones de $\quad 2,5$-DCP en agua destilada (S1) y en agua residual (S2) ............................160

Tabla 5-8 Tratamiento con ozono-UV. Valores de DQO en las soluciones de 2,5-DCP en agua destilada (S1) y en agua residual (S2)

Tabla 5-9 Tratamiento con ozono. Relación entre la remoción de DQO $(\mathrm{mg} / \mathrm{L})$ y el consumo de ozono en la ozonación del 2,5-DCP (500 mg/L) en agua destilada y en agua residual 
Tabla 5-10 Tratamiento con ozono-UV. Relación entre la remoción de DQO (mg/L) y el ozono consumido en la oxidación del 2,5-DCP $(500 \mathrm{mg} / \mathrm{L})$ en agua destilada y en agua residual.

Tabla 5-11 Pruebas de $\mathrm{DBO}_{5}$ con una solución estándar de glucosa y ácido glutámico ..168 Tabla 5-12 Valores de la $\mathrm{DBO}_{5}$ y la desviación estándar de las pruebas del 2,5-DCP tratado con ozono en soluciones de S1: con agua destilada y en S2: con agua residual. 169

Tabla 5-13 Valores de la $\mathrm{DBO}_{5}$ y la desviación estándar de las pruebas de oxidación del 2,5-DCP en S1: con agua destilada y S2: con agua tratadas con ozono-UV 169

Tabla 5-14 Resultados de la degradación del 2,5-DCP en soluciones S1: con agua destilada y S2: con agua residual durante 60 minutos de tratamiento con $\mathrm{O}_{3}$ y $\mathrm{O}_{3}-\mathrm{UV}$ 176

Tabla 5-15 Resultados del estudio cinético de la DQO en la oxidación con $\mathrm{O}_{3}$ y $\mathrm{O}_{3}$-UV.. 183 Tabla 5-16 Resultados de la cinética del COT en la oxidación del 2,5-DCP en agua destilada (S1) y en agua residual (S2) tratada con $\mathrm{O}_{3}$ y $\mathrm{O}_{3}-\mathrm{UV}$. 185

Tabla 5-17 Resultados de la cinética del 2,5-DCP en agua destilada (S1) y en agua residual (S2) tratada con $\mathrm{O}_{3}$ y $\mathrm{O}_{3}-\mathrm{UV}$ 186

Tabla 5-19 Pruebas de Toxicidad del 2,5-DCP en lodos activados de cero a 60 min de tratamiento con $\mathrm{O}_{3}$ y $\mathrm{O}_{3} / \mathrm{UV}$ en soluciones $\mathrm{S} 1$ y $\mathrm{S} 2$ 199

Tabla 5-20 Distribución de colonias en dilución 205

Tabla 5-21 Resultados de las Pruebas bioquímicas de API 20E más características de especies de Pseudomonas 207

Tabla 5-22 Volumen ocupado por la fase de lodos y solidos suspendidas totales 211

Tabla 5-23 Índice Volumétrico de Lodos 212

Tabla 5-24 resultados de VUO y VUOS en el Reactor 1 213

Tabla 5-25 resultados de VUO y VUOS en el Reactor 2 214

Tabla 5-26 Resultados de VUO y VUOS en el Reactor 3 ...........................................214

Tabla 5-27 Demanda química de oxígeno en los reactores adaptados. 216

Tabla 5-28 Demanda química de oxígeno en los reactores con solución preozonizada ..218 Tabla 5-29 Distribución de colonias en dilución de los diferentes biorreactores: Fase II 220

Tabla 5-30 Resultados de las pruebas bioquímicas para identificar la cepa bacteriana 221 
Tabla 5-31 Demanda química de oxígeno eliminada en los biorreactores de agitación alimentada con solución de 2,5-DCP en S1: con agua destilada y en S2: con agua residual, pretratadas.

Tabla 5-32 Demanda química de oxígeno eliminada del reactor C1: con lodos del reactor R3 (adaptada a fenol) y alimentado con agua residual. 224 Tabla 5-33 Demanda química de oxígeno del reactor R30A: con solución pretratada ...224 Tabla 5-34 Demanda química de oxígeno del reactor R30B: con solución pretratada con 60 $\min$ de ozonación en agua residual $\mathbf{S 2 :} \mathrm{O}_{3}$ 225

Tabla 5-35 Demanda química de oxígeno del reactor R31A: con solución pretratada con 60 min de ozonación-UV en agua destilada S1: $\mathrm{O}_{3}-\mathrm{UV}$ 225

Tabla 5-36 Demanda química de oxígeno del reactor R31B: con solución pretratada ...226 Tabla 5-37 Distribución de colonias en dilución de los diferentes biorreactores en la Fase 3. 227

Tabla 5-38 Resultados de las pruebas bioquímicas para identificar la cepa bacteriana 227 Tabla 5-39 Factores de la prueba y la respuesta para el experimento 230

Tabla 5-40 Combinación de los tratamientos AOP .231

Tabla A-7-1 Datos de los ensayos 250

Tabla A-7-2 Resultados de los ensayos 250

Tabla A-7-3 Demanda química de oxígeno solubles en los reactores .251 


\section{ÍNDICE DE FIGURAS}

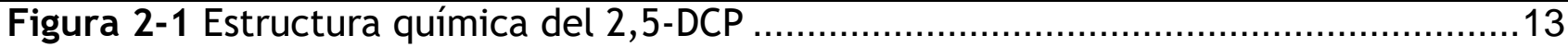

Figura 2-2 Reacciones de sustratos $(\mathrm{S})$ con $\mathrm{O}_{3}$ y la reacción de descomposición de $\mathrm{O}_{3}$ en pugna por consumo de $\mathrm{O}_{3}$ (Hoigné y Bader [38])

Figura 2-3 Esquema mostrando la descomposición del ozono iniciado por ion hidróxido en agua destilada; Glaze y col. [33]

Figura 2-4 Esquema de la teoría de la doble capa para la transferencia de gases (Roustan y col.) [127].

Figura 2-5 Fotografía al microscopio electrónico de trasmisión una célula de $P$. putida (tomadao de Harwood y col. [156]) .72

Figura 2-6 Cinética de Crecimiento Bacteriano .73

Figura 4-1 Diagrama de bloques de la metodología experimental. 101

Figura 4-2 Dispositivo experimental de la ozonación y con tratamiento ozono-UV (recuadro). 103

Figura 4-3 Esquema del dispositivo experimental de la ozonización . 104

Figura 4-4 Montaje de una prueba de respirometría 109

Figura 4-5 Diagrama de bloques del procedimiento de la prueba de respirometría 111

Figura 4-6 Dispositivo experimental: Reactor de columna de burbuja con a) agua destilada y. 125

Figura 4-7 Reactor biológico discontinuo secuencial. ...............................................126

Figura 4-8 Reactores con agitación completa (R1, R3, R4 y R2) ..............................127

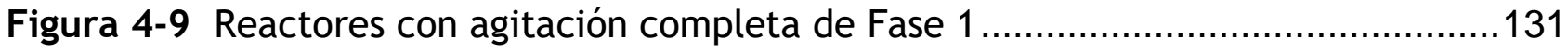

Figura 4-10 Reactores con agitación completa de Fase II..........................................134

Figura 4-11 Reactores de unidades de Husmann adaptadas (Foto) .............................136

Figura 4-12 Esquema del diapositivo experimental de tratamiento POA combinado con un

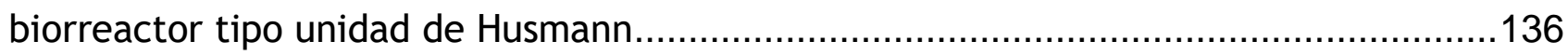

Figura 5-1 Cambios del color durante la ozonación del 2,5-DCP en agua destilada.......155

Figura 5-2 Cambios del color durante la ozonación del 2,5-DCP en agua residual .........155

Figura 5-3 Cambios del color durante la ozono-UV del 2,5-DCP en agua destilada........156

Figura 5-4 Cambios del color durante la ozono-UV del 2,5-DCP en agua residual ..........156

Figura 5-5 Análisis espectral de masas de 2,5-DCP ..................................................190 
Figura 5-6 Análisis espectral de masas de hidroquinona...........................................190

Figura 5-7 Distribución de compuestos intermedios a lo largo del tratamiento con ozonación en solución acuosa de 2,5-DCP en S1: con agua destilada $(\mathrm{pH} 7)$.

Figura 5-8 Distribución de compuestos intermedios a lo largo del tratamiento con ozonación en solución acuosa de 2,5-DCP en S2: con agua residual ( $\mathrm{pH} 7)$. 193

Figura 5-9 Distribución de compuestos intermedios a lo largo del tratamiento con ozonación-UV en solución acuosa de 2,5-DCP en S1: con agua destilada (pH 7) ..... 194

Figura 5-10 Distribución de compuestos intermedios a lo largo del tratamiento con ozonación-UV en solución acuosa de 2,5-DCP en S2: con agua residual $(\mathrm{pH} 7)$. 194

Figura 5-11 Observación microscópica (40X) de Reactor 1 (control) .............................202 Figura 5-12 Observación microscópica (40X) de Reactor 2 (Fenol /DCP) ......................202

Figura 5-13 Observación microscópica (40X) de Reactor 3 (Fenol)...............................203

Figura 5-14 Observación microscópica (40X) de Reactor 4 (DCP) …….......................203

Figura 5-15 Observación macroscópica de los diferentes reactores sobre agar de ........204

Figura 5-16 Observación macroscópica de los diferentes reactores .............................206

Figura 5-17 Resultados de las Pruebas Bioquímicas de API 20E de los reactores ...........207 Figura 5-18 Fotografía de la microscópica (40X) de las muestras tomadas de los biorreactores de agitación alimentada con soluciones pretratadas de S1 y S2 con ozono y ozono-UV a los $60 \mathrm{~min}$. 219

Figura 5-19 Observación macroscópica de los diferentes biorreactores .......................220

Figura 5-20 Resultados de las Pruebas Bioquímicas de los reactores R1 y R3 ................226

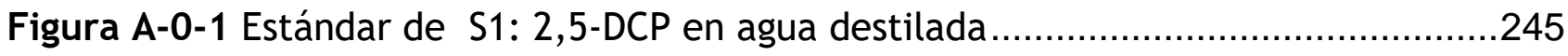

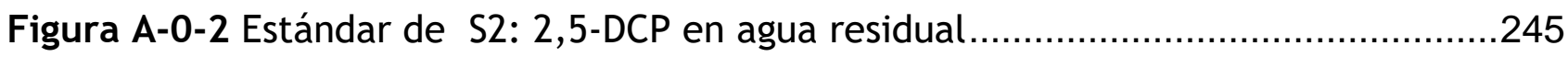

Figura A-0-3 Cromatograma obtenido por HPLC de 2,5-DCP en agua destilada tratado con ozono: (a) Tiempo = $0 \mathrm{~min}$; (b) Tiempo = $5 \mathrm{~min}$; (c) Tiempo = $10 \mathrm{~min}$; (d) Tiempo = $20 \mathrm{~min}$; 246

Figura A-0-4 Cromatograma obtenido por HPLC de 2,5-DCP en agua residual tratado con ozono: (a) Tiempo = $0 \mathrm{~min}$; (b) Tiempo = $5 \mathrm{~min}$; (c) Tiempo = $10 \mathrm{~min}$; (d) Tiempo $=20 \mathrm{~min}$; 
Figura A-0-5 Cromatograma obtenido por HPLC de 2,5-DCP en agua destilada tratado con $\mathrm{O}_{3}$-UV : (a)Tiempo = $0 \mathrm{~min}$; (b) Tiempo = $5 \mathrm{~min}$; (c) Tiempo = $10 \mathrm{~min}$; (d) Tiempo = $20 \mathrm{~min}$; 248

Figura A-0-6 Cromatograma obtenido por HPLC de 2,5-DCP en agua residual tratado con O3-UV: (a) Tiempo = $0 \mathrm{~min}$; (b) Tiempo $=5 \mathrm{~min}$; (c) Tiempo $=10 \mathrm{~min}$; (d) Tiempo $=20 \mathrm{~min}$; (e) Tiempo = 30min; (f) Tiempo $=40 \mathrm{~min} ;(\mathrm{g})$ Tiempo $=50 \mathrm{~min}(\mathrm{~h})$ Tiempo $=60 \mathrm{~min} \ldots \ldots . .249$ 


\section{ÍNDICE DE GRÁFICAS}

Gráfica 5-1 KLa del oxígeno en agua potable a $25^{\circ} \mathrm{C}$ en una columna de burbuja .........142 Gráfica 5-2 $\mathrm{K}$ a del oxígeno en agua desionizada a $20{ }^{\circ} \mathrm{C}$ en una columna de burbuja ..143 Gráfica 5-3 K Ka del oxígeno en agua desionizada a $20{ }^{\circ} \mathrm{C}$ en una columna de burbuja ..143 Gráfica 5-4 K $\mathrm{La}$ del oxígeno en agua residual a $20^{\circ} \mathrm{C}$ en una columna de burbuja ........143 Gráfica 5-5 Cambios en pH durante la ozonación de agua residual con dos flujos.........152 Gráfica 5-6 Cambio del pH durante tratamiento con ozonación de soluciones acuosas de 2,5-DCP en agua destilada $\left(\mathrm{S}_{1}: \mathrm{O}_{3}\right)$ y en agua residual $\left(\mathrm{S}_{2}: \mathrm{O}_{3}\right)$

Gráfica 5-7 Cambio del pH durante el tratamiento con ozono-ultravioleta de soluciones acuosas de 2,5-DCP en con agua destilada ( $\mathrm{S} 1: \mathrm{O}_{3}-\mathrm{UV}$ ) y con agua residual ( $\mathrm{S} 2: \mathrm{O}_{3}-\mathrm{UV}$ ).

Gráfica 5-8 DQO eliminada por $\mathrm{mg} / \mathrm{L}$ de ozono consumido durante el tratamiento con ozono en las soluciones de 2,5-DCP en S1: con agua destilada y S2: con agua residual.. 162 Gráfica 5-9 DQO eliminada por $\mathrm{mg} / \mathrm{L}$ de ozono consumido durante el tratamiento con ozono-UV en las soluciones de 2,5-DCP en S1: con agua destilada y S2: con agua residual

Gráfica 5-10 Espectros de absorción de 2,5-DCP a diferentes pH...............................165

Gráfica 5-11 Espectros de absorción de 2,5-DCP en agua destilada .............................165

Gráfica 5-12 Espectros de absorción de 2,5-DCP en agua residual ...............................166

Gráfica 5-13 Espectros de absorción de 2,5-DCP en agua destilada .............................166

Gráfica 5-14 Espectros de absorción de 2,5-DCP en agua residual ..............................167

Gráfica 5-15 Relación $\mathrm{DBO}_{5} / \mathrm{DQO}$ de 2,5-DCP en agua destilada con tratamiento de oxidación .

Gráfica 5-16 Relación $\mathrm{DBO}_{5} / \mathrm{DQO}$ de 2,5-DCP en agua residual con tratamiento de oxidación

Gráfica 5-17 Relación DQO/COT de 2,5-DCP en S1: con agua destilada y en S2: con agua residual con tratamiento de oxidación de $\mathrm{O}_{3}$.

Gráfica 5-18 Relación DQO/COT de 2,5-DCP en S1: con agua destilada y en S2: con agua residual con tratamiento de oxidación de $\mathrm{O}_{3}-\mathrm{UV}$. 
Gráfica 5-20 Relación de ozono consumido $(\mathrm{mM})$ por $\mathrm{mM}$ de 2,5-DCP removido en las soluciones S1: con agua destilada y S2: con agua residual de tratamiento con ozono y ozono-UV durante 60 minutos a pH inicial de $7,\left[D C P_{\text {inicial }}\right]=3.07 \mathrm{mM}$ (Ozono aplicado de $1.3 \mathrm{~g} / \mathrm{h})$. 177

Gráfica 5-21 Formación de iones cloruros y degradación del 2,5-DCP $(3.07 \mathrm{mM})$ durante 179

Gráfica 5-22 Formación de iones cloruros y degradación del 2,5-DCP $(3.07 \mathrm{mM})$ durante 179

Gráfica 5-23 Constante cinética de pseudo primer orden de la DQO en la oxidación del 2,5-DCP en S1: con agua destilada y en S2: con agua residual tratada con $\mathrm{O}_{3}$ 182

Gráfica 5-24 Constante cinética de pseudo primer orden de la DQO en la oxidación del 2,5-DCP en S1: con agua destilada y en S2: con agua residual tratada con $\mathrm{O}_{3}$-UV. 183

Gráfica 5-25 Absorbancias a $250 \mathrm{~nm}$ de la solución acuosa de 2,5-DCP en agua destilada a diferentes $\mathrm{pH}$. 188

Gráfica 5-26 Determinación de Constante de disociación $\left(\mathrm{K}_{\mathrm{a}}\right)$ de 2,5-DCP 188

Gráfica 5-27 Prueba de Toxicidad con 2,5-DCP en agua destilada (S1) sin tratamiento 198 Gráfica 5-28 Prueba de Toxicidad con 2,5-DCP en agua residual (S2) sin tratamiento. .198 Gráfica 5-29 Cambios del pH en los diferentes biorreactores durante 6 meses.... 208

Gráfica 5-30 Sólidos suspendidos totales en el Reactor 1 ..........................................209

Gráfica 5-31 Sólidos suspendidos totales en el Reactor 2 ….....................................210

Gráfica 5-32 Sólidos suspendidos totales en el Reactor 3 …...................................210

Gráfica 5-33 Sólidos suspendidos totales en el Reactor 4 .......................................210

Gráfica 5-34 Gráfica de velocidad de consumo de oxígeno en R1 ..............................213

Gráfica 5-35 Gráfica de velocidad de consumo de oxígeno en R2 ...............................214

Gráfica 5-36 Gráfica de velocidad de consumo de oxígeno en R3 ..............................215

Jacqueline C. Alexander $\quad$ XIX 


\section{Capítulo 1. INTRODUCCIÓN}

En el 2015 todavía hay 663 millones de personas que no tienen acceso al agua potable según los datos del reporte del Fondo de las Naciones Unidas para la Infancia, UNICEF* y la Organización Mundial de la Salud, WHO* [1]. El agua es el recurso natural más valioso para los humanos y para todas nuestras actividades. Sin agua la vida dejaría de existir. El agua es necesaria para la agricultura, las actividades industriales y recreativas entre otros usos. Según los datos de la Organización de las Naciones Unidas para la Alimentación y la Agricultura -conocida como FAO* la reserva mundial del agua es aproximadamente 1,400 millones de kilómetros cúbicos, pero solo una centésima parte del agua se encuentra disponible para uso humano [2]. La realidad de la disponibilidad del agua mundial no refleja exactamente la magnitud del problema que enfrentamos.

En primer lugar, enfrentamos la desigual distribución de agua a través de los continentes [2]. Además se ve afectada por el clima, la contaminación, los desperdicios y la mala administración del agua. El problema más grande del agua es la contaminación, debido a la descarga continua de las aguas residuales de determinadas industrias y municipales sin tratamiento adecuado que eliminan los compuestos orgánicos recalcitrantes que contienen. De acuerdo con los datos de la FAO, más de 450 kilómetros cúbicos de aguas residuales se vierten en las aguas superficiales del mundo cada año. Estos contaminantes afectan negativamente la calidad de las aguas superficiales y subterráneas, lo cual pone en peligro la salud de la población y causa daños a los ecosistemas [2].

En los últimos años, la producción y uso de los químicos sintéticos se ha incrementado para satisfacer la creciente necesidad en la producción agrícola, la productividad industrial y medicinal, lo cual contribuye a la contaminación de las aguas. Un grupo importante de los químicos sintéticos son los clorofenoles que se utilizan extensamente

\footnotetext{
* Por sus siglas en inglés.
} 


\section{CAPÍTULO 1. INTRODUCCIÓN}

en el medio ambiente debido a sus diversas propiedades antimicrobianas. Se han utilizado en la conservación de madera, pesticidas, desinfectantes, tintes y como intermediarios en la producción de productos farmacéuticos [3-6]. Debido al amplio uso de los clorofenoles, se pueden encontrar no solo en las aguas residuales industriales, sino también en el suelo y en diferentes tipos de cuerpos de agua; como consecuencia de su descarga en efluentes industriales o la práctica de eliminación de desechos inadecuada o por fugas accidentales [7]. Además, los clorofenoles han logrado notoriedad como sustancias peligrosas porque son tóxicos, pocos biodegradables y constituyen una amenaza a nuestra salud y al medio ambiente.

El clorofenol de especial interés en este estudio es el 2,5-diclorofenol (DCP). El 2,5-DCP es un fenol con dos átomos de cloro en posiciones orto y meta al grupo hidróxido. El Paradiclorobenceno (p-DCB) y su principal metabolito el 2,5-DCP, están en la lista de Alto volumen de Producción ( $\mathrm{HPV}^{\dagger}$ ) de la Agencia de Protección del Medio ambiente de los Estados Unidos (USEPA ${ }^{\dagger}$ ) y la Organización para la Cooperación y el Desarrollo Económico (OCDE) [8, 9], lo cual significa que se producen más de 1000 toneladas al año.

Asimismo, el 2,5-DCP se ha detectado en los efluentes de algunos productos industriales de aguas residuales, aguas subterráneas y aguas superficiales [10-12] También se ha determinado como un factor potencial de estrés y riesgo ecológico en las aguas superficiales [12]. El 2,5-DCP es un compuesto orgánico recalcitrante, por ende, tiene un efecto inhibitorio en la actividad biológica asociada a su toxicidad, impone ciertas restricciones a los microorganismos [13].

Como se mencionó anteriormente, los compuestos fenólicos no solo son problemáticos para el medio ambiente, sino también para la salud humana. Los compuestos fenólicos pueden penetrar al cuerpo humano a través de aguas contaminadas, alimentos y otros productos que los contengan. Es fácilmente absorbido a través de la piel, o las

\footnotetext{
† Por sus siglas en inglés
} 


\section{CAPÍTULO 1. INTRODUCCIÓN}

mucosas, particularmente por el tracto gastrointestinal e igualmente puede ser inhalado con el aire o el humo. La cantidad de fenol que ingresa al cuerpo depende de la forma como esté presente y del tiempo de la exposición. El hígado, los riñones, los pulmones y la mucosa gastrointestinal constituyen los sitios más importantes del metabolismo fenólico. En estudios de animales se ha encontrado que la exposición a corto plazo a altos niveles de fenol ha causado irritación de las vías respiratorias, espasmos musculares, lesiones renales, daño del corazón, temblores musculares, daño hepático, quemaduras en la piel, irritación de las vías respiratorias y colapso cardiovascular [14].

El 2,5-DCP pertenece a un grupo de sustancias conocidas como disruptores endocrinos químicos, que se han asociado con un aumento en la obesidad [15-18], diabetes tipo 2 [19] y las alergias a los alimentos [20] en adultos, adolescentes y niños, así como la reducción de peso en los niños al nacer [21]. Además, algunos estudios han demostrado que las concentraciones más altas de diclorofenoles se encuentran en el hígado, el riñón y bazo y pueden afectar sus funcionalidades con niveles pico que ocurren 15 minutos después de la administración. Cuando el 2,5-DCP y sus sales se someten por conjugación directa del grupo hidroxilo con un glucurónido o sulfato, pueden ser eliminados rápidamente del cuerpo a través de la orina [22].

A pesar de los problemas que puede causar en la salud, el 2,5-DCP es un compuesto fenólico que no es regulado en muchos países y por lo tanto, debido a sus propiedades refractarias aún pueden estar presentes en el efluente de las aguas residuales tratadas y sin tratar de ser descargado en los mares.

El agua contaminada tiene un coste elevado para la salud y el ecosistema. Por eso, es necesario desarrollar métodos efectivos para reducir y eliminar estos contaminantes del agua. En la práctica, las aguas contaminadas normalmente se tratan por métodos biológicos debido al bajo costo en relación con los procesos físico-químicos. Sin embargo, los compuestos clorofenólicos presentes en aguas residuales son difíciles de tratar, ya que la actividad microbiológica puede ser inhibida por la toxicidad ejercida por las altas concentraciones del propio sustrato. Aun así, el tratamiento biológico de 


\section{CAPÍTULO 1. INTRODUCCIÓN}

algunos compuestos clorofenólicos en aguas residuales se logra con sistemas convencionales de lodos activados [22, 23]. Asimismo, a veces hay aumento en la inhibición del sistema de tratamiento biológico para eliminar los compuestos clorofenólicos, lo cual puede originar problemas en efluentes secundarios [22]. También han resultado colapsados los procesos biológicos debido a las fluctuaciones en la carga de los compuestos clorofenólicos o por la exposición a altas tasas de carga de fenoles, superiores a $1 \mathrm{~kg}$ fenol $\mathrm{m}^{-3}$ días $^{-1}$ [24].

Además, la normatividad vigente en México (MOD.NOM-127-SSA1-1994) para el agua potable, con respecto a los compuestos fenólicos, establece que la concentración máxima permisible en agua no debe exceder de $1 \mu \mathrm{g} / \mathrm{L}$ [25], mientras la concentración máxima permisible en compuestos fenólicos para la recarga artificial de acuíferos con agua residual tratada es de $0.3 \mathrm{mg} / \mathrm{L}$ [26]. Igualmente, en otra parte del mundo hay restricciones de la concentración máxima permisible de los clorofenoles aún por debajo de estos límites o similares [27]. Debido a estas restricciones, es necesario incorporar nuevas tecnologías de tratamiento para complementar los tratamientos convencionales.

Actualmente hay una inquietud mundial por el desarrollo de tecnologías alternativas para el tratamiento de agua residual. El tratamiento de agua residual con tecnologías alternativas permite la reutilización de un mayor volumen de agua tratada, reduciendo importantes volúmenes de agua de primer uso para el consumo de la población [28]. Dentro de la gama de posibilidades, los procesos de oxidación avanzada (POAs) han mostrado su efectividad en la oxidación de compuestos orgánicos.

Los procesos de oxidación avanzada son tratamientos fisicoquímicos basados en la generación de radicales hidroxilos que son poderosos oxidantes y pueden degradar parcial o completamente los contaminantes a otros productos de degradación. Los métodos fisicoquímicos como las oxidaciones combinadas o solas, con ozono, reactivo Fenton, radiación UV, peróxido de hidrógeno y catalizadores, son adecuados para la degradación y eliminación completa de los compuestos clorofenólicos. Sin embargo, 


\section{CAPÍTULO 1. INTRODUCCIÓN}

muchos de estos tratamientos oxidativos, son caros. Por esta razón, el interés en la utilización de POAs combinados con métodos biológicos se ha incrementado, ya que es una opción más económica para reducir el costo de tratamiento [29-32].

Hay muchos estudios publicados sobre la degradación de los compuestos fenólicos, que están listados como contaminantes prioritarios por la USEPA [33]. Los compuestos fenólicos más estudiados son: el fenol, 2,4-DCP, 2,4,6-triclorofenol(TCP), 2clorofenol(CP), 3-CP, 4-CP y pentaclorofenol (PCP), usando diferentes procesos de oxidación avanzada, tales como: el ozono $\left(\mathrm{O}_{3}\right)$, la radiación ultravioleta (UV), ozonoUV ( $\left.\mathrm{O}_{3}-\mathrm{UV}\right)$, Ultravioleta de vacío (VUV), peróxido de hidrógeno $\left(\mathrm{H}_{2} \mathrm{O}_{2}\right), \mathrm{UV}-\mathrm{H}_{2} \mathrm{O}_{2}, \mathrm{O}_{3}-$ $\mathrm{UV} / \mathrm{H}_{2} \mathrm{O}_{2}$, óxido de titanio $\left(\mathrm{TiO}_{2}\right), \mathrm{UV}-\mathrm{TiO}_{2}, \mathrm{O}_{3}-\mathrm{TiO}_{2}$, Foto-Fenton y Fenton [34-43].

Sin embargo, como se cita en diversas investigaciones, la posición del átomo de cloro en los compuestos de fenol desempeña un papel importante en la degradación y la formación de intermediarios, lo cual puede variar dependiendo del tipo de tratamiento de oxidación [44, 45]. No obstante, hay insuficientes estudios publicados sobre el tratamiento oxidativo del 2,5- DCP.

\section{Alcances de la tesis}

En esta investigación el 2,5-DCP se usa como compuesto clorofenólico de referencia. En este trabajo se estudia la degradación del 2,5-DCP en solución de agua destilada y en solución de agua residual. Por medio de dos tratamientos de oxidación: ozono y ozono-UV. La alta concentración de 2,5-DCP (500 mg/L) usada en esta tesis se habilitó para simular un efluente industrial sin tratamiento con alta concentración de compuestos clorofenólicos [46, 47]; lo que permitió estudiar el comportamiento de 2,5DCP en agua residual. La velocidad de las reacciones, los compuestos intermediarios formados y su toxicidad son una aportación a la escasa literatura sobre el estudio de compuestos diclorofenoles, en particular el 2,5-DCP en agua residual. Adicionalmente, este trabajo mostró nueva información sobre la reacción de 2,5-DCP con el tratamiento de ozono combinado con radiación ultravioleta, lo cual no está publicado por otros excepto por [48]. 


\section{CAPÍTULO 1. INTRODUCCIÓN}

Temas a tratar en esta tesis:

En el segundo capítulo del Estado del arte, se comparan los trabajos que se han desarrollo sobre los temas importantes de esta tesis. Los temas se separan en cuatro subtítulos: en la Sección 2.1, se explorarán las propiedades fisicoquímicas del 2,5DCP, sus usos, su contribución a la degradación del medio ambiente, su toxicidad para los animales y para los seres humanos. Además, se examina el compuesto que lo genera en el ambiente: el Para-Diclorobenceno ( $p$-DCB) mientras que en la Sección 2.2, se discuten los diferentes POAs estudiados en los tratamientos de clorofenoles; además, se destacan los estudios importantes que se han hecho sobre el 2,5-DCP. En la Sección 2.3, se exploran las diferentes pruebas de Biodegradabilidad y los diferentes procesos biológicos usados para remover contaminantes. Finalmente, en la Sección 2.4, se identifican las diferentes Pruebas de Toxicidad usadas durante los estudios de oxidaciones, para comparar la toxicidad del compuesto original con los productos de oxidación.

En el tercer capítulo se exponen la hipótesis y los objetivos de este trabajo. En el cuarto capítulo, se expone la metodología de este trabajo. De esta manera, se muestran los equipos y se explican la metodología experimental desarrollada de esta tesis, para facilitar la reproducción de las pruebas y las técnicas. El quinto capítulo de Resultados y Discusión presenta los resultados de esta investigación. Asimismo, se discuten los resultados y se comparan con los resultados de otros estudios. En el sexto capítulo de Conclusiones se resumen los resultados importantes logrados en este trabajo de investigación. Finalmente, los anexos muestran los materiales adicionales de soporte de este trabajo.

Con este estudio se pretende profundizar y expandir el conocimiento sobre el uso de ozono y ozono-UV para oxidar el 2,5-DCP. Además, conocer la importancia de medir la toxicidad de los nuevos intermediarios formados de la oxidación del 2,5-DCP. Asimismo, se pretende que sea un incentivo para trabajos futuros de la oxidación de clorofenoles en aguas residuales contaminadas y un aporte al conocimiento sobre ese tema por la poca literatura existente actualmente. 


\section{REFERENCIAS}

[1] UNICEF-WHO, «Progress on Sanitation and Drinking Water and : 2015 Update and MDG assessment,» 2015. [En línea]. Available: http://apps.who.int/iris/bitstream/10665/177752/1/9789241509145_eng.pdf?ua=1. [Último acceso: 0910 2015].

[2] FAO, Dimensions of Need: An Atlas of Food and Agriculture, T. Loftas, Ed., Rome, 1995.

[3] F. J. Benitez, J. Beltra-Heredia, J. L. Acero y F. J. Rubio, «Oxidation of several chlorophenolic derivatives by UV irradiation and hydroxyl radicals,» J. Chem Technol Biotechnol, 76, 312-320, 2001.

[4] M. Pera-Titus, V. García-Molina, M. A. Baños, J. Giménez y S. Esplugas, «Degradation of clorophenols by means of advanced oxidation processes: a general review., " Appl Catal B: Environmental, 47, 219 - 256, 2004.

[5] Y. Qiu, M. E. Zappi, M. ASCE, C. Kuo y E. C. Fleming, «Kinetic and mechanisitic study of ozonation of three dichlorophenols in aqueous solutions,» J. Environ Eng., 125, 441-450, 1999.

[6] T. Poznyak, R. Tapia, J. Vivero y I. Chairez, «Effect of $\mathrm{pH}$ to the decomposition of aqueous phenosl mixture by ozone,» J. Mex. Chem. Soc., 50, 28-35, 2006.

[7] F. J. Benitez, J. Beltran-Heredia, J. L. Acero y F. Rubio, «Contribution of free radicals to chlorophenols decomposition by several advanced oxidation processes," Chemosphere, 41, 1271-1277, 2000.

[8] HSDB, «Bethesda (MD): National Library of Medicine (US)- Toxicology Data Network,» 2008 2009. [En línea]. Available: http://toxnet.nlm.nih.gov/cgibin/sis/search2/f?./temp/ DAdyZf:1. [Último acceso: 1003 2015].

[9] OECD, «The 2004 OECD list of High production volume chemicals, Environment Directorate organisation for economic co-operation and development, Paris, 2004.

[10] R. C. C. Wegman y A. W. M. HOFSTEE, « Chlorophenols in surface waters of the Netherlands (1976-1977),» Water res., 13, 651-657, 1979.

[11] R. C. C. Wegman y H. H. van Den Broek, «Chlorophenols in river sediments in the netherlands, "Water Res., 17, 227-230, 1983.

[12] W. Zhong, D. Wang y X. Xu, «Phenol removal efficiencies of sewage treatment processes and ecological risks associated with phenols in effluents, » J. Hazard Mat., 217, 218, 286-292, 2012.

[13] R. S. Ingols, P. E. Gaffney y P. C. Stevenson, «Biological Activity of Halophenols,» J. Water Pollut Control Fed., 38, 629-635, 1966. 


\section{CAPÍTULO 1. INTRODUCCIÓN}

[14] Agency for Toxic Substances and Disease Registry (ATSDR), «Toxicological profile for Phenol,» U.S. Department of Health and Human Services, Public Health Service., Atlanta, GA, 2008.

[15] P. Baillie-Hamilton, «Chemical Toxins: A Hypothesis to Explain the Global Obesity Epidemic., 》 J Altern Complem Med, 8, 185-192., 2002.

[16] M. Buser, H. Murray y F. Scinicariello, «Association of Urinary Phenols with Increased Body Weight Measures and Obesity in Children and Adolescents,» $\mathrm{J}$. Pediatr., 165, 744-749, 2014.

[17] Y. Wei, J. Zhu y A. Nguyen, «Urinary concentrations of dichlorophenol pesticides and obesity among adult participants in the U.S. National Health and Nutrition Examination Survey (NHANES) 2005-2008,» Int. J. Hyg. Envir. Heal., vol. 217, pp. 294-299, 2014.

[18] C. Twum y Y. Wei, «The association between urinary concentration of dichlorophenol pesticides and obesity in children,» Res. Environ. Health, 26, 215-219, 2011.

[19] Y. Wei y J. Zhu, «Urinary concentrations of 2,5-dichlorophenol and diabetes in US adults,» J Expo Sci Environ Epidemiol, Falta volumen 1-5, 2015.

[20] E. Jerschow, A. P. McGinn, G. de Vos, N. Vernon, S. Jariwala, G. Hudes y D. Rosenstreich, "Dichlorophenol-containing pesticides and allergies: results from the US National Health and Nutrition Examination Survey 2005-2006,» Ann. Allerg Asthma Im., 109, 420- 425, 2012.

[21] C. Philippat, M. Mortamais, C. Chevrier, C. Petit, A. M. Calafat, X. Ye, M. J. Silva, C. Brambilla, I. Pin, M. Charles, S. Cordier y R. Slama, «Exposure to Phthalates and Phenols during Pregnancy and Offspring Size at Birth,» Environ Health Persp, 120, 464-470, 2012.

[22] M. Mohajerani, M. Mehrvar y F. Ein-Mozaffari, «An Overview of the Integration of Advanced Oxidation Technologies and other processes for water and wastewater treatment.," International Journal of Engineering (IJE), vol. 3, no 2, pp. 120-146, 2009.

[23] K. Watanabe, M. Miyashita y S. Harayama, «Starvation improves survival of bacteria introduced into activated sludge,» Appl Environ Microbiol., 66, 3905-3910, 2000.

[24] K. Watanabe, M. Teramoto y S. Harayama, «An outbreak of nonflocculating catabolic populations caused the breakdown of a phenol-digesting activated-sludge process,» Appl Environ Microbiol., 65, 2813-2819, 1999.

[25] MODIFICACION A LA NOM-127-SSA1-1994, «Norma Oficial Mexicana-Salud ambiental, agua para uso y consumo humano-limites permisibles de calidad y tratamientos a que debe someterse el agua para su potabilización,» México, 01-1896. 


\section{CAPÍTULO 1. INTRODUCCIÓN}

[26] NOM-014-CONAGUA-2003, «Norma Oficial Mexicana-Requisitos para la recarga artificial de acuíferos con agua residual tratada.,» CONAGUA, México, 18-08-2009.

[27] D. R. Boyd, «The Water We Drink: An International Comparison of Drinking Water Standards and Guidelines,» David Suzuki Foundation, 2006.

[28] M. E. De la Peña, J. Ducci y V. Zamora Plascencia, «De la Peña, M. E., Ducci, J., \& Zamora Plascencia, V. Tratamiento de aguas residuales en México. Inter-American Development Bank.,» Inter-American Development Bank, 2013.

[29] S. Contreras, M. Rodríguez, F. Al-Momani, C. Sans y S. Esplugas, «Contribution of the ozonation pre-treatment to the biodegradation of aqueous solutions of 2,4diclorophenol,» Water Res., 37, 3164-3171, 2003.

[30] I. Oller, S. Malato y J. A. Sánchez-Pérez, "Combination of Advance Oxidation Processes and biological treatments for wastewater decontamination- A review,» $\mathrm{J}$. Sci Total Environ., 409, 4141-4166, 2011.

[31] R. F. Dantas, S. Contrearas, C. Sans y S. Esplugas, «Abatement of 4-Chlorophenol in Aqueous Phase by Ozonation Coupled with a sequencing Batch Biofilm Reactor (SBBR),» Ozone Sci. Eng., 30, 447-455, 2008.

[32] T. Essam, M. A. Amin, O. El Tayeb, B. Mattiasson y B. Guieysse, «Sequential photochemical-biological degradation of chlorophenols,» Chemosphere, 66, 22012209, 2007.

[33] USEPA, «Priority Pollutants, United States Environmental Protection Agency, 2013. [En línea]. Available: http://water.epa.gov/scitech/methods/cwa/pollutants.cfm. [Último acceso: 2701 2013].

[34] A. M. Abeish, H. M. Ang y H. Znad, "Solar photocatalytic degradation of chlorophenols mixture (4-CP and 2,4-DCP): Mechanism and kinetic modelling,» $\mathrm{J}$. Env. Sci. \& Health, 50, 125-134, 2015.

[35] F. Al Momani, S. C. y S. Esplugas, «A comparative study of the advanced oxidation of 2,4-dichlorophenol,» J. Hazard. Mat. B, 107, 123 -129, 2004.

[36] T. Alapi y A. Dombi, «Comparative study of the UV and UV/VUV-induced photolysis of phenol in aqueous solution,» J. Photochem. Photobiol. A., 188, 409 - 418, 2007. 


\section{CAPÍTULO 1. INTRODUCCIÓN}

[37] P. Andrew Hong y Y. Zeng, "Degradation of pentachlorophenol by ozonation and biodegradability of intermediates,» Water Res., 36, 4243-4254, 2002.

[38] F. J. Benitez, J. Beltrán-Heredia, J. Acero y F. Rubio, «Chemical Decomposition of 2,4,6-Trichlorophenol by Ozone, Fenton's Reagent and UV radiation,»Ind. Eng. Chem. Res., 38, 1341-1349, 1999.

[39] M. D. Gurol y R. Vatistas, "Oxidation of Phenolic Compounds by Ozone and Ozone+UV Radiation: A Comparative Study,» Water Res., 21, 895-900, 1987.

[40] M. Dore, B. Langlais y B. Legube, "Ozonation des phenols et des acides phenoxyacetiques, " Water Res., 12, 413- 425, 1978.

[41] A. Karci, I. Arslan-Alaton, T. Olmez-Hanci y M. Bekbolet, «Transformation of 2,4dichlorophenol by H2O2/UV-C, Fenton and photo-Fenton processes: Oxidation products and toxicity evolution,》 J. Photochemistry and photobiology A: Chemistry, 230, 65-73, 2012.

[42] P. Van Aken, R. Van den Broeck, J. Degreve y R. Dewil, «The effect of ozonation on the toxicity and biodegradabiliy of 2,4-dichlorophenol-containing wastewater, $\gg \mathrm{Chem}$. Eng. J., 280, 728- 736, 2015.

[43] S. Yung-SHen, Y. Ku y K.-C. Lee, «The effect of light absorbance on the decomposition of chlorophenols by ultraviolet radiation and UV/H2O2 processes,» Water Res., 29, 907-914, 1995.

[44] C. H. Kuo y C. H. Huang, «Aqueous phase ozonation of chlorophenols,» J. Hazard Mat., 41, 31-45, 1995.

[45] Y. Song-hu y L. Xiao-hua, "Comparison treatment of various chlorophenols by electro-Fenton method: relationship between chlorine content and degradation,» $J$. Hazard Mat., vol. B118, pp. 85-92, 2005.

[46] M. Goel, J. Chovelon, C. Ferronato y T. Sreekrishnan, «The remediation of wastewater containing 4-chlorophenol using integrated photocatalytic and biological treatment.,» J. Photochem Photobiol B., 98, no 1, 1-6, 2010.

[47] L. Ioannou, G. Li Puma y D. Fatta-Kassinos, «Treatment of winery wastewater by physicochemical, biological and advanced processes: A review,» J. Hazard. Mat., 286, 343-368, 2015.

[48] J. C. Alexander y C. R. Ramírez-Cortina, «A Comparative Study: Degradation of 2,5Dichlorophenol in Wastewater and Distilled Water by Ozone and Ozone-UV,» Ozone Sci. Eng., 38 , 179-191, 2016. 


\section{Capítulo 2. MARCO TEÓRICO}

\subsection{Antecedentes de la Investigación}

Muchos compuestos orgánicos son descargados al ambiente acuático - a través de la descarga de los efluentes industriales - sin tratar o siendo poco tratados a los océanos, ríos, etc. La mayoría de los compuestos fenólicos son tóxicos y/o poco biodegradables, por consiguiente, no son fácilmente eliminados con los tratamientos convencionales: biológicos, químicos y físicos. Por esta razón, existe la necesidad de desarrollar otras técnicas y métodos más efectivos como los procesos de oxidación avanzada (POAs), los que son capaces de reducir los compuestos refractarios a compuestos más biodegradables o mineralizar los compuestos orgánicos completamente a dióxido de carbono, el agua y sus sales.

Esta sección de la tesis está dedicada a resumir la información encontrada en diferentes investigaciones que se han hecho sobre los temas correspondientes a este estudio como: características del 2,5-DCP, los procesos de oxidación avanzada, los procesos biológicos, y las pruebas de toxicidad. Con este fin, fueron revisadas unas doscientas referencias de la literatura incluyendo libros, artículos, etc.

Recordando los inicios de la síntesis química de los Halogenuros orgánicos, el compuesto orgánico naftaleno, más conocido como el ingrediente principal de las bolas de naftalina, es un hidrocarburo aromático cristalino, blanco, volátil, descubierto en la década de 1820, por los químicos Brande y Garden, procedente de la destilación del alquitrán de hulla. John Kidd en 1821, propuso algunas características fisicoquímicas de la naftalina y los medios para su producción. En 1826, Michael Faraday determinó la fórmula molecular $\left(\mathrm{C}_{10} \mathrm{H}_{8}\right)$. Después, en 1866, Emil Erlenmeyer propuso su estructura teórica, de dos anillos de bencenos fusionados, y Carl Graebe confirmó esta teoría tres años después. El naftaleno tiene punto de fusión de $80.2^{\circ} \mathrm{C}$ y punto de ebullición de $218^{\circ} \mathrm{C}$. Se deriva del alquitrán de hulla o petróleo crudo. Aunque años después, el naftaleno por su alta inflamabilidad fue reemplazado en las bolas para combatir a las polillas, por el paradiclorobenceno ( $p$-DCB) $[1,2]$. 


\section{CAPÍTULO 2. MARCO TEÓRICO}

El primer uso industrial del p-DCB fue como fumigante, en 1915, para matar al barrenador del árbol de melocotón [3], aunque, después se destinó a otros usos inclusive el de plaguicida para matar polilla y moho. El p-DCB se aplica también como precursor en la producción de polímeros que se usan en bloques de desodorante orinal, para desodorizar baños y envases de desechos. El p-DCB es un hidrocarburo clorado volátil que tiene dos átomos de cloro unidos a un anillo de benceno. La fórmula molecular de p-DCB es $\mathrm{C}_{6} \mathrm{H}_{4} \mathrm{Cl}_{2}$ y tiene el peso molecular de $147.02 \mathrm{~g} / \mathrm{mol}$, punto de fusión de $53{ }^{\circ} \mathrm{C}$ y punto de ebullición de $174{ }^{\circ} \mathrm{C}[4,5]$. El riesgo de exposición es principalmente mediante la inhalación del aire contaminado. Por consiguiente, el pDCB es responsable de daños en los tejidos del sistema nervioso central, degeneración de las funciones neurológicas, efectos adversos en hígado y el riñón [68].

\subsection{El Diclorofenol Estudiado}

En 1836, el diclorofenol (acide chlorophénesique), fue aislado por primera vez por el científico Laurent durante la destilación del alquitrán pasándolo a través de una corriente de cloro [9]. El 2,5-DCP es el principal metabolito del paradiclorobenceno [10] y un derivado del lindano (insecticida) y el 2,4,5-TCP (fumigante) [11]. El 2,5-DCP es producido industrialmente a partir de diferentes procedimientos: 1). La separación de 2,5-DCP desde las mezclas de isómeros de DCP por Nicolaisen y Jenney en 1955 [12]. 2). La separación de 2,5-DCP, debida a Lowe, fue a partir del 3,4-DCP y 2,4DCP isómero usando urea y un solvente como tolueno [13] 3) La combinación de 1bromo-2,5-diclorobenceno con hidróxido de sodio en metanol y en presencia de cobre catalizador a altas temperaturas por Carlson [14] y 4) La preparación del 2,5-DCP a partir del 1,2,4-triclorobenceno por Sehring [15].

El 2,5-DCP es un derivado químico de fenol con dos átomos de cloro que están en posición para entre sí. El 2,5-DCP tiene número de identificación CAS: 583-78-8, la fórmula empírica $\mathrm{C}_{6} \mathrm{H}_{4} \mathrm{Cl}_{2} \mathrm{O}$, y peso molecular de $163 \mathrm{~g} / \mathrm{mol}$. El 2,5-DCP tiene un punto de fusión de $59{ }^{\circ} \mathrm{C}$ y un punto de ebullición de $211^{\circ} \mathrm{C}$. La solubilidad en agua es $3 \mathrm{~g} / \mathrm{L}$ 


\section{CAPÍTULO 2. MARCO TEÓRICO}

a $20{ }^{\circ} \mathrm{C}$ y la presión de vapor es de $16.6 \mathrm{~Pa}$ a $25{ }^{\circ} \mathrm{C}$. El coeficiente de reparto octanol/agua (log Kow): 2.92 a 3.06 y una constante de disociación ácida $\left(\mathrm{pK}_{\mathrm{a}}\right)$ de 7.5 , lo que significa que existirá parcialmente en su forma aniónica. Asimismo, un estimado de la constante de la ley de Henry $\left(\mathrm{K}_{\mathrm{H}}\right)$ del 2,5-DCP es $6.03 \times 10^{-6} \mathrm{~atm}-\mathrm{m}^{3} \mathrm{~mol}^{-1}$ [16]. Adicionalmente, otro estudio ha reportado un $\mathrm{pK}_{\mathrm{a}}$ de 6.45 y $\log \mathrm{K}_{\text {ow }}$ de 3.2 [17]. La estructura química del 2,5-DCP se muestra en la figura 2-1.

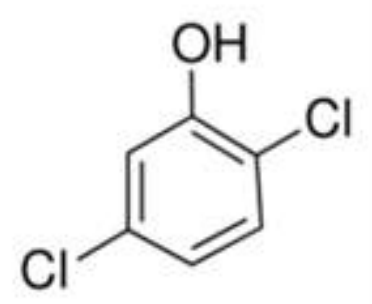

Figura 2-1 Estructura química del 2,5-DCP

El 2,5-DCP es usado en la manufactura de resinas [12], para síntesis farmacéutica y otros compuestos, como plaguicidas entre otros $[13,15]$.

\subsubsection{Toxicidad en animales}

Los datos de toxicidad aguda del 2,5-DCP en animales de laboratorio son los siguientes: en rata: dosis letal oral media ( $\left.\mathrm{DL}_{50}\right)$ de $2,475 \mathrm{mg} / \mathrm{kg}$ y la concentración letal media (CL50) por inhalación fue mayor de 185,000 mg/m³ (por 4 horas), en conejo: dérmica $\mathrm{DL}_{50}$ fue mayor que $8,000 \mathrm{mg} / \mathrm{kg}[16]$.

Adicionalmente, un estudio por Tegethoff y col., demostró que el 2,5-DCP no causa toxicidad genética [18].

Borzelleca y colaboradores encontraron que los datos de toxicidad aguda del 2,5-DCP en ratones midió valores de la DL50 oral para machos de $(1600 \mathrm{mg} / \mathrm{kg})$ y hembras $(946$ $\mathrm{mg} / \mathrm{kg}$ ); de lo cual se concluye que el 2,5-DCP fue más toxico para ratones hembras [19]. 


\section{CAPÍTULO 2. MARCO TEÓRICO}

\subsubsection{Toxicidad y efectos en la salud humana}

El 2,5-DCP es tóxico para los seres humanos, y continúa siendo el sujeto de muchos estudios médicos debido a su creciente asociación con diferentes condiciones médicas. En un estudio por Hill y col. (1995), se midieron doce analitos en las muestras de orina de 1000 adultos en los Estados Unidos (EE.UU.) para encontrar información sobre la exposición de los seres humanos a pesticidas. Se encontró la presencia del 2,5 -DCP en las muestras de orina de $98 \%$ de la población de estudio, lo cual sugiere exposición a paradiclorobenceno de casi toda la población de estudio [20].

En otros estudios encontraron la presencia del 2,5-DCP no solo en muestras de orina sino en la leche materna [21-23], estos estudios corroboran los resultados de Hill y otros, lo que significa que mucha de la población mundial está expuesta a p-DCB.

La Dra. Baillie-Hamilton (2002) asocia la obesidad y la producción de químicos entre 1990 a 2000. Ella encontró una relación positiva entre ambos (los casos de obesidad y la producción de químicos). Por eso, se sugiere que la exposición de los seres humanos a bajos niveles de los químicos sintéticos en la comida y en el medio ambiente puede ser la razón del aumento de los casos de obesidad [24]. Otro estudio encontró una asociación entre DCP y el aumento en peso corporal en adolescentes [25]. Un nuevo estudio reportó que también el DCP puede afectar el momento de la pubertad, telarca y la menarquia, lo que lleva a la pubertad precoz. Por eso, puede resultar en enfermedades tales como la obesidad, la diabetes y el cáncer, además de que tiene consecuencias psicológicas [26].

Igualmente, otros investigadores sugieren una posible relación entre la exposición al 2,5-DCP y la obesidad en los niños [27]. Un trabajo del Alergista Jerschow y col. (2012), hace una asociación entre exposición a DCP y sensibilización alérgica por nivel de IgE sérica específica ante determinado alérgeno. Se realizaron pruebas con 2,211 participantes de 6 años y mayores, expuestos a metabolitos de DCP en su ambiente. Encontraron que 411 participantes tenían alergia alimentaria, mientras 1,016 participantes tenían alergia ambiental. Por lo demás, la sensibilización a 1 o más 


\section{CAPÍTULO 2. MARCO TEÓRICO}

alimentos alérgenos fue más común cuando los participantes fueron expuestos a 2 metabolitos de los DCP.. Se encontraron que el nivel de DCP en muestras de orina al más del $75^{\text {th }}$ percentil, se asoció con la presencia de sensibilización a alimentos en una población de EE.UU. Por eso, concluyeron que el excesivo uso de DCP se puede contribuir al aumento de incidencias de alergias a alimentos en sociedades occidentales [28]. Adicionalmente, se asocian alto nivel de DCP en muestras de orina con la morbilidad del asma, en pacientes con atopia y una historia de sibilancias [29].

Otro estudio relacionó la exposición prenatal a la concentración alta del 2,5-DCP con bajo peso al nacer entre los bebés varones [30], mientras otra investigación sugiere una relación entre la exposición de p-DCB y el síndrome metabólico en adultos no diabéticos [31]. Otra publicación propuso una relación potencial entre la exposición de p-DCB y la incidencia de diabetes en adultos [32].

\subsection{Los Procesos de Oxidación Avanzada}

El tratamiento de aguas residuales puede comprender tres tipos principales de procesos:

1. Métodos Físicos: que no generan sustancias nuevas, sino que concentran los contaminantes al evaporar el agua o por gravedad o por filtrado de sólidos de tamaño considerable. Por ejemplo: Cribado, Sedimentación, Flotación y Filtración.

2. Métodos Biológicos: son métodos que utilizan microorganismos para biodegradar los contaminantes. Por ejemplo: la condición Aerobia, la condición Anóxica y la condición Anaerobia.

3. Métodos Químicos: son métodos que utilizan reactivos químicos, para realizar reacciones químicas que resultan en la formación de nuevas sustancias.

Bajo los métodos químicos, hay un grupo que continúa atrayendo mucho la atención de los expertos en aguas, conocido como "Procesos de Oxidación Avanzada". 


\section{CAPÍTULO 2. MARCO TEÓRICO}

\section{Los Procesos de Oxidación Avanzada (POA)}

El término de POA fue usado primero por Glaze y col. [33], para describir todas las oxidaciones químicas basadas en la generación in situ de radicales hidroxilo $\left(\mathrm{OH}^{*}\right)$ altamente reactivos como oxidantes principales. Se hizo un resumen de la química de algunos procesos de tratamientos $\left(\mathrm{O}_{3}, \mathrm{O}_{3}-\mathrm{H}_{2} \mathrm{O}_{2}\right.$ y $\left.\mathrm{O}_{3}-\mathrm{UV}\right)$ y se encontró que todos los procesos son mecánicamente comunes pero tienen diferencias significativas para hacer uno más práctico que el otro, dependiendo de la calidad del agua y los objetivos de su tratamiento.

Los Procesos de Oxidación Avanzada constituyen una tecnología prominente para afrontar el tratamiento de aguas residuales y aguas subterráneas que contienen compuestos orgánicos difíciles de remover; bajo condiciones óptimas se logran reducir la sustancia tóxica a $\mathrm{CO}_{2}$, agua y sales minerales, por eso no se generan contaminantes secundarios como con los métodos convencionales [34, 35].

Los POAs son más aptos para la degradación de tóxicos orgánicos en soluciones con bajo contenido de sólidos suspendidos y de contaminantes orgánicos. Los POAs pueden ser aplicados como un proceso de tratamiento único o como pasos de pretratamiento o post tratamiento en procesos convencionales como parte de un sistema de tratamiento integral [35].

Las principales ventajas de los métodos POAs, son su capacidad de oxidar y mineralizar completamente los compuestos orgánicos complejos, mientras las principales desventajas son: los altos costos de operación, la formación de intermediarios con una toxicidad mayor que compuestos madres [36, 37] ; y los secuestradores de radicales por compuestos como carbonatos y bicarbonatos que pueden reducir las eficacias de los POAs [38].

Wohlers y col. [39], estudiaron el uso de la ionización del aire en la degradación de plaguicidas, incluidos los 2,5-DCP a una concentración inicial de $5 \mathrm{mg} / \mathrm{L}$ en agua bidestilada y agua bidestilada adicionada con diferentes cantidades de ácidos húmicos. 


\section{CAPÍTULO 2. MARCO TEÓRICO}

Se encontró que a bajas concentraciones, el ácido húmico no interfirió con la velocidad de degradación, sin embargo en una concentración elevada de éste ( $\geq 15 \mathrm{mg} / \mathrm{L}$ ), la velocidad de descomposición del compuesto era más lenta. Esto podría ser debido a la reacción competitiva de ácido húmico con oxidante, lo que podría dar lugar a especies deficientes en oxígeno en la solución acuosa [49].

Muchos sistemas son calificados bajo la definición de POA: la Tabla 2-1proporciona una lista típica de los POAs más conocidos y/o empleados en el tratamiento de los compuestos clorofenólicos. Se clasifican en procesos fotoquímicos y no fotoquímicos. Los POAs más reportados se basan en las diferentes combinaciones de Luz UV: Benitez, y col. [40], Gurol y Vatistas [41]; Ozono:Dore, y col. [42], Esplugas, y col. [43], Glaze, y col. [33], von Gunten [44], Hoigné y Bader [38], Shiyun, y col. [45]; Peróxido de hidrógeno: Mokrini, y col. [46], Kusic, y col. [47]; Dióxido de titanio y el reactivo Fenton: Esplugas, y col. [43], Vogelpohl y Kim [35].

Tabla 2-1 Principales tecnologías de los Procesos de Oxidación Avanzada.

\begin{tabular}{|c|c|}
\hline No-fotoquímicos & Fotoquímicos \\
\hline Ozonación $\left(\mathrm{O}_{3} / \mathrm{OH}\right)$ & $\mathrm{UV}-\mathrm{O}_{3}$ \\
\hline $\mathrm{O}_{3} / \mathrm{H}_{2} \mathrm{O}_{2}$ & Ultravioleta de vacío (VUV) \\
\hline Fenton: $\mathrm{Fe}^{2+} / \mathrm{Fe}^{3+}+\mathrm{H}_{2} \mathrm{O}_{2}$ & $\mathrm{UV}-\mathrm{H}_{2} \mathrm{O}_{2}$ \\
\hline $\mathrm{O}_{3}-\mathrm{TiO}_{2}$ & $\mathrm{UV}-\mathrm{TiO}_{2}$ \\
\hline Oxidación electroquímica & $\mathrm{UV}-\mathrm{O}_{3}-\mathrm{H}_{2} \mathrm{O}_{2}$ \\
\hline Descarga electrohidráulica & Fotólisis/Fenton \\
\hline $\begin{array}{c}\text { Oxidación en agua subcrítica y } \\
\text { supercrítica (SCW) }\end{array}$ & Fotocatálisis homogénea \\
\hline $\begin{array}{c}\text { Radiólisis y tratamiento con haces } \\
\text { de electrones }\end{array}$ & Fotocatálisis heterogénea \\
\hline $\begin{array}{c}\text { Oxidación catalítica por vía } \\
\text { húmeda (CWAO) }\end{array}$ & $\begin{array}{c}\text { Con sensibilizadores orgánicos o complejos de } \\
\text { metales de transición }\end{array}$ \\
\hline Ultrasonido & Electrofotocatálisis \\
\hline
\end{tabular}

A partir de entonces muchas investigaciones se han enfocado a la aplicación de los POAs en el tratamiento de agua contaminada con compuestos fenólicos. 


\section{CAPÍTULO 2. MARCO TEÓRICO}

\subsubsection{Oxidación en agua supercrítica}

El fenómeno de fluido supercrítico, fue descubierto en 1821 por el científico francés, Charles Cagniard de la Tour [48]. La oxidación en agua supercrítica (SCWO) es una tecnología que se ha utilizado para tratar aguas residuales con elementos refractarios

y lodos de aguas residuales en el laboratorio o escala comercial. La SCWO usa agua en condiciones de presión y temperatura superiores a las del punto crítico ( $T>647 \mathrm{~K}$, $\mathrm{P}>22.1 \mathrm{MPa}$ ). Las características físico-químicas del agua supercrítica, como la densidad, la entalpía y la constante dieléctrica relativa se cambian continuamente con la temperatura [49].

En condición supercrítica, el agua tiene una constante dieléctrica pequeña, enlaces de hidrógeno débiles, baja viscosidad del fluido y alto coeficiente de difusión, etc., en esta condición el agua se convierte en un disolvente completamente apolar. Debido a que los enlaces de hidrógeno son más débiles en el agua supercrítica, se disminuye la solubilidad de los electrolitos y aumenta la solubilidad de las moléculas apolares tales como $\mathrm{O}_{2}, \mathrm{CO}_{2}$, o de materia orgánicas [49-51].

En un proceso de oxidación supercrítica en agua, los materiales orgánicos son rápidamente oxidados e integrados en moléculas pequeñas tales como $\mathrm{CO}_{2}, \mathrm{~N}_{2}, \mathrm{H}_{2} \mathrm{O}$, y las moléculas heterocíclicas se convierten en ácidos 0 sales orgánicas correspondientes que el agua puede formar una fase homogénea con $\mathrm{O}_{2}$ y $\mathrm{CO}_{2}$ para eliminar las resistencias a la transferencia de calor y masa entre la interfase de las fases [51]. Asimismo, en estado supercrítico, el agua existe como una sola fase con propiedades intermedias entre las de los gases y los líquidos $[49,50]$

Hace más de tres décadas, el potencial de la oxidación en agua supercrítica fue reconocido por primera vez, desde entonces muchos estudios en agua supercrítica y oxidación supercrítica en agua se han llevado a cabo por muchos investigadores [53]. La primer compañía comercial de oxidación supercrítica del agua, MODAR, se estableció en 1980 (se compró por General Atomics en 1996). La mayoría de las aplicaciones comerciales de SCWO son para residuos orgánicos acuosos en el 


\section{CAPÍTULO 2. MARCO TEÓRICO}

intervalo de 1 a $20 \%$ en peso orgánico; demasiado concentrado para eliminar económicamente con carbón activado y demasiado diluido para la incineración de manera eficiente. Los residuos más fáciles al proceso son los que contienen solo los elementos Carbono, Hidrógeno, Oxígeno, y residuos de Nitratos [50].

Esta tecnología puede lograr una eficiencia de oxidación mayor al 99\% en tiempos de contacto muy breves, que no requiere ningún tratamiento adicional de los productos gaseosos. La SCWO ofrece algunas otras ventajas potenciales, tales como: las sales proporcionan una separación más fácil debido a sus bajas solubilidades en agua supercrítica (SCW), se logra autosuficiencia calórica y ahorro de energía con una concentración de masa de la materia orgánica superior al $2 \%$ en peso, debido a que el exceso de calor puede ser recuperado para producir vapor o agua caliente, lo que lleva a un bajo costo de operación [52, 54]. Sin embargo, la corrosión y problemas de taponamiento, especialmente durante el período de precalentamiento, debido a las sales disueltas en el agua, restringen esta tecnología [49, 54].

Algunos investigadores [55] estudiaron la aplicación de oxidación en agua supercrítica y SCWO con hidróxido de sodio (SCWO y $\mathrm{NaOH})$ para tratar 2-CP $\left(3.89 \times 10^{-3} \mathrm{M}\right)$ y fenol $\left(5.3 \times 10^{-3} \mathrm{M}\right)$. El estudio se llevó a cabo a temperatura de $713 \mathrm{~K}$ y $26 \mathrm{MPa}$.

Los resultados muestran que con el proceso de SCWO 20\% se logra la degradación del 2-CP y $7 \%$ de la degradación de fenol durante el tiempo de residencia de 0.51 segundos, mientras que al mismo tiempo de residencia con el proceso de SCWO con $\mathrm{NaOH}$, se lograron $56 \%$ de la degradación de 2-CP y resultados similares para el fenol.

Por otra parte, después de la aplicación de SCWO de 2-CP por 0.25 segundos, Lee y col. [55] detectaron productos intermedios como cloro, 2,4-DCP, 4-CP, 3-CP y dímeros (1-clorodibenzodioxina y diclorofenoxifenol), mientras que los productos intermedios de fenol fueron 1,4-benzoquinona, dibenzofurano, 2-fenoxifenol, bifenoles y 4fenoxifenol, los resultados obtenidos fueron similares a los obtenidos por Guan y col. [56]. 


\section{CAPÍTULO 2. MARCO TEÓRICO}

Los resultados obtenidos por Lee y col. [55] muestran que la adición de $\mathrm{NaOH}$ promueve la decloración de 2CP y la aceleración de la descomposición de ambos compuestos. Los dímeros detectados en el análisis de 2CP y fenol fueron formados a través del mecanismo de radicales libres.

Lin y col. [57] en su estudio de SCWO (673K) de 2,4-DCP identificaron 2,7-diclorodibenzodioxina, 2,4-DCP, 2,5-DCP, 3,5-DCP 2,3,4-TCP, 2,3,5-TCP, 2,4,5-TCP y 3,5dicloro-hidroxibenzaldehído.

En otra investigación [58] de la aplicación de oxidación en agua supercrítica de 2,4-DCP, los autores encontraron que la velocidad de descomposición aumentó notablemente con el aumento de la temperatura y con el aumento de la concentración de $\mathrm{H}_{2} \mathrm{O}_{2}$. Por lo tanto, la temperatura de reacción en el proceso de SCWO desempeña un papel clave en el aumento de la velocidad de descomposición de 2,4-DCP.

En la degradación de 2,4-DCP $\left(6.135 \times 10^{-3} \mathrm{M}\right)$, la descomposición fue cercana al

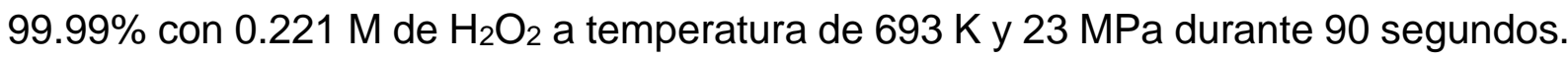
En su estudio, los productos de reacción de 2,4-DCP bajo experimento condición (673 $\mathrm{K}, 23 \mathrm{MPa}$ y $0.147 \mathrm{M} \mathrm{H}_{2} \mathrm{O}_{2}$ ) consisten en 2-metil-2-ciclopenteno, fenol, 2-metil-fenol, 2,3-dimetil-2-ciclopenteno, 2,3,4-trimetil-2-ciclopenteno, 2,4-DCP, 2-metil-5-clorofenol, 2,4-dicloro-6-metilfenol, clorohidroxibenzaldehído, diclorofenoxifenol, 3,5-dicloro-2hidroxiacetofeno.

Adicionalmente, la reacción en la SCWO usando peróxido de hidrógeno, es un mecanismo de reacción vía radicales libres con formación de radical, remoción de hidrógeno y reacciones de cambio de radical. Los productos identificados como 3,5dicloro-2-hidroxiacetofeno y diclorofenoxifenol pueden ser probables productos intermedios primarios de la SCWO de 2,4-DCP. La oxidación adicional podría resultar en un solo anillo y productos de apertura del anillo, tales como fenol y dióxido de carbono [58]. 


\section{CAPÍTULO 2. MARCO TEÓRICO}

\subsubsection{Irradiación ultrasónica}

En 1927, el efecto de ultrasonido en medio líquido fue descubierto por Alfred L. Loonis, pero no fue hasta 1980s que los principales desarrollos en sonoquímica se llevaron a cabo con la llegada de los generadores de ultrasonido de bajo costo. El proceso de irradiación ultrasónica usa frecuencia ultrasónica de $20 \mathrm{kHz}$ hasta $10 \mathrm{MHz}$, y energía eléctrica de varios cientos de vatios (W). La sonoquímica está basada en la cavitación acústica, es decir, la formación, el crecimiento y colapso implosivo de burbujas en líquido. La implosión de cavidades se produce cuando ya no absorben la energía de las ondas de sonido eficiente, lo cual causa que el líquido se precipita en la cavidad. Un punto caliente ("hot spot") localizado de corta duración se produce a partir del calor generado del gas y los vapores comprimidos dentro de la cavidad. Esto causa un colapso de la cavidad, lo que crea un ambiente de temperaturas elevadas ( $>3000 \mathrm{~K}$ ), altas presiones (>1000 bar) y tiempos de calentamiento de menos de un microsegundo, suficientemente alta como para romper cualquier enlace químico [59, 60]. Dentro de una burbuja gaseosa, el oxidante principal es $\mathrm{H}_{2} \mathrm{O}_{2}$, pero como la temperatura al final del colapso de la burbuja está en el rango de 4000-6500 K y el átomo de oxígeno $(\mathrm{O})$ es superior a $6500 \mathrm{~K}$. Estas especies activas reaccionan con solutos volátiles en la fase de gas o reaccionan con solutos disueltos en una zona interfase o incluso en el seno de la solución [61].

La degradación de materia orgánica ocurre por las reacciones con los radicales o en la presencia de oxígeno [62].

Interior de cavidad:
$\mathrm{H}_{2} \mathrm{O} \rightarrow \mathrm{H}^{-}+\mathrm{HO}^{-}$
Ecuación 2-1
$\mathrm{O}_{2} \rightarrow 2 \mathrm{O}$
Ecuación 2-2

Interfase gas- líquido
$\mathrm{O}+\mathrm{H}_{2} \mathrm{O} \rightarrow 2 \mathrm{HO}^{-}$
Ecuación 2-3
$\mathrm{H}^{\mathbf{*}}+\mathrm{HO}^{\mathbf{*}} \rightarrow \mathrm{H}_{2} \mathrm{O}$
Ecuación 2-4
2HO" $\rightarrow \mathrm{O}+\mathrm{H}_{2} \mathrm{O}$
Ecuación 2-5 
Seno de la solución
$\mathrm{H}^{*}+\mathrm{O}_{2} \rightarrow \mathrm{HOO}^{\prime}$
Ecuación 2-6
$2 \mathrm{HO}^{-} \rightarrow \mathrm{H}_{2} \mathrm{O}_{2}$
Ecuación 2-7
$2 \mathrm{HOO}^{-} \rightarrow \mathrm{H}_{2} \mathrm{O}_{2}+\mathrm{O}_{2}$
Ecuación 2-8

Algunos investigadores [60] estudiaron el tratamiento sonoquímico de 4-DCP en una solución acuosa de $35 \mathrm{mg} / \mathrm{L}$, usando ultrasonido de $1.7 \mathrm{mHz}$ con una potencia eléctrica de entrada de $35 \mathrm{~W}$ y temperatura de solución a $298 \mathrm{~K}$. Los resultados muestran una degradación de $21 \%$ del 4 -CP después de 60 min y una velocidad de reacción $\mathrm{K} 1.7 \mathrm{mHz}=3.9 \times 10^{-3} \mathrm{~min}^{-1}$. Aparte, los autores no detectaron productos orgánicos ni productos intermedios en el agua después de la irradiación ultrasónica de 4-CP. Por eso, concluyeron que la degradación de 4-CP es una reacción de una etapa, y las moléculas de 4-CP se descomponen directamente en materia inorgánica como el ion cloruro, el dióxido de carbono y agua bajo irradiación ultrasónica.

Hamdaoui y Naffrechoux [62] estudiaron la sonólisis de 4-CP en $90 \mathrm{~mL}$ de una solución acuosa de $0.78 \mathrm{mM}$, con ultrasonido a $516 \mathrm{kHz}$, una potencia acústica de $38.3 \mathrm{~W}$ y temperatura de solución a $294 \mathrm{~K}$ a valores de pH 5.5 y 12.7. Se reportó que la degradación de 4-CP sigue una cinética de pseudo-primer orden de casi $0.016 \mathrm{~min}^{-1}$ (pH 5.5) y casi $0.012 \mathrm{~min}^{-1}(\mathrm{pH} 12.7)$. Estos resultados muestran que la degradación sonolítica de 4-CP fue más efectiva bajo la condición ácida (5.5) que bajo la condición alcalina ( $\mathrm{pH}$ 12.7). Los autores proponen que la diferencia en la reactividad a estos dos valores de $\mathrm{pH}$ surge de la diferencia en la capacidad de absorción de las formas protonada y desprotonada de 4-CP a las burbujas de ultrasonido.

Además, el efecto del pH sobre las tasas de degradación depende del estado de la molécula, es decir, si el contaminante está presente como especies iónicas (forma desprotonada) o como una molécula (forma protonada, $\mathrm{pH}<\mathrm{pKa}$ ). Debido a que 4-CP es un compuesto novolátil, se espera que la reacción sonoquímica con el radical hidroxilo tenga lugar en la interfase de la burbuja de cavitación, donde la concentración de radicales hidroxilos está al máximo. En su forma protonada, el 4-CP existe en 


\section{CAPÍTULO 2. MARCO TEÓRICO}

concentración más alta en la superficie de burbuja y, por tanto, se expone más fácilmente al ataque de radical hidroxilo.

En condiciones alcalinas, el 4-CP está en su forma desprotonada y no se acumula fácilmente en la interfase de la burbuja ni se adsorbe tan bien en la interfase aire/agua como la forma protonada, lo cual se puede confirmar por el tiempo de degradación más largo del 4-CP a pH alcalino (160 minutos) comparado con el tiempo de degradación a pH ácido (70 minutos) [62].

Un comportamiento similar respecto del $\mathrm{pH}$ ha sido reportado por Uddin y Hayashi [63] en el estudio de sonólisis de $50 \mathrm{~mL}$ de soluciones acuosas de 2,4-DCP (50 mg/L) a diferentes $\mathrm{pH}$ (2, 6.3 y 11), 20 minutos de burbujeo con oxígeno antes de irradiación ultrasónica de $489 \mathrm{kHz}$, con una potencia de casi 20 W y temperatura de solución de 293 K. Asimismo, los autores reportaron que la degradación de 2,4-CP sigue una reacción cinética de primer orden de $0.0517 \mathrm{~min}^{-1}(\mathrm{pH} 6.3)$.

Goskonda y col. [64] estudiaron la sonólisis de compuestos aromáticos usando $40 \mathrm{~mL}$ de soluciones acuosas de $250 \mathrm{mg} / \mathrm{L}$ de $4-\mathrm{CP}$ y $2,4-\mathrm{DCP}$ en agua, con ultrasonido de $20 \mathrm{kHz}$ y máxima potencia de salida de sonda de $190 \mathrm{~W} \mathrm{~cm}^{-2}$. Ellos reportaron la degradación de 78\% (4-CP) y 82\% (2,4-DCP) a una concentración de cloruros de 1.46 x $10^{-3} \mathrm{~mol} / \mathrm{L}$ y $3.17 \times 10^{-3} \mathrm{~mol} / \mathrm{L}$, respectivamente después de $32 \mathrm{~h}$. Además, no se detectaron cantidades significantes de compuestos orgánicos. Por otra parte, la adición de $500 \mathrm{mg} / \mathrm{L}$ de dodecilsulfato de sodio o ácidos húmicos (como sales de sodio) a una solución acuosa de $250 \mathrm{mg} / \mathrm{L}$ de $4-C P$, resultando en un aumento pequeño aunque significativo a la tasa de sonólisis de 4-CP.

Los autores sugieren que la existencia de una fase acuosa sobrecalentada en los sitios de cavitación, aunque importante, no puede explicar por sí misma la falta de productos de degradación orgánicos, en comparación con la hidrólisis acuosa. Por otra parte, los autores reportaron que la significante diferencia entre la tasa de sonólisis de 4fluorofenol y 4-CP indican que la incineración directa en las condiciones extremas que 


\section{CAPÍTULO 2. MARCO TEÓRICO}

se encuentran dentro de las cavidades colapsándose, no puede ser el principal contribuyente de la degradación sonolítica. En tales condiciones, las estructuras químicas de los sustratos deben jugar un papel menor.

Por eso, concluyeron que la sonólisis se produce en la vecindad y no dentro de los puntos calientes ("hot spots") de sonoquímica; lo cual apoya la noción que la sonólisis se llevaba a cabo por especies reactivas como los radicales hidroxilos.

Jiang y col. [65] investigaron la sonólisis de 4-CP en una solución acuosa de $500 \mu \mathrm{M}$, con ultrasonido de $500 \mathrm{kHz}$, una potencia ultrasónica de $30 \mathrm{~W}$ y temperatura de solución a 293 K. Reportaron la degradación completa de 4-CP después de 300 minutos y encontraron que el 4-CP a baja concentración se degrada en el seno de la solución y a mayor concentración, el 4-CP se degrada principalmente en la interfase líquido-burbujas de gas. Consiguiente, la degradación sonoquímica de 4-CP depende de la frecuencia, con mayor degradación de 4-CP a una frecuencia de $200 \mathrm{kHz}$ (de la gama de las frecuencias de 20 a $800 \mathrm{kHz}$ ).

\subsubsection{La oxidación por vía húmeda}

El método de la oxidación por vía húmeda (WAO) fue desarrollado en 1950s, por Zimmermann que puede ser utilizado para tratar efluentes industriales que contienen compuestos recalcitrantes que no son aptos para incineración o tratamientos biológicos. El proceso WAO utiliza oxígeno puro o aire como agente oxidante; se lleva a cabo a temperatura elevada (473 - 623 K) y a alta presión (2 - 15 MPa) con tiempo de residencia de la fase líquida de $15-20 \mathrm{~min}$. El rango recomendado de carga DQO es de 10 a $100 \mathrm{~g} / \mathrm{L}$ con una remoción típica de la DQO de 75 a $90 \%$.

La oxidación por vía húmeda involucra muchas reacciones de oxidación e hidrólisis, incluyendo la formación de radicales hidroxilos, y la capacidad de degradar los contaminantes orgánicos a dióxido de carbono $\left(\mathrm{CO}_{2}\right)$, agua y compuestos biodegradables como ácidos orgánicos de cadenas cortas. Las siguientes reacciones muestran la reacción del proceso WAO y diferentes tipos de orgánicos de interés [66]: 


\section{CAPÍTULO 2. MARCO TEÓRICO}

Orgánicos $+\mathrm{O}_{2} \rightarrow \mathrm{CO}_{2}+\mathrm{H}_{2} \mathrm{O}+\mathrm{RCOOH}^{*} \quad$ Ecuación 2-9

Cloruros Orgánicos $+\mathrm{O}_{2} \rightarrow \mathrm{Cl}^{-1}+\mathrm{CO}_{2}+\mathrm{RCOOH}^{*} \quad$ Ecuación 2-10

El rendimiento del proceso WAO se puede mejorar aplicando catalizadores homogéneos $(\mathrm{Cu}, \mathrm{Fe}, \mathrm{Ni}, \mathrm{Co}$ y $\mathrm{Mn})$ o heterogéneos: rutenio $(\mathrm{Ru})$, rodio $(\mathrm{Rh})$, paladio (Pd), Iridio (Ir) y platino (Pt), así como óxidos de metales (Cr, Mn, Fe, Co, $\mathrm{Ni}, \mathrm{Cu}, \mathrm{Zn}$, Mo y Ce) [67]. Por la acción del catalizador se busca aumentar la velocidad y disminuir el tiempo de la reacción.

En el tratamiento de la oxidación catalítica por vía húmeda (CWAO) de los compuestos orgánicos, normalmente, un metal noble como: Ru, Rh, Ir, Pd y Pt muestran mayor actividad catalítica, mayor estabilidad y mayor resistencia a la lixiviación del metal que el catalizador óxido de metal base, como el cobre. Por lo general, se usaron soportes de $\mathrm{y}$-alúmina $\left(\mathrm{y}-\mathrm{Al}_{2} \mathrm{O}_{3}\right)$, óxido de titanio $\left(\mathrm{TiO}_{2}\right)$ y óxido de cerio $\left(\mathrm{CeO}_{2}\right)$, óxido de circonio $\left(\mathrm{ZrO}_{2}\right)$ y el carbón, entre 0.1 y $5 \%$ wt, del metal noble [68].

Algunos investigadores [69-71] aplicaron CWAO para tratar fenoles y ácidos fórmico, acético y oxálico. Se han reportado que los compuestos clorados pueden causar problemas de desgaste a temperatura y presión elevada como resultado de generar $\mathrm{HCl}$ durante la descomposición y problemas con la remoción de los catalizadores homogéneos. Para resolver este problema se propone usar temperatura y presión más bajas con catalizadores muy activos. Por eso, el proceso de CWAO ha sido estudiado por muchos investigadores para encontrar condiciones operativas óptimas y catalizadores adecuados.

Li y col. [72] estudiaron la degradación por CWAO de los monoclorofenoles (2, 3 y 4CP). Los experimentos fueron llevados a cabo en un autoclave con un volumen de 150 $\mathrm{mL}$ del 2-CP $(2 \mathrm{~g} / \mathrm{L})$, catalizador $(0.5 \mathrm{~g})$, temperatura de $413 \mathrm{~K}$ y presión menor de 5 $\mathrm{MPa}$. Los autores estudiaron al Pt, Pd y Ru soportados sobre óxido de circonio $\left(\mathrm{ZrO}_{2}\right)$. Obtuvieron $100 \%$ de degradación del 2-CP y $83 \%$ de remoción de COT con 3wt. $\% \mathrm{Ru} / \mathrm{ZrO}_{2}$ después de $8 \mathrm{~h}$. Aunque la tasa inicial de reacción fue similar a la del $\mathrm{Ru} / \mathrm{ZrO}_{2}$ y $\mathrm{Pt} / \mathrm{ZrO}_{2}$ de 6.7 y 6.3 mol$_{2}$-cp. $\mathrm{mol}^{-1}$ respectivamente, el catalizador de $\mathrm{Pt} / \mathrm{ZrO}_{2}$ 


\section{CAPÍTULO 2. MARCO TEÓRICO}

no fue tan eficiente en la degradación de los ácidos carboxílicos formados, y solo alcanzó 54\% de remoción del COT. La secuencia de la reactividad de catalizador fue $\mathrm{Ru} / \mathrm{ZrO}_{2}>\mathrm{Pt} / \mathrm{ZrO}_{2}>\mathrm{Pd} / \mathrm{ZrO}_{2}$. A partir del análisis, cantidad de trazas de los catecoles, cloro-hidroquinona, hidroquinona, cloro-p-benzoquinona y benzoquinona fueron identificados al inicio de la reacción y después los ácidos carboxílicos de cadena pequeña tales como acético, cloroacético y ácido succínico. Asimismo, se obtuvieron $100 \%$ degradación del 3-CP y del 4-CP y hasta $80 \%$ de la remoción de COT con 3wt. $\% \mathrm{Ru} / \mathrm{ZrO}_{2}$ después de $10 \mathrm{~h}$.

Otros investigadores [71] han reportado resultados similares en la reactividad del catalizador de Ru soportado en óxido cerio (IV), en la CWAO de fenol, donde la secuencia fue $\mathrm{Ru} / \mathrm{CeO}_{2}>\mathrm{Pt} / \mathrm{CeO}_{2}>\mathrm{Pd} / \mathrm{CeO}_{2}$; se reportó la degradación casi total del fenol a $433 \mathrm{~K}$ y $2 \mathrm{MPa}$ de oxígeno después de $3 \mathrm{~h}$.

En otro estudio usando Pt/TiO2-Ce como catalizador los principales intermediarios identificados por cromatografía de gases (GC) fueron: catecol, hidroquinona, ácido oxálico y ácido maleico [68]. En otra investigación [73], se utilizó un catalizador del óxido de hierro soportado sobre carbón derivado de lodos de depuración en la oxidación catalítica por vía húmeda de 2-CP. Los experimentos se llevaron a cabo en un reactor batch con un volumen $150 \mathrm{~mL}$ de $2-\mathrm{CP}(2 \mathrm{~g} / \mathrm{L})$ operado a $393 \mathrm{~K}$ y presión parcial menor de 0.9 MPa, logrando una descomposición completa de 2-CP después de 5 h y $90 \%$ de la remoción de COT después de 24 h. Los intermediarios identificados fueron ácido fórmico, ácido oxálico, ácido succínico, hidroquinona, clorohidroquinona, 4-clororesorcinol, catecol y ácido maleico. Además, se reportaron lixiviación de hierro a pH ácido, lo cual es un problema con tratamiento catalítico homogéneo.

Asimismo, Chaliha y col. [74], estudiaron la aplicación de oxidación catalítica por vía húmeda con y sin peróxido hidrógeno, para el tratamiento de compuestos clorofenólicos. Ellos usaron el metal de transición Manganeso (Mn) y soportado de catalizador MCM41, sintetizado con óxido de silicio [SiOz: 0.27], cloruro de hexadeciltrimetilamonio [HDTMA-Cl: 0.06 , sulfato de aluminio $\left[\mathrm{Al}_{2}\left(\mathrm{SO}_{4}\right)_{3} \cdot 18 \mathrm{H}_{2} \mathrm{O}\right.$ : 


\section{CAPÍTULO 2. MARCO TEÓRICO}

0.03], óxido de sodio [ $\mathrm{Na}_{2} \mathrm{O}: 0.33$ ] e hidróxido de amonio tetrametilo [TMAOH: $20 \mathrm{H}_{2} \mathrm{O}$ ]. La oxidación catalítica se llevó a cabo en un reactor agitado con un volumen de $25 \mathrm{~mL}$ de 2,4-DCP $\left(10^{-3} \mathrm{M}\right)$ a pH 6.2, carga de catalizador Mn(II)-MCM41 (2 g/L), agitación de $180 \mathrm{rpm}$, temperatura elevada (de $333 \mathrm{~K}$ a $413 \mathrm{~K}$ ) y presión de $0.2 \mathrm{MPa}$ durante 5 horas.

El análisis de la preparación de catalizador por dos métodos demuestra que introducir el metal de transición, Mn (II) soportado en MCM41 a través del método de impregnación formó catalizadores más eficaces para la oxidación húmeda de 2,4-DCP que los catalizadores formados a partir del método de hidrotérmico. El catalizador impregnado Mn(II)-MCM41 muestra que un aumento en la temperatura de la reacción de $333 \mathrm{~K}$ a $373 \mathrm{~K}$ resultó en un aumento de la eliminación de DCP de $84.5 \%$ a $88 \%$, $\sin \mathrm{H}_{2} \mathrm{O}_{2}$.

Sin embargo, en la presencia de $\mathrm{H}_{2} \mathrm{O}_{2}(1: 1)$, un aumento en la temperatura de $333 \mathrm{~K} \mathrm{a}$ $393 \mathrm{~K}$ resultó en una remoción de DCP de solo $75.5 \%$ a $85 \%$. En ambos casos, no se reportó más eliminación del DCP con el aumento continuo de la temperatura hasta 413 $\mathrm{K}$, así que, el porcentaje final de remoción de DCP fue mejor $\sin \mathrm{H}_{2} \mathrm{O}_{2}$ que con ella. Las reacciones catalíticas fueron del primer orden, con el coeficiente de velocidad $k_{1}$ $=1.4 \times 10^{-2} \mathrm{~min}^{-1} \sin \mathrm{H}_{2} \mathrm{O}_{2}$ y k $1=9.4 \times 10^{-3} \min ^{-1}$ con $\mathrm{H}_{2} \mathrm{O}_{2}$. El pH del medio influye en la oxidación y se observó que la oxidación de 2,4-DCP fue favorecida un pH ácido. Del mismo modo, se reportaron lixiviación de Manganeso ( $\mathrm{Mn}<0.4 \mathrm{mg} / \mathrm{L})$ [74].

Por otro lado, la oxidación húmeda peróxido con (WPO) fue estudiada para tratar efluentes industriales. La WPO es una adaptación del reactivo de Fenton clásico. La WPO se permite altas eficiencias de oxidación en condiciones operacionales (90 - 130 ${ }^{\circ} \mathrm{C}$ y 0.1 - $0.5 \mathrm{MPa}$ ), usando peróxido de hidrógeno y una metálica homogénea $\mathrm{Fe}^{2+}$ catalizador a pH 3. Este proceso fue empleado con éxito en España en 1992 en dos diferentes acuíferos con una unidad de demostración destinado para un caudal de 5 $\mathrm{m}^{3} / \mathrm{h}$ cerca de Madrid y Barcelona [75]. 


\section{CAPÍTULO 2. MARCO TEÓRICO}

García-Molina y col. [76] aplicaron la WPO para tratar 4-CP y 2,4-DCP (1000 mg/L). Se reportaron $100 \%$ de la degradación de 4-CP y 2,4-DCP; remoción de COT de 75.9\% y $72.1 \%$ por 4 -CP y 2,4-DCP respectivamente a $100{ }^{\circ} \mathrm{C}$ con $5 \mathrm{~mL}$ de $\mathrm{H}_{2} \mathrm{O}_{2}$ después de 90 minutos.

De esta manera, Kurian y col. [77] investigaron el tratamiento CWPO de 2,4-DCP (500 $\mathrm{mg} / \mathrm{L})$. Los resultados mostraron $100 \%$ de la degradación de $2,4-\mathrm{DCP}, 22 \%$ de la remoción de COT y 45\% remoción de DQO usando una carga de catalizador $\mathrm{Ce}_{0.5} \mathrm{~V}_{0.5} \mathrm{O}_{2}$ de $0.5 \mathrm{~g} / \mathrm{L}, 0.06 \mathrm{~mol} \mathrm{~L}^{-1} \mathrm{H}_{2} \mathrm{O}_{2}$, a temperatura de $343 \mathrm{~K}$ por 60 minutos.

Aunque el proceso de WAO tiene muchos beneficios como se mencionó anteriormente, también tiene algunas desventajas como su inhabilidad para mineralizar completamente los compuestos orgánicos y los altos costos de energía empleada. Aunque, los catalizadores homogéneos son efectivos para tratar efluentes industriales, se necesita un paso adicional para eliminar o recuperar los iones de metal del efluente tratado debido, en algunos casos, a su toxicidad, y por consecuencia aumentarán los costos operacionales.

Por lo tanto, el desarrollo de catalizadores heterogéneos ha recibido una gran atención porque no necesita un paso adicional para separar los catalizadores. Pero, una de las principales limitaciones en la aplicación de catalizadores sólidos es la relativamente rápida desactivación en condiciones de reacción de CWAO. Los catalizadores heterogéneos se desactivan en CWAO debido principalmente a envenenamiento, la deposición de coque, y la lixiviación de metales especialmente en condiciones ácidas [78].

En general, óxidos de cerio y titanio son los soportes para catalizadores más usados $[78,68]$ en el proceso de CWAO. En especial el catalizador de cerio por asegurar una alta resistencia química bajo condiciones de CWAO y por promover la funcionalidad total de la oxidación debido a su capacidad de almacenar oxígeno, basado en el comportamiento redox, entre $\mathrm{Ce}^{4+} \mathrm{y} \mathrm{Ce}^{3+}[68,77]$. 


\section{CAPÍTULO 2. MARCO TEÓRICO}

\subsubsection{Procesos del reactivo Fenton y Foto-Fenton}

Los procesos del reactivo Fenton y Foto-Fenton están incluidos en los POAs conocidos como fotocatálisis homogénea.

\section{Fenton Clásico}

El proceso de Fenton fue llamado así por Henry Fenton 1894; se emplea peróxido de hidrógeno y especies de hierro a temperatura y presión atmosférica. Algunos autores han investigado el efecto positivo de aumentar la temperatura ([79, 80]). La combinación del hierro $\left(\mathrm{Fe}^{2+}\right)$ y peróxido de hidrógeno $\left(\mathrm{H}_{2} \mathrm{O}_{2}\right)$ genera radicales hidroxilo $\left(\mathrm{OH}^{*}\right)$, ion de Hidróxido $\left(\mathrm{OH}^{-}\right)$y Hierro (III) $\left(\mathrm{Fe}^{3+}\right)$ [80]. El óptimo pH es alrededor 2.5 - 5.0 [81], con una óptima relación molar de $\mathrm{H}_{2} \mathrm{O}_{2}$ de 25 [79] y una concentración de $\mathrm{Fe}^{2+}$ menor de $15 \mathrm{mg} / \mathrm{L}$ [82].

$\mathrm{Fe}^{2+}+\mathrm{H}_{2} \mathrm{O}_{2} \rightarrow \mathrm{Fe}^{3+}+\mathrm{OH}^{-}+\mathrm{OH}^{-} ; \quad \mathrm{k}=76 \mathrm{M}^{-1} \mathrm{~s}^{-1}[83] \quad$ Ecuación 2-11

Los radicales hidroxilos formados pueden reaccionar con los compuestos orgánicos $(\mathrm{M})$, resultando en sus descomposiciones a diferentes productos intermedios y finales (Moxid.).

$$
\mathrm{M}+\mathrm{OH}^{\cdot} \rightarrow \text { Moxid. } \quad \text { Ecuación 2-12 }
$$

Al mismo tiempo, se produce un efecto secuestrante cuando se reaccionan los radicales con Hierro (II) y peróxido de hidrógeno [79]:

$$
\begin{array}{cr}
\mathrm{OH}^{\cdot}+\mathrm{Fe}^{2+} \rightarrow \mathrm{Fe}^{3+}+\mathrm{OH}^{-} \quad \mathrm{k}=3 \times 10^{8} \mathrm{M}^{-1} \mathrm{~s}^{-1} & \text { Ecuación 2-13 } \\
\mathrm{OH}^{\cdot}+\mathrm{H}_{2} \mathrm{O}_{2} \rightarrow \mathrm{H}_{2} \mathrm{O}+\mathrm{HO}_{2} & \text { Ecuación 2-14 }
\end{array}
$$

El Hierro (II) en la presencia de un exceso de $\mathrm{H}_{2} \mathrm{O}_{2}$ se oxida a Hierro (III), el peróxido de hidrógeno se descompone catalíticamente por $\mathrm{Fe}^{3+}$ y se generan radicales hidroxilo de nuevo. El sistema de $\mathrm{Fe}$ (III) con $\mathrm{H}_{2} \mathrm{O}_{2}$ es conocido como el proceso de tipo Fenton homogéneo; se genera Fe(II) in situ [82, 83]:

$$
\mathrm{Fe}^{3+}+\mathrm{H}_{2} \mathrm{O}_{2} \leftrightarrow \mathrm{H}^{+}+\mathrm{Fe}^{-} \mathrm{OOH}^{2+} \quad \text { Ecuación 2-15 }
$$




$$
\mathrm{Fe}-\mathrm{OOH}^{2+} \rightarrow \mathrm{Fe}^{2+}+\mathrm{HO}_{2} \cdot \quad \text { Ecuación 2-16 }
$$

Las principales ventajas asociadas al proceso de Fenton son: muy eficaz para generar radicales hidroxilo, es fácil de manejar, utiliza reactivos muy comunes de bajos costos y no tóxicos (hierro y peróxido de hidrógeno). Las principales desventajas de este proceso son el consumo rápido de $\mathrm{Fe}^{2+}$ en comparación con su tasa de regeneración (necesita una molécula de $\mathrm{Fe}^{2+}$ para cada $\mathrm{OH}^{*}$ producido), la producción de un lodo que necesita de pos-tratamiento, el pH limitado de operación (pH 2 a 5.3), la formación de complejos de algunas especies de hierro y la posible pérdida de oxidantes (debido al efecto secuestrante de $\mathrm{H}_{2} \mathrm{O}_{2}$ ) o por auto-descomposición [80, 84] y la formación de productos intermedios tóxicos $[83,80,85]$.

Por ejemplo, en un estudio [82] alcanzó una degradación completa de 2,4-DCP (0.61 $\mathrm{mM}$ ) a pH 4.5-6 usando Fenton, con $2.84 \mathrm{mM}$ de $\mathrm{H}_{2} \mathrm{O}_{2}$ y $10 \mathrm{mg} / \mathrm{L} \mathrm{Fe}(\mathrm{II})$ en 60 minutos. También se observó que el aumento de la concentración de iones hierro (a menos de $15 \mathrm{mg} / \mathrm{L}$ ) tuvo un efecto positivo en la remoción de DCP, aunque la remoción de COT quedó bajo (12\%), mientras que en otro estudio [81], de la degradación de 2,4-DCP ( $0.15 \mathrm{mM}$ ) a pH 3 con Fenton usando $10 \mathrm{mM}$ de $\mathrm{H}_{2} \mathrm{O}_{2}$ y $0.2 \mathrm{mM}$ de $\mathrm{Fe}(\mathrm{II})$, se reportó una remoción de 100\% después de 90 minutos y una velocidad de reacción, k2,4-DCP = $0.10 \mathrm{~min}^{-1}$. Por otra parte, el proceso de Fenton resultó inefectivo en la mineralización de 2,4-DCP [81, 82]. De esta forma, se muestra 48\% inhibición a las bacterias de Vibrio fischeri en las pruebas de toxicidad de BioTox ${ }^{\mathrm{TM}}$ en estudio.

Andreozzi y col. [83] en su estudio sobre la oxidación de tipo Fenton homogénea $\left(\mathrm{H}_{2} \mathrm{O}_{2} / \mathrm{Fe}^{3+}\right)$ de 2,4-DCP y 3,4-DCP, se obtuvieron una degradación completa en 15 minutos $\left(\mathrm{Fe}^{3+}=2 \times 10^{-4} \mathrm{~mol} \mathrm{~L}^{-1}\right)$ de 2,4-DCP con una mineralización de $50 \%$. Los resultados de las pruebas de toxicidad para las algas Pseudokirchneriella subcapitata en muestras de soluciones acuosas sin tratamiento de 2,4-DCP $\left(6 \times 10^{-5} \mathrm{~mol} \mathrm{~L}^{-1}\right)$ son tóxicos y la toxicidad para las algas disminuye durante el tratamiento de 2,4-DCP (60 $\mathrm{min})$. Por otra parte, las soluciones acuosas sin tratamiento de 3,4-DCP $\left(6 \times 10^{-5} \mathrm{~mol}\right.$ $\mathrm{L}^{-1}$ ) no resultan tóxicos a las algas, pero las muestras tratadas de 20 y 60 min muestran 


\section{CAPÍTULO 2. MARCO TEÓRICO}

toxicidad a las algas, y solo después de 120 minutos disminuye esta toxicidad a las algas. Por otra parte, los resultados de la decloración de 2,4-DCP y 3,4-DCP fueron menos de $45 \%$. Por lo tanto, indica la presencia de especies orgánicas altamente cloradas, refractaria a la mineralización, entre los compuestos intermedios y productos de reacción.

Tang y Huang investigaron el efecto de la posición de los átomos de cloro en clorofenoles en su cinética de decloración por reactivos Fenton. Los autores encontraron que la posición de los átomos de cloro en el anillo aromático tuvo un efecto diferente en la constante de velocidad de decloración; se encontró que el átomo de cloro en la posición meta tuvo una tasa de decloración constantemente más rápida que la del átomo de cloro en la posición orto. Además, el efecto de la posición de cloro en la decloración de DCP se nota mejor cuando la relación de $\mathrm{H}_{2} \mathrm{O}_{2}$ y DCP fue de 20 , la constante de velocidad de decloración disminuyó como se muestra: 2,5-DCP > 3,5DCP $>$ 2,3-DCP > 2,6-DCP > 2,4-DCP [45].

Por otro lado un estudio [86] de la degradación de 2,4-DCP y PCP usando hidrodecloración y unos novedosos procesos de oxidación tipo Fenton heterogéneos, que se llevaron a cabo en condiciones ambientales $\left(25 \pm 2^{\circ} \mathrm{C}\right.$ y presión atmosférica) como una reacción en un solo recipiente ("one-pot reaction") que involucró el ácido fórmico como fuente de hidrógeno $\left(\mathrm{H}_{2}\right)$, para hidrodecloración de CP y la formación de $\mathrm{H}_{2} \mathrm{O}_{2}$. Se aplicó un catalizador de $\mathrm{Pd}-\mathrm{Fe}$ soportado en alúmina se aplicó, para descomponer el ácido fórmico en los sitios de $\mathrm{Pd}$, formando $\mathrm{H}_{2}$ y $\mathrm{CO}_{2}$, y también $\mathrm{H}_{2} \mathrm{O}_{2}$ en presencia de $\mathrm{O}_{2}$. Por ende, debido a la presencia de sitios de hierro en el catalizador, el $\mathrm{H}_{2} \mathrm{O}_{2}$ formado puede ser utilizado para una reacción de oxidación de tipo Fenton. Se observaron alta mineralización $(70 \%)$ y degradación completa para DCP y PCP.

\section{Foto-Fenton}

El proceso de Fenton puede mejorar por la adición de una fuente de irradiación luminosa, ya que la luz UV puede acelerar la velocidad de regeneración de $\mathrm{Fe}^{2+}$ a partir 


\section{CAPÍTULO 2. MARCO TEÓRICO}

de $\mathrm{Fe}^{3+}$ complejos, mientras que la reacción adicional, el complejo $\mathrm{Fe}(\mathrm{OH})^{2+}$ se forma en condición ácida $(\mathrm{pH} 3)$ :

$$
\begin{array}{ll}
\mathrm{Fe}^{3+}+\mathrm{H}_{2} \mathrm{O} \rightarrow \mathrm{Fe}(\mathrm{OH})^{2+}+\mathrm{H}^{+} & \text {Ecuación 2-17 } \\
\mathrm{Fe}(\mathrm{OH})^{2+} \leftrightarrow \mathrm{Fe}^{3+}+\mathrm{OH}^{-} & \text {Ecuación 2-18 }
\end{array}
$$

Cuando se expone a la irradiación UV, el complejo se somete también a descomposición y producirá iones $\mathrm{OH}^{*}$ y $\mathrm{Fe}^{2+}$ :

$$
\mathrm{Fe}(\mathrm{OH})^{2+}+\lambda \mathrm{u} \rightarrow \mathrm{Fe}^{2+}+\mathrm{OH}^{\cdot} \quad \text { Ecuación 2-19 }
$$

El proceso de foto-Fenton se utiliza de manera eficiente el fotón y la fotolisis de $\mathrm{Fe}$ (III) e intermedios de quelatos orgánicos [82]. El peróxido de hidrógeno no absorbe luz más allá de $300 \mathrm{~nm}$ y tiene un bajo coeficiente de extinción cerca de $250 \mathrm{~nm}$. Por otro lado, el ion férrico se extiende cerca de la región de UV-visible, permitiendo así la fotooxidación y mineralización incluso por luz visible [84]. El foto-Fenton es más eficiente al generar radicales hidroxilo que el proceso de Fenton clásico y por eso la velocidad de descomposición de compuestos orgánicos es más rápida.

Al momani y col. [82] en su estudio demostraron que el proceso de foto-Fenton se degrada el 2,4-DCP más rápido que el proceso de Fenton. Resultados similares fueron obtenidos en otro estudio [40]. En el estudio de la degradación de 2,4-DCP con el proceso de foto-Fenton $\left(\mathrm{k}=88 \mathrm{~min}^{-1}\right)$ fue más rápido que con el proceso de Fenton ( $\mathrm{k}$ = $\left.38 \mathrm{~min}^{-1}\right)$. La descomposición de 2,4-DCP después de 5 minutos fueron de 19.4\% y $38.7 \%$, respectivamente por los procesos de Fenton y foto-Fenton respectivamente.

\subsubsection{Ultravioleta con peróxido de hidrógeno}

La fotólisis del peróxido de hidrógeno $\left(\mathrm{UV}-\mathrm{H}_{2} \mathrm{O}_{2}\right)$ se realiza utilizando lámparas de intensidad alta, media o baja. En esta fotolisis con longitud de onda $(\lambda)$ menor de 370 $\mathrm{nm}$, el peróxido de hidrógeno se somete a ruptura homolítica y logra formar radicales hidroxilo $[84,87]$ : 


$$
\mathrm{H}_{2} \mathrm{O}_{2}+\lambda \mathrm{u} \rightarrow 2 \mathrm{OH}^{\cdot} \quad \text { Ecuación 2-20 }
$$

En exceso de peróxido y con altas concentraciones de $\mathrm{HO}$ - tienen lugar reacciones competitivas que producen un efecto inhibitorio para la degradación. Los $\mathrm{HO}$ - son susceptibles de recombinarse o de reaccionar de acuerdo con el siguiente esquema [84]:

$$
\begin{array}{lr}
\mathrm{OH}^{\cdot}+\mathrm{H}_{2} \mathrm{O}_{2} \rightarrow \mathrm{HO}_{2}{ }^{\cdot}+\mathrm{H}_{2} \mathrm{O} & \text { Ecuación 2-21 } \\
\mathrm{HO}_{2}{ }^{\circ}+\mathrm{H}_{2} \mathrm{O}_{2} \rightarrow \mathrm{OH}^{\cdot}+\mathrm{H}_{2} \mathrm{O}+\mathrm{O}_{2} & \text { Ecuación 2-22 } \\
2 \mathrm{HO}_{2}{ }^{\cdot} \rightarrow \mathrm{H}_{2} \mathrm{O}_{2}+\mathrm{O}_{2} & \text { Ecuación 2-23 } \\
\mathrm{HO}_{2}{ }^{\cdot}+\mathrm{OH}^{\cdot} \rightarrow \mathrm{H}_{2} \mathrm{O}+\mathrm{O}_{2} & \text { Ecuación 2-24 }
\end{array}
$$

Antonaraki y col. [87] en su estudio de la foto-degradación $(\lambda>320 \mathrm{~nm})$ de los DCPes $(0.001 \mathrm{M})$ a $\mathrm{pH} 1$ con peróxido de hidrógeno $(0.1 \mathrm{M})$ encontraron que la inicial velocidad de degradación en M.min ${ }^{-1}$ fueron de $4.22 \times 10^{5}, 3.94 \times 10^{5}, 5.00 \times 10^{5}, 3.90$ x $10^{5}, 4.92$ x $10^{5}$ y $5.8 \times 10^{5}$ por 2,3-DCP, 2,4-DCP, 2,5-DCP, 2,6-DCP, 3,4-DCP y 3,5DCP, respectivamente. Pues, el radical hidroxilo, un reactivo electrófilo, ataca los CPs en las posiciones ricas de electrones y causa que estos substratos se oxiden más rápido. Por eso, la presencia de dos sustituyentes de cloro en las posiciones meta del anillo fenólico, aumenta la velocidad de foto-degradación como puede verse en los resultados.

Huang y col. [88] en su investigación de la reacción de fenol con UV- $\mathrm{H}_{2} \mathrm{O}_{2}$ por 104 minutos encontraron las siguientes intermediaros por GC-MS: hidroquinona, catecol y algunos otros compuestos de alto peso molecular como 2 -fenoxi-fenol, ácido 1,4bencenodicarboxílico, (1,1-dimetiletil)-2-metoxi-fenol, 2,6-bis(1,1-dimetiletil)-naftaleno, 2,3-dihidro-1,4-benzodioxin-2- metanol y 1,1'-bifenil-2,2'-diol.

\subsubsection{Ozonización con peróxido de hidrógeno}

La ozonización transforma los contaminantes en compuestos más simples. Agregando peróxido de hidrógeno a ozono $\left(\mathrm{O}_{3}-\mathrm{H}_{2} \mathrm{O}_{2}\right)$ mejora el poder de este oxidante 


\section{CAPÍTULO 2. MARCO TEÓRICO}

para descomponer compuestos orgánicos refractarios, ya que la reacción entre $\mathrm{H}_{2} \mathrm{O}_{2}$ y ozono genera radicales hidroxilo [47, 89]:

$$
\begin{array}{lcc}
\mathrm{H}_{2} \mathrm{O}_{2} \rightarrow \mathrm{HO}_{2}^{-}+\mathrm{H}^{+} & \text {Ecuación 2-25 } \\
\mathrm{HO}_{2}^{-}+\mathrm{O}_{3} \rightarrow \mathrm{O}_{3}{ }^{-}+\mathrm{HO}_{2}{ }^{\cdot} & \mathrm{k}=2,8 \times 10^{6} \mathrm{M}^{-1} \mathrm{~s}^{-1} & \text { Ecuación 2-26 } \\
\mathrm{O}_{2}{ }^{-}+\mathrm{O}_{3} \rightarrow \mathrm{O}_{3}{ }^{-}+\mathrm{O}_{2} & \mathrm{k}=1,6 \times 10^{9} \mathrm{M}^{-1} \mathrm{~s}^{-1} & \text { Ecuación 2-27 } \\
\mathrm{O}_{3}^{-}+\mathrm{H}^{+} \rightarrow \mathrm{HO}_{3}+\mathrm{O}_{2} & \mathrm{k}=5,2 \times 10^{10} \mathrm{M}^{-1} \mathrm{~s}^{-1} & \text { Ecuación 2-28 } \\
\mathrm{HO}_{3}{ }^{-} \rightarrow \mathrm{OH}^{-}+\mathrm{O}_{2} & \mathrm{k}=1,1 \times 10^{5} \mathrm{~s}^{-1} & \text { Ecuación 2-29 } \\
\mathrm{O}_{3}+\mathrm{OH}^{-} \rightarrow \mathrm{O}_{2}+\mathrm{HO}_{2} & \mathrm{k}=1.1 \times 10^{8} \mathrm{M}^{-1} \mathrm{~s}^{-1} & \text { Ecuación 2-30 } \\
\mathrm{O}_{3}+\mathrm{HO}_{2} \cdot \rightarrow 2 \mathrm{O}_{2}+\mathrm{HO} & & \text { Ecuación 2-31 }
\end{array}
$$

Kusic y col. [47] en su estudio de la degradación de fenol con ozono y peróxido de hidrógeno, se encontraron que la adición de peróxido de hidrógeno a ozono si mejora el proceso.

También algunos autores investigaron la combinación de dos o más procesos de oxidación avanzada para el tratamiento de aguas residuales. Por ejemplo, RuedaMaruqez y col. [90] investigaron el tratamiento de un efluente de aguas residuales municipales con adición de fenol, 4-CP, naranja-Il y fenantreno con múltiples tratamientos: microfiltración $(0.7 \mu \mathrm{m})$, después $\mathrm{H}_{2} \mathrm{O}_{2}-\mathrm{UVC}$ y finalmente la oxidación húmeda catalítica de peróxido (CWPO) de $\mathrm{H}_{2} \mathrm{O}_{2} / \mathrm{GAC}$ por 2.3 minutos de contacto. Los resultados mostraron que los tratamientos múltiples se mejoran la calidad de las aguas residuales con adición de los compuestos y reducen la toxicidad medida por pruebas de toxicidad con $V$. fischeri y S. aurata.

\subsubsection{Oxidación fotocatalítica}

En la oxidación fotocatalítica ( $\mathrm{TiO}_{2}-\mathrm{UV}$ ), el semiconductor absorbe la luz UV y genera principalmente radicales hidroxilo $\left(\mathrm{OH}^{\circ}\right)$ del agua adsorbida, y iones de hidróxido $\left(\mathrm{OH}^{-}\right.$ ) [91]. Ya que, la irradiación de la superficie fotocatalítica con suficiente energía, conduce a la formación de un agujero positivo $\left(\mathrm{h}^{+}\right)$en la banda de valencia y un electrón (e $e^{-}$en la banda de conducción. El agujero positivo se oxida, ya sea el contaminante directamente o agua para producir el radical hidroxilo $\left(\mathrm{OH}^{\circ}\right)$, mientras 


\section{CAPÍTULO 2. MARCO TEÓRICO}

que el electrón en la banda de conducción reduce el oxígeno adsorbido en el fotocatalizador $\left(\mathrm{TiO}_{2}\right)$. La presencia de oxígeno puede prevenir la recombinación de un "par hueco-electrón". La activación de $\mathrm{TiO}_{2}$ por la luz UV se representa por las siguientes etapas [92]:

$$
\begin{array}{ll}
\mathrm{TiO}_{2}+\lambda \mathrm{v}(\lambda<387 \mathrm{~nm}) \rightarrow \mathrm{e}^{-}+\mathrm{h}^{+} & \text {Ecuación 2-32 } \\
\mathrm{e}^{-}+\mathrm{O}_{2} \rightarrow \mathrm{O}_{2}{ }^{-} & \text {Ecuación 2-33 }
\end{array}
$$

Dónde, $\mathrm{h}^{+}$y e- son poderosos agentes oxidantes y reductores, respectivamente.

Reacción oxidativa:

$$
\begin{aligned}
& \mathrm{h}^{+}+\text {Orgánicos }(\mathrm{R}) \rightarrow \text { Intermediarios } \rightarrow \mathrm{CO}_{2}+\mathrm{H}_{2} \mathrm{O} \quad \text { Ecuación 2-34 } \\
& \mathrm{h}^{+}+\mathrm{H}_{2} \mathrm{O} \rightarrow \mathrm{OH}^{+}+\mathrm{H}^{+} \quad \text { Ecuación 2-35 }
\end{aligned}
$$

Reacción reductiva:

$$
\mathrm{OH}^{\bullet}+\text { Orgánicos }(\mathrm{R}) \rightarrow \text { Intermediarios } \rightarrow \mathrm{CO}_{2}+\mathrm{H}_{2} \mathrm{O} \text { Ecuación 2-36 }
$$

Albeish y col. [93] estudiaron el tratamiento de 4-CP y 2,4-DCP con simulador de luz solar $\left(1000 \mathrm{~mW} \mathrm{~cm}^{-2}\right)$ y catalizador TiO2 $(0.5 \mathrm{~g} / \mathrm{L})$. Ellos encontraron que la degradación de 4-CP fue más rápido que la del 2,4-DCP, lo cual puede ser por el negativo efecto de los iones cloruros sobre el catalizador. Los principales productos intermedios fueron de hidroquinona, 4-clorocatecol y fenol (concentración traza) para 4-CP y, fenol y 4-CP para 2,4-DCP. La reacción constante sigue un pseudo-primer orden de $0.814 \mathrm{~min}^{-1}(4-\mathrm{CP})$ y $0.512 \mathrm{~min}^{-1}(2,4-\mathrm{DCP})$.

llya y col. [94] investigaron la degradación foto-catalítica de 2,4-DCP y 2,5-DCP con plata y óxido de titanio $\left(\mathrm{Ag}-\mathrm{TiO}_{2}\right)$ a condiciones ácidas $(\mathrm{pH} 4)$. Los autores encontraron que el tratamiento de $\mathrm{Ag}-\mathrm{TiO}_{2}$ durante una hora puede degradar $99 \%$ de 2,4-DCP y $98 \%$ del 2,5-DCP, mientras que el 2,4-DCP fue mineralizado completamente después de 2 horas del tratamiento, el 2,5-DCP fue mineralizado a solo 95\%. Adicionalmente, el pseudo-primer orden constante de reacción de 2,4-DCP $\left(k=7.7 \times 10^{-2} \mathrm{~min}^{-1}\right)$ fue más rápido que el de 2,5-DCP $\left(\mathrm{k}=6.2 \times 10^{-2} \mathrm{~min}^{-1}\right)$. 


\section{CAPÍTULO 2. MARCO TEÓRICO}

\subsubsection{Procesos de fotólisis}

El proceso de fotólisis involucra la interacción entre la luz UV y las móleculas del substrato. Por consiguiente, se alcanza la disociación de las móleculas a fragmentos como muestran las siguientes ecuaciones (ec.2-37 y ec.2-38) de mecanismos de reacción [34]:

Degradación del CP

$$
\begin{array}{lr}
\mathrm{CP}+\lambda v \rightarrow \text { Intermediarios } & \text { Ecuación 2-37 } \\
\text { Intermediarios }+\lambda v \rightarrow \mathrm{CO}_{2}+\mathrm{H}_{2} \mathrm{O}+\mathrm{Cl}^{-} & \text {Ecuación 2-38 }
\end{array}
$$

Legrini [91] en su revisión de los procesos fotoquímicos para el tratamiento de agua, reportó la fotólisis de compuestos fenólicos con luz UV suministrada por 8 lámparas de baja presión de $\mathrm{Hg}$, cada una con $51.7 \mathrm{~W}$, donde los resultados mostraron que $23 \%$ del fenol (10 mg/L) a pH 4 fue degradado después de $40 \mathrm{~min}$, mientras que 2-CP (13.6 $\mathrm{mg} / \mathrm{L})$ y $2,5-\mathrm{DCP}(17.3 \mathrm{mg} / \mathrm{L})$ se degradaron completamente (> 99\%) en 80 y 210 minutos respectivamente a $\mathrm{pH}$ rango de 7.8 a 8.5 .

Benitez y col. [95] estudiaron la descomposición química de varios clorofenoles en solución acuosa (4- CP, 2,4-DCP, 2,4,6-TCP y 2,3,4,6-TeCP) por medio de varios oxidantes. Los resultados obtenidos por luz UV, mostraron que la descomposición de 4-CP fue la más rápida y el 2,3,4,6-TeCP presentó la constante de velocidad más lenta.

Benitez y col. [40] reportaron que durante los tratamientos fotoquímicos, se genera una excitación del estado electrónico de los fenoles policlorados. En este estado de excitación las moléculas de clorofenoles están sujetas a transformación intermolecular y el estado estabilizado con diferentes distribuciones de electrones, seguidas por productos radicales o moleculares. En la Tabla 2-2, se presenta un resumen de algunos resultados de los CPs con la luz UV. 


\section{CAPÍTULO 2. MARCO TEÓRICO}

Tabla 2-2 Radiación UV de diferentes Clorofenoles. (Benitez y col. [40])

\begin{tabular}{|c|c|c|c|c|c|}
\hline Compuesto & $\begin{array}{c}\text { Concentración } \\
\text { inicial (M) }\end{array}$ & $\mathrm{pH}$ & $\begin{array}{l}{ }^{*} X_{5} \\
(\%)\end{array}$ & $\begin{array}{l}\mathrm{k \times 10^{3 }} \\
\left(\mathrm{min}^{-1}\right)\end{array}$ & $\begin{array}{c}\Phi \times 10^{3} \\
\left(\mathrm{~mol} \mathrm{Eins}^{-1}\right)\end{array}$ \\
\hline \multirow{2}{*}{ 4-CP } & \multirow{6}{*}{$3 \times 10^{-4}$} & 2 & 93.4 & 539 & 584 \\
\hline & & 9 & & 433 & 288 \\
\hline \multirow{2}{*}{ 2,4-DCP } & & 2 & 19.4 & 38 & 35 \\
\hline & & 9 & & 173 & 37 \\
\hline \multirow{2}{*}{ 2,4,6-TCP } & & 2 & 14.4 & 26 & 18 \\
\hline & & 9 & & 81 & 15 \\
\hline
\end{tabular}

${ }^{*} X_{5}$ : porcentaje de degradación del compuesto después 5 minutos

\subsubsection{Proceso de oxidación con ozono}

En 1785, Van Marum, se dio cuenta de un olor característico en el aire cerca de su máquina electrostática y algunos años más tarde en 1801, Cruickshank igualmente percibió un olor similar en el gas formado en el ánodo durante la electrólisis del agua. Pero, no fue hasta la década de 1840 que el nombre de ozono fue dado por Schónbein, tomado de la palabra griega "ozein" (oler).

En 1857 Werner von Simens en Alemania, diseñó un sistema de generación de ozono por descarga eléctrica. Hoy en día muchos generadores de ozono están modelados en este diseño [96].

Ozono es un gas inestable, con punto de ebullición de $-112{ }^{\circ} \mathrm{C}$ y punto de fusión -192 ${ }^{\circ} \mathrm{C}$ a presión atmosférica, es parcialmente soluble en agua $\left(8.92 \mathrm{mg} / \mathrm{L}\right.$ a $\left.20{ }^{\circ} \mathrm{C}\right)$ y un olor acre, detectable fácilmente a baja concentración, sobretodo es un poderoso oxidante. A baja concentración no se espera que sea un riesgo de explosión, pero por otro lado es un gas tóxico y en caso de súbita exposición podría ser perjudicial. Por lo tanto, se deben tener muchos cuidados cuando se trabaja con ozono.

En una solución acuosa de agua destilada, el ozono tiene una vida media corta de aproximadamente 20 a 30 min a $20^{\circ} \mathrm{C}$. Aún, en la presencia del material en demanda de oxígeno se puede esperar una vida media más corta [96, 97]. Sin embargo, la presencia de los carbonatos y una disminución en la temperatura puede extender las vidas medias de ozono [98, 96]. El ozono se produce por la ruptura de una molécula 


\section{CAPÍTULO 2. MARCO TEÓRICO}

de oxígeno para formar dos fragmentos de oxígeno que pueden recombinarse con una molécula de oxígeno para formar ozono, como se muestra en las ecuaciones 2-39 y $2-40[96,97]$.

$$
\begin{array}{ll}
\mathrm{O}_{2} \leftrightarrow 2 \mathrm{O} & \text { Ecuación 2-39 } \\
\mathrm{O}_{2}+2 \mathrm{O} \leftrightarrow 2 \mathrm{O}_{3} & \text { Ecuación 2-40 }
\end{array}
$$

Hoigné y Bader [99] observaron que la reacción de ozono es conocida por su alta selectividad y carácter especifico, por eso tiene una amplia aplicación en química orgánica analítica y sintética. En la Tabla 2-3 se muestran los potenciales de oxidación de algunas especies y se observa que el $\mathrm{OH}^{*}$ es el oxidante más potente despues del flúor.

Tabla 2-3 Potenciales redox estandares de algunos oxidantes en medio ácido

(Pera-Titus y otros [34])

\begin{tabular}{|l|l|}
\hline Oxidante & Eo $(V$ vs.NHE) \\
\hline Flúor $\left(\mathrm{F}_{2}\right)$ & 3.03 \\
\hline Radical hidroxilo $\left(\mathrm{OH}^{\circ}\right)$ & 2.80 \\
\hline Oxígeno atómico $(\mathrm{O})$ & 2.42 \\
\hline Ozono $\left(\mathrm{O}_{3}\right)$ & 2.07 \\
\hline Peróxido de hidrógeno $\left(\mathrm{H}_{2} \mathrm{O}_{2}\right)$ & 1.77 \\
\hline Permanganato de pótasio $\left(\mathrm{KmnO}_{4}\right)$ & 1.67 \\
\hline Ácido hipobromoso $(\mathrm{HbrO})$ & 1.59 \\
\hline Dióxido de cloro $\left(\mathrm{ClO}_{2}\right)$ & 1.50 \\
\hline Acido hipocloroso $(\mathrm{HClO})$ & 1.49 \\
\hline Cloro $\left(\mathrm{Cl}_{2}\right)$ & 1.36 \\
\hline Bromo $\left(\mathrm{Br}_{2}\right)$ & 1.09 \\
\hline
\end{tabular}

- NHE- Electrodo Normal de Hidrógeno

El modelo para soluciones acuosas propuesto por Hoigné y Bader [38], muestra que las condiciones de reacción por ozonación pueden ocurrir desde los dos diferentes mecanismos de oxidación postulados en un esquema de reacción en la figura 2-2. La ruta primaria en la region ácida es cuando los solutos presentes reacciónan rapidamente con ozono molecular de forma directa, el cual es altamente selectivo y es conocida como reacciones directas de ozono molecular. Por otro lado, si las 


\section{CAPÍTULO 2. MARCO TEÓRICO}

condiciones de reacción escogidas están dirigidas por ozono con alto $\mathrm{pH}$, los radicales hidroxilo $\left(\mathrm{OH}^{\circ}\right)$ son los principales especies oxidativos.

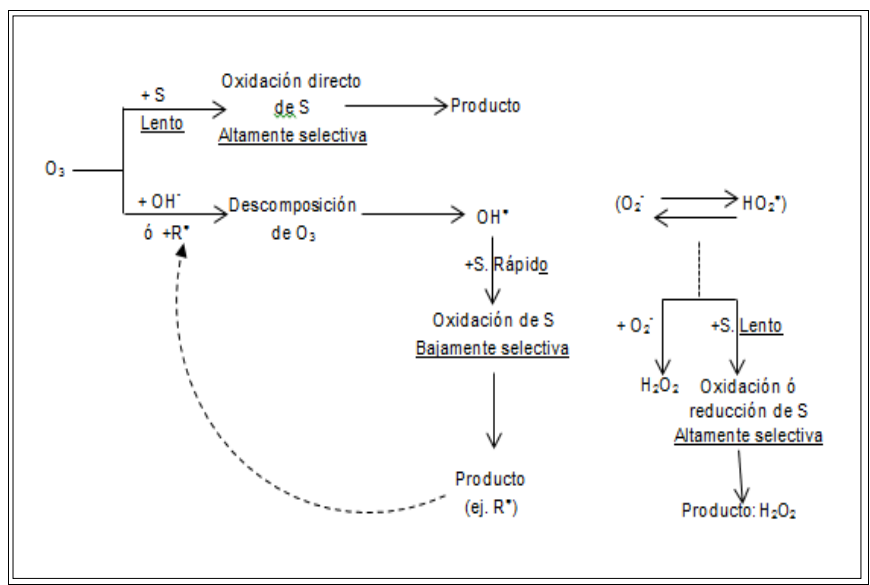

Figura 2-2 Reacciones de sustratos $(\mathrm{S})$ con $\mathrm{O}_{3}$ y la reacción de descomposición de $\mathrm{O}_{3}$ en pugna por consumo de $\mathrm{O}_{3}$ (Hoigné y Bader [38])

La figura 2-3 es un esquema que muestra las especies principales presentes en la descomposición de ozono por reacción radical en un proceso de cadena cíclica. La cadena cíclica esta iniciada por un alcalino tal como un ion hidróxido $\left(\mathrm{OH}^{-}\right)$o por la adición directa de peróxido de hidrógeno para formar radicales hidroxilo $\left(\mathrm{OH}^{*}\right)$, la cual no es selectiva en su reacción de oxidación y por eso puede oxidar muchos compuestos orgánicos.

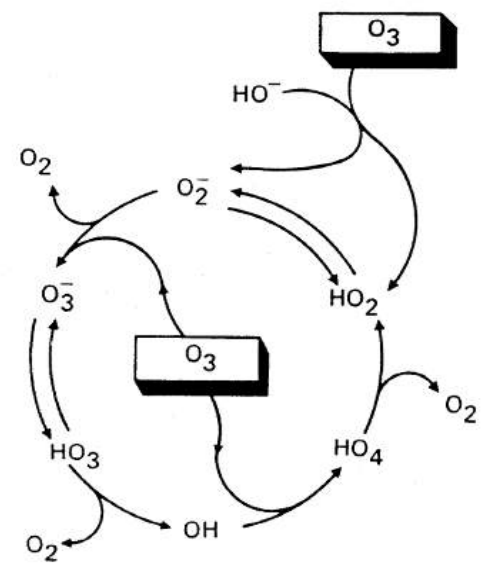

Figura 2-3 Esquema mostrando la descomposición del ozono iniciado por ion hidróxido en agua destilada; Glaze y col. [33] 


\section{CAPÍTULO 2. MARCO TEÓRICO}

Por otra parte, la constante de velocidad de los radicales $\mathrm{OH}^{*}$ en muchas substancias es muy rápida; ocurren reacciones cada vez que un radical $\mathrm{OH}^{\cdot}$ choca con una molécula de la substancia. El ion Bicarbonato secuestra radicales hidroxilo con mucha eficiencia y hace que la vida media de ozono en agua destilada a un $\mathrm{pH} 7$ aumente desde $10^{3}$ segundos en agua destilada a $10^{4}$ segundos en $2 \mathrm{mM} \mathrm{HCO}_{3}^{-}$[33].

La reacción de ozono en solución acuosa básica es iniciada por una o más de las siguientes tres reacciones (Ecuaciones 2-41 a 2-43) [100].

$$
\begin{array}{ll}
\mathrm{O}_{3}+\mathrm{OH}^{-} \rightarrow \mathrm{O}_{3}^{-}+\mathrm{OH} & \text { Ecuación 2-41 } \\
\mathrm{O}_{3}+\mathrm{OH}^{-} \rightarrow \mathrm{HO}_{2}^{-}+\mathrm{O}_{2} & \text { Ecuación 2-42 } \\
\mathrm{O}_{3}+\mathrm{OH}^{-} \rightarrow \mathrm{O}_{2}^{-}+\mathrm{HO}_{2} & \text { Ecuación 2-43 }
\end{array}
$$

Aquí es donde el anión peróxido $\left(\mathrm{HO}_{2}\right)$ estaría en rápido equilibrio con el anión superóxido $\left(\mathrm{O}_{2}^{-}\right)$

$$
\mathrm{HO}_{2} \leftrightarrow \mathrm{H}^{+}+\mathrm{O}_{2}^{-} \quad(\mathrm{pKa}=4.8) \quad \text { Ecuación 2-44 }
$$

Aunque el $\mathrm{O}_{3}$ podría descomponerse en agua antes de reaccionar con sustratos, ésta descomposición está dirigida a más especies reactivas lo cual determina la reacción oxidativa subsecuente. Esta descomposición de $\mathrm{O}_{3}$ es el resultado de una reacción en cadena donde iones hidroxilo actúan como iniciadores. Generalmente, es aceptado que la descomposición del $\mathrm{O}_{3}$ puede dirigirse así a radicales libres. Se comenta que las condiciones que aceleran una previa descomposición de $\mathrm{O}_{3}$ son frecuentemente favorables para la oxidación de impurezas recalcitrantes en procesos de tratamiento de agua [99].

En la Tabla 2-4 se comparan algunas constantes de velocidad conocidas para una reacción directa de $\mathrm{O}_{3}$ con solutos fenolicos y ácidos carboxilicos. Los resultados con ácidos carboxílicos alifáticos son muy bajos, cuando los compuestos no contienen otros grupos quimicos con que pueden reaccionar. Por otra parte, el ácido acético y el ácido oxálico y sus iones reaccionan tan lentos que no velocidad de reacción puede ser determinada. Las constantes de velocidad de los fenoles y fenoles sustituidos y 


\section{CAPÍTULO 2. MARCO TEÓRICO}

sus especies disociadas como iones fenolatos tienen velocidades de reacción muy altas [101].

Tabla 2-4 Constantes de velocidad de reacción con $\mathrm{O}_{3}$ de
los solutos en forma molecular por Hoigné y Bader $[101]$
\begin{tabular}{|l|l|l|}
\hline Soluto & Rango de $\mathbf{~ p H ~}$ & $\mathbf{k}\left(\mathbf{M}^{-1} . \mathbf{s}^{-1}\right)$ \\
\hline Ácido acético & $2.5 / 5$ & $\leq 3.1 \times 10^{-5}$ \\
\hline Acido propiónico & $2 / 5$ & $\leq 4.1 \times 10^{-4}$ \\
\hline Ácido glutárico & $5-6$ & $\leq 8.1 \times 10^{-3}$ \\
\hline Ácido glioxílico & $1.5-5$ & 0.17 \\
\hline Ácido malónico & 2 & $<4.0$ \\
\hline Ácido fórmico & 2 & 5.0 \\
\hline Ácido Maleico & $2 \mathrm{y} 6$ & $1 \times 10^{3}$ \\
\hline Ácido fumárico & 2 & $6 \times 10^{3}$ \\
\hline Fenol & $2-6$ & $1.3 \times 10^{3}$ \\
\hline 2-CP & $1.8-4$ & $1.1 \times 10^{3}$ \\
\hline 4-CP & $1.5-6$ & $6.0 \times 10^{2}$ \\
\hline $2,3-D C P$ & 2 & $<2 \times 10^{3}$ \\
\hline $2,4-D C P$ & $1.5-3$ & $<1.5 \times 10^{3}$ \\
\hline Resorcinol & 2 & $>3 \times 10^{3}$ \\
\hline
\end{tabular}

Además, Hoigné y Bader [99] encontraron que la constante de velocidad de reacción del ozono molecular con diferentes sustratos varía sobre una gama de $10^{-2}$ a $10^{9} \mathrm{M}^{-1} \mathrm{~s}$ 1. Por otro lado, cuando el valor del pH es superior a los valores de pKa de fenol sustituido, los aniones fenolatos generan radicales fenoxi, los que se consideran como más reactivos que la forma protonada. Hoigné y Bader [102], en otro estudio reportaron que el ion cloruro, consume ozono a una constante de velocidad de solo $0.003 \mathrm{M}^{-1} \mathrm{~s}^{-1}$ a $23^{\circ} \mathrm{C}$, cuando se mide a un $\mathrm{pH}>2$.

Benitez y col. [95] llevaron a cabo algunos experimentos donde oxidaron algunos compuestos clorofenoles en soluciones acuosas con ozono en medio ácido ( $\mathrm{pH} 2)$. Ellos encontraron que a este $\mathrm{pH}$ la descomposición de ozono, que es iniciada por la acción de iones hidroxilo es demasiado baja y consecuentemente la formación de radicales hidroxilo está limitada. Observaron que la descomposición de compuestos orgánicos por ozono puede ser representa por una sola reacción global la cual sigue una cinética de primer orden: 


$$
P+\mathrm{O}_{3} \stackrel{k_{03}}{\longrightarrow} P_{\text {oxid. }} \quad \text { Ecuación 2-45 }
$$

Cuando los CPs fueron ozonados, se observó que la constante de velocidad ko3 representada por la ecuación $2-45$, sigue una tasa decreciente según el siguiente orden: 2,3,4,6-TeCP $>2,4,6-\mathrm{TCP}>2,4-\mathrm{DCP}>4-\mathrm{CP}$. Ellos concluyeron que la secuencia de degradación es inversa a la de fotodegradación. Los autores propusieron una ruta para describir la ozonación completa del 2,4-DCP con hidroxilación, decloración y división del anillo. De acuerdo con este mecanismo, la presencia de más átomos de cloro aumenta el paso de decloración y por lo tanto la degradación es más rápida.

Otros experimentos se llevaron a cabo a un $\mathrm{pH}$ básico $(\mathrm{pH}$ 9). En este caso, las curvas de degradación estuvieron muy cerca para todos los CPs estudiados con similar conversión por cada CP. Los valores calculados para la constante velocidad de primer orden ko3, confirma las pequeñas diferencias en la eliminación de los CPs a este pH. Por otra parte, se encontraron que la constante de velocidad de primer orden de la degradación de 2,4-DCP con el proceso de ozonación a pH alcalino $\left(k=315 \times 10^{3}\right.$ min $^{-}$ $\left.{ }^{1}\right)$ fue más rápida que con el proceso de Fenton $\left(k=209 \times 10^{3} \mathrm{~min}^{-1}\right)$, mientras que la fotolisis $\left(\mathrm{k}=38 \times 10^{3} \mathrm{~min}^{-1}\right)$ y el proceso de ozonación en condición ácida $\left(\mathrm{k}=24 \times 10^{3}\right.$ $\mathrm{min}^{-1}$ ) fueron más lentos para degradar al 2,4-DCP [95].

Al comparar los resultados obtenidos a $\mathrm{pH} 2$ y $\mathrm{pH} 9$, se observó un aumento significativo en la velocidad de degradación con el aumento del pH. Este resultado puede ser explicado por la producción de radicales hidroxilo más rápidos a pH básico y la disociación de fenoles a iones fenolato que son capaces a reaccionar con ozono más rápido que la especie no disociada [101].

Vogelpol y Kim [35] revisaron diversas publicaciones sobre los procesos de oxidación avanzada con respecto a la aplicación práctica y potencial en el tratamiento de aguas residuales industriales. Se encontraron que la vida media del ozono en aguas residuales de origen industrial puede variar de menos de un minuto a 30 minutos, lo 


\section{CAPÍTULO 2. MARCO TEÓRICO}

cual depende de la reactividad del ozono con los contaminantes y del pH de las aguas residuales. Cuando aumenta el $\mathrm{pH}$, la tasa de descomposición del ozono en agua aumenta igualmente.

Wang y col. [103] estudiaron el efecto de la ozonación como un pretratamiento del 2,5DCP $(100 \mathrm{mg} / \mathrm{L}$ y $600 \mathrm{mg} / \mathrm{L})$ a pH 3 y pH 9 en agua desionizada destilada para combinarlos con un proceso anaeróbico. Los autores estudiaron la biodegradabilidad y la toxicidad de los productos de reacción formados en condiciones anaeróbicas. Encontraron que los productos de reacción de $100 \mathrm{mg} / \mathrm{L}$ de 2,5-DCP se biodegradan fácilmente a metano después una dosis de $2.5 \mathrm{~g} \mathrm{O}_{3} / \mathrm{g}$ 2,5-DCP.

Los productos de oxidación que se identificaron fueron ácido glioxálico, ácido oxálico, ácido propiónico, ácido acético y ácido fórmico. Se demostró que los productos de reacción que se formaron en el rango de $\mathrm{pH}$ básico eran menos inhibitorios que los formados en el rango de $\mathrm{pH}$ ácido. La toxicidad de 2,5-DCP se reduce con el aumento de la dosis de ozono. Por lo tanto, los productos de ozonación formados en el rango de $\mathrm{pH}$ básico fueron menos tóxicos que el propio 2,5-DCP en el ensayo de toxicidad anaerobia $[103,104]$.

En otra publicación reportaron que se necesitan 4 moles de ozono por cada mol de fenol removido $(\mathrm{pH} 7)$ y 2 moles de ozono por cada mol de fenol removido $(\mathrm{pH} 12)$ [105]. En otro estudio, el ozono reacciona mejor a pH 9 que a pH 6 para las muestras evaluadas. Asimismo, encontraron que la complejidad de la muestra industrial hace que la reacción sea más lenta (20 - 40\%) comparada con la solución de fenol grado analítico. Esta diferencia se debe principalmente a la naturaleza de las mezclas de compuestos fenólicos naturales y a su contenido de sales que pueden actuar como inhibidores.

Adams y col. [106] estudiaron el efecto de ozonación sobre la biodegradabilidad de 2,4 DCP, 4 clorofenol y fenol en agua destilada. Ellos observaron que la ozonación fue efectivo para degradar los compuestos fenólicos y para disminuir la toxicidad sobre los microorganismos, medido por bioensayos de Microtox. 


\section{CAPÍTULO 2. MARCO TEÓRICO}

Dore y col. [42] estudiaron fenol y 4-CP tratados con ozono (46 mg/L) con contaminantes aromáticos solubles. Los resultados que obtuvieron durante la ozonación de los compuestos aromáticos en solución acuosa, demostraron que la reacción ocurre en dos pasos: uno relativamente rápido, primera fase dirigida a abrir el anillo aromático, y una segunda fase en donde los subproductos, resultado de la primera fase, son estables a más oxidación. Por eso, los subproductos no consumen ozono y son rápidamente biodegradables. Por otra parte, encontraron que la ozonación parcial puede resultar en la formación de sustancia más toxica de la compuesta madre. Por eso, proponen la ozonación del compuesto madre hasta la perdida de su aromaticidad y no solo hasta su degradación total.

Van Aken y col. [107] estudiaron la degradación de 2,4-DCP (100 mg/L) en tres tipos de solución: 1) solución acuosa de acetato de sodio (380 mg/L) y glucosa $(235 \mathrm{mg} / \mathrm{L})$ 2) solución acuosa de acetato de sodio y leche en polvo (Nestlé beba 1, $159 \mathrm{mg} / \mathrm{L}$ ) y 3) agua destilada; para comparar el efecto de la naturaleza de fracción biodegradable tienen sobre la ozonación de 2,4-DCP. Los experimentos se llevaron a cabo en un reactor con $2 \mathrm{~L}$ de solución con un flujo de ozono de $6 \mathrm{gO} / \mathrm{h}$.

Los autores observaron que después de 10 minutos de oxidación, la solución acuosa de 2,4-DCP con acetato de sodio y glucosa consumó $624 \mathrm{mgO}_{3}$ y tuvo $96 \%$ de la remoción de 2,4-DCP, mientras que la solución acuosa de 2,4-DCP con acetato de sodio y leche en polvo consumió $534 \mathrm{mgO}_{3}$ y tuvo $90 \%$ de remoción del 2,4-DCP. Por otra parte la solución acuosa que contiene solo 2,4-DCP consumió $590 \mathrm{mgO}_{3}$ y tuvo 97\% de degradación del 2,4-DCP.

Estos resultados indicaron que el acetato de sodio y/o glucosa reaccionan con ozono y/o radicales hidroxilo. Los autores sugieren que la velocidad de degradación de 2,4DCP disminuye cuando hay presencia de la materia orgánica fácilmente biodegradable en la solución de agua residual y la medida de esta disminución depende de la naturaleza del material [35]. De lo contrario, en otros estudios [81, 143] encontraron 


\section{CAPÍTULO 2. MARCO TEÓRICO}

que cuando la concentración de materia orgánica presente en el agua residual fue menos que la concentración de DCP, no había un efecto negativo sobre la velocidad de degradación de DCP.

Por otra parte, se sugiere que la liberación de iones de cloruros es inversamente proporcional a la degradación de 2,4-DCP, lo que implica la decloración del anillo aromático como un primer paso en su descomposición. Además se propone que los aumentos en degradación de 4-CP y 2,4-DCP fueron por la producción rápida de radicales hidroxilo a $\mathrm{pH}$ alto y la disociación de fenoles a iones fenolato que pueden reaccionar más rápido con ozono que las especies no disociadas. Generalmente, 1.5 mol de $\mathrm{O}_{3}$ reacciona para dar $1 \mathrm{~mol}$ de radical hidroxilo [35].

Poznyak y Vivero [109] estudiaron la degradación del fenol, 4-CP y 2,4-DCP oxidados con ozono a diferentes $\mathrm{pH}$ de 2 a 12. Observaron que a $\mathrm{pH} 1.8$ el tiempo de descomposición total de los tres compuestos fueron muy similares alrededor de 75 minutos. Por otra parte, a pH 7, la degradación total de los compuestos fenol, 4-CP y 2,4-DCP ocurren después de $60 \mathrm{~min}, 40$ minutos y 25 minutos, respectivamente, mientras que a pH 12, la descomposición completa de fenol, 4-CP y 2,4-DCP fueron a $17 \mathrm{~min}, 10 \mathrm{~min}$ y $6 \mathrm{~min}$, respectivamente. Por lo tanto, sugiere que el $\mathrm{pH}$ influye la cinética de reacción inicial de los 3 compuestos mencionados. Los productos de oxidación que se identificaron fueron ácido glioxálico, ácido oxálico, ácido propiónico, ácido acético y ácido fórmico. Se demostró que los productos de reacción que se formaron en el rango de $\mathrm{pH}$ básico eran menos inhibitorios que los formados en el rango de $\mathrm{pH}$ ácido.

Beltran y col. [110] estudiaron la ozonación de aguas residuales de planta de tomates y destilería. Los autores se observaron un aumento ligero del pH (7.2 a 8.6) de las aguas residuales durante una hora de tratamiento con ozonización. Además se añadieron que la transferencia de masa y la reacción química son importantes factores por la ozonación. 


\section{CAPÍTULO 2. MARCO TEÓRICO}

Bollyky [111] en su estudio de la ozonación de fenol en agua, se observó que la reacción con ozono y los alcoholes alifáticos, ácidos e hidrocarburos es relativamente lenta en la ausencia de luz UV. Además, se propuso que los radicales hidroxilo producidos por la descomposición de ozono era el principal oxidante en estas reacciones y así como en la mayoría de las reacciones de ozono con compuestos orgánicos refractarios en agua.

Graham y col. [112] estudiaron la reactividad de 2,4,6-TCP con ozono en un reactor tipo columna de burbujas. Los autores encontraron que la constante de la tasa de degradación fueron 7.6 y $77.2 \mathrm{M}^{-1} \mathrm{~s}^{-1}$ a pH 2 y pH 7.5 respectivamente. La diferencia en los resultados obtenidos a pH 2 y a pH 7.5 es debido a la baja reactividad del 2,4,6TCP no disociado ( $\mathrm{pH}$ 2) con ozono molecular a comparación con el 2,4,6-TCP disociado ( $\mathrm{pH}$ 7.5) con el ozono molecular y en menor grado el efecto oxidante de las reacciones de radicales hidroxilo.

Por otro lado, la adición de peróxido de hidrógeno al ozono, solo mostraron un pequeño aumento en la tasa de degradación de 2,4,6-TCP. Por el contrario, había mayor producción de cloruro con el proceso de $\mathrm{O}_{3}-\mathrm{H}_{2} \mathrm{O}_{2}$ comparado con el proceso de ozonación solo. Esta considerable mayor productividad de iones de cloruro, sin un aumento proporcional en la degradación de TCP, sugiere que el $\mathrm{O}_{3}-\mathrm{H}_{2} \mathrm{O}_{2}$ como oxidante es capaz de liberar fácilmente cloruro de los compuestos intermedios formados de la oxidación de TCP.

Las sustancias húmicas (ácido húmico, HA), están típicamente presentes en cantidades significativas (2 a $20 \mathrm{mg} / \mathrm{L}$ ) en aguas naturales, y en aguas residuales. Además, las sustancias húmicas tienen diferente comportamiento en las reacciones con ozono en que pueden actuar como iniciadores, promotores y eliminadores de los radicales hidroxilo, así como un sustrato para las reacciones con ozono molecular. Los autores demostraron que las concentraciones relativamente bajas de las sustancias húmicas mejoran la degradación de sustratos orgánicos. Por otra parte, la presencia de sustancias húmicas en altas concentraciones en las aguas reducen la tasa de degradación de TCP [112]. 


\section{CAPÍTULO 2. MARCO TEÓRICO}

En un estudio [113], los autores observaron que la adición de ácido benzoico $(3 \mu \mathrm{M})$ ha mejorado la descomposición de ozono, que resulta en más del $60 \%$ de la descomposición de ozono durante 10 minutos, mientras que, en ausencia de ácido benzoico, la descomposición de ozono fue menos de 15\%. Además, los autores propusieron que la rápida degradación simultánea de ácido benzoico y la descomposición del ozono indicó que la descomposición de ozono inducida por ácido benzoico resultó en la producción de radicales hidroxilo $\left(\mathrm{OH}^{*}\right)$. Por otra parte, la tasa de degradación inicial de ácido benzoico mejoró con el aumento de la concentración de ácido benzoico, reacción de auto-mejora. Asimismo, los intermedios hidroxilados tuvieron un efecto positivo en la producción de $\mathrm{OH}^{\circ}$.

Turhan y col. [114], en su estudio de la degradación de fenol con ozono, encontraron que la reacción inicial de ozono molecular con fenol, lleva a la formación de subproductos hidroxilados orto y para que son altamente susceptibles a ozonación adicional. Los compuestos llevan a la formación de quinoide, y la apertura del anillo aromático para formar productos alifáticos con función carbonilo y carboxilo. Los productos intermedios de ozonación de fenol identificados por GC-MS son catecol, hidroquinona, p-benzoquinona, o-benzoquinona, ácido maleico y ácido oxálico.

\subsubsection{Fotólisis de ozono ( $\left.\mathrm{O}_{3}-\mathrm{UV}\right)$}

Glaze y col. [33], mencionaron que Prengle y colaboradores de Houston Resarch Inc (HRI) en 1977, fueron los primeros en ver el potencial comercial del sistema $\mathrm{O}_{3}-\mathrm{UV}$. $\mathrm{HRI}$ demostró que $\mathrm{O}_{3}-\mathrm{UV}$ mejora la oxidación de complejos de cianuros, solventes, pesticidas y misceláneos; con parámetros como DQO, DBO $\left(\begin{array}{lll}5-8 & d\end{array}\right)$. Subsecuentemente, el proceso fue comercializado por Westgate Research de Los Angeles (ahora ULTROX Internacional) donde Zeff y col., expandieron más las aplicaciones del proceso.

Durante este proceso se forma $\mathrm{H}_{2} \mathrm{O}_{2}$ y la Ecuación 2-46 muestra la reacción global (Glaze y col. [33]): 


$$
\mathrm{O}_{3}+\lambda \mathrm{U}+\mathrm{H}_{2} \mathrm{O} \rightarrow \mathrm{H}_{2} \mathrm{O}_{2} \quad \text { Ecuación 2-46 }
$$

La Ecuación 2-46 parece mostrar que los procesos $\mathrm{O}_{3}-\mathrm{UV}$ y $\mathrm{O}_{3}-\mathrm{H}_{2} \mathrm{O}_{2}$ son uno en el mismo, en que el primero simplemente está formando el $\mathrm{H}_{2} \mathrm{O}_{2}$ in situ, en lugar de agregarlo desde el exterior. De hecho, en algunos sustratos éste es el caso pero en otros sustratos que absorben la radiación ultravioleta, el proceso $\mathrm{O}_{3}-\mathrm{UV}$ puede ser mucho más complejo. Un ejemplo de este caso es la oxidación de tetracloroetileno (PCE).

EI PCE absorbe débilmente la radiación de UV a $254 \mathrm{~nm}$, Pero lo suficiente como para que la fotólisis directa sea un importante contribuyente a la descomposición del PCE, cuando el compuesto está expuesto al ozono y radiación de $254 \mathrm{~nm}$ en un reactor CSTR [33].

En otro estudio [62], los autores resumen las primeras reacciones de ozono-UV como sigue:

$$
\begin{array}{lll}
\mathrm{O}_{3}+\lambda v \rightarrow \mathrm{O}+\mathrm{O}_{2} & & \text { Ecuación 2-47 } \\
\mathrm{O}+\mathrm{H}_{2} \mathrm{O} \rightarrow 2 \mathrm{OH}^{\cdot} & \mathrm{k}=1.1 \times 10^{7} \mathrm{~s}^{-1} & \text { Ecuación 2-48 } \\
\mathrm{O}+\mathrm{H} 2 \mathrm{O} \rightarrow \mathrm{H}_{2} \mathrm{O}_{2} & \mathrm{k}=2.2 \times 10^{8} \mathrm{~s}^{-1} & \text { Ecuación 2-49 } \\
\mathrm{O}_{3}+\mathrm{OH}^{\cdot} \rightarrow \mathrm{HO}_{2}{ }^{-}+\mathrm{O}_{2}^{-\cdot} & \mathrm{k}=70 \mathrm{M}^{-1} \mathrm{~s}^{-1} & \text { Ecuación 2-50 }
\end{array}
$$

Huataniemi y col., [115], reportaron variación en los mecanismos del tratamiento de 2,4-DCP con ozono y ozono-UV, con respecto a la formación de peróxido de hidrógeno e iones de cloruros, baja condiciones ácidas.

Otro estudio [116] se investigó el tratamiento de 2,4-DCP con ozono y ozono-UV bajo condiciones alcalinas de ozonación. Los autores reportaron que las reacciones de radicales hidroxilo no contribuyen a la velocidad de oxidación del clorofeno en condiciones básicas $(\mathrm{pH}=9.5)$. Esto debido a la muy alta velocidad de reacción del ion fenolato con ozono en condiciones de alto $\mathrm{pH}$ que normalmente favorecen la oxidación por radicales hidroxilo. Aunque, concluyeron que los mecanismos de oxidación en condiciones básicas y condiciones ácidas parecían ser diferentes. 


\section{CAPÍTULO 2. MARCO TEÓRICO}

Benitez y col. [95], mencionaron que la fotólisis de peróxido de hidrógeno genera radicales hidroxilo (ecuaciones $2-51$ y $2-52$ ).

$$
\mathrm{H}_{2} \mathrm{O}_{2}+\lambda \mathrm{u} \rightarrow 2 \mathrm{OH}^{\cdot} \quad \text { Ecuación 2-51 }
$$

Además, el $\mathrm{H}_{2} \mathrm{O}_{2}$ acelera la descomposición de $\mathrm{O}_{3}$ en radicales $\mathrm{OH}^{*}$ según:

$$
\mathrm{O}_{3}+\mathrm{H}_{2} \mathrm{O}_{2} \rightarrow \mathrm{OH}^{\cdot} \quad \text { Ecuación 2-52 }
$$

Estos radicales generados por las ecuaciones ).

$\mathrm{H} 2 \mathrm{O} 2+\lambda \mathrm{v} \rightarrow 2 \mathrm{OH}^{\circ} \quad$ Ecuación 2-511 y O3 + $\mathrm{H} 2 \mathrm{O} 2$ $\rightarrow \mathrm{OH}^{\circ} \quad$ Ecuación 2-5252 constituyen las principales especies activas en la ozonación fotolítica. En el proceso de $\mathrm{O}_{3}-\mathrm{UV}$, hay un efecto sinérgico de varias reacciones individuales: ozonación directa, fotólisis directa y descomposición del radical hidroxilo. Aunque, en el proceso de $\mathrm{O}_{3}-\mathrm{UV}$, ellos no podrían dar razón de esta sinergia con base en un efecto aditivo y variación de magnitud de sustrato a sustrato.

Pera-Titus y col. [34], revisaron algunos trabajos de investigadores y encontraron que la ozonación fotolítica fué más efectiva para destruir algunos compuestos orgánicos que la UV-fotólisis ó el ozono solos. Del mismo modo, se mencionaron que en uno de estos trabajos, los autores comparan la destrucción de 2-CP, 4-CP y 2,4-DCP por ozonación, radiación UV y su combinación ( $\left.\mathrm{O}_{3}-\mathrm{UV}\right)$, y encontraron que el efecto sinérgico del proceso combinado aumentó con el aumento del pH inicial de la solución a básico. Lo anterior indica que la iniciación de la ozonación puede ser catalizada por iones de $\mathrm{OH}^{-}$.

Boncz y col. [117], estudiaron 2-CP y 4-CP usando ozono y ozono-UV con dosis de ozono de $12.5 \mathrm{~L} \mathrm{~h}^{-1}$ y seis lámparas de UV de $15 \mathrm{~W}$, concentración de solución fue de $0.001 \mathrm{M}$ a pH 5 y 11 , con tiempo de reacción de 100 minutos, encontraron que reacción 


\section{CAPÍTULO 2. MARCO TEÓRICO}

cinética fue más rápida en medios alcalinos que en ácidos, asociado a que los aniones reaccionan más rápido que las moléculas.

Gurol y Vatistas [41] en su estudio de oxidación de compuestos fenólicos por ozono y ozono-UV a pH 7 y pH 9, encontraron que los resultados obtenidos de la tasa de remoción de los compuestos fenólicos a pH 7 fueron similares a los obtenidos a pH 9. Asimismo, ellos concluyeron que las reacciones de radicales son los mecanismos predominantes incluso a pH neutro de la oxidación de fenol con ozono. A pH 7 y pH 9 la tasa de formación de radicales hidroxilo de ion hidróxido- descomposición catalizador del ozono es bastante lenta, especialmente en la presencia de carbonatos que son eliminadores eficaces de radicales. Por lo tanto los autores concluyeron que los propios compuestos fenoles estaban actuando como los promotores de la descomposición del ozono y la formación de radicales libres.

Los compuestos promotores son probablemente los iones fenolato, porque no había evidencia de la descomposición del ozono a pH ácido. Cuando se encuentra en su forma molecular la radiación UV es absorbida por el agua en la presencia de oxígeno, y se inicia una reacción en cadena con hidroxilo, generando los radicales hidroperóxido en el agua. Las velocidades de eliminación son los más altas en los tratamientos con ozono-UV, debido a un efecto aditivo y es casi igual a la absorción por ozono y por UV.

Contreras y col. [118], en su estudio encontraron las siguientes tasas de degradación de 2,4-DCP por: ozono $\left(k=0.0876 \mathrm{~min}^{-1}\right)$, ozono-UV $\left(k=0.0813 \mathrm{~min}^{-1}\right), \mathrm{UV}-\mathrm{H}_{2} \mathrm{O}_{2}(k=$ $\left.0.0729 \mathrm{~min}^{-1}\right)$, ozono-UV-Fe(III) $\left(\mathrm{k}=0.0728 \mathrm{~min}^{-1}\right)$, ozono-UV- $\mathrm{H}_{2} \mathrm{O}_{2}\left(\mathrm{k}=0.0643 \mathrm{~min}^{-1}\right)$. A partir de estos resultados se puede observar que la tasa de degradación de 2,4-DCP fue con tratamiento de ozono, lo cual es contrario a los resultados observados por otros autores.

Huang y Shu [88] proponen que la reacción de fenol con ozono-UV, puede ocurrir vía la reacción del fenol con las siguientes oxidantes: ozono, radicales hidroxilo y radicales hidroperoxilos para formar productos de descomposición. Además, los autores 


\section{CAPÍTULO 2. MARCO TEÓRICO}

calcularon la constante de velocidad de foto-descomposición de ozono-UV de ser $0.145 \mathrm{~s}^{-1}$.

Kilici y col. [119], reportaron que el radical hidroxilo reacciona con compuestos aromáticos vía dos rutas de reacción: la abstracción del átomo de $\mathrm{H}$ de los enlaces $\mathrm{C}$ $\mathrm{H}$ u O-H y la adición a los anillos aromáticos. En la reacción de adición, el radical hidroxilo ataca un carbono del anillo con su electrón desapareado y por contacto forma un enlace $\mathrm{C}-\mathrm{O}$, mientras que un enlace pi del sistema aromático se rompe y se forma un radical del tipo hidroxiciclohexadienilo.

En la ruta de abstracción de $\mathrm{H}$, se forma un radical de oxígeno-centrado tipo fenoxi y una molécula de agua se forman. El proceso de abstracción de $\mathrm{H}$ por el radical hidroxilo es una reacción simple de transferencia de átomo en que el enlace al átomo de hidrógeno en el grupo funcional $(-\mathrm{OH})$ se rompe y se forma un nuevo enlace con el átomo de oxígeno del radical $\mathrm{OH}^{\circ}$.

\subsection{Cinética y Mecanismos de Reacción de los Diclorofenoles}

Chaliha y col. [74], investigaron los mecanismos de las reacciones oxidativa de 2,4DCP. Ellos sugirieron que la descomposición oxidativa de 2,4-DCP es a través de radicales hidroxilo producido por la descomposición del peróxido de hidrógeno o por disolución de oxígeno atmosférico durante la agitación bajo la influencia de los catalizadores. Ellos se sugieren que el mecanismo por vía radicales hidroxilo se basa en radicales $\mathrm{OH}^{\circ}$ atacando y sustituyendo los átomos de cloruros.

En el caso de 2,4-DCP, es probable que los grupos $\mathrm{OH}$ reemplacen los átomos de cloruros sucesivamente por la conversión de 2,4-DCP a clorocatecol, después a 2 cloro-1,4- benzoquinona y finalmente a ácidos carboxílicos insaturados. Los grupos $\mathrm{OH}$ también interactúan con los ácidos carboxílicos insaturados transformándolos en ácidos simples como ácido acético, ácido oxálico, etc., como los productos finales. De igual forma, propusieron otra ruta, donde un grupo $\mathrm{OH}$ electrófilo se agrega sobre el anillo aromático de la 2,4-DCP, para la formación de isómeros de 3,5-diclorocatecol, 


\section{CAPÍTULO 2. MARCO TEÓRICO}

2,4-diclororesorcinol y 4,6-diclororesorcinol. El último isómero fue el producto hidroxilado de 2,4-DCP. Los tres isómeros serán objeto de posterior hidroxilaciones, produciéndose así, rápidamente, intermediarios deshidrogenados a sus correspondientes quinonas, uno de los cuales se identificó como 3,5-dicloro-2-hidroxi1,4-benzoquinona. Las benzoquinonas se convierten en los ácidos orgánicos simples por la misma ruta.

Hao y col. [60], estudiaron los mecanismos de la reacción oxidativa de 4-CP. Ellos sugieren bajo la teoría de la colisión que la descomposición oxidativa de 4-CP concentrada $(25.2 \mathrm{~g} / \mathrm{L})$ es principalmente a través del mecanismo de pirolisis (alta temperatura), como resulta en las moléculas de 4- CP, impactado y vaporizado en las burbujas. Bajo la misma irradiación ultrasónica, la densidad de burbujas en el agua es igual aproximadamente igual. Por otra parte, el vapor de agua en la cavidad se puede descomponer a radicales hidroxilos libres y átomos de hidrógeno. Estos radicales $\mathrm{OH}^{*}$ y átomos de $\mathrm{H}$ pueden combinarse para formar $\mathrm{H}_{2}$ y $\mathrm{H}_{2} \mathrm{O}_{2}$. Los radicales $\mathrm{OH} \circ \mathrm{H}_{2} \mathrm{O}_{2}$ al tener una fuerte oxidabilidad son capaces de penetrar el agua y oxidar compuestos orgánicos disueltos. Si se somete una solución acuosa que contiene contaminantes a ondas ultrasónicas, éstas causarán su degradación por radicales hidroxilo (mecanismo de oxidación) y / o alta temperatura (mecanismo de pirólisis).

Qiu y col. (1999), investigaron los parámetros cinéticos asociados con la ozonación de compuestos diclorofenólicos, entre ellos, el 2,5-DCP, en solución acuosa a $25{ }^{\circ} \mathrm{C}$. Encontraron que la ozonación del 2,5-DCP fue más rápida que para los otros dos diclorofenoles (DCPs) estudiados (2,3-DCP y 2,4-DCP) en un rango de $\mathrm{pH}$ de $2.1 \mathrm{a}$ 5.0 .

En general la tasa constante aumenta con el pH por el aumento en el grado de disociación de las moléculas de DCP en iones diclorofenóxidos. Asimismo, postulan que el mecanismo de degradación de los DCPs forma clorobenzenodioles, monoclorofenoles, cloro-ciclohexadienos, etilacetatos, heptano, ácidos carboxílicos y otros subproductos. 


\section{CAPÍTULO 2. MARCO TEÓRICO}

Además, encontraron que el ozono reacciona más rápidamente con los iones de DCP que con las moléculas de DCP. Por lo que es más ventajoso ozonar esos compuestos a pH alto, debido a la ionización parcial de las moléculas de DCP. Por lo tanto el 2,5DCP puede ser eliminado con ozonación, pero como un proceso de oxidación con radicales $\mathrm{OH}^{*}$ se logra una reacción más rápida y completa de los sub-productos de la oxidación de los DCPs [120].

Qiu y col. (2004) estudiaron los mecanismos y la cinética de las reacciones de ozonación de tres DCPs (2,6-DCP, 3,4-DCP y 3,5-DCP) y han reportado una relación de 2 moles de ozono por $1 \mathrm{~mol}$ de DCP. La reacción completa entre ozono y DCP fue de segundo orden (de primer orden para cada reactante). Las constantes de reacción en todos los casos aumentaron con el pH, debido al grado de ionización de los DCPs estudiados, identificaron los compuestos intermedios durante la ozonación de los DCPs y propusieron mecanismos de reacción. Para la ozonación se realizaron pruebas a $\mathrm{pH}$ de 2 a 13 y no se encontraron diferencias entre las respuestas de los tres isómeros estudiados. De acuerdo a sus resultados los autores sugieren aplicar la ozonación a un pH de 9 aproximadamente ya que en éste las moléculas de DCP se ionizan casi en su totalidad y la reacción con ozono es más rápida [121].

Rice [122] en su estudio hace una adaptación de Hoigne de las diferentes vías de reacción de ozono con un soluto $(P)$ y la formación de oxidantes secundarios, que igualmente reaccionan con solutos $\mathrm{P}$ pero que pueden producir diferentes productos, los que se forman en la reacción directa con ozono molecular (Ecuación 2-53).

La reacción de ozono con soluto $(\mathrm{P})$ para producir productos oxidantes ( $\left.\mathrm{P}_{\text {oxid. }}\right)$ :

$$
\mathrm{O}_{3}+\mathrm{P} \rightarrow \text { Poxid. }\left(+\mathrm{H}_{2} \mathrm{O}_{2} \text {, etc. }\right) \quad \text { Ecuación } 2-53
$$

La descomposición del radical hidroxilo (reacción reversible):

$$
\mathrm{OH}^{\cdot} \leftrightarrow \mathrm{H}^{+}+\mathrm{O}^{\bullet} \quad \text { Ecuación 2-54 }
$$




\section{CAPÍTULO 2. MARCO TEÓRICO}

El soluto $\mathrm{P}$ reaccionó rápidamente con el radical $\mathrm{OH}^{\bullet}$ y los oxidantes secundarios, para producir nuevos intermediarios ( $\mathrm{P}^{\prime}$ oxid.):

$$
\mathrm{P}+\mathrm{OH}^{\cdot} \rightarrow \mathrm{R}^{\cdot}+\mathrm{O}_{2} \rightarrow \mathrm{ROO}^{*}+\mathrm{P} \rightarrow \mathrm{P}^{\prime} \text { oxid. } \quad \text { Ecuación 2-55 }
$$

El soluto $P$ reaccionó lentamente con el radical $\mathrm{HO}_{2}{ }^{\circ}$ para producir productos intermedios ( $\mathrm{P}$ "oxid.):

$$
\mathrm{HO}_{2}{ }^{\circ}+\mathrm{P} \rightarrow \mathrm{P}^{\prime \prime} \text { oxid. } \quad \text { Ecuación 2-56 }
$$

Singer y Gurol [123] propusieron los siguientes mecanismos de oxidación de fenol por ozono molecular:

1. Vía ataque electrofílico, se producen productos hidroxilados:

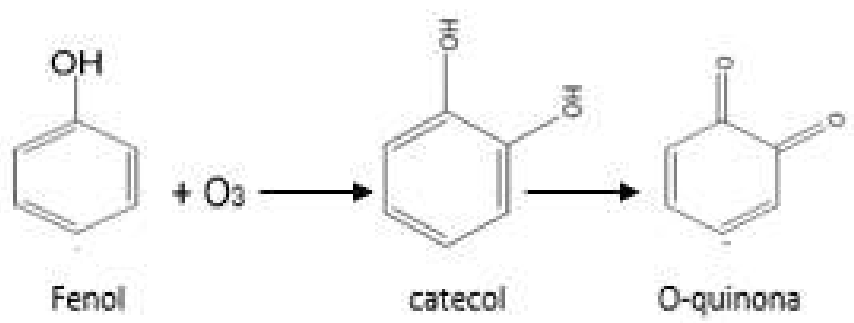

Continuando la ozonación, el catecol se puede oxidar para formar ácido mucónico, mientras la o-quinona se oxida para formar nuevos productos de oxidación.

2. Vía cicloadición dipolar, se causa la escisión directa de los anillos para producir ácidos o aldehídos:

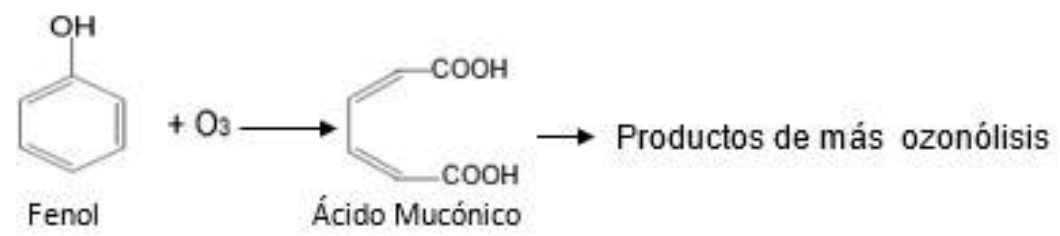

3. Otra Vía cicloadición dipolar, se causa la escisión directa de los anillos para producir ácidos o aldehídos: 


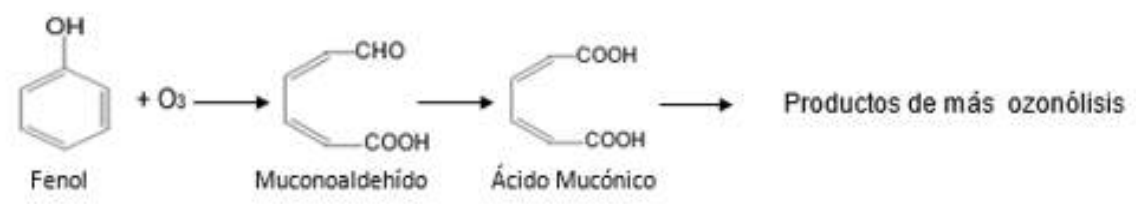

Merle y col. [124], en su estudio propusieron un mecanismo de reacción similar al de Rice [122] para la degradación del 2,4-DCP por ozono, el cual consiste en un ataque electrofílico en el anillo aromático, que se activa por el efecto donante del grupo hidroxilo $(\mathrm{OH})$, seguido por una cicloadición 1,3 dipolar (Mecanismo de Criegee). Los subproductos reportados en la oxidación de 2,4-DCP por ozono son: 3,5Diclorocatecol, 4-Clorocatecol, 2-Clorohidroquinona, Hidroquinona, 2Clorobenzoquinona, 4,6-Diclororesorinol, Catecol, Ácido acético y Ácido oxálico.

Huang y col. [88], proponen las siguientes rutas de reacción de fenol con ozono:

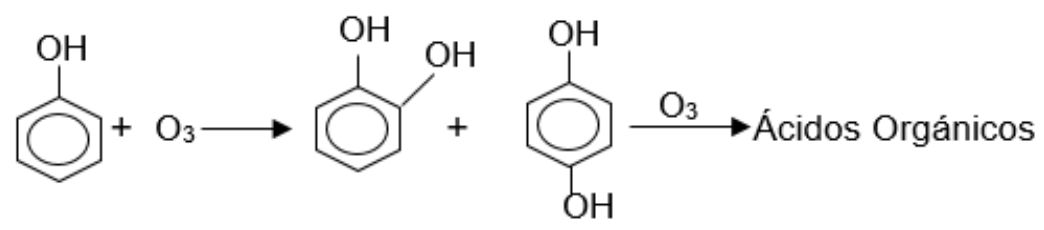

$Y$ con radicales hidroxilo:

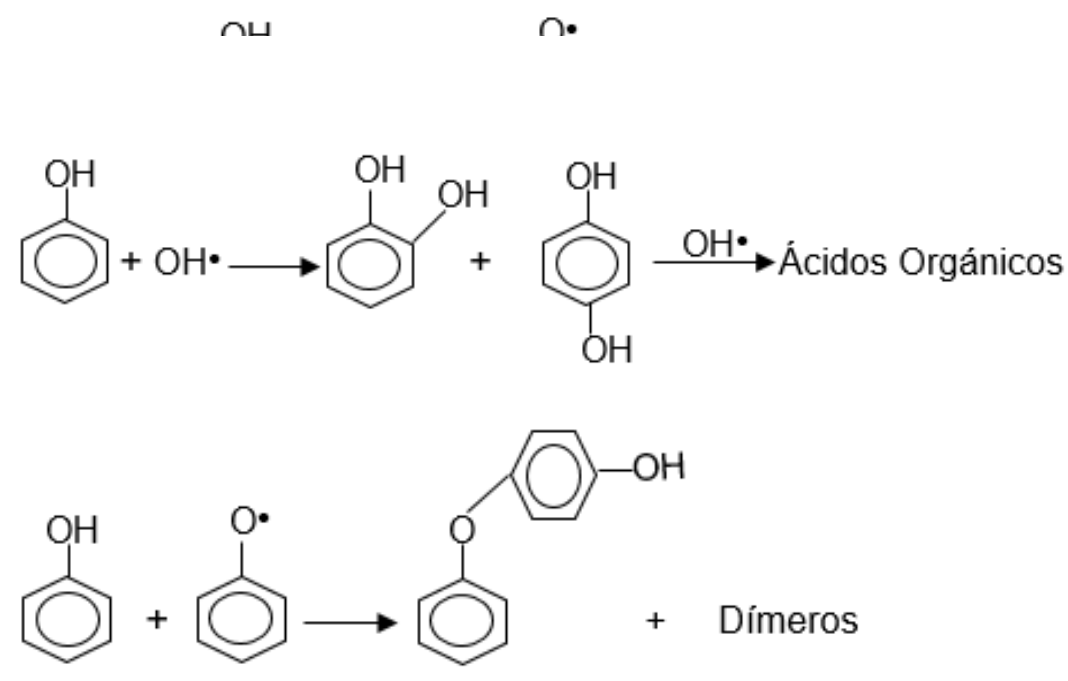

La ruta de reacción de fenol con $\mathrm{O}_{3}-\mathrm{UV}$ fue similar a la reacción de ozono con fenol. 


\section{CAPÍTULO 2. MARCO TEÓRICO}

Aunque, algunos compuestos de altos pesos moleculares se formaron como intermediarios a muy bajas concentraciones, fueron identificados por GC-MS como: 2fenoxi-fenol, 1,1'-bifenil-2,2'-diol, éster diisooctilo, 1,2-bencenodicarboxílico y éster diciclohexil de ácido 1,2-bencenodicarboxílico. La formación de estos compuestos es debido a la conversión de fenol por los radicales hidroxilo libres a un radical fenólico. Posteriormente este radical fenólico reacciona con fenol para producir los compuestos de altos pesos moleculares [88].

\subsection{Transferencia de Masa}

La transferencia de masa juega un papel muy importante en el proceso de ozonización. Típicamente, los experimentos de la transferencia de masa se llevan a cabo a escala laboratorio en columnas de burbujas o tanques con agitación. En el caso de columnas de burbujas, normalmente tienen una altura de no más de $2 \mathrm{~m}$ de tal modo que es posible suponer un modelado sencillo de transferencia de masa, por ejemplo, con mezcla perfecta en la fase líquida y sin variación de la presión a lo largo de la altura de la columna.

\subsubsection{Transferencia de gas-líquido aplicada a ozono en agua}

El ozono es un oxidante poderoso y reacciona químicamente con compuestos orgánicos e inorgánicos en soluciones acuosas, basado en mecanismos de reacciones directas e indirectas. La reacción indirecta es el resultado de las reacciones de especies de radicales libres como los radicales hidroxilo $\left(\mathrm{OH}^{\circ}\right)$ formados con el ozono disuelto en el agua. La ozonización ha sido aplicada al tratamiento de agua potable y agua residual como desinfectante, desodorizante, para remoción de color y descomposición de contaminantes tóxicos.

El ozono es menos soluble en agua que el cloro, y por eso necesita técnicas especiales de mezclado. Generalmente, los procesos de ozonización en la fase acuosa son realizados a través de formación de burbujas del gas dentro de una solución acuosa usando tanques de contacto de ozono-agua como columnas de burbujas e inyectores 


\section{CAPÍTULO 2. MARCO TEÓRICO}

tipo Venturi. En estos procesos, el ozono se transfiere de la fase gaseosa a la solución acuosa a tratar. Para mejorar la transferencia de ozono, es necesario aumentar el área de contacto interfase gas-líquido. Una forma de conseguir tal efecto es disminuir el tamaño de la burbuja [125].

La teoría más utilizada para explicar el mecanismo de transferencia de masa en el intercambio gas-líquido es la teoría de la doble capa, modelo que se basa en la existencia de dos capas, una de líquido y otra de gas entre la interfase gas-líquido. Ambas capas dan una resistencia al paso de moléculas de gas en la interfase líquida y gaseosa. En la transferencia de moléculas de gas de la fase gaseosa a líquida, los gases ligeramente solubles encuentran la resistencia principal a la transferencia en la capa líquida, en tanto que los gases muy solubles hallan dicha resistencia en la capa gaseosa. Los gases de solubilidad intermedia hallan una importante resistencia en ambas capas. La tasa de transferencia del gas es en general proporcional a la diferencia entre la concentración existente y la concentración de saturación del gas en la solución.

El coeficiente de transferencia volumétrico puede ser derivado de la ecuación 2-57 [126]:

$$
\mathrm{dC} / \mathrm{dt}=\mathrm{KLa}\left(\mathrm{C}_{\mathrm{s}}-\mathrm{C}\right) \quad \text { Ecuación 2-57 }
$$

Siendo: $\quad \mathrm{C}=$ concentración del gas a un tiempo $\mathrm{t}(\mathrm{mg} / \mathrm{L})$

$$
\mathrm{t}=\text { tiempo }(\mathrm{s})
$$

$\mathrm{C}_{\mathrm{s}}=$ concentración de saturación del gas $(\mathrm{mg} / \mathrm{L})$

$\mathrm{K} \mathrm{La}=$ coeficiente de transferencia volumétrico $\left(\mathrm{s}^{-1}\right)$

$\mathrm{K}\llcorner a$ incluye en este caso, el efecto de la resistencia de una y otra capa, en función del área de la interfase gas-líquido que existe por volumen unitario de fluido.

La teoría de Doble Película de Lewis-Whitman puede ser usada para explicar la tasa de trasferencia de un material de una fase a otra. Estas posibilidades se muestran en la Figura 2-4. 


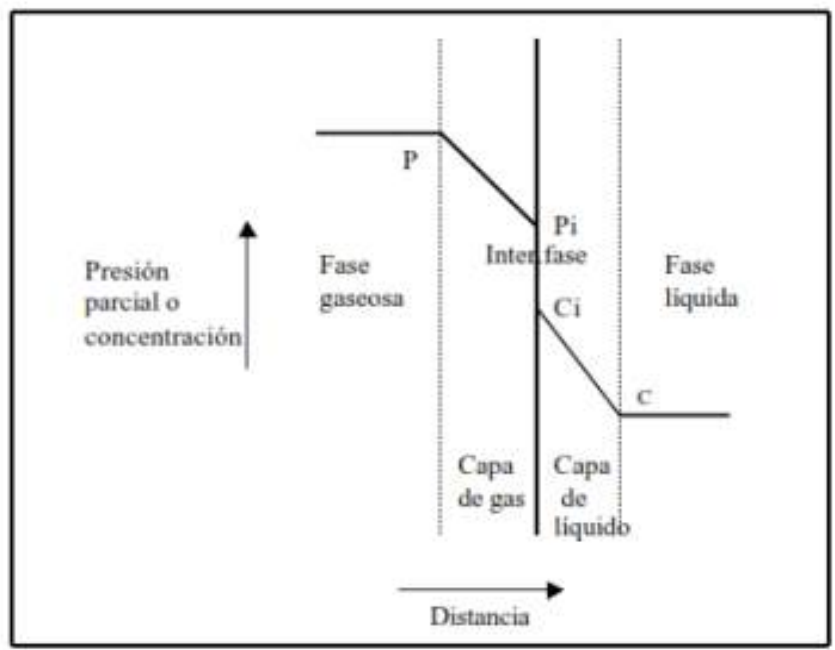

Figura 2-4 Esquema de la teoría de la doble capa para la transferencia de gases (Roustan y col.) [127].

La concentración de equilibrio del gas disuelto en un líquido es función de la presión parcial del gas en contacto con el líquido. Esta relación viene dada por la ley de Henry, ver $\mathrm{Pg}=\mathrm{HXg}$ Ecuación 2-58:

$$
\mathrm{Pg}=\mathrm{HXg} \quad \text { Ecuación 2-58 }
$$

Siendo:

$\mathrm{Pg}=$ presión parcial del gas en atmósferas

$\mathrm{H}=$ constante de la ley de Henry, está en función de la temperatura y naturaleza del sistema.

$\mathrm{Xg}=$ fracción molar de equilibrio del gas disuelto en la fase líquida.

Las burbujas de aire tienen efecto ascensional debido al arrastre viscoso y favorecen la turbulencia y circulación del líquido; conforme suben las burbujas de aire éstas tienden a aumentar de tamaño debido a la reducción de presión y coalescencia.

Al considerar resistencia nula a la transferencia de masa en la fase gaseosa, y según la teoría de película, durante la absorción de un gas entre un líquido, la única resistencia se encuentra en una película líquida cerca de la interfase. Si la absorción está acompañada por una reacción química irreversible en el líquido, esta reacción ocurrirá en la masa de líquido (régimen cinético lento), o en la película (régimen 


\section{CAPÍTULO 2. MARCO TEÓRICO}

cinético rápido), dependiendo de la relación entre la tasa de proceso de reacción química máxima en la película y la tasa máxima de absorción física.

El número Hatta $\mathrm{(Ha}$ ) es un grupo adimensional importante en la reacción gas - líquido. El cuadrado del número de Hatta, adimensional, es denominado módulo de conversión en la película líquida está presente en las ecuaciones cinéticas derivadas de la teoría por cualquier absorción [128]:

$$
H a=\frac{\sqrt{(2 / m+1) D_{A} k\left[A^{*}\right]^{m-1}}}{k_{L}}
$$

Ecuación 2-59

Donde $k$ es la constante cinética, $D_{A} y\left[A^{*}\right]$ la difusividad y solubilidad de gas $A$ respectivamente, $\mathrm{m}$ el orden cinético de gas y kı el coeficiente de transferencia de masa. Los valores de esta relación permiten deducir el tipo de régimen de cinético: valores bajos de $\mathrm{Ha}$ (menor de 0.3 ) indica que la reacción es lenta, por lo que la tasa de absorción gaseosa será:

$$
\mathbf{N}_{\mathbf{A}} \mathbf{a}=\mathbf{k}_{\mathbf{L}} \mathbf{a}\left(\left[\mathbf{A}^{*}\right]-[\mathbf{A}]\right)
$$

Ecuación

2-60

Siendo a el área superficial, y [A] la concentración del gas disuelto en la masa del líquido.

Si el régimen de reacción es rápido (valores de $\mathrm{Ha}>3$ ), la absorción gaseosa se puede escribir como:

$$
\mathbf{N}_{\mathbf{A}} \mathbf{a}=\mathbf{k}_{\mathbf{L}} \mathbf{a}\left[\mathbf{A}^{*}\right] \mathbf{E} \quad \text { Ecuación 2-61 }
$$

Donde $E$ representa el factor por el cual la presencia de una reacción química aumenta la absorción física máxima, igual a kıa [A*], (Sotelo y otros [128]).

\subsubsection{Tipos de reactores para el tratamiento de aguas residuales}

Las tres clases principales de los reactores multifásicos son: el reactor de lecho percolador (fijo o de lecho compacto), el reactor de lecho fluidizado, y el reactor de columna de burbujas. Un reactor de columna de burbujas es un dispositivo en que el 


\section{CAPÍTULO 2. MARCO TEÓRICO}

gas entra por la parte inferior de la columna y el gas es expulsado en forma de burbujas hacia una fase líquida o hacia una suspensión líquida-sólida.

Normalmente, los reactores industriales de tipo columna de burbujas se operan con una proporción de longitud a diámetro o una proporción de aspecto de al menos 5 . Aún en la aplicación bioquímica este valor puede variar entre 2 y 5 . La selección de dimensiones de columna puede influir los caudales de gas, niveles de conversión, así como en la facilidad de operación [129]. Por lo tanto, es un factor importante para dar el mejor resultado, el diseño del reactor de columna de burbujas para la optimización de los procesos.

Los reactores de columna de burbujas pueden operar de dos modos: el modo semicontinuo ("semi-batch") y el modo continuo. En el modo semi-continuo la suspensión es estacionaria, es decir que el caudal de líquido es cero, y el gas se burbujea hacia arriba en la columna [129]. El reactor de columna de burbujas o alguna variación de ese, es el reactor más usado debido al bajo costo de operación y a un consumo energético mínimo [111].

\subsubsection{Determinación de coeficiente de la transferencia de masa de ozono indirectamente}

Las mediciones de la transferencia de oxígeno se pueden utilizar para obtener k $\mathrm{ka}\left(\mathrm{O}_{3}\right)$ y a veces es el único método disponible. En estos casos se emplea la relación de los coeficientes de difusión, a decir la ecuación (2-58):

$$
k_{L} a_{O_{3}}=\left(\frac{D_{O_{3}}}{D_{O_{2}}}\right)^{n} \cdot k_{L} a_{O_{2}}=0.622 \cdot k_{L} a_{O_{2}} \quad \text { Ecuación 2-62 }
$$

Gottschalk y col. [130] citaron los valores experimentales determinados de coeficiente de difusión para ozono $\mathrm{D}_{(\mathrm{O} 3)}=1.26 \times 10^{-9} \mathrm{~m}^{2} \mathrm{~s}^{-1}$ por Matrozov y otros, y el oxígeno $\mathrm{D}_{(\mathrm{O} 2)}$ $=2.025 \times 10^{-9} \mathrm{~m}^{2} \mathrm{~s}^{-1}$ St. Denis y otros, dando como resultado un factor arriba de 0.622 para $\mathrm{n}=1$. Los autores reportan que la potencia, $n$ puede variar desde 0.5 hasta 1 en función de las condiciones hidrodinámicas en el reactor. Para la ozonación en las 


\section{CAPÍTULO 2. MARCO TEÓRICO}

columnas de burbujas, $\mathrm{n}$ generalmente es tomado como 1. Los valores de coeficientes de difusión son válidos para gas/agua (limpia) a temperatura de $20^{\circ} \mathrm{C}$.

Otros valores para $D_{(\mathrm{O})}$ y $D_{(\mathrm{O} 2)}$ se pueden encontrar en la literatura $[130,127,131]$ y el valor del factor puede variar considerablemente dependiendo de los valores tomados por $\mathrm{D}_{(\mathrm{O})}$ y $\mathrm{D}_{(\mathrm{O} 2)}$, Por ejemplo, usando el coeficiente de difusión para el ozono derivados de la consideración teórica de Wilke y Chang (1955) o Scheibel (1958) (mencionado por Gottschalk y col.) con el $\mathrm{D}_{(\mathrm{O} 2)}$ igual y como se mencionó anteriormente, resultarán en diferentes factores para $\mathrm{D}_{(\mathrm{O} 3)} / \mathrm{D}_{(\mathrm{O} 2)}(0.864$ y 0.899 , respectivamente) y por lo tanto diferentes valores de kıa $\left(\mathrm{O}_{3}\right)[130]$.

Por ejemplo, algunos valores calculados del coeficiente de transferencia de masa de ozono usando en reactor de columna burbujas en diferentes estudios son: $\mathrm{kLa}=0.64$ $1.8 \mathrm{~min}^{-1}$ [132], $\mathrm{kLa}=0.17-1.2 \mathrm{~min}^{-1}$ [126] y kıa $=0.025 \mathrm{~s}^{-1}$ [133].

Con base en estas consideraciones, es preferible llevar a cabo las mediciones de la transferencia de masa usando ozono, cuando sea posible. Las mediciones se deben de realizar con la misma agua y si es posible, bajo los mismos rangos de parámetros de operación en los que la reacción de oxidación se llevará a cabo. Sin embargo, las reacciones del ozono y $\mathrm{OH}^{*}$ pueden causar complicaciones. Un valor de $\mathrm{pH}$ alto, por ejemplo, puede causar una tasa rápida de decaimiento de ozono. Por lo tanto, los radicales hidroxilos altamente reactivos pueden ser producidos y pueden cambiar la composición del agua. Es importante tener en cuenta estos cambios. Desafortunadamente, incluso en agua limpia, un $\mathrm{pH}$ alto puede afectar las mediciones de la transferencia de masa de ozono. Debido a la descomposición del ozono, la concentración de ozono en el estado estacionario en el líquido, $\mathrm{C}_{\llcorner\infty}$, no es igual a $\mathrm{C}_{\llcorner}{ }^{*}$ calculada a partir de la ley de Henry para $\mathrm{C}_{\mathrm{G}}$.

Además, es casi imposible usar ozono para mediciones de k $\mathrm{ka}$ en la presencia de sustancias químicas orgánicas que están (fácilmente) oxidadas por el ozono molecular. La intensificación de la transferencia de masa puede ocurrir durante estas mediciones, y la manera en que la transferencia de masa, basada solo en el proceso físico, no puede ser determinada. En este caso, la transferencia de masa del oxígeno 


\section{CAPÍTULO 2. MARCO TEÓRICO}

debe determinarse para evaluar la tasa de transferencia de masa sin reacción. La transferencia de masa intensificada por causa de la reacción debe ser considerada por separado, porque no solo depende de los parámetros (presión, volumen del reactor, velocidad de gas superficial, gravedad, viscosidad cinética, densidad, tensión superficial, comportamiento de la fusión de burbujas y coeficiente de difusión), sino también depende de la concentración de los reactantes [130].

Otros parámetros importantes que necesitan calcularse son:

El coeficiente de la transferencia de masa por la fase líquida es [134]:

$$
k_{L}=0.42 \sqrt[3]{\frac{\mu_{L} g}{\rho_{L}}} \sqrt{\frac{\rho_{L} D_{A_{L}}}{\mu_{L}}} \quad \text { por } \mathrm{db}_{\mathrm{b}} \geq 2 \mathrm{~mm} \quad \text { Ecuación 2-63 }
$$

$\mathrm{k} L$ es independiente de tamaño de burbuja y velocidad de burbuja y dependiente solo de las propiedades físicas del sistema. Cuando $\mathrm{db}_{\mathrm{b}}<2 \mathrm{~mm}$,

$$
k_{L}\left(\frac{m}{s}\right)=k_{L}(2 \mathrm{~mm}) \times 500 d_{b} \quad \text { Ecuación 2-64 }
$$

Por otro lado, Roustan y col. [127], calcularon el coeficiente de transferencia de masa por la fase líquida por medio de:

$$
\begin{aligned}
& k_{L}=1.13 \sqrt{\frac{D}{t_{c}}} \\
& t_{c}=\frac{d_{B}}{U_{s}}
\end{aligned}
$$

Para una columna de burbujas, $\mathrm{U}_{\mathrm{s}}$ es el aumento de la velocidad de la burbuja con respecto al líquido. Los resultados solo aplican si la burbuja es más grande que $d_{b}>$ $2.5 \mathrm{~mm}$ y tc es el tiempo de contacto.

En el caso de líquidos puros, el diámetro de burbuja $\left(\mathrm{db}_{\mathrm{b}}\right)$ está calculado por:

$$
d_{b}(\mathrm{~cm})=4.15\left[\frac{\sigma_{L}^{0.6}}{\left(\frac{P}{\varepsilon_{L} V}\right)^{0.4} \rho_{L}^{0.2}}\right] \varepsilon^{0.5}+0.09
$$

Ecuación 2-67 


\section{CAPÍTULO 2. MARCO TEÓRICO}

$\mathrm{Y}$ la retención de gas $(\varepsilon \mathrm{G})$ por:

$$
\varepsilon_{G}=\left(\frac{\varepsilon u_{S G}}{u_{b}}\right)^{0.5}+0.0216\left[\frac{\left(P / \varepsilon_{L} V\right)^{0.4} \rho_{L}^{0.2}}{\sigma_{L}^{0.6}}\right]\left(\frac{u_{S G}}{u_{b}}\right)^{0.5}
$$

Donde $\mathrm{P}$ es la entrada de alimentación, $\mathrm{P} / \varepsilon\llcorner\mathrm{V}$ es la entrada de alimentación por unidad de volumen líquido, y ub es la velocidad de ascenso libre (free-rising) de la burbuja:

$$
u_{b}=0.711\left(g d_{b}\right)^{0.5}
$$

Ecuación 2-69

Otras ecuaciones propuestas para la retención de gas $(\varepsilon G)$ son:

Con líquidos puros:

$$
\varepsilon_{G}=0.31\left(\frac{u_{s G}}{\sqrt[4]{\frac{\sigma_{L} g}{\rho_{L}}}}\right)^{2 / 3}+0.45 \frac{\left(N-N_{0}^{*}\right) d_{S}^{2}}{d_{r} \sqrt{g d_{r}}}
$$

Ecuación 2-70

Cuando las siguientes condiciones se cumplen:

$\varepsilon<0.25,0<\mathrm{U}_{\mathrm{sG}}<0.05 \mathrm{~m} / \mathrm{s}, \mathrm{Z} / \mathrm{d}_{\mathrm{r}}=1, \mathrm{y} \mathrm{H} \mathrm{L}-\mathrm{H}_{\mathrm{s}}=0.5 \mathrm{H} \mathrm{L}$

Con soluciones:

$$
\varepsilon_{G}=0.075 \frac{\left(N-N_{0}^{*}\right) d_{s}^{2}}{\sqrt[4]{\frac{\sigma_{L} g}{\rho_{L}} d_{r}}}\left(\frac{d_{r}}{H_{L}}\right)
$$

Ecuación 2-71

Siempre que se cumplan las siguientes condiciones:

$\varepsilon \leq 0.3,0.003<\mathrm{U}_{\mathrm{sG}}<0.03 \mathrm{~m} / \mathrm{s}, 0.7<\mathrm{H}_{\mathrm{L}} / \mathrm{d}_{\mathrm{r}}<1.4$, y $\mathrm{H}_{\mathrm{L}}-\mathrm{H}_{\mathrm{s}}=0.5 \mathrm{H}_{\mathrm{L}}$.

El área de interfase por unidad de volumen de dispersión se puede derivar de la relación: 


$$
a=6\left(\varepsilon / d_{b}\right)
$$

Por otra parte, cuando el ozono se dispersa en forma de burbujas en una columna, pueden identificarse las siguientes variables: la retención de la fase gaseosa, h; el diámetro de burbuja, db; el área de interfase, a [127]:

$$
a=\frac{6}{d_{b}} \frac{h}{1-h}
$$

\subsection{Tratamientos Biológicos}

El proceso biológico de lodos activados fue desarrollado en 1913 en la estación experimental de Lawrence en Massachusetts por Clark y Gage, y 1914 por Ardern y Lockett en la estación depuradora de Manchester en Londres. El nombre proviene de la producción de una masa activada de microorganismos capaz de estabilizar un residuo bajo condiciones aeróbicas. En el tanque de aireación, el tiempo de contacto está dado por el mezclado y la aireación del afluente de agua residual con suspensión microbiana, conocido como licor mezclado [135].

\subsubsection{Procesos aerobios}

Los procesos aerobios son tratamientos biológicos que ocurren en la presencia de oxígeno utilizando microorganismos (M.O.) aerobios para poder llevar a cabo la depuración del agua. Con el objetivo de transformar $u$ oxidar materiales biodegradables coloidales o finas partículas y orgánicos disueltos en otros productos como dióxido de carbono, agua y nueva biomasa. Como resultado de este proceso se producen flóculos que pueden ser removidos por sedimentación. Existen diversos procesos aerobios como: procesos de lodos activados, lagunas aireadas, digestión aerobia, filtros percoladores, filtros de desbaste, sistemas biológicos rotativos de contacto (RBC). 


\section{CAPÍTULO 2. MARCO TEÓRICO}

\subsubsection{Tipos de biorreactores}

Los reactores se dividen en dos tipos [136]:

1) Reactores intermitentes. Los materiales se adicionan al tanque, se mezclan perfectamente, y se dejan el tiempo suficiente para que la reacción se lleve a cabo. Al final del tiempo establecido, la mezcla se saca del tanque. Como el material normalmente está bien mezclado, la composición dentro del reactor es uniforme en cualquier instante. Se describe también como una operación en estado no estacionario.

2) Reactores de flujo continuo. La materia entra al reactor, lo atraviesa y sale de él. De acuerdo con las condiciones de mezclado y los patrones de flujo dentro del tanque, hablamos de reactores ideales y reales. Hay dos tipos de biorreactores:

a) Rector tubular de flujo pistón (RTFP). En este tipo de reactor, los patrones de flujo dentro del tanque se caracterizan como uniformes; esto es que las partículas fluidas pasan a través del tanque y se descargan con la misma secuencia que entraron al tanque. Las partículas permanecen en el tanque un tiempo igual al tiempo de retención teórico. No hay mezcla entre reactivos y productos, por ser separados con la distancia.

b) Reactor de tanque completamente mezclado (RTCM). Este tipo de reactor tiene como característica que el contenido del tanque se mezcla completamente y que la composición es uniforme. Por lo cual, la composición de efluente es igual a la del líquido del tanque.

\section{Los biorreactores pueden operar de tres formas [137]:}

Reactor discontinuo ("Batch"): es la forma tradicional más usada. Se emplea usualmente en la industria farmacéutica, alimentaria y biotecnológica. Se pueden asegurar de forma fácil las condiciones asépticas durante todo el proceso de reacción. Los microorganismos y el caldo de nutrientes se introducen conjuntamente en el instante inicial y la reacción se procede. Al finalizar el proceso, cuando se ha llegado a una conversión fijada, la concentración de salida de cada componente será la misma en el interior del reactor. Será necesario limpiar, llenar, inocular el reactor para comenzar el proceso de nuevo. 


\section{CAPÍTULO 2. MARCO TEÓRICO}

Reactor con alimentación discontinua ("Fed-Batch"): en los reactores semi-continuos el sustrato es alimentado en cargas sucesivas y el producto se retira hasta finalizar el proceso. Esto indica que el volumen del medio de reacción va variando conforme avanza el proceso.

Reactor con alimentación continua (Continuos): la forma de operar continua indica que existe una corriente de entrada y otra de salida de tal modo que el volumen de líquido en el interior del reactor permanece constante. Como resultado, las células reciben continuamente sustrato fresco y los productos y productos de descargas son removidos continuamente para ser procesados. En la operación continua hay más aumento en la productividad que en los reactores discontinuos.

\section{Reactor discontinuo secuencial}

Un reactor discontinuo secuencial (SBR) es un sistema de tratamiento de lodos activados cuyo funcionamiento se basa en la secuencia de ciclos de llenado y vaciado. Los procesos son la aireación y la sedimentación-clarificación que tienen lugar secuencialmente en el mismo tanque.

\subsubsection{Velocidad de utilización de oxígeno en los microorganismos}

La transferencia de oxígeno es necesaria en los procesos aerobios biológicos. Los microorganismos presentes en el proceso de lodos activados usan oxígeno a medida que consumen nutrimentos. Por eso es importante un suministro adecuado de oxígeno para satisfacer los requerimientos metabólicos de los microorganismos.

La velocidad de utilización de oxígeno (VUO) en biorreactores está proporcionada por los microorganismos existentes en el medio en un determinado tiempo y por su consumo unitario. Los factores que influyen esta demanda de oxígeno son la especie celular utilizada, la fase de crecimiento del cultivo y la naturaleza de la fuente de carbono en el medio [138]. Por lo tanto, VUO se puede tomar como una medida de la actividad biológica. 


\section{CAPÍTULO 2. MARCO TEÓRICO}

\subsubsection{Rol de los microorganismos}

El rol principal de los microorganismos es eliminar la materia carbonosa soluble (DBO disuelto) y estabilizar la materia orgánica presente en el agua residual. Esta reacción se realiza biológicamente mediante el uso de una variedad de microorganismos, principalmente bacterias. Los microorganismos pueden oxidar la materia orgánica carbonosa disuelta para formar productos finales simples y nueva biomasa, como se muestra en la siguiente ecuación (ec. 2-73).

$\mathbf{v}_{1}($ mat. org. $)+\mathbf{v}_{2} \mathbf{O}_{2}+\mathbf{v}_{3} \mathrm{NH}_{3}+\mathbf{v}_{4} \mathrm{PO}_{4}^{3-}+$ M. O. $\rightarrow \mathbf{v}_{5}($ n. c. $)+\mathbf{v}_{6} \mathrm{CO}_{2}+\mathbf{v}_{7} \quad$ Ecuación 2-73

Donde $\mathrm{v}_{1}$ es el coeficiente estequiométrico. El oxígeno $\left(\mathrm{O}_{2}\right)$, el amoniaco $\left(\mathrm{NH}_{3}\right)$ y el fosfato $\left(\mathrm{PO}_{4}{ }^{3-}\right)$ representan los nutrientes necesarios para la conversión de la materia orgánica (mat.org.) en la presencia de M.O. en productos finales simples (dióxido de carbono $\left(\mathrm{CO}_{2}\right)$ y agua $\left(\mathrm{H}_{2} \mathrm{O}\right)$ ) y nuevas células (n.c.), la biomasa como resultado de la oxidación de la mat.org. Los M.O. son utilizados para la remoción de nitrógeno y fósforo en el proceso de tratamiento de agua residual. La biomasa producida tiene una gravedad específica mayor al agua, por eso puede ser removida del efluente tratado mediante sedimentación gravitacional. Es importante señalar que si no existe una remoción periódica de la biomasa, el proceso de tratamiento no se ha completado, ya que la biomasa es orgánica y tiene un valor medido en $\mathrm{DBO}_{5}$ en el efluente [135].

\subsubsection{Tipo de microorganismos presentes en los lodos activados}

Los principales microorganismos presentes en un proceso aerobio son los siguientes [139-141]:

Bacterias: Constituyen el 95\% de la biomasa (formadoras de flóculo, filamentosas, nitrificantes, etc.)

Hongos: Son poco comunes en los sistemas de tratamiento de aguas residuales urbanas. Su presencia en abundancia se asocia, por lo general, a condiciones de $\mathrm{pH}$ demasiado bajas. Pueden ser usuales en procesos industriales. 


\section{CAPÍTULO 2. MARCO TEÓRICO}

Protozoos: Heterótrofos que se encuentran libremente en la naturaleza, son predadores de las bacterias, son: Flagelados, Rizópodos (Amebas), Ciliados (libres nadadores, libres reptantes, etc.).

Algas: Su importancia estriba en su capacidad fotosintética, aportando oxígeno. Por ser autótrofas permiten el aumento de la materia orgánica sintetizando el carbón mineral.

Metazoos: Son pluricelulares, muy abundantes en los sistemas que emplean soporte fijo. Se alimentan de sustrato y de bacterias (Rotíferos, Nemátodos, Oligoquetos y otros).

\subsubsection{Identificación de los microorganismos}

Hay seis métodos más utilizados para la identificación microbiana, clasificados en: criterios morfológicos, tinción diferencial, pruebas bioquímicas, pruebas serológicas, tipificación con fagos y detección molecular.

En la mayoría de los casos la identificación no se realiza con base a un solo método, sino a una combinación de los métodos [139-141].

Métodos basados en criterios morfológicos. Usan los rasgos morfológicos (estructurales) aunque con respecto a los M.O., éstos lucen tan similares bajo el microscopio que se dificulta su clasificación. No obstante, cuando la morfología celular dice poco sobre las relaciones filogenéticas, sigue siendo útil para la identificación bacteriana.

Métodos basados en tinción diferencial. Ayudan a sacar conclusiones en relación con la morfología de una bacteria, examinando una lámina que haya sido sometida a un proceso de tinción diferencial. Estos criterios morfológicos encabezan las primeras etapas del proceso de identificación bacteriana. La mayor parte de las bacterias, teñidas con Gram, pueden ser clasificadas como Gram positivas o Gram negativas según sea el caso.

Métodos basados en pruebas bioquímicas. Son ampliamente utilizadas para diferenciar bacterias. Estas pruebas pueden demostrar si el M.O. es capaz de 


\section{CAPÍTULO 2. MARCO TEÓRICO}

fermentar azúcares, por la presencia de enzimas, la degradación de compuestos, la producción de compuestos coloreados, etc.

Métodos basados en tipificación con fagos. La interacción entre un virus bacteriano y su célula bacteriana sensible es intensamente específica, ya que el proceso de adsorción se encuentra mediado por receptores específicos tanto en el virus como en la célula bacteriana. A una placa con medio de cultivo sólido inoculado con un cultivo puro de una determinada bacteria, se le añade una alícuota de un fago específico; éste puede ocasionar la lisis de las bacterias, hecho que se evidencia en el cultivo como zonas claras definidas, denominadas placas, que indican que hubo infección y lisis celular. El uso de fagos específicos permite identificar y subclasificar bacterias dentro de una misma especie.

Ejemplos de algunos M.O. en lodos activados [142]: P. putida, Citrobacer sp., Enterobacter sp., Acinetobacter spp., Nostocoida limícola, Aeromas, Shewanella, Rhodococcus, comamonas, Bacillus subtilis, Phanerochaete chrysosporium, Rhizopus sp., Fusarium sp., Burkholderia cepcia y Escherichia coli entre otros.

Tabla 2-5 Organismos indicadores que se encuentran en Lodos Activados [143, 144]

\begin{tabular}{|l|l|l|}
\hline Condiciones de Lodos & Cargas & Grupos predominantes \\
\hline Crecimiento Disperso & Alta & $\begin{array}{l}\text { Muchos flagelados, amebas y pocos ciliados } \\
\text { nadadores }\end{array}$ \\
\hline Flóculo es bueno & & $\begin{array}{l}\text { Buena diversidad de M.O. dominado por } \\
\text { Ciliados pedunculados, Ciliados nadadores } \\
\text { libres. } \\
\text { Pocos: rotíferos, amebas y flagelados }\end{array}$ \\
\hline Flóculo en punta de aguja & Óptima & $\begin{array}{l}\text { Mayor presencia de nematodos, rotíferos, } \\
\text { Pocos: ciliados pedunculados, ciliados } \\
\text { nadadores libres, flagelados y amebas }\end{array}$ \\
\hline
\end{tabular}




\subsubsection{Microorganismos importantes en la degradación de compuestos fenólicos}

Existen muchos M.O. con capacidad de degradar los compuestos fenólicos como las bacterias Bacillus insolitus [145], Azobacter sp., Alcaligenes sp., Acinetobacter sp. P. putida [146], Bacillus cereus [147] y hongos, ver Tabla 2-6. Estos M.O. son capaces de utilizar compuestos fenólicos de origen natural o químicamente sintetizados como única fuente de carbono y de energía.

Tabla 2-6 Lista de varios M.O. involucrados en la degradación de Fenol (Basha y col. [148]).

\begin{tabular}{|l|l|l|}
\hline Fuentes & Género & Especies \\
\hline \multirow{5}{*}{ Bacteria } & Alcaligenes & Alcaligenes faecalis; Alcaligenes Xylosoxidans Y234 \\
\cline { 2 - 3 } & Arthrobacter & Arthrobacter sp.; Arthrobacter citreus; Arthrobacter chlorphenolicus A6 \\
\cline { 2 - 3 } & Pseudomonas & P. putida; P. pictorum; P. aeruginosa \\
\cline { 2 - 3 } & CyanoBacterium & CyanoBacterium synechococcus \\
\cline { 2 - 3 } & Bacillus & Bacillus sp,; Bacillus brevis \\
\cline { 2 - 3 } & Candida & Candida tropicalis \\
\cline { 2 - 3 } & Fusarium & Fusarium sp. \\
\cline { 2 - 3 } & Graphium & Graphium sp. \\
\cline { 2 - 3 } & Ochromonas & Ochromonas danica \\
\cline { 2 - 3 } & Aspergillius & Aspergillius awamori \\
\hline \multirow{5}{*}{ Levadura } & Phanerochaete & Phanerochaete chrysosporium \\
\cline { 2 - 3 } & Rhodococus & Rhodococus erythropolis UPV-1 \\
\cline { 2 - 3 } & Rhodotorula & Rhodotorula creatinivora \\
\cline { 2 - 3 } & Sphigmonas & Sphigmonas chlorophenolica RA 2 \\
\cline { 2 - 3 } & Trichosporon & Trichosporon sp. LE3; Trichosporon cutaneum R57 \\
\hline
\end{tabular}

Nakagawa y col. [149] mostraron que el hongo Mortierella sp. (zygomycetes) utiliza dos vías diferentes de degradación para degradar 2,4-DCP. La primera ruta es por orto-oxidación de DCP, que resulta en la formación de 3,5-diclorocatecol, el cual se convirtió en dos diferentes compuestos 3,5-dicloroguaiacoles y 4,6-dicloroguaiacoles. La segunda ruta es de decloración de DCP para formar clorohidroquinona e hidroquinona. 


\section{CAPÍTULO 2. MARCO TEÓRICO}

Mars y col. [150] han estudiado la degradación microbiana de cloroaromáticos y el uso de la vía de meta-escisión para la mineralización de los compuestos clorados, demostrando los estudios de degradación P. putida GJ31 en tolueno y clorobenceno.

Por otra parte, algunos autores degradaron 2,4-DCP usando lodos activados. Se sugieren concentraciones menores a $150 \mathrm{mg} / \mathrm{L}$ de 2,4-DCP para lograr remociones mayores al 90\% para DQO y DCP [151]. Además, otros autores encontraron que la degradación de DCP mejoró con el aumento de la edad de los lodos. Se recomienda la operación a una edad de los lodos de 25 días [152].

Como se mencionó anteriormente los compuestos fenólicos son una gran amenaza al medio ambiente ya que son recalcitrantes y tóxicos. Para ayudar a disminuir la contaminación en el ambiente por estos compuestos, se han utilizado muchos de estos M.O., especialmente las bacterias, las cuales tienen diferentes rutas metabólicas.

Para medir la efectividad de los diferentes M.O. para degradar compuestos fenólicos, muchos investigadores han estudiado los resultados obtenidos con cultivos puros y mixtos, ya que esta característica, como la selección del medio, ya sea aerobio o anaerobio, es muy importante.

En algunos estudios se ha optado por tratar los compuestos fenólicos con cultivos puros de M.O. para su degradación, como es el caso del estudio realizado por Wang y col. [145] quienes utilizaron una cepa de Bacillus insolitus aislada de algunos lodos activados adaptados a clorofenoles. Ellos estudiaron esta cepa bacteriana en formas de suspensión e inmovilizada. Los resultados mostraron que a concentraciones iniciales bajas de 2,4-DCP (10 - 50 mg/L) la Bacillus insolitus en forma inmovilizada logra la remoción más alta de 2,4-DCP que cuando está en suspensión. Pero cuando aumentaron la concentración de 2,4-DCP (50 - $200 \mathrm{mg} / \mathrm{L})$ ambas formas mostraron aproximadamente la misma eficiencia de remoción.

Pseudomona putida (P. putida) son bacterias en forma de bacilos rectos o curvados, saprófitos, Gram negativos, aerobios, sin esporas, sin metabolismo fermentativo, quimioorganotrofos con flagelos polares (Figura 2-5). Son del género Pseudomonas 


\section{CAPÍTULO 2. MARCO TEÓRICO}

que son Proteobacterias de subgrupos fluorescente y grupo filogenético de Gamma, con un tamaño entre de 0.7- $0.8 \mu \mathrm{m}$ por 1-2 $\mu \mathrm{m}$. Las Pseudomonas tienen requerimientos nutritivos muy simples y conocidos, siendo capaces de usar compuestos aromáticos como el fenol como única fuente de carbono y energía. Su óptima condición de crecimiento microbiano es de $30^{\circ} \mathrm{C}$ y pH neutro $[140,153]$. Por otra parte, la $P$. putida es estudiada por muchos investigadores para la degradación de compuestos fenólicos [154, 146, 148, 155].

\section{$B a r=1 \mu \mathrm{m}$}

Figura 2-5 Fotografía al microscopio electrónico de trasmisión una célula de $P$. putida (tomadao de Harwood y col. [156])

\section{Preparación del medio para crecimiento}

Un medio de sal mineral básico (medio MS) fue usado para aislar el organismo. Las bacterias crecieron a pH neutro sobre medio MS conteniendo (por litro): $27.5 \mathrm{~g} \mathrm{~K}_{2}$ $\mathrm{HPO}_{4}, 22.5 \mathrm{~g} \mathrm{KH}_{2} \mathrm{PO}_{4}, 1 \mathrm{~g}\left(\mathrm{NH}_{4}\right)_{2} \mathrm{SO}_{4}, 0.2 \mathrm{~g} \mathrm{MgCl}_{2} .6 \mathrm{H}_{2} \mathrm{O}, 0.1 \mathrm{~g} \mathrm{NaCl}, 0.02 \mathrm{~g}$ $\mathrm{FeCl}_{3} .6 \mathrm{H}_{2} \mathrm{O}$ y $0.01 \mathrm{~g} \mathrm{CaCl}_{2}$ (Watanabe y col. [157]).

\section{Aislamiento de una cepa bacteriana}

El primer paso para aislar una cepa bacteriana fue con una muestra de agua residual de una planta de tratamiento. De esta misma muestra se tomaron $10 \mathrm{~mL}$ y se inocularon en un frasco de $250 \mathrm{~mL}$ con $100 \mathrm{~mL}$ de medio suplementario MS con 200 $\mathrm{mg} / \mathrm{L}$ fenol. El frasco fue incubado a $30^{\circ} \mathrm{C}$ con agitación de $170 \mathrm{rpm}$ por una semana. En el segundo paso, $1 \mathrm{~mL}$ del primer frasco fue añadido a un nuevo frasco conteniendo $100 \mathrm{~mL}$ de medio MS e incubado bajo las mismas condiciones. En el tercer paso, la muestra anterior se sembró sobre un medio de agar sólido de MS y fenol, y después cada colonia específica fue inoculada separadamente sobre caldo nutritivo y agar. De esa manera los cultivos puros que pueden degradar fenol fueron aislados. El fenol se 


\section{CAPÍTULO 2. MARCO TEÓRICO}

determinó cuantitativamente utilizando 4-aminoantipirina como color reactivo [158] y la tasa de crecimiento bacteriano fue leída por densidad óptica a 600 nm (DO600) con el espectrofotómetro [153].

\section{Cinética de crecimiento bacteriano.}

Las cuatro etapas de un crecimiento microbiano típico son:

La primera se llama la fase de adaptación o de latencia y es inmediatamente después de la inoculación. Durante esta fase no se produce un aumento significativo en el número de células y por eso la velocidad de crecimiento es casi cero. Las células utilizan esta fase para adaptarse a su nuevo ambiente y pueden sintetizar nuevas enzimas o componentes estructurales.

La segunda etapa se llama fase exponencial, en la cual la población se duplica a intervalos regulares. Bajo condiciones óptimas, esta fase alcanza su máxima velocidad de crecimiento. La tercera etapa se llama fase estacionaria ya que no hay cambios en la cantidad de biomasa, es decir, el número de células que son producidas son iguales al número de células que mueren, estableciéndose un equilibrio dinámico en el cual no existe un mayor crecimiento. Por carencia de algún nutriente, o algún cambio en el entorno fisicoquímico, el crecimiento se hace más lento.

Finalmente, en la fase de muerte las células comienzan a morir y se supera la tasa de crecimiento y como consecuencia disminuye la población celular. En la Figura 2-6 se muestran las cuatro etapas de un crecimiento microbiano típico [140].

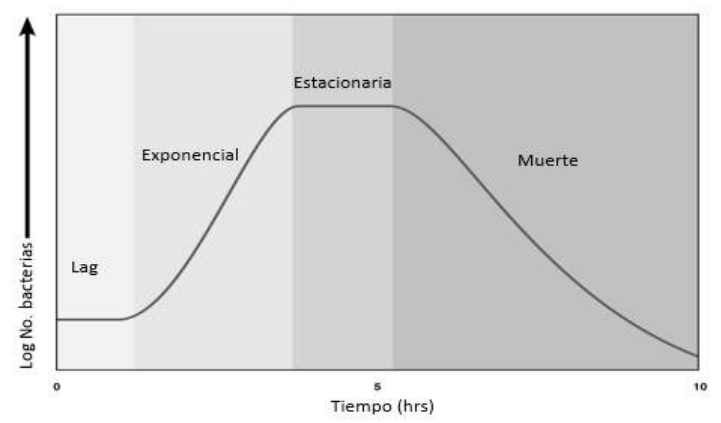

Figura 2-6 Cinética de Crecimiento Bacteriano 


\section{CAPÍTULO 2. MARCO TEÓRICO}

\section{Requerimientos para el crecimiento.}

Los requerimientos para el crecimiento microbiano se dividen en dos grupos principales: físicos y químicos. Los aspectos físicos comprenden la temperatura, el pH y la presión osmótica mientras que los químicos son fuentes de carbono, nitrógeno, azufre, fósforo, oligoelementos, oxígeno y factores de crecimiento orgánico.

Tabla 2-7 Temperatura Óptima de Crecimiento

\begin{tabular}{|c|c|c|}
\hline Clasificación & Rango $\left({ }^{\circ} \mathbf{C}\right)$ & $\begin{array}{c}\text { Rango óptimo de } \\
\text { crecimiento }\left({ }^{\circ} \mathbf{C}\right)\end{array}$ \\
\hline Psicrófilos & -5 a 30 & 10 a 20 \\
\hline Mesófilos & 10 a 45 & 20 a 40 \\
\hline Termófilos & 25 a 80 & 50 a 60 \\
\hline
\end{tabular}

\section{Clasificar los microorganismos según el pH [159]:}

Basófilos: necesitan un $\mathrm{pH}$ elevado para poder vivir ( 7.5 a 11.5)

Neutrófilos: requieren un $\mathrm{pH}$ neutro, alrededor de 7.

Acidófilos: requieren un $\mathrm{pH}$ bajo $(1-4)$

Las pruebas bioquímicas consisten en distintas pruebas químicas aplicadas en medios biológicos, las cuales, conociendo las actividades metabólicas y enzimáticas, permiten identificar distintos M.O. presentes. Los sistemas de funcionamiento generalmente consisten en determinar la actividad de una ruta metabólica a partir de un sustrato que se incorpora en un medio de cultivo y que la bacteria al crecer incorpora o no incorpora.

\section{Para identificar un cepa bacteriana de Pseudomonas sp. se deben de cumplir las siguientes pruebas:}

1- Observar el color rosa con tinción Gram (Bacteria Gram -)

2- En las pruebas de Tres azúcares-Hierro (TSI) no debe fermentar la glucosa ni lactosa y no se tornan los colores de medios amarillos, indicando reacciones negativas 


\section{CAPÍTULO 2. MARCO TEÓRICO}

3- En las pruebas de citratos debe observarse crecimiento a lo largo de la estría, y éste se acompaña o no de un viraje del indicador de verde a azul, indicando una reacción positiva

4- En las pruebas de Rojo de Metilo (MR) y Voges Proskauer (VP) deben de dar resultados negativos. Es decir, en la prueba de MR debe verse un color amarillo, no producción de ácidos estables y en la prueba de VP no desarrollo de color rosa, ausencia de acetoína.

5- En las pruebas de nitrato se debe de observar el color rojo (sin echar el polvo de Cinc), indicando una reacción positiva

6- En las pruebas de Leche Litmus no debe ocurrir peptización, dando resultados negativos.

Las Pseudomonas son bacilos rectos o curvados de tamaño $0.5-1.0 \mu \mathrm{m}$ por 1.5-4.0 $\mu \mathrm{m}$; son Gram negativas; flagelos polares, metabolismo oxidativo [140]. En la Tabla 2-8 se muestran los resultados de las pruebas bioquímicas y características para identificar las diferencias de las bacterias Pseudomonas.

Tabla 2-8 Características Fenotípicas de especies de Pseudomonas [160-162]

\begin{tabular}{|c|c|c|c|c|}
\hline & P. aeruginosa & P. fluorescens & P. cepacia & P. putida \\
\hline Agar MacConnkey & Crece & Crece & Crece & Crece \\
\hline Nitratos & + & variable & + & - \\
\hline Motilidad & + & + & + & + \\
\hline Citrato & + & + & + & + \\
\hline Lecitinasa & - & + & & - \\
\hline Pigmentación & Verde & Verde & & Variable \\
\hline Gelatina & + & + & + & - \\
\hline $\begin{array}{l}\text { Temperatura } \\
\left(42^{\circ} \mathrm{C}\right)\end{array}$ & Crece & No crece & variable & No crece \\
\hline \multicolumn{5}{|l|}{ Acidificación: } \\
\hline Maltosa & - & - & + & - \\
\hline Glucosa & + & + & + & + \\
\hline Lactosa & - & - & + & - \\
\hline Manitol & Variable & + & + & - \\
\hline
\end{tabular}




\section{CAPÍTULO 2. MARCO TEÓRICO}

\subsection{Pruebas de Toxicidad}

La prueba de toxicidad es una matriz de prueba usando diferentes concentraciones de la sustancia tóxica para encontrar la concentración que causa una tasa de mortalidad de $50 \%$ en los organismos de pruebas. La toxicidad se define como la capacidad de una sustancia o mezla de provocar efectos adversos en la salud o en los ecosistemas [163]. Por eso, la toxicidad de un compuesto químico es importante en la evaluación de su impacto sobre el medio ambiente y los ecosistemas. El conocimiento de la toxicidad de un compuesto sobre los M.O. tiene dos usos: puede ser usado para evaluar el efecto químico sobre las bacterias en el medio ambiente o en un sistema de tratamiento de agua residual por procesos biológicos.

Por otra parte, la toxicidad de una substancia sobre un microorganismo puede ser usada para estimar la toxicidad en otros M.O. o en organismos superiores como peces, si puede establecerse una relación entre la respuesta tóxica de los dos organismos. Por esto, las determinaciones preliminares de toxicidad basadas en pruebas de bacterias resultan ventajosas, ya que se reducen el costo y el tiempo involucrado en hacer las pruebas en organismos superiores [164].

Las pruebas de toxicidad resultan muy importantes en estudios sobre tratamientos de aguas residuales industriales, ya que muchos de los efluentes industriales contienen químicos que pueden resultar tóxicos al momento de su descarga para las especies en sistemas acuáticos [165] o para los M.O. en los procesos biológicos. Adicionalmente, un corto tratamiento con oxidación avanzada al compuesto fenólico puede formar compuestos intermedios más toxicos.

Los ensayos de toxicidad se han llevado a cabo en los clorofenoles para probar su toxicidad en lodos activados, bacterias, algas y otros. Algunas pruebas de toxicidad como Microtox ${ }^{T m}$, BioTox, LUMIStox, ToxAlert 10 usaron bacteria Vibrio fischeri y la Photobacterium phosphoreum en solución salina. Se mide la iluminación durante 15 a 30 min para calcular $\mathrm{EC}_{50} \circ \mathrm{IC}_{50}$ [166-168]. Estas pruebas son apropiadas para efluentes antes de su descarga a agua salina, marina. 


\section{CAPÍTULO 2. MARCO TEÓRICO}

Otra prueba utilizada para medir la toxicidad de los compuestos fenólicos es la prueba Toxichromo. Este ensayo está basado en la capacidad de las sustancias tóxicas en la síntesis de novo de inhibición de $\beta$-galactosidasa a partir de una cepa mutante de Escherichia coli. La respuesta bacteriana a la muestra tóxica se determina por la intensidad de color azul en la muestra. Se mide la absorbancia de las muestras a 610 $\mathrm{nm}$, con el fin de calcular el factor de toxicidad [169].

Por otra parte, se puede encontrar mucha literatura sobre la toxicidad de clorofenoles en diferentes organismos, desde bacterias hasta peces. Por ejemplo, algunos autores estudiaron el efecto de toxicidad de compuestos fenólicos en otras bacterias: $P$. fluorescens [170], Bacillus subtilis y P. putida [171]; en las algas Selenastrum capricornutum [172], Pseudokirchneriella subcapita [173] y Dunaliella tertiolecta [174]; en los protozoos Tetrahymena thermophila [167] y Tetrahymen pyriformis [175]; en los crustáceos (Daphnia magna, Thamnocephalus platyurus [167]); Lodos activados [176] y en Peces Oryzias latipes [177], Pimephales promelas [164] y Lebistes reticulatus [178]).

Wang y col. [179] estudiaron el efecto de los compuestos fenólicos en la semilla de Mijo (Panicum miliacecum). Ellos encontraron valores de $\mathrm{EC}_{50}$ de fenol de $170 \mathrm{mg} / \mathrm{L}$, $3-\mathrm{CP}$ de $32 \mathrm{mg} / \mathrm{L}$ y de $2,6-\mathrm{DCP}$ de $5 \mathrm{mg} / \mathrm{L}$.

Erturk y otros analizaron la toxicidad de 30 compuestos fenólicos con bioensayos de algas basándose en los criterios de la OECD, usando algas de agua dulce, Chlorella vulgaris, por $96 \mathrm{~h}$ a una temperatura de $24{ }^{\circ} \mathrm{C}$ [180].

Además, algunos investigadores han estudiado nuevas técnicas y variaciones en las pruebas de toxicidad para encontrar métodos más sencillos y rápidos. Por ejemplo, Dolezalova y Rumlova [181] hicieron una nueva prueba de toxicidad con Levadura (Saccharomyces cerevisiae), la cual consiste en medir la conductividad de la solución y calcular la toxicidad a partir de estos datos. Los beneficios de esta prueba son muy sencillos y baratos, ya que se requiere de la solución acuosa, el azúcar, la levadura y 


\section{CAPÍTULO 2. MARCO TEÓRICO}

un equipo para medir la conductividad. En las pruebas con fenol se calcularon un $\mathrm{EC}_{50}$ de $523.7 \mathrm{mg} / \mathrm{L}$ con $S$. cerevisiae.

Las pruebas de toxicidad pueden variar en la sensibilización hacia la solución tóxica, así que pueden variar los valores de $\mathrm{EC}_{50}$ dependiendo de los organismos usados, del $\mathrm{pH}$ de la solución tóxica y el tiempo de contacto, entre otros. Además, diferentes pruebas de toxicidad pueden mostrar correlación entre los valores de $\mathrm{EC}_{50}$ usando diferentes organismos. La Tabla 2-9 muestra la toxicidad de algunos compuestos fenólicos en algunas bacterias luminiscentes.

Tabla 2-9 Los valores de $\mathrm{EC}_{50}$ de algunos compuestos orgánicos usando diferentes pruebas de toxicidad.

\begin{tabular}{|c|c|c|c|c|c|}
\hline \multirow[b]{2}{*}{$\begin{array}{l}\text { Compuestos } \\
\text { orgánicos }\end{array}$} & \multicolumn{5}{|c|}{$\mathrm{EC}_{50}(\mathrm{mg} / \mathrm{L})$} \\
\hline & $\begin{array}{l}{ }^{1} \text { Microtox } \\
\text { (V. fischeri) }\end{array}$ & $\begin{array}{c}{ }^{2} \text { BioTox } \\
\text { (V. fischeri) }\end{array}$ & $\begin{array}{l}\text { 3LUMIStox } \\
\text { (V. fischeri) }\end{array}$ & $\begin{array}{r}{ }^{3} \text { ToxAlert } 10 \\
\text { (V. fischeri) }\end{array}$ & ${ }^{4}$ P. phosphoreum \\
\hline phenol & 18 & 33 & 30.3 & 42.5 & 34.2 \\
\hline $2-C P$ & 18 & & 18 & 27.2 & 39.73 \\
\hline 3-CP & 6.1 & & & - & 13.16 \\
\hline 4-CP & 1.0 & & 1.14 & 1.45 & 9.1 \\
\hline 2,3-DCP & 3.6 & & & - & 4.81 \\
\hline 2,4-DCP & 2.0 & & & - & 5.04 \\
\hline 2,5-DCP & 6.9 & & & - & 9.6 \\
\hline 2,6-DCP & 10.0 & & & - & 13.56 \\
\hline 3,4-DCP & 0.5 & & & - & 1.67 \\
\hline 3,5-DCP & 7.3 & & 4.8 & 4.42 & 3.18 \\
\hline Catecol & 32 & & 86.2 & 40.3 & - \\
\hline Resorcinol & 370 & 340 & 386 & 684 & - \\
\hline
\end{tabular}

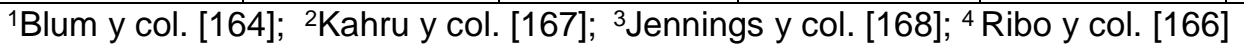

Por otra parte, no es práctica común entre científicos el hacer pruebas de toxicidad a la solución oxidada para verificar la toxicidad de los productos intermedios ya que puede resultar más tóxica que la compuesta madre, y además de ser todavía tóxica, su descarga puede tener efectos tóxicos en organismos acuáticos o lodos activados según sea el caso. Entre los investigadores hay algunos autores que reportaron sobre las pruebas de toxicidad que se aplicaron a las soluciones oxidadas de los procesos de oxidación avanzada [81, 182-186]. 


\section{REFERENCIAS}

[1] S. E. Agary, O. O. Ogunleye y O. A. Aworanti, «Biosorption equilibrium, kinetic and thermodynamic modelling of naphthalene removal from aqueous solution onto modified spent tea leaves,» Environ Technol, 34, 825-839, 2013.

[2] New World Encyclopedia contributors, « Naphthalene,» 20 Deciembre 2014. [En línea].

Available:

http://www.newworldencyclopedia.org/p/index.php?title=Naphthalene\&oldid=985882. [Último acceso: 15 Noviembre 2015].

[3] A. B. Duckett, «Para-Dichlorobenzene as an insect fumigant,» Bull. -U.S., Dep. Agric., 167, 1-7, 1915.

[4] K. Newhart, «Environmental Fate of Paradichlorobenzene,» California Environmental Protection Agency; California Department of Pesticide Regulation, Sacramento, CA, 2007.

[5] A. Jori, D. Calamari, F. Cattabeni, A. Di Domenico, C. L. Galli, E. Galli, A. Ramundo y V. Silano, «Ecotoxicological profile of p-dichlorobenzene,» Ecotox Environ Safe, 6, 413-432, 1982.

[6] D. Dubey, V. D. Sharma, S. E. Pass, A. Sawhney y O. Stuve, «Para-dichlorobenzene toxicity - a review of potential neurotoxic manifestations,» Ther Adv Neurol Disord., 7, 177-187, 2014.

[7] Hsiao, P., Y. Lin, T. Shih y Y. Chiung, «Effects of occupational exposure to 1,4Diclorobenzene on hematologic, kidney and liver function,» J. Int Arch Occ Env Hea., 82, 1077-1085, 2009.

[8] J. T. Haney, « Development Support Documents (DSDs)-1,4-Dichlorobenzene,» Texas Commission on Environmental Quality, 2015.

[9] M. A. Laurent, "Sur la Chlorophénise et les Acides Chlorophénisique et Chlorophénesique,» Ann. Chim. Phys., 63,. 27-45, 1836.

[10] J. Barlow y J. Johnson, «Breast cancer and the environment research centers early life exposure to phenols and breast cancer risk in later year-fact sheet on phenols.,» 2007. 


\section{CAPÍTULO 2. MARCO TEÓRICO}

[11] T. Edgerton, R. Moseman y L. Wright, «Method development for the assessment of possible human exposure to pesticides and Industrial,» USEPA, 1981.

[12] B. H. Nicolaisen y T. M. Jenney, «Process for selective crystallization of 2,5dichlorophenol». United States of America Patente 2,708,209, 10051955.

[13] W. Lowe, «Process for isolation of 2,5-dichlorophenol from an isomeric mixture of dichlorophenols». United States of America Patente 3,462,498, 19081969.

[14] A. W. Calson, «Process for the preparation of 2,5-dichlorophenol». United States of America Patente 4,094,913, 13061978.

[15] R. H. Sehring, «Preparation of 2,5-Dichlorophenol». United States of America Patente 4,670,610, 02061987.

[16] TOXNET, «TOXNET- Toxicology Data Network. (National Library of Medincine. National Institutes of Health),» 2008 2009. [En línea]. Available: http://toxnet.nlm.nih.gov. [Último acceso: 0210 2014].

[17] B. Gunawardana, N. Singhal y P. Swedlund, «Degradation of Chlorophenols by Zero Valent,» Environ. Eng. Res., 16, 187-203, 2011.

[18] K. Tegethoff, B. A. Herbold y E. M. Bomhard, «nvestigations on the mutagenicity of 1,4-dichlorobenzene and its main metabolite 2,5-dichlorophenol in vivo and in vitro,» Mutat Res-Gen Tox En, 470, 161-167, 2000.

[19] J. F. Borzelleca, J. R. Hayes, L. W. Condie y J. I. Egle, «Acute toxicity of monochlorophenols, dichlorophenols and pentachlorophenols in the mouse,» Toxicol lett, 29, 39-42, 1985.

[20] R. H. Hill, S. L. Head, S. Baker, M. Gregg, D. B. Shealy, S. L. Baile, C. C. Williams, E. J. Sampson y L. L. Needham, «Residues in urine of adults living in the United States: reference range concentration,» J. Environ Res, 71, 99-108, 1995.

[21] X. Ye, L.-Y. Wong, X. Zhou y A. M. Calafat, "Urinary Concentrations of 2,4Dichlorophenol and 2,5-Dichlorophenol in the U.S. Population (National Health and Nutrition Examination Survey, 2003-2010): Trends and Predictors,» Environ Health Persp, 122, 351-355, 2014. 


\section{CAPÍTULO 2. MARCO TEÓRICO}

[22] M. Casas, C. Chevrier, E. Den Hond, M. F. Fernandez, F. Pierik, C. Philippat, R. Slama, G. Toft, S. Vandentorren, M. Wilhelm y M. Vrijheid, «Exposure to brominated flame retardants, perfluorinated compounds, phthalates and phenols in European birth cohorts: ENRIECO evaluation, first human bimonitoring results and recomendations,» Int. J. Hyg. Envir Heal, 216, 230-242, 2013.

[23] X. Ye, Z. Kuklenyik, L. L. Needham y A. M. Calafat, "Quantification of urinary conjugates of bisphenol A, 2,5-dichlorophenol, and 2-hydroxy-4methoxybenzophenone in humans by online solid phase extraction-high performance liquid chromatography-tandem mass spectrometry,» Anal. Bioanal. Chem., 383, 638644, 2005.

[24] P. Baillie-Hamilton, "Chemical Toxins: A Hypothesis to Explain the Global Obesity Epidemic.,» J Altern Complem Med, 8, 185-192., 2002.

[25] M. Buser, H. Murray y F. Scinicariello, «Association of Urinary Phenols with Increased Body Weight Measures and Obesity in Children and Adolescents,» J. Pediatr., 165, 744-749, 2014.

[26] T. R. Chakraborty, E. Alicea y S. Chakraborty, «Relationships between urinary biomarkers of phytoestrogens, phthalates, phenols and pubertal stages in girls,» Adolescent Health, Medicine and Therapeutics, 3, 17-26, 2012.

[27] C. Twum y Y. Wei, «The association between urinary concentration of dichlorophenol pesticides and obesity in children,» Res. Environ. Health, 26, 215-219, 2011.

[28] E. Jerschow, A. P. McGinn, G. de Vos, N. Vernon, S. Jariwala, G. Hudes y D. Rosenstreich, «Dichlorophenol-containing pesticides and allergies: results from the US National Health and Nutrition Examination Survey 2005-2006,» Ann. Allerg Asthma Im., 109, 420- 425, 2012.

[29] E. Jerschow, P. Parikh, A. P. McGinn, G. de Vos, S. Jariwala, G. Hudes y D. Rosenstreich, «Relationship between urine dichlorophenol levels and astma morbidity,» Ann. Allerg. Asthma IM., 112, 511-518, 2014. 


\section{CAPÍTULO 2. MARCO TEÓRICO}

[30] M. S. Wolff, S. M. Engel, G. S. Berkowitz, X. Ye, M. J. Silva, C. Zhu, J. Wetmur y A. M. Calafat, «Prenatal phenol and phthalate exposure and birth outcomes,» Environ Health Persp, 116, 1092-1097, 2008.

[31] Y. Wei y J. Zhu, «Associations between urinary concentrations of 2,5-dichlorophenol and metabolic syndrome among non-diabetic adults,» Environ Sci. Pollut R., pp. 1-8, 2015.

[32] Y. Wei y J. Zhu, "Urinary concentration of 2,5-dichlorophenol and diabetes in US adults,» J. Expo. Sci. Env. Epid., 2015. Falta volumen y páginas

[33] W. H. Glaze, J.-W. Kang y D. H. Chapin, «The chemistry of water treatment processes involving ozone, hydrogen peroxide, ultraviolet radiation,» Ozone Sci. Eng., 9, 335352, 1987.

[34] M. Pera-Titus, V. García-Molina, M. A. Baños, J. Giménez y S. Esplugas, «Degradation of clorophenols by means of advanced oxidation processes: a general review.,» Appl Catal B: Environmental, 47, 219 - 256, 2004.

[35] A. Vogelpohl y S.-M. Kim, «Advanced Oxidation Processes (AOPs) in Wastewater Treatment,» J. Ind. Eng. Chem., 10, 33-40, 2004.

[36] M. Mohajerani, M. Mehrvar y F. Ein-Mozaffari, «An Overview of the Integration of Advanced Oxidation Technologies and other processes for water and wastewater treatment.,» International Journal of Engineering (IJE), 3, 120-146, 2009.

[37] I. Oller, S. Malato y J. A. Sánchez-Pérez, «Combination of Advance Oxidation Processes and biological treatments for wastewater decontamination- A review,» J. Sci Total Environ., 409, 4141-4166, 2011.

[38] J. Hoigné y $\mathrm{H}$. Bader, «The role of Hydroxyl radical reactions in ozonation processes in aqueous solutions,» Water Res., 10, 377-386, 1976.

[39] J. Wohlers, I. Koh, T. Wolfram y R. Wolfgang, «Application of air ionization device using an atmospheric pressure corona discharge process for water purification,» $J$. Water Air Soil Poll, 196, 101-114, 2009. 


\section{CAPÍTULO 2. MARCO TEÓRICO}

[40] F. J. Benitez, J. Beltra-Heredia, J. L. Acero y F. J. Rubio, «Oxidation of several chlorophenolic derivatives by UV irradiation and hydroxyl radicals,» J. Chem Technol Biotechnol, 76, 312-320, 2001.

[41] M. D. Gurol y R. Vatistas, "Oxidation of Phenolic Compounds by Ozone and Ozone+UV Radiation: A Comparative Study,» Water Res., 21, 895-900, 1987.

[42] M. Dore, B. Langlais y B. Legube, "Ozonation des phenols et des acides phenoxyacetiques,» Water Res., 12, 413- 425, 1978.

[43] S. Esplugas, J. Giménez, S. Contreras, E. Pascual y M. Rodríguez, "Comparison of different advance oxidation processes for phenol degradation,» Water Res., 36, 10341042, 2002.

[44] U. von Gunten, «Ozonation of drinking water: Part I. Oxidation kinetics and product formation,» Water Res., -1467, 2003.

[45] Z. Shiyun, Z. Xuesong y L. \& Daotang, «Ozonation of naphthalene sulfonic acids in aqueous solutions. Part I: elimination of COD, TOC and increase of their biodegradability,» Water Res., 36, 1237-1243, 2002.

[46] A. Mokrini, D. Oussi y S. Esplugas, "Oxidation of aromatic compounds with UV radiation/ozone/hydrogen peroxide,» Water Sci. Technol, 35, 95-102, 1997.

[47] H. Kusic, N. Koprivanac y A. L. Bozic, «Minimization of organic pollutant content in aqueous solution by means of AOPs: UV-and ozone-based technologies., Chem Eng., 123, 127-137, 2006.

[48] D. Hendricks, Fundamentals of water treatment unit processes: Physical, Chemical, and Biological, Boca Raton, Florida: CRC Press, 2011, p. 644.

[49] L. Qian, S. Wang, D. Xu, Y. Guo, X. Tang y L. Wang, «Treatment of municipal sewage sludge in supercritical water: A review,» Water Res., 89,

[50] P. A. Marrone, «Supercritical water oxidation-Current status of full-scale commercial activity for waste destruction,» J. Supercrit. Fluid., 79, 283-288, 2013.

[51] T. Zhang, S. Z. Wang, Z. Q. Zhang, J. Q. Yang y M. Wang, "Treatment of sludge and wastewater mixture by Supercritical Water Oxidation,» de Resources, Environment and Engineering II: Proceedings of the 2nd Technical Congress on Resources, 


\section{CAPÍTULO 2. MARCO TEÓRICO}

Environment and Engineering (CREE 2015, Hong Kong, 25-26 September 2015), L. Xie, Ed., Leiden, The Netherlands, CRC Press/Balkema, 2015, pp. 499-504.

[52] D. Xu, S. Wang, J. Zhang, X. Tang, Y. Guo y C. Huang, «Supercritical water oxidation of a pesticide wastewater,» Chem. Eng. Res. Des., 94, 396-406, 2015.

[53] J. M. Prado, D. Lachos-Perez, T. Forster-Carneiro y M. A. Rostagno, «Sub- and supercritical water hydrolysis of agricultural and food industry residues for the production of fermentable sugars: A review,» Food and Bioprod. Process., 98, 95-123, 2016.

[54] D. Xu, C. Huang, S. Wang, G. Lin y Y. Guo, «Salt deposition problems in supercritical water oxidation,» Chem. Eng. J., 279, 1010-1022, 2015.

[55] G. Lee, T. Nunoura, Y. Matsumura y K. Yamamoto, "Comparison of the effects of the addition of $\mathrm{NaOH}$ on the decomposition of 2-chlorophenol and phenol in supercritical water and under supercritical water oxidation conditions,» J. Suprcrit. Fluid., 24, 239250, 2002.

[56] Q. Guan, C. Wei y X.-S. Chai, «Pathways and kinetics of partial oxidation of phenol in supercritical water,» Chem Eng. J., 175, 201-206, 2011.

[57] K. S. Lin, H. P. Wang y M. C. Li, «Oxidation of 2,4-dichlorophenol in supercritical water,» Chemosphere, 36, 2075-2083, 1998.

[58] H.-C. Lee, J.-H. In, J.-H. Kim, K.-Y. Hwang y C.-H. Lee, «Kinetic Analysis for Decomposition of 2,4-Dichlorophenol by Supercritical Water Oxidation,» Korean J. Chem. Eng., 22, 882-888, 2005.

[59] P. Chowdhury y T. Viraraghavan, «Sonochemical degradation of chlorinated organic compounds, phenolic compounds and organic dyes-A review,» Sci. Total Environ., 407, 2474-2492, 2009.

[60] H. Hao, Y. Chen, M. Wu, H. Wang, Y. Yin y Z. Lü, « Sonochemistry of degrading pchlorophenol in water by high frequency ultrasound,» Ultrason. Sonochem., 11, 4346, 2004.

[61] Z. Wu, G. Cravotto, M. Adrians, B. Ondruschka y W. Li, «Critical factors in sonochemical degradation of fumaric acid,» Ultrason. Sonochem., 27, 148-152, 2015. 


\section{CAPÍTULO 2. MARCO TEÓRICO}

[62] O. Hamdaoui y E. Naffrechoux, «Sonochemical and photosonochemical degradation of 4-chlorophenol in aqueous media,» Ultrason. Sonochem., 15, 981-987, 2008.

[63] M. Uddin y S. Hayashi, «Effects of dissolved gases and $\mathrm{pH}$ on sonolysis of 2,4dichlorophenol,» J. Hazard. Mater., 170, 1273-1276, 2009.

[64] S. Goskonda, W. J. Catallo y T. Junk, «Sonochemical degradation of aromatic organic pollutants,» Waste Manage., 22, 351-356, 2002.

[65] Y. Jiang, C. Petrier y T. D. Waite, «Sonolysis of 4-chlorophenol in aqueous solution: Effects of substrate concentration, aqueous temperature and ultrasonic frequency,» Ultrason. Sonochem., vol. 13, 415-422, 2006.

[66] L. Y. Zou, Y. Li y Y.-T. Hung, «Wet Air Oxidation for Water Treatment,» de Handbook of Environmental Engineering: Advanced Physicochemical Treatment Technologies, vol. 5, L. K. Wang, Y. Hung y N. K. Shammas, Edits., Totowa, NJ: The Humana Press Inc., 2007, pp. 575-610.

[67] G. Centi y S. Perathoner, «Advanced Oxidation Processes in Water Treatment,» de Handbook of Advanced Methods and Processes in Oxidation Catalysis: From Laboratory to Industry, London, Imperial College Press, 2014, pp. 251-283.

[68] M. A. Lunagómez Rocha, G. Del Angel, G. Torres-Torres, A. Cervantes, A. Vázquez, A. Arrieta y J. N. Beltramini, «Effect of the Pt oxidation state and $\mathrm{Ce} 3+/ \mathrm{Ce} 4+$ ratio on the $\mathrm{Pt} / \mathrm{TiO} 2-\mathrm{CeO} 2$ catalysts in the phenol degradation by catalytic wet air oxidation (CWAO), (Catal. Today, 250, 145-154, 2013.

[69] M. Alame, A. Abusaloua, M. Pera-Titus, N. Guilhaume, K. Fiaty y A. Giroir-Fendler, «High-performance catalytic wet air oxidation (CWAO) of organic acids and phenol in interfacial catalytic membrane contactors under optimized wetting conditions, Catal. Today, 157, 327-333, 2010.

[70] F. Arena, C. Italiano, A. Raneri y C. Saja, «Mechanistic and kinetic insights into the wet air oxidation of phenol with oxygen (CWAO) by homogeneous and heterogeneous transition-metal catalysts,» Appl Catal B, 99, 321-328, 2010.

[71] K.-H. Kim y S.-K. Ihm, «Heterogeneous catalytic wet air oxidation of refractory organic pollutants in industrial wastewaters: A review,» J. Hazard. Mater, 186, 16-34, 2011. 


\section{CAPÍTULO 2. MARCO TEÓRICO}

[72] N. Li, C. Descorme y M. Besson, "Catalytic wet air oxidation of chlorophenols over supported ruthenium catalysts,» J.Hazard Mater, 146, 602-609, 2007.

[73] Y. Tu, Y. Xiong, S. Tiah, L. Kong y C. Descorme, "Catalytic wet air oxidation of 2chlorophenol over sewage sludge-derived carbon-based catalysts,» J. Hazard. Mater., 276, 88-96, 2014.

[74] S. Chaliha y K. G. Bhattacharyya, "Catalytic wet oxidation of 2-chlorophenol, 2,4dichlorophenol and,» Chem. Eng. J., 139, 575-588, 2008.

[75] F. Luck, «A review of industrial catalytic wet air oxidation processes,» Catal. Today, 27, 195-202, 1996.

[76] V. García-Molina, M. López-Arias, M. Florczyk, E. Chamarro y S. Esplugas, «Wet peroxide oxidation of chlorophenols,» Water Res., 39, 795-802, 2005.

[77] M. Kurian y C. Kunjachan, "CexV1-xO2 (x:0, 0.25-1) nanocomposites as efficient catalysts for degradation of 2,4 dichlorophenol,» J. Environ. Chem. Eng., 4, 13591366, 2016.

[78] J. Levec y A. Pintar, "Catalytic wet-air oxidation processes: A review,» Catal Today, 124, 172-184, 2007.

[79] F. J. Benitez, J. Beltrán-Heredia, J. Acero y F. Rubio, «Chemical Decomposition of 2,4,6-Trichlorophenol by Ozone, Fenton's Reagent and UV radiation,» Ind. Eng. Chem. Res., 38, 1341-1349, 1999.

[80] A. R. Ribiero, O. C. Nunes, M. F. R. Pereira y A. M. T. Silva, «An overview on the advanced oxidation processes applied for the treatment of water pollutants defined in the recently launched Directive 2013/39/EU,» Environ. Int., 75, 33-51, 2015.

[81] A. Karci, I. Arslan-Alaton, T. Olmez-Hanci y M. Bekbolet, "Transformation of 2,4dichlorophenol by H2O2/UV-C, Fenton and photo-Fenton processes: Oxidation products and toxicity evolution,» J. Photochemistry and photobiology A: Chemistry, 230, 65-73, 2012.

[82] F. Al Momani, S. C. y S. Esplugas, «A comparative study of the advanced oxidation of 2,4-dichlorophenol,» J. Hazard. Mat. B, 107, 123 -129, 2004. 


\section{CAPÍTULO 2. MARCO TEÓRICO}

[83] R. Andreozzi, I. Di Somma, R. Marotta, G. Pinto, A. Pollio y D. Spasiano, «Oxidation of 2,4-dichlorophenol and 3,4-dichlorophenol by means of $\mathrm{Fe}$ (III)-homogeneous photocatalysis and algal toxicity assessment of the treated solutions, "Water Res., 45, 2038-2048, 2011.

[84] R. Munter, «Advanced oxidation processes- current status and prospects,» Proc. Estonian Acad. Sci. Chem., 50, 59-80, 2001.

[85] M. D. Murcia, M. Gomez, E. Gomez, J. L. Gomez y N. Christofi, «Comparison of different Advanced Oxidation Processes for degrading 4-chlorophenol,» World Academy of Science, Engineering and Technology , 31, 245-249, 2009.

[86] M. S. Yalfani, A. Georgi, S. Contreras, F. Medina y F.-D. Kopinke, «Chlorophenol degradation using a one-pot reduction-oxidation process,» Appl. Catal. B-Environ., 104, 161-168, 2011.

[87] S. Antonaraki, E. Androulaki, D. Dimotikali, A. Hiskia y E. Papaconstantinou, «Photolytic degradation of all chlorophenols with polyoxometallates and $\mathrm{H} 2 \mathrm{O} 2$,» $\mathrm{J}$. Phtotoch. Photobio. A, 148, 191-197, 2002.

[88] C.-R. Huang y H.-Y. Shu, «The reaction kinetics, decomposition pathways and intermediate formation of phenol in ozonation, UV/O3 and UV/H2O2 processes,» $\mathrm{J}$. Hazard Mat., 41, 47-64, 1995.

[89] S. Esplugas, P. L. Yue y M. I. Perez, «Degradation of 4-Chlorophenol by Photolytic oxidation,» Water Res., 28, 1323-1328, 1994.

[90] J. J. Rueda-Márquez, M. Sillanpää, P. Pocostles y A. Acevedo, «Post-treatment of biologically treated wastewater containing organic contaminants using a sequence of H2O2 based advanced oxidation processes: Photolysis and catalytic wet oxidation,» Water Res., 71, 85-96, 2015.

[91] O. Legrin, E. Oliveros y A. M. Braun, «Photochemical processes for water treatment,» Chem. Rev., 93, 671-698, 1993.

[92] S. Ahmed, M. G. Rasul y M. A. Hashib, "Influence of parameters on the heterogeneous photocatalytic degradation of pesticides and phenolic contaminants in wastewater: A short review,» J. Environ. Manage., 92, № 3, 311-330, 2011. 


\section{CAPÍTULO 2. MARCO TEÓRICO}

[93] A. M. Abeish, H. M. Ang y H. Znad, «Solar photocatalytic degradation of chlorophenols mixture (4-CP and 2,4-DCP): Mechanism and kinetic modelling,» J. Env. Sci. \& Health, $50,125-134,2015$.

[94] H. Ilyas, I. A. Qazi, W. Asgar, M. A. Awan y Z. Khan, «Photocatalytic Degradation of Nitro and Chlorophenols Using Doped and Undoped Titanium Dioxide Nanoparticles,» J. Nanomater., 2011, 8, 2011.

[95] F. J. Benitez, J. Beltran-Heredia, J. L. Acero y F. Rubio, «Contribution of free radicals to chlorophenols decomposition by several advanced oxidation processes,» Chemosphere, 41, 1271-1277, 2000.

[96] R. G. Rice y M. E. Browning, «Ozone for Industrial water and wastewater treatment, A Literature survey,» USEPA, 1980.

[97] K. L. Rakeness, Ozone in Drinking Water Treatment: Process Design, Operation, and Optimization, 1st Ed. ed., Denver, CO.: America Water Works Association, 2005.

[98] J. L. B. F. J. Sotelo, F. J. Benitez y J. Beltrán-Heredia, «Ozone Descomposition in Water: Kinetic Study,» Ind. Eng. Chem. Res., 26, 39-43, 1987.

[99] J. Hoigné y H. Bader, «Rate constants of reactions of ozone with organic and inorganic compounds in water-I Non-dissociating organic compounds,» Water Res., 17, p173183, 1983.

[100] H. F. H. Tomiyasu y G. Gordon, «Kinetics and Mechanism of Ozone Decomposition in Basic Aqueous Solution,» Inorg. Chem., 24, 2962-2966, 1985.

[101] J. Hoigné y H. Bader, «Rate constants of reactions of ozone with organic and inorganic compounds in water-II: Dissociating organic compounds,»17, 185-194, 1983.

[102] J. Hoigné, H. Bader, R. Haag y J. Staehelin, «Rate Constans of reaction of ozone with organic and inorganic compounds in water-III,» Water Res., 19, 993-1004, 1985.

[103] Y. Wang, P. Pai y J. Latchaw, «Effects of preozonation on the methanogenic toxicity of 2,5-DCP,» J. Water Pollut Control Fed., 61, 1989.

[104] Y. Wang, «Methanogenic degradation of ozonation products of biorefractory or toxic aromatic compounds,» Water Res., 24, 185-190, 1990. 


\section{CAPÍTULO 2. MARCO TEÓRICO}

[105] E. Gilbert, «Chemical changes and reaction products in ozonization of organic water constituents, » de Oxidation techniques in drinking water treatment, Karlsruhe, Federal Republic of Germany, 1978.

[106] C. D. Adams, R. A. Cozzens y B. J. Kim, «Effects of ozonation on the biodegradability of substituted phenols,» Water Res., 31, 2655-2663, 1997.

[107] P. Van Aken, R. Van den Broeck, J. Degrève y R. Dewil, «The effect of ozonation on the toxicity and biodegradability of 2,4-dichlorophenol-containing wastewater,» Chem. Eng. J., 280, 728-736, 2015.

[108] J. C. Alexander y C. R. Ramírez-Cortina, «A Comparative Study: Degradation of 2,5Dichlorophenol in Wastewater and Distilled Water by Ozone and Ozone-UV,» Ozone Sci. Eng., 38, 181-193, 2016.

[109] T. Poznyak y J. Vivero, «Degradation of aqueous phenol and chlorinated phenols by ozone,» Ozone Sci. \& Eng., 27, 447-458, 2005.

[110] F. J. Beltrán, J. M. Encinar, J. F. García-Araya y M. G. Muñoz, «Modelling Industrial Wastewater Ozonation in Bubble Contactors. 1. Rate Coefficient Determination,» Ozone Sci. Eng., 17, 355-378, 1995.

[111] L. J. Bollyky, «The Mass Transfer of ozone into water : Energy requirements-state of the art,» Ozone Sci. Eng., 3, 181-210, 1981.

[112] N. Graham, W. Chu y Lau.C., «Observations of 2,4,6-trichlorophenol degradation by ozone,» Chemosphere, 51, 237-243, 2003.

[113] X. Huang, X. Li, B. Pan, H. Li, Y. Zhang y B. Xe, «Self enhanced ozonation of benzoic acid at acidic condition,» Water Res., 73, 9-16, 2015.

[114] K. Turhan y S. Uzman, «Removal of phenol from water using ozone,» Desalination, 229, 257-263, 2008.

[115] Huataniemi, M., J. Kallas, R. Munter y M. Trapido, «Modelling of Chlorophenol Treatment in Aqueous Solutions. 1. Ozonation and Ozonation combined with UV radiation under acidic conditions,» Ozone Sci. Eng., 20, 259-282, 1998. 


\section{CAPÍTULO 2. MARCO TEÓRICO}

[116] Huataniemi, M., J. Kallas, R. Munter, M. Trapido y A. Laari, «Modelling of Chlorophenol Treatment in Aqueous solutions. 2. Ozonation under Basic Conditions,» Ozone Sci. Eng., 20, 283-302, 1998.

[117] M. A. Boncz, H. Bruning, W. H. Rulkens, E. J. R. Sudholter, G. H. Harmsen y J. W. Bijsterbosch, «Kinetic and Mechanistic aspects of the oxidation of chlorophenols by ozone,» Water Sci. Technol, 35, 65-72, 1997.

[118] S. Contreras, J. Piatkowska, M. Rodríguez, C. Sans y S. Esplugas, «Biodegradability improvement of aqueous 2,4-Dichlorophenol and Nitrobenzene Solutions by means of Single Ozonation,» Ozone Sci. Eng., 27, 381-387, 2005.

[119] M. Kilici, G. Koctürk, N. San y Z. Cinar, «A model for prediction of product distributions for the reactions of phenol derivatives with hydroxyl radicals,» Chemosphere, 69, 1396-1408, 2007.

[120] Y. Qiu, M. E. Zappi, M. ASCE, C. Kuo y E. C. Fleming, "Kinetic and mechanisitic study of ozonation of three dichlorophenols in aqueous solutions,» J. Environ Eng., 125, 441-450, 1999.

[121] Y. Qui, C. Kuo, M. E. Zappi y E. C. Fleming, "Ozonation of 2,6-, 3,4- and 3,5Dichlorophenol isomers within Aqueous Solutions,» J. Environ. Eng., 130, 408-416, 2004.

[122] R. G. Rice, «Applications of ozone for industrial wastewater treatment-A review,» Ozone Sci. Eng., 18, 477-515, 1996.

[123] P. C. Singer y M. D. Gurol, «Dynamics of the Ozonation of Phenol-I Experimental Observation,» Water Res., 17, № 9, 1163-1171, 1983.

[124] T. Merle, J. S. Pic, M. H. Manero, S. Mathé y H. Debellefontaine, «Influence of activated carbons on the kinetics and mechanisms of aromatic molecules ozonation,» Catal. Today, 151, 166-172, 2010.

[125] M. Kukuzaki, K. K. S. Fujimoto, K. Ohe, T. Oshima y Y. Baba, «Ozone mass transfer in an ozone- water contacting process with Shirasu Porous glass (SPG) membranesA comparative study of hydrophilic and hydrophobic membranes,» Separation and Purification Techn., 72, 347-356, 2010. 


\section{CAPÍTULO 2. MARCO TEÓRICO}

[126] M.-T. Gao, M. Hirata, H. Takanashi y T. Hano, «Ozone mass transfer in a new gasliquid contactor-Karman contactor,» Sep. Purif. Techhnol., 42, 145-149, 2005.

[127] M. Roustan, J. Mallevialle, H. Roques y J. P. Jones, «Mass Transfer of Ozone to Water,» Ozone Sci. Eng., 2, 337-344, 1981.

[128] J. L. Sotelo, F. J. Beltran, F. Benitez y J. Beltrán-Heredia, «Henry's Law constant for the ozone-water syster, "Water Res., 23, 1239-1246, 1989.

[129] N. Kantarci, F. Borak y K. O. Ulgen, «Bubblecolumn reactors,» Process Biochem., 40, pp. 2263-2283, 2005.

[130] C. Gottschalk, J. A. Libra y A. Saupe, Ozonation of water and wastewater: A practical Guide to Understanding Ozone and its Application, Wiley-VCH, 2000, pp. 104-106.

[131] P. N. Johnson y R. A. Davis, «Diffusivity of ozone in water,» J. Chem. Eng. Data, 41, 1485-1487, 1996.

[132] M. Matheswaran y I.-S. Moon, «Influence parameters in the ozonation of phenol wastewater treatment using bubble column reactor under continuous circulation,» $\mathrm{J}$. Ind. Eng. Chem., 15, 287-292, 2009.

[133] G. Tiwari y P. Bode, «Determination of ozone mass transfer coefficient in a tall continuous flow counter-current bubble contactor,» Chem. Eng. J., 132, 215-225, 2007.

[134] G. F. Froment, K. B. Bischoff y J. D. Wilde, Chemical Reacator Analysis and Design, 3rd Ed. ed., John Wiley \& Sons, Inc., 2011.

[135] G. Tchobanoglous, F. L. Burton y H. D. Stensel, Wastewater Engineering Treatment and Reuse/ Metcalf \& Eddy Inc., 4th Ed. ed., I. Metcalf \& Eddy, Ed., New York, NY 10020: McGraw Hill companies Inc., 2003.

[136] J. G. Henry y G. W. Heinke, Ingeniería Ambiental, Segunda ed., Pearson Educación, 1999, pp. 339-379.

[137] J. C. Crittenden, R. R. Trussell, D. W. Hand, K. J. Howe y T. G. , MWH Water Treatment Principles and Design, 2nd ed. ed., New Jersey: John Wiley \& Sons Inc., 2005. 


\section{CAPÍTULO 2. MARCO TEÓRICO}

[138] A. M. Torres López, J. C. Quintero Díaz y L. Atehortúa Garcés, «Determinación de la velocidad específica de consumo de oxígeno en M.O. incluyendo el tiempo de respuesta del electrodo de oxígeno,» Quintero Díaz, Juan Carlos; Torres López, Ana María; Atehortúa Garcés, Lucía; 2008. Determinación de la velocidad específRev. Fac. Ing. Univ. Antioquia, no 43, pp. 33-41, 2008.

[139] W. Wan Ishak, S. Jamek, N. Jalanni y N. Mohd Jamaludin, «Isolation and Identification of Bacteria from Activated Sludge and Compost for Municipal Solid Waste Treatment System,» de International Conference on Biology, Environment and Chemistry, Signaporte, 2011.

[140] M. T. Madigan, J. M. Martinko, J. Parker, T. D. Brock, C. Rodríguez Fernández y M. Sánchez Pérez, Brock Biología de los M.O., 10 ed. ed., P. Eduacación, Ed., Prentice Hall, 2004.

[141] G. Farqhuar y W. C. Boyle, «Identification of Filamentous M.O. in Activated Sludge,» J. Wat. Poll. Control. Fed., 43, 604-622, 1971.

[142] T. G. Ellis, E. Boris, C. G. Schmit, K. Jahan y K. Y. Park, «Activated Sludge and Other Aerobic Suspended Culture Processes,» Wat. Env. Res., 74,

[143] M. D. Motta, M. N. Pons, H. Vivier, A. L. Amaral, E. C. Ferreira, N. Roche y M. Mota, "Study of Protozoa population in wastewater treatment plants by image analysis," Brazalian J. Chem. Eng., 18, 103-111, 2001.

[144] F. R. Spellman, «Process Control Sampling and Testing,» de Handbook of Water and Wastewater Treatment Plant Operations, 3rd Ed. ed., CRC Press, 2013CR, p. 741.

[145] C. C. Wang, C. M. Lee y C. H. Kuan, «Removal of 2,4-dichlorophenol by suspended and immobilized Bacillus insolitus., " Chemosphere, 41, 447-452, 2000.

[146] F. Kargi y E. Serkan, «Toxicity and batch biodegradation kinetics of 2,4-dichlorophenol by pure Pseudomonas putida culture,» Enzyme Microb. Tech., 35, 424-428, 2004.

[147] G. G. Matafonova, G. S. Shirapova, C. Zimmer, G.-W. Kohring, F. Giffhorn, V. B. Batoev y V. J. Tsyrenov, "Bacillus cereus is a Microbial Decomposer of 2,4Dichlorophenol,» Biol Bull Acad Sci USSR, 34, 442-445, 2007. 


\section{CAPÍTULO 2. MARCO TEÓRICO}

[148] K. M. Basha, A. Rajendran y V. Thangavelu, «Recent advances in biodegradation of phenol- A review,» Asian J. Exp. Biol. Sci., 2, 219-234, 2010.

[149] A. Nakagawa, S. Osawa, T. Hirata, Y. Yamagishi, J. Hosoda y T. Horikoshi, «2,4Dichlorophenol degradation by the soil fungus Mortierella sp.,» Biosci. Biotechnol. Biochem., 70, 525-527, 2006.

[150] A. E. Mars, T. Kasberg, S. R. Kaschabek, M. H. van Agteren, D. B. Janssen y W. Reineke, "Microbial degradation of chloroaromatics: use of the meta-cleavage pathway for mineralization of chlorobenzene,» J. Bacteriol., 179, 4530-4537, 1997.

[151] F. Kargi, S. Eker y A. Uygur, «Biological treatment of synthetic wastewater containing 2,4 dichlorophenol (DCP) in an activated sludge unit,» J. Environ. Manage., 76, 191196, 2005.

[152] F. Kargi y S. Eker, «Effect of sludge age on performance of an activated sludge unit treating 2,4 dichlorophenol-containing synthetic wastewater,» Enzyme Microb. Tech., 38, 60-64, 2006.

[153] H. Movahedyan, H. Khorsandi, R. Salehi y M. Nikaeen, «Detection of Phenol degrading bacteria and Pseudomonas putida in activated sludge by Polymerase Chain Reaction,»Iran J. Environ. Health Sci. Eng., 6, 115-120, 2009.

[154] K. Bandyopadhyay, D. Das y B. R. Maiti, «Kinetics of phenol degradation using Pseudomonas putida MTCC 1194,» Bioproc. Eng., 18, 373-377, 1998.

[155] Y. Kaymaz, A. Babaoglu y N. K. Pazarlioglu, «Biodegradation kinetics of o-cresol by Pseudomonas putida DSM 548 (pJP4) and o-cresol removal in a batch-recirculation bioreactor system,» Electron. J. Biotechnol., 15, 1-10, 2012.

[156] C. S. Harwood, K. Fosnaugh y M. Dispensa, «Flagellation of Pseudomonas putida and analysis of its motile behavior,» J Bacteriol., 171, 4063-4066, 1989.

[157] K. Watanabe, M. Miyashita y S. Harayama, «Starvation improves survival of bacteria introduced into activated sludge,» Appl Environ Microbiol., 66, 3905-3910, 2000.

[158] APHA, AWWA y WEF, Standard Methods for the Examination of Water and Wastewater, 21st ed., Washington, D.C: America Public Health Association, 2005. 


\section{CAPÍTULO 2. MARCO TEÓRICO}

[159] B. M. J. G. y G. M. C. S., Manual Del Técnico Superior de Laboratorio de Analisis Clinicos. Modulo li., Primera Ed. ed., vol. II, MAD S.L., 2004, p. 52.

[160] P. Tryfinopoulou, E. Tsakalidou y G.-J. E. Nychas, «Characterization of Pseudomonas spp. Associated with Spoilage of Gilt-Head Sea Bream Stored under Various Conditions,» Appl. Environ. Microb., 68, 65-72, 2002.

[161] J. P. Harley y L. M. Prescott, Laboratory Exercises in Microbiology, 5th Ed. ed., McGraw-Hill, 2002.

[162] V. K. Deshwal, S. B. Singh, A. Chubey y P. Kumar, «Isolation and characterization of Pseudomonas strains from Potatoes Rhizosphere at Dehradun Valley, India,» Int. J. Basic Appl. Sci. , 2, 53-55, 2013.

[163] NOM-052-SEMARNAT-2005, «Norma Oficial Mexicana-Que establece las características, el procedimiento de identificación, clasificación y los listados de los residuos peligrosos.

[164] D. J. W. Blum y R. E. Speece, «A database of chemical toxicity to environmental bacteria and its use in interspecies comparisons and correlations,» J. Water Pollut. Control Fed., 63, 198-207, 1991.

[165] E. Cho, J. Khim, S. Chung, D. Seo y Y. Son, "Occurence of micropollutants in four major rivers in Korea,» Sci Total Environ, 491-492, 138-147, 2014.

[166] J. M. Ribo y K. L. E. Kaiser, «Effects of selected chemical to photoluminescent bacteria and their correlations with acute and sublethal effects on other organisms,» Chemosphere, 12, 1421-1442, 1983.

[167] A. Kahru, L. Põllumaa, R. Reiman, A. Rätsep, M. Liiders y A. Maloveryan, «The Toxicity and Biodegradability of Eight Main Phenolic Compounds Characteristic to the Oil-Shale Industry Wastewaters: A Test Battery Approach,» J. Environ Toxicol, 15, 431-442, 2000.

[168] V. L. Jennings, M. H. Rayner-Brandes y D. J. Bird, «Assessing chemical toxicity with bioluminescent photobacterium (Vibrio fischeri): A comparison of three commercial systems,» Water Res., 35, 3448-3456, 2001. 


\section{CAPÍTULO 2. MARCO TEÓRICO}

[169] T. L. Ho y J. R. Bolton, «Toxicity changes during the UV treatment of pentachlorophenol in dilute aqueous soluton,» Water Res., 32, 489-497, 1998.

[170] E. M. Boyd, K. Killham y A. A. Meharg, «Toxicity of mono-, di- and tri-chlorophenols to lux marked terrestrial bacteria, Burkholderia species Rasc c2 and Pseudomonas fluorescens,» Chemosphere, 43, 157-166, 2001.

[171] A. Tizzard, J. Webber, R. Gooneratne, R. John, J. Hay y N. Pasco, «MICREDOX: application for rapid biotoxicity assessment,» Anal. Chim. Acta., 522, 197-205, 2004.

[172] Y. G. Lee, S. H. Hwang y S. D. Kim, «Predicting the Toxicity of Substituted Phenols to Aquatic Species and Its Changes in the Stream and Effluent Waters,» Arch. Environ. Contam. Toxicol., 50, 213-219, 2006.

[173] C.-Y. Chen y J. Lin, «Toxcity of chlorophenols to Pseudokirchneriella subcapitata under air-tight test environment,» Chemosphere, 62, 503-509, 2006.

[174] M. D. Erturk y M. T. Sacan, «First Toxicity Data of Chlorophenols on Marine Alga Dinaiella tertiolecta: Correlation of Marine Algal Toxicity with Hydrophobicity and Interspecies Toxicity Relationship,» Environ. Toxicol. Chem., 31, 1113-1120, 2012.

[175] Y. Yoshioka, H. Nagase, Y. Ose y T. Sato, «Evaluation of the Test Method "Activated Sludge, Respiration Inhibition Test" Proposed by the OECD,» Ecotox. Environ. Safe., 12, 206-212, 1986.

[176] E. Hall, B. Sun, J. Prakash y N. Nirmalakhandan, «Toxicity of organic chemicals and their mixtures to activated sludge microorganisms,» J. Environ Eng., 122, 424-429, 1996.

[177] A. Miyazaki, T. Amano, H. Saito y Y. Nakano, «Acute toxicity of chlorophenols to earthworms using a simple paper contact method and comparison with toxicities to fresh water organisms,» chemosphere, 47, 65-69, 2002.

[178] J.-L. Benoit-Guyod, C. Andre, G. Taillandier, J. Rochat y A. Boucherle, «Toxicity and QSAR of Chlorophenols on Lebistes reticulatus,» Ecotox. Environ. Safe, 8, 227-235, 1984.

[179] W. Wang, «Use of millet root elongation for toxicity tests of phenolic compounds,» Environ. Int., 11, 95-98, 1985. 


\section{CAPÍTULO 2. MARCO TEÓRICO}

[180] M. Erturk y M. T. Sacan, «Assessment and modeling of the novel toxicity data set of phenols to Chlorella vulgaris,» Ecotox. Environ. Safe, 90, 61-68, 2013.

[181] J. Dolesalova y L. Rumlova, «A new biological test of water toxicityyeastSaccharomyces cerevisiae conductometric test,» Environ. Toxicol. Pharm., 38, 977-981, 2014.

[182] R. Andreozzi, I. Di Somma, R. Marotta, G. Pinto, A. Pollio y D. Spasiano, «Oxidation of 2,4-dichlorophenol and 3,4-dichlorophenol by means of $\mathrm{Fe}$ (III)-homogeneous photocatalysis and algal toxicity assessment of the treated solutions, " Water Res., 45, 2038-2048, 2010.

[183] A. Karci, «Degradation of chlorophenols and alkylphenol ethoxylates, two representative textile chemicals, in water by advanced oxidation processes: The state of the art on transformation products and toxicity,» Chemosphere, 99, 1-18, 2014.

[184] A. Karci, I. Alaton-Arslan, T. Olmez-Hanci y M. Bekbolet, «Degradation and detoxification of industrially important phenol derivatives in water by direct UV-C photolysis and H2O2/UV-C process: A comparative study,» Chem Eng J., p. Article in press., 2012.

[185] N.-C. Shang, Y.-H. Yu, Ma, Hqong-Wen, C.-H. Chang y M.-L. Liou, «Toxicity measurements in aqueous solution during ozonation of mono-chlorophenols,» $\mathrm{J}$. Environ Manage, 78, 216-222, 2006.

[186] L. Rizzo, «Bioassays as a tool for evaluating advanced oxidation processes in water and wastewater treatment,» Water Res., 45, 4311-4340, 2011. 


\section{Capítulo 3. HIPÓTESIS Y OBJETIVOS}

\subsection{Hipótesis}

Los procesos de oxidación avanzada con ozono y ozono-UV pueden aplicarse como pretratamiento para un proceso de tratamiento de aguas residuales con lodos activados, con el fin de disminuir la toxicidad de las altas concentraciones de 2,5-diclorofenol y aumentar su biodegradabilidad.

\subsection{Objetivos}

Los procesos de oxidación avanzada para la mineralización completa de un compuesto son generalmente costosos. Por eso sus usos como un pretratamiento se divulgan extensivamente como su combinación con un tratamiento biológico para reducir los costos de operación Mohajerani, y col. 2009 [1]; Oller, y col., 2011 [2]; Di laconi, 2012 [3]).

Además, los compuestos fenólicos, 2,5-DCP de especial interés en esta investigación, son substancias que por su naturaleza son tóxicas a los M.O.

El anterior es particularmente pertinente si se considera que el método de tratamiento de aguas residuales contaminadas con esta familia de compuestos es habitualmente a través de lodos activados.

Con base en lo anterior, se plantea el siguiente objetivo general:

\subsubsection{Objetivo General}

- Comparar la efectividad de los procesos oxidación avanzada con $\mathrm{O}_{3}$ y $\mathrm{O}_{3}-\mathrm{UV}$ en la degradación del 2,5-DCP cuando se tiene en una solución de agua destilada y cuando se tiene en agua residual. $Y$ evaluar el efecto de los procesos de oxidación avanzada como pretratamiento del 2,5-DCP para un proceso biológico de lodos activados. 


\section{CAPÍTULO 3. HIPÓTESIS Y OBJETIVOS}

Para alcanzar este objetivo, se proponen los siguientes objetivos específicos.

\subsubsection{Objetivos Específicos}

> Comparar la efectividad de los procesos oxidación con $\mathrm{O}_{3}$ y $\mathrm{O}_{3}-\mathrm{UV}$ en la degradación del 2,5-DCP en una solución de agua destilada y en solución de agua residual.

$>$ Investigar la cinética y los mecanismos de reacción del 2,5-DCP durante la oxidación con POAs.

Analizar el efecto de los POAs sobre la biodegradabilidad del 2,5-DCP en solución de agua destilada y en solución de agua residual.

$>$ Identificar los compuestos intermediarios que se forman durante la oxidación del 2,5-DCP.

Analizar el efecto de los POAs sobre la toxicidad de 2,5-DCP y los productos intermediarios en solución de agua destilada y en solución de agua residual.

> Evaluar la eficiencia de los POAs para agua residual con 2,5-DCP como pretratamiento de un proceso biológico de lodos activados, en reactores a escala de laboratorio. 


\section{REFERENCIAS}

[1] I. Oller, S. Malato y J. A. Sánchez-Pérez, «Combination of Advance Oxidation Processes and biological treatments for wastewater decontamination- A review,» J. Sci Total Environ., vol. 409, pp. 4141-4166, 2011.

[2] M. Mohajerani, M. Mehrvar y F. Ein-Mozaffari, «An Overview of the Integration of Advanced Oxidation Technologies and other processes for water and wastewater treatment.,» International Journal of Engineering (IJE), vol. 3, no 2, pp. 120-146, 2009.

[3] C. Di laconi, «Biolgical treatment and ozone oxidation: Integration or coupling,» Bioresource Technol, vol. 106, pp. 63-68, 2012. 


\section{Capítulo 4. METODOLOGÍA}

\subsection{Desarrollo experimental}

El desarrollo experimental de este trabajo abarca de las siguientes tres etapas:

Etapa 1. Aplicación de los procesos de oxidación con ozono y ozono-UV, para la degradación de DCPes en aguas residuales.

En esta investigación se utilizó 2,5-DCP a una concentración relativamente alta [1], para representar los efluentes de agua residual sin tratar, procedentes de las industrias con concentraciones altas de compuestos fenólicos $[2,3]$. Las pruebas se prepararon soluciones acuosas de 2,5-DCP a una concentración de $500 \mathrm{mg} / \mathrm{L}$ en agua destilada y en agua residual. Se aplicaron dos Procesos de Oxidación Avanzada ( $\mathrm{O}_{3}$ y $\left.\mathrm{O}_{3}-\mathrm{UV}\right)$, a cada tipo de la solución (en agua destilada y en agua residual).

Los experimentos se llevaron a cabo a $\mathrm{pH}$ neutro, dado que este fue el $\mathrm{pH}$ de la solución con agua residual después de añadir el 2,5-DCP. Además, está dentro del rango del pH de la mayor parte de las aguas residuales ( $\mathrm{pH} 7-8)$, como se menciona en la literatura [4]. El flujo de gas $\left(\mathrm{O}_{2}\right.$ con $\left.\mathrm{O}_{3}\right)$ fue de 0.6 a $0.7 \mathrm{~L} / \mathrm{min}$. Las pruebas de oxidación se hicieron durante 60 minutos y por triplicado. Se colectaron muestras de la solución tratada a diversos intervalos de tiempo durante la oxidación. Se hicieron análisis de DQO, DBO5, COT, pH, GC y/o HPLC y el espectro de absorbancia en la región UV-VIS. Todas las pruebas analíticas se hicieron por triplicado.

Etapa 2. Ensayos de toxicidad y biodegradabilidad durante los tratamientos con ozono y ozono-UV:

Se realizaron ensayos de toxicidad con las pruebas de Inhibición de la respiración (IR) en lodos activados a las muestras colectadas durante el tiempo de oxidación, en cada proceso con ozonación y ozono-UV, en ambas soluciones acuosas de 2,5-DCP.

El estudio del efecto inhibitorio del 2,5-DCP y sus productos oxidados con ozono y con ozonoUV sobre los lodos activados, ayuda a conocer si los productos intermedios de oxidación continúan siendo muy tóxicos. Se midieron los porcentajes de inhibición de la respiración (IR) de lodos activados con la concentración de inhibición media $\left(\mathrm{IC}_{50}\right)$. 
Por otra parte, se evaluó la biodegradabilidad de las muestras sin tratamiento y con tratamientos de ozono y ozono-UV en las dos soluciones acuosas mediante la relación DBO5/DQO [5-7]. Estos experimentos permiten determinar cuándo las soluciones oxidadas son suficientemente biodegradables para combinar los POAs (ozono y ozono-UV) con un tratamiento biológico aerobio.

Etapa 3. Pruebas de pretratamiento con ozono y ozono-UV acoplado con un proceso biológico de lodos activados para biodegradar aún más los productos intermedios de la oxidación.

Por último, para medir la eficiencia global del sistema combinado, se llevaron a cabo los ensayos con soluciones acuosas pretratadas con ozono y ozono-UV y un proceso biológico de lodos activados a escala laboratorio, operando tanto en modo continuo como discontinuo. El proceso biológico se llevó a cabo en unos reactores biológicos secuenciales y con unidad de Husmann, inoculados con lodos activados procedentes de aguas residuales "el Rosario" del municipio de Azcapotzalco. El diagrama de la Figura 4-1 muestra el desarrollo de la metodología experimental.

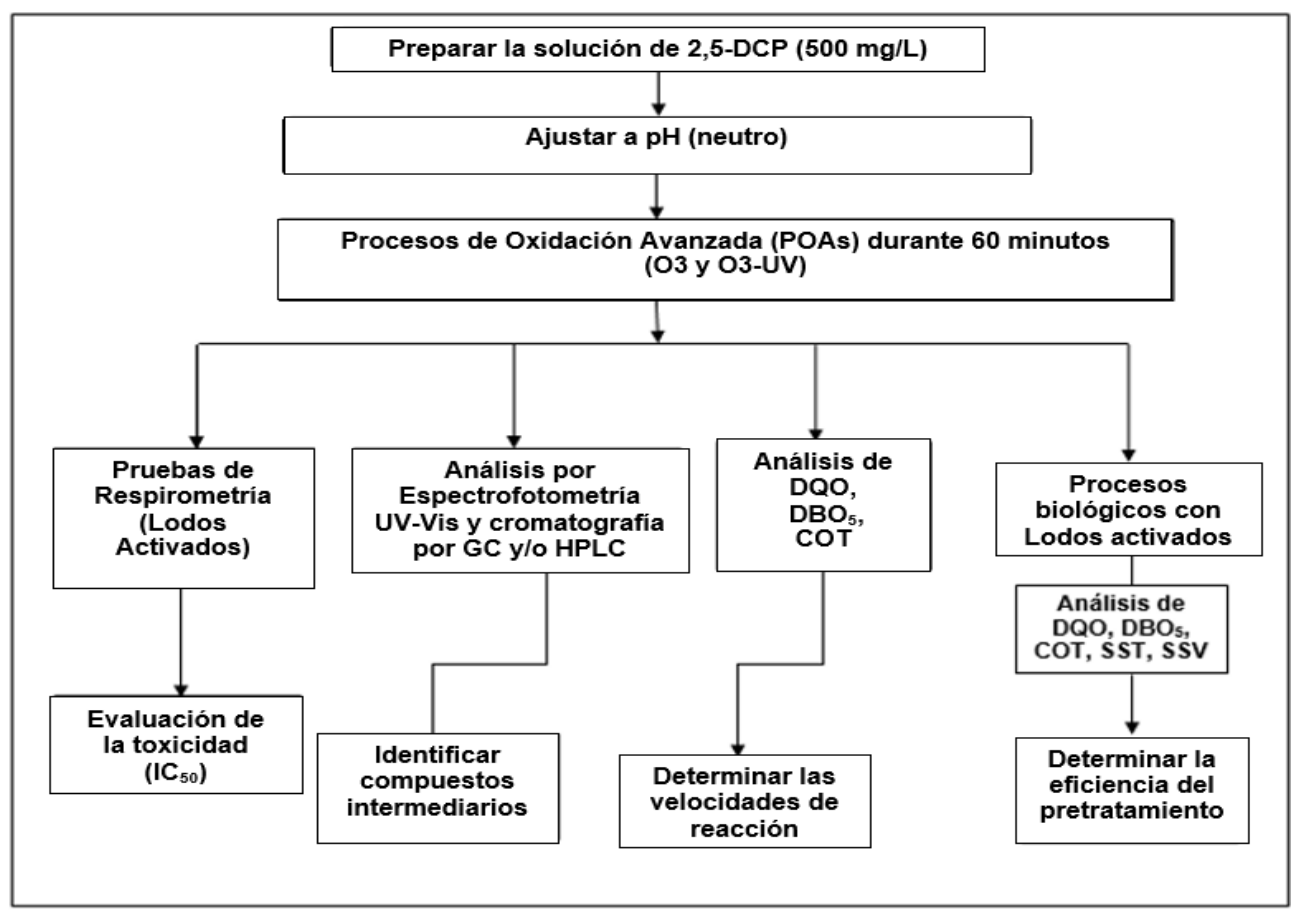

Figura 4-1 Diagrama de bloques de la metodología experimental 


\subsection{Procesos de Oxidación con ozono y ozono-UV}

Las muestras con tratamiento con ozono y ozono-UV se obtuvieron sometiendo a ozonificación un volumen de $1.5 \mathrm{~L}$ de $2,5 \mathrm{DCP}$ de $500 \mathrm{mg} / \mathrm{L}$ en una solución de agua destilada (S1) y en una solución de agua residual (S2) durante 60 minutos. Usando un flujo de gas de 0.6 a $0.7 \mathrm{~L} / \mathrm{min}$. Se comparó el efecto de la oxidación mediante análisis de DQO, GC-MS, HPLC, COT, DBO5 y pruebas de toxicidad en lodos activados. Todas las pruebas analíticas se hicieron por triplicado para confirmar la reproducibilidad de los resultados. Los análisis fisicoquímicos se realizaron con los métodos que se recomiendan en los métodos estándar [8]. Los experimentos de oxidación se llevaron a cabo en el dispositivo experimental que aparece en la Figura 4-2.

\subsubsection{Preparación de la solución tóxica de 2,5-diclorofenol}

Las soluciones acuosas de 2,5-DCP se prepararon con agua destilada (S1) y con agua residual (S2).

\subsubsection{Solución de 2,5-DCP en agua destilada (S1)}

Se preparó esta solución tóxica disolviendo $2.5 \mathrm{~g}$ de 2,5-DCP en agua destilada y diluyendo hasta un volumen de $5 \mathrm{~L}$ en un matraz volumétrico y se agitó hasta que todo el DCP estuvo disuelto. Después se ajustó el pH a 7 con una solución de $\mathrm{H}_{2} \mathrm{SO}_{4}$ $1 \mathrm{~N}$ o con $\mathrm{NaOH} 1 \mathrm{~N}$. Esta mezcla acuosa fue la solución madre de $\mathrm{S} 1$ para hacer las pruebas de los POAs con concentración de $500 \mathrm{mg} / \mathrm{L}$ (3.06 mM).

\subsubsection{Solución de 2,5-DCP en agua residual (S2)}

Se preparó esta solución tóxica disolviendo $2.5 \mathrm{~g}$ de 2,5-DCP en agua residual filtrada y diluyendo hasta un volumen de $5 \mathrm{~L}$ en un matraz volumétrico y agitando hasta que todo el DCP estuvo disuelto. Después se ajustó el pH a 7 con la solución de $\mathrm{H}_{2} \mathrm{SO}_{4} 1 \mathrm{~N}$ o $\mathrm{NaOH} 1 \mathrm{~N}$. Esta solución acuosa fue la solución madre de S2 para hacer las pruebas de los POAs con concentración de 500 mg/L (3.06 mM). 


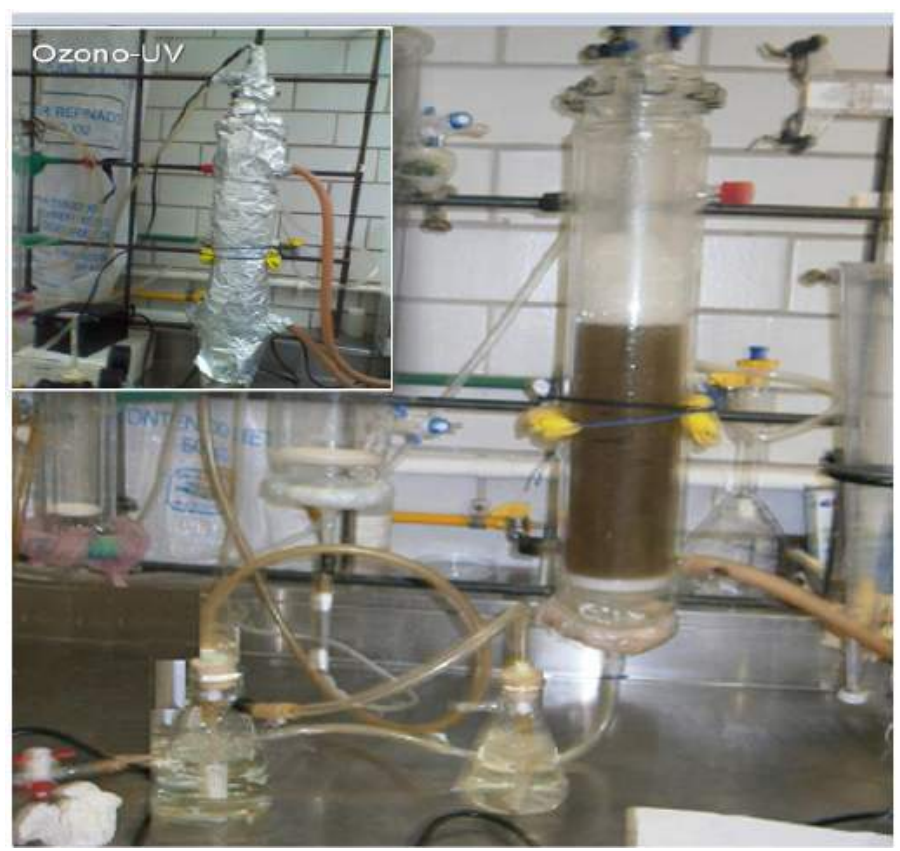

Figura 4-2 Dispositivo experimental de la ozonación y con tratamiento ozono-UV (recuadro)

\subsubsection{Descripción del proceso de oxidación}

En la

Figura 4-3 se presenta un esquema del dispositivo experimental para las pruebas de POAs. Se ocupó un reactor de vidrio de $3000 \mathrm{~mL}$ (5), equipado con difusores de vidrio poroso de burbuja fina para la aplicación del ozono. Durante el proceso con ozono-UV, una lámpara UV Pen- Ray UV (6) fue colocada en el centro del reactor en un tubo de cuarzo y fue conectada a la alimentación (7). La radiación UV fue de $4 \mathrm{~mW} / \mathrm{cm}^{2}$ a una distancia de $2.54 \mathrm{~cm}$ usando radiómetro UVX - 25. La corriente de ozono que abandona el generador va hacia el destructor de ozono ( 8 y 9 ) donde el exceso de ozono se midió utilizando una solución de yoduro de potasio al 2\% según de los métodos estándar sección 2350 E [8]. La concentración del ozono disuelto se midió por el método colorimétrico de Índigo -sección $4500-\mathrm{O}_{3}$ de los métodos estándar [8] y por el método basado en colorimetría del DPD -sección $4500 \mathrm{Cl}$ G- de los metodos estándar [8] con el equipo HANNA (HI 93758-01). 


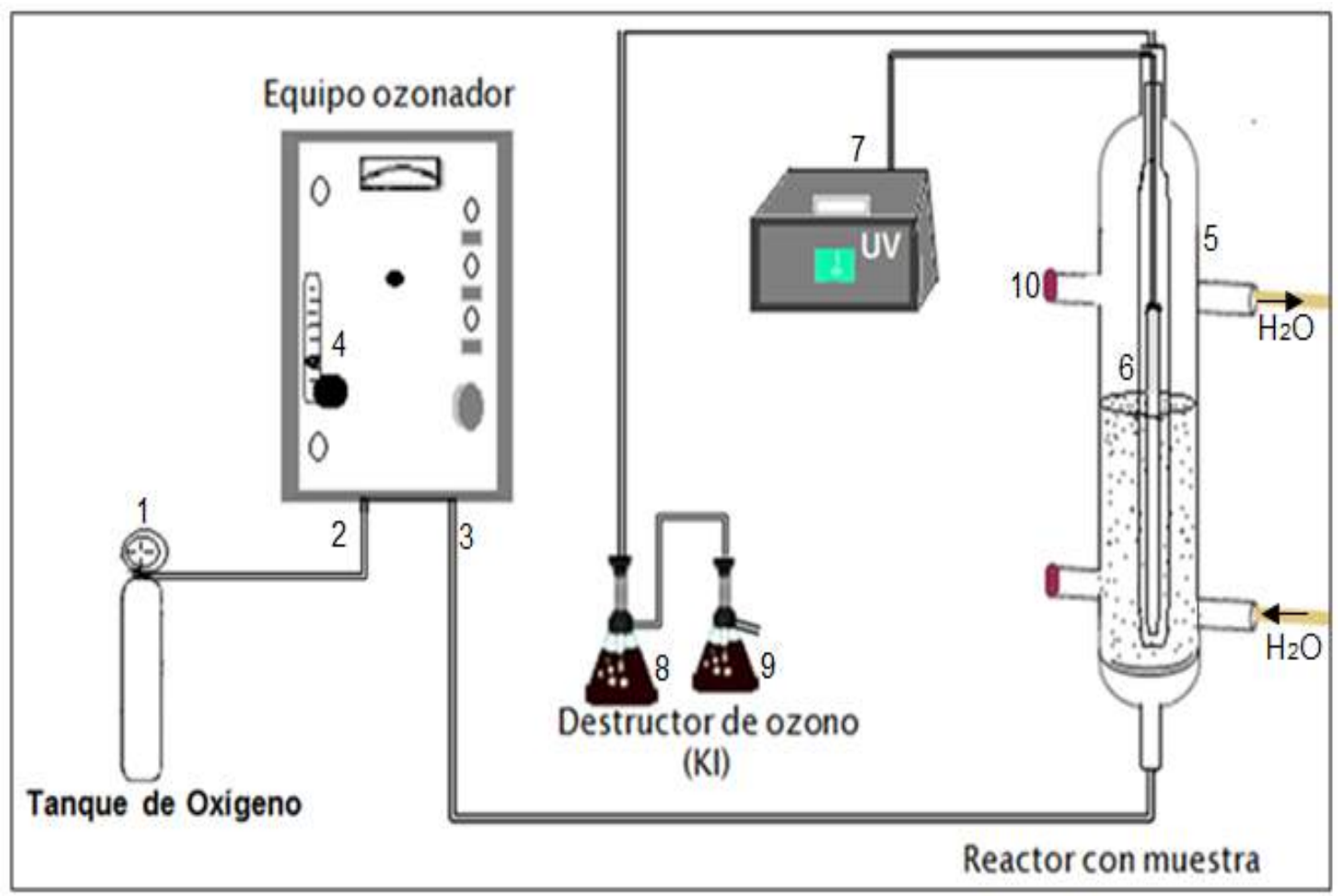

Figura 4-3 Esquema del dispositivo experimental de la ozonización

\subsection{Métodos Analíticos}

\subsubsection{Determinación de la Demanda Química de Oxígeno}

Para la determinación de Demanda Química de Oxígeno (DQO) se aplicó el método de la Técnica de reflujo cerrado, Método colorimétrico sección 5520 D de los métodos estándar [8]. La cantidad de oxidante consumida se expresó en términos de su equivalencia en oxígeno como DQO en $\mathrm{mg} / \mathrm{L}$.

La determinación más general para la DQO, es con Dicromato potásico en exceso, en medio ácido, en presencia de sulfato de plata $\left(\mathrm{Ag}_{2} \mathrm{SO}_{4}\right)$ que actúa como agente catalizador, y de sulfato mercúrico $\left(\mathrm{HgSO}_{4}\right)$ adicionado para remover la interferencia de los cloruros. El Dicromato oxida la materia orgánica y la inorgánica presentes en la muestra, reduciéndose de $\mathrm{Cr}^{+6} \mathrm{a} \mathrm{Cr}^{+3}$. El ensayo se realizó a $150 \stackrel{\circ}{ } \mathrm{C}$, a reflujo total durante 2 horas en termo reactores de marca HACH. Después de la digestión, el dicromato de potasio remanente se determinó espectrofotométricamente a $600 \mathrm{~nm}$ con un espectrofotómetro de marca HANNA. 


\subsubsection{Determinación de Carbono Orgánico Total}

Se usó el Método total COT de la sección 5310 A de los métodos estándar [8]. La medida del carbono orgánico total COT presente en una muestra se llevó a término mediante un método instrumental ad hoc. Se realizó mediante un analizador Apollo 9000. El proceso se basó en medir la cantidad total de carbón y se le restó la cantidad correspondiente de carbono inorgánico. El sistema consistió en un inyector automático que toma una pequeña cantidad determinada de la muestra. Esta alícuota se quemó en un horno con un catalizador de platino y a una temperatura de $680^{\circ} \mathrm{C}$, donde toda la materia orgánica pasó a $\mathrm{CO}_{2}$ y $\mathrm{H}_{2} \mathrm{O}$. El agua se eliminó mediante un deshumidicador de manera que sea solamente el $\mathrm{CO}_{2}$ el que pase hacia el detector de luz infrarroja. También se eliminaron los cloruros mediante un scrubber para evitar que llegaran al detector. Para determinar la cantidad de carbono inorgánico se introdujo una pequeña cantidad de muestra en un reactor con agua acidulada que transforma todos los carbonatos a $\mathrm{CO}_{2}$.

\subsubsection{Determinación de Demanda Bioquímica de Oxígeno}

La demanda bioquímica de oxígeno (DBO) es una prueba empírica usada para la determinación de los requerimientos de oxígeno para la degradación de la materia orgánica por M.O. presentes en las aguas residuales, se incubó la muestra por cinco días a $20^{\circ} \mathrm{C}$ en la oscuridad. La disminución de la concentración de oxígeno disuelto (OD) fue medida por el método Winkler. Se utilizó el método tradicional de Pruebas de $\mathrm{DBO}_{5}$ de la Sección 5210 B de los métodos estándar [8]. El oxígeno disuelto se midió usando la Azida como modificación del método yodométrico (sección 4500-O C) de los métodos estándar [8].

\subsubsection{DBO Método Respirométrico}

\subsubsection{Principio del método}

Se utilizó un respirómetro tipo manómetro de HACH BODTrak que consiste en medir la presión en un sistema cerrado: los M.O. que se encuentran en la muestra consumen oxígeno y generan $\mathrm{CO}_{2}$. El $\mathrm{CO}_{2}$ se absorbe con $\mathrm{NaOH}$ creando una presión negativa que puede leerse directamente como valor de DBO en $\mathrm{mg} / \mathrm{L}$, con almacenamiento automático de los valores de DBO (un valor cada día). 


\subsubsection{Preparación del Inóculo de microorganismos}

En un vaso de precipitado se colocaron aproximadamente $300 \mathrm{~mL}$ de agua destilada. Después se añadieron $0,5 \mathrm{~mL}$ de cada uno de los siguientes nutrientes: $\mathrm{MgCl}_{2}$, Solución tampón, $\mathrm{CaCl}_{2}$, $\mathrm{FeCl}_{3}$, luego se añadió una cápsula de inóculo DBO (polyseed, $\mathrm{HACH}$ ) y se aforó a $500 \mathrm{~mL}$. Se dejó airear durante 2 horas con agitación constante. Posteriormente, se detuvo la agitación y se dejó reposar durante 5 minutos y se tomaron aproximadamente $200 \mathrm{~mL}$ del sobrenadante. De esta mezcla se añadieron $4 \mathrm{~mL}$ a cada botella de muestra y $40 \mathrm{~mL}$ a cada botella de blanco.

\subsubsection{Cromatografía Líquida de Alta Precisión}

La degradación del 2,5-DCP en las reacciones con $\mathrm{O}_{3}$ y con $\mathrm{O}_{3}-\mathrm{UV}$ se determinó mediante inyección de las muestras en un cromatógrafo de líquidos de alta precisión HPLC. EI HPLC utilizado está constituido por: un desgasificador ACCELA, un controlador ACCELA 600, un automuestreador ACCELA, un horno tubular, un controlador de temperatura, un detector de fotodiodo y un ordenador que trabaja con el software XCALIBUR 2.1. La columna utilizada tiene las siguientes características: relleno HYPERSIL GOLD con tamaño de partícula de 1.9 $\mu \mathrm{m}$, longitud de $50 \mathrm{~cm}$ y $0.21 \mathrm{~cm}$ de diámetro interno. La fase móvil utilizada fue una mezcla de agua (ajustada el agua a pH 3 con $\mathrm{H}_{3} \mathrm{PO}_{4}$ ) y acetonitrilo (50:50) suministrada a un flujo de $200 \mu \mathrm{L} / \mathrm{min}$. La longitud de onda del detector de ultravioleta se fijó en $223 \mathrm{~nm}$ porque se ha determinado que la máxima absorción del 2,5-DCP corresponde a esta longitud de onda Se inyectaron $10 \mu \mathrm{L}$ de cada muestra a una temperatura de $30 \stackrel{\circ}{\circ}$. Bajo estas condiciones, el pico de 2,5-DCP tiene un tiempo de retención de aproximadamente tres minutos. Esta técnica fue usada para determinar la concentración de 2,5-DCP en las soluciones. Se realizó la calibración de 2,5-DCP con cinco estándares del 2,5-DCP de 5 a 100 ppm (Anexo A-1).

\subsubsection{Cromatografía de Gases acoplado a Espectrometría de masas}

Los intermedios formados del 2,5-DCP en las reacciones con $\mathrm{O}_{3}$ y con $\mathrm{O}_{3}-\mathrm{UV}$ se determinaron mediante inyección de las muestras en un Cromatógrafo de Gases acoplado a Espectrometría de masas (GC/MS). El GC/MS utilizado, está constituido por: un cromatógrafo de gases Agilent modelo 7890 B acoplado a un detector de masas Agilent modelo 5975 A. La columna utilizada tiene las siguientes características: HP-5ms con diámetro interna de $0.25 \mathrm{~mm}$, longitud de 30 $\mathrm{m}, \quad 0.25 \mu \mathrm{m}$ de espesor de fase estacionaria, composición de $5 \%$ fenil y $95 \%$ 


\section{CAPÍTULO 4. METODOLOGÍA}

polidimetilsiloxano. Se utilizó un inyector automatizado con bandeja de muestreador, Agilent 7693 y helio como gas portador. El ordenador trabaja con el software CHEMSTATION (proporcionada por Agilent). Los espectros de masas obtenidos se compararon con la base de datos de espectros de masas en la Biblioteca Instituto Nacional de Estándares y Tecnología (NIST) y se eligieron los espectros más cercanos. Para validar la biblioteca NIST, se utilizó una solución de referencia de la mezcla de seis compuestos orgánicos en diclorometano: hidroquinona, p-benzoquinona, 4-CP, catecol, 2,5-DCP y fenol. Todos los compuestos fueron identificados con precisiones mayores que $90 \%$, lo cual mostró la fiabilidad de la biblioteca.

Al inicio del análisis, el detector del espectrómetro de masas (MSD) fue sintonizado con perfluorotributilamina (PFTBA). EI MSD usó dos modos de adquisición: barrido completo (full scan) de 50 a 500 amu y monitoreo de iones selectivos (SIM) mediante grupos de los iones a adquirir a $\mathrm{m} / \mathrm{z}=181, \mathrm{~m} / \mathrm{Z}=254 \mathrm{y} \mathrm{m} / \mathrm{z}=290$. La línea de transferencia mantuvo $250{ }^{\circ} \mathrm{C}$; y la temperatura de fuente de iones en $280^{\circ} \mathrm{C}$. El volumen de cada muestra inyectada fue de $1 \mu \mathrm{L}$ y la inyección en modo sin división (splitless). El flujo de gas portador fue $1.2 \mathrm{~mL} / \mathrm{min}$. El programa utilizado tuvo una duración de 20.5 minutos. La temperatura inicial fue de $60{ }^{\circ} \mathrm{C}$ y se mantuvo durante 2 minutos. Después de este tiempo se inició un gradiente de temperatura $20^{\circ} \mathrm{C} / \mathrm{min}$ a $130^{\circ} \mathrm{C}, 15^{\circ} \mathrm{C} / \mathrm{min}$ a $250^{\circ} \mathrm{C}$ y finalmente $10^{\circ} \mathrm{C} / \mathrm{min}$ a $310^{\circ} \mathrm{C}$ y se mantuvo durante 1 minuto. EI MSD operó en el modo de ionización electrónica (EI) de 70 eV.

\subsubsection{Preparación de muestras de GC-MS}

Las muestras por análisis de GC-MS se prepararon por dos métodos:

1) La extracción Líquido-Líquido, usando el solvente diclorometano/hexano. Se añadió un volumen $1 \mu \mathrm{L}$ de diclorometano/hexano a una muestra de $0.5 \mu \mathrm{L}$ y luego, se agitó. Se extrajo la partición de diclorometano/hexano de los dos líquidos inmiscibles y se transfirió a un frasco limpio. A este frasco, se añadió $1 \mu \mathrm{L}$ de diclorometano/hexano, se agitó con un vórtice; luego, se transfirió un volumen de $1 \mu \mathrm{L}$ de la muestra a otro frasco limpio, para analizarlo por GC-MS. 
2) La extracción en fase sólida (SPE), se llevó a cabo usando un cartucho de SPE de fase inversa LC-18 (Sigma-Aldrich).

Las muestras de extracción por ambos métodos se derivatizaron con el kit de BF3- metanol 10\% (w / w) (Sigma-Aldrich). Las muestras fueron analizadas con y sin derivatización (por triplicado).

\subsubsection{Determinación del pH}

El equipo empleado fue un potenciómetro ( $\mathrm{pH}$-metro) HANNA modelo $\mathrm{HI} 223$, con electrodos de $\mathrm{pH}$ de vidrio y temperatura con microprocesador y registro de datos con funciones de comprobación. Se calibró con soluciones estándares.

\subsubsection{Espectrofotometría}

Con un espectrofotómetro UV-Visible se determinó indirectamente la degradación del 2,5-DCP con los diferentes tipos de tratamiento $\left(\mathrm{O}_{3}\right.$ y $\left.\mathrm{O}_{3}-\mathrm{UV}\right)$. Se registró el espectro UV-VIS de las muestras de las soluciones tóxicas con tratamientos de $\mathrm{O}_{3}$ у $\mathrm{O}_{3}-\mathrm{UV}$ a diferentes intervalos durante 60 min y a pH 7, en el intervalo de longitud de onda 200-800 nm.

\subsubsection{Conductividad eléctrica}

Para medir la conductividad eléctrica $(\mu S)$ se utilizó un conductímetro portátil de 3 en 1 , con medidor de los sólidos disueltos totales (ppm) y con compensador automático de temperatura.

\subsection{Método de las Pruebas de Toxicidad}

Las pruebas de toxicidad consistieron en poner en contacto los M.O. con diferentes concentraciones de la solución tóxica de 2,5-DCP sin tratamiento y después de 5, 20, 40 y 60 minutos de tratamiento con Ozono y Ozono-UV bajo condiciones controladas, con la finalidad de evaluar el efecto tóxico de estas sustancias, midiendo valores de la concentración de inhibición media (IC50). 


\subsubsection{Método de las pruebas de respirometría}

Este método sirve para evaluar el efecto que la sustancia objeto de ensayo tiene sobre los M.O. (lodos activados), se mide la tasa de respiración en condiciones controladas y en presencia de concentraciones diferentes del tóxico. En la Figura 4-4 se muestra el montaje de una de las pruebas de respirometría.

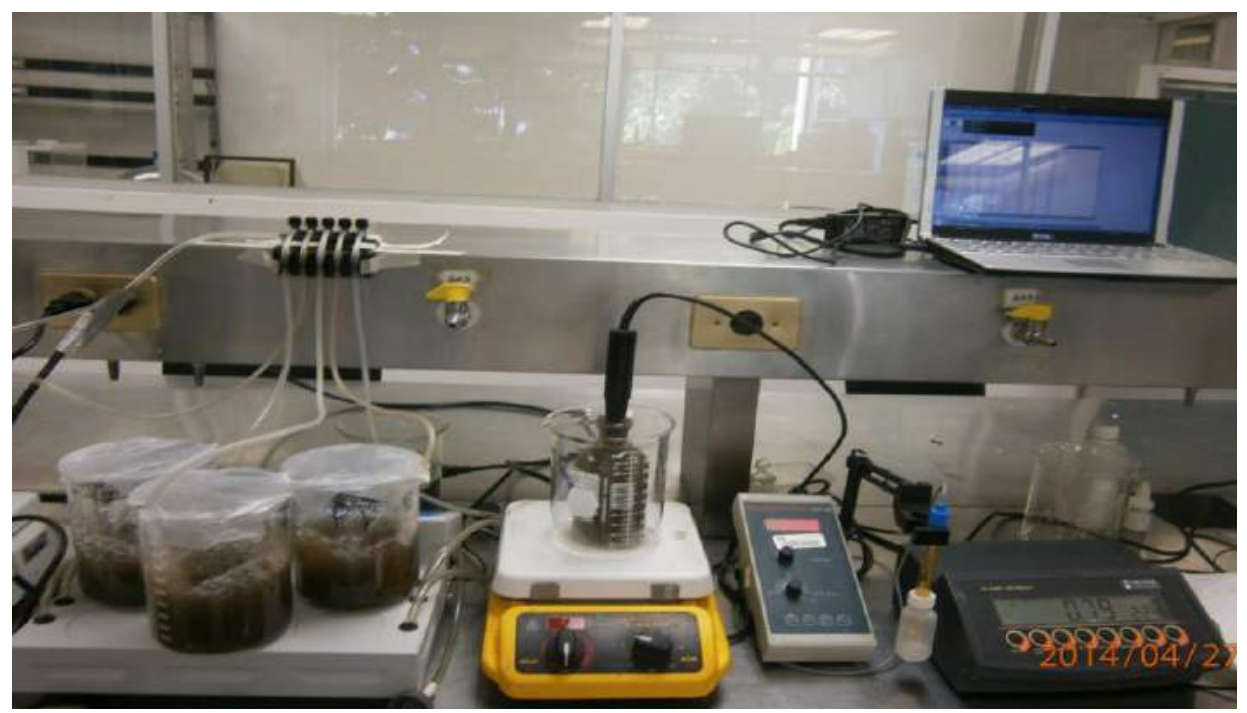

Figura 4-4 Montaje de una prueba de respirometría

\section{Principio del método}

La tasa de respiración de un lodo activado alimentado con una cantidad estándar de agua residual sintética, se determina después de un tiempo de contacto de 30 minutos, con un medidor de oxígeno disuelto. La tasa de respiración de los mismos lodos activados se mide también en presencia de varias concentraciones de la sustancia de prueba y en condiciones idénticas. El efecto inhibitorio de la sustancia de prueba, a una determinada concentración, se expresa como porcentaje de la media de las tasas de respiración de dos muestras control. El valor de $\mathrm{IC}_{50}$ se calcula mediante determinaciones realizadas a diferentes concentraciones [9, $10]$.

Primero se mide la toxicidad $\mathrm{IC}_{50}$ del compuesto fenólico, en este caso el 2,5-DCP. Este dato servirá para comparar la toxicidad del 2,5-DCP después del tratamiento con los POAs. Este método intenta representar las condiciones de una planta de tratamiento biológico de agua residual doméstica. Proporciona información de efectos inhibitorios o estimulantes después de 


\section{CAPÍTULO 4. METODOLOGÍA}

una exposición corta de la muestra a evaluar con M.O. de lodos activados. Se aplica en agua, agua residual, compuestos químicos puros y mezclas de compuestos químicos. Las sustancias a evaluar deben ser solubles.

En presencia de sustancias fácilmente biodegradables, los lodos activados consumen oxígeno a una mayor tasa que en su ausencia, dependiendo de la concentración de M.O. La adición de una concentración tóxica de la muestra da como resultado una disminución de la tasa de consumo de oxígeno. El porcentaje de inhibición del consumo de oxígeno se estimó comparándolo con la tasa de un control sin material de prueba. Se centrifugó un volumen de los lodos activados obtenidos de PTAR, el Rosario y se eliminó el sobrenadante. Se lavó con agua de la llave y se centrifugó otra vez, quitando el sobrenadante. Después se añadió agua de la llave otra vez y se dejó airear. Para la prueba de respirometría se preparó una solución nutritiva y el lodo activado con una concentración de $1.6 \mathrm{~g} / \mathrm{L}$.

Figura 4-5 se presenta un diagrama de bloques con el procedimiento de las pruebas de respirometría.

Los criterios de calidad que deben de cumplir para que los resultados de las pruebas sean válidos de acuerdo a ISO 8192:2007, [11] son: Las tasas de respiración de las muestras de control difieren una de la otra en menos de 15\%; El valor de $\mathrm{IC}_{50}$ (30 minutos) del tóxico esté dentro de los límites aceptados.

\subsubsection{Preparación de la solución nutritiva para alimentar los biorreactores}

La solución nutritiva se preparó disolviendo las siguientes cantidades de los reactivos en un 1 litro de agua destilada [9]: Extracto de carne, $11 \mathrm{~g} / \mathrm{L}$; Peptona, $16 \mathrm{~g} / \mathrm{L}$; Urea [CO(NH 2$)_{2}$ ], $3 \mathrm{~g} / \mathrm{L}$; Cloruro de sodio ( $\mathrm{NaCl}), 0.7 \mathrm{~g} / \mathrm{L}$; Cloruro de calcio dihidratado $\left(\mathrm{CaCl}_{2} .2 \mathrm{H}_{2} \mathrm{O}\right), 0.4 \mathrm{~g} / \mathrm{L}$; Sulfato de magnesio heptahidratado $\left(\mathrm{MgSO}_{4} .7 \mathrm{H}_{2} \mathrm{O}\right), 0.2 \mathrm{~g} / \mathrm{L} ;$ Fosfato de potasio anhidro monohidrogenado $\left(\mathrm{K}_{2} \mathrm{HPO}_{4}\right), 2.8 \mathrm{~g} / \mathrm{L}$. Con el fin de tener una solución homogeneizarla, es necesario de calentar la solución un poco para ayudar a la disolución. 


\section{Preparación del Inóculo de microorganismos}

Se centrifugó un volumen de los lodos activados obtenidos de PTAR, el Rosario y se eliminó el sobrenadante. Se lavó con agua de la llave y se centrifugó otra vez, quitando el sobrenadante. Después se añadió agua de la llave otra vez y se dejó airear. Para la prueba de respirometría se preparó una solución nutritiva y el lodo activado con una concentración de 1.6 g/L.

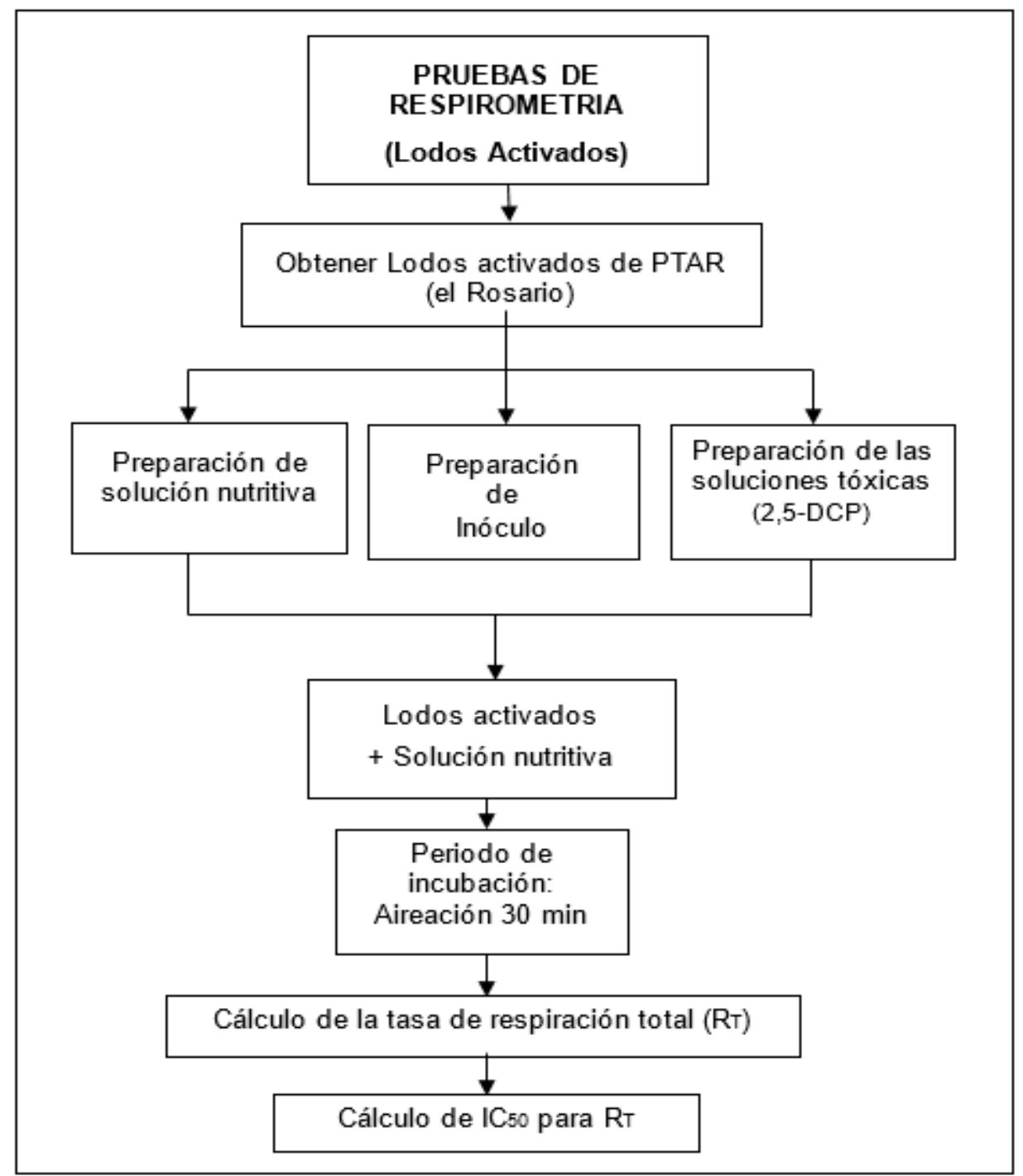

Figura 4-5 Diagrama de bloques del procedimiento de la prueba de respirometría

\section{Cálculo de la tasa de consumo de oxígeno}

Par calcular la tasa de consumo de oxígeno $(R)$, se expresa en miligramos por litro por hora (mg/Lh), según Ecuación 4-1 [9]: 


$$
R=\left(\frac{P_{1}-P_{2}}{\Delta_{t}}\right)
$$

Donde:

$\mathrm{P}_{1}$ es la concentración de oxígeno al inicio de la sección lineal $(\mathrm{mg} / \mathrm{L})$;

$\mathrm{P}_{2}$ es la concentración de oxígeno al final de la sección lineal ( $\left.\mathrm{mg} / \mathrm{L}\right)$;

$\Delta t$ es el intervalo de tiempo entre estas dos mediciones, en horas.

Y la tasa de respiración específica $\left(R_{\mathrm{s}}\right)$, es expresada como la cantidad de oxígeno consumido

por peso seco de lodo por hora, según la $R_{s}=\left(\frac{R}{S S}\right)$

$$
R_{s}=\left(\frac{R}{S S}\right)
$$

Ecuación 4-2

Donde SS es la concentración de sólidos suspendidos en la dilución de la muestra, en g/L.

El porcentaje de inhibición, I, del consumo total de oxígeno está dado por ec. 4-3 [9]:

$$
I_{T}=\left[1-\left(\frac{R_{T}}{R_{B}}\right)\right] \times 100 \% \quad \text { Ecuación 4-3 }
$$

Donde:

$R_{B}$ se refiere al blanco de control (promedio)

$\mathrm{R}_{\mathrm{T}}$ tasa de respiración total 


\subsubsection{Centrifugado de los lodos}

La centrifugadora se usa para concentrar los lodos activados para los pruebas de toxicidad y para preparar inóculo de M.O. para las pruebas de $\mathrm{DBO}_{5}$. Además se usa para centrifugar las muestras de los reactores biológicos.

\subsection{Tratamiento y análisis de las soluciones acuosas}

Se realizó el análisis fisicoquímico del agua residual que se utilizó para la disolución del 2,5 $\mathrm{DCP}$, para lo cual se midieron parámetros como $\mathrm{pH}$, conductividad eléctrica, alcalinidad, acidez, dureza, DQO, DBO5, Nitrógeno total, Fosfatos, Fenoles, Sólidos Suspendidos Totales, Sólidos Disueltos Totales, Índice Volumétrico de Lodos, Tasa de utilización de oxígeno, Velocidad específica de consumo de oxígeno. Además se hizo la identificación de los M.O. en los lodos.

\subsubsection{Identificación de los microorganismos}

\subsubsection{Métodos basados en Criterios Morfológicos}

\section{Estudio microscópico de los microorganismos}

Preparaciones en fresco: Se coloca una gota de fluido que contiene a los M.O. sobre un portaobjetos y cubrirlo con un cubreobjetos rápidamente. Este tipo de preparaciones son especialmente útiles para detectar la movilidad de los M.O. Las algas y los protozoarios pueden ser observados con los objetivos de 10X y 40X, mientras las bacterias pueden ser observadas con aceite de inmersión y con el objetivo de inmersión. Las preparaciones han de cubrirse con una gota de aceite de inmersión, en la cual se sumerge el objetivo 100X.

Preparaciones fijas: Se coloca una gota de agua esterilizada sobre el portaobjetos. Después, se toma una pequeña muestra de la bacteria aislada (de una placa de Petri) usando un asa bacteriológica esterilizada y revolverla suavemente en el agua. Esta muestra extendida se deja secar al aire, para asegurar que las células queden adheridas al portaobjetos. La preparación se fija con calor moderado, pasando el portaobjetos cuatro veces sobre la flama del mechero [12]. 


\section{CAPÍTULO 4. METODOLOGÍA}

Las observaciones microscópicas se determinaron usando un Microscopio óptico de Marca Motic serie B3 profesional con cámara digital de alta resolución CCD, con un programa procesador de imágenes (Motic Image Plus 2.0) se pueden tomar y guardar las fotos.

\subsubsection{Métodos basados en Tinción Diferencial}

Tinción de Gram. Esta técnica consiste en aplicar varias gotas de 4 reactivos en serie sobre un frote, el primero es el cristal violeta, se añade a la preparación fija, lo cual imparte color a todos los M.O. del frote; se deja actuar durante un minuto y después se enjuaga suavemente. El segundo reactivo es una solución de iodo llamado lugol de Gram, ésta actúa como mordiente, aumentando o reforzando la unión entre el colorante y el sustrato, formando un complejo cristal violeta-iodo-ribonucleato de magnesio, y como antes se deja actuar durante un minuto y después se enjuaga suavemente. El tercer reactivo es el alcohol-acetona, se añade a la preparación mientras se sostiene ligeramente inclinada para que el decolorante resbale lentamente por ella y luego se enjuaga rápidamente, este reactivo actúa como decolorante al colorante primario. El cuarto reactivo es el colorante de contraste, el safranina, se añade a la preparación, se deja actuar por un minuto; después se enjuaga y se deja secar al aire. Se observan las preparaciones al microscopio, y las observaciones microscópicas se ven teñidas las bacterias decoloradas (Gram negativas) de rojo y las bacterias que no reaccionan con el colorante de contraste, Gram positivo, se ven teñidas de morado [12].

\subsubsection{Cuantificación de los Microorganismos}

La cuantificación de M.O. es muy útil para los estudios de proceso biológico para tener estimación del número de bacterias en el reactor. Para cuantificar los M.O. se usó el método de recuento de bacterias viables en placa. El método utiliza estimación de bacterias viables en término de unidades formadoras de colonias por mililitro (UFC/mL).

Procedimiento: En condiciones de asepsia, se añade $1 \mathrm{~mL}$ de la muestra microbiana con punto de pipeta estéril al primer tubo $\left(10^{-1}\right)$ que contiene una dilución blanco (solución salina estéril) de $9 \mathrm{~mL}$, se mezcla bien y con otro punto de pipeta estéril se transfiere $1 \mathrm{~mL}$ de la suspensión microbiana del primer tubo al segundo tubo $\left(10^{-2}\right)$ con dilución blanco de $9 \mathrm{~mL}$ y se mezcla bien. Usando otro punto de pipeta estéril se transfiere $1 \mathrm{~mL}$ de la suspensión 


\section{CAPÍTULO 4. METODOLOGÍA}

microbiana del segundo tubo al tercer tubo $\left(10^{-3}\right)$ y se mezcla bien. Se repite el procedimiento y se preparon las diluciones, transfiriendo en cada ocasión $1 \mathrm{~mL}$ de la dilución anterior al siguiente tubo que contiene $9 \mathrm{ml}$ de diluyente, hasta lograr la dilución deseada.

A continuación, en condición estéril, se coloca $1 \mathrm{~mL}$ de la suspensión microbiana de cada una de los tubos de diluciones seriadas en las placas por triplicado (es decir, se preparan tres series de diluciones iguales). Se vacía 15 a $20 \mathrm{~mL}$ del medio del cultivo a punto de gelificar (agar aproximadamente a $45^{\circ} \mathrm{C}$ a $50^{\circ} \mathrm{C}$ ) y se rotan para mezclar las muestras en el agar. Después se deja solidificar el medio del cultivo en las placas. Se invierten y se incuban las placas a $35^{\circ} \mathrm{C}$ por $24 \mathrm{~h}$. Se hace el recuento de las colonias tras la incubación. Se observan las colonias bacterianas y se seleccionan las placas de la dilución que haya producido un número de colonias comprendido entre 30 y 300 . Se cuenta el número de colonias presentes usando una cámara cuenta colonias, las que se reportan como (UFC/mL) [12].

Cálculo:

$$
\frac{U F C}{m L}=\frac{(\text { No. de colonias por placa } \mathrm{x} \text { el factor de dilución })}{\text { mL de muestra sembrada }} \quad \text { Ecuación 4-4 }
$$

\section{Solución salina isotónica:}

Se utiliza la solución salina para hacer dilución de los M.O. estudiados, para cuantificarlos y también para hacer dilución de cultivo puros para pruebas de bioquímicas. La solución se prepara con el siguiente procedimiento: Disolver $8.5 \mathrm{~g}$ de cloruro de sodio $(\mathrm{NaCl})$ en $1 \mathrm{~L}$ de agua destilada. Distribuir $9 \mathrm{~mL}$ de la solución salina en tubos de vidrio de $15 \mathrm{~mL}$. Tapar los tubos y esterilizarlos en autoclave a temperatura de $121^{\circ} \mathrm{C}\left(15 \mathrm{lb} / \mathrm{in}^{2}\right.$ de presión) durante 15 minutos

\section{Medios de cultivo:}

Agar MacConkey: Suspender $50 \mathrm{~g}$ del polvo en $1 \mathrm{~L}$ de agua destilada. Mezclar hasta uniformar. Calentar suavemente y hervir 1 a 2 minutos hasta disolver. Tapar el matraz con algodón envuelto en gasa. Esterilizar en autoclave a $121^{\circ} \mathrm{C}\left(15 \mathrm{lb} / \mathrm{in}^{2}\right.$ de presión) durante 15 minutos. 
Agar Infusión Cerebro-Corazón (BHI): Disolver $52 \mathrm{~g}$ del Agar $\mathrm{BH}$ en un litro de agua destilada. Calentar a ebullición hasta su disolución total. Tapar el matraz con algodón envuelto en gasa. Esterilizar en autoclave a $121^{\circ} \mathrm{C}\left(15 \mathrm{lb} / \mathrm{in}^{2}\right.$ de presión) durante 15 minutos. Enfriar entre $45 \stackrel{\circ}{\circ}$ y $50 \stackrel{\circ}{\circ}$, colocar 20 a $30 \mathrm{~mL}$ de medio en algunas placas y se deja solidificar

Agar de Muller-Hinton: Suspender $38 \mathrm{~g}$ del Agar Muller-Hinton en un litro de agua destilada. Tapar el matraz con algodón envuelto en gasa. Calentar con agitación frecuente y hervir durante 1 a 2 minutos hasta disolver. Esterilizar en autoclave a $121^{\circ} \mathrm{C}\left(15 \mathrm{lb} / \mathrm{in}^{2}\right.$ de presión) durante 15 minutos. Enfriar entre $45{ }^{\circ} \mathrm{C}$ y $50 \stackrel{\circ}{\circ}$, colocar 20 a $30 \mathrm{~mL}$ de medio en algunas placas Petri y dejar solidificar.

Cetrimida Agar: se utiliza para el aislamiento selectivo de $P$. aeruginosa. Suspender $45.3 \mathrm{~g}$ del cetrimida agar base en $1 \mathrm{~L}$ de agua destilada. Añadir $10 \mathrm{~mL}$ de glicerina y tapar el matraz con algodón envuelto en gasa y calentar agitando frecuentemente y dejar hervir 1 a 2 minutos hasta disolver completamente. Esterilizar en autoclave a $121^{\circ} \mathrm{C}\left(15 \mathrm{lb} / \mathrm{in}^{2}\right.$ de presión) durante 15 minutos. Enfriar entre $45{ }^{\circ} \mathrm{C}$ y $50 \stackrel{\circ}{\circ}$, colocar 20 a $30 \mathrm{~mL}$ de medio en algunas placas Petri y dejar solidificar. La prueba consiste en añadir medio de cultivo de agar cetrimida fundido y enfriado a $45^{\circ} \mathrm{C}$ sobre cajas de Petri que contiene $1 \mathrm{~mL}$ de las muestras de diferentes reactores. Se tapan las placas y. Cuando el agar solidifica se incuban las placas. Las colonias se desarrollan tanto dentro del agar como en la superficie. Enfriar entre $45 \stackrel{\circ}{\circ}$ y $50 \stackrel{\circ}{ }$, colocar $20 \mathrm{~mL}$ de medio en algunas placas y dejar solidificar [12].

\subsubsection{Aislamiento de bacterias}

Para tener cultivos puros, se aísla una colonia de las colonias superficiales que crecen sobre el agar cetrimida y se siembra una asada de la muestra en el medio agar cetrimida, haciendo estría muy cerrada, en una parte muy pequeña de la caja. Esterilizar el asa y continuar las estrías pero tomando muestra, únicamente de la zona de la descarga. Incubar las placas invertidas, a la temperatura óptima del microorganismo que desea aislar por $24 \mathrm{~h}$.

Después, se repite los procedimientos y se siembran otras dos veces, escogiendo las colonias muy aisladas. Por último, se siembra las colonias puras aisladas sobre el agar $\mathrm{BHI}$. 


\subsubsection{Pruebas Bioquímicas}

Las pruebas Bioquímicas determinan la actividad metabólica de una cepa pura. Se emplea en este estudio principalmente para la identificación y clasificación de bacterias Pseudomonas.

- Medio SIM: Este medio se utiliza para comprobar, la formación de $\mathrm{H}_{2} \mathrm{~S}$ (S), la producción de indol (I) y la movilidad (M) por parte de las bacterias. La preparación se hace así: Disolver $1.5 \mathrm{~g}$ del medio en $50 \mathrm{~mL}$ de agua destilada en un matraz Erlenmeyer. Tapar el matraz con algodón envuelto en gasa y deja reposar 10 minutos. Calentar agitando hasta su punto de ebullición y dejar enfriar. Distribuir $4 \mathrm{~mL}$ del medio en cada tubo de ensayo y esterilizar en autoclave a $121^{\circ} \mathrm{C}$ (15 lb/in ${ }^{2}$ de presión) durante 15 minutos. Dejar que el medio se solidifique en posición vertical.

Se siembra la muestra y se incuba en un periodo de 24 horas a temperatura de $37^{\circ} \mathrm{C}$. Luego de la incubación, agregar 3-5 gotas de reactivo de Kovac o de Erlich.

- Medio -MR-VP. Este medio se utiliza para la realización del ensayo de Rojo de Metilo (MR) y Voges Proskauer (VP). Estas pruebas se realizan para determinar la capacidad de un microorganismo de fermentar la glucosa con producción de ácido por la vía ácido mixta o con producción de un producto final neutro (acetoína) por la vía butanodiólica.

Preparación: Suspender $1.7 \mathrm{~g}$ del polvo de medio VP-MR en $100 \mathrm{~mL}$ de agua destilada. Tapar el matraz con algodón envuelto en gasa. Calentar suavemente con agitación hasta disolver. Distribuir en tubos de ensayos y esterilizar en autoclave a $121^{\circ} \mathrm{C}$ durante 15 minutos.

Siembra: Inocular con asa estéril transfiriendo una porción de cultivo puro a dos tubos e Incubar a $35-37^{\circ} \mathrm{C}$ por 2 a 3 días. Uniformizar

Revelado: Prueba de Voges Proskauer: a $1 \mathrm{~mL}$ de cultivo añada 12 gotas $( \pm 0.6 \mathrm{~mL}$ ) de $\alpha$ naftol al $5 \%$ en etanol y 4 gotas $( \pm 0.2 \mathrm{~mL})$ de $\mathrm{KOH}$ al $40 \%$, agite y deje reposar por 5 a 10 minutos. Y prueba de Rojo de Metilo Transfiera $5 \mathrm{~mL}$ del cultivo a un tubo y añada 5 gotas de solución indicadora de Rojo de Metilo. 
- O.F. Medio Basal de Hugh y Leifson. Esta prueba se utiliza para identificación bacteriana con base en el metabolismo oxidativo-fermentativo de las bacterias Gram negativas, a la movilidad y producción de gas.

- Preparación: Suspender $0.98 \mathrm{~g}$ del polvo de medio basal O.F. en $100 \mathrm{~mL}$ de agua destilada. Tapar el matraz con algodón envuelto en gasa y deja reposar durante 5 minutos. Calentar con agitación frecuente hasta obtener una disolución total. Agregar $1 \%$ de glucosa ( $0.1 \mathrm{~g}$ de glucosa) a esta solución. Distribuir 4 a $5 \mathrm{~mL}$ en cada tubo de ensayo y esterilizar en autoclave a $118{ }^{\circ} \mathrm{C}$ durante 10 minutos. Dejar solidificar en posición vertical.

- Siembra: Inocular en 2 tubos conteniendo este medio. Rotular un tubo con la inscripción: "Abierto" y otro tubo con la inscripción: "Cerrado" (sellado). A partir de un cultivo puro de 18 a 24 horas del microorganismo en estudio, preparar un inóculo poco denso y sembrar utilizando aguja de inoculación. Picar hasta aproximadamente $0.6 \mathrm{~mm}$ del fondo de los tubos. Agregar al tubo "cerrado" (sellado) 1 o $2 \mathrm{~mL}$ de parafina fundida estéril, para excluir el oxígeno. Tapar ambos tubos bien e incubar los tubos a 35-37 ํㅡ en aerobiosis, durante 48 horas. Algunos M.O. pueden requerir hasta 4 días de incubación.

\section{Agar Hierro de Kligler}

El agar hierro de Kligler (KIA), es un medio empleado para la diferenciación de cultivos puros de bacilos gram negativos con base en su capacidad para fermentar la dextrosa y la lactosa y a la producción de sulfuro de hidrógeno.

Procedimiento: Suspender $2.75 \mathrm{~g}$ en $50 \mathrm{~mL}$ de agua destilada. Tapar el matraz con algodón envuelto en gasa y se deja remojar por 10 minutos. Calentar suavemente hasta su disolución total. Distribuir $3 \mathrm{~mL}$ del medio en cada tubo de ensayo y esterilizar en autoclave a $121^{\circ} \mathrm{C}$ (15 $\mathrm{lb} / \mathrm{in}^{2}$ de presión) durante 15 minutos. Dejar que el medio se solidifique en posición inclinada. Inocular los tubos inicialmente por picadura en el fondo del tubo (de 3 a $5 \mathrm{~mm}$ ) y posteriormente por estría en la superficie. Incubar los tubos con las tapas flojas a $35-37 \stackrel{\circ}{ } \mathrm{C}$ durante 18 a 48 horas.

\section{Medio de Citrato de Simmons}




\section{CAPÍTULO 4. METODOLOGÍA}

Esta prueba sirve para determinar la capacidad de un organismo de utilizar citrato como única fuente de carbono y compuestos amoniacales como única fuente de nitrógeno en su metabolismo, provocando una alcalinización del medio.

Preparación: Disolver $1.21 \mathrm{~g}$ del medio (agar citrato de Simmons) en $50 \mathrm{~mL}$ de agua destilada. Poner tapón de algodón envuelto en gasa y dejar remojar durante 5 a 10 minutos. Mezclar bien y calentar suavemente hasta su punto de ebullición sin dejar de agitar. Distribuir $3 \mathrm{~mL}$ del medio en cada tubo de ensayo y esterilizar en autoclave a $121^{\circ} \mathrm{C}\left(15 \mathrm{lb} / \mathrm{in}^{2}\right.$ de presión) durante 15 minutos. Dejar que el medio se solidifique en posición inclinada.

Se siembra la muestra y se incuba en un periodo de 4 días a temperatura de 35 a $37 \stackrel{\circ}{\circ}$. [12].

\section{Prueba de Citocromo Oxidasa}

Se diluye un poco de N,N,N'N'-diclorhidrato de tetrametil-p-fenilendiamina (TPD) en agua destilada. Después se añade una porción de cultivo puro sobre un papel filtro y unas gotas de solución TPD.

\section{Prueba bioquímica de API 20 E y API 20 NE}

El sistema API 20E y API 20 NE (Biomériux 2010) son sistemas de pruebas bioquímicas para la identificación de bacterias de la familia Enterobacteriaceae y otros bacilos Gram-negativos, mediante 21 pruebas bioquímicas estandarizadas y miniaturizadas y una base de datos. Este sistema puede identificar, Por ejemplo, Pseudomonas, Acinetobacter, Flavobacterium, Moraxella, Vibrio, Aeromonas, etc. Las tiras API 20E y API 20 NE consta de 20 microtubos que contienen los sustratos deshidratados de las pruebas bioquímicas convencionales y/o pruebas de asimilación. Se inoculan con una suspensión bacteriana que rehidrata los medios y después de la inoculación se observan los cambios de color con o sin adición de reactivos según el caso. La lectura de las reacciones se hace de acuerdo con la tabla de lectura y la identificación mediante la tabla de identificación "Analytical Profile Index API 20 E o API 20 NE", según el caso o el software "APILAB".

\section{Procedimiento para las pruebas bioquímicas.}


Preparación de la suspensión bacteriana: A partir de una colonia bien aislada del microorganismo (con edad de 18 a 24 horas), hace una suspensión en $5 \mathrm{ml}$ de solución salina al $0.85 \%(\mathrm{NaCl} 0.85 \%)$ hasta igualar turbidez del 0.5 de MacFarland.

Para API 20 E: Llenar con la suspensión bacteriana los tubos y la cúpula de las pruebas citrato (CIT), voges-proskauer (VP) y gelatinasa (GEL). Llenar los tubos pero no las cúpulas de los demás pocillos. Llenar la cúpula de las pruebas arginina deshidrolasa (ADH), lisina descarboxilasa (LDC), ornitina descarboxilasa (ODC), ureasa (URE) y azufre $\left(\mathrm{H}_{2} \mathrm{~S}\right)$ con aceite mineral estéril para obtener anaerobiosis. Previamente poner agua en los alvéolos de la cámara para proporcionar una atmósfera húmeda durante la incubación e incubar a $36^{\circ} \mathrm{C} \pm 2$ ${ }^{\circ} \mathrm{C}$ durante 18 a $24 \mathrm{~h}$.

Para API 20 NE: Llenar con la suspensión bacteriana todos los tubos pero no las cúpulas de pocillos. Llenar la cúpula de las pruebas glucosa (GLU), arabinosa (ARA) manosa (MNE), manitol (MAN), N-Acetil-Glucosamina (NAG), maltosa (MAL), gluconato de potasio (GNT), Ácido cáprico (CAP), Ácido adipico (ADI), malato (MLT), CIT y Ácido fenilacético (PAC). Llenar la cúpula de las pruebas $\underline{\mathrm{GLU}}, \underline{\mathrm{ADH}}$ y $\underline{\mathrm{URE}}$ con aceite mineral estéril para obtener anaerobiosis. Poner agua en los alvéolos de la cámara para proporcionar una atmósfera húmeda durante la incubación e incubar a $29^{\circ} \mathrm{C} \pm 2{ }^{\circ} \mathrm{C}$ durante $24 \mathrm{~h}( \pm 2 \mathrm{~h})$.

La descripción de las Pruebas Bioquímicas de API 20 E y API 20 NE se presenta en la Tabla 4-1 
Tabla 4-1 Descripción de las Pruebas Bioquímicas de API 20 E y API 20 NE [13, 14]

\begin{tabular}{|c|c|c|c|c|}
\hline & \multicolumn{2}{|r|}{ API $20 \mathrm{E}$} & \multicolumn{2}{|r|}{ API $20 \mathrm{NE}$} \\
\hline No. & Prueba & Reacción / Enzimas & Prueba & Reacción / Enzimas \\
\hline 1 & ONPG & $\begin{array}{l}\text { Beta-galactosidasa } \\
\text { (Orto Nitrofenil-BD- } \\
\text { Galactopiranosida) }\end{array}$ & $\mathrm{NO}_{3}$ & $\begin{array}{l}\text { Reducción de nitratos a nitritos; } \\
\text { Reducción de nitratos a } \\
\text { nitrógeno }\end{array}$ \\
\hline 2 & ADH & Arginina deshidrolasa & TRP & Producción de indol (Triptófano) \\
\hline 3 & LDC & Lisina descarboxilasa & GLU & Fermentación de glucosa \\
\hline 4 & ODC & Ornitina descarboxilasa & $\overline{\overline{\mathrm{ADH}}}$ & Arginina deshidrolasa \\
\hline 5 & CIT & Utilización del citrato & $\overline{\overline{\text { URE }}}$ & Ureasa \\
\hline 6 & $\mathrm{H}_{2} \mathrm{~S}$ & Producción de $\mathrm{H}_{2} \mathrm{~S}$ & ESC & $\begin{array}{l}\text { Hidrólisis ( } \beta \text {-glucosidasa) } \\
\text { (esculina) }\end{array}$ \\
\hline 7 & URE & Ureasa & GEL & Hidrólisis (proteasa) (gelatin \\
\hline 8 & TDA & Triptófano desaminasa & PNPG & $\begin{array}{c}\text { B-galactosidasa (Para- } \\
\text { Nitrofenil-BD- } \\
\text { Galactopiranosida) }\end{array}$ \\
\hline 9 & IND & Producción de indol & GLU & Asimilación (Glucosa) \\
\hline 10 & VP & $\begin{array}{c}\text { Producción de acetoína } \\
\text { (Voges-Proskauer) }\end{array}$ & ARA & Asimilación (Arabinosa) \\
\hline 11 & GEL & Gelatinasa & MNE & Asimilación (Manosa) \\
\hline 12 & GLU & $\begin{array}{c}\text { Fermentación/oxidación } \\
\text { de glucosa }\end{array}$ & MAN & Asimilación (Manitol) \\
\hline 13 & MAN & $\begin{array}{c}\text { Fermentación/oxidación } \\
\text { de manitol }\end{array}$ & NAG & $\begin{array}{l}\text { Asimilación (N-Acetil- } \\
\text { Glucosamina) }\end{array}$ \\
\hline 14 & INO & $\begin{array}{c}\text { Fermentación/oxidación } \\
\text { de inositol }\end{array}$ & MAL & Asimilación (maltosa) \\
\hline 15 & SOR & $\begin{array}{c}\text { Fermentación/oxidación } \\
\text { de sorbitol }\end{array}$ & GNT & $\begin{array}{l}\text { Asimilación (Gluconato de } \\
\text { potasio) }\end{array}$ \\
\hline 16 & RHA & $\begin{array}{c}\text { Fermentación/oxidación } \\
\text { de ramnosa }\end{array}$ & CAP & Asimilación (Ácido cáprico) \\
\hline 17 & SAC & $\begin{array}{c}\text { Fermentación/oxidación } \\
\text { de sacarosa }\end{array}$ & ADI & Asimilación (Ácido adipico) \\
\hline 18 & MEL & $\begin{array}{c}\text { Fermentación/oxidación } \\
\text { de melobiosa }\end{array}$ & MLT & Asimilación (Malato) \\
\hline 19 & AMY & $\begin{array}{c}\text { Fermentación/oxidación } \\
\text { de amigdalina }\end{array}$ & CIT & Asimilación (Citrato trisódico) \\
\hline 20 & ARA & $\begin{array}{c}\text { Fermentación/oxidación } \\
\text { de arabinosa }\end{array}$ & PAC & Asimilación (Ácido fenilacético) \\
\hline 21 & OX & Citocromo oxidasa & OX & Citocromo oxidasa \\
\hline
\end{tabular}




\subsubsection{Determinación de aniones}

Los aniones: Cloruros $\left(\mathrm{Cl}^{-}\right)$, Nitratos $\left(\mathrm{NO}^{-3}-\mathrm{N}\right)$ y Fosfatos $\left(\mathrm{PO}_{4}^{3-}\right)$, se midieron con los estuches HANNA HI 3815-0, HI 3874 y HI 3833, respectivamente usaron los accesorios HANNA. Las pruebas se basan en los métodos estándar $4500 \mathrm{Cl}$ - C (titulación de Mercúrico nitrato), 4500$\mathrm{NO}_{3}$ - E (Reducción de Cadmio), y 4500-P E (Método del Ácido Ascórbico), respectivamente [8].

\subsubsection{Determinación de alcalinidad}

La alcalinidad se mide como $\mathrm{CaCO}_{3}$, usando tiras de reactivos de $\mathrm{HACH}$ de Alcalinidad por el método fenolftaleína. Estas tiras de reactivos dan resultados aproximados de la alcalinidad del agua residual en esta investigación.

\subsubsection{Determinación de Fenoles}

La cantidad de fenoles totales en las muestras de los biorreactores fueron medidos con un estuche de HANNA HI 3864. Esta técnica consiste en los compuestos fenólicos reaccionan para formar un color amarillo a naranja con tinte 4-aminoantipirina en solución alcalina tamponada a un $\mathrm{pH}$ de aproximadamente 10. La absorbancia de este producto coloreado es proporcional a la concentración de fenoles presentes en la muestra acuosa. Esta técnica está basada en el 4-aminoantipirina método colorimétrico de los métodos estándar -Sección 5530 $\mathrm{D}[8]$.

\subsubsection{Determinación de sólidos suspendidos totales}

La biomasa de los lodos activados se determina gravimétricamente midiendo los sólidos suspendidos totales (SST) según los métodos estándar -Sección 2450 D [8].

\subsubsection{Determinación de oxígeno disuelto}

Se determina el oxígeno disuelto (OD) por el método de electrodo de membrana según los métodos estándar, Sección 4500-O G [8]. El oxígeno disuelto de los pruebas de toxicidad y con los biorreactores fue medido con un equipo de oxígeno disuelto marca HANNA. 


\subsubsection{Determinación de la velocidad de utilización de oxígeno}

Se usa el Método de velocidad de utilización de oxígeno VUO de la sección 2710 B de los métodos estándar [8]. Esta prueba es para determinar la velocidad de consumo de oxígeno de una muestra de una biomasa de suspensión como lodos activados. Es un indicador de los cambios en las condiciones operacionales a una etapa temprana.

El procedimiento de esta medición se realiza tomando muestras representativas de licor mezclado y llenado una botella de Winkler con agitación, se mide el consumo de oxígeno utilizando un medidor de oxígeno disuelto (previamente calibrado) durante un tiempo de contacto de 15 minutos o cuando el valor OD es mayor o igual que $1 \mathrm{mg} / \mathrm{L}$.

La tasa de consumo de oxígeno se determina gráficamente por la relación entre la disminución de la concentración de oxígeno y el tiempo, normalmente se encuentran los datos de forma lineal y se puede calcular la VUO que es la pendiente de la curva de esta gráfica.

\subsubsection{Cálculo de la Velocidad específica de utilización de oxígeno}

La velocidad específica de utilización de oxígeno (VUOS) se calculó dividiendo la VUO por los sólidos suspendidos en la solución. La $\operatorname{VUOS}\left(\frac{m g / g}{h}\right)=\frac{V U O\left(\frac{m g / L}{\min }\right)}{\text { Solidos suspendidos }(g / L)} \times \frac{60 \mathrm{~min}}{h}$

Ecuación 4-5 muestra el cálculo de VUOS:

$$
\operatorname{VUOS}\left(\frac{m g / g}{h}\right)=\frac{V U O\left(\frac{m g / L}{\min }\right)}{\text { Solidos suspendidos }(g / L)} \times \frac{60 \mathrm{~min}}{h} \quad \text { Ecuación 4-5 }
$$

\subsubsection{Determinación del Índice Volumétrico de Lodos}

Se usa el Método de índice volumétrico de lodos (IVL) de la sección 2710 D de los métodos estándar [8]. Es un indicador para determinar la sedimentabilidad de un lodo. Por definición es el volumen ocupado por un gramo de una suspensión después de 30 minutos de sedimentación. 


\section{CAPÍTULO 4. METODOLOGÍA}

El procedimiento de esta medida se realiza tomando muestra representativas de un litro de licor mezclado y midiendo el volumen de los lodos sedimentados en la probeta graduada (1L) durante 30 minutos en reposo. La calculación de IVL se muestra en la $I V L\left(\frac{m L}{m g}\right)=\frac{L o d o s \text { Sedim entados }(m L / L) \times 1000}{\text { Solidos suspendidos }(m g / L)}$

Ecuación 4-6.

$$
I V L\left(\frac{m L}{m g}\right)=\frac{\text { Lodos Sedim entados }(m L / L) \times 1000}{\text { Solidos suspendido }(m g / L)} \quad \text { Ecuación 4-6 }
$$

\subsubsection{Coeficiente de transferencia gas/líquido en el reactor}

El coeficiente de transferencia de ozono en el reactor (Figura 4-6) se calculó en forma indirecta aplicando la ecuación propuesta por Gottschalk [15], con datos experimentales del coeficiente de transferencia de oxígeno, esta ecuación relaciona el coeficiente de transferencia volumétrico del ozono $\left(\mathrm{K}_{\mathrm{La}} \mathrm{O}_{3}\right)$ con el coeficiente de transferencia volumétrico del oxígeno ( $\mathrm{k}\llcorner\mathrm{a}$ $\mathrm{O}_{2}$ ) y la relación entre la difusividad de los dos gases (oxígeno y ozono).

Los experimentos se llevaron a cabo con agua potable, agua desionizada y agua residual, como fase líquida. El estudio se llevó a cabo en el reactor tubular de vidrio equipado con difusor de burbuja fina en el fondo, con poros de $100 \mu \mathrm{m}$ (Figura 4-6). Las pruebas se hicieron a temperatura ambiente de aproximadamente 20 a $25^{\circ} \mathrm{C}$ y presión atmosférica, en la Ciudad de México es de $585 \mathrm{~mm}$ de mercurio. La alimentación del gas de 14.9-20 psi, y se alimentó un flujo de gas variando de 0.5589 a $0.632 \mathrm{~L} / \mathrm{min}$.

Primero, se desoxigenó el agua hasta una concentración de oxígeno disuelto de cero. Esto se hizo añadiendo sulfito de sodio $\left(\mathrm{Na}_{2} \mathrm{SO}_{3}\right)$ y cloruro de cobalto $\left(\mathrm{CoCl}_{2}\right)$ como catalizador. Después de desoxigenar completamente el agua, se inició la oxigenación. Se midió el oxígeno disuelto en intervalos de 2 a 5 segundos hasta llegar a su saturación (Cs). Como la concentración de oxígeno disuelto aumentó con el tiempo, este método se denomina de aireación en régimen transitorio. Las mediciones de oxígeno disuelto se hicieron con el equipo de oxígeno disuelto de HANNA (HI 2400) [16]. Además se empleó un manómetro hidrostático 
diferencial en $U$ con mercurio, para medir la caída de presión en el reactor, para calcular el coeficiente de transferencia de masa del oxígeno, kL, con la ecuación propuesta por Azbel [17].

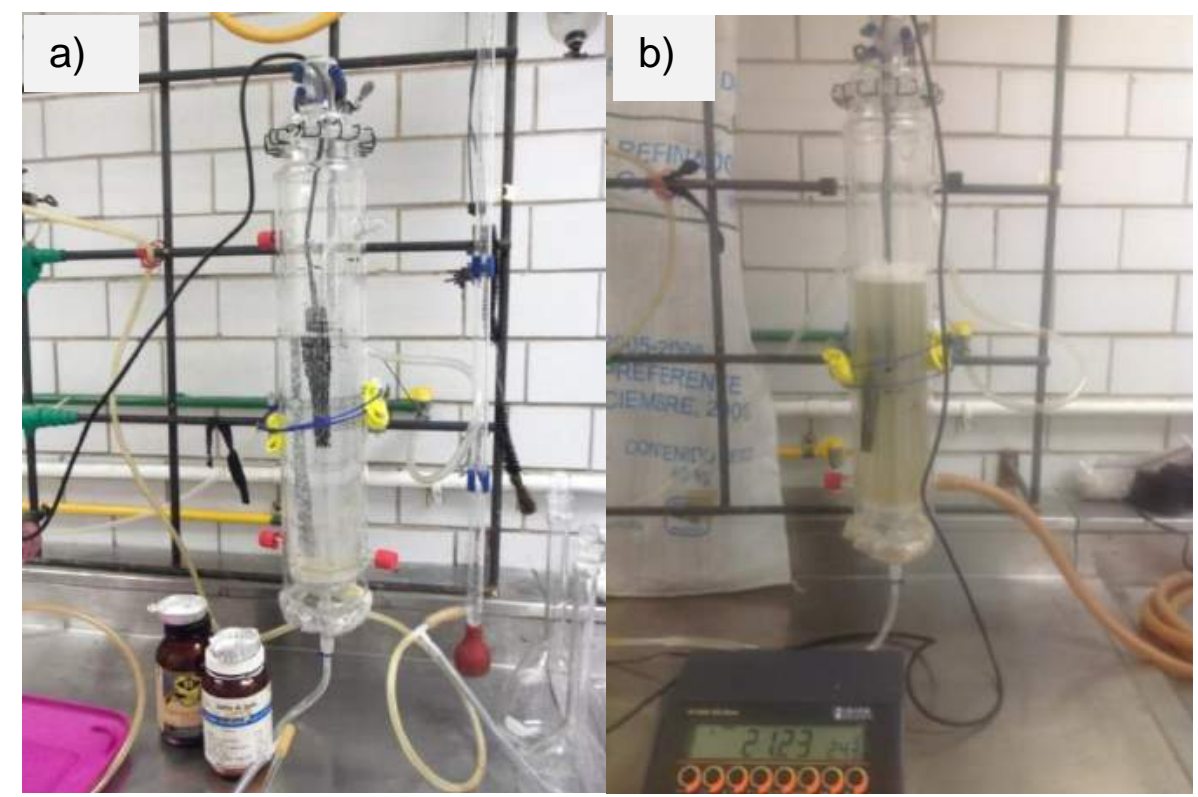

Figura 4-6 Dispositivo experimental: Reactor de columna de burbuja con a) agua destilada y b) agua residual

\subsubsection{Reactor Biológico semi-continuo}

Se llevaron a cabo experimentos de procesos biológicos aerobios con un SBR para investigar la eficiencia de los tratamientos de POAs combinados con los Procesos biológicos de lodos activados, y para conocer la biodegradabilidad de los productos intermedios formados durante la oxidación de la solución de 2,5-DCP con ozono y con ozono-UV.

Los sistemas SBR (Figura 4-7) tienen cinco etapas que tienen lugar de forma secuencial: (1) llenado; (2) reacción (Agitación y aireación); (3) sedimentación (clarificación); (4) extracción (vaciado por decantación), y (5) fase inactiva (esperar a rellenarlo con solución fresca y nutrientes) 


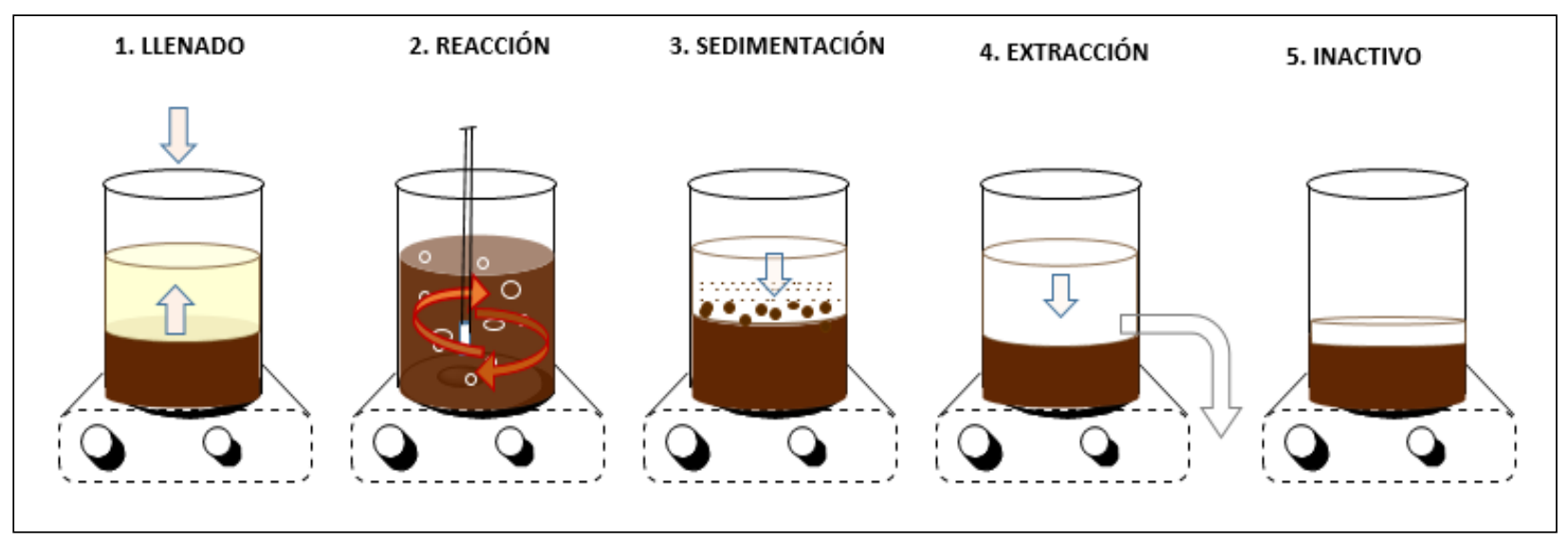

Figura 4-7 Reactor biológico discontinuo secuencial.

Primero se hicieron pruebas en los reactores para las muestras del 2,5-DCP en solución de agua destilada (Fase I); y se tomaron muestras de decantación para hacer análisis. Y después se repitieron estas pruebas con las soluciones del 2,5-DCP en agua residual y en agua destilada (Fase II). Se usaron lodos adaptados al 2,5-DCP y sin previa adaptación, para comparar la eficiencia de los lodos para biodegradar las soluciones del 2,5-DCP pretratadas. Uniformizar la forma de escribir.

\subsubsection{FASE I de los experimentos de los biorreactores}

Se emplearon cuatro reactores con agitación completa tipo "Batch". Tres de ellos Reactor 1 (R1), Reactor 2 (R2) y Reactor 3 (R3) con una capacidad de $3.5 \mathrm{~L}$ y un volumen operacional de $2.5 \mathrm{~L}$ y el Reactor 4 (R4) con un volumen operacional de $1 \mathrm{~L}$ (Figura 4-8). Los reactores ( $R 1, R 2, R 3$ y R4) fueron equipados con difusores de aire con un flujo continuo de aire entre 70-100 $\mathrm{Lh}^{-1}$ y distribuido uniformemente en toda la base del reactor, también se usó agitación para hacer la solución homogénea dentro del reactor. La biomasa usada fue de muestras de lodos activados provenientes de la recirculación al tanque de aireación de la planta de tratamiento de aguas residuales municipales El Rosario de la $\mathrm{Cd}$. de México.

Uniformizar la forma de escribir. 


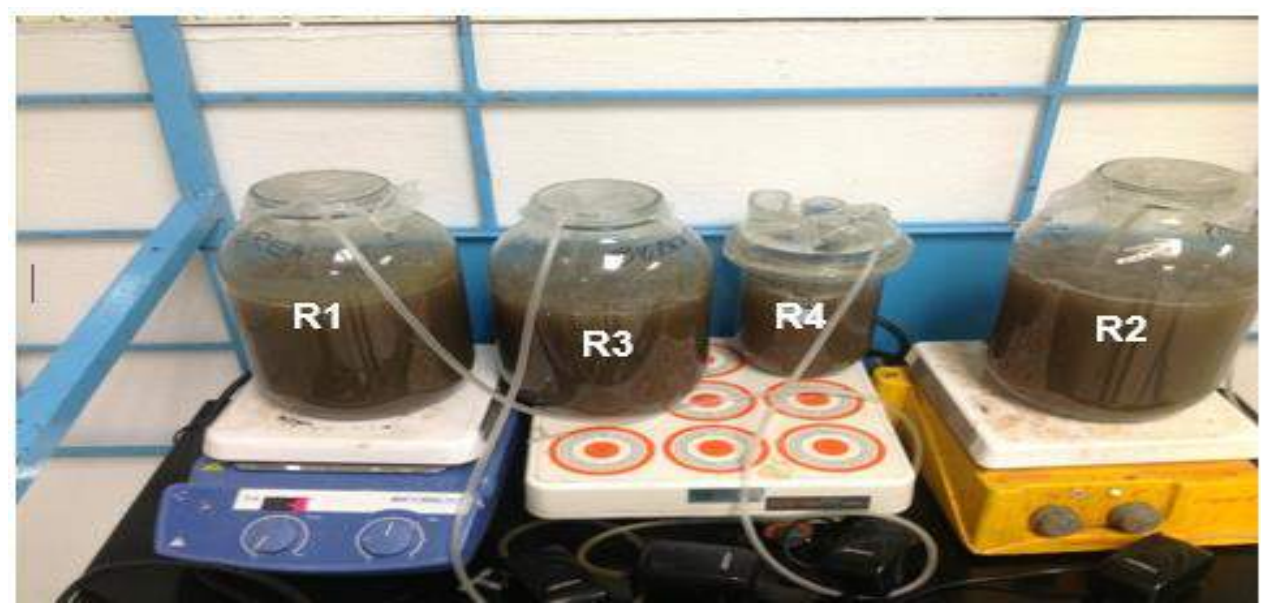

Figura 4-8 Reactores con agitación completa (R1, R3, R4 y R2)

\subsubsection{Reactores de lodos adaptados}

En estos reactores la biomasa de lodos activados fue adaptada con soluciones de fenol (R3), fenol y DCP (R2) y DCP (R4). Para poner en marcha estos reactores se siguieron los siguientes pasos:

Para los cuatros reactores el procedimiento fue igual y los volúmenes de la muestras fueron iguales, con la excepción del reactor 4 que trabajó con un volumen menor que los otros tres. La biomasa fue adaptada previamente a una solución de fenol en los reactores 2 y 3 , ya que es menos tóxico que el 2,5-DCP y es parte de la familia de compuestos fenólicos. Los reactores fueron operados en proceso semi-continuo. El medio de cultivo que se utilizó se basó en los métodos estándar $5210 \mathrm{D}$ [8] y en la literatura [7, 18]. Los reactores fueron montados con la siguiente mezcla:

\section{Reactor 1: Reactor sin tóxico (Control)}

- Con $675 \mathrm{~mL}$ de biomasa de lodos activados de PTAR, el Rosario

- $425 \mathrm{~mL}$ de agua destilada

- $1400 \mathrm{~mL}$ de agua residual

- Macronutrientes: $5 \mathrm{~mL}$ de solución $\mathrm{NH}_{4} \mathrm{Cl}, 5 \mathrm{~mL}$ de solución $\mathrm{CaCl}_{2}, 5 \mathrm{~mL}$ de solución $\mathrm{FeCl}_{3}, 5 \mathrm{~mL}$ de solución $\mathrm{MgSO}_{4}$ y $15 \mathrm{~mL}$ de Solución tampón de fosfato $\left(\mathrm{NaH}_{2} \mathrm{PO}_{4}\right.$ ajustado a pH 7 con $\mathrm{KOH}$ ). 
CAPÍTULO 4. METODOLOGÍA

\section{Los Reactores 2 y 3 adaptados con fenol}

\section{Medio de cultivo}

- $675 \mathrm{~mL}$ de biomasa de lodos activados de la PTAR, el Rosario

- $425 \mathrm{~mL}$ de solución de Fenol (250 mg/L)

- $1400 \mathrm{~mL}$ de agua residual

- Macronutrientes: $5 \mathrm{~mL}$ de solución $\mathrm{NH}_{4} \mathrm{Cl}, 5 \mathrm{~mL}$ de solución $\mathrm{CaCl}_{2}, 5 \mathrm{~mL}$ de solución $\mathrm{FeCl}_{3}, 5 \mathrm{~mL}$ de solución $\mathrm{MgSO}_{4}$ y $15 \mathrm{~mL}$ de Solución tampón de fosfato.

\section{Reactor 4 adaptado al DCP}

\section{Medio de cultivo}

- $270 \mathrm{~mL}$ de biomasa de lodos activados de PTAR, el Rosario

- $170 \mathrm{~mL}$ de solución de DCP (10 - $50 \mathrm{mg} / \mathrm{L})$

- $560 \mathrm{~mL}$ de agua residual doméstica

- Macronutrientes: $2 \mathrm{~mL}$ de solución $\mathrm{NH}_{4} \mathrm{Cl}, 2 \mathrm{~mL}$ de solución $\mathrm{CaCl}_{2}, 2 \mathrm{~mL}$ de solución $\mathrm{FeCl}_{3}, 2 \mathrm{~mL}$ de solución $\mathrm{MgSO}_{4}$ y $6 \mathrm{~mL}$ de Solución tampón de fosfato.

\section{Procedimiento operacional:}

1. Después del proceso de aireación, se apagó la entrada del aire y la agitación y se dejó sedimentar por 1 hora

2. Se purgó un volumen determinado $(Q)$ del reactor (ver tabla 4-2)

3. Se alimentó el reactor con una solución fresca (según corresponda de agua residual o fenol o DCP y los macronutrientes) del mismo volumen removido del reactor (en el paso 2).

4. Se determinaron los siguientes parámetros de cada muestra: $\mathrm{pH}, \mathrm{SST}$, DQO, IVL, VUO y VUOS.

Muestreos: se midieron diariamente los siguientes parámetros como: $\mathrm{pH}$, SST y DQO y semanalmente VUO, VUOS y mensualmente IVL, que permitieron evaluar la eficiencia del reactor.

Al final del primer ciclo (10 días) estuvo funcionando eficazmente el reactor, por eso durante el ciclo 2 y 6 se empezó a alimentar los reactores 2 y 3 solo con solución de fenol y 
macronutrientes, mientras que el reactor 4 se alimentó solo con solución de DCP y macronutrientes. El reactor 1 , de control, se continuó alimentando con agua residual y macronutrientes. Además, por cada ciclo se continuó alimentando los reactores con la misma cantidad de las soluciones macronutrientes como se describe anteriormente según el caso del reactor. Los lodos activados fueron añadidos y removidos cuando fue necesario, para mantener la concentración en los reactores de $1.5 \mathrm{~g} / \mathrm{L}$ y por consiguiente para no tener lodos muy viejos. Se reemplazó el volumen de la muestra removida $(Q)$ con un volumen igual de las soluciones de alimentación, diariamente a cada ciclo durante la aclimatación de los reactores. La concentración de biomasa se midió como sólidos suspendidos totales (SST), en cada reactor fue $1.5 \mathrm{~g} / \mathrm{L}$. En cada reactor se removió un poco de lodo cada día y se reemplazó con lodo fresco, para mantener la biomasa a su concentración inicial y activos los lodos.

Tabla 4-2 Volumen a purgar y alimentar en cada ciclo durante la aclimatación de los sistemas

\begin{tabular}{|c|c|c|c|c|c|c|}
\hline Ciclo & $\begin{array}{l}\theta_{\mathrm{h}} \\
\text { (d) }\end{array}$ & $\begin{array}{l}\text { Solución de } \\
\text { alimentación }\end{array}$ & $\begin{array}{l}\text { Reactor R1 } \\
(\mathrm{mL})\end{array}$ & $\begin{array}{c}\text { Reactor R2 } \\
(\mathrm{mL})\end{array}$ & $\begin{array}{c}\text { Reactor R3 } \\
(\mathrm{mL})\end{array}$ & $\begin{array}{c}\text { Reactor R4 } \\
(\mathrm{mL})\end{array}$ \\
\hline \multirow{3}{*}{1} & \multirow{3}{*}{10} & Agua residual & 250 & 192 & 192 & 77 \\
\hline & & Fenol & 0 & 58 & 58 & 0 \\
\hline & & DCP & 0 & 0 & 0 & 23 \\
\hline \multirow{3}{*}{2} & \multirow{3}{*}{5} & Agua residual & 500 & 0 & 0 & 0 \\
\hline & & Fenol & 0 & 500 & 500 & 0 \\
\hline & & DCP & 0 & 0 & 0 & 200 \\
\hline \multirow{3}{*}{3} & \multirow{3}{*}{2} & Agua residual & 1250 & 0 & 0 & 0 \\
\hline & & Fenol & 0 & 1250 & 1250 & 0 \\
\hline & & DCP & 0 & 0 & 0 & 500 \\
\hline \multirow{3}{*}{4} & \multirow{3}{*}{2} & Agua residual & 1250 & 0 & 0 & 0 \\
\hline & & Fenol & 0 & 1250 & 1250 & 0 \\
\hline & & DCP & 0 & 0 & 0 & 500 \\
\hline \multirow{3}{*}{5} & \multirow{3}{*}{2} & Agua residual & 1250 & 0 & 0 & 0 \\
\hline & & Fenol & 0 & 1250 & 1250 & 0 \\
\hline & & DCP & 0 & 0 & 0 & 500 \\
\hline \multirow{3}{*}{6} & \multirow{3}{*}{2} & Agua residual & 1250 & 0 & 0 & 0 \\
\hline & & Fenol & 0 & 1250 & 1250 & 0 \\
\hline & & DCP & 0 & 0 & 0 & 500 \\
\hline
\end{tabular}

Después de 6 ciclos (23 días) los reactores se consideraron aclimatados a las soluciones de fenol y DCP. Después se alimentó el reactor 2 con la solución (2,5-DCP $10 \mathrm{mg} / \mathrm{L})$, al reactor 3 se le redujo la concentración de Fenol a $100 \mathrm{mg} / \mathrm{L}$ y al reactor 4 no se le hicieron cambios. 


\section{CAPÍTULO 4. METODOLOGÍA}

Cálculo: Se calcula el volumen para ser removido diariamente $(Q)$ de los reactores, dividiéndolo el volumen total del reactor $\left(\mathrm{V}_{\mathrm{T}}\right)$ por el tiempo de retención hidráulica $\left(\theta_{\mathrm{h}}\right)$ (calculado en la ecuación 4-7) -es decir el número de días en el ciclo [19]. En la Y por eso

$$
Q=\frac{V_{T}}{\theta_{h}}
$$

Ecuación

4-8 se muestran los cálculos de $\mathrm{Q}$, respectivamente dado en $\mathrm{mL} / \mathrm{d}$ :

$$
\theta_{h}=\frac{V_{T}}{Q}
$$

Ecuación 4-7

Y por eso

$$
\boldsymbol{Q}=\frac{V_{T}}{\boldsymbol{\theta}_{\boldsymbol{h}}} \quad \text { Ecuación 4-8 }
$$

Cuando los M.O. de Reactor 2 y Reactor 4 fueron adaptados (alrededor de 50 días) se unieron los dos reactores para formar solo uno el Reactor 2 (R2), para reducir la cantidad de tóxico que se descargó diariamente de los reactores, ya que diariamente se desechó una parte de líquido sobrenadante y se aplicó nueva solución de tóxico.

\subsubsection{Procedimiento de Bioensayo en soluciones preozonizadas}

Los bioensayos se realizaron en las soluciones preozonizadas por 60 minutos con tratamientos de ozonización y su combinación ozono-UV. Las soluciones pre-ozonizadas se dejaron reposar por 24 horas antes de alimentar los reactores biológicos para evitar la presencia de residuos de ozono.

Los bioensayos se llevaron a cabo en reactores de vidrio con volumen operacional de $400 \mathrm{~mL}$ con agitación magnética, equipados con difusores de aire, con un flujo continuo de aire entre 70-100 Lh-1 y MLSS inicial de $1500 \mathrm{mg} / \mathrm{L}$. Se estudiaron diferentes porcentajes de mezclas (solución preozonizada y aguas residuales municipales o solución de fenol de 100 ppm o solución de 2,5- DCP de 10 ppm).

Se alimentaron los reactores con la solución tóxica o agua residual según el caso y la cantidad adecuada de solución de macronutrientes conteniendo: $\mathrm{NH}_{4} \mathrm{Cl}, \mathrm{CaCl}_{2}, \mathrm{FeCl}_{3}, \mathrm{MgSO}_{4}$ y una 
solución tampón de fosfatos. La biomasa se obtuvo de los lodos activados anteriormente durante la Fase I.

El estudio se llevó a cabo en reactores con agitación, semi-continuo, con un tiempo de retención hidráulica $\left(\theta_{h}\right)$ variable, dependiendo de los ciclos (Tabla 4-3) y el volumen de la muestra que se sacó de cada reactor se analizó con pH, SST, DQO, IVL, VUO y estudios microbiológicos.

Se emplearon seis reactores con agitación operando en discontinuo. Tres de ellos con solución de 2,5-DCP pre-ozonada (R1OA, R2OA y R3OA) y los otros tres con solución de 2,5-DCP oxidada con ozono-UV durante 60 min (R1OB, R2OB y R3OB). Los reactores se muestran en la Figura 4-9.

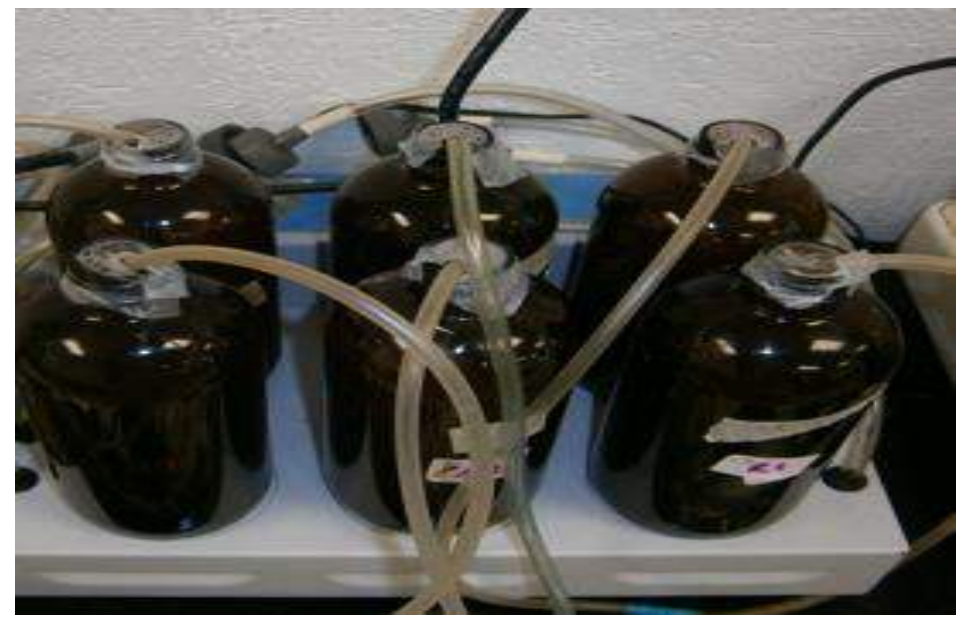

Figura 4-9 Reactores con agitación completa de Fase 1

Tabla 4-3 Fase I: Volumen a purgar y reemplazar durante cada ciclo $(\mathrm{mL})$

\begin{tabular}{|c|c|c|c|c|c|c|c|}
\hline Ciclo & $\begin{array}{c}\boldsymbol{\theta}_{\mathbf{h}} \\
(\mathbf{d})\end{array}$ & $\begin{array}{c}\text { Reactor } \\
\mathbf{R 1 O A} \\
(\mathbf{m L})\end{array}$ & $\begin{array}{c}\text { Reactor } \\
\mathbf{R 1 O B} \\
(\mathbf{m L})\end{array}$ & $\begin{array}{c}\text { Reactor } \\
\text { R2OA } \\
(\mathbf{m L})\end{array}$ & $\begin{array}{c}\text { Reactor } \\
\mathbf{R 2 O B} \\
(\mathbf{m L})\end{array}$ & $\begin{array}{c}\text { Reactor } \\
\text { R3OA } \\
(\mathbf{m L})\end{array}$ & $\begin{array}{c}\text { Reactor } \\
\text { R3OB } \\
(\mathbf{m L})\end{array}$ \\
\hline 1 & 8 & 50 & 50 & 50 & 50 & 50 & 50 \\
\hline 2 & 5 & 80 & 80 & 80 & 80 & 80 & 80 \\
\hline 3 & 2 & 200 & 200 & 200 & 200 & 200 & 200 \\
\hline 4 & 2 & 200 & 200 & 200 & 200 & 200 & 200 \\
\hline 5 & 2 & 200 & 200 & 200 & 200 & 200 & 200 \\
\hline 6 & 1 & 400 & 400 & 400 & 400 & 400 & 400 \\
\hline
\end{tabular}




\subsubsection{Pruebas de Biodegradabilidad - Fase II}

En esta segunda fase, se eliminó el uso del reactor con DCP (R2) ya que aún a baja concentración resultó tóxico a los M.O. Por eso, en esta segunda fase se emplearon lodos aclimatados en el laboratorio de la Fase I del Reactor 1 (R1- el control) y del Reactor 3 (R3adaptado a fenol). Algunos estudios han reportado mejores resultados usando lodo activado sin aclimatación para biodegradar solución pretratada [7], por eso en esta investigación se propone otro reactor ( $\mathrm{R} 0)$, para hacer comparación de eficiencias entre lodos adaptados y lodos sin adaptación, para degradar soluciones de 2,5-DCP pretratadas con ozono y con ozono-UV. El Reactor adicional se operó con lodos frescos de la PTAR, el Rosario, sin previa aclimatación.

Los bioensayos se llevaron a cabo en biorreactores con un volumen operacional de $400 \mathrm{~mL}$ con agitación magnética, equipados con difusores de aire, con un flujo continuo de aire entre 70-100 Lh-1 y MLSS inicial de 1500 mg/L (Tabla 4-4). Los biorreactores tuvieron un tiempo de retención hidráulica volumen $\left(\theta_{h}\right)$ variable (dependiendo de ciclos y de la muestra que se purga de cada reactor). Se analizó con pH, SST, DQO, IVL, VUO y estudios microbiológicos

Se emplearon quince biorreactores operando en semicontinuo. Seis de ellos con A1: solución pre-ozonada de 2,5-DCP en agua destilada con dilución (1:3): (R0A1, R1A1 R3A1) y A2: solución pre-ozonada de 2,5-DCP en agua residual con dilución (1:3): (R0A2, R1A2 R3A2). Otros tres biorreactores se alimentan con A3: solución pretratada de ozono-UV de 2,5-DCP en agua destilada con dilución (1:3): (R0A3, R1A3 y R3A3) y A4: solución pretratada de ozonoUV de 2,5-DCP en agua residual con dilución (1:3): (R0A4, R1A4, R3A4). Los otros tres biorreactores fueron los controles $(\mathrm{R} 0, \mathrm{R} 1, \mathrm{R} 3)$ y no se alimentaron con solución pretratada. Los biorreactores se muestran en la Figura 4-10. 
Tabla 4-4 Fase 2: Volumen a remover durante cada ciclo $(\mathrm{mL})$

\begin{tabular}{|c|c|c|c|c|c|c|c|c|}
\hline \multirow{2}{*}{$\begin{array}{c}\text { Solución } \\
\text { preozonizada }\end{array}$} & \multirow{2}{*}{ Reactor } & $\begin{array}{c}\text { Ciclo } \\
\text { I }\end{array}$ & $\begin{array}{c}\text { Ciclo } \\
\text { II }\end{array}$ & $\begin{array}{c}\text { Ciclo } \\
\text { III }\end{array}$ & $\begin{array}{l}\text { Ciclo } \\
\text { IV }\end{array}$ & $\begin{array}{c}\text { Ciclo } \\
\text { V }\end{array}$ & $\begin{array}{c}\text { Ciclo } \\
\text { VI }\end{array}$ & $\begin{array}{l}\text { Ciclo } \\
\text { VII }\end{array}$ \\
\hline & & 8 días & 5 días & 2 días & 2 días & 2 días & 2 días & 1 día \\
\hline \multirow{3}{*}{ CONTROL } & Ro & 50 & 80 & 200 & 200 & 200 & 200 & 400 \\
\hline & $\mathrm{R} 1$ & 50 & 80 & 200 & 200 & 200 & 200 & 400 \\
\hline & R3 & 50 & 80 & 200 & 200 & 200 & 200 & 400 \\
\hline \multirow{3}{*}{$\begin{array}{c}\text { OZONO } \\
\text { AGUA } \\
\text { DESTILADA }\end{array}$} & R0A1 & 50 & 80 & 200 & 200 & 200 & 200 & 400 \\
\hline & $\mathrm{R} 1 \mathrm{~A} 1$ & 50 & 80 & 200 & 200 & 200 & 200 & 400 \\
\hline & R3A1 & 50 & 80 & 200 & 200 & 200 & 200 & 400 \\
\hline \multirow{3}{*}{$\begin{array}{c}\text { OZONO } \\
\text { AGUA } \\
\text { RESIDUAL }\end{array}$} & R0A2 & 50 & 80 & 200 & 200 & 200 & 200 & 400 \\
\hline & $\mathrm{R} 1 \mathrm{~A} 2$ & 50 & 80 & 200 & 200 & 200 & 200 & 400 \\
\hline & R3A2 & 50 & 80 & 200 & 200 & 200 & 200 & 400 \\
\hline \multirow{3}{*}{$\begin{array}{c}\text { OZONO } \\
\text { AGUA } \\
\text { DESTILADA }\end{array}$} & R0A3 & 50 & 80 & 200 & 200 & 200 & 200 & 400 \\
\hline & R1A3 & 50 & 80 & 200 & 200 & 200 & 200 & 400 \\
\hline & R3A3 & 50 & 80 & 200 & 200 & 200 & 200 & 400 \\
\hline \multirow{3}{*}{$\begin{array}{l}\text { OZONO } \\
\text { AGUA } \\
\text { RESIDUAL }\end{array}$} & R0A4 & 50 & 80 & 200 & 200 & 200 & 200 & 400 \\
\hline & R1A4 & 50 & 80 & 200 & 200 & 200 & 200 & 400 \\
\hline & R3A4 & 50 & 80 & 200 & 200 & 200 & 200 & 400 \\
\hline
\end{tabular}




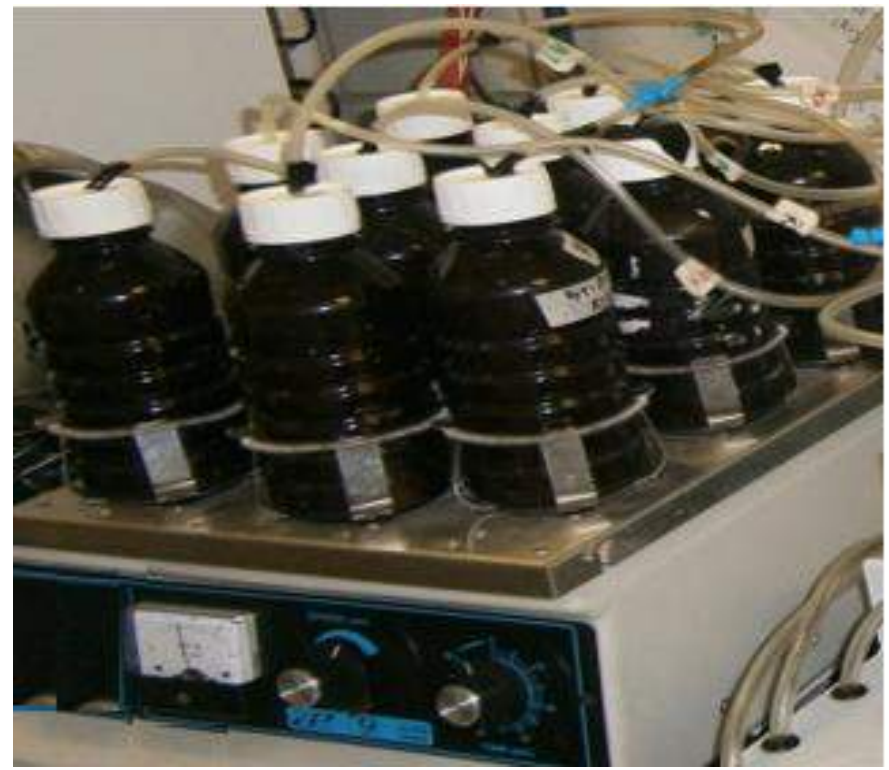

Figura 4-10 Reactores con agitación completa de Fase II

\subsubsection{Prueba de Biodegradabilidad con Unidad Husmann}

El presente método se utiliza para determinar la biodegradabilidad de soluciones pretratadas con ozono y ozono-UV por M.O. aerobios en un sistema de funcionamiento continuo de ensayo que simula el proceso de los lodos activados en una planta de tratamiento biológico. Las fuentes de carbono y de energía para los M.O. son materia orgánica fácilmente biodegradable y las soluciones pretratadas que son biodegradables. Se utiliza el procedimiento de las pruebas con unidades de Husmann descrito para la evaluación de biodegradabilidad por la OCDE 303 [20]. Además, la prueba sirve para medir la eficiencia de combinando el tratamiento oxidativo de ozono u ozono-UV con un proceso biológicos de lodos activados.

Los intercambios de lodos pueden transferir parte de la sustancia tóxica, dando la apariencia de una eliminación considerable. Las concentraciones de la sustancia tóxica en los efluentes de bioensayo y de control llegan a equilibrarse más. Por eso, es necesario utilizar factores de corrección, que dependen de la fracción intercambiada y del tiempo medio de retención hidráulica. Uniformizar la forma de escribir.

El porcentaje para corregir la eliminación de DQO utilizando la fórmula general se obtiene con la siguiente ecuación: 


$$
D_{t c}=\left(\frac{D_{t}-100 \times a \times r}{12}\right) /\left(\frac{1-a \times r}{12}\right) \%
$$

Donde:

$\mathrm{D}_{\mathrm{tc}}=$ porcentaje corregido de eliminación de DQO;

$D_{t}=$ porcentaje determinado de eliminación de DQO;

a = fracción intercambiada del volumen de las unidades de lodo activado;

$r \quad=\quad$ tiempo medio de retención hidráulica $(\mathrm{h})$.

$\mathrm{Si}$, por ejemplo, se intercambia la mitad del volumen del tanque de aireación $(\mathrm{a}=0.5)$ y el tiempo medio de retención hidráulica es de 6 h, la fórmula de corrección es la siguiente:

$$
\mathrm{D}_{\mathrm{tc}}=\frac{4 \mathrm{D}_{\mathrm{t}}-100}{3}
$$

Las pruebas se llevaron a cabo con seis unidades de Husman. Se alimentaron los biorreactores con solución pretratada o agua residual y solución nutritiva (se describe en la sección 4.4.1.1del método de las pruebas de respirometría). Se inocularon los biorreactores con lodos frescos de la PTAR El Rosario, con concentración inicial de $2.5 \mathrm{~g} / \mathrm{L}$.

Se operaron con una unidad (C1) como control que se alimentó con lodos activados, agua residual y solución nutritiva. Las otras unidades se operaron con soluciones pretratadas de ozono a 60 min y ozono-UV a 60 min. Los reactores R30A y R30B se operaron con soluciones de 2,5-DCP pretratada en agua destilada con ozono a $60 \mathrm{~min}$ y ozono-UV a $60 \mathrm{~min}$ respectivamente. Los reactores R31A y R31B se operaron con soluciones de 2,5-DCP pretratada en agua residual con ozono y ozono-UV a 60 min cada una. La Figura 4-11 y Figura 4-12 muestra el montaje de los biorreactores de unidades empleados en esta investigación. 


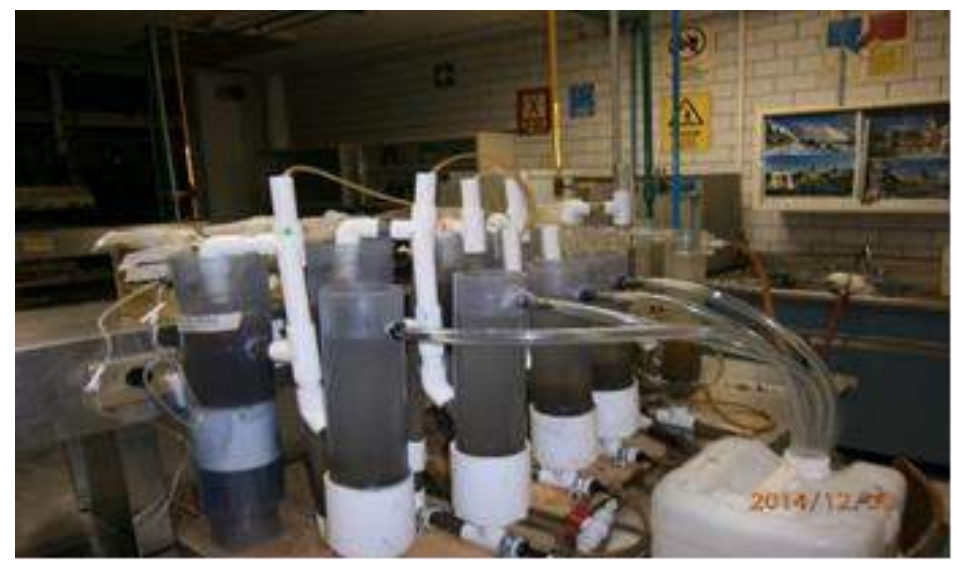

Figura 4-11 Reactores de unidades de Husmann adaptadas (Foto)

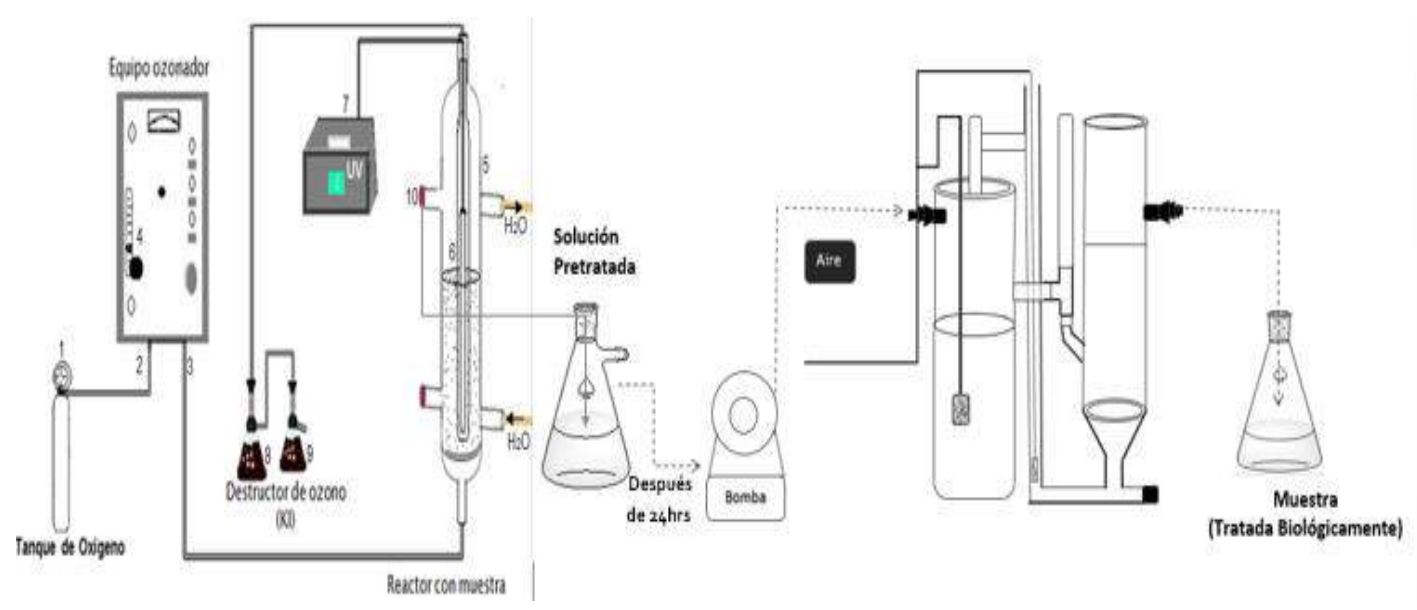

Figura 4-12 Esquema del diapositivo experimental de tratamiento POA combinado con un biorreactor tipo unidad de Husmann

\section{Biodegradabilidad}

La biodegradabilidad ha sido definida como la capacidad intrínseca de una sustancia a ser transformada en una estructura química más simple por vía microbiana. En el mismo sentido una sustancia es biodegradable cuando puede ser descompuesta con cierta rapidez por organismos vivientes (bacterias, hongos, gusanos e insectos), de los cuales los más importantes bacterias aerobias. Hay diferentes pruebas y métodos usaron para su determinación como se han descrito anterioriormente. 


\subsection{Reactivos}

Lista de los reactivos usados en el parte experimental:

AGUA: Agua de Millipore (Milli-Q Millipore system, con resistividad de $18 \mathrm{M} \Omega . \mathrm{cm}^{-1}$ ), Agua desionizada (UAM-A) y Agua destilada (Hycel). AIRE LIQUIDE: Oxígeno, $\mathrm{O}_{2}$ (>99.9). ALDRICH: 2,5-DCP, $\mathrm{C}_{6} \mathrm{H}_{4} \mathrm{Cl}_{2} \mathrm{O}$ (>98\%); Indigotrisulfonato de potasio, $\mathrm{C}_{16} \mathrm{H}_{7} \mathrm{~N}_{2} \mathrm{O}_{11} \mathrm{~S}_{3} \mathrm{~K}_{3}(75 \%)$ y N-Aliltiourea, $\mathrm{C}_{4} \mathrm{H}_{8} \mathrm{~N}_{2} \mathrm{~S}$ (98\%). HANNA: Disoluciones estándares de $\mathrm{pH}(4,7$ y 10). J.T.BAKER: Ácido clorhídrico, $\mathrm{HCl}\left(37 \%\right.$ pureza d=1.19 kg/L); Ácido malónico, $\mathrm{CH}_{2}(\mathrm{COOH})_{2}$. (99\%); Ácido salićlico, $\mathrm{C}_{7} \mathrm{H}_{6} \mathrm{O}_{3}$ (grado analítico); Cloruro de Sodio $\mathrm{NaCl}$ (99.5\%); Almidón soluble $\left(\mathrm{C}_{6} \mathrm{H}_{10} \mathrm{O}_{5}\right)_{6}$ (grado analítico); Cloruro de Amonio, $\mathrm{NH}_{4} \mathrm{Cl}(99.5 \%)$; D+ Glucosa, $\mathrm{C}_{6} \mathrm{H}_{12} \mathrm{O}_{6}$ (grado analítico); Dicromato de potasio, $\mathrm{K}_{2} \mathrm{Cr}_{2} \mathrm{O}_{7}(99 \%)$; Fosfato diácido de potásio, $\mathrm{KH}_{2} \mathrm{PO}_{4}$ (99\%); Fosfato diácido de sodio, $\mathrm{NaH}_{2} \mathrm{PO}_{4} \cdot \mathrm{H}_{2} \mathrm{O}(99 \%)$; Fosfato monoácido de potásio, $\mathrm{K}_{2} \mathrm{HPO}_{4}$ (99\%); Fosfato monoácido de sodio, $\mathrm{Na}_{2} \mathrm{HPO}_{4} .7 \mathrm{H}_{2} \mathrm{O}$ (98\%); Glicerina, $\mathrm{C}_{2} \mathrm{H}_{5} \mathrm{NO}_{2}$ (99.5\%); Hidróxido de Potasio, $\mathrm{KOH}$ (85\%); Hidróxido de Sodio, $\mathrm{NaOH}(98 \%)$; Sulfatoférrico, $\mathrm{Fe}_{2}\left(\mathrm{SO}_{4}\right)_{3}$ (73\%); L- Ácido glutámico, $\mathrm{C}_{5} \mathrm{H}_{9} \mathrm{NO}_{4}$ (grado analítico); Permanganato de Potasio, $\mathrm{KMnO}_{4}$ (99\%); Sulfato de Magnesio, $\mathrm{MgSO}_{4} .7 \mathrm{H}_{2} \mathrm{O}$ (99\%); Sulfato de Mercurio, $\mathrm{HgSO}_{4}$ (99\%); Sulfato de plata, $\mathrm{Ag}_{2} \mathrm{SO}_{4}$ (99.5\%); Sulfato de Sodio, $\mathrm{Na}_{2} \mathrm{SO}_{4}$ (99\%); Sulfito de Sodio, $\mathrm{Na}_{2} \mathrm{SO}_{3}$ (95\%); Yoduro de Potasio, KI (99\%); Yoduro de Sodio, $\mathrm{Nal}$, (99\%) y Tisulfato de Sodio, $\mathrm{Na}_{2} \mathrm{~S}_{2} \mathrm{O}_{3}$ (98\%). MERCK: 1,10 fenantrolina monohidrato (grado analítico); Ácido Sulfúrico, $\mathrm{H}_{2} \mathrm{SO}_{4}$ (98\%) y Acetonitrilo, $\mathrm{CH}_{3} \mathrm{CN}$ (99.8\%, grado isocrático por HPLC). PANREAC: Cloruro de Calcio $\mathrm{CaCl}_{2}$ (95\%) y Sulfato ferroso, $\mathrm{Fe}_{2} \mathrm{SO}_{4} .7 \mathrm{H}_{2} \mathrm{O}$ (98\%). PROBUS: Ácido fosfórico, $\mathrm{H}_{3} \mathrm{PO}_{4}$ (85\%); Cloruro férrico, $\mathrm{FeCl}_{3} .6 \mathrm{H}_{2} \mathrm{O}(98 \%)$ y Monohidrógeno ftalato potásico, $\mathrm{C}_{6} \mathrm{H}_{5} \mathrm{O}_{4} \mathrm{~K}(99.9 \%)$. 


\section{CAPÍTULO 4. METODOLOGÍA}

\subsection{Diseño de Experimentos}

La comparación entre los tratamientos en las soluciones (S1: con agua destilada y S2: con agua residual) para cada variable se realizó en forma completamente aleatoria con tres repeticiones por cada tratamiento, considerando como tal tres tratamientos de la solución 2,5DCP. El control será las soluciones de 2,5-DCP sin tratamiento de POA. Los otros dos

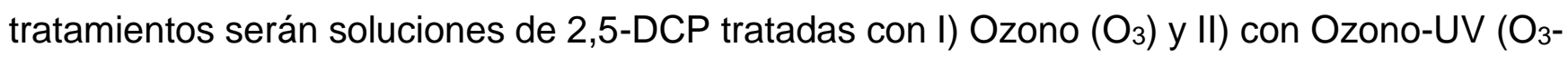
UV) por un tiempo de los 60 minutos. Se midió la biodegradabilidad del 2,5-DCP como la relación entre $\mathrm{DBO}_{5} / \mathrm{DQO}$ de los resultados obtenidos de las pruebas en solución (S1: con agua destilada y $\mathrm{S} 2$ : con agua residual).

Variable de Respuesta: son la medida $\mathrm{DBO}_{5}, \mathrm{DQO}$ en $\mathrm{mgO}_{2} / \mathrm{L}$ y la relación entre $\mathrm{DBO}_{5} / \mathrm{DQO}$.

Variable Control: es el tratamiento de 2,5-DCP sin aplicación de POAs, se considera como tratamiento a tiempo de 0 minutos.

Variables Independientes: son la dosis de ozono aplicado en los tratamientos (aproximadamente $22 \mathrm{mg} / \mathrm{min}$ ) con o sin luz UV y el 2,5-DCP

Variables Constantes: son la temperatura ambiental, temperatura de la solución, el pH inicial y la concentración inicial de las soluciones de 2,5-DCP en S1: con agua destilada y en S2: con agua residual.

Para probar la hipótesis se realizó el Análisis de variancia (ANADEVA) y la Prueba t en Microsoft Office Excel. 
[1] J. C. Alexander, «Estudio de Biodegradabilidad de 2,5-DCP después del tratamiento con los procesos de oxidación avanzada de ozono y radiación ultravioleta,» Universidad Autonoma Metropolitana-Azcapotzalco, Mexico, D.F., 22 de Noviembre de 2012.

[2] M. Goel, J. Chovelon, C. Ferronato y T. Sreekrishnan, «The remediation of wastewater containing 4-chlorophenol using integrated photocatalytic and biological treatment.,» $\mathrm{J}$. Photochem Photobiol B., 98, 1-6, 2010.

[3] L. Ioannou, G. Li Puma y D. Fatta-Kassinos, «Treatment of winery wastewater by physicochemical, biological and advanced processes: A review,» J. Hazard. Mat., 286, 343-368, 2015.

[4] E. Gilbert, "Chemical changes and reaction products in ozonization of organic water constituents,» de Oxidation techniques in drinking water treatment, Karlsruhe, Federal Republic of Germany, 1978.

[5] J. Wohlers, I. Koh, T. Wolfram y R. Wolfgang, «Application of air ionization device using an atmospheric pressure corona discharge process for water purification,» J. Water Air Soil Poll, 196, 101-114, 2009.

[6] T. Poznyak, R. Tapia, J. Vivero y I. Chairez, «Effect of $\mathrm{pH}$ to the decomposition of aqueous phenosl mixture by ozone,» J. Mex. Chem. Soc., 50, 28-35, 2006.

[7] S. Contreras, M. Rodríguez, F. Al-Momani, C. Sans y S. Esplugas, "Contribution of the ozonation pre-treatment to the biodegradation of aqueous solutions of 2,4-diclorophenol,» Water Res., 37, 3164-3171, 2003.

[8] APHA, AWWA y WEF, Standard Methods for the Examination of Water and Wastewater, 21st ed., Washington, D.C: America Public Health Association, 2005.

[9] OECD, «OECD Guideline for Testing of Chemicals "Activated Sludge, Respiration Inhibition Test (Carbon and Ammonium Oxidation)".,» 2010.

[10] Y. Yoshioka, H. Nagase, Y. Ose y T. Sato, «Evaluation of the Test Method "Activated Sludge, Respiration Inhibition Test" Proposed by the OECD,» Ecotox. Environ. Safe., 12, 206-212, 1986.

[11] ISO8192, «International Organization for Standarization. Water quality-Test for inhibition of oxygen consumption by activated sludge for carbonaceous and ammonium oxidation,» 2007.

[12] R. M. Ramírez-Gama, B. Luna Millán, O. Velázquez Madrazo, G. Tsuzuki Reyes, L. Vierna García, L. Hernández Gómez y I. Müggenburg, Manual de Prácticas de Microbiología General, 3ero Ed. ed., R. M. R. Gama, Ed., Laboratorio de Microbiologia Experimental, Facultad de Quimica, UNAM, 1996.

[13] Biomérieux, «Manual-Identification system for Enterobacteriaceae and other nonfastidious Gram-negative rods API 20 e,» Biomérieux S. A., France, 2002.

[14] Biomérieux, "Manual API 20 NE- Identification system for non-fastidious, non-enteric Gram-negative rods,» Biomérieux S. A., 2003.

[15] C. Gottschalk, J. A. Libra y A. Saupe, Ozonation of water and wastewater: A practical Guide to Understanding Ozone and its Application, Wiley-VCH, 2000, pp. 104-106. 


\section{CAPÍTULO 4. METODOLOGÍA}

[16] R. Ramalho, «Teoría y práctica de la aireación en tratamientos de aguas residuales,» de ratamiento de Aguas Residuales, 2 ed. ed., 08029 Barcelona, Editorial Reverté, S.A., 1990, pp. 199-252.

[17] D. Azbel, Two-phase flows in chemical engineering., Cambridge University Press, 1981.

[18] R. F. Dantas, S. Contrearas, C. Sans y S. Esplugas, "Abatement of 4-Chlorophenol in Aqueous Phase by Ozonation Coupled with a sequencing Batch Biofilm Reactor (SBBR), 》 Ozone Sci. Eng., 30, 447-455, 2008.

[19] D. Orbon, F. Germirli Babuna y K. Ozlem, «Sequencing batch reactor technology,» de Industrial Wastewater Treatment by Activated Sludge, London, UK, IWA Publishing, 2009, pp. 257-301.

[20] OECD, «OECD Guideline for teh Testing of Chemicals, Simulation Test - Aerobic Sewage Treatment: Activated Sludge Units, Guideline 303A,» 2001.

[21] F. Al Momani, S. C. y S. Esplugas, "A comparative study of the advanced oxidation of 2,4-dichlorophenol,» J. Hazard. Mat. B, 107, 123 -129, 2004. 


\section{Capítulo 5. RESULTADOS Y DISCUSIÓN}

Los experimentos para las pruebas de oxidación del 2,5-DCP con ozono se llevaron a cabo en un reactor de vidrio de $3 \mathrm{~L}$, equipado con una placa de vidrio poroso en la base del reactor para la aplicación del ozono. Para el proceso de ozono-UV se empleó una lámpara de UV con una longitud de onda 254 nm, como se describe en la sección 0.

Se estudió la oxidación de 2,5-DCP con ozono y ozono-UV a pH neutro para observar el efecto sobre la degradación, biodegradación y mineralización del DCP. La degradación de 2,5-DCP formó nuevos compuestos intermediarios, los cuales fueron identificados por cromatografía de HPLC y GC-MS. La toxicidad de los compuestos intermedios se evaluó con pruebas de inhibición de la respiración de lodos activados. Asimismo, se calcularon las constantes cinéticas de primer orden y los tiempos de vida media ( $\left.t_{1 / 2}\right)$ del 2,5-DCP en los diferentes tratamientos oxidativos.

Este capítulo está dividido en cinco temas:

* Transferencia de Masa del reactor,

* Pretratamiento con procesos de Oxidación avanzada,

* Estudio cinético y Mecanismos de reacción de la oxidación del 2,5-DCP,

* Pruebas de Toxicidad y

* Procesos biológicos con lodos activados. 


\section{CAPÍTULO 5. RESULTADOS Y DISCUSIÓN}

\subsection{Transferencia de Masa en el Reactor}

\subsubsection{Determinación indirecta del coeficiente volumétrico de transferencia de ozono}

En esta investigación el experimento de la transferencia de masa se realizó en un reactor de columna de burbujas, con un diámetro de $0.085 \mathrm{~m}$ y altura de $0.58 \mathrm{~m}$. La generación de burbujas se llevó a cabo usando difusores, con poros de $100 \mu \mathrm{m}$. Se pasó un flujo de oxígeno de 0.5 a $0.7 \mathrm{~L} / \mathrm{min}$ en el líquido, con volumen de $1.5 \mathrm{~L}$, y se midió el oxígeno disuelto con un medidor de oxígeno disuelto de HANNA HI 2400 cada 2- 5 segundos hasta su saturación en el agua. Los datos de los ensayos se presentan en el anexo en la Tabla A-0-1 y Tabla A-0-2. Las gráficas (5-1 a 5-4) muestran los diferentes ensayos utilizados para calcular los coeficientes volumétricos de transferencia de oxígeno en diversos tipos de agua: potable, desionizada y residual, y los cálculos del coeficiente de transferencia de ozono en el reactor con el método indirecto.

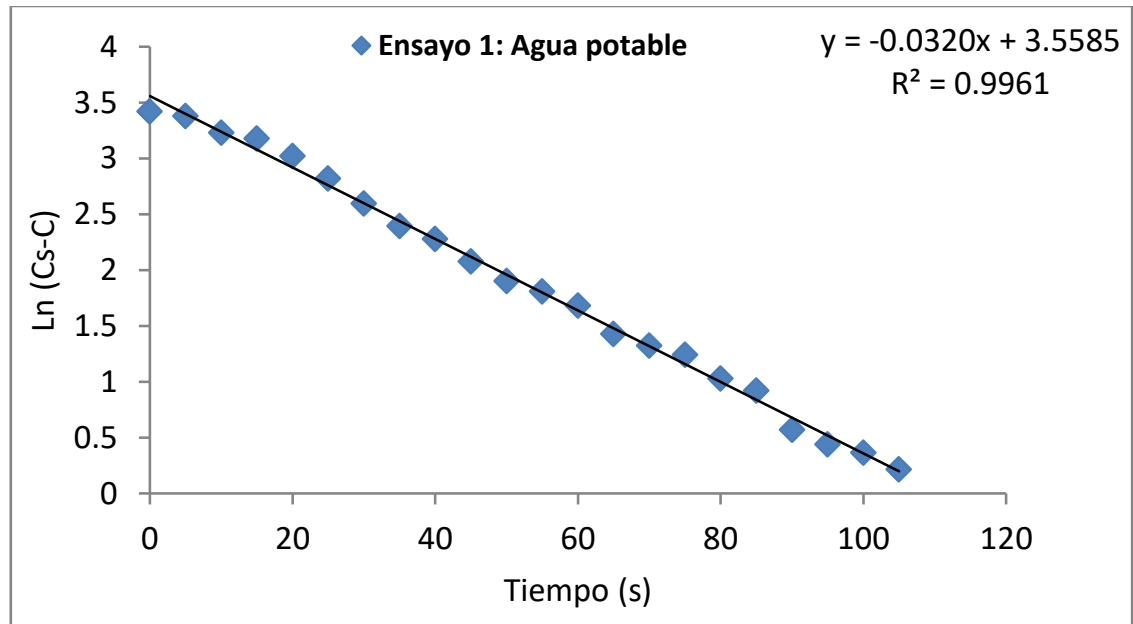

Gráfica 5-1 K $\mathrm{L}$ a del oxígeno en agua potable a $25^{\circ} \mathrm{C}$ en una columna de burbuja con un flujo de oxígeno puro de $0.652 \mathrm{~L} / \mathrm{min}$ 
CAPÍTULO 5. RESULTADOS Y DISCUSIÓN

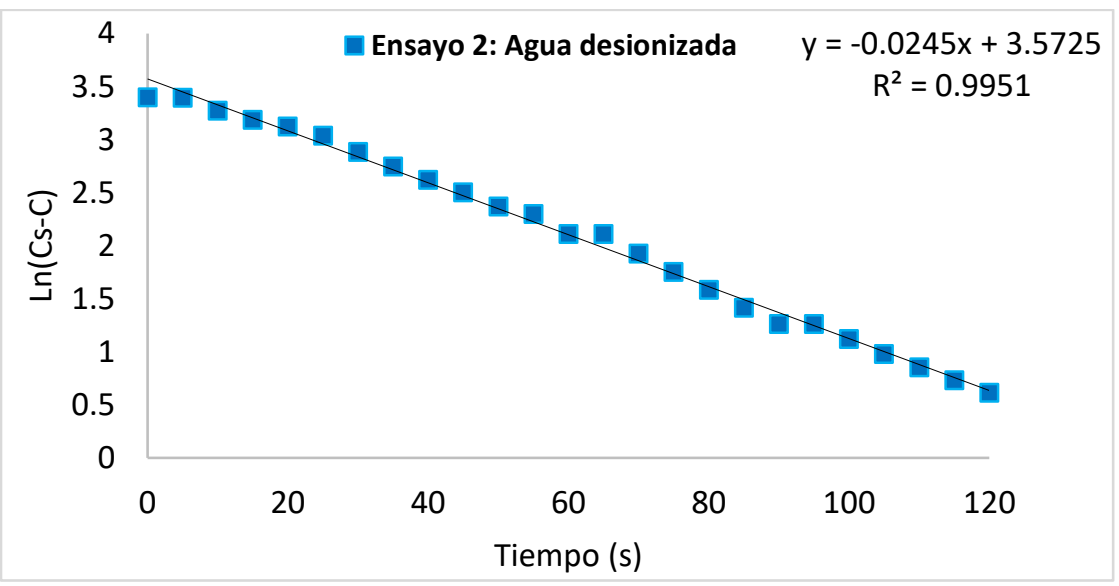

Gráfica 5-2 KLa del oxígeno en agua desionizada a $20^{\circ} \mathrm{C}$ en una columna de burbuja con un flujo de oxígeno puro de $0.5589 \mathrm{~L} / \mathrm{min}$

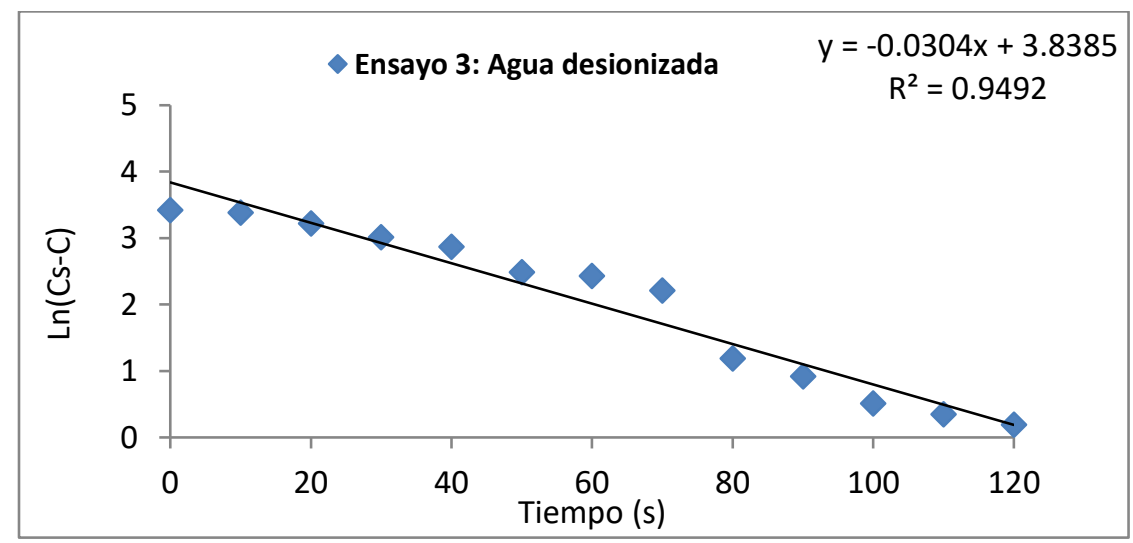

Gráfica 5-3 $\mathrm{K} \mathrm{L}$ a del oxígeno en agua desionizada a $20^{\circ} \mathrm{C}$ en una columna de burbuja con un flujo de oxígeno puro de $0.606 \mathrm{~L} / \mathrm{min}$

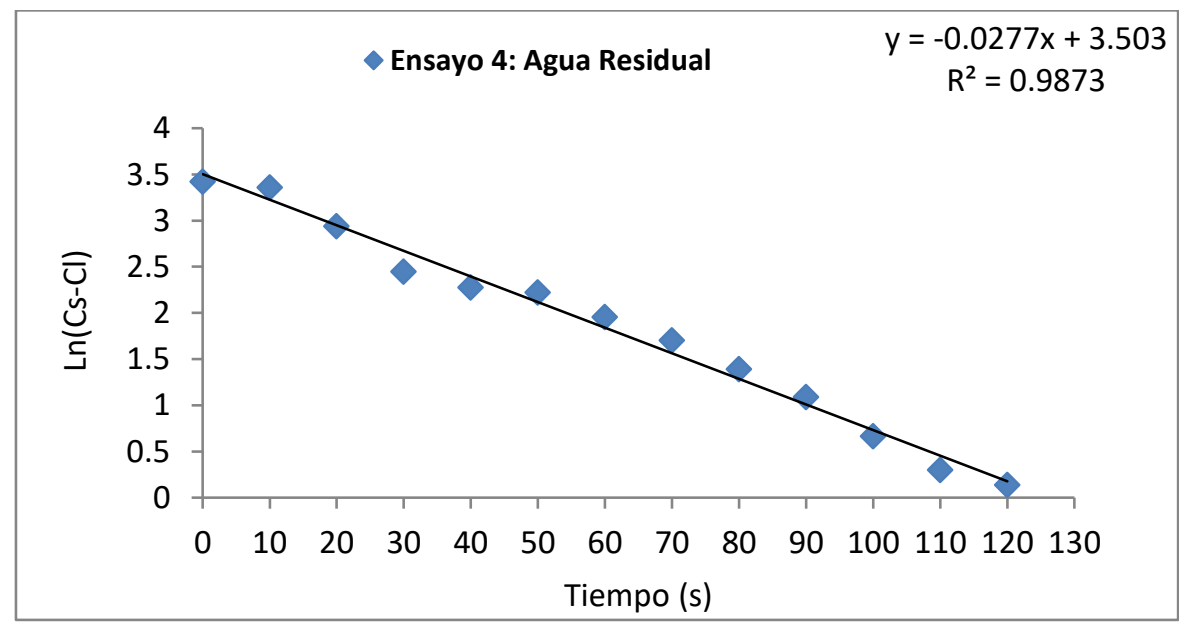

Gráfica 5-4 $\mathrm{K}$ La del oxígeno en agua residual a $20^{\circ} \mathrm{C}$ en una columna de burbuja con un flujo de oxígeno puro de $0.606 \mathrm{~L} / \mathrm{min}$ 


\section{CAPÍTULO 5. RESULTADOS Y DISCUSIÓN}

\subsubsection{Cálculos del coeficiente de transferencia gas/líquido}

El cálculo del coeficiente de transferencia de masa de oxígeno, kıa, se calculó aparte de la ecuación diferencial [1]:

$$
\frac{d C}{d t}=k_{L} a\left(C_{s}-C\right)
$$

Ecuación 5-1

Donde $\mathrm{C}$ es la concentración $(\mathrm{mg} / \mathrm{L}), \mathrm{C}_{i}$ es la concentración inicial $(\mathrm{mg} / \mathrm{L})$ y $\mathrm{C}_{\mathrm{s}}$ es la concentración de saturación de Oxígeno Disuelto (mg/L) en el ensayo.

Dando:

$$
\operatorname{Ln}(C s-C)=\operatorname{Ln}\left(C_{s}-C_{i}\right)-k_{L} a . t
$$

Ecuación 5-2

El kLa del oxígeno se determinó por la pendiente de la ecuación lineal Ln (Cs-C) contra tiempo (t) en segundos (ec.5-2).

Las pendientes de las Gráfica 5-1 a 5-4 dan el valor negativo del coeficiente de oxígeno en el agua $-k_{L} a_{O_{2}}$. Después, se calcula el coeficiente de transferencia de masa de ozono $\left(k_{L} a_{O_{3}}\right)$ por el método indirecto, usando el coeficiente de transferencia de masa de oxígeno $\left(k_{L} a_{O_{2}}\right)$ y una relación de los coeficientes de difusión a una Temperatura de $20^{\circ} \mathrm{C}$ (ec. 5-3). Se hicieron cuatro ensayos y los resultados se muestran en la Tabla 5-1.

$$
k_{L} a_{O_{3}}\left(s^{-1}\right)=\left(\frac{D_{O_{3}}}{D_{O_{2}}}\right)^{n} \cdot k_{L} a_{O_{2}}=0.622 \cdot k_{L} a_{O_{2}}
$$

Ecuación 5-3

Para el ensayo 1 se aplicaó el factor de corrección del valor de $\mathrm{k}\left\llcorner a, \mathrm{O}_{3}\right.$, por la diferencia de temperatura con la siguiente ecuación (ec. 5-4) [2]:

$$
k_{L} a_{T}=\frac{k_{L} a_{20}}{\Theta^{(20-T)}}
$$

Ecuación 5-4

Donde el factor de corrección de la temperatura $\Theta$ es 1.024, para el ensayo 1 (ec. 5-5):

$$
k_{L} a_{25}, O_{3}=\frac{0.038 s^{-1}}{1.024^{(20-25)}}=0.0429 s^{-1}
$$

Retención de gas (ec. 5-6): 


$$
\varepsilon_{G}=\frac{h_{T}-h_{o}}{h_{T}}
$$

Ecuación 5-6

Altura del líquido con aireación ( $\left.h_{T}\right)$ y Altura del líquido sin aireación (ho)
Área de base:
$\left(A_{b}\right)=\frac{\pi \mathrm{D}^{2}}{4}$
Ecuación 5-7

Se calculó la retención de gas, como $\theta$ con la ecuación de Azbel (1981):

$$
\boldsymbol{\theta}=\frac{\mathbf{v}_{\mathrm{g}}}{\mathrm{V}_{\mathrm{g}}+\mathrm{V}_{\mathbf{L}}}
$$

Ecuación 5-8

Donde:

Volumen de gas:

$$
V_{g}=A_{b} \times \Delta h-h o
$$

Ecuación 5-9

Volumen de líquido:

$$
V_{L}=A_{b} \times h_{0}
$$

Ecuación 5-10

Para calcular el coeficiente de transferencia, KL, se usó el método descrito por Azbel (1981), en el cual se hizo el cálculo con la siguiente ecuación por el sistema Aire $\left(\mathrm{O}_{2}\right)$ - agua con sulfito de sodio $\left(\mathrm{Na}_{2} \mathrm{SO}_{3}\right)$ usando como catalizador cloruro de cobalto $\left(\mathrm{CoCl}_{2}\right)$ [3]:

$$
\mathrm{k}_{\mathrm{L}} \mathrm{O}_{2}=1.22 \mathrm{~h}^{1.13}(\theta / 1-\theta)^{0.19}
$$

Y se calculó la presión, h, con datos de la caída de presión de la entrada y salida del reactor (usando un manómetro diferencial en $U$ con mercurio):

$$
\mathbf{h}(\mathrm{cm} \mathrm{de} \mathrm{Hg})=\frac{\Delta P}{\rho g}
$$

a $20^{\circ} \mathrm{C}$ Densidad de mercurio $(\rho \mathrm{Hg})=13.560 \mathrm{~g} / \mathrm{cm}^{3}$

El factor de corrección de temperatura $=1+0.00018(20-25)=1.009$

Y por eso a $25{ }^{\circ} \mathrm{C} \rho \mathrm{Hg}=13.560 / 1.009=13.547 \mathrm{~g} / \mathrm{cm}^{3}$ 


\section{CAPÍTULO 5. RESULTADOS Y DISCUSIÓN}

Gravedad $(\mathrm{g})=980 \mathrm{~cm} / \mathrm{s}$

Cambio de presión $(\Delta \mathrm{P}) \frac{\mathrm{cm}}{\mathrm{Hg}}$

$$
k_{\mathrm{LO}_{3}}=\left(\frac{1.26 \times 10^{-9} \frac{m^{2}}{s}}{2.025 \times 10^{-9} \frac{m^{2}}{s}}\right)^{n} \times\left(k_{L} O_{2}\right)
$$

Ecuación 5-13

Se calculó el valor de la velocidad de ascenso de las burbujas de gas (ub) con la ecuación de Deckwer (citado por Rollbusch y col. [4]):

$$
\boldsymbol{u}_{b}(\mathbf{m} / \mathbf{s})=\frac{u_{g}}{\varepsilon_{g}}
$$

Ecuación 5-14

Asimismo, se calculó la velocidad superficial del gas $\left(u_{g}\right)$ por la ecuación [3]:

$$
\mathbf{u}_{\mathbf{g}}\left(\frac{m}{s}\right)=\frac{Q_{g}}{A}
$$

Ecuación 5-15

Se calculóel diámetro promedio sauter, db, desde la siguiente ecuación [5]:

$$
\mathbf{d}_{\mathbf{b}}(\mathbf{m})=\frac{6 \varepsilon_{G}}{a\left(1-\varepsilon_{G}\right)}
$$

Ecuación 5-16

Se calculó el área interfacial (a) con la siguiente ecuación [5]:

$$
a\left(m^{-1}\right)=\frac{k_{L} a}{k_{L}}
$$

El factor de corrección, a para estimar el KLa real del sistema se calculó con la ecuación:

$$
\begin{gathered}
\alpha=\mathrm{K} L \mathrm{a}(\text { agua residual) } \div \mathrm{K}\llcorner\mathrm{a} \text { (agua desionizada) } \\
\alpha=0.91
\end{gathered}
$$

Ecuación 5-18

El valor de a fue de 0.91 con agua desionizada, los dos valores están dentro del rango dado por Metcalf y Eddy [6] donde los valores de a varían de 0.3 a 1.2 . 
CAPÍTULO 5. RESULTADOS Y DISCUSIÓN

Tabla 5-1 Resultados de la transferencia de oxígeno y de ozono en el reactor

\begin{tabular}{|c|c|c|c|c|}
\hline Parámetro & Ensayo 1 & Ensayo 2 & Ensayo 3 & Ensayo 4 \\
\hline Tipo de agua & Potable & Desionizada & Desionizada & Residual \\
\hline$Q_{g}\left(m^{3} / s\right)$ & $1.087 \mathrm{E}-05$ & 9.317E-06 & $1.01 \mathrm{E}-05$ & $1.01 \mathrm{E}-05$ \\
\hline $\mathbf{T}\left({ }^{\circ} \mathrm{C}\right)$ & 25 & 20 & 20 & 20 \\
\hline$D_{c}(m)$ & 0.085 & 0.085 & 0.085 & 0.085 \\
\hline$h_{0}(m)$ & 0.26 & 0.26 & 0.26 & 0.26 \\
\hline$H / D$ & 3.06 & 3.06 & 3.06 & 3.06 \\
\hline$d_{0}(m)$ & 0.0001 & 0.0001 & 0.0001 & 0.0001 \\
\hline$A\left(m^{2}\right)$ & 0.0056745 & 0.0056745 & 0.0056745 & 0.0056745 \\
\hline$h_{T}(m)$ & 0.2645 & 0.263 & 0.264 & 0.264 \\
\hline$\Delta \mathbf{P}_{\mathrm{m}}(\mathbf{c m H g})$ & 21 & 21 & 21 & 19 \\
\hline$\Delta_{\mathrm{h}-\mathrm{ho}}(\mathrm{m})$ & 0.0045 & 0.003 & 0.004 & 0.004 \\
\hline $\mathrm{Do3}_{\left(\mathrm{m}^{2} / \mathrm{s}\right)}$ & 1.26E-09 & $1.26 \mathrm{E}-09$ & 1.26E-09 & $1.26 \mathrm{E}-09$ \\
\hline $\mathrm{Do}_{2}\left(\mathrm{~m}^{2} / \mathrm{s}\right)$ & 2.025E-09 & 2.025E-09 & 2.025E-09 & 2.025E-09 \\
\hline$k\left\llcorner a, O_{2}\left(s^{-1}\right)\right.$ & 0.032 & 0.0245 & 0.0304 & 0.0277 \\
\hline $\mathrm{kLa}, \mathrm{O}_{3}\left(\mathbf{s}^{-1}\right)$ & 0.019904 & 0.0152444 & 0.01891556 & 0.01723556 \\
\hline $\mathbf{N}$ & 1 & 1 & 1 & 1 \\
\hline h (cm de $\mathrm{Hg})$ & 0.0015803 & 0.0015803 & 0.00158028 & 0.00142978 \\
\hline$\varepsilon_{G}$ & 0.017013 & 0.011407 & 0.015152 & 0.015152 \\
\hline $\operatorname{kLO2}\left(\mathrm{s}^{-1}\right)$ & 0.0003857 & 0.0003571 & 0.00037712 & 0.00033679 \\
\hline $\mathrm{kLO}_{3}\left(\mathrm{~s}^{-1}\right)$ & 0.00024 & 0.0002222 & 0.00023465 & 0.00020956 \\
\hline$V_{g}\left(m^{3}\right)$ & $2.554 \mathrm{E}-05$ & $1.702 \mathrm{E}-05$ & $2.2698 \mathrm{E}-05$ & $2.2698 \mathrm{E}-05$ \\
\hline$V_{L}\left(m^{3}\right)$ & 0.001475 & 0.001475 & 0.001475 & 0.001475 \\
\hline$\theta$ & 0.017013 & 0.011407 & 0.015152 & 0.015152 \\
\hline$u_{g}(m / s)$ & 0.001915 & 0.001642 & 0.001780 & 0.001780 \\
\hline$u_{b}(m / s)$ & 0.1125594 & 0.1439353 & 0.11747287 & 0.11747287 \\
\hline$d_{b}(m)$ & $1.25 \mathrm{E}-03$ & 1.01E-03 & $1.15 \mathrm{E}-03$ & $1.12 \mathrm{E}-03$ \\
\hline$a\left(m^{-1}\right)$ & 82.976635 & 68.616611 & 80.6117598 & 82.2471432 \\
\hline
\end{tabular}




\section{CAPÍTULO 5. RESULTADOS Y DISCUSIÓN}

\subsubsection{Discusión sobre la transferencia gas/líquido}

El coeficiente de transferencia de masa volumétrica, kıa, es importante para comparar con los resultados de diferentes investigadores. Además para el diseño de una columna de burbuja a mayor escala, la retención de gas, $\varepsilon$ G, y otras características de la transferencia de masa son importantes.

La relación $H / D$ de una columna de burbuja puede afectar las características de transferencia de masa, por eso en esta investigación se ha calculado esta relación. El reactor de columna de burbuja que se usó en este trabajo tiene una relación $H / D$ de aproximadamente 3 y un diámetro de 0.085 . Estos valores son menores de los valores reportados $(H / D$ de 5 y diámetro mínimo de $0.15 \mathrm{~m}$ ) que se necesitan para evitar el efecto de pared sobre la retención de gas por otros autores [4]. Además, una relación de H/D entre 2 a 5 es usada normalmente en los procesos bioquímicos para trabajos experimentales.

En este estudio se obtuvieron valores de la velocidad superficial del gas, $u_{g}$, entre 0.16 a 0.19 $\mathrm{cm} / \mathrm{s}$. De acuerdo con el mapa del flujo de régimen por columnas de burbujas citado del Kantarci [7] y los valores obtenidos, se considera que todos los ensayos en este estudio estuvieron operando en régimen de flujo de burbujas homogéneo. Por otra parte, otros autores han reportado que las burbujas se empiezan a unir a una velocidad superficial del gas, $u_{g}$ de aproximadamente $2 \mathrm{~cm} / \mathrm{s}$, mientras que la transición hacia un flujo heterogéneo se ocurre a ug entre 4 a $5 \mathrm{~cm} / \mathrm{s}[8]$.

En los experimentos de la transferencia de masa de la columna de burbujas, se observó la formación de burbujas más esféricas, pequeñas y uniformes en el agua residual que en el agua desionizada, al mismo flujo de gas y a la misma temperatura. Además con el aumento del flujo de gas en los experimentos con el agua de llave y agua desionizada, se observó que las burbujas fueron más grandes y elipsoides en tamaño al comparar con las burbujas en el agua residual, se reportaron similares resultados en la literatura [5].

Hay un desacuerdo entre autores sobre del comportamiento del coeficiente de transferencia de masa en fase líquida, k k. Algunos creen que el kı se aumenta con el aumento de la temperatura debido a la menor viscosidad, como el modelo de velocidad de deslizamiento 


\section{CAPÍTULO 5. RESULTADOS Y DISCUSIÓN}

(slip velocity) por Calderbank, mientras otros autores creen que el kL, se disminuye con el aumento de la temperatura debido a la menor tensión superficial y turbulencia. Por lo tanto, la transferencia de masa en fase líquida, kı podría aumentar y disminuir según un equilibrio entre las dos fuerzas a medida que aumenta la temperatura [8]. En los experimentos se observó un pequeño aumento del kL con el aumento de la temperatura de 20 a $25^{\circ} \mathrm{C}$ y también con el aumento de la velocidad superficial de gas, similar a la literatura.

Por otra parte, no se observó un cambio entre la retención de gas en agua desionizada y en agua residual, al mismo flujo y a la misma temperatura, lo cual confirmó que el aumento del área interfacial, a, es debido a la formación de las burbujas más pequeñas [9]. Según los resultados de los experimentos el valor de kıa del agua residual fue más bajo que el valor obtenido del agua desionizada al mismo flujo, debido a la presencia de los sólidos suspendidos en el agua residual.

En general, hay gran variación entre los resultados obtenidos y los diferentes parámetros de la literatura, esto es debido a la variación de las ecuaciones para calcular los parámetros de la transferencia de masa. Los valores obtenidos en este estudio pueden ser un poco más altos a bajos de los reportados por otros autores [10], según las ecuaciones usadas para el cálculo de los parámetros, en la literatura algunos valores de k L para una columna de burbuja son de 0.01 y $0.05 \mathrm{~cm} / \mathrm{s}$. También, depende del tamaño de burbuja, $d \mathrm{~b}$, se obtuvieron valores de $\mathrm{k}$ L de $0.005 \mathrm{~cm} / \mathrm{s}$ y de $0.03 \mathrm{~cm} / \mathrm{s}$ para un db menor a $2 \mathrm{~mm}$ y db mayor a $2.5 \mathrm{~mm}$ respectivamente. Pero en general, el comportamiento de los parámetros de este estudio fue similar a lo reportado en la literatura $[4,5,7,9,11,12]$.

\subsection{Procesos de Oxidación Avanzada con Ozono y Radiación UV}

En la Tabla 5-2 se presentan los detalles de operación de los procesos de oxidación con ozono y ozono-UV, del 2,5-DCP en agua destilada (S1) y en agua residual (S2). 
Tabla 5-2 Características de los Sistemas de POA

\begin{tabular}{|c|c|c|c|}
\hline \multirow{2}{*}{\multicolumn{2}{|c|}{ CARACTERÍSTICAS }} & \multicolumn{2}{|c|}{ 2,5-DCP en solución } \\
\hline & & S1: con agua destilada & S2: con agua residual \\
\hline \multirow{16}{*}{$\begin{array}{l}\text { CONDICIONES } \\
\text { EXPERIMENTALES }\end{array}$} & Tipo de reactor & $\begin{array}{c}\text { Batch } \\
\text { sin recirculación }\end{array}$ & $\begin{array}{c}\text { Batch } \\
\text { sin recirculación }\end{array}$ \\
\hline & Tamaño de reactor & $\begin{aligned} H & =0.58 \mathrm{~m} \\
\mathrm{I} . \mathrm{D} & =0.085 \mathrm{~m}\end{aligned}$ & $\begin{aligned} H & =0.58 \mathrm{~m} \\
\mathrm{I} . \mathrm{D} & =0.085 \mathrm{~m}\end{aligned}$ \\
\hline & Marca de 2,5-DCP & ALDRICH (> 98\%) & ALDRICH (> 98\%) \\
\hline & Concentración (2,5-DCP) & 500 mg/L (3.07mM) & $500 \mathrm{mg} / \mathrm{L}(3.07 \mathrm{mM})$ \\
\hline & pH iniciales & 7 & 7 \\
\hline & Volumen Inicial & $1.5 \mathrm{~L}$ & $1.5 \mathrm{~L}$ \\
\hline & Tipo de Oxígeno & $\mathrm{O}_{2}$ puro & $\mathrm{O}_{2}$ puro \\
\hline & Tipo de difusores & $\begin{array}{l}\text { difusores de vidrio } \\
\text { poroso de burbuja fina; } \\
(\mathrm{D}=100 \mu \mathrm{m})\end{array}$ & $\begin{array}{l}\text { difusores de vidrio } \\
\text { poroso de burbuja fina; } \\
(D=100 \mu \mathrm{m})\end{array}$ \\
\hline & Entrada de $\mathrm{O}_{3}$ al reactor & Por abajo & Por abajo \\
\hline & \begin{tabular}{|c} 
Dosis de Ozono Aplicada \\
en fase gas
\end{tabular} & Aprox. $20 \mathrm{mg} / \mathrm{min}$ & Aprox. $20 \mathrm{mg} / \mathrm{min}$ \\
\hline & $\begin{array}{l}\text { Flujo del gas } \\
\text { (Promedio) }\end{array}$ & $0.7 \mathrm{~L} / \mathrm{min}$ & $0.7 \mathrm{~L} / \mathrm{min}$ \\
\hline & Medidor de $\mathrm{O}_{3}$ & Manual (KI) & Manual (KI) \\
\hline & $\begin{array}{c}\text { Irradiación de lámpara UV } \\
\text { (distancia de } 2.54 \mathrm{~cm} \text { ) }\end{array}$ & $4 \mathrm{~mW} / \mathrm{cm}^{2}$ & $4 \mathrm{~mW} / \mathrm{cm}^{2}$ \\
\hline & Presión (aprox.) & 14.9 psi & 14.9 psi \\
\hline & Temperatura de reacción & Ambiental $\left(20-25^{\circ} \mathrm{C}\right)$ & Ambiental $\left(20-25^{\circ} \mathrm{C}\right)$ \\
\hline & Tiempo de reacción & $60 \mathrm{~min}$ & $60 \mathrm{~min}$ \\
\hline \multirow{7}{*}{$\begin{array}{l}\text { PARÁMETROS } \\
\text { MEDIDOS }\end{array}$} & $\mathrm{DQO}(\mathrm{mg} / \mathrm{L})$ & \begin{tabular}{|l|l|} 
Técnica de reflujo \\
cerrado, colorimétrico
\end{tabular} & $\begin{array}{l}\text { Técnica de reflujo } \\
\text { cerrado, colorimétrico }\end{array}$ \\
\hline & $\mathrm{DBO}_{5}(\mathrm{mg} / \mathrm{L})$ & $\begin{array}{l}\text { Método Winkler, } \\
\text { Método Respirométrico }\end{array}$ & $\begin{array}{l}\text { Método Winkler, } \\
\text { Método Respirométrico }\end{array}$ \\
\hline & Espectro de absorción & $\begin{array}{l}\text { Barrido completo de } \\
200-800 \mathrm{~nm}\end{array}$ & $\begin{array}{l}\text { Barrido completo de } \\
200-800 \mathrm{~nm}\end{array}$ \\
\hline & COT (mg/L) & \begin{tabular}{|c|}
$\begin{array}{c}\text { Detección de combustión } \\
\text { de infrarrojos }\end{array}$ \\
\end{tabular} & $\begin{array}{c}\text { Detección de combustión } \\
\text { de infrarrojos }\end{array}$ \\
\hline & 2,5-DCP (mg/L) & Por HPLC y GC-MS & Por HPLC y GC-MS \\
\hline & $\mathrm{pH}$ finales & $\begin{array}{l}\text { La actividad de iones de } \\
\text { hidrógeno }\end{array}$ & $\begin{array}{c}\text { la actividad de iones de } \\
\text { hidrógeno }\end{array}$ \\
\hline & $\begin{array}{l}\text { Toxicidad } \\
\text { (mg/L) }\end{array}$ & $\begin{array}{c}\text { Pruebas de RI } \\
\text { (Lodos Activados) }\end{array}$ & $\begin{array}{l}\text { Pruebas de RI } \\
\text { (Lodos Activados }\end{array}$ \\
\hline
\end{tabular}




\subsubsection{Análisis del agua residual}

\section{Características del agua residual sin tratamiento}

Se realizaron análisis fisicoquímicos al agua residual en las diversas pruebas realizadas y los resultados promedio se presentan en la Tabla 5-3, la temperatura varió entre $22 \pm 7^{\circ} \mathrm{C}$.

Tabla 5-3 Características Fisicoquímicas del Agua residual

\begin{tabular}{|l|r|r|}
\hline \multicolumn{1}{|c|}{ Parámetros } & \multicolumn{1}{c|}{ Valores } & Desviación estándar $( \pm \mathrm{sD})$ \\
\hline $\mathrm{pH}$ & 7.69 & 0.11 \\
\hline Solidos Suspendidos Totales, SST $(\mathrm{mg} / \mathrm{L})$ & 130 & 51.3 \\
\hline $\mathrm{COT}(\mathrm{mg} / \mathrm{L})$ & 115 & 21.8 \\
\hline $\mathrm{DBO}_{5}(\mathrm{mg} / \mathrm{L})$ & 198 & 11.0 \\
\hline $\mathrm{DQO}(\mathrm{mg} / \mathrm{L})$ & 250 & 30 \\
\hline Nitratos $\left(\mathrm{NO}^{-3}-\mathrm{N}\right)(\mathrm{mg} / \mathrm{L})$ & 10 & 2.1 \\
\hline Fosfatos $\left(\mathrm{PO}_{4}{ }^{-}\right)(\mathrm{mg} / \mathrm{L})$ & 6 & 2.0 \\
\hline Conductividad eléctrica $(\mu \mathrm{s} / \mathrm{cm})$ & 1048 & 16.1 \\
\hline Sólidos Disueltos Totales $(\mathrm{SDT})(\mathrm{mg} / \mathrm{L})$ & 548 & 7.0 \\
\hline Alcalinidad $(\mathrm{como} \mathrm{mg/L} \mathrm{de} \mathrm{CaCO} 3)$ & 90 & 5.3 \\
\hline Cloruros $(\mathrm{Cl})(\mathrm{mg} / \mathrm{L})$ & 30 & 5.0 \\
\hline
\end{tabular}

\section{Comportamiento del pH en el agua residual con tratamiento de ozonización}

A continuación se muestran en las tablas 5-4 y 5-5, el cambio del pH y la dosis de Ozono (aplicada, consumida y que no reacciona) del agua residual tratada con ozono a dos flujos de gas $(0.51 \mathrm{~L} / \mathrm{min}$ y $0.73 \mathrm{~L} / \mathrm{min})$. La dosis de ozono para el flujo de gas de $0.7 \mathrm{~L} / \mathrm{min}$ fue de 27.3 $\mathrm{mg} \mathrm{O} / 3 \mathrm{~min}$, y la dosis de ozono para el flujo de gas de $0.5 \mathrm{~L} / \mathrm{min}$ fue de $15.64 \mathrm{mg} \mathrm{O} / / \mathrm{min}$. En la gráfica 5.5 se muestra la variación del pH en función del tiempo de ozonación en min.

Tabla 5-4 Resultados de Agua residual tratada con ozonización con 0.5 L/min

\begin{tabular}{|r|r|r|r|r|r|}
\hline $\begin{array}{c}\mathbf{T} \\
(\mathbf{m i n})\end{array}$ & $\begin{array}{c}\text { Cambios de } \\
\mathbf{p H}\end{array}$ & $\begin{array}{c}\text { Dosis de } \mathbf{O}_{3} \\
\mathbf{m g} / \mathbf{m i n}\end{array}$ & $\begin{array}{c}\text { Dosis de } \mathbf{O}_{3} \\
\text { aplicada } \\
(\mathbf{m g})\end{array}$ & $\begin{array}{c}\text { Dosis de } \mathbf{O}_{3} \text { que } \\
\text { no Reacciona (mg) }\end{array}$ & $\begin{array}{c}\text { Dosis de } \mathbf{O}_{3} \\
\text { consumido (mg) }\end{array}$ \\
\hline 0 & 7.69 & 0 & 0 & 0 & 0 \\
\hline 5 & 8.67 & 1.152 & 78.2 & 5.76 & 72.44 \\
\hline 10 & 8.63 & 1.68 & 156.4 & 8.4 & 148 \\
\hline 15 & 8.65 & 2.688 & 234.6 & 13.44 & 221.16 \\
\hline 20 & 8.65 & 2.736 & 312.8 & 13.68 & 299.12 \\
\hline 30 & 8.65 & 3.072 & 469.2 & 30.72 & 438.48 \\
\hline
\end{tabular}

Tabla 5-5 Resultados de Agua residual tratada con ozonización con $0.7 \mathrm{~L} / \mathrm{min}$ 
CAPÍTULO 5. RESULTADOS Y DISCUSIÓN

\begin{tabular}{|c|c|c|c|c|c|}
\hline$T(\min )$ & Cambios de pH & $\begin{array}{c}\text { Dosis de } \mathrm{O}_{3} \\
\mathrm{mg} / \mathrm{min}\end{array}$ & $\begin{array}{l}\text { Dosis de } \mathrm{O}_{3} \\
\text { aplicada } \\
\text { (mg) }\end{array}$ & $\begin{array}{c}\text { Dosis de } \mathrm{O}_{3} \\
\text { no } \\
\text { Reacciona } \\
\text { (mg) }\end{array}$ & $\begin{array}{c}\text { Dosis de } \mathrm{O}_{3} \\
\text { consumido } \\
(\mathrm{mg})\end{array}$ \\
\hline 0 & 7.69 & 0 & 0 & 0 & 0 \\
\hline 2 & 8.1 & 0 & 31.28 & 0 & 31.28 \\
\hline 4 & 8.38 & 6 & 62.56 & 12 & 50.56 \\
\hline 6 & 8.55 & 6.6 & 93.84 & 13.2 & 80.64 \\
\hline 10 & 8.69 & 4.8 & 156.4 & 19.2 & 137.2 \\
\hline 15 & 8.77 & 5.76 & 234.6 & 28.8 & 205.8 \\
\hline 25 & 8.79 & 6.96 & 391 & 69.6 & 321.4 \\
\hline
\end{tabular}

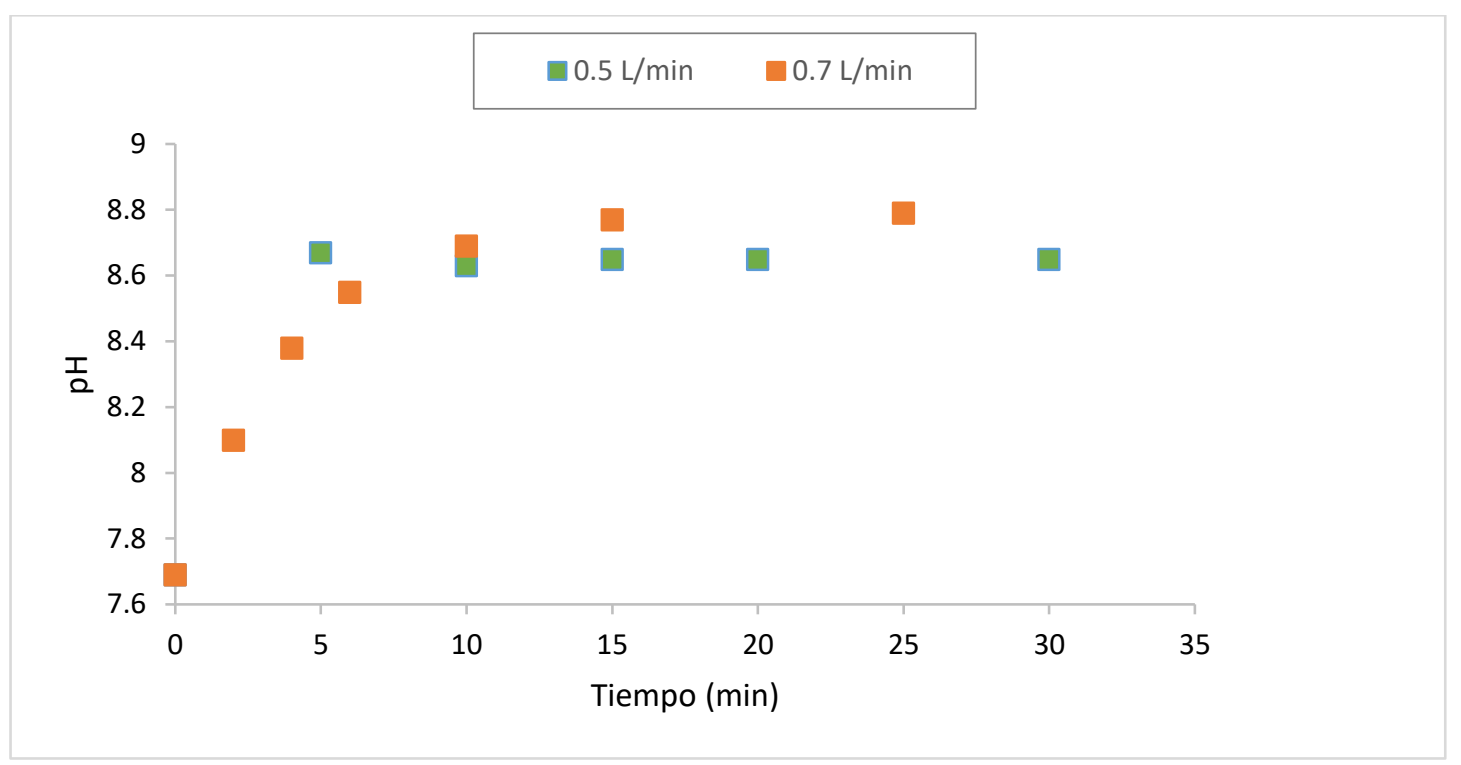

Gráfica 5-5 Cambios en pH durante la ozonación de agua residual con dos flujos

\subsubsection{Discusión sobre el cambio de pH durante la ozonación de agua residual}

Se nota un ligero aumento en los valores del pH a causa de la ozonización de agua residual con 0.5 y $0.7 \mathrm{~L} / \mathrm{min}$. Esto es probablemente el efecto del dióxido de carbono al ser expulsado de la solución por la alimentación de gas de ozono por los difusores [13] o por la presencia de sustancias presentes en el agua residual que pueden aumentar la alcalinidad de la solución. 


\subsubsection{Resultados de las pruebas de oxidación con agua residual}

Para evaluar la eficiencia de la oxidación de ozonación se midieron los porcentajes de remoción de DQO en muestras de agua residual a diferentes tiempos de oxidación, se muestran los resultados en la Tabla 5-6. En esta sección del trabajo se describen los resultados obtenidos de las pruebas de la DQO para los dos flujos de agua residual para encontrar la demanda de ozono.

Tabla 5-6 Resultados de la DQO del agua residual con tratamiento de oxidación de Ozonación a dos flujos durante 30 minutos

\begin{tabular}{|r|c|c|c|c|c|}
\hline \multirow{2}{*}{ Muestra } & \multirow{2}{*}{$\begin{array}{c}\text { Tiempo de } \\
\text { ozonación }\end{array}$} & \multicolumn{2}{|c|}{ Flujo 0.5 L/min } & \multicolumn{2}{c|}{ Flujo 0.7 L/min } \\
\cline { 3 - 6 } & & $\begin{array}{c}\text { DQO +/- sD } \\
(\mathbf{m g} / \mathbf{L})\end{array}$ & $\begin{array}{c}\text { DQO } \\
\text { Eliminada } \\
(\%)\end{array}$ & $\begin{array}{c}\text { DQO +/- sD } \\
(\mathbf{m g} / \mathbf{L})\end{array}$ & $\begin{array}{c}\text { DQO } \\
\text { Eliminada } \\
(\%)\end{array}$ \\
\hline 1 & 0 & $250 \pm 30$ & 0 & $250 \pm 30$ & 0 \\
\hline 2 & 2 & - & - & $78 \pm 6$ & $38 \%$ \\
\hline 3 & 4 & - & - & $95 \pm 4$ & $44 \%$ \\
\hline 4 & 5 & $85 \pm 10$ & $34 \%$ & - & - \\
\hline 5 & 6 & - & - & $109 \pm 5$ & - \\
\hline 6 & 10 & $103 \pm 4$ & $41 \%$ & $179 \pm 3$ & $72 \%$ \\
\hline 7 & 15 & $112 \pm 4$ & $45 \%$ & $207 \pm 8$ & $83 \%$ \\
\hline 8 & 20 & $131 \pm 31$ & $52 \%$ & - & - \\
\hline 9 & 25 & - & - & $231 \pm 10$ & $92 \%$ \\
\hline 10 & 30 & $183 \pm 10$ & $73 \%$ & - & - \\
\hline
\end{tabular}

\subsubsection{Discusión sobre la remoción de la DQO durante la ozonación del agua residual}

En la Tabla 5-6 se observó que con el aumento del tiempo de ozonación se incrementó la remoción de la DQO. Esto es debido a la oxidación de la materia orgánica en el agua residual transformándose a una nueva sustancia. Por otra parte hubo un cambio de color de agua residual de amarillo ligero a transparente después de 15 minutos del tratamiento con ozonación.

Los resultados obtenidos de la ozonación del agua residual se usaron para compensar la DQO de la materia orgánica presente en el agua residual, en las pruebas de 2,5-DCP en agua 


\section{CAPÍTULO 5. RESULTADOS Y DISCUSIÓN}

residual. Al principio se dieron 15 minutos adicionales al tiempo de oxidación de las pruebas de oxidación de la solución 2,5-DCP en agua residual. Sin embargo, se observó que los resultados obtenidos a los 60 minutos con agua residual eran mejores que los obtenidos con agua destilada. Se hicieron las demás pruebas a 60 minutos, como en el caso del agua destilada.

\subsubsection{Pruebas de oxidación del 2,5-DCP}

\subsubsection{Variación del color durante las pruebas de oxidación del 2,5-DCP}

Las observaciones visuales del cambio de color de la solución de 2,5-DCP durante los tratamientos de ozonación y ozono-UV para los dos tipos de soluciones (S1 y S2), se describen a continuación (Figuras 5-1 a 5-4).

\section{Tratamiento con $\mathrm{O}_{3}$}

La solución acuosa del 2,5-DCP en agua destilada, $\mathrm{S} 1$, a pH 7 fue inicialmente incolora pero al poco tiempo después de iniciada la ozonación se notó el cambio del color a un amarillo oscuro y luego disminuyó la intensidad del color a un amarillo transparente. Similares resultados con DCPs fueron observados por Qiu, y col. en 2004 [19]. Sin embargo, en la solución acuosa de 2,5-DCP con agua residual, S2, a pH 7 se formó mucha espuma (que puede ser un inconveniente) y se intensificó el color a un ámbar, a partir de los 20 minutos se detuvo la formación de espuma y disminuyó la intensidad del color a más pálido.

En laFigura 5-1 y Figura 5-2 se muestran los cambios del color desde 0 a 60 minutos de ozonación del 2,5-DCP en una solución de agua destilada y en agua residual respectivamente. 


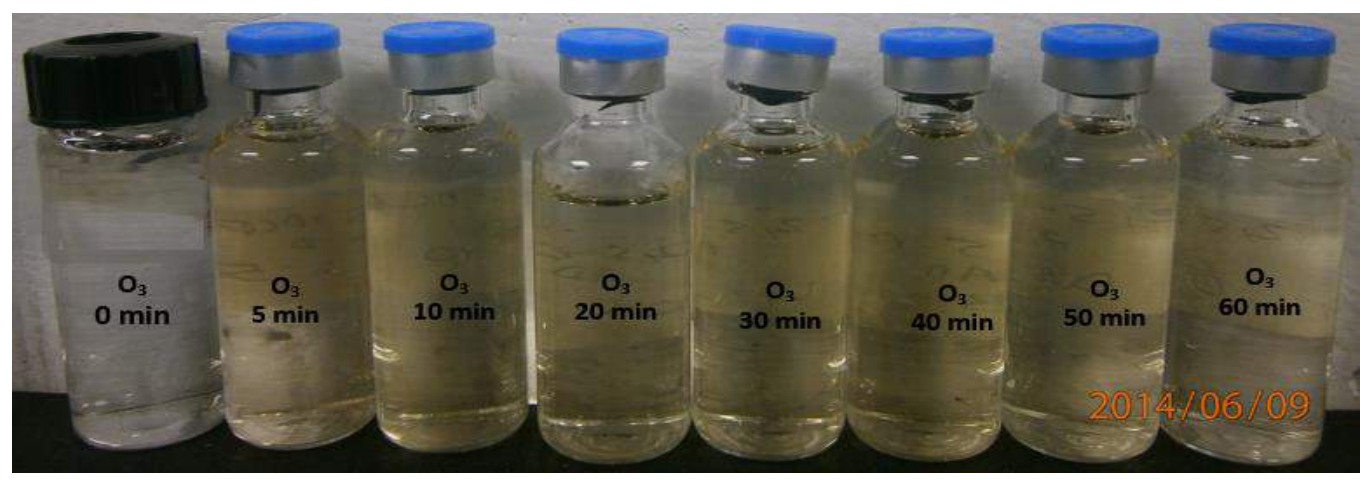

Figura 5-1 Cambios del color durante la ozonación del 2,5-DCP en agua destilada.

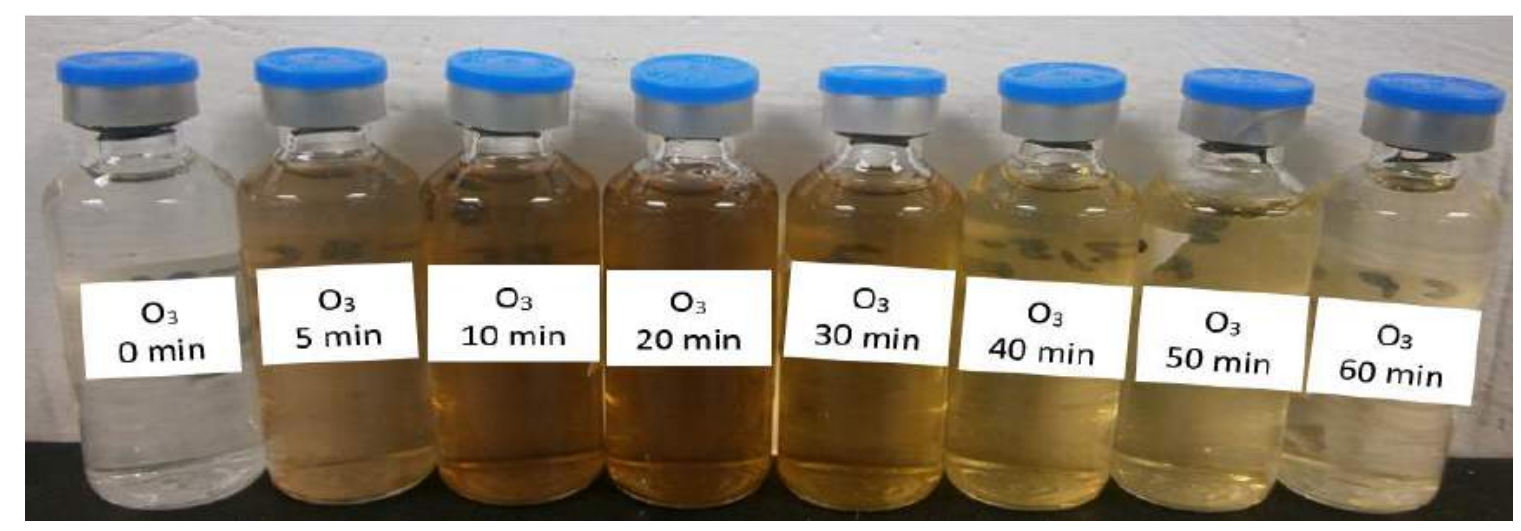

Figura 5-2 Cambios del color durante la ozonación del 2,5-DCP en agua residual

\section{Tratamiento con $\mathrm{O}_{3}-\mathrm{UV}$}

La solución acuosa de 2,5-DCP en agua destilada, $\mathrm{S} 1$, a pH 7 fue inicialmente incolora pero al poco tiempo después de iniciada la ozonación con la radiación UV se formó espuma y cambió el color a un amarillo oscuro y a partir de los 15 minutos se detuvo la formación de espuma y disminuyó la intensidad del color a un amarillo transparente. En el caso de la solución 2,5-DCP en S2: con agua residual a pH 7 fue inicialmente incolora pero al poco tiempo después de iniciada la ozonación con la radiación UV se formó mucha espuma y la solución cambió de color a un café oscuro y se siguió intensificando el color hasta los primeros 10 minutos y a partir de los 20 minutos se detuvo la formación de espuma y disminuyó la intensidad del color de café a un amarillo transparente. En la Figura 5-3 y Figura 5-4 se muestran los cambios del color desde el inicio (0 minutos) hasta 60 minutos de ozonación de 2,5-DCP en una solución de agua destilada y en agua residual respectivamente. 


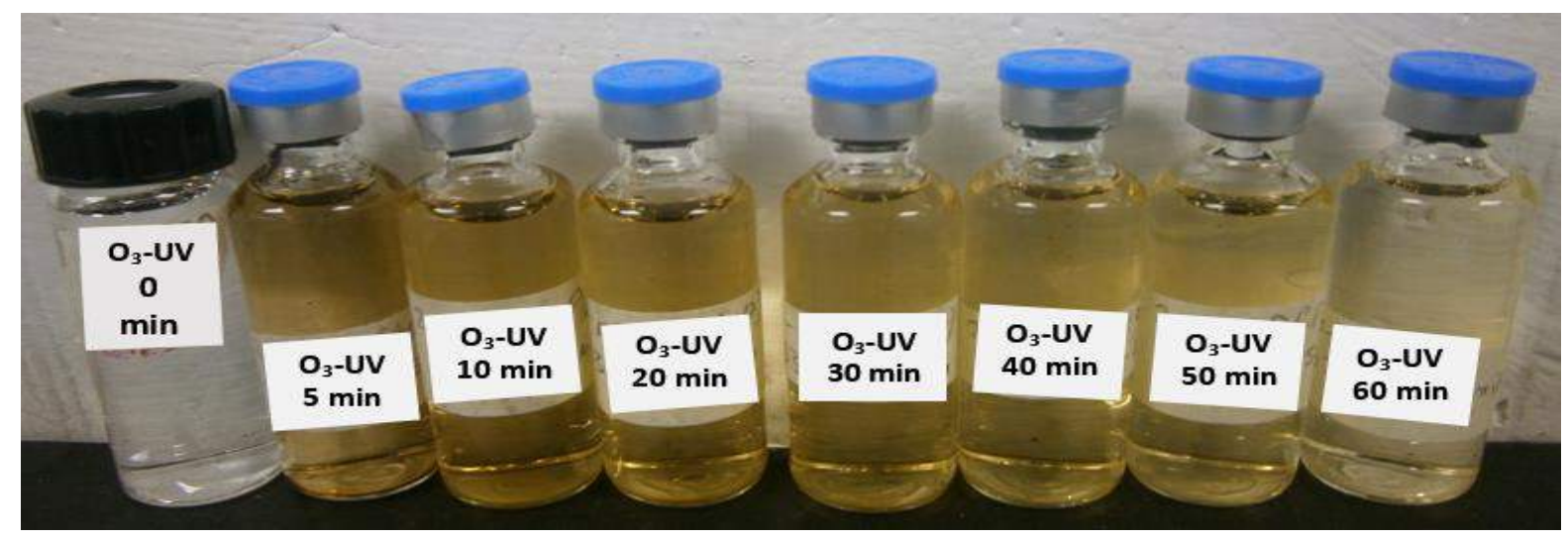

Figura 5-3 Cambios del color durante la ozono-UV del 2,5-DCP en agua destilada.

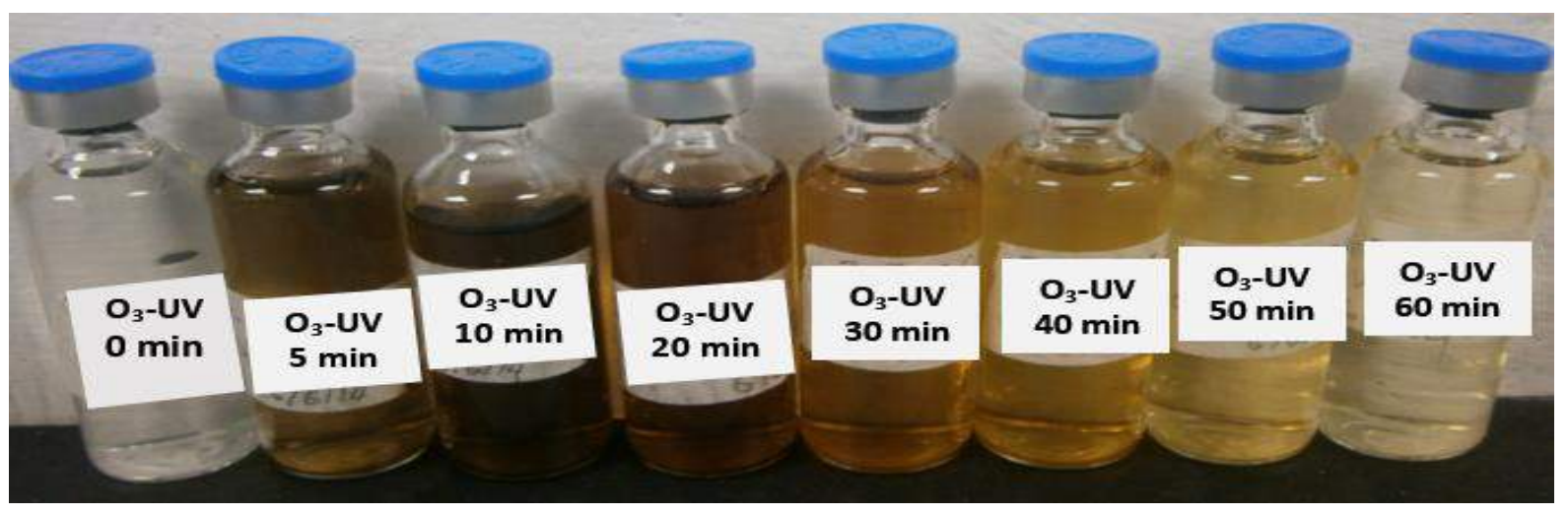

Figura 5-4 Cambios del color durante la ozono-UV del 2,5-DCP en agua residual

\subsubsection{Discusión sobre la variación del color durante los procesos de oxidación}

En las figuras 5-1 a Figura 5-4 se observaron los cambios de color de las soluciones inicialmente incoloras a un amarillo oscuro, a café y luego a un amarillo transparente. Estos cambios del color son debidos a la degradación del 2,5-DCP (una solución incolora) para formar nuevos productos intermedios coloreados o productos con alta absorbancia de luz [14], como son algunas quinonas y aldehídos, mientras que con más tiempo de ozonación las soluciones oxidadas disminuyeron el color y finalmente fueron incoloras, esto ocurre al aumentar la dosis de ozono. Las soluciones de agua residual tuvieron mayor intensidad del color, esto fue debido a que tuvieron mayor concentración de los productos con alta absorbancia de luz en sus soluciones en comparación con las soluciones del agua destilada. La presencia en solución de quinonas, aldehídos y ácidos orgánicos como productos intermedios de la oxidación del DCP ya ha sido reportado [14-16]. 


\section{CAPÍTULO 5. RESULTADOS Y DISCUSIÓN}

\subsubsection{Cambios del pH durante la oxidación del 2,5-DCP}

En la Gráfica 5-6 y Gráfica 5-7 se presentan los resultados de la variación del pH en función

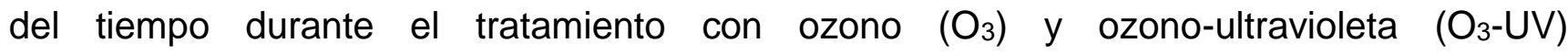
respectivamente, de 2,5-DCP en una solución de agua destilada y en agua residual. Los experimentos se llevaron a cabo a pH neutro $(\mathrm{pH} 7)$ ajustados con hidróxido de sodio al inicio de la oxidación.

Tratamiento con $\mathrm{O}_{3}$. Los resultados de la variación del pH en las dos soluciones de 2,5-DCP estudiados (agua destilada y agua residual) se presentan en la Gráfica 5-6. Al inicio de la oxidación se observó un ligero aumento de pH en la solución de 2,5-DCP en agua residual y al final de la oxidación disminuyeron los valores de $\mathrm{pH}$ iniciales. La mayor disminución de los valores de $\mathrm{pH}$ iniciales se observaron durante los tratamientos de 2,5-DCP en agua destilada. Durante el tratamiento con ozono de las soluciones acuosas de 2,5-DCP en agua destilada y en agua residual se observó que disminuyeron los valores de $\mathrm{pH}$ iniciales de 7.07 a 2.28 y 3.01 respectivamente.

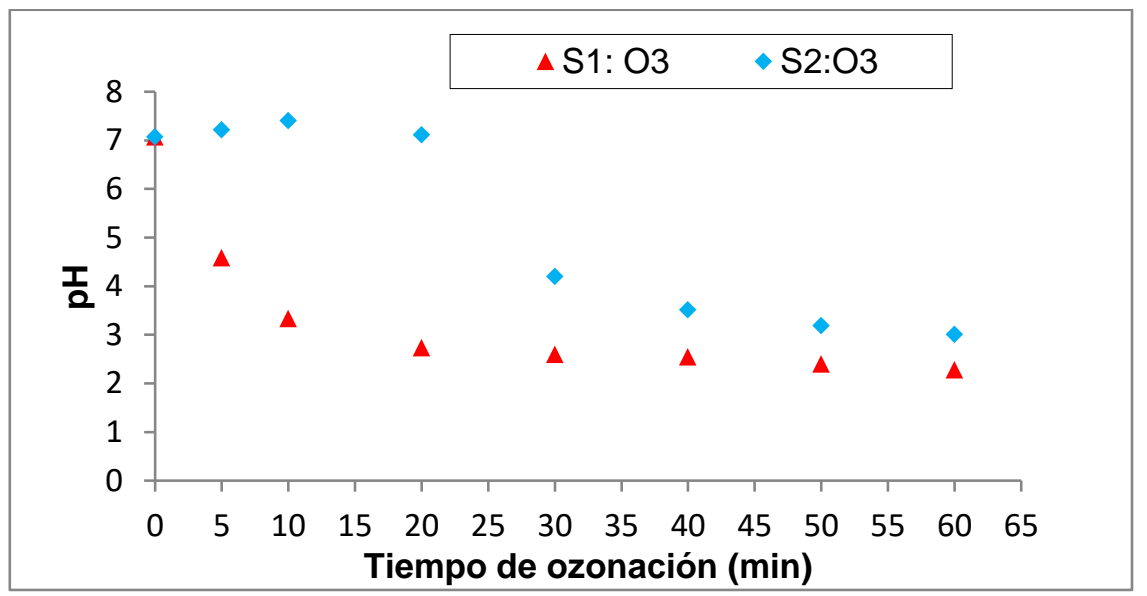

Gráfica 5-6 Cambio del pH durante tratamiento con ozonación de soluciones acuosas de 2,5-DCP en agua destilada $\left(\mathrm{S} 1: \mathrm{O}_{3}\right)$ y en agua residual $\left(\mathrm{S} 2: \mathrm{O}_{3}\right)$

Tratamiento con $\mathrm{O}_{3}$-UV. En la Gráfica 5-7 se presentan los cambios del pH a lo largo de tiempo de las soluciones $\mathrm{S} 1$ : con agua destilada y $\mathrm{S} 2$ : con agua residual con tratamientos de $\mathrm{O}_{3}-\mathrm{UV}$. Al inicio de la oxidación con $\mathrm{O}_{3}-\mathrm{UV}$ se observó también un ligero aumento de $\mathrm{pH}$ en la solución de 2,5-DCP en agua residual, como en el caso del tratamiento con ozono, y al final 


\section{CAPÍTULO 5. RESULTADOS Y DISCUSIÓN}

de la oxidación disminuyeron los valores de $\mathrm{pH}$ iniciales en las soluciones acuosas de 2,5DCP en agua destilada y en agua residual de 7.07 a 2.15 y 2.95 respectivamente.

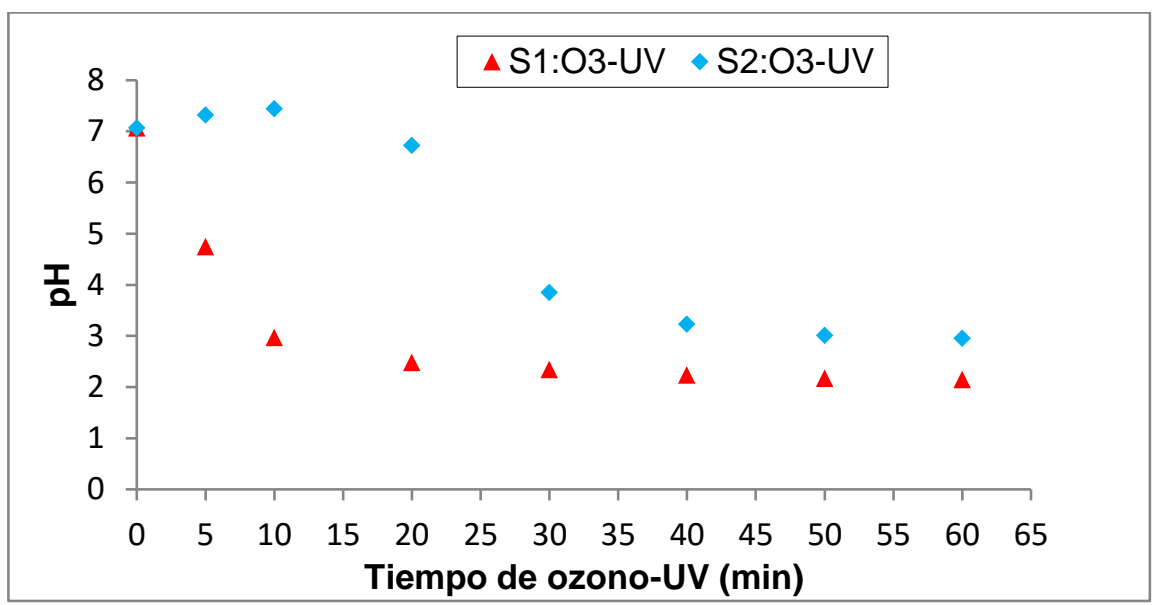

Gráfica 5-7 Cambio del pH durante el tratamiento con ozono-ultravioleta de soluciones acuosas de 2,5-DCP en con agua destilada ( $\left.\mathrm{S} 1: \mathrm{O}_{3}-\mathrm{UV}\right)$ y con agua residual ( $\left.\mathrm{S} 2: \mathrm{O}_{3}-\mathrm{UV}\right)$.

\subsubsection{Discusión sobre los cambios del pH durante los tratamientos de oxidación}

Se aplicó una dosis inicial del ozono de $1.3 \mathrm{~g} / \mathrm{h}$ en las soluciones del 2,5-DCP en S1: con agua destilada y S2: con agua residual a un $\mathrm{pH}$ neutro. Los resultados obtenidos para la solución S1: con agua destilada mostraron una disminución rápida a un $\mathrm{pH}$ ácido de 2.28 y de 2.15 con tratamiento de ozono y ozono-UV respectivamente. Eisenhauer [17] y Wang [18] observaron similares comportamientos en sus investigaciones en la ozonación de compuestos fenólicos, sin buffer, donde el pH disminuyó rápidamente a un valor de 3 .

La disminución del pH inicial $(\mathrm{pH}$ 7) durante el tratamiento con ozono es debido a la formación de productos intermedios que son ácidos orgánicos. En diversas literaturas se reportaron formaciones de productos intermedios ácidos por ozonación de 2,5-DCP [16, 19, 20]. En el trabajo de Wang y col. [16] se investigaron los productos de la ozonación de 2,5-DCP (100 mg/L) a pH 3 y 9, se encontró que en la solución a pH ácido se bajó a un valor de pH 3 a 2.2 durante la ozonación. Los productos de oxidación que se identificaron fueron ácidos orgánicos. 


\section{CAPÍTULO 5. RESULTADOS Y DISCUSIÓN}

Sin embargo, en las soluciones acuosas del 2,5-DCP en S2: con agua residual, tratada con ozono y ozono-UV se observaron unos ligeros aumentos de los valores de $\mathrm{pH}$ iniciales de 7.07 a 7.44 y a 7.41 durante de los primeros 10 minutos de ozonación y ozono-UV respectivamente antes de que empezaran a disminuir a pH finales de 3.01 y 2.95 respectivamente. Este aumento es debido probablemente a las sustancias presentes en el agua residual como la materia orgánica, carbonatos e hidróxidos que pueden aumentar la alcalinidad de la solución, dando un efecto buffer a las soluciones [21, 22]. La disminución en las soluciones S2: con agua residual a pH ácido es debido a la formación de compuestos ácidos y ácidos orgánicos [15].

\subsubsection{Eficiencia de la oxidación del 2,5-DC medida como DQO}

Para evaluar la eficiencia de la oxidación se midieron los porcentajes de remoción de DQO en muestras a diversos tiempos de oxidación. Los resultados se muestran en las tablas 5-7 y 5-8. En esta sección del trabajo se describen los resultados obtenidos de las pruebas de DQO para las diferentes muestras de 2,5-DCP a pH inicial de 7 con tratamiento de oxidación de ozono y ozono-UV a diferentes tiempos. Generalmente, el porcentaje de la DQO eliminada va aumentando con respecto al tiempo para todos los tratamientos de oxidación. Se calcula la remoción de $\mathrm{DQO}$ en función de $\mathrm{DQO}$ inicial [DQO]o y a diferente tiempo (t) usando la Ecuación 5-19.

$$
\% D Q O \text { eliminada }=\frac{[D Q O]_{0}-[D Q O]_{t}}{[D Q O]_{0}} \times 100 \quad \text { Ecuación 5-19 }
$$


Tabla 5-7 Tratamiento con ozono. Valores de DQO y Desviación estándar en las soluciones de 2,5-DCP en agua destilada (S1) y en agua residual (S2)

\begin{tabular}{|c|r|c|r|}
\hline SOLUCIÓN & TIEMPO (min) & DQO (mg/L) +/- sD & \%DQO eliminada \\
\hline \multirow{4}{*}{ S1: con agua destilada } & 0 & $607 \pm 8$ & 0 \\
\cline { 2 - 4 } & 5 & $454 \pm 7$ & 25 \\
\cline { 2 - 4 } & 10 & $423 \pm 4$ & 30 \\
\cline { 2 - 4 } & 20 & $409 \pm 4$ & 33 \\
\cline { 2 - 4 } & 30 & $378 \pm 10$ & 38 \\
\cline { 2 - 4 } & 40 & $320 \pm 5$ & 47 \\
\hline \multirow{4}{*}{ S2: con agua residual } & 50 & $272 \pm 26$ & 55 \\
\cline { 2 - 4 } & 60 & $250 \pm 11$ & 59 \\
\cline { 2 - 4 } & 0 & $870 \pm 3$ & 0 \\
\cline { 2 - 4 } & 5 & $596 \pm 3$ & 32 \\
\cline { 2 - 4 } & 10 & $566 \pm 3$ & 45 \\
\cline { 2 - 4 } & 20 & $478 \pm 10$ & 48 \\
\cline { 2 - 4 } & 30 & $449 \pm 6$ & 58 \\
\cline { 2 - 4 } & 40 & $362 \pm 8$ & 60 \\
\hline
\end{tabular}

Tabla 5-8 Tratamiento con ozono-UV. Valores de DQO en las soluciones de 2,5-DCP en agua destilada (S1) y en agua residual (S2)

\begin{tabular}{|c|r|c|r|}
\hline SOLUCIÓN & \multicolumn{1}{|c|}{ TIEMPO (min) } & DQO (mg/L) +/- sD & \%DQO eliminada \\
\hline \multirow{4}{*}{ S1: con agua destilada } & 0 & $607 \pm 3$ & 0 \\
\cline { 2 - 4 } & 5 & $379 \pm 8$ & 29 \\
\cline { 2 - 4 } & 10 & $360 \pm 3$ & 41 \\
\cline { 2 - 4 } & 20 & $333 \pm 5$ & 45 \\
\cline { 2 - 4 } & 30 & $313 \pm 3$ & 48 \\
\cline { 2 - 4 } & 40 & $279 \pm 7$ & 54 \\
\hline & 50 & $217 \pm 8$ & 61 \\
\cline { 2 - 4 } & 60 & $183 \pm 5$ & 69 \\
\cline { 2 - 4 } & 0 & $870 \pm 3$ & 32 \\
\cline { 2 - 4 } & 5 & $636 \pm 7$ & 44 \\
\cline { 2 - 4 } & 10 & $487 \pm 3$ & 53 \\
\cline { 2 - 4 } & 20 & $404 \pm 7$ & 58 \\
\cline { 2 - 4 } & 30 & $351 \pm 3$ & 71 \\
\cline { 2 - 4 } & 40 & $311 \pm 5$ & 75 \\
\cline { 2 - 4 } & 50 & $273 \pm 11$ & $218 \pm 6$ \\
\hline
\end{tabular}




\section{CAPÍTULO 5. RESULTADOS Y DISCUSIÓN}

\subsubsection{Discusión sobre la eficiencia de la eliminación de DQO}

En general, se puede observar que se incrementó la remoción de DQO con ozonación y ozono-UV. Los experimentos llevados a cabo en las soluciones acuosas 2,5-DCP en agua residual (S2) tuvieron los mejores resultados en cada oxidación (S2: Оз y S2: $\mathrm{O}_{3}-\mathrm{UV}$ ). En los experimentos se puede observar que las oxidaciones de S2: con agua residual son mejores que las oxidaciones de S1: con agua destilada. Esto podría ser debido a que algunas de las sustancias presentes actúan como buffer, tomando en cuenta que hubo un aumento en el $\mathrm{pH}$ al inicio de los experimentos en las soluciones S2: con agua residual; ya que según la literatura [23, 24], el mecanismo predominante de la ozonación de fenoles a pH neutro y alcalino es por la reacción de radicales libres y al aumentar el pH se forman más radicales hidroxilo para degradar el compuesto orgánico y así se obtiene mejor remoción de DQO. Otra razón puede ser por algunas sustancias que actúan como catalizador en la reacción con ozono y ozono-UV y así aumentan la formación de radicales.

\subsubsection{Relación entre el consumo de ozono y la remoción de DQO Tratamiento con Ozono}

En esta sección se hacen comparaciones del tratamiento de $\mathrm{O}_{3}$ en la remoción de $\mathrm{DQO}(\mathrm{mg} / \mathrm{L})$ en las soluciones de 2,5-DCP en agua destilada (S1) y en agua residual (S2). En la Tabla 5-9 se muestran los resultados para la remoción de DQO durante el tratamiento a los 60 minutos. La Gráfica 5-8 se muestra la relación de DQO removida por $\mathrm{mg} / \mathrm{L}$ de ozono consumido a lo largo del tiempo de ozonación. 


\section{CAPÍTULO 5. RESULTADOS Y DISCUSIÓN}

Tabla 5-9 Tratamiento con ozono. Relación entre la remoción de DQO (mg/L) y el consumo de ozono en la ozonación del 2,5-DCP $(500 \mathrm{mg} / \mathrm{L})$ en agua destilada y en agua residual

\begin{tabular}{|c|c|c|}
\hline Compuesto & 2, 5-DCP ( & $0.003067 \mathrm{M})$ \\
\hline Tipo de solución acuosa & $\begin{array}{c}\text { S1 } \\
\text { Agua destilada }\end{array}$ & $\begin{array}{c}\mathrm{S} 2 \\
\text { Agua residual }\end{array}$ \\
\hline pH inicial & 7 & 7 \\
\hline Ozono producido (mg/min) & 22 & 22 \\
\hline Concentración de $\mathrm{O} 3$ entrada $(\mathrm{mg} / \mathrm{L})$ en gas & 30 & 30 \\
\hline Flujo del gas (L/min) & 0.7 & 0.7 \\
\hline DQO inicial (mg/L) & 607 & 870 \\
\hline DQO removida a $60 \mathrm{~min}(\mathrm{mg} / \mathrm{L})$ & 357 & 571 \\
\hline Ozono aplicado durante $60 \mathrm{~min}(\mathrm{mg} / \mathrm{L})$ & 1420 & 1420 \\
\hline Ozono consumido en $60 \mathrm{~min}(\mathrm{mg} / \mathrm{L})$ & 1099 & 1087 \\
\hline $\mathrm{R}=[\mathrm{DQO}$ removida $(\mathrm{mg} / \mathrm{L})] /[$ Ozono consumido $(\mathrm{mg} / \mathrm{L})]$ & 0.32 & 0.53 \\
\hline Tiempo de Reacción (min) & 60 & 60 \\
\hline
\end{tabular}

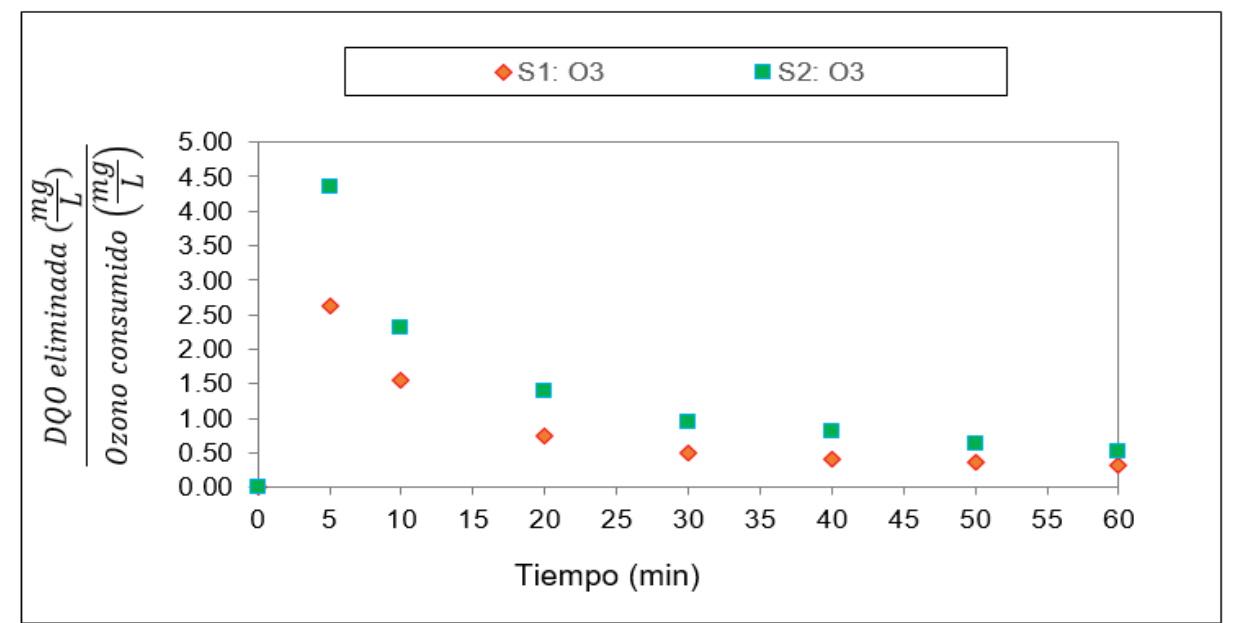

Gráfica 5-8 DQO eliminada por mg/L de ozono consumido durante el tratamiento con ozono en las soluciones de 2,5-DCP en S1: con agua destilada y S2: con agua residual

\section{Tratamiento con ozono-UV}

En esta sección se hacen comparaciones del tratamiento de $\mathrm{O}_{3}-\mathrm{UV}$ en la remoción de DQO (mg/L) en las soluciones de 2,5-DCP en agua destilada y en agua residual. En la Tabla 5-10 se muestran los resultados para la remoción de DQO durante el tratamiento a los 60 minutos. La Gráfica 5-9 se muestra la relación de la DQO removida por $\mathrm{mg} / \mathrm{L}$ de ozono consumido a largo del tiempo de ozonación. 


\section{CAPÍTULO 5. RESULTADOS Y DISCUSIÓN}

Tabla 5-10 Tratamiento con ozono-UV. Relación entre la remoción de DQO (mg/L) y el ozono consumido en la oxidación del 2,5-DCP $(500 \mathrm{mg} / \mathrm{L})$ en agua destilada y en agua residual

\begin{tabular}{|c|c|c|}
\hline Compuesto & 2, 5-DCP $(C$ & $.003067 \mathrm{M})$ \\
\hline Tipo de solución acuosa & $\begin{array}{c}\text { S1 } \\
\text { Agua destilada }\end{array}$ & $\begin{array}{c}\text { S2 } \\
\text { Agua residual }\end{array}$ \\
\hline pH inicial & 7 & 7 \\
\hline Ozono producido (mg/min) & 22 & 22 \\
\hline Concentración de $\mathrm{O}_{3}$ entrada $(\mathrm{mg} / \mathrm{L})$ en gas & 31 & 31 \\
\hline Flujo del gas (L/min) & 0.7 & 0.7 \\
\hline DQO inicial (mg/L) & 607 & 870 \\
\hline DQO removida a $60 \mathrm{~min}(\mathrm{mg} / \mathrm{L})$ & 424 & 656 \\
\hline Ozono aplicado durante $60 \mathrm{~min}(\mathrm{mg} / \mathrm{L})$ & 1420 & 1420 \\
\hline Ozono consumido en $60 \mathrm{~min}(\mathrm{mg} / \mathrm{L})$ & 1116 & 1102 \\
\hline$R=[\mathrm{DQO}$ removida $(\mathrm{mg} / \mathrm{L})] /[$ Ozono consumido $(\mathrm{mg} / \mathrm{L})]$ & 0.38 & 0.60 \\
\hline Tiempo de Reacción (min) & 60 & 60 \\
\hline
\end{tabular}

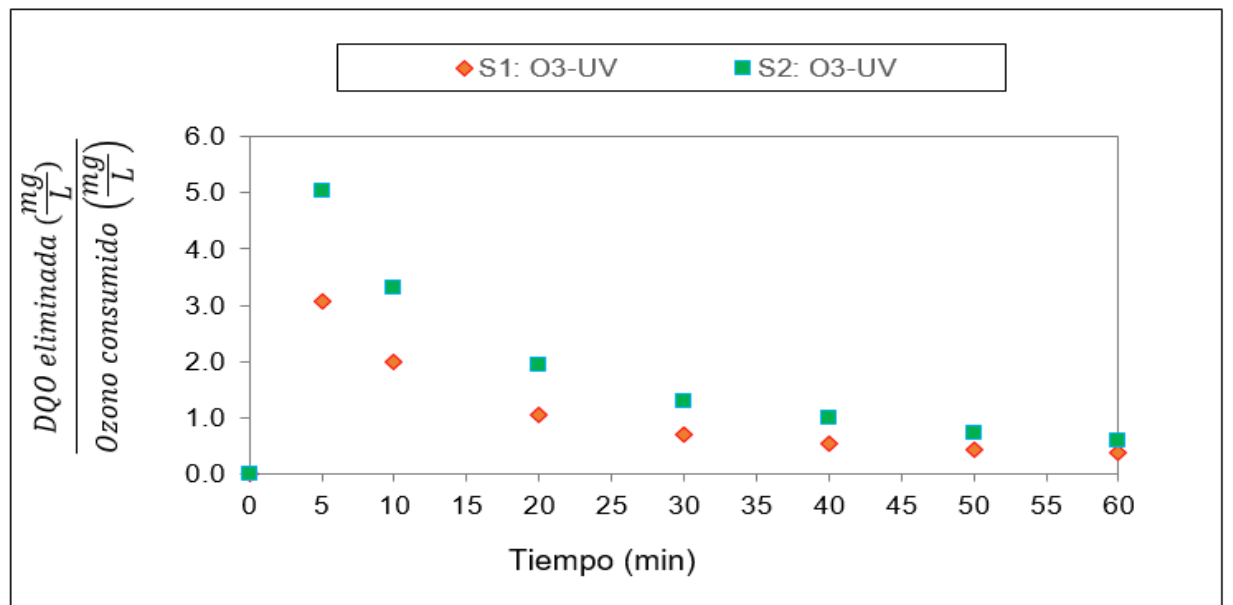

Gráfica 5-9 DQO eliminada por mg/L de ozono consumido durante el tratamiento con ozono-UV en las soluciones de 2,5-DCP en S1: con agua destilada y S2: con agua residual

\subsubsection{Discusión sobre el consumo de ozono y la remoción de DQO}

Los resultados obtenidos de la relación de DQO removida entre el ozono consumido, en los experimentos de oxidación con ozono y ozono-UV, muestran que los productos de oxidación del 2,5-DCP fueron más difíciles de oxidar en comparación con el 2,5-DCP. Después de 5 minutos de tratamiento en las soluciones $\mathrm{S} 1$ : con agua destilada $2.63 \mathrm{mg} / \mathrm{L}$ y $3.08 \mathrm{mg} / \mathrm{L}$ de la DQO fue removida por $\mathrm{mg} / \mathrm{L}$ del ozono consumido con tratamiento de ozono y ozono-UV respectivamente. Sin embargo, en las soluciones S2: con agua residual la DQO removida por 


\section{CAPÍTULO 5. RESULTADOS Y DISCUSIÓN}

$\mathrm{mg} / \mathrm{L}$ del ozono consumido fue de $4.34 \mathrm{mg} / \mathrm{L}$ y $5.03 \mathrm{mg} / \mathrm{L}$ con tratamiento de ozono y ozonoUV respectivamente de 2,5-DCP.

La mayor remoción de DQO en agua residual puede ser debida a la presencia de materia orgánica que se oxida fácilmente. Por eso, dando una eliminación de DQO más alta que en las soluciones S1: con agua destilada (que no contiene materia orgánica). Sin embargo a lo largo de los experimentos se notó que los tratamientos con oxidación $\left(\mathrm{O}_{3}\right.$ y $\left.\mathrm{O}_{3}-\mathrm{UV}\right)$ en las soluciones S2: con agua residual fueron más eficaces en la remoción de DQO por mg/L de ozono consumido (Tabla 5-9 y Tabla 5-10). Esto puede ser por mayor formación de radicales hidroxilo y/o por la presencia de algunas sustancias en el agua residual que actúan como promotores o catalizadores. Por lo tanto estas sustancias aceleraron las reacciones de oxidación en las soluciones S2: con agua residual, por la formación de radicales incluyendo radicales hidroxilo. Algunos autores han reportado mejores reacciones del ozono por la presencia de fenol, clorofenol y ácido benzoico que producen radicales hidroxilo entre otros [25-27].

Por otra parte, a lo largo del tiempo de oxidación con ozono y ozono-UV de la soluciones S1: con agua destilada y S2: con agua residual, se observó que la cantidad de DQO removida por $\mathrm{mg} / \mathrm{L}$ de ozono consumida disminuyó mucho. Al final del experimento (a los 60 minutos) los subproductos formados requieren un mayor consumo de ozono, aproximadamente 8 veces más, que al principio (a los 5 minutos) para la remoción de la misma cantidad de DQO. Estos resultados mostraron que algunos de los subproductos de oxidación formados en las dos soluciones reaccionaron más lento que el compuesto original (2,5-DCP) y/o la presencia de productos intermedios que reaccionaron más lento con ozono o radicales hidroxilo [15]. 


\section{CAPÍTULO 5. RESULTADOS Y DISCUSIÓN}

\subsubsection{Resultados del espectro de absorción (UV-Vis)}

El espectro de absorción UV-VIS fue uno de los primeros métodos físicos que se aplicaron al análisis cuantitativo y a la determinación de estructuras moleculares. En la Gráfica 5-10 se puede observar el comportamiento del 2,5-DCP sin tratamiento a diferentes cambios del pH.

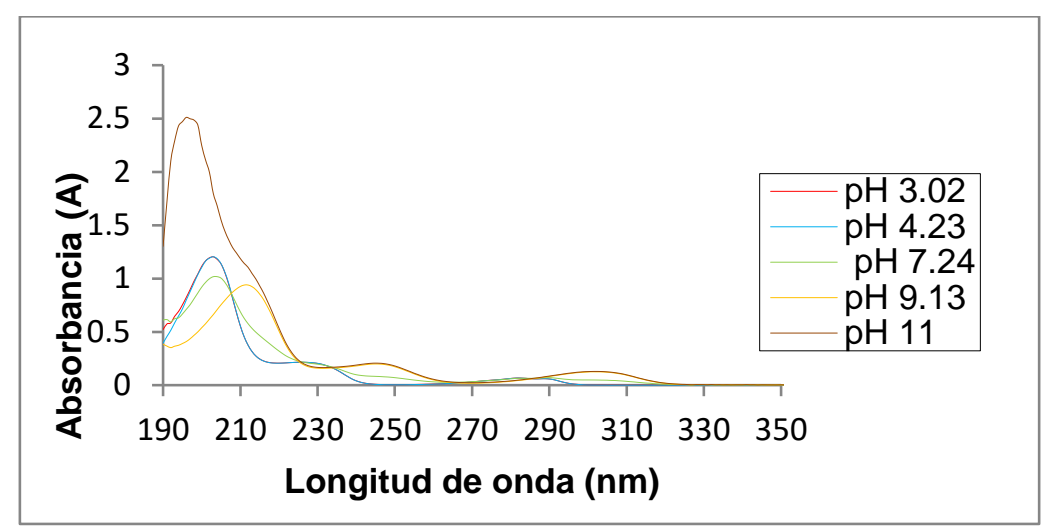

Gráfica 5-10 Espectros de absorción de 2,5-DCP a diferentes $\mathrm{pH}$

Las gráficas 5-11 a 514 corresponden a los espectros de absorción de 2,5-DCP diluída a una concentración de 10 ppm y en estas gráficas se puede ver como disminuye la concentración de 2,5-DCP con el tratamiento a través del tiempo. Se puede observar el comportamiento de las soluciones $\mathrm{S} 1$ y S2 con los tratamientos de ozono (Gráfica 5-11 y

Gráfica 5-12) y con los tratamientos de ozono-UV ( Gráfica 5-13 y Gráfica 5-14).

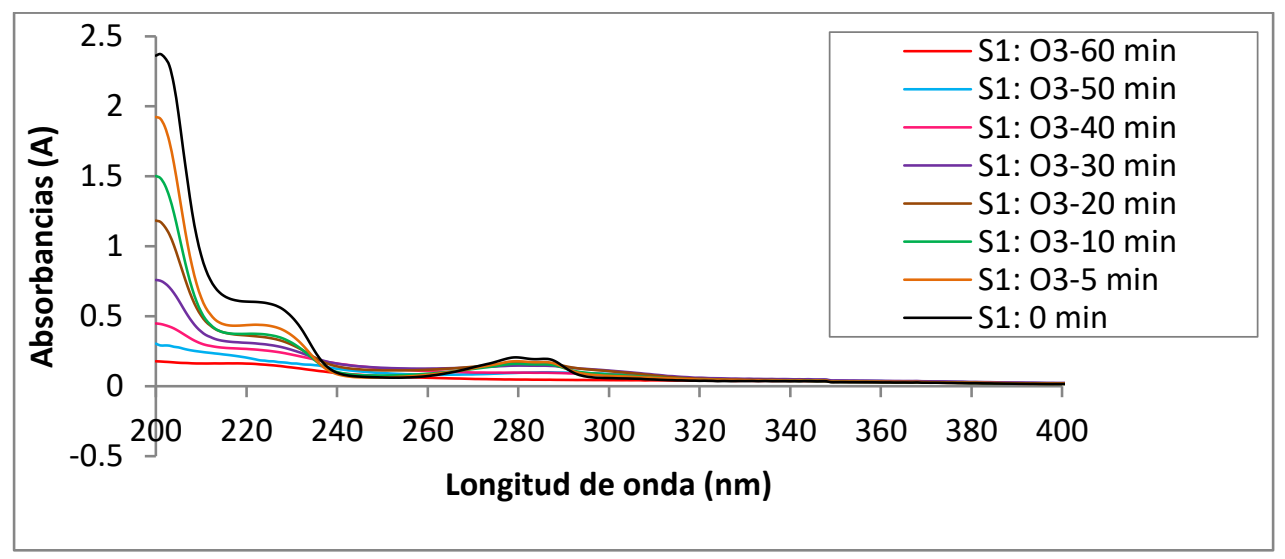

Gráfica 5-11 Espectros de absorción de 2,5-DCP en agua destilada a pH 7 tratada con ozonación ( $\left.\mathrm{S} 1: \mathrm{O}_{3}\right)$ a diferentes tiempos (0-60 minutos) 


\section{CAPÍTULO 5. RESULTADOS Y DISCUSIÓN}

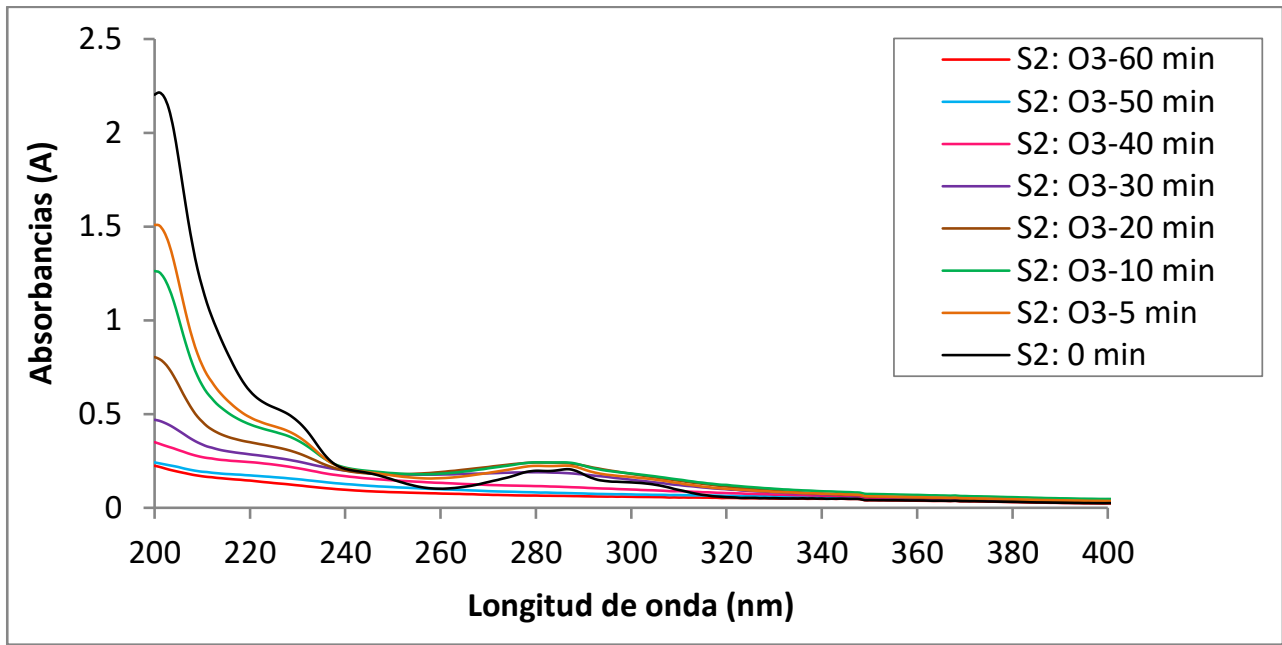

Gráfica 5-12 Espectros de absorción de 2,5-DCP en agua residual

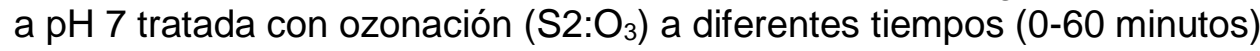

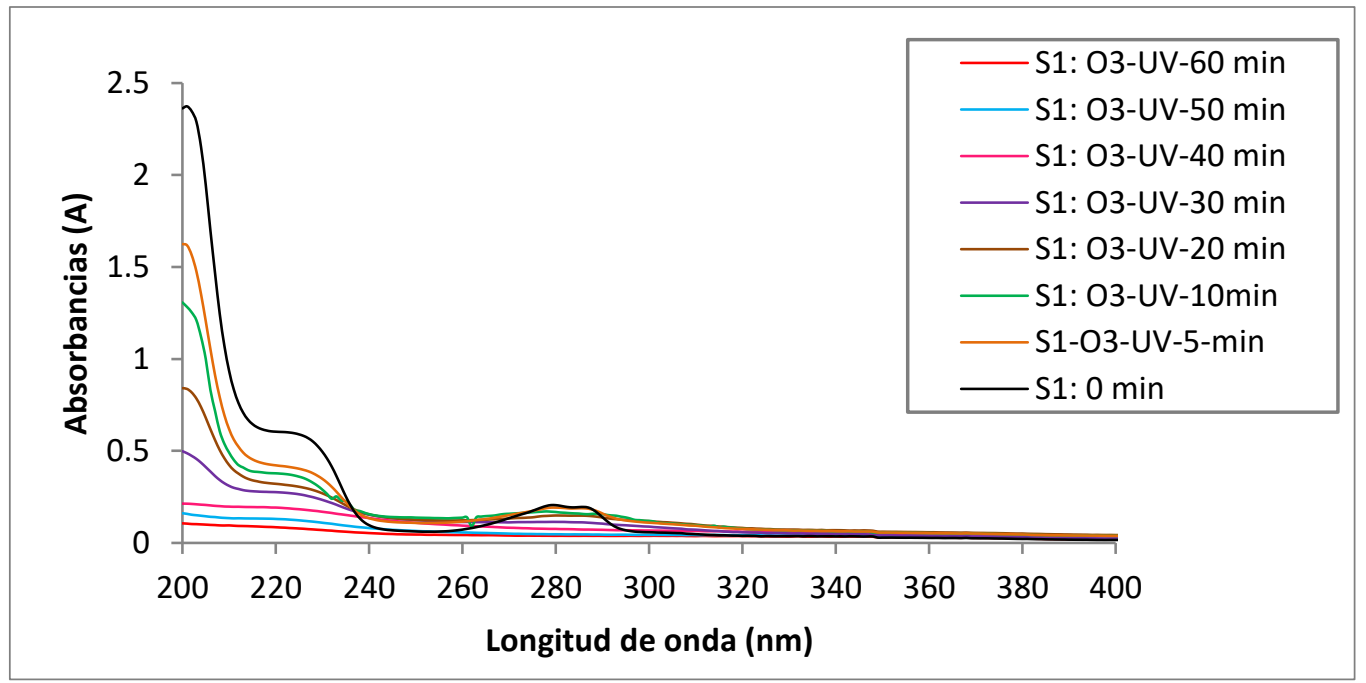

Gráfica 5-13 Espectros de absorción de 2,5-DCP en agua destilada a pH 7 tratada con ozonación ( $\mathrm{S}_{1}: \mathrm{O}_{3} \mathrm{UVV}$ ) a diferentes tiempos (0-60 minutos) 


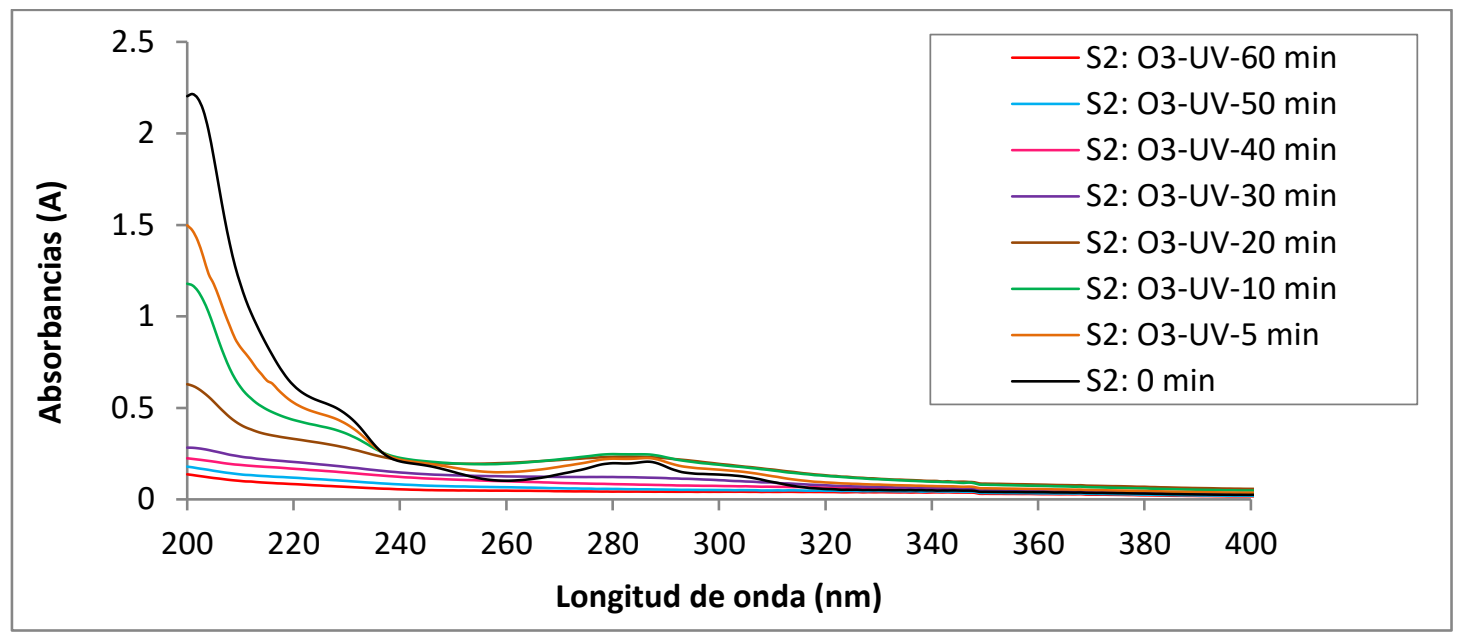

Gráfica 5-14 Espectros de absorción de 2,5-DCP en agua residual a pH 7 tratada con ozonación ( $\mathrm{S} 2: \mathrm{O}_{3}-\mathrm{UV}$ ) a diferentes tiempos (0-60 minutos)

\subsubsection{Discusión sobre los resultados del espectro de absorción (UV-Vis)}

Se usó el pH original de la solución del 2,5-DCP a $0.0614 \mathrm{mM}(\mathrm{pH}=4.23)$ para comparar el efecto que el cambio del pH tuvo sobre la solución de 2,5-DCP (Gráfica 5-11). Primeramente se puede observar que con pH ácidos (3 y 4) los espectros están uno encima del otro con longitudes de onda máxima $\left(\lambda_{\max }\right)$ de $203 \mathrm{~nm}\left(\varepsilon=39240 \mathrm{~L} \mathrm{~mol}^{-1} \mathrm{~cm}^{-1}\right)$. En el caso de pH 9 hay desplazamientos hacia la derecha de la máxima absorción $\left(\lambda_{\max }=203 \mathrm{~nm}\right)$. También los pH 7 y pH 9 tienen absorbancias más bajas que el pH 4. En el caso del pH 11, hay un desplazamiento hacia la izquierda de la máxima absorción de $\lambda_{\max }=203 \mathrm{~nm}$ hacia $\lambda_{\max }=196$ $\mathrm{nm}\left(\varepsilon=81,833 \mathrm{~L} \mathrm{~mol}^{-1} \mathrm{~cm}^{-1}\right)$. Estos desplazamientos son debido a la presencia de los iones hidróxido $\left(\mathrm{OH}^{-}\right)$sustituyentes en el 2,5-DCP a pH alcalino.

La máxima absorción del 2,5-DCP a pH 7 corresponde a una longitud de onda de $223 \mathrm{~nm}$ en las dos soluciones. En las Gráfica $5-11$ y

Gráfica 5-12, se notó que a esta longitud de onda máxima $\left(\lambda_{\max }=223 \mathrm{~nm}\right)$ las absorbancias disminuyeron con el aumento del tiempo de oxidación en ambos sistemas, lo cual corresponde a la degradación del 2,5-DCP en las dos soluciones estudiadas, a los 50 minutos de ozonación en S1: con agua destilada y de 40 minutos en S2: con agua residual todo el 2,5-DCP presente en la solución se degrada (se confirmó con los análisis de GC-MS), mientras que con el tratamiento de ozono-UV la degradación fue más rápida, de 40 minutos en S1: con agua destilada y de 30 minutos en S2: con agua residual. Estos resultados se 


\section{CAPÍTULO 5. RESULTADOS Y DISCUSIÓN}

pueden relacionar con el trabajo de Poznyak y col. [20] donde se observó una disminución de absorbancias a $\lambda=230 \mathrm{~nm}$ de 2,4-DCP a pH 7 con el tratamiento de ozonación y concluyen que esta disminución confirmó la descomposición de 2,4-DCP.

\subsubsection{Evolución de la DBO en la degradación del 2,5-DCP en los POA}

Al iniciar los análisis de $\mathrm{DBO}_{5}$ se hicieron pruebas con una solución estándar de $\mathrm{DBO}_{5}$ de glucosa y ácido glutámico con el fin de verificar que los análisis cumplen con los criterios de verificación según la sección 5210 B de los métodos estándar (APHA y col. 2005) [28] para la solución estándar la $\mathrm{DBO}_{5}$ debe ser de $198 \pm 30.5 \mathrm{mg} / \mathrm{L}$, en la Tabla 5-11 se puede observar que los resultados están dentro del rango de valores esperados.

Tabla 5-11 Pruebas de $\mathrm{DBO}_{5}$ con una solución estándar de glucosa y ácido glutámico

\begin{tabular}{|c|c|c|c|}
\hline \multirow{2}{*}{ Nombre } & Prueba 1 & Prueba 2 & Prueba 2 \\
\cline { 2 - 4 } & $\mathrm{DBO}_{5}(\mathbf{m g} / \mathbf{L})$ & $\mathrm{DBO}_{5}(\mathbf{m g} / \mathbf{L})$ & $\mathrm{DBO}_{5}(\mathrm{mg} / \mathrm{L})$ \\
\hline Agua de dilución & 0.1 & 0.2 & 0.1 \\
\hline $\begin{array}{c}\text { Agua de dilución } \\
\text { inoculada (polyseed) }\end{array}$ & 98 & 105 & 102 \\
\hline Glucosa y ácido glutámico & 180 & 200 & 190 \\
\hline \hline
\end{tabular}

\section{Tratamiento con ozono}

Los resultados obtenidos en las pruebas de $\mathrm{DBO}_{5}$ en la solución acuosa de 2,5-DCP en S1: con agua destilada con tratamiento de oxidación con ozono fueron más bajos que los obtenidos en la solución acuosa S2: con agua residual. Los resultados se muestran en la Tabla 5-12. 
Tabla 5-12 Valores de la $\mathrm{DBO}_{5}$ y la desviación estándar de las pruebas del 2,5-DCP tratado con ozono en soluciones de S1: con agua destilada y en S2: con agua residual

\begin{tabular}{|c|c|c|c|}
\hline \multicolumn{2}{|c|}{ S2: con agua residual } & \multicolumn{2}{|c|}{ S1: con agua destilada } \\
\hline $\begin{array}{c}\text { O3-TIEMPO } \\
\text { (min) }\end{array}$ & $\operatorname{CONC} \mathrm{DBO}_{5}(\mathrm{mg} / \mathrm{L}) \pm \mathrm{sD}$ & $\begin{array}{c}\mathrm{O}_{3} \text {-TIEMPO } \\
\text { (min) }\end{array}$ & $\operatorname{CONC} \mathrm{DBO}_{5}(\mathrm{mg} / \mathrm{L}) \pm \mathrm{sD}$ \\
\hline 0 & $141 \pm 23$ & 0 & $3 \pm 2$ \\
\hline 5 & $85 \pm 5$ & 5 & $8 \pm 1$ \\
\hline 10 & $112 \pm 6$ & 10 & $30 \pm 3$ \\
\hline 20 & $123 \pm 9$ & 20 & $38 \pm 4$ \\
\hline 30 & $157 \pm 8$ & 30 & $53 \pm 3$ \\
\hline 40 & $168 \pm 10$ & 40 & $58 \pm 5$ \\
\hline 50 & $176 \pm 4$ & 50 & $80 \pm 6$ \\
\hline 60 & $180 \pm 8$ & 60 & $103 \pm 3$ \\
\hline
\end{tabular}

\section{Tratamiento con ozono-UV}

Los resultados obtenidos en las pruebas de $\mathrm{DBO}_{5}$ en la solución acuosa de 2,5-DCP en S1: con agua destilada y en S2: con agua residual con tratamiento de oxidación con ozono-UV se pueden observar en la

Tabla 5-13. Los resultados obtenidos durante el tratamiento con ozono-UV muestran que la solución S2: con agua residual tenían valores de $\mathrm{DBO}_{5}$ más altos que la solución $\mathrm{S} 1$ : con agua destilada.

Tabla 5-13 Valores de la $\mathrm{DBO}_{5}$ y la desviación estándar de las pruebas de oxidación del 2,5-DCP en S1: con agua destilada y S2: con agua tratadas con ozono-UV

\begin{tabular}{|c|c|c|c|}
\hline \multicolumn{2}{|c|}{ S2: con agua residual } & \multicolumn{2}{|c|}{ S1: con agua destilada) } \\
\hline $\begin{array}{c}\begin{array}{c}\mathrm{O}_{3} / \text { UV-TIEMPO } \\
\text { (min) }\end{array} \\
\end{array}$ & CONC. DBO $5(\mathrm{mg} / \mathrm{L}) \pm \mathrm{sD}$ & $\begin{array}{c}\mathrm{O}_{3} / \text { UV-TIEMPO } \\
\text { (min) }\end{array}$ & $\mathrm{CONC} \mathrm{DBO}_{5}(\mathrm{mg} / \mathrm{L}) \pm \mathrm{sD}$ \\
\hline 0 & $141 \pm 23$ & 0 & $3 \pm 2$ \\
\hline 5 & $90 \pm 3$ & 5 & $52 \pm 3$ \\
\hline 10 & $121 \pm 4$ & 10 & $65 \pm 2$ \\
\hline 20 & $130 \pm 3$ & 20 & $70 \pm 3$ \\
\hline 30 & $168 \pm 7$ & 30 & $85 \pm 3$ \\
\hline 40 & $175 \pm 13$ & 40 & $106 \pm 6$ \\
\hline 50 & $181 \pm 6$ & 50 & $111 \pm 4$ \\
\hline 60 & $187 \pm 5$ & 60 & $121 \pm 2$ \\
\hline
\end{tabular}




\subsubsection{Biodegradabilidad del 2,5-DCP}

Se evaluó el efecto de la oxidación sobre la biodegradabilidad del 2,5-DCP en agua destilada (S1) y en agua residual (S2), usando los análisis de la Demanda Bioquímica de Oxígeno (DBO5) (Tabla 5-12 a

Tabla 5-13) y la Demanda Química de Oxígeno (DQO) de las muestras antes y después de la oxidación. Se usaron los resultados obtenidos de los análisis para calcular la relación $\mathrm{DBO}_{5} / \mathrm{DQO}$ de los diferentes tiempos de ozonación; (Gráfica 5-15 y Gráfica 5-16).

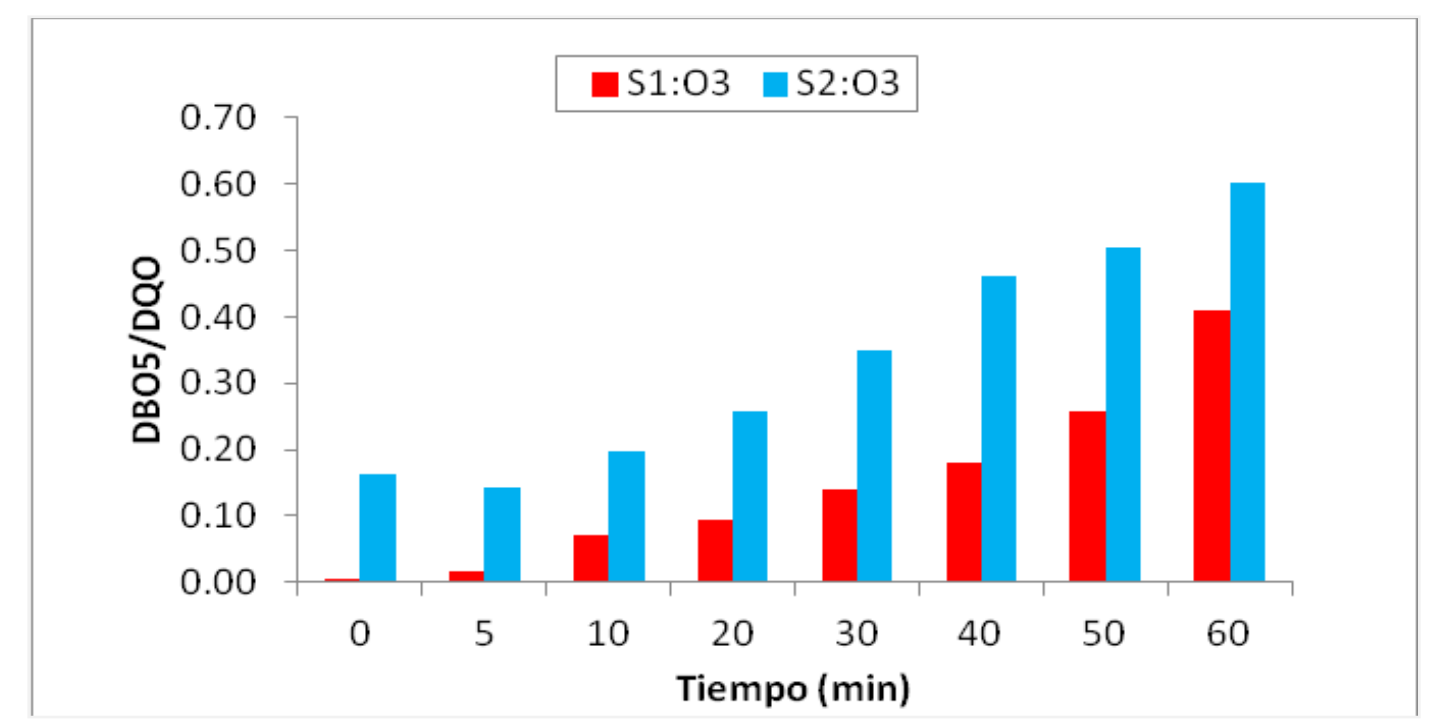

Gráfica 5-15 Relación $\mathrm{DBO}_{5} / \mathrm{DQO}$ de 2,5-DCP en agua destilada con tratamiento de oxidación con $\mathrm{O}_{3}$ durante 60 minutos

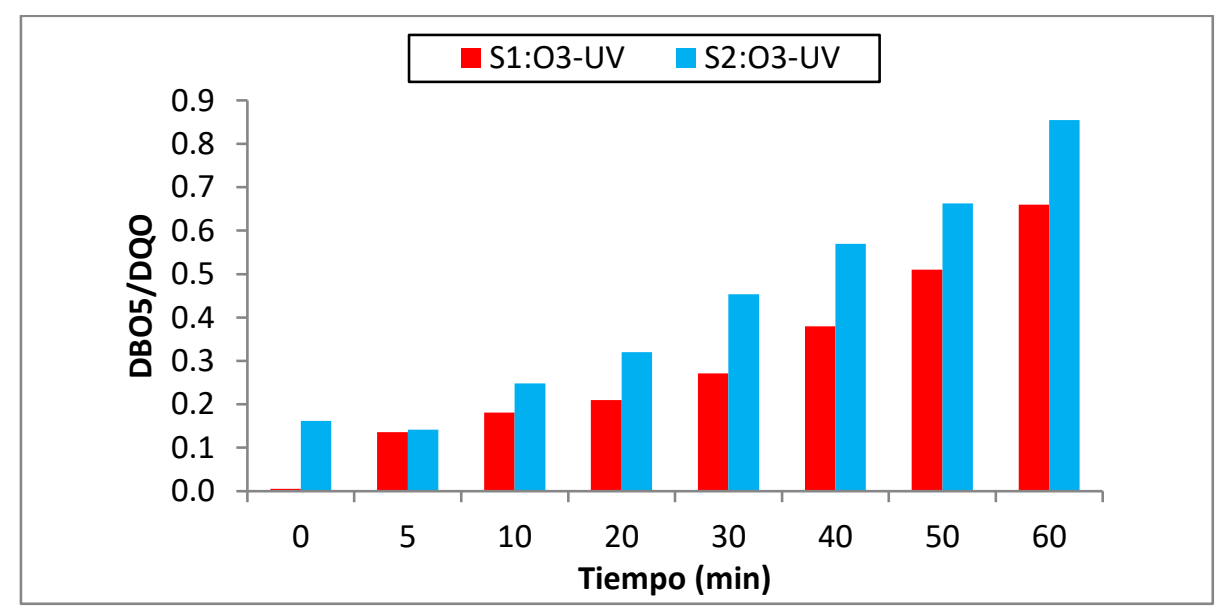

Gráfica 5-16 Relación $\mathrm{DBO}_{5} / \mathrm{DQO}$ de 2,5-DCP en agua residual con tratamiento de oxidación con $\mathrm{O}_{3}$-UV durante 60 minutos 


\section{CAPÍTULO 5. RESULTADOS Y DISCUSIÓN}

\subsubsection{Discusión sobre la biodegradación del 2,5-DCP}

La biodegradabilidad de un agua residual puede ser estimada por medio de la relación $\mathrm{DBO}_{5} / \mathrm{DQO}[29,30]$. Como referencia, un índice de $\mathrm{DBO}_{5} / \mathrm{DQO}$ de 0.4 es generalmente considerado el corte entre poco biodegradable y difícil de biodegradar [31, 32].

En las tablas 5-12 y 5-13 se notó que al tiempo cero la concentración de $\mathrm{DBO}_{5}$ en solución acuosa de 2,5-DCP en agua residual fue más alta $\left(\mathrm{DBO}_{5}=141 \mathrm{mg} / \mathrm{L}\right)$, que los tratadas de 5 a 30 minutos con ozono, lo cual representa la $\mathrm{DBO}_{5}$ por la materia orgánica presente en el agua residual. En general los resultados de $\mathrm{DBO}_{5}$ para $\mathrm{S} 1$ : con agua destilada fueron más bajos que los resultados de $\mathrm{DBO}_{5}$ en agua residual. $\mathrm{La}^{\mathrm{DBO}_{5}}$ de las soluciones $\mathrm{S} 1$ : con agua destilada fue de $3 \mathrm{mg} / \mathrm{L}$.

Las relaciones iniciales de $\mathrm{DBO} / \mathrm{DQO}$ fueron muy bajas, para las soluciones S2: con agua residual fue de 0.2 y asimismo, como el 2,5-DCP no es muy biodegradable en el agua destilada la relación $\mathrm{DBO} / \mathrm{DQO}$ fue de 0.01 .

La ozonación y ozono-UV tuvieron un efecto positivo sobre la biodegradabilidad del 2,5-DCP en agua destilada (S1) y en agua residual (S2). En las dos soluciones se aumentó la biodegradabilidad con oxidación de ozono. Las dos soluciones oxidadas con ozonación alcanzaron a ser biodegradables, ya que tuvo un índice $\mathrm{DBO}_{5} / \mathrm{DQO}$ de 0.4 después de 60 minutos en la solución S1: con agua destilada y después de 40 minutos en la solución S2: con agua residual, hasta una proporción de 0.6 al final del experimento (60 min) como se puede observar en la gráfica 5-5, mientras que, con los tratamientos con ozono-UV (Gráfica 5 -16) se logró la biodegradabilidad $\left(\mathrm{DBO}_{5} / \mathrm{DQO}=0.4\right.$ ) después de $40 \mathrm{~min}$ y $30 \mathrm{~min}$ en las soluciones acuosas $\mathrm{S} 1$ : con agua destilada y $\mathrm{S} 2$ : con agua residual respectivamente.

En general, los tratamientos de ozono y ozono-UV mejoran la biodegradabilidad de 2,5-DCP, lo cual es consistente con los resultados obtenidos por Wohlers y col. [30]. Los resultados con máxima biodegradabilidad se obtuvieron de los tratamientos con ozono-UV de 60 minutos en las soluciones de 2,5-DCP S1: con agua destilada (S1) y agua residual (S2) con valores de $\mathrm{DBO}_{5} / \mathrm{DQO}$ de aproximadamente 0.6 y 0.8 respectivamente. 


\subsubsection{Eficiencia de los POAs en la eliminación de Carbono Orgánico Total}

La eliminación de COT mediante ozono aumentó usando una solución acuosa de 2,5-DCP en S2: con agua residual y en la presencia de Luz UV. La tasa de eliminación de COT fue más rápida con la solución $\mathrm{S} 2: \mathrm{O}_{3}-\mathrm{UV}$ de $53 \%$ y seguido por $\mathrm{S} 2: \mathrm{O}_{3}$ de $45 \%$. En los casos de las soluciones $\mathrm{S} 1$ : con agua destilada las tasas de eliminación de COT fueron casi iguales de $38 \%$ y $40 \%$ con ozono y ozono-UV respectivamente.

\subsubsection{Discusión sobre la eficiencia de los POAs en la eliminación de Carbono Orgánico Total}

Los resultados obtenidos mostraron que la aplicación de $1.3 \mathrm{~g} / \mathrm{h}$ de ozono no fue suficiente para mineralizar completamente las soluciones acuosas de 2,5-DCP en las dos soluciones. Sin embargo, los resultados obtenidos de esta investigación son comparables con los de la literatura, teniendo en cuenta la alta concentración inicial de 2,5-DCP $(3.07 \mathrm{mM})$ y la baja dosis de ozono aplicado en comparación con otros trabajos [32]. Tuvieron mayor mineralización en las soluciones S1: con agua destilada y S2: con agua residual con los tratamientos con ozono-UV, lo cual demostró que la fotólisis de UV si influyó el proceso de ozono en las dos soluciones, ya que puede causar la descomposición instantánea del ozono acuoso en radicales $\mathrm{OH}^{\bullet}$. Esto aumenta la fuerza impulsora para la absorción de ozono, además, los radicales $\mathrm{OH}^{\bullet}$ son oxidantes más eficaces que el ozono molecular. En general, el comportamiento del COT fue similar al de la DQO.

Se tuvo un aumento de $2 \%$ y $8 \%$ de remoción de COT en las soluciones S1: con agua destilada y S2: con agua residual, respectivamente, con tratamiento de $\mathrm{O}_{3}-\mathrm{UV}$. Otros investigadores han reportado similares resultados, donde obtuvieron mejor remoción de COT con ozono-UV que ozono solo [23, 33, 34]. 


\subsubsection{Cambio en estado de Oxidación del DCP}

La degradación de 2,5-DCP para formar otros productos intermedios fue estudiada por el cambio en el grado de oxidación. Para eso se estudiaron dos parámetros: DQO y COT.

1) La relación $\mathrm{DQO} / \mathrm{COT}$ da información sobre el grado de oxidación, mientras más baja es la relación $\mathrm{DQO} / \mathrm{COT}$ más alto es el grado de oxidación y esta se refleja en una mejor degradabilidad. Las gráficas 5-17 y 5-18 muestran la relación DQO/COT para los diferentes $\mathrm{POA}\left(\mathrm{O}_{3}\right.$ y $\left.\mathrm{O}_{3}-\mathrm{UV}\right)$ en $\mathrm{S} 1$ : con agua destilada y en $\mathrm{S} 2$ : con agua residual durante 60 minutos.

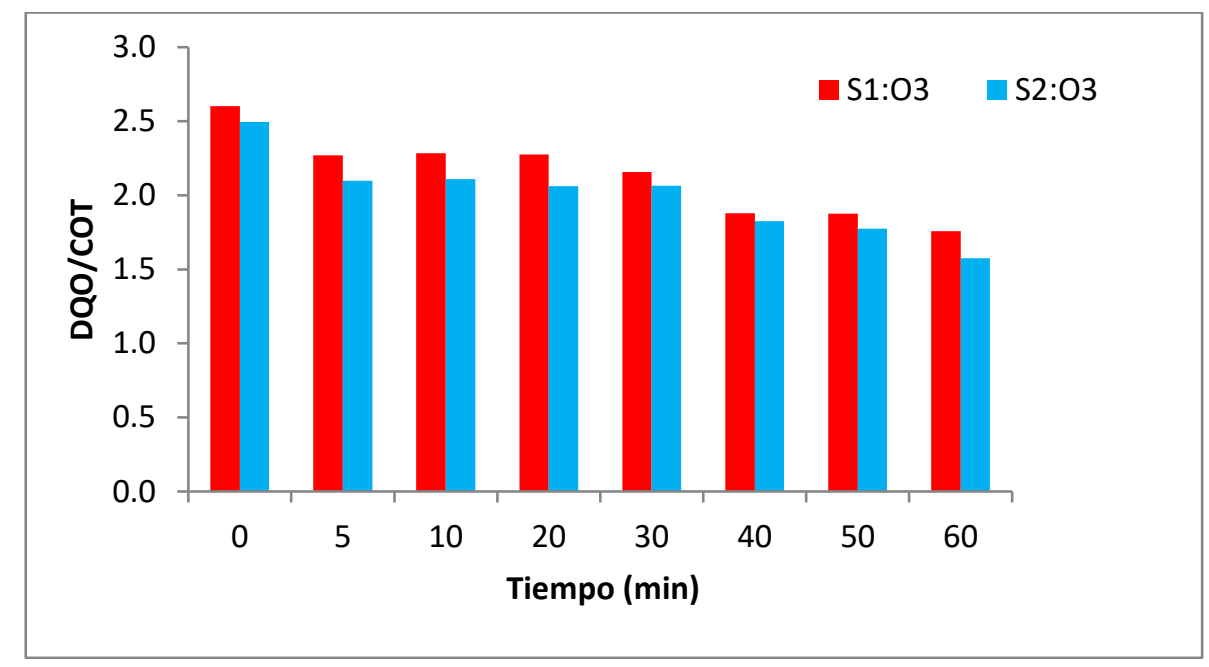

Gráfica 5-17 Relación DQO/COT de 2,5-DCP en S1: con agua destilada y en S2: con agua residual con tratamiento de oxidación de $\mathrm{O}_{3}$.

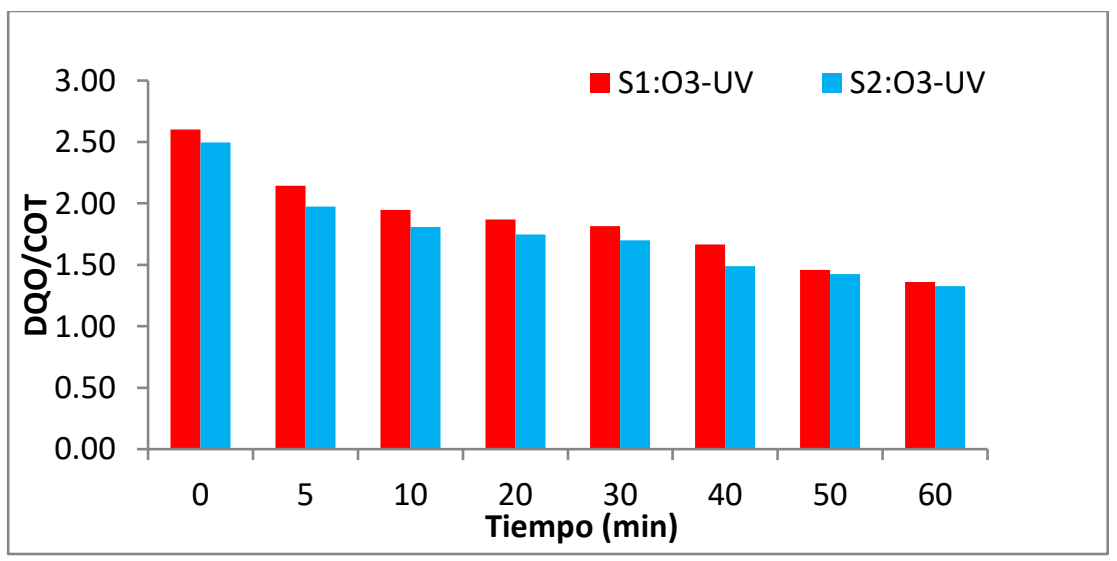

Gráfica 5-18 Relación DQO/COT de 2,5-DCP en S1: con agua destilada y en S2: con agua residual con tratamiento de oxidación de $\mathrm{O}_{3}-\mathrm{UV}$. 
2) El estado de oxidación promedio (AOS) es un indicador del grado de oxidación. Se mide este parámetro usando la siguiente ecuación (Stumm y Morgan, [35])

$$
A O S=\frac{4(C O T-D Q O)}{C O T} \quad \text { Ecuación 5-20 }
$$

El COT y la DQO se expresan en moles de C.L. $\mathrm{L}^{-1}$ y moles de $\mathrm{O}_{2} \cdot \mathrm{L}^{-1}$, respectivamente.

EI AOS se muestra en función de ozono consumido en la Gráfica 5-19.

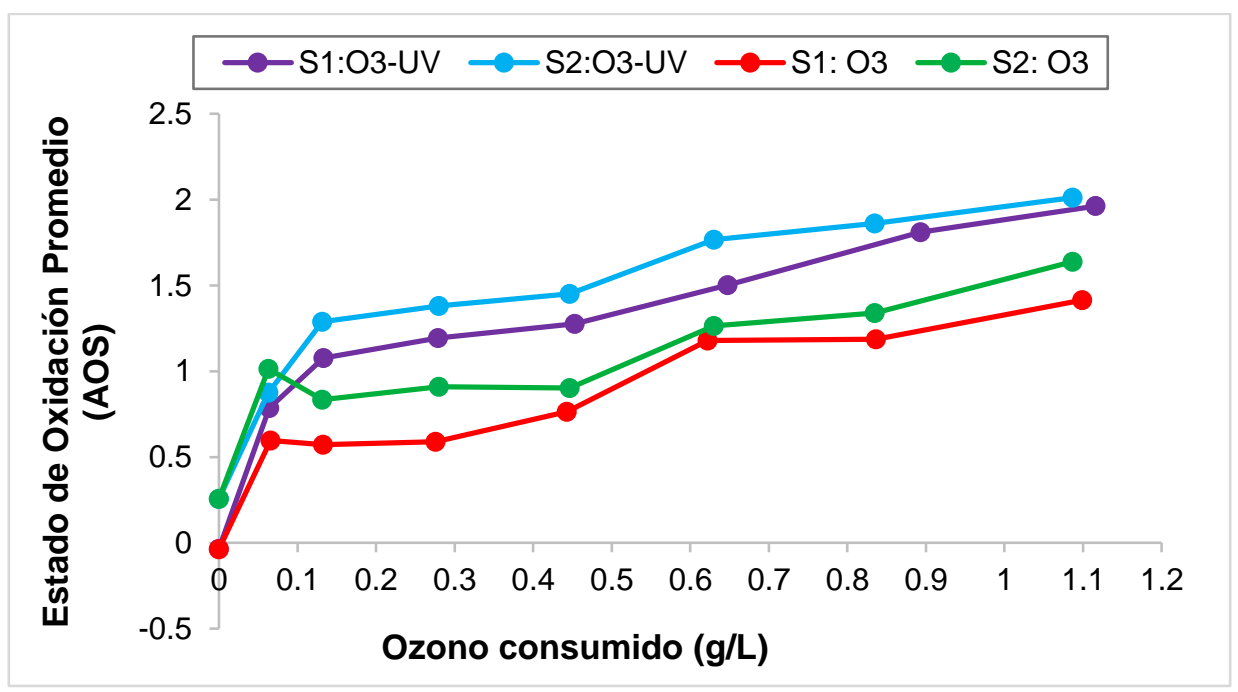

Gráfica 5-19 Estado de oxidación promedio (AOS) en función de ozono consumido $(\mathrm{g} / \mathrm{L})$, en S1: con agua destilada y en S2: con agua residual tratado con $\mathrm{O}_{3}$ y $\mathrm{O}_{3}-\mathrm{UV}$.

\subsubsection{Discusión sobre el Cambio en el estado de Oxidación}

Para tener mayor información sobre el grado de oxidación se evaluó el cambio en el estado de oxidación por la relación DQO/COT y el estado de oxidación promedio (AOS). La relación DQO/COT fue calculada, las gráficas 5-17 y 5-18 muestran su relación a lo largo de los experimentos con tratamiento de $\mathrm{O}_{3}$ y $\mathrm{O}_{3}-\mathrm{UV}$ en las soluciones $\mathrm{S} 1$ : con agua destilada y $\mathrm{S} 2$ : con agua residual. Se notó que la relación DQO/COT disminuyó de 2.6 ( $\mathrm{t}=0 \mathrm{~min}$ ) a 1.72 y 1.36 en las soluciones S1: con agua destilada tratada con ozono y ozono-UV respectivamente. En las soluciones S2: con agua residual tratada con ozono y ozono-UV, la relación $\mathrm{DQO} / \mathrm{COT}$ disminuyó de 2.5 ( $\mathrm{t}=0 \mathrm{~min}$ ) a 1.57 y 1.33 , respectivamente. 


\section{CAPÍTULO 5. RESULTADOS Y DISCUSIÓN}

Los resultados del cálculo de AOS en función del ozono consumido $(\mathrm{g} / \mathrm{L})$ se muestran en la

Gráfica 5-19. El AOS toma valores entre +4 para $\mathrm{CO}_{2}$, el estado máximo de carbono, +3 para ácido oxálico, +2 para ácido fórmico, 0 para ácido acético, -1 para benceno y -4 para $\mathrm{CH}_{4} \mathrm{el}$ estado mínimo de carbono. Por eso, entre más alto sea el valor de AOS, más alto es el grado de oxidación y mejor la degradabilidad.

En general el AOS se incrementó con el aumento en el consumo de ozono. En el caso de las soluciones S1: con agua destilada el AOS se incrementó de -0.04 a 1.40 y 1.96 con tratamiento de ozono y ozono-UV, mientras que, las soluciones S2: con agua residual AOS se incrementó de 0.26 a 1.64 y 2.01 con tratamiento de ozono y ozono-UV.

Los resultados muestran que los tratamientos con ozono-UV tuvieron los más altos estados de oxidación y así la mejor degradabilidad del 2,5-DCP y sus productos intermedios. Además los resultados muestran que el estado de oxidación con el tratamiento de ozono-UV cuando todo el 2,5-DCP fue degradado fue de aproximadamente 1.5, similar a los resultados obtenidos en otro trabajo para el 2,4-DCP con ozonación [32].

El mayor grado de oxidación medido por la relación DQO/COT y AOS, fue para las soluciones tratadas con ozono-UV, lo cual es debido a una mayor producción de los radicales hidroxilo en los tratamientos con ozono-UV, los que permitieron la degradación de más materia orgánica que las soluciones tratadas con ozono solo.

Por otro parte, se observó una relación entre la biodegradabilidad y el cambio en el estado de oxidación de los compuestos intermedios formados. A mayor oxidación de materia orgánica mejor fue la biodegradabilidad, con lo cual se puede inferir que la oxidación con ozono y ozono-UV lograron oxidar el 2,5-DCP en productos intermedios más pequeños que son más fáciles de biodegradar.

\subsubsection{Degradación del 2,5-DCP}

Los análisis de cromatografía con HPLC permitieron confirmar la degradación del 2,5-DCP con los dos procesos de oxidación estudiados. La concentración de 2,5-DCP en agua destilada y en agua residual, se miden por abatimiento del área bajo la curva usando los 


\section{CAPÍTULO 5. RESULTADOS Y DISCUSIÓN}

estándares (Figura A-0-1 y Figura A-0-2). El tiempo de retención para el 2,5-DCP fue de aproximadamente 3 minutos (Figura A-0-3 a Figura A-0-6).

En general, hubo degradación completa de 2,5-DCP con tratamiento de $\mathrm{O}_{3}$ y $\mathrm{O}_{3}-\mathrm{UV}$ en $\mathrm{S} 1$ : con agua destilada y en S2: con agua residual. La Tabla 5-14 muestra las degradaciones del 2,5-DCP, calculadas a partir de las cromatografías para cada proceso de oxidación. La Gráfica 5-20 muestra la relación de ozono consumido por 2,5-DCP removido.

Tabla 5-14 Resultados de la degradación del 2,5-DCP en soluciones S1: con agua destilada y S2: con agua residual durante 60 minutos de tratamiento con $\mathrm{O}_{3}$ y $\mathrm{O}_{3}-\mathrm{UV}$

\begin{tabular}{|c|c|c|c|}
\hline \multirow{2}{*}{ TRATAMIENTO } & OZONO & OZONO-UV \\
\hline \multirow{3}{*}{ Solución (2,5-DCP } & Tiempo de $\mathbf{O}_{\mathbf{3}}$ (min) & DCP(mg/L) & DCP(mg/L) \\
\hline \multirow{4}{*}{ S1: con agua destilada } & 0 & 500 & 500 \\
\cline { 2 - 4 } & 5 & 450 & 292 \\
\cline { 2 - 4 } & 10 & 350 & 220 \\
\cline { 2 - 4 } & 20 & 217 & 130 \\
\cline { 2 - 4 } & 30 & 120 & 99 \\
\cline { 2 - 4 } & 40 & 68 & 5 \\
\cline { 2 - 4 } & 50 & 33 & 0 \\
\hline \hline \multirow{5}{*}{ S2: con agua residual } & 60 & 0 & 500 \\
\cline { 2 - 4 } & 0 & 415 & 271 \\
\cline { 2 - 4 } & 5 & 310 & 176 \\
\cline { 2 - 4 } & 10 & 182 & 35 \\
\cline { 2 - 4 } & 20 & 75 & 16 \\
\cline { 2 - 4 } & 30 & 10 & 0 \\
\cline { 2 - 4 } & 40 & 0 & 0 \\
\cline { 2 - 4 } & 50 & 0 & 0 \\
\hline
\end{tabular}




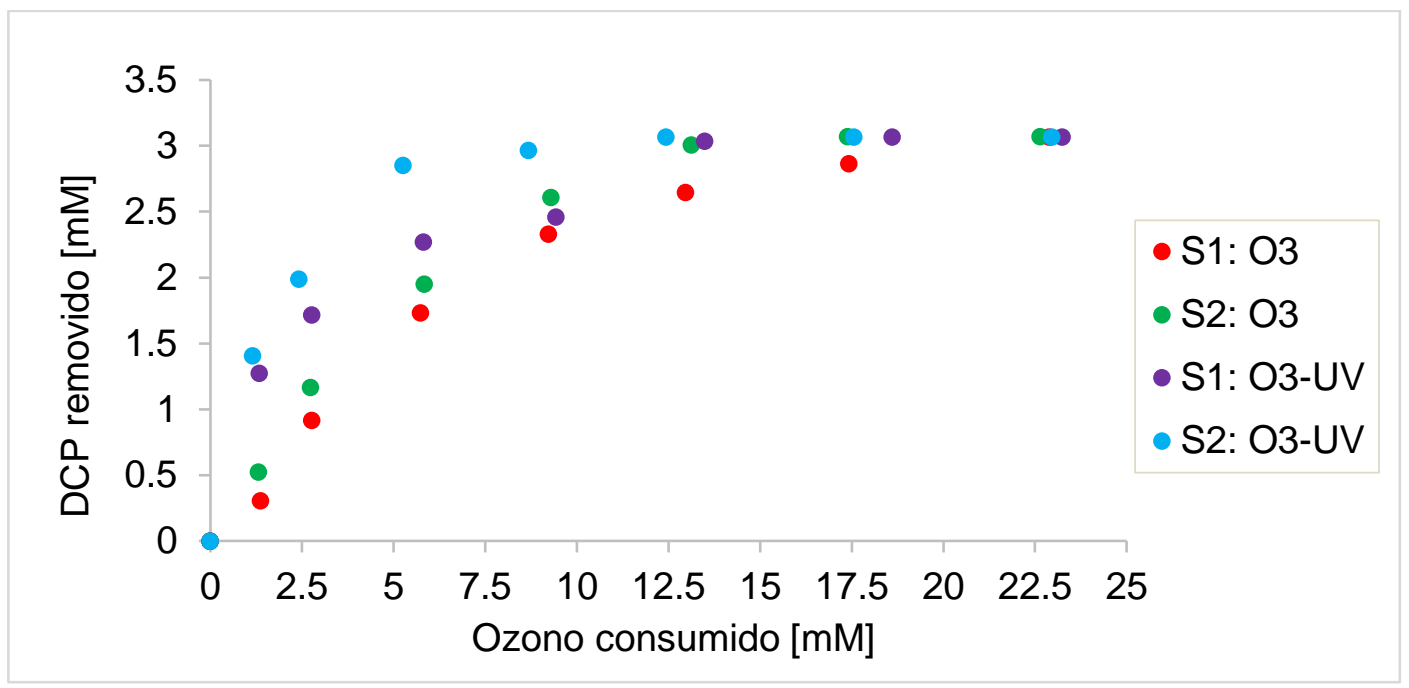

Gráfica 5-20 Relación de ozono consumido $(\mathrm{mM})$ por $\mathrm{mM}$ de 2,5-DCP removido en las soluciones S1: con agua destilada y S2: con agua residual de tratamiento con ozono y ozono-UV durante 60 minutos a $\mathrm{pH}$ inicial de $7,\left[\mathrm{DCP}_{\text {inicial }}\right]=3.07 \mathrm{mM}($ Ozono aplicado de $1.3 \mathrm{~g} / \mathrm{h})$.

\subsubsection{Discusión de la degradación del 2,5-DCP}

Para evaluar la eficiencia de los tratamientos de oxidación con ozonación y con ozonaciónUV para degradar el 2,5-DCP, en dos soluciones acuosas de 2,5-DCP de S1: con agua destilada y de S2: con agua residual, a una concentración de $3.07 \mathrm{mM}$ de 2,5-DCP, fueron tratadas con tiempos de oxidación de 60 minutos. Durante los procesos se colectaron muestras a intervalos de tiempo $(0,5,10,20,30,4050$ y $60 \mathrm{~min})$, estas soluciones fueron diluidas 1:5 para hacer análisis en HPLC. La tabla 5-14 muestra la degradación del 2,5-DCP con los análisis de cromatografía por HPLC.

Generalmente, la concentración del 2,5-DCP disminuyó con el aumento del tiempo de tratamiento de oxidación con $\mathrm{O}_{3}$ y $\mathrm{O}_{3}-\mathrm{UV}$ en las dos soluciones $\mathrm{S} 1$ : con agua destilada y $\mathrm{S} 2$ : con agua residual. En los cromatogramas (Figura A-0-3 a Figura A-0-6) se observó que las soluciones S1: con agua destilada tuvieron más picos que las soluciones S2: con agua residual. Estos resultados podrían ser por la formación de mayores productos intermedios y su presencia en el agua destilada a concentraciones más altas (se confirmó con los resultados de GC-MS). Los resultados mostraron que el 2,5-DCP fue completamente degradado a los 50 min y 40 min en las dos soluciones. 


\section{CAPÍTULO 5. RESULTADOS Y DISCUSIÓN}

Los resultados del consumo de ozono por cada mol de 2,5-DCP eliminado en la oxidación fueron calculados para todas las muestras (Gráfica 5-20). Los resultados del estudio del consumo de ozono por mol de 2,5-DCP degradado, después de los primeros 10 minutos de tratamiento con ozono y ozono-UV en las soluciones acuosa de 2,5-DCP en S1: con agua destilada y en S2: con agua residual, muestran que aproximadamente 3.0, 2.3, 1.6 y 1.2 moles de ozono fue consumido por mol de 2,5-DCP para $\mathrm{S} 1: \mathrm{O}_{3}, \mathrm{~S}_{2}: \mathrm{O}_{3}, \mathrm{~S} 1: \mathrm{O}_{3}-\mathrm{UV}$ y $\mathrm{S} 2: \mathrm{O}_{3}-\mathrm{UV}$, respectivamente. Los resultados obtenidos con los procesos de ozono-UV implican que la degradación de 2,5-DCP (medida a los $10 \mathrm{~min}$ ) fue casi dos veces más rápida que el tratamiento solo con ozonización, lo cual podría ser explicado por la formación de más radicales hidroxilo en soluciones tratadas con ozono-UV.

El tratamiento de la solución de 2,5-DCP en agua destilada con ozono $\left(\mathrm{S} 1: \mathrm{O}_{3}\right)$ fue más alto que el reportado por Qui y col. [19] de 2 moles de ozono consumido por mol de DCP eliminado, pero éste fue medido por mol de DCP inicial, lo cual no fue el caso en este trabajo. Sin embargo, los resultados obtenidos en este estudio están en el rango dado por Gilbert [39], quien reportó que aproximadamente 2 a 6 moles de ozono son consumidos por mol del compuesto aromático eliminado al inicio de la reacción.

\subsubsection{Decloración del 2,5-DCP y sus productos intermedios}

Se estudió la formación de iones de cloro inorgánico durante la degradación 2,5-DCP durante la reacción de ozono y ozono-UV. Las gráficas 5-21 y 5-22 presentan la formación de iones cloruro a lo largo del tiempo con la degradación del 2,5-DCP en las soluciones S1: con agua destilada y S2: con agua residual. 


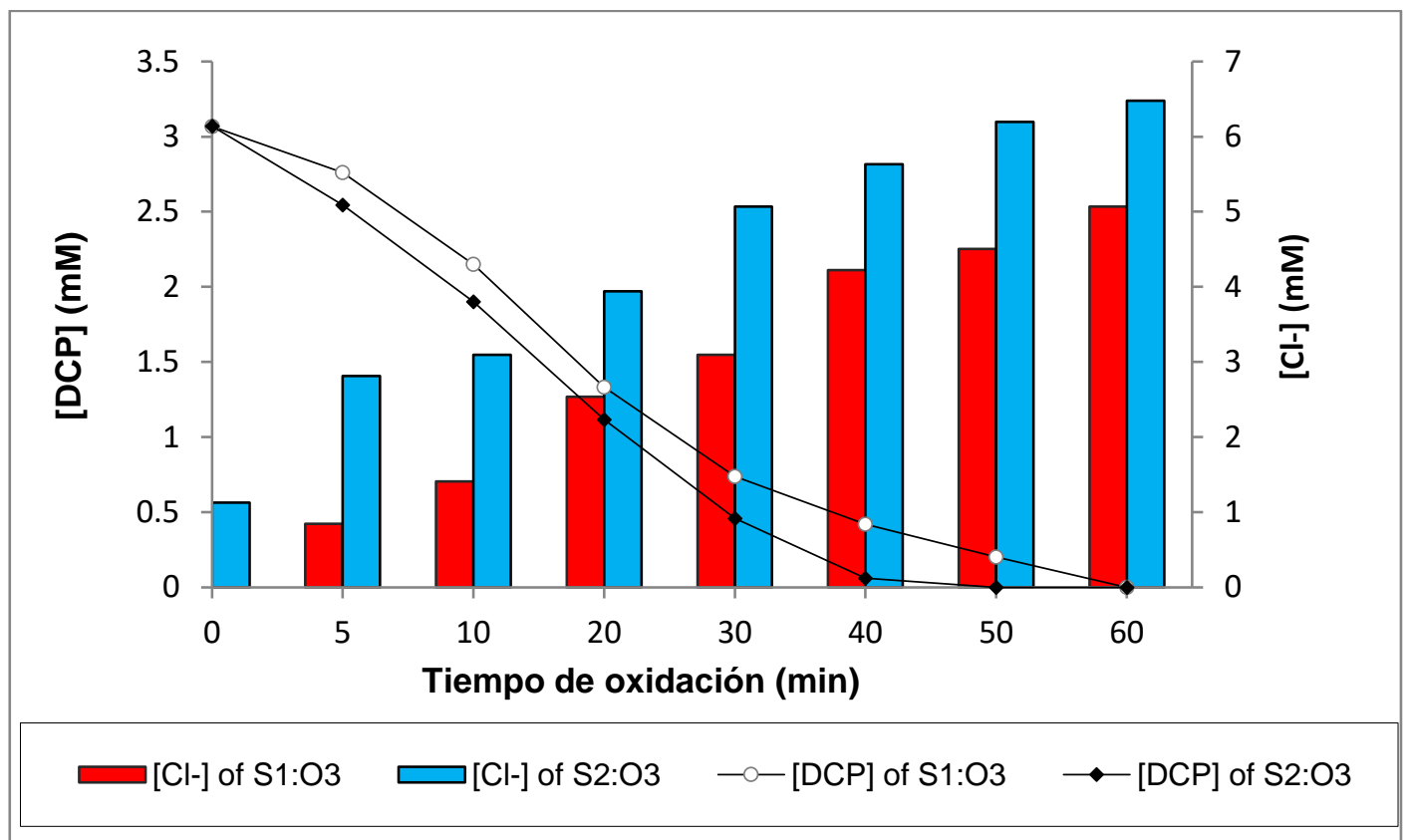

Gráfica 5-21 Formación de iones cloruros y degradación del 2,5-DCP (3.07 mM) durante el tratamiento de soluciones $\mathrm{S} 1$ : con agua destilada y $\mathrm{S} 2$ : con agua residual con $\mathrm{O}_{3}$

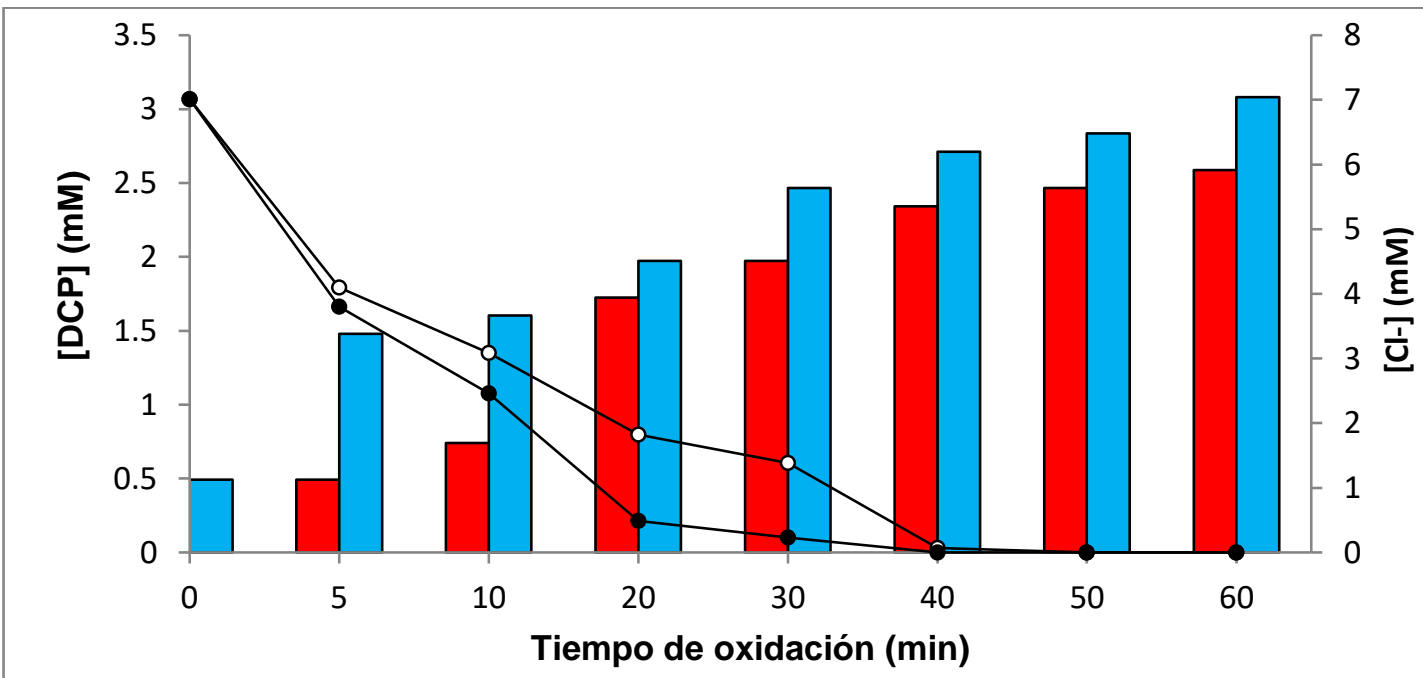

$\varpi$ [Cl-] of S1:O3-UV $\square[\mathrm{Cl}]$ of S2:O3-UV $\multimap$ [DCP] of S1:O3-UV $\bullet-[D C P]$ of S2:O3-UV

Gráfica 5-22 Formación de iones cloruros y degradación del 2,5-DCP (3.07 mM) durante el tratamiento de soluciones $\mathrm{S} 1$ : con agua destilada y $\mathrm{S} 2$ : con agua residual con $\mathrm{O}_{3}-\mathrm{UV}$ 


\section{CAPÍTULO 5. RESULTADOS Y DISCUSIÓN}

\subsubsection{Discusión sobre la degradación del DCP y la Decloración}

Los resultados muestran que los iones de cloruros son liberados cuando el cloro se separa del anillo de benceno durante las reacciones con ozono y ozono-UV. La concentración de iones de cloro aumentó cuando el nivel de degradación de DCP aumentó durante las reacciones con ozono y ozono-UV en las dos soluciones acuosas (S1 y S2), lo cual sugiere que la ozono y ozono-UV de 2,5-DCP produce algunos productos intermedios clorados que se descomponen más para liberar iones de cloro. Adicionalmente, se observó que los cloruros fueron liberados en los primeros minutos del tratamiento con ozonación y ozono-UV en las soluciones S1: con agua destilada y S2: con agua residual, lo cual sugiere que la decloración del 2,5-DCP fue el paso inicial de la degradación en las dos soluciones. Similares resultados han sido reportados [36, 37].

Por otra parte Boncz y col. [38] explicaron que la degradación de un compuesto aromático por la reacción directa con ozono es vía hidroxilación donde el grupo de alquilo y iones de haluros no son afectados dado que la deshalogenación ocurre en una etapa posterior a la degradación. En el caso del mecanismo de radicales, un radical hidroxilo ataca el anillo aromático y un átomo de cloro se libera, ya que la disociación del enlace de $\mathrm{C}-\mathrm{OH}$ requiere aproximadamente $10 \mathrm{kcal} / \mathrm{mol}$, más energía que la disociación del enlace $\mathrm{C}-\mathrm{Cl}$. Tomando esto en cuenta se esperaba que la deshalogenación ocurriera a la misma velocidad que la degradación del compuesto aromático, como fue el caso de este estudio.

En las soluciones S1 y S2 tratadas con ozono-UV se logró la decloración completa a los 60 minutos (Gráficas 5-21 y 5-22), mientras que las soluciones tratadas con ozonación alcanzaron la decloración de $86 \%$ y $90 \%$ en soluciones S1 y S2 respectivamente. Qui y col. [19] reportaron $87 \%$ de decloración de 2,5-DCP en agua destilada, lo cual es similar a los resultados obtenidos en este trabajo. Los resultados sugieren la presencia de subproductos clorados en las soluciones tratadas con ozonación.

Normalmente, la cantidad de ozono consumido por mol de DCP degradado aumenta a lo largo del tiempo, debido a que los productos intermedios de oxidación tienen una mayor demanda de ozono y también porque los cloruros formados en la solución pueden actuar como 


\section{CAPÍTULO 5. RESULTADOS Y DISCUSIÓN}

secuestradores de radicales, pero en este estudio, la cantidad de ozono consumido por mol de DCP degradado con el tratamiento de ozono a los 5 minutos fueron más altos que a los 10 minutos, lo cual podría ser explicado por la presencia de dímeros o algunos otros productos intermedios en mayor concentración como fenol y 3-CP que requieren mayor consumo de ozono $[39,40]$ que los productos intermedios formados a los 10 minutos. No se observó un comportamiento similar en las soluciones tratadas cono ozono-UV debido a que a los 5 minutos, ya tuvieron $42 \%$ y $46 \%$ degradación de DCP.

Los resultados de este estudio son muy optimistas para su aplicación en tratamiento de aguas residuales contaminados con compuestos refractantes. Normalmente, los estudios de laboratorio se llevan a cabo utilizando agua destilada y agua sintética para evitar incontrolables factores e interferencias negativas de substancias orgánicas naturales y materias inorgánicas presentes en las aguas residuales. Sin embargo, en este estudio, se demostró que la presencia de estas materias orgánicas e inorgánicas no inhibe el efecto de la oxidación en el DCP. Por el contrario, tuvieron un efecto positivo, actúan como iniciador o promotor de reacciones de radicales, lo cual permitió que la reacción de oxidación se produjera más rápido en la solución S2: con agua residual que en la solución S1: con agua destilada, tanto para el tratamiento con ozono, como con ozono-UV. En este estudio no se identificaron las sustancias que actuaron como promotores o iniciadores en los procesos de oxidación con ozono y ozono-UV en las soluciones con agua residual. En los pocos estudios publicados por otros investigadores sobre los clorofenoles en el agua residual sintética, las concentraciones del tóxico estaban a menor concentración que las materias orgánicas presenten en las soluciones acuosas estudiadas [41]. Esto puede ser una de las razones del efecto inhibitorio de la materia orgánica, como ha sido reportado por Wohlers y col. [30] en su estudio. Sin embargo, en este estudio la concentración del tóxico fue mucho más alta que la materia orgánica en las soluciones acuosas estudiadas, lo que podría ser la razón de que ningún efecto inhibidor fue observado bajo las condiciones experimentales de este estudio.

Asimismo, los tratamientos de oxidación con ozono y ozono-UV de las soluciones S2: con aguas residuales dieron los mejores resultados en la degradación del 2,5-DCP, eliminación de COT, remoción de DQO y biodegradabilidad. 


\subsection{Cinética y Mecanismos de Reacción de la Oxidación del 2,5-DCP}

\subsubsection{Estudio de la cinética de la oxidación del 2,5-DCP}

En esta parte se presentan los resultados de la degradación del DCP en los procesos de oxidación, de acuerdo a la variación del contenido de DQO, COT y 2,5-DCP.

\subsubsection{Constantes de la velocidad de reacción de la $D Q O$}

Se hizo un estudio de la cinética de oxidación del 2,5-DCP en agua destilada y en agua residual a pH 7 con ozonación y ozono-UV usando una relación de [DQO]t/[DQO]. Las constantes cinéticas fueron de pseudo primer orden durante los 60 minutos (Gráficas 5-23 y 5-24) y los resultados de la constante cinética y del tiempo medio se presentan en la Tabla 515.

Para las dos soluciones acuosas (S1 y S2), la constante cinética de pseudo primer orden para la DQO y su degradación por ozonación y ozono-UV fue calculada por la ecuación 5-21.

$$
\operatorname{Ln} \frac{[D Q O]}{[D Q O]_{0}}=-k t
$$

Ecuación 5-21

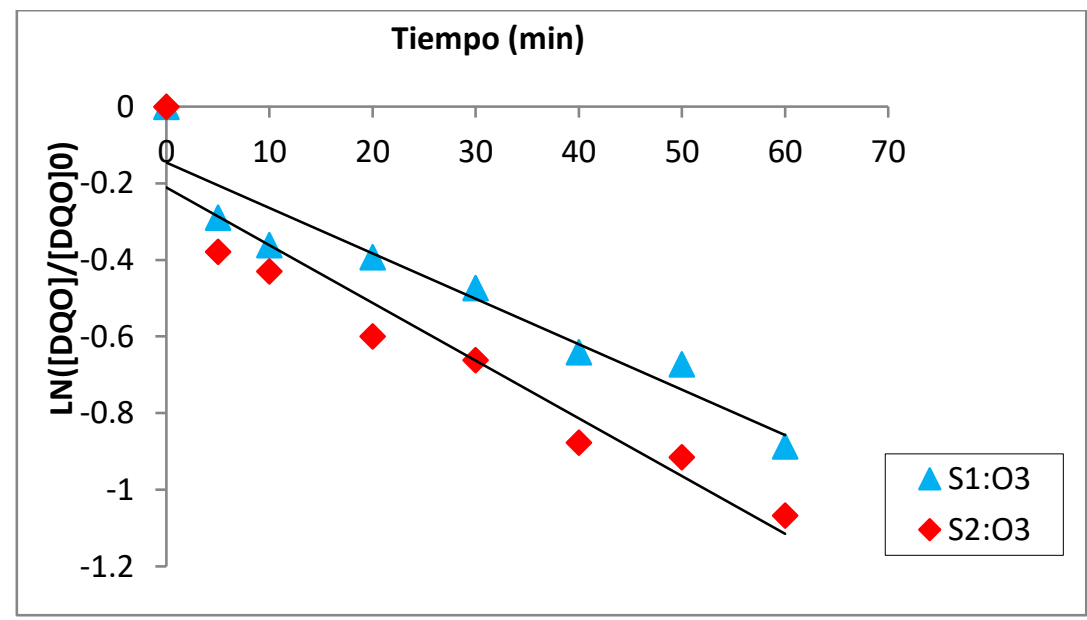

Gráfica 5-23 Constante cinética de pseudo primer orden de la DQO en la oxidación del en S1: con agua destilada y en S2: con agua residual tratada con $\mathrm{O}_{3}$ 


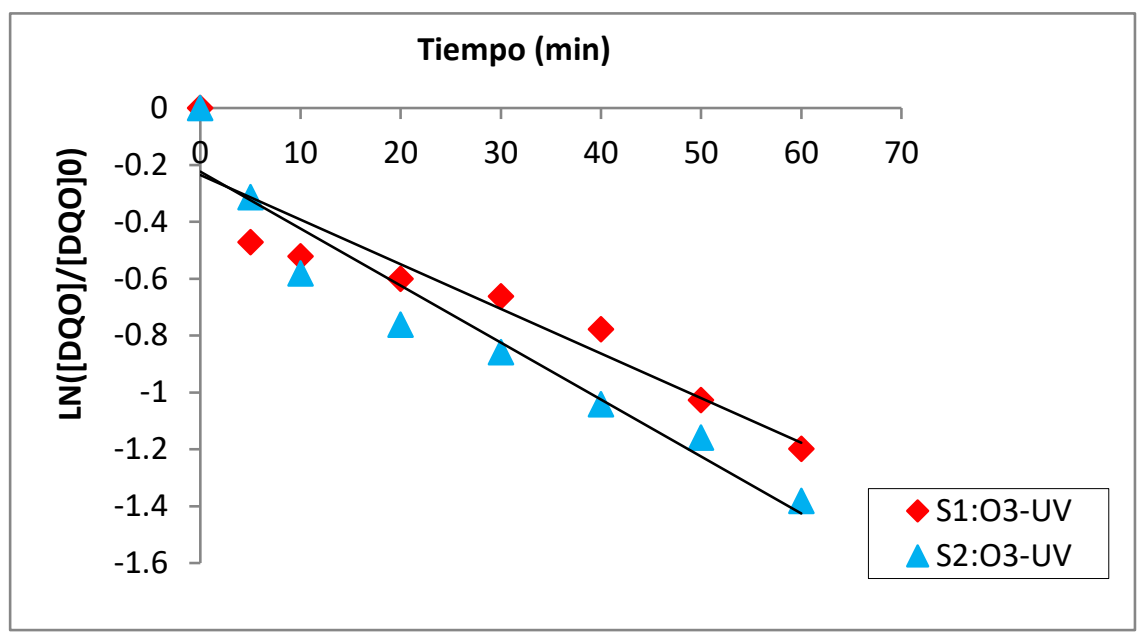

Gráfica 5-24 Constante cinética de pseudo primer orden de la DQO en la oxidación del 2,5-DCP en $\mathrm{S} 1$ : con agua destilada y en S2: con agua residual tratada con $\mathrm{O}_{3}-\mathrm{UV}$

Tabla 5-15 Resultados del estudio cinético de la DQO en la oxidación con $\mathrm{O}_{3}$ y $\mathrm{O}_{3}-\mathrm{UV}$ del 2,5-DCP en S1: con agua destilada y en S2: con agua residual

\begin{tabular}{|c|c|c|c|c|}
\hline Solución & Oxidación & $k\left(\min ^{-1}\right)$ & R2 & $\begin{array}{c}t_{1 / 2} \\
(\mathrm{~min})\end{array}$ \\
\hline $\mathrm{S} 1: \mathrm{O}_{3}$ & \multirow{2}{*}{ OZONO } & 0.011 & 0.90 & 63 \\
\hline $\mathrm{S} 2: \mathrm{O}_{3}$ & & 0.015 & 0.91 & 46 \\
\hline $\mathrm{S} 1: \mathrm{O}_{3}-\mathrm{UV}$ & \multirow{2}{*}{ OZONO-UV } & 0.016 & 0.93 & 43 \\
\hline $\mathrm{S} 2: \mathrm{O}_{3}-\mathrm{UV}$ & & 0.020 & 0.93 & 35 \\
\hline
\end{tabular}




\section{CAPÍTULO 5. RESULTADOS Y DISCUSIÓN}

\subsubsection{Discusión sobre los resultados de la cinética de la DQO}

Se estudió la cinética del 2,5-DCP en dos soluciones acuosas S1: con aguas destilada y S2: con agua residual a pH inicial de 7 con oxidación de ozono y ozono-UV para cuantificar la rapidez de remoción de la materia orgánica medida como DQO en las distintas muestras colectadas, se aplicó una cinética de primer orden. En la de tratamiento con ozono y ozonoUV, se resumen los valores de las constantes cinéticas obtenidas así como los correspondientes coeficientes de correlación. Los resultados sugieren que la máxima remoción de DQO puede obtenerse con tratamientos con ozono-UV. Además, se notó un ligero aumento en la constante cinética en las soluciones S2: con agua residual, puede ser como resultados de mayor efecto en la formación de radicales en estas soluciones por la presencia de la materia orgánica. Los valores de $\mathrm{k}$ fueron de $0.011 \mathrm{~min}^{-1}, 0.015 \mathrm{~min}^{-1}, 0.016$ $\mathrm{min}^{-1}$ y $0.020 \mathrm{~min}^{-1}$ para los tratamientos $\mathrm{S} 1: \mathrm{O}_{3}, \mathrm{~S} 2: \mathrm{O}_{3}, \mathrm{~S} 1: \mathrm{O}_{3}-\mathrm{UV}$ y $\mathrm{S} 2: \mathrm{O}_{3}-\mathrm{UV}$, respectivamente.

\subsubsection{Constantes de la velocidad de reacción del COT}

En la Tabla 5-16 se presentan los valores de las constantes de velocidad de reacción de la cinética del COT en la oxidación del 2,5-DCP en agua destilada (S1) y en agua residual (S2) tratada con $\mathrm{O}_{3}$ у Оз-UV respectivamente para cada prueba y los tiempos de vida media del COT de las soluciones durante los primeros 60 minutos. Donde $k_{1}$ fue calculado por los primeros 10 min y $\mathrm{k}_{2}$ de los últimos 50 minutos. 


\section{CAPÍTULO 5. RESULTADOS Y DISCUSIÓN}

Tabla 5-16 Resultados de la cinética del COT en la oxidación del 2,5-DCP en agua destilada (S1) y en agua residual (S2) tratada con $\mathrm{O}_{3}$ y $\mathrm{O}_{3}-\mathrm{UV}$

\begin{tabular}{|c|l|c|c|c|c|c|c|}
\hline POA & 2,5-DCP en solución & $\begin{array}{c}\mathbf{k}_{1} \\
\left(\mathbf{m i n}^{-1}\right)\end{array}$ & $\begin{array}{c}\mathbf{t}_{1 / 2} \\
(\mathbf{m i n})\end{array}$ & $\mathbf{R}^{\mathbf{2}}$ & $\begin{array}{c}\mathbf{k}_{2} \\
\left(\mathbf{m i n}^{-1}\right)\end{array}$ & $\begin{array}{c}\mathbf{t} 1 / \mathbf{2} \\
(\mathbf{m i n})\end{array}$ & $\mathbf{R}^{\mathbf{2}}$ \\
\hline \multirow{2}{*}{$\mathbf{O}_{3}$} & S1:con agua destilada & 0.023 & 30 & 0.97 & 0.003 & 239 & 0.99 \\
\cline { 2 - 8 } & S2:con agua residual & 0.026 & 26 & 0.90 & 0.005 & 139 & 0.92 \\
\hline \multirow{2}{*}{ O $_{3}$-UV } & S1:con agua destilada & 0.023 & 30 & 0.97 & 0.005 & 124 & 0.87 \\
\cline { 2 - 8 } & S2:con agua residual & 0.026 & 26 & 0.99 & 0.007 & 104 & 0.97 \\
\hline
\end{tabular}

\subsubsection{Discusión sobre la constante cinética del COT}

Se estudió la cinética de remoción del COT en los distintos analitos. Se aplicó una cinética de primer orden, y los valores de las constantes cinéticas obtenidas fueron del mismo orden que el anterior, donde la adición de UV a los tratamientos de ozonación mejoró la mineralización del 2,5-DCP y sus productos intermedios. La remoción del COT en la oxidación con ozono y ozono-UV fue rápida durante los primeros 10 minutos y después la velocidad de remoción de COT disminuyó mucho (Tabla 5-16). La disminución de remoción en COT es debido a la formación de intermedios refractarios. Esplugas y col. [33] reportaron similar comportamiento con respecto a la cinética de la mineralización de 4-CP.

Los resultados indican que los productos intermedios formados fueron más resistentes a los tratamientos aplicados y se necesitaría aumentar la producción de radicales hidroxilo que son más eficaces en la reducción de estos compuestos. Además el comportamiento de las dos oxidaciones en la remoción de COT fue de la misma magnitud, lo cual sugiere que operan con el mismo mecanismo de reacción.

\subsubsection{Constantes de la velocidad de reacción del 2,5-DCP}

Los resultados de la cinética de oxidación del 2,5-DCP tratada con POAs $\left(\mathrm{O}_{3}\right.$ y $\left.\mathrm{O}_{3}-\mathrm{UV}\right)$ en agua destilada (S1) y en agua residual (S2) se muestran en la Tabla 5-17 se presentan los valores de las constantes de velocidad de reacción para cada prueba, además los tiempos de vida media del 2,5-DCP de las soluciones. 


\section{CAPÍTULO 5. RESULTADOS Y DISCUSIÓN}

Tabla 5-17 Resultados de la cinética del 2,5-DCP en agua destilada (S1) y en agua residual (S2)

\begin{tabular}{|c|c|c|c|c|}
\hline POA & 2,5-DCP en solución & $\begin{array}{c}k \\
(1 / \mathrm{min})\end{array}$ & $\mathbf{R}^{2}$ & $\begin{array}{c}\mathrm{t}_{1 / 2} \\
(\mathrm{~min})\end{array}$ \\
\hline \multirow[b]{2}{*}{$\mathbf{O}_{3}$} & S1:con agua destilada & 0.0542 & 0.99 & 13 \\
\hline & S2:con agua residual & 0.0803 & 0.91 & 8 \\
\hline \multirow[b]{2}{*}{$\mathrm{O}_{3}-\mathrm{UV}$} & S1:con agua destilada & 0.0973 & 0.90 & 7 \\
\hline & S2:con agua residual & 0.121 & 0.99 & 6 \\
\hline
\end{tabular}

\subsubsection{Discusión sobre la constante cinética de la oxidación del 2,5-DCP}

Con respecto a la velocidad de reacción, se adaptan mejor los datos con el modelo de pseudoprimer orden [42]. Las constantes cinéticas, se calcularon k, para los diferentes procesos de oxidación en soluciones S1 y S2 como se muestra en la Tabla 5-17. Los valores calculados para los procesos de oxidación se comportan de manera similar a los reportados en la literatura, donde la reacción de DCP fue más rápida con $\mathrm{O}_{3}-U V$ que solo con $\mathrm{O}_{3}$ [43-45]. La constante calculada por Trapido y col. [46] para la ozonización de 2,4-DCP con una concentración de $0.4 \mathrm{mM}$ fue de 0,0586 $\mathrm{min}^{-1}$, que está en el mismo orden de magnitud encontrada en este estudio para el tratamiento de ozonización de 2,5-DCP en soluciones S1 y S2. Qiu y col. [19] en su estudio de la constante de velocidad calculada para el 2,5-DCP fue de $58.000 \mathrm{M}^{-1} \mathrm{~s}^{-1}$ para DCP molecular y $2.6 \times 10^{9} \mathrm{M}^{-1} \mathrm{~s}^{-1}$ para el ion de DCP con tratamientos de ozono. Estas constantes son mucho más rápidas que los valores de este estudio. Sin embargo, en comparación con este estudio, la proporción de dosis de ozono con respecto a la concentración de DCP fue mayor y la concentración de DCP fue mucho menor en el estudio de Qiu y col. [19]. Tomando en consideración que en este estudio se usó una concentración de DCP muy alta y una dosis baja de ozono aplicada en comparación a la literatura, por ejemplo, Wang y col. [16] aplicaron aproximadamente $4.2 \mathrm{mM}$ de ozono para una degradación completa de $0.2 \mathrm{~L}$ de $2,5-\mathrm{DCP}$, mientras que en este estudio para degradar el mismo volumen de 2,5-DCP se requirió aplicar $3 \mathrm{mM}$ de ozono. Esto puede ser por la mezcla eficiente del ozono en las soluciones de DCP, debido a las pequeñas burbujas uniformes esféricas creadas en el reactor durante la oxidación. 


\section{CAPÍTULO 5. RESULTADOS Y DISCUSIÓN}

En general, los estudios cinéticos mostraron que las constantes de velocidad obtenidas para los tratamientos de ozono-UV fueron 1.5 veces más rápidas que las constantes calculadas para los tratamientos con ozono. Esto puede ser debido a la alta capacidad de absorción molar de clorofenoles en la región UV y la mayor concentración de radicales hidroxilo en la solución.

\subsubsection{Determinación de la constante de disociación del 2,5-DCP}

La constante de disociación se determinó como está descrito por Qiu y col. [19], donde S, fue tomada como absorbancia total en la suma de las concentraciones de DCP molecular [DCPmol] y el ion de diclorofenoxido [DCPion]; b es el ancho de la celda espectrofotométrica y $\varepsilon_{1}$ y $\varepsilon_{2}$ son los coeficientes de absorbancias de $\mathrm{DCP}_{\text {mol }}$ y $\mathrm{DCP}_{\text {ion }}$ respectivamente. Según la $S=\varepsilon_{1} b\left[D C P_{M O L}\right]+\varepsilon_{2} b\left[D C P_{I O N}\right]$

Ecuación 5-22 [19]:

$$
S=\varepsilon_{1} b\left[D C P_{M O L}\right]+\varepsilon_{2} b\left[D C P_{I O N}\right]
$$

Ecuación 5-22

Para calcular el grado de disociación $(\alpha)$ :

$$
\alpha=\frac{S-\varepsilon_{1} b[D C P]}{\varepsilon_{2} b[D C P]-\varepsilon_{1} b[D C P]}=\frac{S-S_{1}}{S_{2}-S_{1}}
$$

Donde $S_{1}$ es la absorbancia de DCP mol (sin disociación) y $S_{2}$ es la absorbancia del ion de diclorofenoxido (disociación completa). Según los Datos de los Experimentos de Qu y col. [19] se sugiere usar $\mathrm{S}_{1}$ a valores de $\mathrm{pH}$ bajos $(\mathrm{pH}<6)$ y $\mathrm{S}_{2}$ a valores de $\mathrm{pH}$ altos $(\mathrm{pH}>10)$. Por eso, en este estudio las absorbancias a valores de $\mathrm{pH} 3$ y $\mathrm{pH} 11$ se utilizaron para $\mathrm{S}_{1}$ y $\mathrm{S}_{2}$, respectivamente.

En la Gráfica 5-25 se pueden ver las absorbancias en función de diferentes valores de pH de la solución acuosa de 2,5-DCP en agua destilada. Gráfica 5-25 Absorbancias a $250 \mathrm{~nm}$ de la solución acuosa de 2,5-DCP en agua destilada. 


\section{CAPÍTULO 5. RESULTADOS Y DISCUSIÓN}

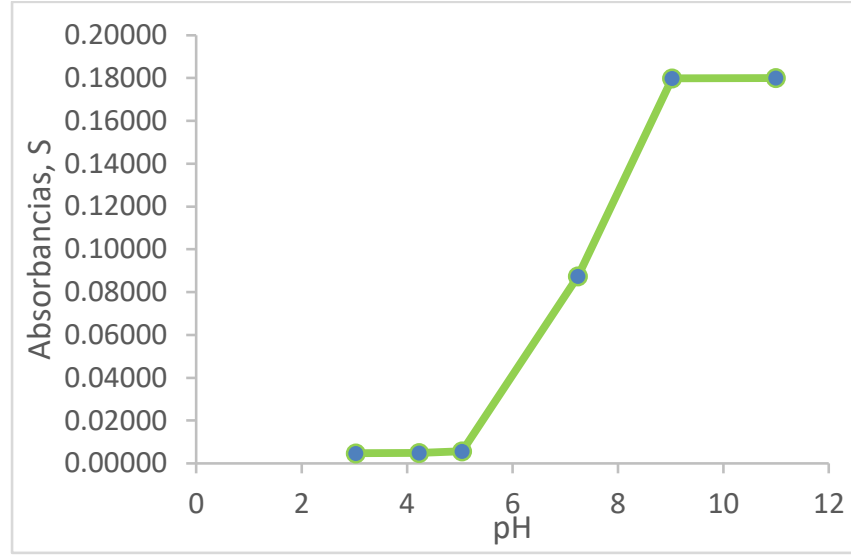

Gráfica 5-25 Absorbancias a $250 \mathrm{~nm}$ de la solución acuosa de 2,5-DCP en agua destilada a diferentes $\mathrm{pH}$.

$[D C P]=0.0613 \mathrm{mM}$ a diferentes valores de $\mathrm{pH}$

Por otra parte la constante de disociación $\mathrm{K}_{\mathrm{a}}$, puede ser calculada según la siguiente ecuación (ec.5-24):

$$
K_{a}=\frac{\left[D C P_{I O N}\right]\left[H^{+}\right]}{\left[D C P_{M O L}\right]}=\left(\frac{\alpha}{1-\alpha}\right)\left(H^{+}\right) \quad \text { Ecuación 5-24 }
$$

Así que, el valor de $\mathrm{K}_{\mathrm{a}}$ fue calculado gráficamente, por la concentración de iones de Hidrógeno $\left[\mathrm{H}^{+}\right]$contra $\left(\alpha^{-1}-1\right)$ que produjo una línea recta con la pendiente siendo $\mathrm{K}_{\mathrm{a}}$ como se demostró en la Gráfica 5-26.

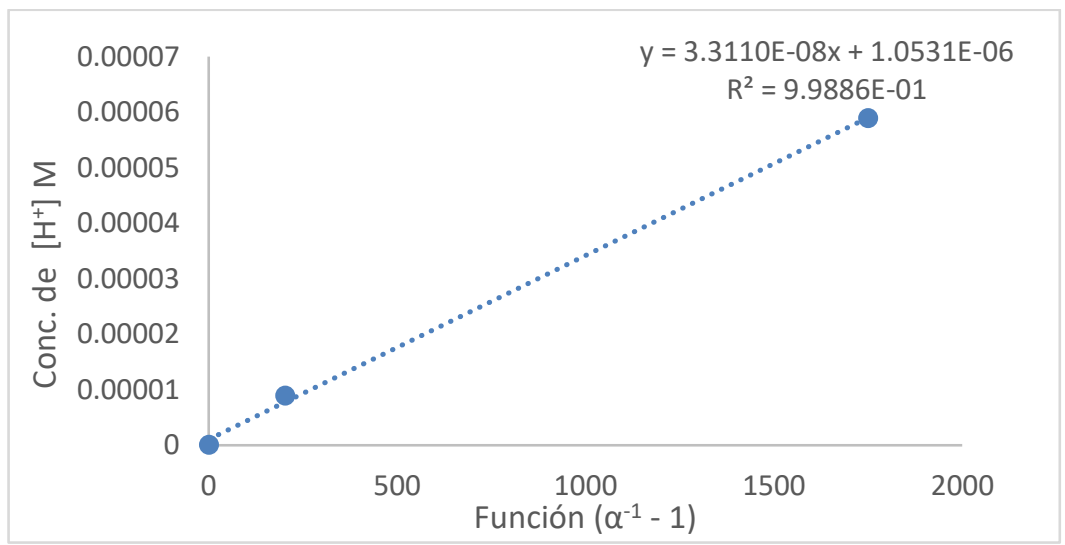

Gráfica 5-26 Determinación de Constante de disociación $\left(\mathrm{K}_{\mathrm{a}}\right)$ de 2,5-DCP 


\section{CAPÍTULO 5. RESULTADOS Y DISCUSIÓN}

También se calculó la concentración del $\mathrm{DCP}_{\text {mol }}$ y DCPion en la solución acuosa de agua destilada a pH 7.07; se usó la ecuación dada por Qui y col [19]:

$$
\begin{array}{rr}
{\left[D C P_{M O L}\right]=(1-\alpha)[D C P]} & \text { Ecuación 5-25 } \\
{\left[D C P_{I O N}\right]=\alpha[D C P]} & \text { Ecuación 5-26 }
\end{array}
$$

A continuación se muestran las concentraciones obtenidas:

$$
\begin{aligned}
{\left[\mathrm{DCP}_{\mathrm{MOL}}\right] } & =6.52 \times 10^{-6} \mathrm{M} \\
{\left[\mathrm{DCP}_{\mathrm{ION}}\right] } & =5.5 \times 10^{-5} \mathrm{M}
\end{aligned}
$$

\subsubsection{Discusión sobre la constante de disociación del 2,5-DCP}

La constante de disociación del 2,5-DCP calculada en este trabajo fue de $3.31 \times 10^{8} \mathrm{M}$ (Grafica 5-26) que da un valor de pKa de 7.48. El pKa obtenido en este estudio está en la misma magnitud del valor de pKa reportado en la literatura por [47] de 7.51 y los valores de pKa obtenidos por Qu y col. [19] de 7.4, también es un poco mayor que el de Gunawardana y col. [46] con un pKa de 6.45. Usando el valor de Ka y a calculados, se pueden calcular las concentraciones de DCPMOL y DCPIon presentes en la solución acuosa de este estudio. Los resultados muestran que la solución 2,5-DCP fue más en su forma aniónica que molecular, así que se espera tener una mayor concentración de iones diclorofenolato que DCP molecular, lo cual sugiere que la ozonación puede reaccionar más rápido con el ion diclorofenolato que con DCP molecular [20].

Productos intermedios de la degradación de 2,5- DCP por reacción con ozono y ozono-UV Los productos intermedios de 2,5-DCP que han sido identificados por cromatografía de gases acoplado a Espectrometría de masas (GC/MS) se muestran en la Tabla 5-18 y las Figura 5-5 y Figura 5-6 muestran la relación masa-carga $(\mathrm{m} / \mathrm{z})$ de (a) 2,5-DCP obtenido a $6.5 \mathrm{~min}$ y (b) Hidroquinona obtenido a $4.3 \mathrm{~min}$.

Además, en las figuras 5-7 a 5-10 se muestra la degradación del 2,5-DCP en las dos soluciones acuosas (S1 y S2) a lo largo del proceso de oxidación con ozono y ozono-UV, así como la formación y/o acumulación de los compuestos fenólicos y ácidos orgánicos identificados. 


\section{CAPÍTULO 5. RESULTADOS Y DISCUSIÓN}

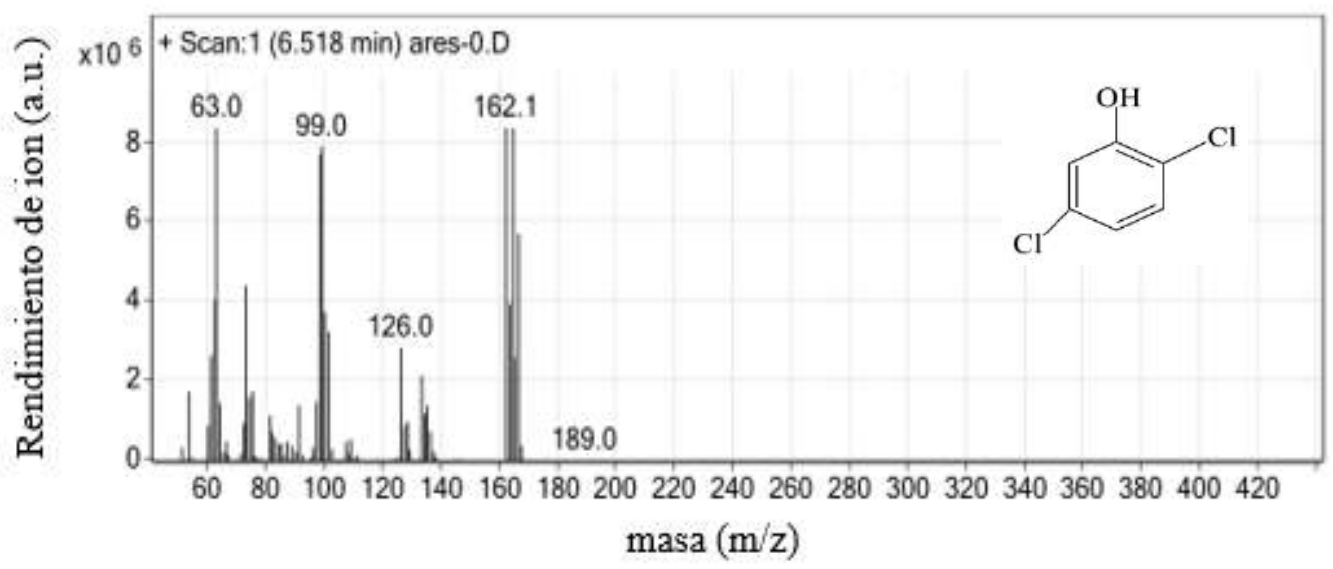

Figura 5-5 Análisis espectral de masas de 2,5-DCP

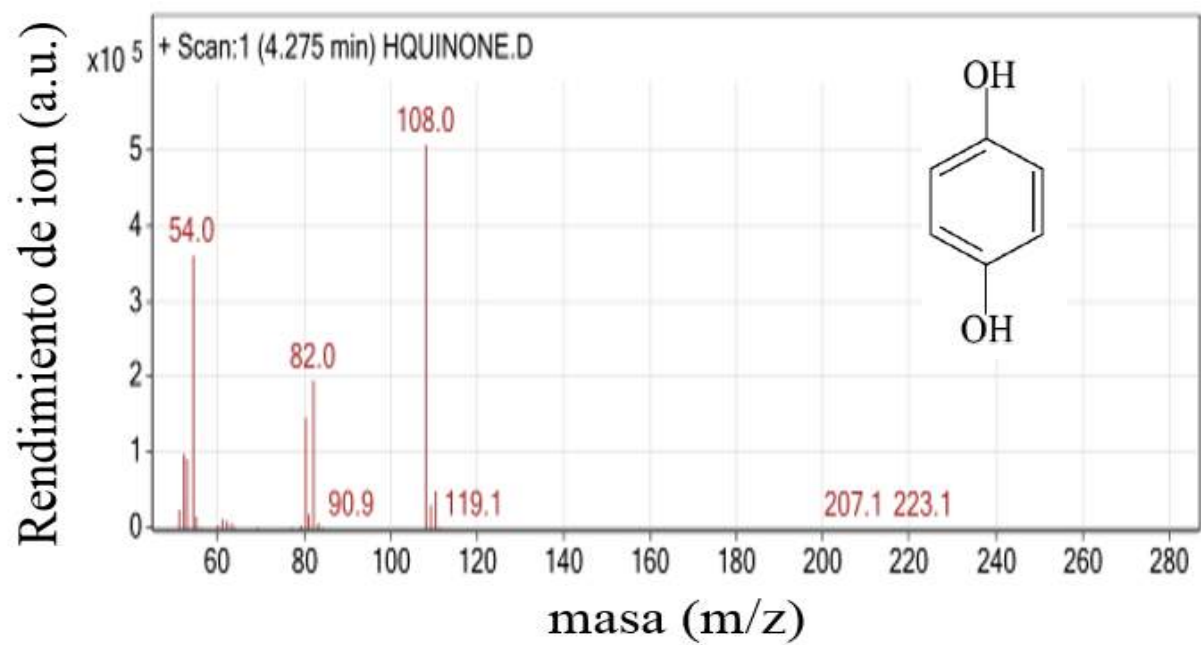

Figura 5-6 Análisis espectral de masas de hidroquinona 


\section{CAPÍTULO 5. RESULTADOS Y DISCUSIÓN}

Tabla 5-18 Lista de los compuestos intermedios formados a partir de la oxidación con ozono y ozonoUV del 2,5-DCP

\begin{tabular}{|c|c|c|c|}
\hline No. & Productos intermedios & Estructura & $\begin{array}{c}(\mathrm{m} / \mathrm{z}) \text { y peso } \\
\text { molecular }\end{array}$ \\
\hline 1 & Ácido acético & & 60 \\
\hline 2 & Fenol & & 94 \\
\hline 3 & Catecol & & 64,110 \\
\hline 4 & 3-Clorofenol & & 65,128 \\
\hline 5 & Hidroquinona & & 81,110 \\
\hline 6 & 2,5-Diclorohidroquinona & & 114,178 \\
\hline 7 & 3,6-Dicloro-1,2-benzendiol & & 106,178 \\
\hline 18 & 4-Clorocatecol & & 146,144 \\
\hline 9 & 4-Clororesorcinol & & $52,81,144$ \\
\hline 10 & Ácido propiónico & & $45,57,73,74$ \\
\hline
\end{tabular}




\section{CAPÍTULO 5. RESULTADOS Y DISCUSIÓN}

Tabla 5-18 Continuación de los compuestos intermedios formados a partir de la oxidación con ozono y ozono-UV del 2,5-DCP.

\begin{tabular}{|c|c|c|c|}
\hline No. & Productos intermedios & Estructura & $\begin{array}{c}(\mathrm{m} / \mathrm{z}) \text { y peso } \\
\text { molecular }\end{array}$ \\
\hline 11 & 2-Chloro-1,4-benzenediol & & $52,80,144$ \\
\hline 12 & Ácido pentanoico & & $60,73,102$ \\
\hline 13 & Resorcinol & & $81,82,110$ \\
\hline 14 & Ácido glicólico & & $44,47,76$ \\
\hline 15 & 2-(2-Hidroxipropoxi)-1-propanol & & 59,13134 \\
\hline 16 & 4,6-diclororesorcinol & & $51,86,178$ \\
\hline 17 & Clorohidroquinona & & $52,80,144$ \\
\hline
\end{tabular}




\section{CAPÍTULO 5. RESULTADOS Y DISCUSIÓN}

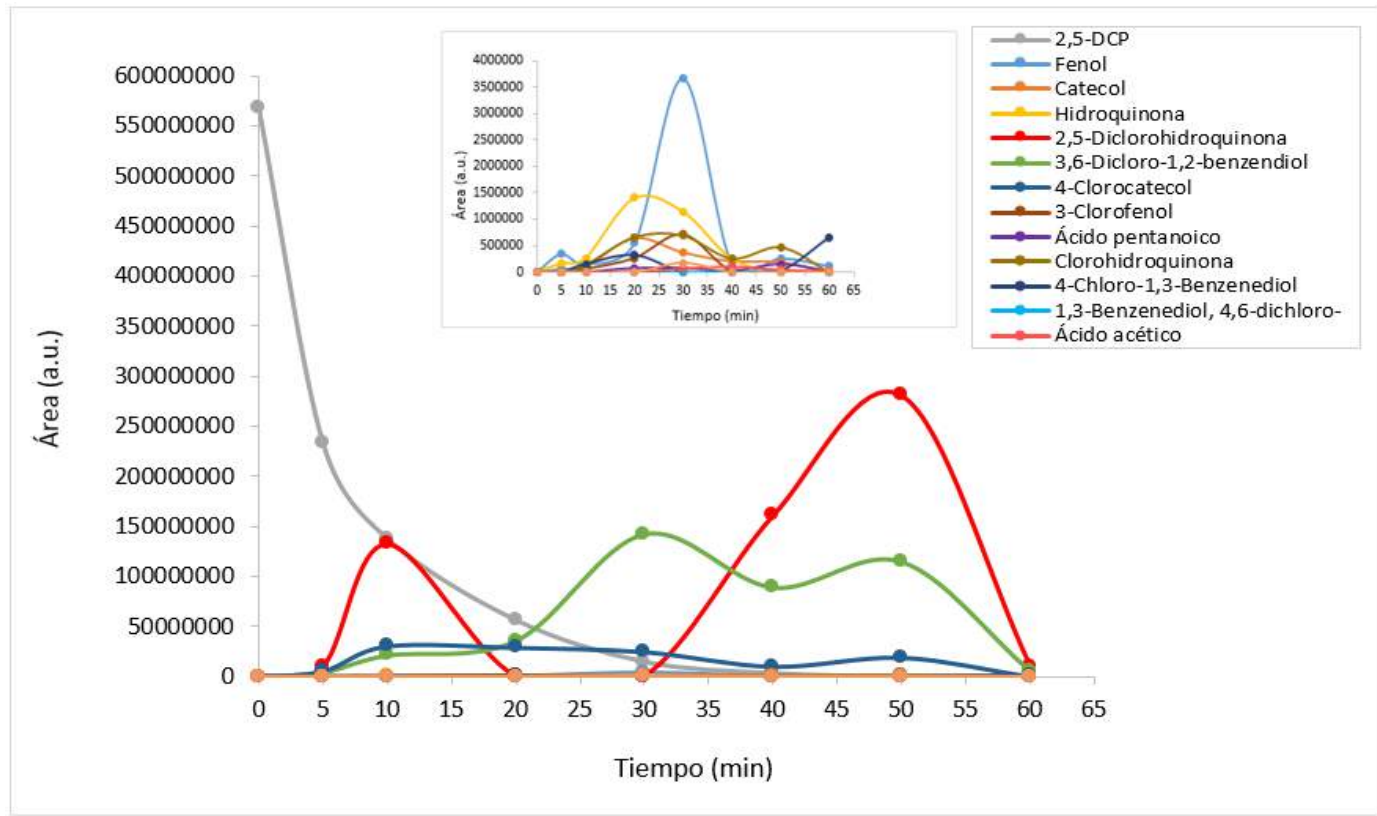

Figura 5-7 Distribución de compuestos intermedios a lo largo del tratamiento con ozonación en solución acuosa de 2,5-DCP en S1: con agua destilada ( $\mathrm{pH} 7$ )

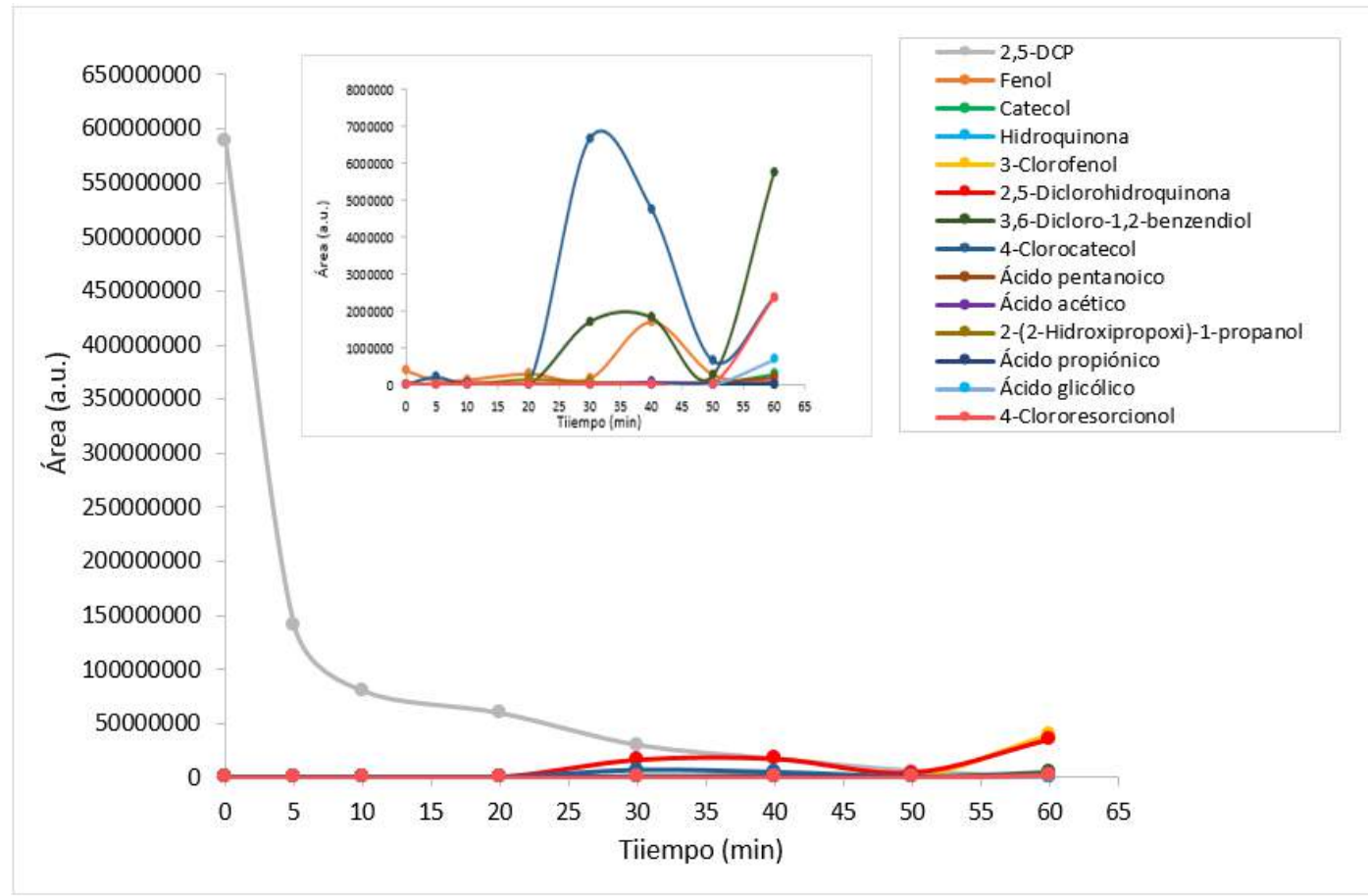

Figura 5-8 Distribución de compuestos intermedios a lo largo del tratamiento con ozonación en solución acuosa de 2,5-DCP en S2: con agua residual ( $\mathrm{pH} 7)$ 


\section{CAPÍTULO 5. RESULTADOS Y DISCUSIÓN}

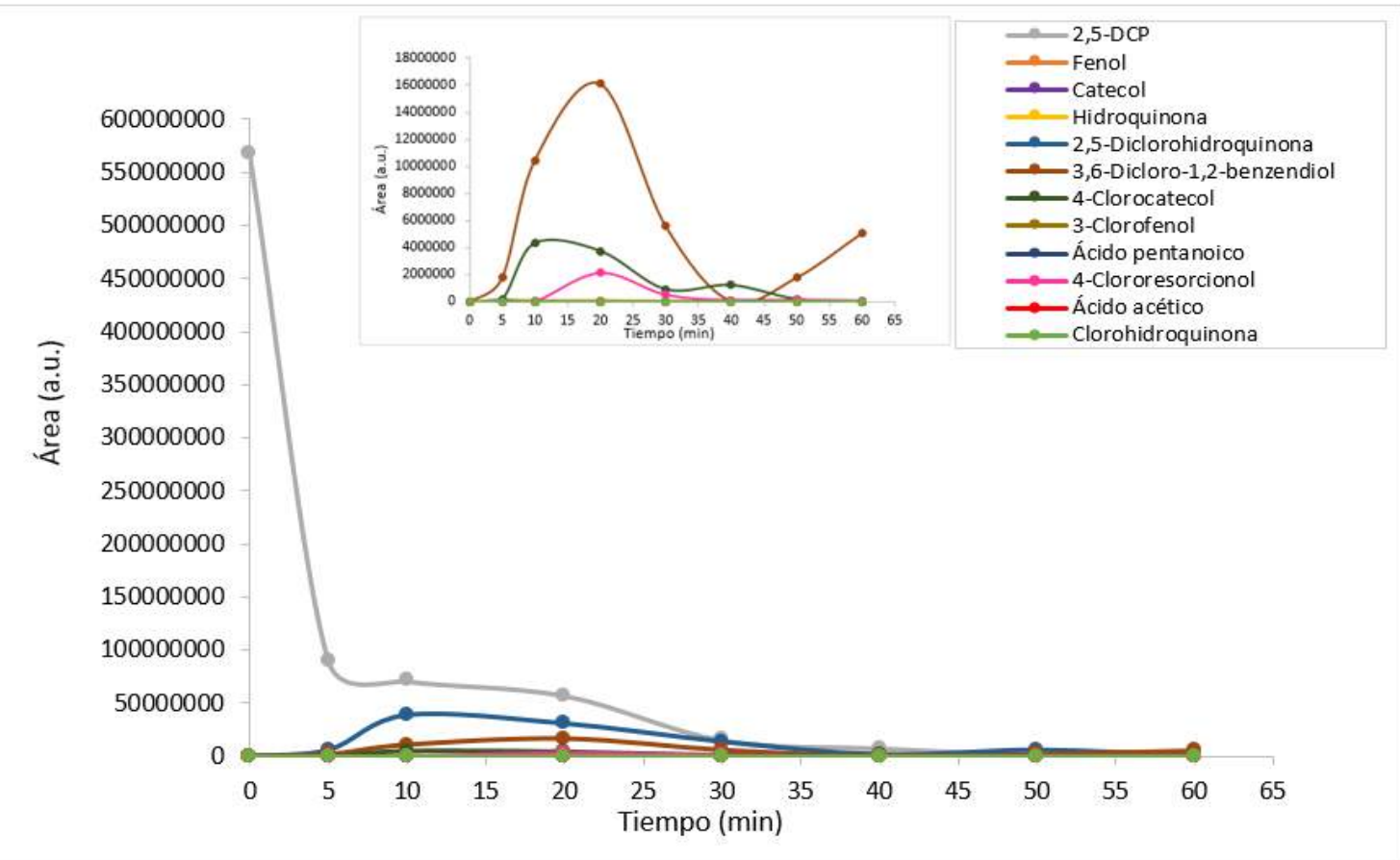

Figura 5-9 Distribución de compuestos intermedios a lo largo del tratamiento con ozonación-UV en solución acuosa de 2,5-DCP en S1: con agua destilada $(\mathrm{pH} 7)$

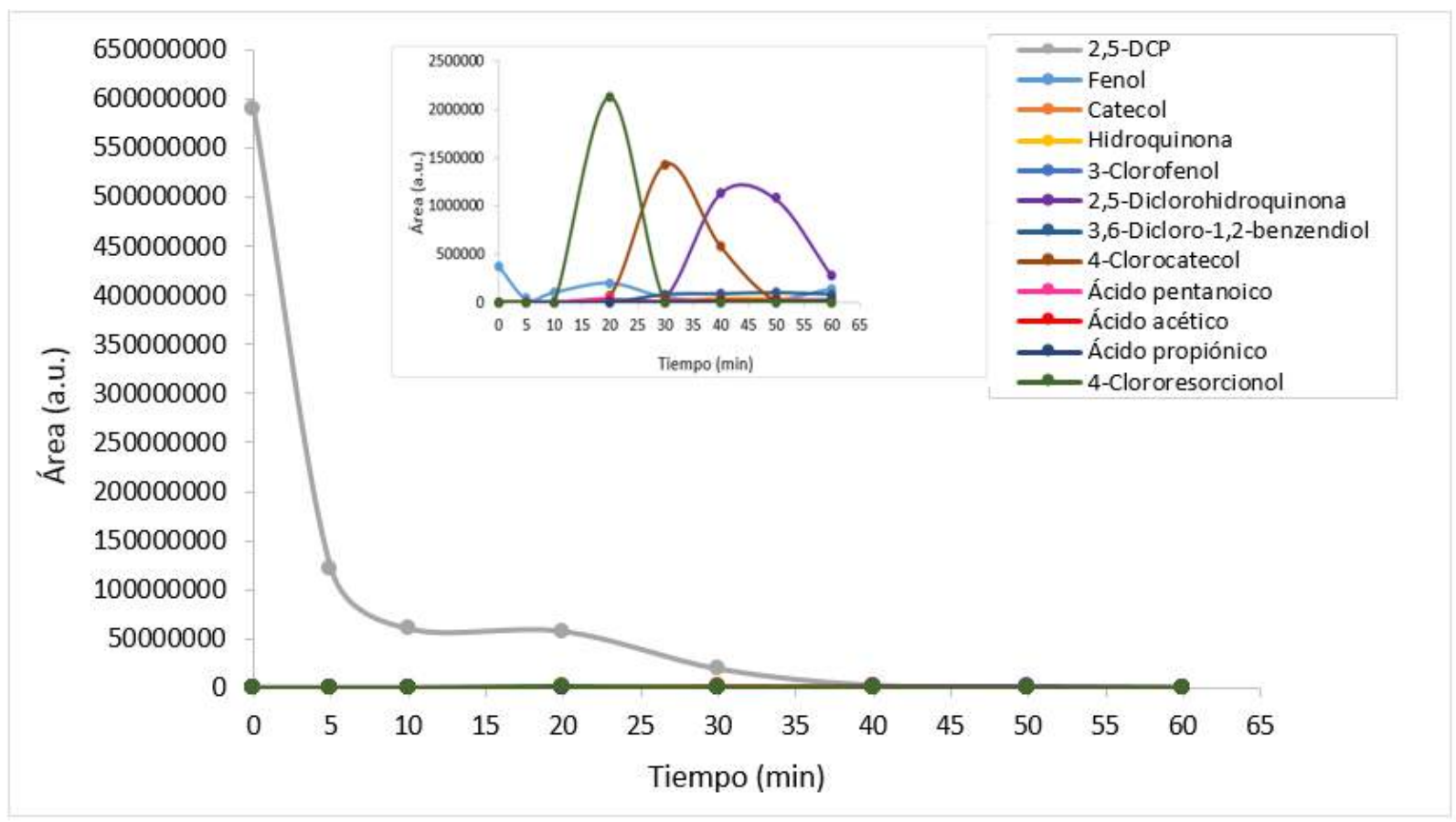

Figura 5-10 Distribución de compuestos intermedios a lo largo del tratamiento con ozonación-UV en solución acuosa de 2,5-DCP en S2: con agua residual $(\mathrm{pH} 7)$ 


\subsubsection{Discusión sobre los productos intermedios de la degradación de 2,5,DCP por reacción con ozono y ozono-UV}

Los productos intermedios de 2,5-DCP fueron identificados por cromatografía de gases acoplado a Espectrometría de masas (GC/MS). Los productos intermedios que se identificaron a lo largo de la oxidación con ozono y ozono-UV fueron similares para ambos procesos: Fenol, 3-clorofenol, catecol, hidroquinona, 2,5-diclorohidroquinona, 3,6-dicloro-1,2benzenediol, 4-clorocatecol, 4.cloro-1,3-benzenediol, ácido acético y ácido pentanoico. Además las soluciones $\mathrm{S} 1: \mathrm{O}_{3}$ y $\mathrm{S} 1: \mathrm{O}_{3}-\mathrm{UV}$ tuvieron clorohidroquinona, mientras que las

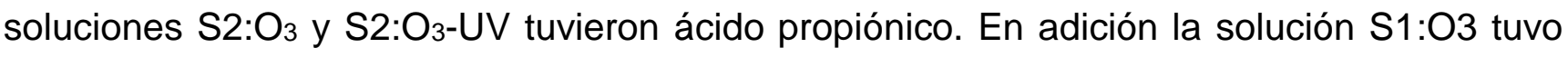
4,6-dicloro-1,3-benzenediol y resorcinol, mientras que $\mathrm{S} 2: \mathrm{O}_{3}$ tuvo ácido glicólico, y 2-(2Hidroxipropoxi)-1-propanol. Se encontraron cantidades pequeñas de ácido fórmico entre otros (Figuras 5-7 a 5-10). Algunos de estos compuestos intermedios son similares a los reportados en la literatura $[16,19,20,49]$.

Por otra parte se puede observar la formación de compuestos clorados en los primeros 5 minutos, lo cual puede explicar la degradación de cloruros en la solución oxidada a lo largo del tiempo. Las soluciones tratadas con ozono-UV tuvieron menos productos intermedios que las soluciones tratadas con ozono. Después de los 60 minutos de tratamiento con ozono-UV solo quedaron trazas de los compuestos clorados.

También se notó la presencia de algunos compuestos más grandes que el 2,5-DCP en los análisis de GC-MS de las soluciones acuosas de 2,5-DCP en S1: con agua destilada y S2: con agua residual tratada con ozono y ozono-UV en concentraciones bajas. Algunos de los compuestos que pueden identificarse por la biblioteca NIST fueron de 4-metoxifenol, 4-metilmetil-éster, ácido de 1,4-benceno-dicarboxílico y metil-éster de ácido benzoico. La formación de estos compuestos de alto peso molecular, puede ser por la conversión de fenol a un radical fenólico por los radicales hidroxilos, lo cual puede reaccionar con fenol para producir estos compuestos [50]. Otros productos intermedios no identificados pueden ser dímeros o trímeros, etc.

Los resultados confirmaron que las oxidaciones con ozono y ozono-UV fueron eficaces para degradar completamente el 2,5-DCP en los 60 minutos con la aplicación de $1.3 \mathrm{~g} / \mathrm{h}$ de ozono a pH 7. 


\section{CAPÍTULO 5. RESULTADOS Y DISCUSIÓN}

\subsubsection{Mecanismo de reacción del 2,5-DCP}

El ozono puede reaccionar con los compuestos orgánicos por la vía directa que involucra un ataque de ozono molecular a los compuestos orgánicos o por la vía indirecta que involucra la descomposición de ozono para formar radicales hidroxilo que reaccionan con los compuestos orgánicos.

De los datos que se obtuvieron sobre la constante de disociación del 2,5-DCP, se puede proponer la siguiente ecuación de la disociación del 2,5-DCP en el agua:

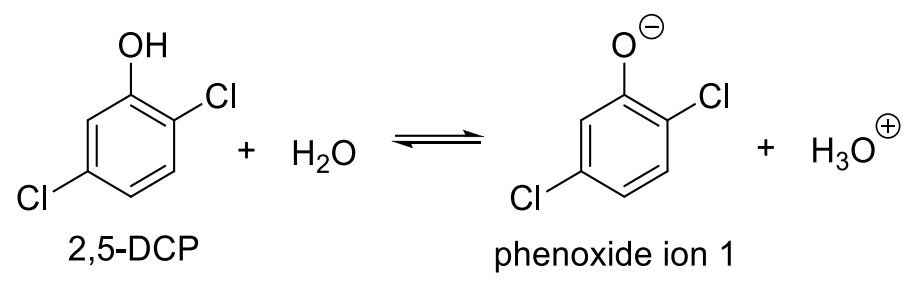

Ecuación 5-27

Este ion diclorofenolato es altamente estable por resonancia y en una solución acuosa con flujo de oxígeno/ozono, y por eso puede ser susceptible a un ataque electrofílico en el anillo aromático, que se activa por el efecto donante del grupo hidroxilo $(\mathrm{OH})$, y los grupos de hidroxilo van reemplazando a los cloros para la formación de los diferentes intermedios oxidados como ha sido explicado en la literatura [19, 49]. Así que, basado en los resultados obtenidos de la identificación de los productos intermedios mencionados en la Tabla 5-18 se puede proponer un mecanismo de reacción similar al que fue descrito por Qiu y col. [19] y Merle y Col. [49] para la degradación del 2,5-DCP en sus subproductos.

\subsection{Pruebas de Toxicdad}

\subsubsection{Los cambios en Toxicidad durante los Tratamientos con $\mathrm{O}_{3}$ y $\mathrm{O}_{3}-\mathrm{UV}$} Las pruebas de Inhibición de la respiración de lodos activados es un método para probar la toxicidad de algunos compuestos químicos en lodos activados. Este método puede clasificarse dentro de las pruebas cortas sin adaptación o aclimatación de los organismos presentes en los lodos activados. La tasa de respiración es una medida de la concentración de oxígeno consumido por los M.O. por unidad de tiempo. 


\section{CAPÍTULO 5. RESULTADOS Y DISCUSIÓN}

Las pruebas de toxicidad en lodos activados se realizaron con 2,5-DCP a una concentración de $3.07 \mathrm{mM}$, en dos soluciones acuosas de 2,5-DCP en S1: con agua destilada y S2: con agua residual, cada una con tratamientos de Oxidación de $\mathrm{O}_{3}$ у Оз-UV a diferentes intervalos del tiempo $(0,5,20,40$ y $60 \mathrm{~min})$.

Se presentan los resultados experimentales, con un análisis y discusión de las pruebas de Toxicidad con lodos activados de la PTAR (El Rosario). Todas las pruebas cumplen con los criterios de las normas mencionadas. Los blancos tienen menos de $15 \%$ de diferencia entre ellos. La temperatura se mantuvo entre $\left(20-23^{\circ} \mathrm{C}\right)$. La inhibición ejercida por el compuesto estudiado (2,5-DCP) y sus productos de oxidación sobre el inóculo microbiano del lodo activado se midió en términos de concentración de inhibición (IC). El valor de IC 50 representa la concentración del 2,5-DCP y de sus subproductos, que se necesita para inhibir mitad de la respiración microbiana.

\subsubsection{Pruebas de toxicidad del 2,5-DCP sin tratamiento}

En las gráficas 5-27 y 5-28 se presentan los resultados de las dos soluciones acuosas de 2,5DCP, en S1: con agua destilada y S2: con agua residual, sin tratamiento. Se observó que en estas pruebas de toxicidad sin tratamiento, el cambio de $\mathrm{pH}$ del tóxico $(2,5-\mathrm{DCP})$ no afecta la prueba porque en la dilución con los lodos activados el pH final queda dentro $7-8 \sin$ necesidad de ajustarlo. En estas pruebas, se obtuvieron valores de $\mathbf{I C}_{\mathbf{5 0}}$ de $\mathbf{5 0}$ y $\mathbf{5 7} \mathbf{~ m g / L}$ para las soluciones S1 y S2 respectivamente.

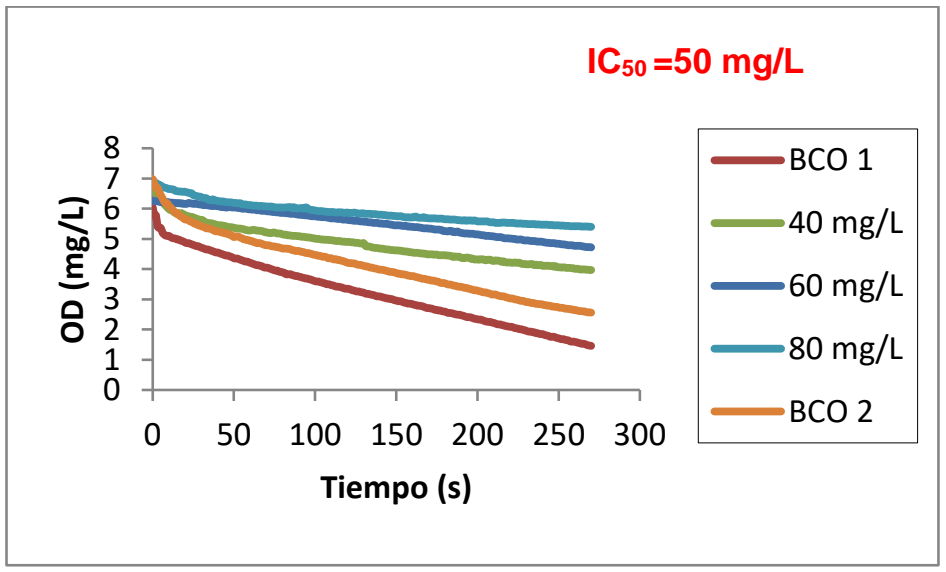

\begin{tabular}{|r|c|r|}
\hline $\begin{array}{c}\text { Conc. } \\
\text { 2,5-DCP } \\
\text { S1 (mg/L) }\end{array}$ & Muestra(s) & Pendiente \\
\hline 0 & B1 & 0.0138 \\
\hline 40 & Dilución 1 & 0.0085 \\
\hline 60 & Dilución 2 & 0.0056 \\
\hline 80 & Dilución 3 & 0.0028 \\
\hline 0 & B2 & 0.0129 \\
\hline
\end{tabular}


Gráfica 5-27 Prueba de Toxicidad con 2,5-DCP en agua destilada (S1) sin tratamiento

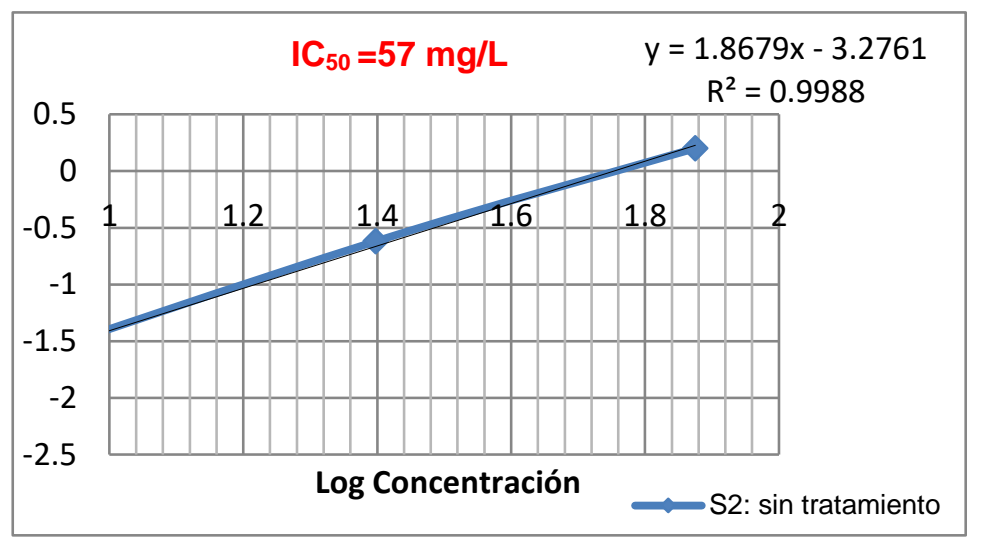

\begin{tabular}{|c|c|c|}
\hline $\begin{array}{c}\text { Conc. } \\
\text { 2,5-DCP } \\
\text { S2 (mg/L) }\end{array}$ & Muestra(s) & Pendiente \\
\hline 0 & B1 & 0.0189 \\
\hline 25 & Dilución 1 & 0.0188 \\
\hline 50 & Dilución 2 & 0.0141 \\
\hline 75 & Dilución 3 & 0.0081 \\
\hline 0 & B2 & 0.0196 \\
\hline
\end{tabular}

Gráfica 5-28 Prueba de Toxicidad con 2,5-DCP en agua residual (S2) sin tratamiento.

\subsubsection{Pruebas de toxicidad después de la ozonación}

Los resultados se muestran en la Tabla 5-18; se llevó a cabo tratamiento con ozono durante 60 minutos. El mejor resultado de las pruebas de toxicidad se obtuvieron con las soluciones acuosas de agua residual (S2) a los $60 \mathrm{~min}$, con $\mathrm{IC}_{30}$ de $110 \mathrm{mg} / \mathrm{L}$ y después para la solución en agua destilada (S1) a los 60 min con IC 30 de 95 mg/L.

\subsubsection{Pruebas de toxicidad después de la ozonación -UV}

En general, se obtuvieron los mejores resultados en las pruebas de ozonación-UV para todas las soluciones acuosas ( $\mathrm{S} 1$ y S2), con el mejor resultado en la solución S2: agua residual con $I_{25}$ de $125 \mathrm{mg} / \mathrm{L}$, mientras que en la solución S1: agua destilada tuvo $I_{C_{30}}$ de $121 \mathrm{mg} / \mathbf{L}$ Se muestran todos los resultados en la Tabla 5-18. 
Tabla 5-18 Pruebas de Toxicidad del 2,5-DCP en lodos activados de cero a 60 min de tratamiento con $\mathrm{O}_{3}$ y $\mathrm{O}_{3} / \mathrm{UV}$ en soluciones $\mathrm{S} 1$ y S2

\begin{tabular}{|c|c|c|c|c|c|c|}
\hline $\begin{array}{c}\text { Solución de } \\
\text { 2,5-DCP }\end{array}$ & AOP & $\begin{array}{c}\text { Tiempo de } \\
\text { oxidación } \\
\text { (min) }\end{array}$ & $\mathrm{IC}_{50}$ & $\begin{array}{l}\text { Conc. } \\
\mathrm{mg} / \mathrm{L}\end{array}$ & $\mathbf{R}^{2}$ & UT \\
\hline S1 & & 0 & 50 & 50 & 0.9978 & 2.00 \\
\hline S2 & Sin Tratamiento & 0 & 50 & 57 & 0.9988 & 1.75 \\
\hline \multirow{4}{*}{ S1 } & \multirow{8}{*}{$\begin{array}{c}\text { Ozono } \\
\qquad\left(\mathrm{O}_{3}\right)\end{array}$} & 60 & 30 & 95 & 0.9945 & 1.05 \\
\hline & & 40 & 40 & 80 & 0.9988 & 1.25 \\
\hline & & 20 & 50 & 85 & 0.9987 & 1.18 \\
\hline & & 5 & 50 & 51 & 0.9963 & 1.96 \\
\hline \multirow{4}{*}{ S2 } & & 60 & 30 & 110 & 0.9939 & 0.91 \\
\hline & & 40 & 40 & 100 & 0.9964 & 1.00 \\
\hline & & 20 & 50 & 95 & 0.9949 & 1.05 \\
\hline & & 5 & 50 & 60 & 0.9929 & 1.67 \\
\hline \multirow{3}{*}{ S1 } & \multirow{6}{*}{$\begin{array}{c}\text { Ozono-UV } \\
\left(\mathrm{O}_{3} / \mathrm{UV}\right)\end{array}$} & 60 & 30 & 121 & 0.9934 & 0.83 \\
\hline & & 40 & 40 & 110 & 0.9953 & 0.91 \\
\hline & & 20 & 50 & 105 & 0.9905 & 0.95 \\
\hline \multirow{3}{*}{ S2 } & & 60 & 25 & 125 & 0.9980 & 0.80 \\
\hline & & 40 & 40 & 125 & 0.9976 & 0.80 \\
\hline & & 20 & 50 & 120 & 0.9903 & 0.83 \\
\hline
\end{tabular}

\subsubsection{Discusión sobre las Pruebas de Toxicidad}

Los ensayos de toxicidad son muy importantes para monitorear la toxicidad de productos intermedios que tienen lugar durante los procesos de oxidación; para el caso de los clorofenoles ya se han reportado compuestos intermedios más tóxicos que el compuesto original [40]. Los cálculos del I $\mathrm{C}_{50}$ se hicieron usando el método estadístico Probit. En la Tabla 5-18 se muestran los resultados de las pruebas de toxicidad en lodos activados: sin tratamiento, con ozonación y con ozono-UV, en las dos soluciones acuosas S1: con agua destilada y S2: con agua residual. Se observó que el rango de $\mathrm{IC}_{50}$ para la solución tóxica de $2,5-\mathrm{DCP}$ se encuentra entre $50 \mathrm{mg} / \mathrm{L}$ y $60 \mathrm{mg} / \mathrm{L}$ similares a los resultados de las pruebas realizadas con 2,5-DCP en agua destilada [51]. 


\section{CAPÍTULO 5. RESULTADOS Y DISCUSIÓN}

De los resultados experimentales se puede observar que las dos soluciones después de los primeros 5 minutos de ozonación tuvieron toxicidades similares a los valores obtenidos para la solución sin tratamiento, lo cual podría ser por la formación de compuestos iniciales con toxicidades similares a la solución inicial, mientras que, los demás resultados de las oxidaciones fueron mucho menos tóxicas que el 2,5-DCP $\sin$ tratamiento en $\mathrm{S} 1$ y $\mathrm{S} 2\left(\mathrm{IC}_{50}=\right.$ 50 y $57 \mathrm{mg} / \mathrm{L}$, respectivamente).

La toxicidad de las soluciones tratadas por 60 minutos sigue el siguiente orden (menos a mas tóxico): S2:O3-UV < S1:O3-UV < S2:O3 < S1:O3. De los dos tratamientos que se estudian se obtienen mejores valores, los más bajos para el porcentaje de inhibición, con los tratamientos de O3-UV de $\mathrm{IC}_{25}$ de $125 \mathrm{mg} / \mathrm{L}$, ya que sus intermedios formados tuvieron efectos menos tóxicos sobre la población microbiana del lodo activado en las pruebas de toxicidad. En la Tabla 5-18 se puede observar el comportamiento con respecto a sus tratamientos en función de los tiempos de oxidación. Con las soluciones tratadas con ozono y ozono-UV se puede ver una disminución de su toxicidad sobre los M.O. con el aumento del tiempo de oxidación.

En general se notó que las oxidaciones con ozono y ozono-UV a los 60 minutos fueron muy eficientes para reducir la toxicidad del 2,5-DCP, lo cual es debido a la formación de nuevos productos intermedios durante la oxidación que son más fácilmente biodegradables y por eso menos tóxicos a la población microbiana del lodo activado.

\subsection{Evaluación de los Procesos Biológicos}

Las soluciones de 2,5-DCP en S1: con agua destilada y S2: con agua residual fueron oxidadas con ozono y ozono-UV para aumentar su biodegradabilidad. Después de $60 \mathrm{~min}$ de tratamiento con ozono y ozono-UV, a las dos soluciones se les aplicó un tratamiento biológico de lodos activados en reactores biológicos a escala laboratorio.

Estas pruebas se dividen en tres fases:

La Fase 1 consiste en la aclimatación de los M.O. al tóxico según el caso (2,5-DCP y fenol). Para monitorear su funcionamiento se analizaron $\mathrm{pH}$, SST, DQO, IVL, VUO y se hicieron estudios microbiológicos a lo largo de su operación. En esta Fase I, las soluciones pretratadas con Ozono y ozono-UV en agua destilada fueron alimentadas a seis reactores de 


\section{CAPÍTULO 5. RESULTADOS Y DISCUSIÓN}

agitación SBR. El primer reactor R1 contuvo biomasa aclimatada a las condiciones del laboratorio, el segundo reactor R2 biomasa aclimatada al fenol + DCP y el tercer reactor R3 biomasa aclimatada al fenol.

En la Fase 2 se alimentaron doce reactores de agitación SBR que contienen biomasa de tres diferentes reactores $(R 0, R 1, R 3)$ con las soluciones acuosas de 2,5-DCP en agua destilada y en agua residual, pretratadas con ozono y ozono-UV.

En la Fase 3 se alimentaron cinco biorreactores tipo Husmann (BHA) que contuvieron biomasa del reactor R3 adapta al fenol con las soluciones acuosas de 2,5-DCP en agua destilada y en agua residual pretratadas con ozono y ozono-UV.

\subsubsection{FASE 1: Evaluación de la eficiencia de los biorreactores de agitación SBR}

Las muestras de los lodos activados adaptados a diferentes tóxicos (fenol y/o DCP) y sin adaptación se usaron para monitorear los cambios en la población microbiana y sus adaptaciones.

\subsubsection{Observación Microscópica de los microorganismos}

El microscopio es una herramienta de gran importancia para la observación e identificación de los M.O. Usando un microscopio digital Profesional serie B3 se pudieron observar los M.O. de los diferentes reactores. Las siguientes fotos muestran las diversas observaciones microscópicas (Figuras 5-11 a 5-14). Al observar los M.O. con el microscopio se pudo ver la movilidad de los M.O. en las muestras de todos los reactores (R1, R2, R3 Y R4). Es decir hay actividad microbiana y sobrevivieron todavía algunos a pesar de la exposición a las diferentes sustancias tóxicas (Fenol y DCP) según el caso. Se observaron los M.O. vivos con los objetivos de 10X, 40X,100X y se usó una cámara de microscopio digital para tomar las fotos. 


\section{CAPÍTULO 5. RESULTADOS Y DISCUSIÓN}

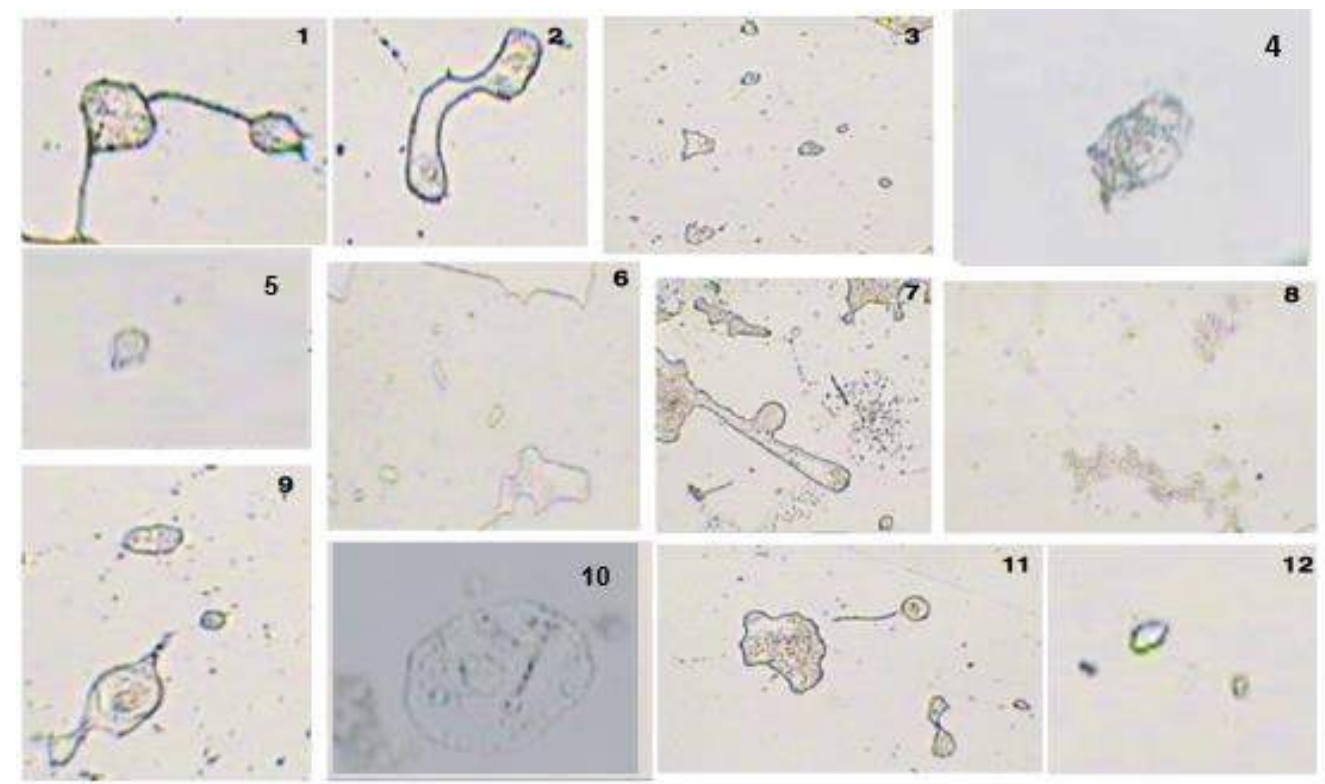

Figura 5-11 Observación microscópica (40X) de Reactor 1 (control)

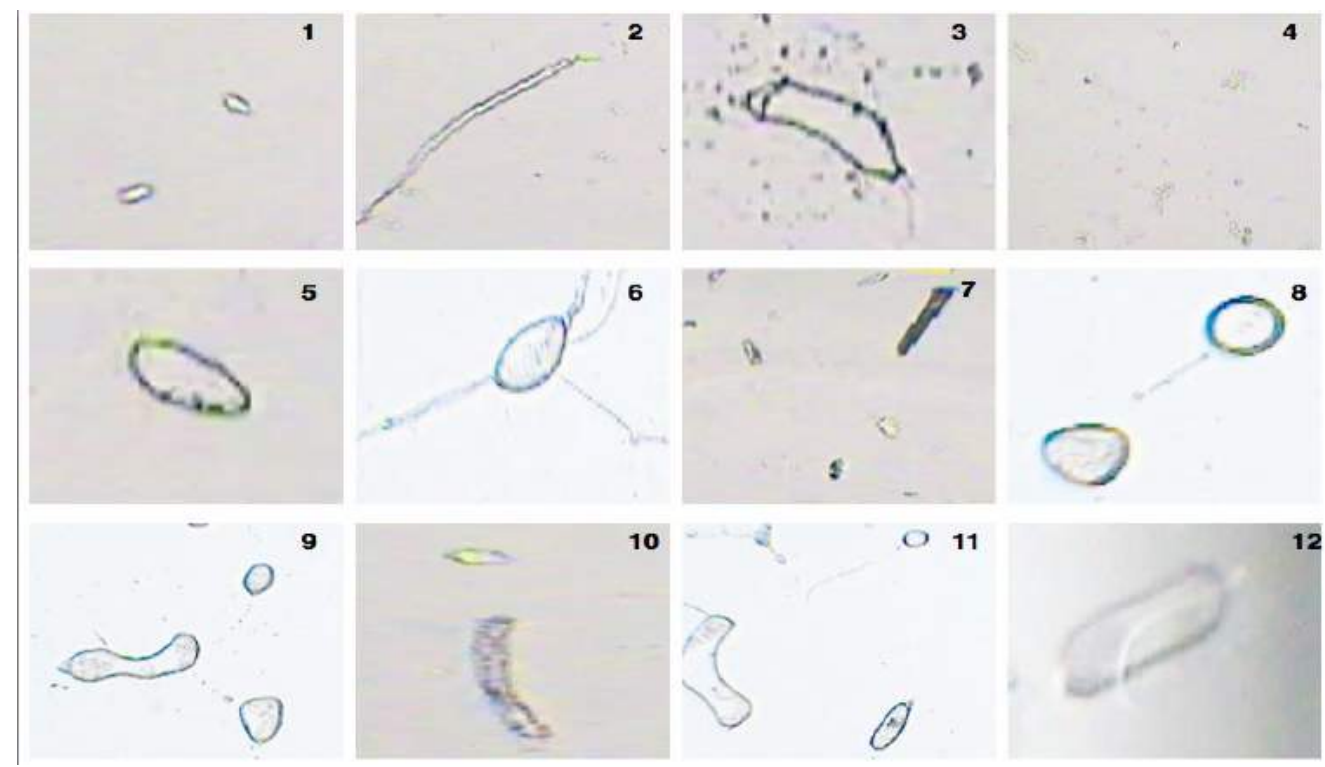

Figura 5-12 Observación microscópica (40X) de Reactor 2 (Fenol /DCP) 


\section{CAPÍTULO 5. RESULTADOS Y DISCUSIÓN}

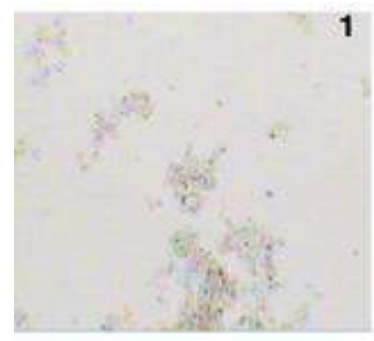

5
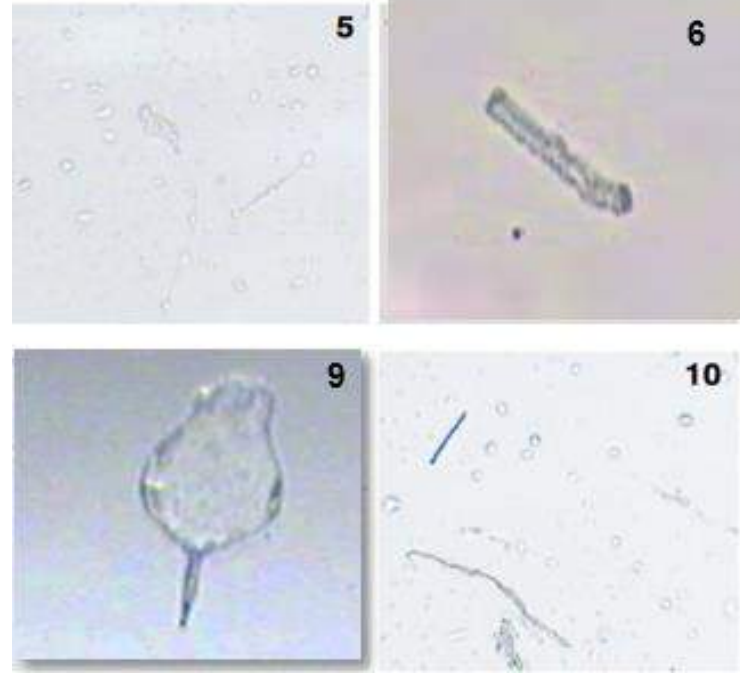

0
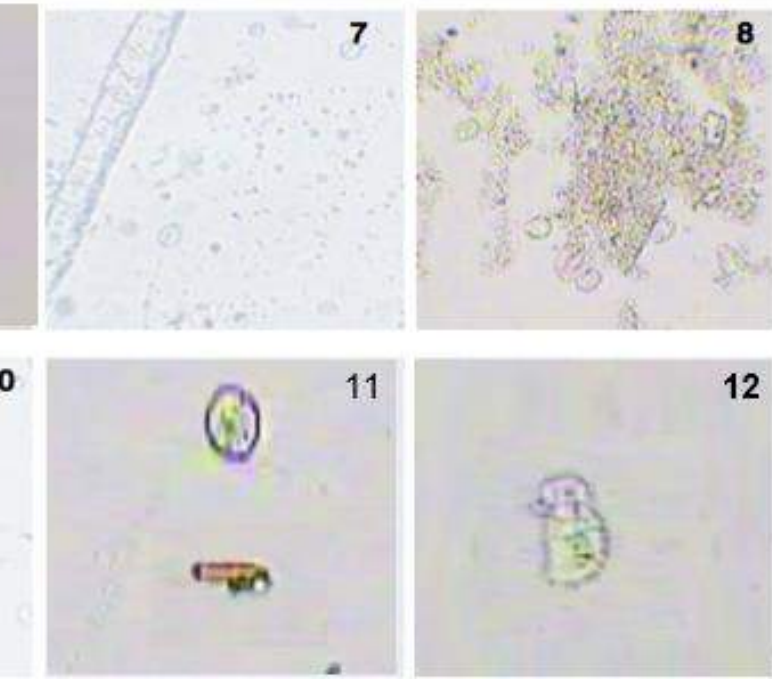

11

12

Figura 5-13 Observación microscópica (40X) de Reactor 3 (Fenol)
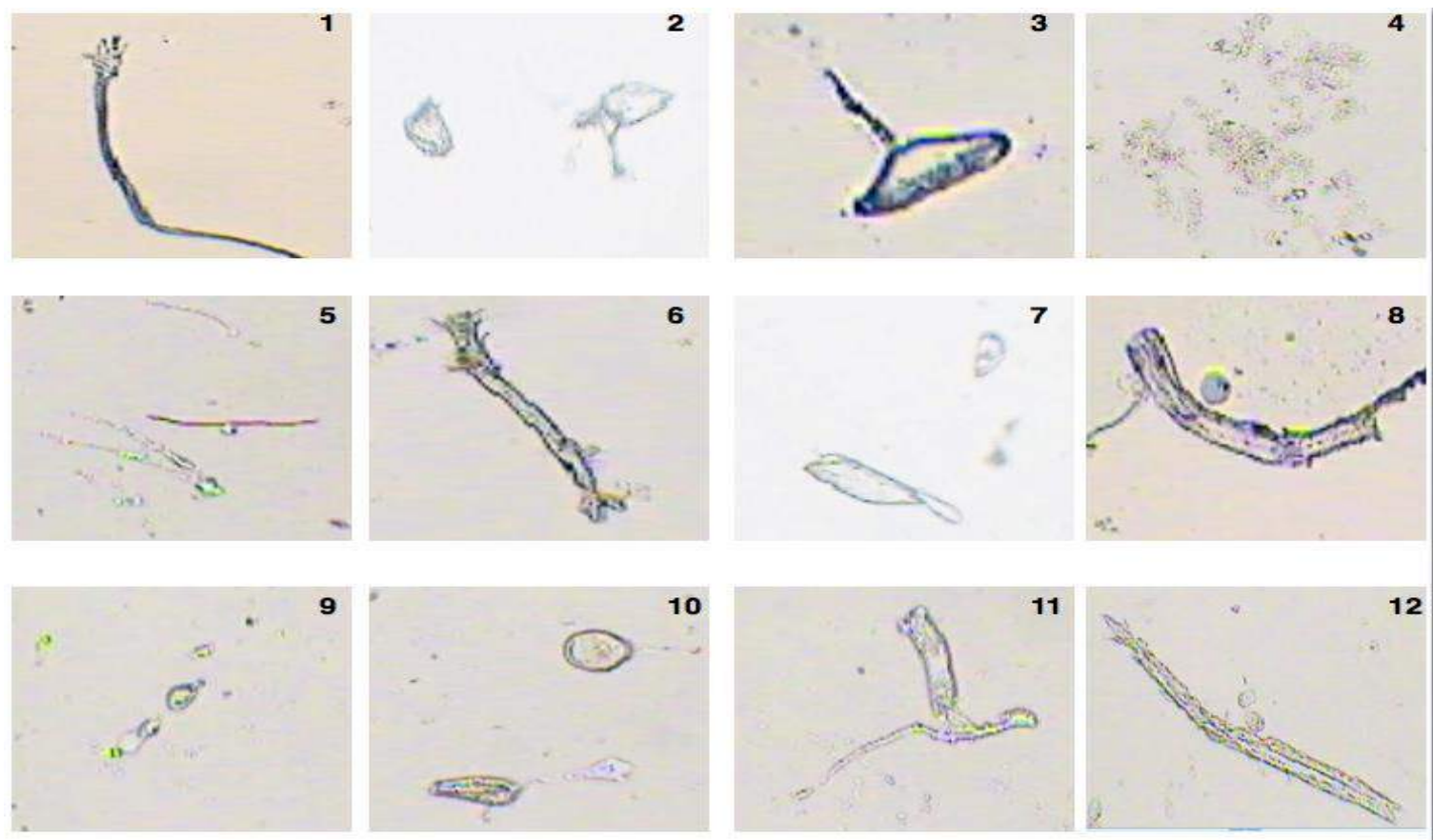

Figura 5-14 Observación microscópica (40X) de Reactor 4 (DCP) 


\subsubsection{Discusión de la observación microscópica}

Como se puede observar en las fotos con el aumento (40x), hay una buena mezcla de M.O. en los reactores. Las bacterias aparecen muy pequeñas pero se pueden observar algunas en la forma de cocos, bacilos y estreptococos. Además hay una buena cantidad de protozoarios en los reactores como: flagelados (No. 6 y 12 de la Figura 5-12); ciliados (No. 12 de la Figura 5-13); amebas (No. 10 de la Figura 5-11); rotíferos (No. 1, 6 y 12 de la Figura 5-14) y vorticela (No. 1 de la Figura 5-11).

\subsubsection{Observaciones macroscópicas}

Crecimiento en medio de agar Muller-Hinton: las células microbianas se reproducen normalmente y a las 24 horas dan lugar a la aparición de masas visibles de células sobre medios sólidos y se denominan colonias. Cada colonia se considera que está formada por un único tipo de microorganismo. Se puede observar visualmente la formación de las colonias en la Figura 5-15.

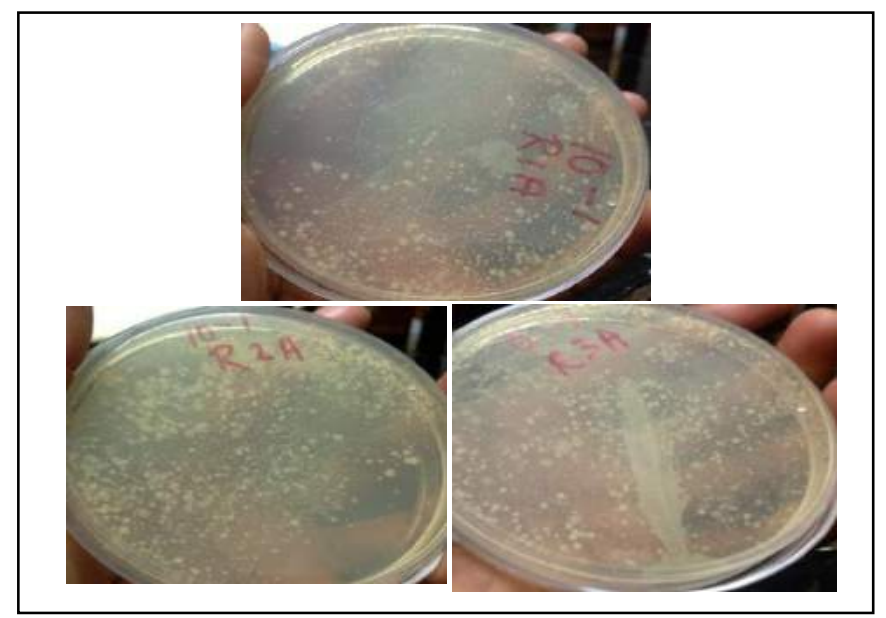

Figura 5-15 Observación macroscópica de los diferentes reactores sobre agar de Muller-Hinton

\subsubsection{Recuento de microorganismos}

Para el recuento de colonias se usó el método de recuento de bacterias viables en placa. Este método tiene la ventaja de cuantificar solo a las bacterias viables presentes en una muestra. Son métodos de estimación de bacterias viables en término de UFC/mL. Los resultados se muestran en la Tabla 5-19. 
Tabla 5-19 Distribución de colonias en dilución

\begin{tabular}{|c|c|c|c|c|c|}
\hline $\begin{array}{c}\text { Número de } \\
\text { Placa }\end{array}$ & $\begin{array}{c}\text { No. de colonias } \\
\text { en placa }\end{array}$ & Dilución & $\begin{array}{l}\text { Volumen de } \\
\text { siembra }(\mathrm{mL})\end{array}$ & $\mathrm{UFC} / \mathrm{mL}$ & $\begin{array}{c}\text { UFC/mL } \\
\text { (Promedio) }\end{array}$ \\
\hline R1 B & 264 & $10^{-3}$ & 1 & 264,000 & \multirow{2}{*}{$2.67 \times 10^{5}$} \\
\hline R1 B & 270 & $10^{-3}$ & 1 & 270,000 & \\
\hline R2 B & 240 & $10^{-3}$ & 1 & 290,000 & \multirow{2}{*}{$2.38 \times 10^{5}$} \\
\hline R2 B & 237 & $10^{-3}$ & 1 & 287,000 & \\
\hline R3 B & 239 & $10^{-3}$ & 1 & 239,000 & \multirow{2}{*}{$2.44 \times 10^{5}$} \\
\hline R3 B & 249 & $10^{-3}$ & 1 & 249,000 & \\
\hline
\end{tabular}

\subsubsection{Discusión sobre el recuento de colonias}

La observación macroscópica da una estimación del número de colonias de bacterias en los diferentes reactores, para el método de recuento de bacterias viable en placa. Las pruebas (R1B, R2B y R3B) se hicieron con muestras tomadas de los reactores antes de alimentar con una solución fresca y las pruebas con dilución menor de $10^{-3}$ fueron incontables y todas las diluciones de los reactores R1A, R2A y R3A (que corresponden a las muestras tomadas de los reactores después de alimentar con una solución fresca) fueron incontables en las diluciones 10-1 a 10-3. De los resultados obtenidos puede ver en la Tabla 5-19 que los reactores tienen casi las mismas cantidades de bacterias y el reactor $\mathrm{R} 1$ (el control sin tóxico) tiene una ligera cantidad mayor. 


\section{CAPÍTULO 5. RESULTADOS Y DISCUSIÓN}

\subsubsection{Crecimiento en agar cetrimida:}

El agar cetrimida se utiliza para el aislamiento selectivo de $P$. aeruginosa. Las colonias se desarrollan tanto dentro del agar como en la superficie, ver .

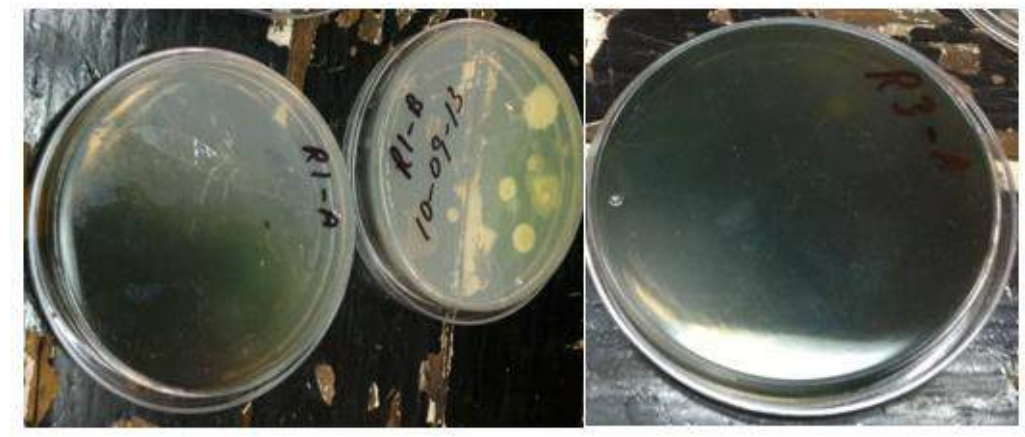

Figura 5-16 Observación macroscópica de los diferentes reactores

\subsubsection{Discusión sobre del crecimiento en agar cetrimida}

Las placas presentan crecimiento y pigmentación verde azulada característica alrededor del crecimiento la cual significa posibilidad de presencia de $P$. aeruginosa también puede observarse una variación tanto en la morfología de colonias como en la formación del pigmento de una cepa a otra en el Reactor 1 antes de añadir solución fresca (R1B), estos resultados se muestran en la.

\subsubsection{Pruebas Bioquímicas}

Para identificar una cepa bacteriana de Pseudomonas sp. se hicieron algunas pruebas bioquímicas (Figura 5-17) y los resultados se muestran en la Tabla 5-20. De acuerdo a los resultados obtenidos en las pruebas bioquímicas y buscando referencias en la bibliografía, así como en tablas de pruebas bioquímicas, se puede decir que el microorganismo de los reactores podría ser Pseudomonas ya que coincidieron algunas de las siguientes pruebas. 


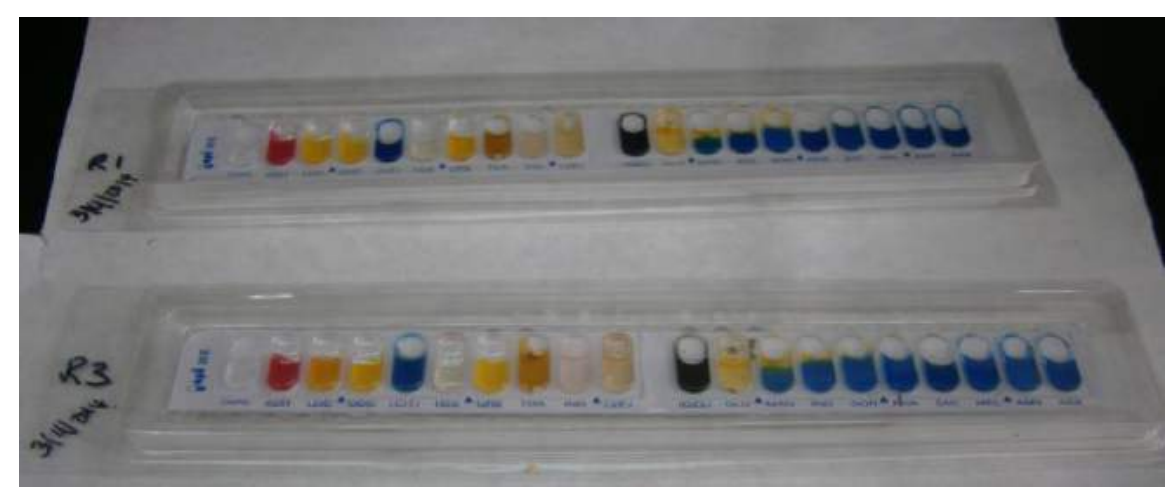

Figura 5-17 Resultados de las Pruebas Bioquímicas de API 20E de los reactores R1 (Control) y R3 (adaptada a fenol)

Tabla 5-20 Resultados de las Pruebas bioquímicas de API 20E más características de especies de Pseudomonas

\begin{tabular}{|c|c|c|}
\hline Pruebas Bioquímicas & Colonia A (R1) & Colonia B (R3) \\
\hline Agar Cetrimida & Crece & Crece \\
\hline Glucosa (fermentación) & - & - \\
\hline Lactosa (fermentación) & - & - \\
\hline Glucosa & + & + \\
\hline Xilosa & - & - \\
\hline Maltosa & - & - \\
\hline Manitol & - & - \\
\hline Pigmentación & Verde & verde \\
\hline Citrato & + & + \\
\hline Nitrato & + & + \\
\hline Lisina & - & - \\
\hline Arginina & + & + \\
\hline Crec. NaCl 6\% & +- & +- \\
\hline Movilidad & - & - \\
\hline H2S & - & - \\
\hline
\end{tabular}

\subsubsection{Discusión sobre las Pruebas bioquímicas}

Para identificar cepas bacterianas dominantes en los diferentes reactores se hicieron pruebas bioquímicas a las bacterias aisladas de los diferentes reactores. Las bacterias de cada colonia observada se aíslan por lo menos tres veces, para tener una muestra pura de la bacteria. En los aislamientos solo quedaban dos colonias diferentes que crecen sobre el agar cetrimida. De los resultados tabulados (Tabla 5-20) de las pruebas bioquímicas de API 20 E, se hace 


\section{CAPÍTULO 5. RESULTADOS Y DISCUSIÓN}

una comparación de los resultados con los de la biblioteca de API y resulta que las colonias si coinciden en $99 \%$ con la bacteria $P$. aeruginosa.

\subsubsection{Comportamiento físico-químico de los reactores.}

En esta parte se presentan los resultados de los parámetros físico-químicos en los reactores durante las pruebas de oxidación. Los parámetros estudiados fueron: la variación del pH, de los SST, del IVL, la VUO y la DQO.

\section{Variación del pH en los reactores.}

Los resultados del $\mathrm{pH}$ en los tres reactores estudiados ( $\mathrm{R} 1, \mathrm{R} 2$ y $\mathrm{R} 3$ ) se presentan en la Gráfica 5-29.

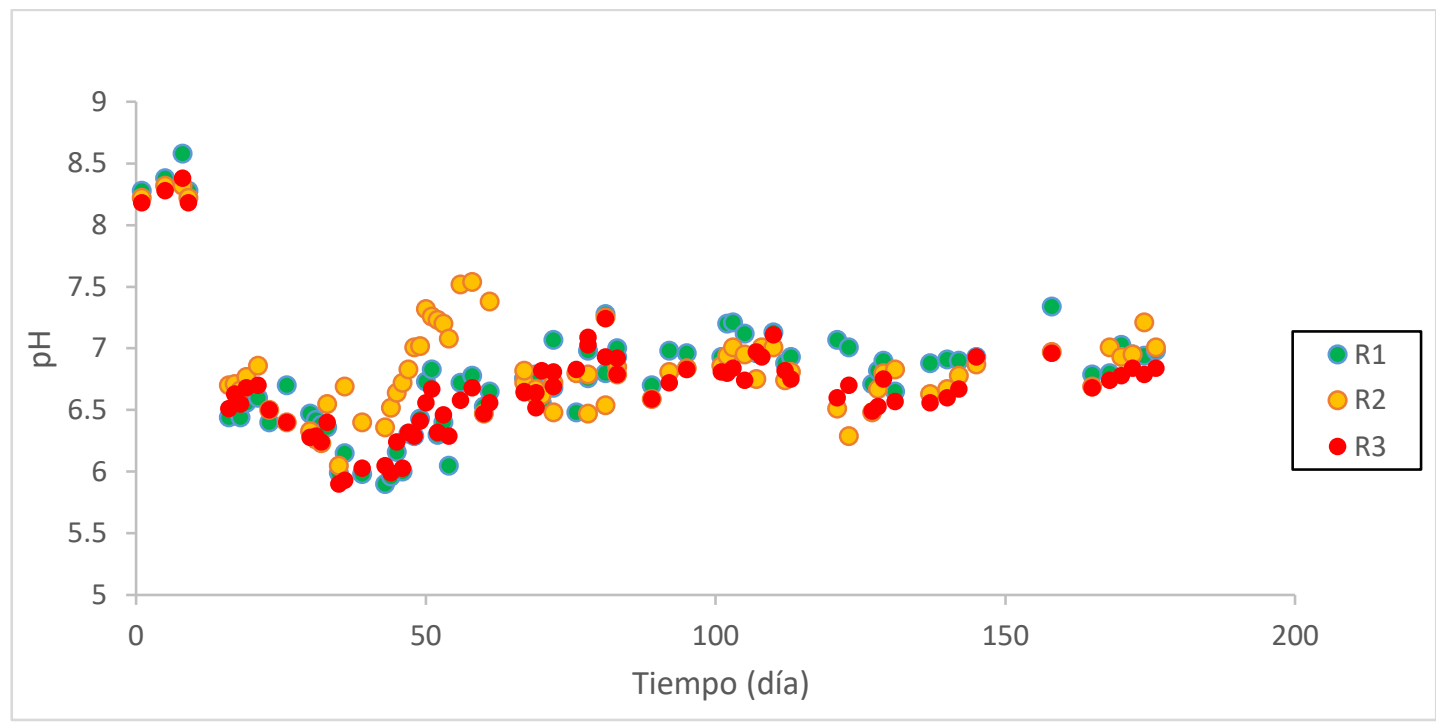

Gráfica 5-29 Cambios del pH en los diferentes biorreactores durante 6 meses

\section{Análisis de los cambios del pH}

En los reactores se observó que al inicio el pH estaba alrededor de 8 y con el tiempo se bajó llegando a veces alrededor de 6. Cuando éste fue menor de 6.0 se añadió $\mathrm{NaOH} 0.1 \mathrm{~N}$ para alcanzar un $\mathrm{pH}$ alrededor de 7. En las medidas diarias del $\mathrm{pH}$ se observaron pequeñas disminuciones de los valores de $\mathrm{pH}$ iniciales. Generalmente, la mayor disminución de los valores de $\mathrm{pH}$ iniciales se observaron en los reactores 2 y 3 estos cambios pueden ser debido 


\section{CAPÍTULO 5. RESULTADOS Y DISCUSIÓN}

a la formación de productos ácidos en la mezcla. Normalmente, se trabajó con un pH entre 6 - 7.5 ya que a estos pH pueden sobrevivir muchos M.O.

\section{Sólidos Suspendidos Totales.}

Al iniciar la operación de los reactores se tuvieron unas concentraciones de SST alrededor de $1200 \mathrm{mg} / \mathrm{L}$, pero a través del tiempo se observó que funcionaron muy lento, por eso se aumentaron los sólidos suspendidos totales hasta $3000 \mathrm{mg} / \mathrm{L}$.

Las gráficas 5-30 a 5-33 muestran los cambios de sólidos suspendidos totales en los reactores.

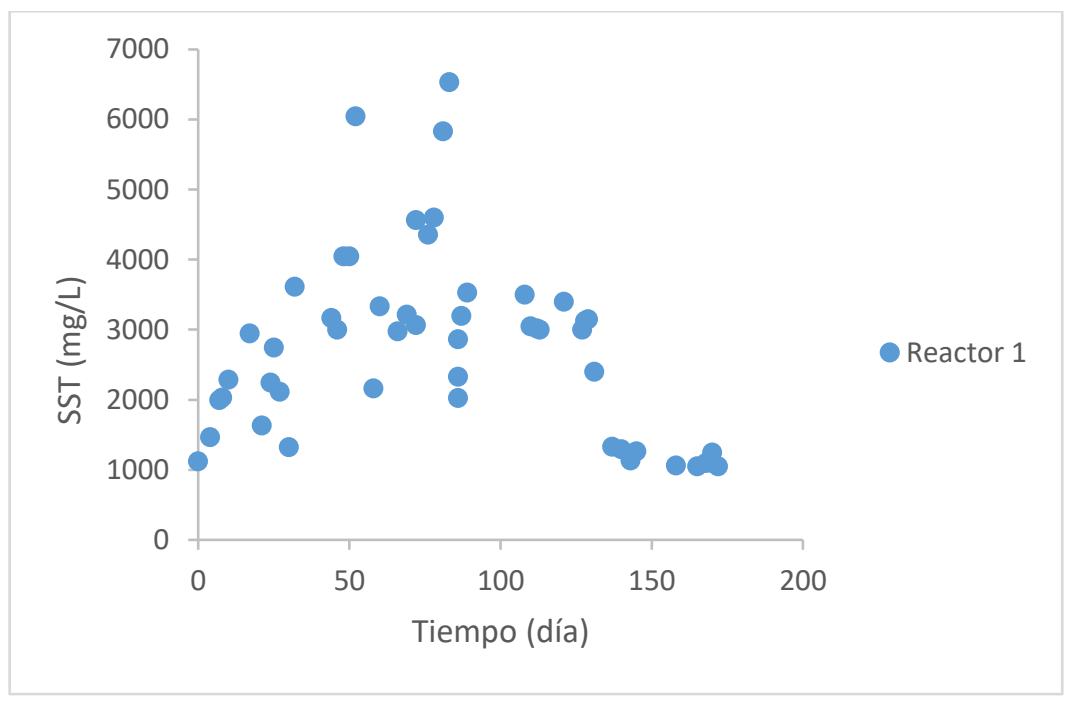

Gráfica 5-30 Sólidos suspendidos totales en el Reactor 1 


\section{CAPÍTULO 5. RESULTADOS Y DISCUSIÓN}

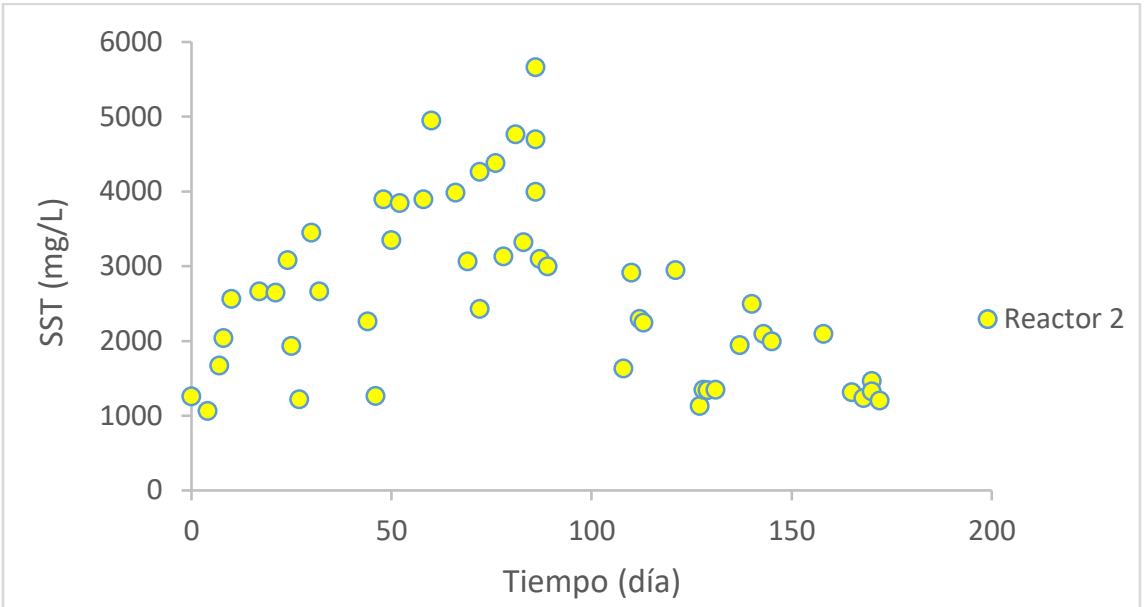

Gráfica 5-31 Sólidos suspendidos totales en el Reactor 2

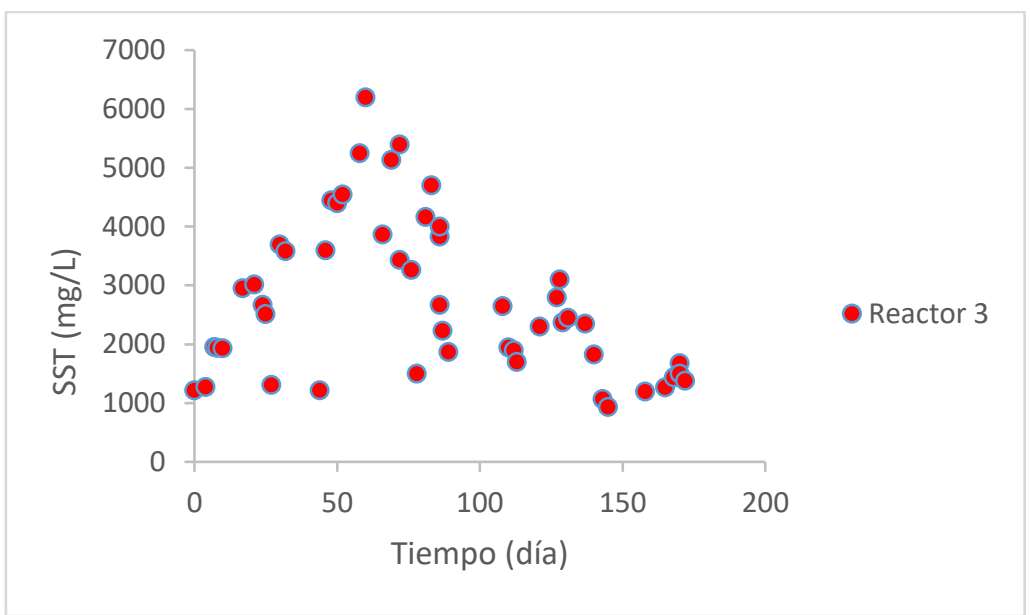

Gráfica 5-32 Sólidos suspendidos totales en el Reactor 3

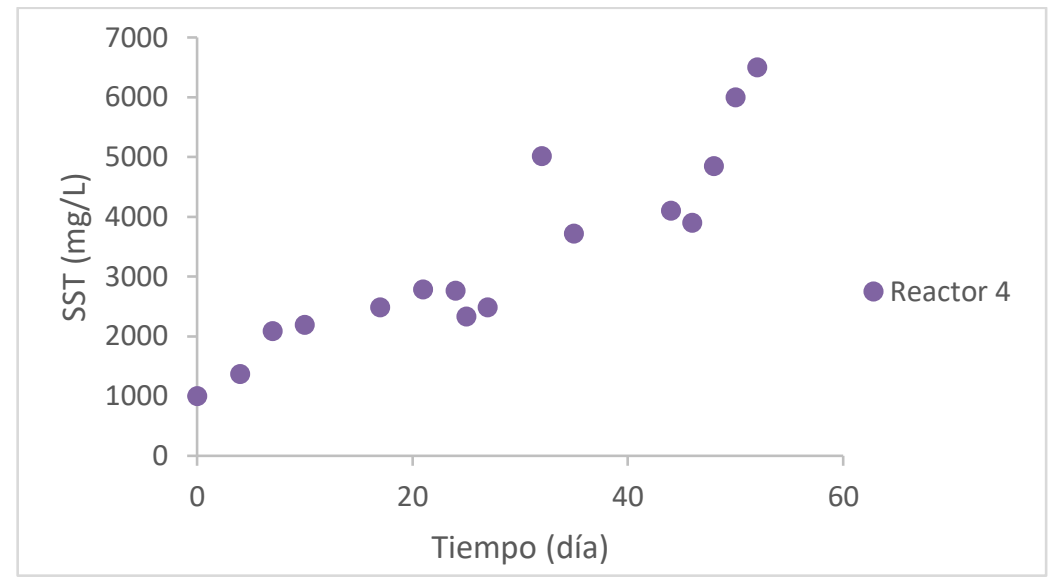

Gráfica 5-33 Sólidos suspendidos totales en el Reactor 4 


\section{Análisis de la variación de los SST}

A lo largo de la operación de los biorreactores de agitación hubo la formación de nueva biomasa por lo cual los SST llegaron entre 5000 a $6500 \mathrm{mg} / \mathrm{L}$ en los primeros 50 días y se tuvo que disminuir la concentración entre $1000 \mathrm{mg} / \mathrm{L}$ y $2500 \mathrm{mg} / \mathrm{L}$ para tener suficientes nutrientes y oxígeno en el reactor para los M.O. En las gráficas 5-30 a 5-33 se pueden observar las variaciones de SST en función del tiempo (días) de operación. En general en todos los reactores hubo formación de nueva biomasa, lo cual sugiere que los M.O. están degradando los compuestos tóxicos según sea el caso (DCP y fenol).

\section{Índice Volumétrico de lodos (IVL)}

Los resultados de IVL durante el tiempo de operación de los reactores se presentan en las tablas 5-22 y 5-23.

Tabla 5-21 Volumen ocupado por la fase de lodos y solidos suspendidas totales

\begin{tabular}{|c|c|c|c|c|c|c|}
\hline \multirow[t]{2}{*}{ Día } & \multicolumn{3}{|c|}{$\begin{array}{l}\text { Volumen ocupado por la fase de lodos (VL) } \\
\qquad(\mathrm{mL} / \mathrm{L})\end{array}$} & \multicolumn{3}{|c|}{$\begin{array}{l}\text { solidos suspendidas totales (SST) } \\
(\mathrm{mg} / \mathrm{L})\end{array}$} \\
\hline & $\mathrm{R} 1$ & $\mathrm{R} 2$ & R3 & $\mathrm{R} 1$ & $\mathrm{R} 2$ & R3 \\
\hline 60 & 180 & 210 & 200 & 3333 & 2433 & 3867 \\
\hline 66 & 110 & 180 & 160 & 1833 & 4267 & 5133 \\
\hline 69 & 100 & 120 & 140 & 3217 & 4383 & 3433 \\
\hline 72 & 135 & 180 & 190 & 3067 & 3133 & 3267 \\
\hline 81 & 140 & 250 & 280 & 5833 & 5667 & 4700 \\
\hline 83 & 160 & 230 & 240 & 6533 & 4700 & 3900 \\
\hline 86 & 170 & 240 & 210 & 2867 & 3100 & 3833 \\
\hline 89 & 260 & 280 & 120 & 3533 & 2917 & 1867 \\
\hline 105 & 330 & 350 & 390 & 3400 & 3133 & 3500 \\
\hline 108 & 300 & 310 & 305 & 3500 & 3300 & 2900 \\
\hline
\end{tabular}

Cálculo: $\quad I V L\left(\frac{m L}{m g}\right)=\frac{V L(m L / L) \times 1000}{S S T(m g / L)}$ 
Tabla 5-22 Índice Volumétrico de Lodos

\begin{tabular}{|c|c|c|c|}
\hline \multirow{2}{*}{ Día } & \multicolumn{3}{|c|}{ Índice Volumétrico de Lodos (IVL) } \\
& \multicolumn{3}{|c|}{$(\mathrm{mL} / \mathrm{L})$} \\
\cline { 2 - 4 } & $\mathrm{R} 1$ & $\mathrm{R} 2$ & $\mathrm{R} 3$ \\
\hline 60 & 54 & 86 & 52 \\
\hline 66 & 60 & 42 & 31 \\
\hline 69 & 31 & 27 & 41 \\
\hline 72 & 44 & 57 & 58 \\
\hline 81 & 24 & 44 & 60 \\
\hline 83 & 24 & 49 & 62 \\
\hline 86 & 59 & 77 & 55 \\
\hline 89 & 74 & 96 & 64 \\
\hline 105 & 97 & 112 & 111 \\
\hline 108 & 86 & 94 & 105 \\
\hline
\end{tabular}

\section{Análisis de los valores de IVL}

Según los resultados obtenidos el rango de operación usual del IVL fue de 50-112, aunque algunas veces se llegaron a tener valores más bajos; esto es debido a la edad de los lodos, que son viejos y su función es más lenta. Para corregir este problema se aumentó la cantidad de lodo que se retira de los reactores.

\section{Velocidad de utilización de oxígeno}

Comparando los valores de las velocidades de consumo de oxígeno en los reactores se puede ver que los M.O. son adaptados cuando los cambios entre los valores de VUO son muy pequeños. En las tablas 5-24 a 5-26 y en las gráficas 5-34 a 5-36 se muestran las VUO de los reactores (R1, $R 2$ y $R 3$ ). Este método es una manera más rápida para ayudar a conocer las características de un lodo pero también se necesita tomar en cuenta otros factores para tener una verdadera caracterización de los lodos (edad de los lodos, actividad microbiológica, etc.). 


\section{Reactor 1 Lodos activados con agua destilada (control)}

Tabla 5-23 resultados de VUO y VUOS en el Reactor 1

\begin{tabular}{|r|r|r|r|r|}
\hline \multicolumn{1}{|c|}{ Día } & Pendiente & $\begin{array}{c}\text { VUO } \\
(\mathrm{mg} / \mathrm{L}) / \mathrm{min}\end{array}$ & $\begin{array}{c}\text { SST } \\
(\mathrm{g} / \mathrm{L})\end{array}$ & $\begin{array}{c}\text { VUOS* } \\
(\mathrm{mg} / \mathrm{g}) / \mathrm{h}\end{array}$ \\
\hline 0 & 0.00828 & 0.4968 & 1.47 & 20 \\
\hline 25 & 0.0025 & 0.15 & 2.75 & 3.2 \\
\hline 36 & 0.0022 & 0.132 & 2.5 & 3.16 \\
\hline 46 & 0.0018 & 0.108 & 3 & 2.16 \\
\hline 103 & 0.0058 & 0.348 & 3.1 & 7 \\
\hline 105 & 0.0043 & 0.258 & 3.4 & 5 \\
\hline 108 & 0.0089 & 0.534 & 3.5 & 9 \\
\hline
\end{tabular}

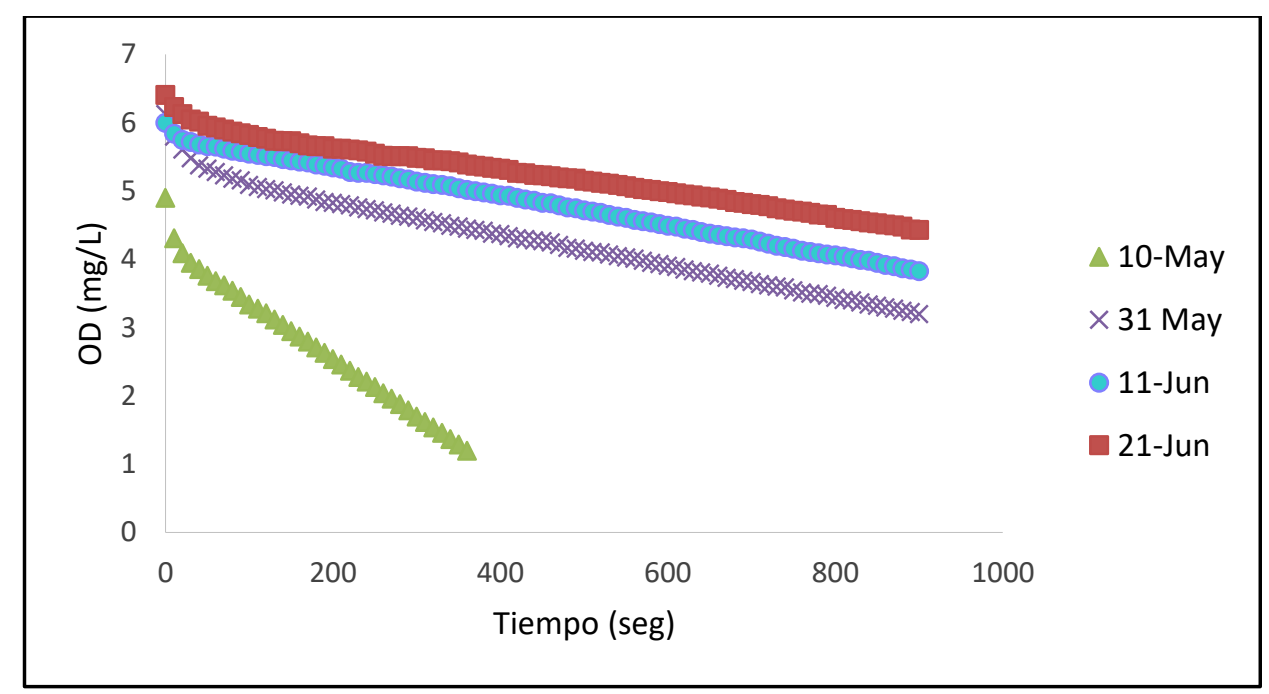

Gráfica 5-34 Gráfica de velocidad de consumo de oxígeno en R1 
Reactor 2 (Lodos activados adaptados primero con fenol y después con 2,5-DCP)

Tabla 5-24 resultados de VUO y VUOS en el Reactor 2

\begin{tabular}{|r|r|r|r|r|}
\hline Día & Pendiente & \multicolumn{1}{|c|}{$\begin{array}{c}\text { VUO } \\
(\mathrm{mg} / \mathrm{L}) / \mathrm{min}\end{array}$} & $\begin{array}{c}\mathrm{SST} \\
(\mathrm{g} / \mathrm{L})\end{array}$ & $\begin{array}{c}\text { VUOS } \\
(\mathrm{mg} / \mathrm{g}) / \mathrm{h}\end{array}$ \\
\hline 0 & 0.0068 & 0.408 & 1.065 & 23 \\
\hline 25 & 0.0024 & 0.144 & 3.083 & 3 \\
\hline 36 & 0.0022 & 0.132 & 2.866 & 3 \\
\hline 46 & 0.0008 & 0.048 & 3.35 & 1 \\
\hline 103 & 0.0022 & 0.132 & 2.95 & 3 \\
\hline 105 & 0.0031 & 0.186 & 1.5 & 7 \\
\hline 108 & 0.0045 & 0.27 & 1.35 & 12 \\
\hline
\end{tabular}

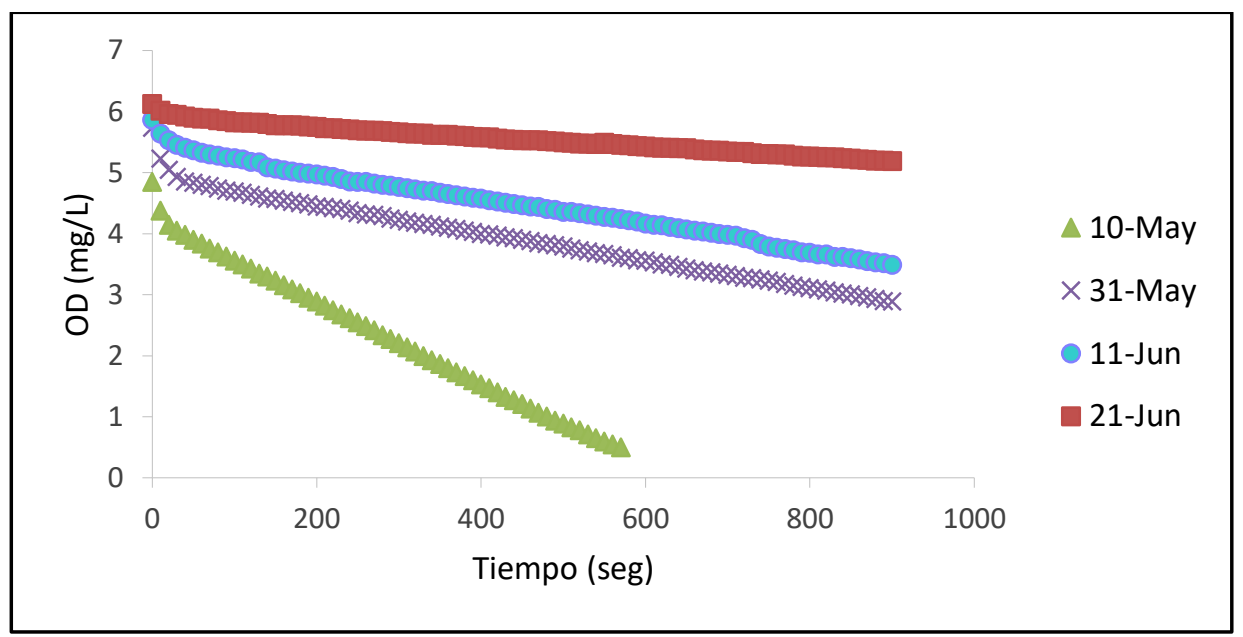

Gráfica 5-35 Gráfica de velocidad de consumo de oxígeno en R2.

\section{Reactor 3 (Lodos activados adaptado al fenol)}

Tabla 5-25 Resultados de VUO y VUOS en el Reactor 3

\begin{tabular}{|r|r|r|r|r|}
\hline Día & Pendiente & VUO $(\mathrm{mg} / \mathrm{L}) / \mathrm{min}$ & SST $(\mathrm{g} / \mathrm{L})$ & VUOS $(\mathrm{mg} / \mathrm{g}) / \mathrm{h}$ \\
\hline 0 & 0.0073 & 0.438 & 1.275 & 21 \\
\hline 25 & 0.0025 & 0.15 & 2.666 & 3 \\
\hline 36 & 0.0016 & 0.096 & 3.35 & 2 \\
\hline 46 & 0.0015 & 0.09 & 4.45 & 1 \\
\hline 103 & 0.0023 & 0.138 & 1.95 & 4 \\
\hline 105 & 0.0052 & 0.312 & 1.86 & 10 \\
\hline 108 & 0.0086 & 0.516 & 1.7 & 18 \\
\hline
\end{tabular}




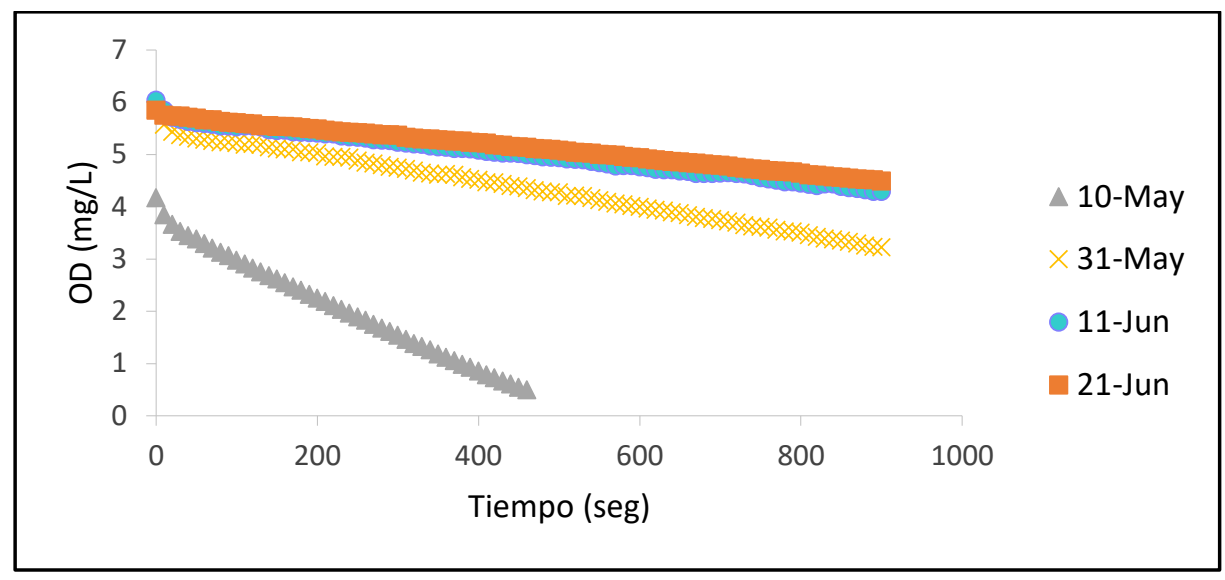

Gráfica 5-36 Gráfica de velocidad de consumo de oxígeno en R3

\section{Análisis de la velocidad de utilización de oxígeno, VUO}

Con los resultados de VUOS (Tabla 5-23) del reactor 1 se puede ver que van bajando a través del tiempo de operación, esto puede ser por el aumento de sólidos en el reactor. Al reducir los sólidos y al reemplazo con lodos nuevos de PTAR, El Rosario, se mejoró el funcionamiento (Gráfica 5-34). En el reactor R2 (adaptada a Fenol +DCP), los valores de VUO y VUOS fueron muy bajos (Tabla 5-24). Estos valores tan bajos muestran la presencia de un tóxico en el reactor, lo cual inhibe a los M.O. su función adecuada. Al reemplazar la mitad de la solución (1250 mL) en el reactor con lodos frescos de PTAR y alimentándolo con agua residual cada dos días sin añadir más tóxicos, se mejora el funcionamiento. En el reactor R3, las valores de VUO muestran que los M.O. fueron capaces de recuperarse con el reemplazo de un poco de lodos viejos con lodos nuevos, estos resultados sugieren que el problema fue por el edad de los lodos como en el reactor R1 y no por la toxicidad como en el caso del reactor R2. Por lo anterior se supone que los lodos ya están adaptados al fenol.

\section{Demanda química de oxígeno}

La Demanda Química de Oxígeno soluble (DQOs) se calculó de 20 a 70 días de operación de los reactores usando un filtro de $0.45 \mu \mathrm{m}$, los resultados se muestran en la Tabla A-0-3 del Anexo A.7. Al continuar la operación se calcula la DQO usando_sobrenadantes centrifugados de los reactores a partir de 89 días de operación. Los resultados se muestran en la Tabla 5-26. 
Tabla 5-26 Demanda química de oxígeno en los reactores adaptados

\begin{tabular}{|c|c|c|c|c|c|c|c|}
\hline \multirow[t]{2}{*}{ Muestra } & \multirow{2}{*}{$\begin{array}{c}\text { Tiempo } \\
\text { (d) }\end{array}$} & \multicolumn{2}{|c|}{ REACTOR 1} & \multicolumn{2}{|c|}{ REACTOR 2} & \multicolumn{2}{|c|}{ REACTOR 3} \\
\hline & & DQO & $\mathrm{DQO}_{\text {Eliminada }}(\%)$ & DQO & $\mathrm{DQO}_{\text {Eliminada }}(\%)$ & DQO & $\mathrm{DQO}_{\text {Eliminada }}(\%)$ \\
\hline $\mathrm{Br}_{\mathrm{r}}$ & \multirow{2}{*}{90} & 34 & \multirow{2}{*}{$45 \%$} & 20 & \multirow{2}{*}{$9 \%$} & 44 & \multirow{2}{*}{$54 \%$} \\
\hline $\mathrm{A}_{\mathrm{r}}$ & & 62 & & 22 & & 95 & \\
\hline$\overline{\mathrm{Br}_{\mathrm{r}}}$ & \multirow{2}{*}{96} & 14 & \multirow{2}{*}{$74 \%$} & 14 & \multirow[b]{2}{*}{$44 \%$} & 4 & \multirow{2}{*}{$79 \%$} \\
\hline $\mathrm{Ar}_{\mathrm{r}}$ & & 53 & & 25 & & 19 & \\
\hline$\overline{\mathrm{Br}_{\mathrm{r}}}$ & \multirow{2}{*}{102} & 60 & \multirow[b]{2}{*}{$55 \%$} & 6 & \multirow{2}{*}{$71 \%$} & 4 & \multirow{2}{*}{$92 \%$} \\
\hline $\mathrm{A}_{\mathrm{r}}$ & & 134 & & 21 & & 53 & \\
\hline $\mathrm{B}_{\mathrm{r}}$ & \multirow{2}{*}{103} & 8 & \multirow{2}{*}{$68 \%$} & 12 & \multirow[b]{2}{*}{$68 \%$} & 6 & \multirow{2}{*}{$54 \%$} \\
\hline$\overline{A_{r}}$ & & 25 & & 38 & & 13 & \\
\hline $\mathrm{B}_{\mathrm{r}}$ & \multirow{2}{*}{105} & 6 & \multirow[b]{2}{*}{$94 \%$} & 16 & \multirow[b]{2}{*}{$56 \%$} & 10 & \multirow[b]{2}{*}{$81 \%$} \\
\hline$\overline{A_{r}}$ & & 106 & & 36 & & 53 & \\
\hline $\mathrm{Br}_{\mathrm{r}}$ & \multirow{2}{*}{107} & 17 & \multirow{2}{*}{$69 \%$} & 77 & & 10 & \\
\hline$A_{r}$ & & 54 & & 89 & $13 \%$ & 44 & $77 \%$ \\
\hline $\mathrm{B}_{\mathrm{r}}$ & & 26 & & 36 & & 6 & \\
\hline$A_{r}$ & 109 & 38 & $58 \%$ & 170 & $79 \%$ & 43 & $86 \%$ \\
\hline $\mathrm{Br}_{\mathrm{r}}$ & 110 & 48 & 500 & 12 & 500 & 34 & ת \\
\hline$\overline{A_{r}}$ & 110 & 99 & $52 \%$ & 29 & $59 \%$ & 51 & $33 \%$ \\
\hline $\mathrm{B}_{\mathrm{r}}$ & 112 & 14 & $580 \%$ & 20 & $65 \%$ & 4 & $80 \%$ \\
\hline$A_{r}$ & 112 & 33 & $58 \%$ & 57 & $65 \%$ & 36 & $89 \%$ \\
\hline $\mathrm{B}_{\mathrm{r}}$ & 120 & 21 & $a^{\prime}$ & 40 & 500 & 12 & 010 \\
\hline $\mathrm{Ar}_{\mathrm{r}}$ & 129 & 29 & $62 \%$ & 96 & $58 \%$ & 74 & $84 \%$ \\
\hline $\mathrm{B}_{\mathrm{r}}$ & 130 & 40 & $50 \%$ & 45 & $30 \%$ & 14 & $58 \%$ \\
\hline $\mathrm{A}_{\mathrm{r}}$ & 139 & 80 & $50 \%$ & 64 & $30 \%$ & 33 & $58 \%$ \\
\hline $\mathrm{B}_{\mathrm{r}}$ & & 34 & & 34 & & 26 & \\
\hline$\overline{A_{r}}$ & 142 & 58 & $41 \%$ & 59 & $42 \%$ & 66 & $61 \%$ \\
\hline $\mathrm{Br}_{\mathrm{r}}$ & 114 & 54 & & 23 & $6 \cap 0$ & 69 & 200 \\
\hline $\mathrm{A}_{\mathrm{r}}$ & 145 & 85 & $4 / \%$ & 74 & $69 \%$ & 98 & $30 \%$ \\
\hline $\mathrm{Br}_{\mathrm{r}}$ & 150 & 20 & 010 & 29 & 6oor & 45 & תחo \\
\hline$A_{r}$ & 159 & 127 & $84 \%$ & 91 & $68 \%$ & 63 & $29 \%$ \\
\hline $\mathrm{B}_{\mathrm{r}}$ & & 36 & & 29 & & 21 & \\
\hline $\mathrm{Ar}_{\mathrm{r}}$ & 164 & 60 & $40 \%$ & 75 & $61 \%$ & 49 & $57 \%$ \\
\hline $\mathrm{B}_{\mathrm{r}}$ & & 27 & & 16 & 600 & 10 & $70 \%$ \\
\hline $\mathrm{Ar}_{\mathrm{r}}$ & $1 / 0$ & 36 & $50 \%$ & 51 & $69 \%$ & 33 & $10 \%$ \\
\hline $\mathrm{B}_{\mathrm{r}}$ & 172 & 35 & & 6 & & 14 & $16 \%$ \\
\hline$\overline{A_{r}}$ & $1 / 2$ & 62 & $44 \%$ & 10 & $40 \%$ & 6 & $46 \%$ \\
\hline
\end{tabular}

$\mathrm{A}_{r}$ - Antes de cambiar el reactor (afluente); $\mathrm{Br}_{\mathrm{r}}$ Después de cambiar el reactor (efluente), R.-Remoción 


\subsubsection{Discusión sobre la Demanda Química de Oxígeno}

Los valores de DQO tomados de las muestras de los reactores muestran que funcionaron bien (Tabla 5-26) y que los M.O. ya están adaptados a las condiciones del laboratorio y al tóxico según el caso de los reactores R2 (Fenol + DCP) y R3 (Fenol).

Los resultados obtenidos de estudios de los diferentes parámetros de los reactores como IVL, OUR, pH, SST, VUO, DQO y estudios microbiológicos durante el tiempo de operación, ayudaron a monitorear el funcionamiento de los reactores durante el proceso de adaptación. En general, se tuvo un lodo café, sobrenadante claro y sin olor, lo que significa que los reactores funcionaron bien.

\subsubsection{Demanda Química de Oxígeno de los reactores con solución pre- ozonizada.}

La DQO se calculó usando los sobrenadantes de los reactores. Los resultados obtenidos de la DQO en los diferentes reactores se muestran en la Tabla 5-27 la degradación de materia orgánica a través del tiempo de los diferentes ciclos (C): C-I (0-8 días), C-II (8-11 días), C-III (11-13 días), C-IV (13-15 días), C-V (15-17 días), CVI (17-19 días). Se operan seis biorreactores que contienen biomasa de los diferentes reactores adaptados (Figura 4-8). Dos biorreactores pequeños con letra R1 contuvieron biomasa aclimatada al laboratorio del Reactor R1 y se alimentaron con S1: ozono (R1OA) y con S1: ozono-UV (R1OB). Otro dos biorreactores pequeños con letra R2 contuvieron biomasa aclimatada al fenol + DCP del Reactor R2 y se alimentaron con S1: ozono (R2OA) y con S1: ozono-UV (R2OB). Los últimos dos biorreactores pequeños con la letra R3 contuvieron biomasa aclimatada al fenol del Reactor R3 se alimentaron con solución pretratada de S1: ozono (R3OA) y con S1: ozonoUV (R3OB). En la Tabla 5-27 se muestran los resultados. 
Tabla 5-27 Demanda química de oxígeno en los reactores con solución preozonizada

\begin{tabular}{|c|c|c|c|c|c|c|c|}
\hline \multirow{3}{*}{ Ciclo } & \multirow{3}{*}{ Cambios } & $\begin{array}{l}\text { REACTOR } \\
\text { R1OA }\end{array}$ & $\begin{array}{l}\text { REACTOR } \\
\text { R1OB }\end{array}$ & $\begin{array}{c}\text { REACTOR } \\
\text { R2OA }\end{array}$ & $\begin{array}{l}\text { REACTOR } \\
\text { R2OB }\end{array}$ & $\begin{array}{c}\text { REACTOR } \\
\text { R3OA }\end{array}$ & $\begin{array}{c}\text { REACTOR } \\
\text { R3OB }\end{array}$ \\
\hline & & DQO & DQO & DQO & DQO & DQO & DQO \\
\hline & & (mg/L) & (mg/L) & (mg/L) & (mg/L) & (mg/L) & $(\mathrm{mg} / \mathrm{L})$ \\
\hline \multirow{3}{*}{ I } & A & 118 & 63 & 39 & 66 & 48 & 79 \\
\hline & $E$ & 57 & 45 & 14 & 43 & 22 & 50 \\
\hline & $\% \mathrm{DQO}_{\mathrm{R}}$ & 52 & 29 & 64 & 35 & 54 & 37 \\
\hline \multirow{3}{*}{ II } & $A_{r}$ & 110 & 61 & 39 & 65 & 48 & 78 \\
\hline & $B_{r}$ & 30 & 42 & 32 & 48 & 24 & 54 \\
\hline & $\% \mathrm{DQO}_{\mathrm{R}}$ & 73 & 31 & 18 & 26 & 50 & 31 \\
\hline \multirow{3}{*}{ III } & $A_{r}$ & 90 & 50 & 37 & 59 & 45 & 65 \\
\hline & $B_{r}$ & 32 & 26 & 29 & 9 & 23 & 13 \\
\hline & $\% D_{R Q}$ & 64 & 48 & 22 & 85 & 49 & 80 \\
\hline \multirow{3}{*}{ IV } & $A_{r}$ & 38 & 60 & 72 & 38 & 67 & 37 \\
\hline & $B_{r}$ & 37 & 44 & 56 & 32 & 24 & 5 \\
\hline & $\% \mathrm{DQO}_{\mathrm{R}}$ & 3 & 27 & 22 & 16 & 64 & 86 \\
\hline \multirow{3}{*}{ V } & $A_{r}$ & 45 & 62 & 74 & 70 & 75 & 87 \\
\hline & $B_{r}$ & 43 & 30 & 33 & 21 & 32 & 24 \\
\hline & $\% \mathrm{DQO}_{\mathrm{R}}$ & 4 & 52 & 55 & 70 & 57 & 72 \\
\hline \multirow{3}{*}{ VI } & $A_{r}$ & 56 & 54 & 67 & 78 & 84 & 74 \\
\hline & $B_{r}$ & 25 & 45 & 50 & 21 & 39 & 23 \\
\hline & $\% \mathrm{DQO}_{\mathrm{R}}$ & 55 & 17 & 25 & 73 & 54 & 69 \\
\hline
\end{tabular}

Ar- Antes de cambiar el reactor (afluente); $\mathrm{B}_{r}$ - Después de cambiar el reactor (efluente), R.-Remoción

\subsubsection{Análisis del comportamiento de la DQO en los biorreactores con solución pretratada}

De los resultados obtenidos de la DQO se notó que los reactores alimentados con biomasas adaptadas al tóxico (R2 y R3) fueron mejores en la remoción de DQO de las soluciones pretratadas. Esto es debido a la presencia de compuestos fenólicos todavía en la solución pretratada según los resultados de compuestos intermedios identificados por cromatografía GC-MS. Los M.O. adaptados de biomasa (R2 y R3) fueron más eficaces para degradarlos. En general, el reactor R1 tuvo más alta remoción de DQO en la solución pretratada con ozono que con ozono-UV, mientras que los reactores R2 y R3 tuvieron mayor degradación en la solución pretratada con ozono-UV. 


\subsubsection{FASE 2: Evaluación de los biorreactores de agitación para biodegradar solución pretratada con ozono y ozono-UV}

\subsubsection{Observación Microscópica de los microorganismos}

Las siguientes fotografías muestran las diferentes observaciones microscópicas (figura 5-18).

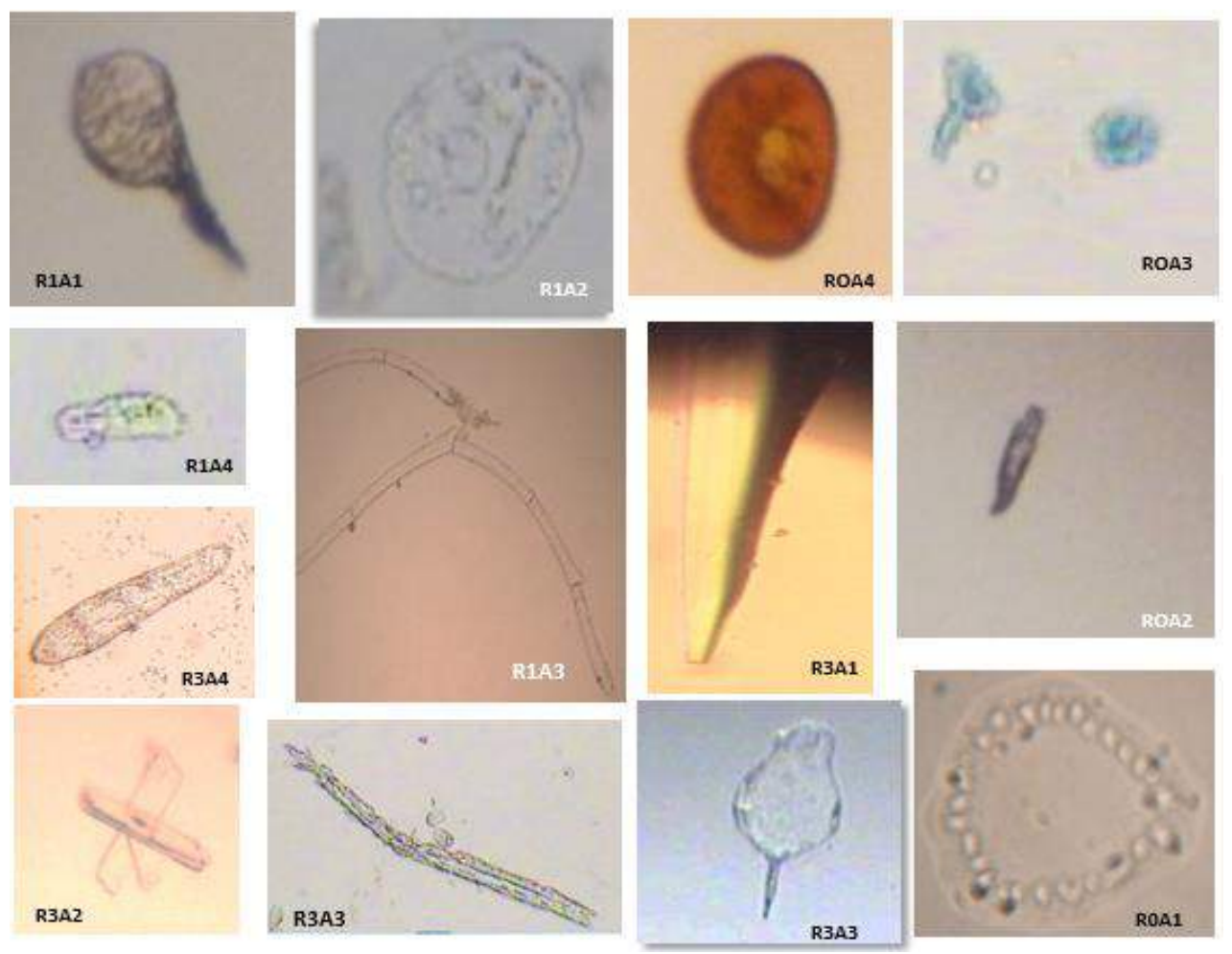

Figura 5-18 Fotografía de la microscópica (40X) de las muestras tomadas de los biorreactores de agitación alimentada con soluciones pretratadas de S1 y S2 con ozono y ozono-UV a los 60 min.

Al observar los M.O. bajo un microscopio se pudo ver la movilidad de los M.O. en las muestras de todos los reactores (R0A1, R0A2, R0A3, R0A4, R1A1, R1A2, R1A3, R1A4, R3A1, R3A2, R3A3 y R3A4). Se pudo ver que había mucha actividad microbiana, lo cual sugiere que las soluciones pretratadas no inhiben las actividades de los M.O. Se observaron los M.O. vivos con los objetivos de 10X, 40X, 100X y se usó una cámara de OLYMPUS digital para tomar las siguientes fotos. Los siguientes M.O. fueron identificados: R1A1 y R3A3 son rotíferos; R1A2: amebas; ROA4: Huevos de helminto, ROA3: vorticela; R1A4 y R3A4: Spirostomum sp., R3A3: Euplotes eurysomus y ROA1: Volvox sp. 


\subsubsection{Observación macroscópica y cuenta de colonias}

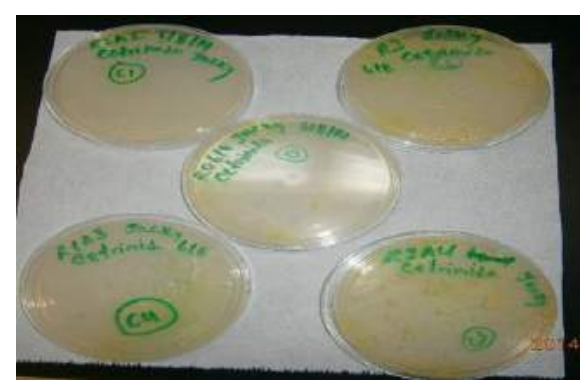

Figura 5-19 Observación macroscópica de los diferentes biorreactores sobre agar cetrimida.

Tabla 5-28 Distribución de colonias en dilución de los diferentes biorreactores: Fase II

\begin{tabular}{|c|c|c|c|c|}
\hline \multirow[b]{2}{*}{ Reactor } & \multirow{2}{*}{$\begin{array}{c}\text { No. de } \\
\text { colonias } \\
\text { en placa }\end{array}$} & \multirow{2}{*}{$\begin{array}{l}\text { Factor de } \\
\text { Dilución } \\
\text { (FD) }\end{array}$} & \multirow{2}{*}{$\begin{array}{l}\text { Volumen de } \\
\text { siembra } \\
(\mathrm{mL})\end{array}$} & UFC/mL \\
\hline & & & & (Promedio) \\
\hline R0 & 267 & $1.00 \mathrm{E}+03$ & 1 & $2.67 \mathrm{E}+05$ \\
\hline $\mathrm{R} 1$ & 180 & $1.00 \mathrm{E}+03$ & 1 & $1.80 \mathrm{E}+05$ \\
\hline R3 & 220 & $1.00 \mathrm{E}+03$ & 1 & $2.20 \mathrm{E}+05$ \\
\hline R0A1 & 287 & $1.00 \mathrm{E}+03$ & 1 & $2.87 E+05$ \\
\hline R0A2 & 288 & $1.00 \mathrm{E}+03$ & 1 & $2.88 \mathrm{E}+05$ \\
\hline R0A3 & 290 & $1.00 E+03$ & 1 & $2.90 \mathrm{E}+05$ \\
\hline R0A4 & 290 & $1.00 E+03$ & 1 & $2.90 \mathrm{E}+05$ \\
\hline $\mathrm{R} 1 \mathrm{~A} 1$ & 278 & $1.00 \mathrm{E}+03$ & 1 & $2.78 \mathrm{E}+05$ \\
\hline R1A2 & 260 & $1.00 \mathrm{E}+03$ & 1 & $2.60 \mathrm{E}+05$ \\
\hline R1A3 & 285 & $1.00 \mathrm{E}+03$ & 1 & $2.85 \mathrm{E}+05$ \\
\hline R1A4 & 288 & $1.00 \mathrm{E}+03$ & 1 & $2.88 \mathrm{E}+05$ \\
\hline R3A1 & 278 & 1.00E+03 & 1 & $2.78 \mathrm{E}+05$ \\
\hline R3A2 & 285 & 1.00E+03 & 1 & $2.85 E+05$ \\
\hline R3A3 & 280 & $1.00 \mathrm{E}+03$ & 1 & $2.80 \mathrm{E}+05$ \\
\hline R3A4 & 288 & $1.00 \mathrm{E}+03$ & 1 & $2.88 \mathrm{E}+05$ \\
\hline
\end{tabular}

\subsubsection{Discusión sobre la concentración de bacterias en los reactores}

En los resultados de la Tabla 5-28 se puede ver que los reactores tienen las mismas concentraciones de bacterias y los reactores con alimentación de lodos traídos del PTAR sin aclimatación (R0) tuvieron la mayor cantidad de M.O. Esto es debido a que los lodos de la PTAR fueron frescos, también puede ser que tienen mayor distribución de M.O. en 


\section{CAPÍTULO 5. RESULTADOS Y DISCUSIÓN}

comparación con los reactores adaptados que tienen mayor cantidad de M.O. que puede degradar los compuestos fenólicos.

\subsubsection{Identificación de bacterias}

Se hicieron pruebas bioquímicas de las muestras tomados de los diferentes reactores para identificar una cepa bacteriana de Pseudomonas sp., ver los resultados en la Tabla 5-29.

Tabla 5-29 Resultados de las pruebas bioquímicas para identificar la cepa bacteriana

\begin{tabular}{|c|c|c|c|c|c|}
\hline Pruebas Bioquímicas & Colonia 1 & Colonia 2 & Colonia 3 & Colonia 4 & Colonia 5 \\
\hline Agar Cetrimida & Crece & Crece & Crece & Crece & Crece \\
\hline Crecimiento a 45ㄷ & + & - & - & + & - \\
\hline S: H2S & + & - & - & - & - \\
\hline I:Indol & - & - & - & - & - \\
\hline M: Motilidad & + & + & + & + & + \\
\hline Oxidativa & + & + & + & + & + \\
\hline VP & - & - & - & - & - \\
\hline MR & - & - & - & - & - \\
\hline Kligler & G-L'S+ & G-L-S & G-L'S- & G-L-S & G-L'S \\
\hline $\begin{array}{c}\text { Oxidativo- } \\
\text { Fermentación }\end{array}$ & - & - & - & - & - \\
\hline Glucosa & + & - & - & - & - \\
\hline Nitrato & + & - & + & + & - \\
\hline Citrato & + & + & - & + & + \\
\hline Color & Blanco & Blanco & Blanco & Verde & Verde \\
\hline
\end{tabular}

G: glucosa; L: lactosa; S: Producción de $\mathrm{H}_{2} \mathrm{~S}$, -: negativo, +: positivo 
Tabla 5-30 Demanda química de oxígeno eliminada en los biorreactores de agitación alimentada con solución de 2,5-DCP en S1: con agua destilada y en S2: con agua residual, pretratadas con ozono y ozono-UV

\begin{tabular}{|c|c|c|c|c|c|c|c|c|}
\hline $\begin{array}{l}\text { Solución } \\
\text { preozonizada }\end{array}$ & Reactor & Ciclo 1 & Ciclo II & Ciclo III & $\begin{array}{c}\text { Ciclo } \\
\text { IV }\end{array}$ & Ciclo V & $\begin{array}{c}\text { Ciclo } \\
\text { VI }\end{array}$ & $\begin{array}{c}\text { Ciclo } \\
\text { VII }\end{array}$ \\
\hline \multicolumn{2}{|c|}{ Tiempo de retención (HRT) } & $\begin{array}{l}\mathrm{DQO}_{\mathrm{R}} \\
(\%)\end{array}$ & $\begin{array}{c}\mathrm{DQO}_{\mathrm{R}} \\
(\%)\end{array}$ & $\begin{array}{c}\mathrm{DQO}_{\mathrm{R}} \\
(\%)\end{array}$ & $\begin{array}{c}\mathrm{DQO}_{\mathrm{R}} \\
(\%)\end{array}$ & $\begin{array}{c}\mathrm{DQO}_{\mathrm{R}} \\
(\%)\end{array}$ & $\begin{array}{c}\mathrm{DQO}_{\mathrm{R}} \\
(\%)\end{array}$ & $\begin{array}{c}\mathrm{DQO}_{\mathrm{R}} \\
(\%)\end{array}$ \\
\hline \multirow{3}{*}{$\begin{array}{r}\mathrm{S} 1: \mathrm{O}_{3} \\
(60 \mathrm{mn})\end{array}$} & R0A1 & 73 & 98 & 95 & 96 & 97 & 84 & 58 \\
\hline & R1A1 & 72 & 90 & 98 & 91 & 93 & 83 & 56 \\
\hline & R3A1 & 75 & 95 & 90 & 98 & 97 & 85 & 59 \\
\hline \multirow{3}{*}{$\begin{array}{r}\mathrm{S} 2: \mathrm{O}_{3} \\
(60 \mathrm{~min})\end{array}$} & R0A2 & 73 & 95 & 96 & 97 & 98 & 86 & 60 \\
\hline & R1A2 & 73 & 98 & 91 & 93 & 93 & 84 & 58 \\
\hline & R3A2 & 75 & 90 & 98 & 97 & 92 & 86 & 60 \\
\hline \multirow{3}{*}{$\begin{array}{l}S 1: O_{3}-U V \\
(60 \mathrm{~min})\end{array}$} & ROA3 & 77 & 95 & 96 & 97 & 98 & 88 & 62 \\
\hline & R1A3 & 77 & 98 & 91 & 93 & 93 & 87 & 60 \\
\hline & R3A3 & 78 & 90 & 98 & 97 & 92 & 89 & 63 \\
\hline \multirow{3}{*}{$\begin{array}{l}\mathrm{S} 2: \mathrm{O}_{3}-\mathrm{UV} \\
(60 \mathrm{~min})\end{array}$} & R0A4 & 79 & 95 & 96 & 97 & 98 & 88 & 63 \\
\hline & R1A4 & 77 & 90 & 91 & 93 & 93 & 87 & 60 \\
\hline & R3A4 & 80 & 95 & 98 & 97 & 92 & 88 & 63 \\
\hline
\end{tabular}

\subsubsection{Discusión sobre los resultados obtenidos en la Fase II: de los biorreactores.}

Para identificar una cepa bacteriana de Pseudomonas $s p$. se hicieron algunas pruebas bioquímicas de las bacterias aisladas de los diferentes biorreactores basados en las apariencias diferentes de las colonias. Se hicieron aislamientos de la bacteriana Pseudomonas sp. Basada en su capacidad de degradar compuestos fenólicos como han sido reportado en la literatura [52-55]. Todos los reactores tuvieron colonias iguales a la Colonia 4 y Colonia 5, mientras Colonia 1, Colonia 2 y Colonia 3 se tomaron de la muestra aislada de los reactores ROA1, ROA2 y R3A4, respectivamente. De acuerdo a los resultados obtenidos en las pruebas bioquímicas en tubos y con API 20 NE, revisión bibliografía de API, y en tablas de pruebas bioquímicas, se encuentra que los M.O. aislados de los reactores podrían ser los siguientes: 


\section{CAPÍTULO 5. RESULTADOS Y DISCUSIÓN}

Colonia 1: Morascella shewanella o Actinobacter sp.

Colonia 2: Pseudomonas sp.

Colonia 3: Alcligenes faecalis

Colonia 4: $P$. aeruginosa

Colonia 5: Pseudomonas sp., pero necesitan hacer más pruebas y estudios para confirmarlos.

Por otra parte, los resultados obtenidos de la remoción de DQO de los diferentes reactores (ver Tabla 5-30) muestran la mayor remoción de DQO de $70 \%$ durante el primer ciclo (HRT $=8 \mathrm{~d})$ con solución pretratada en los diferentes reactores. Durante el ciclo II (HRT=5 d) a Ciclo VI $(H R T=2 d)$ la remoción de DQO se aumentó a 90\%. Sin embargo, las remociones de la $\mathrm{DQO}$ en el último ciclo $(H R T=1 \mathrm{~d})$ bajaron a $60 \%$. Estos cambios en los biorreactores son debidos a su adaptación al inicio y el aumento en el porciento de solución pretratada a $100 \%$ para alimentar los biorreactores y el corto tiempo de retención hidráulica. Los biorreactores con biomasa traída del PTAR $(R 0)$ parecen funcionar ligeramente mejor que los otros biorreactores con biomasa adaptada en el laboratorio, mientras los biorreactores con biomasa de reactor R1, funcionaron más lentos. Sin embargo, todos los biorreactores fueron capaces de degradar las soluciones pretratadas.

\subsubsection{FASE 3: Evaluación de los biorreactores Husman adaptados (BHA) para degradar las soluciones pretradas con ozono y ozono-UV.}

\subsubsection{Demanda química de oxígeno de los biorreactores Husman adaptados} (BHA)

La DQO se calcula a partir del inicio de operación de los reactores por 44 días usando los sobrenadantes de los reactores. Según los resultados obtenidos de la DQO en los diferentes reactores se pueden observar en las tablas 5-32 a 5-36 las degradaciones de materia orgánica a través del tiempo de los diferentes ciclos (C): C-I (0-8 días), C-II (8-11 días), C-III (11-13 días), C-IV (13-15 días), C-V (15-17 días), CVI (17-19 días). 


\section{CAPÍTULO 5. RESULTADOS Y DISCUSIÓN}

Tabla 5-31 Demanda química de oxígeno eliminada del reactor C1: con lodos del reactor R3 (adaptada a fenol) y alimentado con agua residual.

\begin{tabular}{|c|c|c|c|c|c|}
\hline \multicolumn{3}{|c|}{ CONTROL (C1) } & \multicolumn{3}{|c|}{ Volumen $=4 \mathrm{~L}$} \\
\hline $\begin{array}{l}\text { Tiempo } \\
\text { (día) }\end{array}$ & $\begin{array}{c}\text { DQO AFLUENTE } \\
(\mathrm{mg} / \mathrm{L})\end{array}$ & $\begin{array}{c}\text { DQO EFLUENTE } \\
(\mathrm{mg} / \mathrm{L})\end{array}$ & SST (mg/L) & pH & $\begin{array}{c}\mathrm{DQO}_{\text {removida }} \\
(\%)\end{array}$ \\
\hline 1 & 80 & 14 & 2500 & 7.38 & $83 \%$ \\
\hline 3 & 72 & 13 & 2450 & 6.7 & $82 \%$ \\
\hline 7 & 93 & 11 & 2300 & 6.98 & $89 \%$ \\
\hline 11 & 43 & 3 & 2000 & 6.96 & $92 \%$ \\
\hline 16 & 71 & 10 & 1800 & 6.93 & $86 \%$ \\
\hline 21 & 33 & 1 & 1900 & 6.5 & $97 \%$ \\
\hline 23 & 34 & 0 & 1700 & 6.3 & $100 \%$ \\
\hline 28 & 91 & 10 & 1680 & 6.7 & $89 \%$ \\
\hline 30 & 87 & 5 & 1700 & 6.96 & $94 \%$ \\
\hline 34 & 97 & 12 & 1580 & 6.96 & $88 \%$ \\
\hline 38 & 74 & 8 & 1540 & 6.83 & $89 \%$ \\
\hline 40 & 73 & 10 & 1540 & 6.88 & $86 \%$ \\
\hline 42 & 96 & 7 & 1550 & 6.93 & $93 \%$ \\
\hline 44 & 41 & 12 & 1580 & 7.07 & $71 \%$ \\
\hline 45 & 58 & 15 & 1580 & 7.01 & $74 \%$ \\
\hline 50 & 96 & 12 & 1960 & 6.71 & $88 \%$ \\
\hline
\end{tabular}

Tabla 5-32 Demanda química de oxígeno del reactor R30A: con solución pretratada con 60 min de ozonación en agua destilada $\mathbf{S 1 :} \mathbf{O}_{3}$

\begin{tabular}{|r|r|r|r|r|r|}
\hline \multicolumn{7}{|c|}{ REACTOR -R30A } & \multicolumn{2}{l|}{ Volumen = 3 L } \\
\hline $\begin{array}{c}\text { Tiempo } \\
\text { (día) }\end{array}$ & $\begin{array}{c}\text { DQO AFLUENTE } \\
\text { (mg/L) }\end{array}$ & $\begin{array}{c}\text { DQO EFLUENTE } \\
\text { (mg/L) }\end{array}$ & $\begin{array}{c}\text { SST } \\
\text { (mg/L) }\end{array}$ & pH & DQO $_{\text {removida }}$ \\
\hline 1 & 45.0 & 16 & 2520 & 7.38 & $64 \%$ \\
\hline 3 & 97 & 37 & 2160 & 6.69 & $62 \%$ \\
\hline 7 & 87 & 29 & 2000 & 6.81 & $67 \%$ \\
\hline 11 & 41.0 & 11 & 1992 & 6.83 & $74 \%$ \\
\hline 16 & 104.0 & 28 & 1825 & 6.53 & $73 \%$ \\
\hline 21 & 94.0 & 19 & 1980 & 6.09 & $80 \%$ \\
\hline 23 & 87.0 & 32 & 2050 & 6.73 & $63 \%$ \\
\hline 28 & 58.0 & 2 & 2000 & 6.24 & $97 \%$ \\
\hline 30 & 53.0 & 10. & 2160 & 6.92 & $81 \%$ \\
\hline 34 & 82.0 & 41 & 1800 & 6.79 & $50 \%$ \\
\hline 38 & 48.0 & 1 & 1600 & 6.89 & $98 \%$ \\
\hline 40 & 97.0 & 25 & 1640 & 6.72 & $74 \%$ \\
\hline 42 & 53.0 & 20 & 1830 & 6.53 & $62 \%$ \\
\hline 44 & 51.0 & 22 & 2090 & 6.61 & $57 \%$ \\
\hline 45 & 94.0 & 21 & 2080 & 6.8 & $78 \%$ \\
\hline 50 & 72.0 & 19 & 2080 & 6.64 & $74 \%$ \\
\hline
\end{tabular}




\section{CAPÍTULO 5. RESULTADOS Y DISCUSIÓN}

Tabla 5-33 Demanda química de oxígeno del reactor R30B: con solución pretratada con 60 min de ozonación en agua residual $\mathbf{S 2 :} \mathbf{O}_{3}$

\begin{tabular}{|r|r|r|r|r|r|}
\hline \multicolumn{2}{|c|}{ REACTOR: R30B } & \multicolumn{2}{l|}{ Volumen $\mathbf{3}$ L } \\
\hline $\begin{array}{r}\text { Tiempo } \\
\text { (día) }\end{array}$ & $\begin{array}{c}\text { DQO AFLUENTE } \\
\text { (mg/L) }\end{array}$ & $\begin{array}{c}\text { DQO EFLUENTE } \\
\text { (mg/L) }\end{array}$ & $\begin{array}{c}\text { SST } \\
\text { (g/L) }\end{array}$ & pH & DQO $_{\text {removida }}$ \\
\hline 1 & 273 & 67 & 2300 & 7.38 & $75 \%$ \\
\hline 3 & 296 & 64 & 2210 & 6.82 & $78 \%$ \\
\hline 7 & 207 & 58 & 2100 & 6.75 & $72 \%$ \\
\hline 11 & 304 & 68 & 2040 & 6.6 & $78 \%$ \\
\hline 16 & 77 & 12 & 2000 & 6.7 & $84 \%$ \\
\hline 21 & 84 & 5 & 2050 & 6.49 & $94 \%$ \\
\hline 23 & 103 & 39 & 2120 & 6.53 & $62 \%$ \\
\hline 28 & 108 & 36 & 2300 & 6.75 & $67 \%$ \\
\hline 30 & 86 & 20 & 1900 & 6.57 & $77 \%$ \\
\hline 34 & 122 & 45 & 1840 & 6.56 & $63 \%$ \\
\hline 38 & 111 & 26 & 1802 & 6.6 & $77 \%$ \\
\hline 40 & 84 & 12 & 1620 & 6.67 & $86 \%$ \\
\hline 42 & 148 & 34 & 1680 & 6.93 & $77 \%$ \\
\hline 44 & 86 & 18 & 1750 & 6.96 & $79 \%$ \\
\hline 45 & 87 & 10 & 1740 & 6.82 & $89 \%$ \\
\hline 50 & 122 & 17 & 1998 & 6.75 & $86 \%$ \\
\hline
\end{tabular}

Tabla 5-34 Demanda química de oxígeno del reactor R31A: con solución pretratada con 60 min de ozonación-UV en agua destilada $\mathrm{S}_{1}: \mathrm{O}_{3}-\mathrm{UV}$

\begin{tabular}{|c|c|c|c|c|c|}
\hline \multicolumn{3}{|l|}{ Reactor: R31A } & \multicolumn{2}{|l|}{ Volumen $=3 \mathrm{~L}$} & \multirow[b]{2}{*}{$\begin{array}{c}\mathrm{DQO}_{\text {removida }} \\
(\%)\end{array}$} \\
\hline Tiempo (día) & $\begin{array}{c}\text { DQO } \\
\text { AFLUENTE } \\
\text { (mg/L) }\end{array}$ & $\begin{array}{c}\text { DQO } \\
\text { EFLUENTE } \\
(\mathrm{mg} / \mathrm{L})\end{array}$ & SST (g/L) & $\mathrm{pH}$ & \\
\hline 1 & 93 & 13 & 2300 & 7.38 & $86 \%$ \\
\hline 3 & 117 & 37 & 2215 & 6.52 & $68 \%$ \\
\hline 7 & 111 & 10 & 2100 & 6.35 & $91 \%$ \\
\hline 11 & 95 & 34 & 2020 & 6.40 & $64 \%$ \\
\hline 16 & 121 & 41 & 2010 & 6.35 & $66 \%$ \\
\hline 21 & 104 & 39 & 2050 & 6.46 & $63 \%$ \\
\hline 23 & 104 & 24 & 2120 & 6.33 & $77 \%$ \\
\hline 28 & 108 & 3 & 2300 & 6.26 & $97 \%$ \\
\hline 30 & 106 & 16 & 1900 & 6.53 & $85 \%$ \\
\hline 34 & 206 & 73 & 1840 & 6.54 & $65 \%$ \\
\hline 38 & 108 & 31 & 1740 & 6.76 & $71 \%$ \\
\hline 40 & 230 & 75 & 1840 & 6.42 & $67 \%$ \\
\hline 42 & 119 & 2 & 1900 & 6.73 & $99 \%$ \\
\hline 44 & 43 & 5 & 1820 & 6.23 & $88 \%$ \\
\hline 45 & 98 & 4 & 1820 & 6.86 & $96 \%$ \\
\hline 50 & 109 & 15 & 2280 & 6.28 & $86 \%$ \\
\hline
\end{tabular}


Tabla 5-35 Demanda química de oxígeno del reactor R31B: con solución pretratada con 60 min de ozonación-UV en agua residual S2: $\mathbf{O}_{3}$-UV

\begin{tabular}{|r|r|r|r|r|r|}
\hline \multicolumn{7}{|c|}{ REACTOR -R31B } & \multicolumn{1}{l|}{ Volumen = 3 L } \\
\hline $\begin{array}{r}\text { Tiempo } \\
\text { (día) }\end{array}$ & $\begin{array}{c}\text { DQO AFLUENTE } \\
\text { (mg/L) }\end{array}$ & $\begin{array}{c}\text { DQO EFLUENTE } \\
\text { (mg/L) }\end{array}$ & SST (g/L) & pH & DQO removida \\
\hline 1 & 80 & 28 & 2280 & 7.28 & $65 \%$ \\
\hline 3 & 102 & 22 & 2140 & 6.83 & $78 \%$ \\
\hline 7 & 103 & 19 & 2100 & 6.51 & $82 \%$ \\
\hline 11 & 79 & 24 & 2050 & 6.41 & $70 \%$ \\
\hline 16 & 77 & 22 & 1890 & 6.56 & $71 \%$ \\
\hline 21 & 102 & 13 & 1800 & 6.67 & $87 \%$ \\
\hline 23 & 79 & 4 & 1750 & 6.32 & $95 \%$ \\
\hline 28 & 106 & 25 & 1750 & 6.46 & $76 \%$ \\
\hline 30 & 107 & 12 & 1720 & 6.29 & $89 \%$ \\
\hline 34 & 102 & 23 & 1700 & 6.58 & $77 \%$ \\
\hline 38 & 137 & 3 & 1680 & 6.68 & $98 \%$ \\
\hline 40 & 84 & 7 & 1720 & 6.47 & $92 \%$ \\
\hline 42 & 84 & 9 & 1840 & 6.56 & $89 \%$ \\
\hline 44 & 86 & 21 & 1800 & 6.64 & $76 \%$ \\
\hline 45 & 92 & 5 & 1920 & 6.65 & $95 \%$ \\
\hline 50 & 86 & 11 & 2200 & 6.52 & $87 \%$ \\
\hline & & & & & \\
\hline
\end{tabular}

\subsubsection{Caracterización y aislación de Pseudomonas sp.}

Para identificar un cepa bacteriana de Pseudomonas sp. Se hicieron algunas pruebas bioquímicas y los resultados se muestran en la Tabla 5-37 y Figura 5-20. La Tabla 5-36 se muestra la distribución de bacteria en los diferentes reactores biológicos.

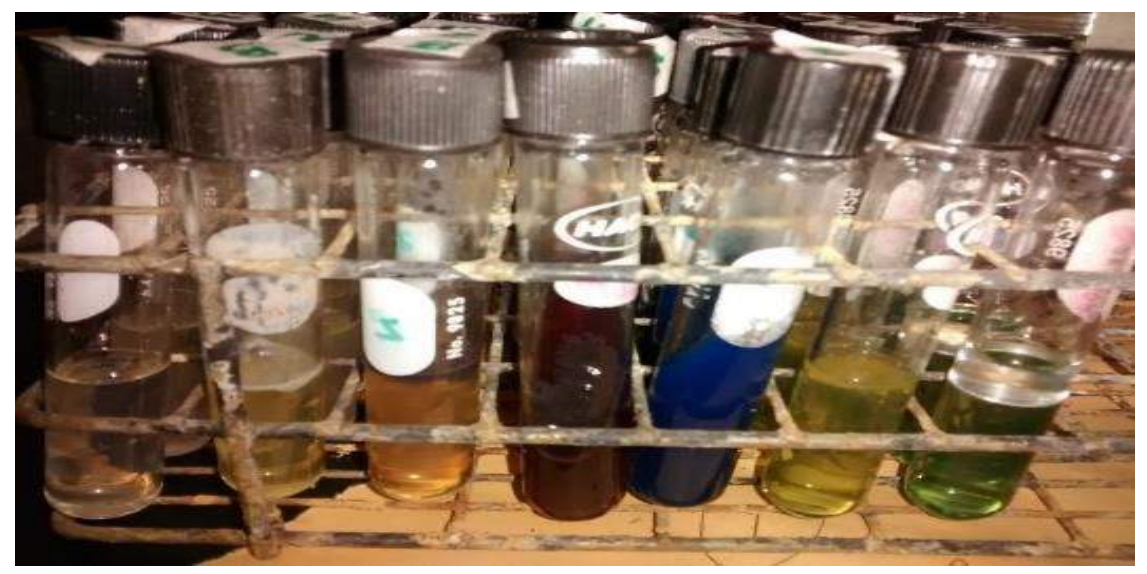

Figura 5-20 Resultados de las Pruebas Bioquímicas de los reactores R1 y R3 Con prueba de API 20E 


\section{CAPÍTULO 5. RESULTADOS Y DISCUSIÓN}

Tabla 5-36 Distribución de colonias en dilución de los diferentes biorreactores en la Fase 3.

\begin{tabular}{|l|l|l|l|l|}
\hline Reactor & $\begin{array}{c}\text { No. de } \\
\text { colonias en } \\
\text { placa }\end{array}$ & $\begin{array}{l}\text { Factor de } \\
\text { Dilución } \\
\text { (FD) }\end{array}$ & $\begin{array}{l}\text { Volumen } \\
\text { de } \\
\text { siembra } \\
(\mathrm{mL})\end{array}$ & UFC/mL \\
\cline { 5 - 6 } & 290 & $1.00 \mathrm{E}+03$ & 1 & 290000 \\
\hline C1 & 285 & $1.00 \mathrm{E}+03$ & 1 & 285000 \\
\hline R30A & 275 & $1.00 \mathrm{E}+03$ & 1 & 275000 \\
\hline R30B & 285 & $1.00 \mathrm{E}+03$ & 1 & 285000 \\
\hline R31A & 260 & $1.00 \mathrm{E}+03$ & 1 & 260000 \\
\hline R31B & & & & \\
\hline
\end{tabular}

Tabla 5-37 Resultados de las pruebas bioquímicas para identificar la cepa bacteriana

\begin{tabular}{|c|c|c|c|c|}
\hline Pruebas Bioquímicas & Colonia 1 & Colonia 2 & Colonia 3 & Colonia 4 \\
\hline Cetrmida & crece & Crece & Crece & Crece \\
\hline Mobilidad & + & + & + & + \\
\hline Citrato & + & + & + & + \\
\hline SIM & $\mathrm{S}^{+} \mathrm{I}^{-}{ }^{+}$ & $\mathrm{S}^{+} \mathrm{I}^{+} \mathrm{M}^{+}$ & $\mathrm{S}^{+} \mathrm{I}^{-} \mathrm{M}^{+}$ & $\mathrm{S}^{+} \mathrm{I}^{+}$ \\
\hline KLIGER & & & & \\
\hline O-F & $\mathrm{O}^{+} \mathrm{F}^{-}$ & $\mathrm{O}^{+} \mathrm{F}^{-}$ & $\mathrm{O}^{+} \mathrm{F}^{-}$ & $\mathrm{O}^{+} \mathrm{F}^{-}$ \\
\hline Oxidasa & + & + & + & - \\
\hline Mc Conkey & $\mathrm{Crece}^{-}$ & Crece & Crece & Crece \\
\hline Crecimiento a $25^{\circ} \mathrm{C}$ & + & + & + & + \\
\hline Crecimiento a $37^{\circ} \mathrm{C}$ & + & + & + & + \\
\hline Crecimiento a $42^{\circ} \mathrm{C}$ & - & + & + & + \\
\hline MR & - & - & - & + \\
\hline VP & - & - & - & + \\
\hline GRAM & - & - & - & + \\
\hline Color & Verde & Verde & Verde & Blanco \\
\hline
\end{tabular}

S: Producción de $\mathrm{H}_{2} \mathrm{~S}$; I: indol; $\mathbf{M}$ : motilidad; L: producción de ácida de la lactosa; $\mathbf{G}$ : producción de ácida de la glucosa; g: producción de gases; O-F: Oxidativa-Fermentación; MR: Rojo de Metilo y VP: Voges Proskauer. 


\section{CAPÍTULO 5. RESULTADOS Y DISCUSIÓN}

\subsubsection{Discusión sobre los resultados de FASE 3: de los biorreactores Husmann}

Los M.O. en las muestras de los biorreactores tipo Husmann fueron similares a los observados en los reactores anteriores con una buena cantidad de protozoarios.

Los resultados obtenidos se pueden ver en la Tabla 5-35 y se observa que los reactores tienen las mismas magnitudes de bacterias y el reactor de control tuvo la mayor cantidad de M.O. Esto es debido a que el reactor se alimenta con agua residual, la cual es fácilmente biodegradable por los M.O. como puede verse en la remoción de DQO en la Tabla 5-31.

Para identificar un cepa bacteriana de Pseudomonas sp. se hicieron algunas pruebas bioquímicas de las bacterias aisladas de los diferentes biorreactores, basados en las apariencias diferentes de las colonias. Colonia 1, Colonia 2, Colonia 3, Colonia 4 se tomaron de la muestra aislada de los reactores $R 30 A, R 30 B, R 31 A$ y $R 31 B$, respectivamente. De acuerdo a los resultados obtenidos en las pruebas bioquímicas en tubos, los M.O. aislados de los reactores son probables los siguientes:

Colonia 1: Pseudomonas sp., Colonia 2: Pseudomonas sp., Colonia 3: P. aeruginosa y Colonia 4: Bacillus subtilis, pero como se mencionó anteriormente, es necesario hacer más pruebas y estudios para confirmarlos.

Por otra parte, los resultados de la remoción de DQO de los diferentes reactores (ver las tablas 5-33 a 5-36) muestran una remoción de DQO de 51\% a 99\% durante el tiempo de operación de los diferentes reactores. La disminución del pH podría ser por la formación de ácidos orgánicos en los reactores, cuando los microorganimos degradan las soluciones pretratadas. Además los sobrenadantes de los efluentes fueron transparentes, debido a la degradación de los compuestos clorados de la solución pretratada. Los biorreactores funcionan en continuo y se alimentan con solución diluida de 1:5 (para tener suficiente solución para la duración de los experimentos). Durante los experimentos se monitorean los SST en los reactores, los cuales se mantienen constantes, debido al tipo del reactor, a diferencia de la disminución y aumento de los SST en los biorreactores con agitación. LoS reactores funcionan bien y fueron muy eficaces en la degradación de las soluciones pretratadas. En general los mejores resultados se obtienen en la degradación de las 


\section{CAPÍTULO 5. RESULTADOS Y DISCUSIÓN}

soluciones pretratadas con ozono-UV, esto es debido a que estas soluciones tuvieron mayor biodegradabilidad que las soluciones tratadas con ozono, y por eso fueron más fáciles de biodegradar.

Los biorreactores fueron capaces de aumentar la biodegradabilidad de las soluciones pretratadas, así que se puede recomendar la combinación de un pretratamiento con ozono u ozono-UV con un tratamiento biológico de lodos activados para aumentar la biodegradabilidad de soluciones de 2,5-DCP.

\subsection{Análisis estadístico de los resultados}

Primeramente se dividen los resultados de los experimentos de los diferentes $\mathrm{POA}\left(\mathrm{O}_{3}, \mathrm{O}_{3}-\right.$ UV) por dos soluciones acuosas de 2,5-DCP (S1: con agua destilado, S2: con agua residual) y usa el mismo diseño experimental de diseño factorial $2^{2}$ para cada solución. Abajo se describe el diseño experimental que se repitió para cada solución.

\section{Diseño factorial $2^{2}$ - Biodegradabilidad de 2,5-DCP con tratamientos de POA en soluciones S1 y S2.}

El diseño experimental que se utiliza en este estudio es un diseño factorial $2^{2}$ con tres repeticiones por cada tratamiento. El control será una solución de 2,5-DCP en S1: con agua destilada y en S2: con agua residual con un $\mathrm{pH}$ inicial de 7 sin aplicar tratamiento de POAs (I). Los otros dos tratamientos serán soluciones de 2,5-DCP en solución acuosa de 2,5-DCP (S1 y S2) y tratados con (II) Ozono $\left(\mathrm{O}_{3}\right)$ y su combinación (III) Ozono-UV $\left(\mathrm{O}_{3}-\mathrm{UV}\right.$ ) por una hora (60 minutos). Se mide la biodegradación del 2,5-DCP para calcular la relación entre $\mathrm{DBO}_{5} / \mathrm{DQO}$ de los datos obtenidos de las cinco pruebas en cada solución (S1 y S2). Después se hacen pruebas de Análisis de Varianza (ANDEVA) y pruebas t para analizar las diferencias entre tratamientos de $\mathrm{AOP}\left(\mathrm{O}_{3}, \mathrm{O}_{3}-\mathrm{UV}\right)$ y la solución acuosa ( $\mathrm{S} 1$ y S2).

\section{Variables Dependientes}

Variable de Respuesta: es la medida $\mathrm{DBO}_{5}, \mathrm{DQO}$ en $\mathrm{mgO}_{2} / \mathrm{L}$ y la relación entre $\mathrm{DBO}_{5} / \mathrm{DQO}$ 


\section{CAPÍTULO 5. RESULTADOS Y DISCUSIÓN}

Variable de Control: es el tratamiento de la solución acuosa de 2,5-DCP sin tratamiento según el caso ( $\mathrm{S} 1$ y $\mathrm{S} 2$ ), se considera como sin tratamiento el tiempo de 0 minutos.

\section{Variables Independientes}

Soluciones acuosas del $2,5-\mathrm{DCP}(\mathrm{S} 1 ; \mathrm{S} 2)$ y tratamientos de $\mathrm{POA}\left(\mathrm{O}_{3} ; \mathrm{O}_{3}-\mathrm{UV}\right)$

\section{Variables Constantes}

Tiempo de tratamiento (hasta $60 \mathrm{~min}$ ), Concentración de solución 2,5-DCP (3.07 mM) Dosis de ozono aplicado en los tratamientos $(1.3 \mathrm{~g} / \mathrm{h})$, Temperatura de la solución $\left(20-25^{\circ} \mathrm{C}\right)$ y $\mathrm{pH}(7.07)$

Fue importante controlar las variables independientes lo más posible sea, ya que cambios en estas variables pueden tener efectos negativos sobre los resultados y también pueden cambiar los resultados entre repeticiones.

Se estudió el efecto de oxidación con ozono y ozono-UV para la biodegradación del 2,5-DCP en soluciones S1: con agua destilada y en S2: con agua residual. Es decir, los efectos del 2,5-DCP en soluciones S1 y en S2: sin tratamiento, con ozonación y con ozono-UV.

Se hace este estudio estadístico para encontrar cual tratamiento mejorará la biodegradabilidad del 2,5-DCP con los tratamientos del ozono y ozono-UV en adición al tipo de la solución acuosa usada (S1 y S2).

Tabla 5-38 Factores de la prueba y la respuesta para el experimento de la biodegradación del 2,5-DCP

\begin{tabular}{|c|c|c|c|}
\hline Factor & AOP & $\begin{array}{c}\text { Nivel bajo } \\
(\mathbf{- 1 )}\end{array}$ & $\begin{array}{c}\text { Nivel alto } \\
(+\mathbf{+ 1})\end{array}$ \\
\hline A & Ultravioleta & $\begin{array}{c}\text { No aplicando } \\
\text { de Luz UV }\end{array}$ & Aplicando UV \\
\hline B & Ozonación & $\begin{array}{c}\text { No aplicando } \\
\text { ozono }\end{array}$ & Aplicando ozono \\
\hline
\end{tabular}

Respuesta (Y): Biodegradabilidad de 2,5-DCP después 60 minutos de tratamiento (DBO5/DQO) 


\section{CAPÍTULO 5. RESULTADOS Y DISCUSIÓN}

El título de "Combinación" es una forma abreviada de escribir las diferentes combinaciones. El "S" significa que los dos factores A y B están en el nivel bajo. El "b" significa que el factor B está en el nivel alto y el factor A está en el nivel bajo. El "ab" significa que ambos factores están en el nivel alto. El "+1" y "-1" indican el nivel de factor A y B para cada combinación. El "+1" significa un nivel alto y el "-1" significa un nivel bajo. Usando el "+1" y "-1" para indicar las combinaciones es el método preferido en la mayoría de softwares para el diseño de experimentos.

La respuesta de interés es la biodegradabilidad de 2,5-DCP (DBO5/DQO).

Tabla 5-39 Combinación de los tratamientos AOP

\begin{tabular}{|c|c|c|c|c|}
\hline Prueba & Combinación & A & B & \begin{tabular}{c} 
Descripción de combinación \\
\hline 1
\end{tabular} \\
\hline 2 & $\mathrm{~S}$ & -1 & -1 & $\begin{array}{c}\text { Sin tratamiento } \\
\text { (no } \mathrm{O}_{3} \text { ni luz UV ) }\end{array}$ \\
\hline 3 & $\mathrm{~b}$ & -1 & +1 & Solo tratada con O3 \\
\hline 3 & $\mathrm{ab}$ & +1 & +1 & $\begin{array}{c}\text { Tratamiento combinado } \mathrm{O}_{3} \text {-UV } \\
\text { ( con } \mathrm{O}_{3} \mathrm{y} \text { UV) }\end{array}$ \\
\hline
\end{tabular}




\section{RESULTADOS DEL ANÁLISIS ESTADÍSTICO}

RESUMEN EN S1: con agua destilada

\begin{tabular}{|l|r|r|r|r|}
\hline \multicolumn{1}{|c|}{ Tratamiento } & Cuenta & \multicolumn{1}{c|}{ Suma } & \multicolumn{1}{c|}{ Promedio } & \multicolumn{1}{c|}{ Varianza } \\
\hline S1: $\sin$ tratamiento & 3 & 0.017004 & 0.005668 & $5.98918 \mathrm{E}-06$ \\
\hline S1:O3 & 3 & 1.228267 & 0.4094221 & 0.0002075 \\
\hline S1:O3-UV & 3 & 1.989059 & 0.663020 & 0.0001437 \\
\hline & & & & \\
\hline
\end{tabular}

\subsubsection{Análisis de varianza de un factor - Biodegradabilidad del 2,5-DCP en S1: con agua destilada con tratamientos de POA (ozono y ozono-UV)}

Ho: No hay diferencias entre tratamientos

Ha: Hay diferencias entre tratamientos

ANÁLISIS DE VARIANZA

\begin{tabular}{|c|c|c|c|c|c|c|}
\hline $\begin{array}{c}\text { Origen de las } \\
\text { variaciones }\end{array}$ & $\begin{array}{l}\text { Suma de } \\
\text { cuadrados }\end{array}$ & $\begin{array}{c}\text { Grados } \\
\text { de } \\
\text { libertad }\end{array}$ & $\begin{array}{c}\text { Promedio de los } \\
\text { cuadrados }\end{array}$ & $F$ & Probabilidad & $\begin{array}{c}\text { Valor } \\
\text { crítico para } \\
f_{o}\end{array}$ \\
\hline Tratamientos & 0.65944 & 2 & 0.32972 & 2769.2521 & $1.27 \mathrm{E}-09$ & 5.143253 \\
\hline Errores & 0.00071 & 6 & 0.00012 & & & \\
\hline Total & 0.66016 & 8 & & & & \\
\hline
\end{tabular}

Si rechazo la hipótesis ya que $F>f_{0}$, entonces, si hay diferencias entre tratamientos en soluciones S1: con agua destilada. 


\subsubsection{Análisis de varianza de un factor - Biodegradabilidad de 2,5-DCP en S2: con agua residual con tratamientos de POA}

Ho: No hay diferencias entre tratamientos

Ha: Hay diferencias entre tratamientos

RESUMEN S2: con agua residual

\begin{tabular}{|l|l|r|r|r|}
\hline \multicolumn{1}{|c|}{ Tratamientos } & Cuenta & \multicolumn{1}{l|}{ Suma } & \multicolumn{1}{c|}{ Promedio } & \multicolumn{1}{l|}{ Varianza } \\
\hline S2: sin tratamiento & 3 & 0.508419 & 0.169473 & 0.000367 \\
\hline S2:O3 & 3 & 1.805068 & 0.601689 & 0.000444 \\
\hline S2:O3-UV & 3 & 2.57483 & 0.858277 & $1.06 \mathrm{E}-05$ \\
\hline
\end{tabular}

ANÁLISIS DE VARIANZA

\begin{tabular}{ccccccc}
\hline $\begin{array}{c}\text { Origen de las } \\
\text { variaciones }\end{array}$ & $\begin{array}{c}\text { Suma de } \\
\text { cuadrados }\end{array}$ & $\begin{array}{c}\text { Grados de } \\
\text { libertad }\end{array}$ & $\begin{array}{c}\text { Promedio de los } \\
\text { cuadrados }\end{array}$ & F & Probabilidad & $\begin{array}{c}\text { Valor } \\
\text { crítico } \\
\text { para } f_{0}\end{array}$ \\
\hline Tratamientos & 0.727099 & 2 & 0.363549 & 1328.684 & $1.14 \mathrm{E}-08$ & 5.143253 \\
Errores & 0.001642 & 6 & 0.000274 & & & \\
& & & & & & \\
Total & 0.728741 & 8 & & & & \\
\hline
\end{tabular}

Si rechazo la hipótesis ya que $\mathrm{F}>f_{o}$, entonces, si hay diferencias entre tratamientos en soluciones S2: con agua residual. 


\subsubsection{Análisis de varianza de dos factores con una sola muestra por grupo - Biodegradabilidad de 2,5-DCP con tratamientos de $\mathrm{POA}\left(\mathrm{O}_{3}\right.$ y $\left.\mathrm{O}_{3}-\mathrm{UV}\right)$ en las soluciones (S1 y S2)}

Ahora nos avocaremos a verificar las siguientes hipótesis usando los promedios obtenidos de las otras pruebas.

$\mathrm{H}_{\mathrm{o}}$ : No hay diferencias entre tratamientos

$\mathrm{H}_{1}$ : No hay diferencias entre las dos soluciones acuosas del 2,5-DCP

\begin{tabular}{lrcrr}
\hline \multicolumn{1}{c}{ RESUMEN } & Cuenta & Suma & Promedio & Varianza \\
\hline S1: con agua destilada & 3 & 1.07579 & 0.35860 & 0.10917 \\
S2: con agua residual & 3 & 1.61759 & 0.53920 & 0.12294 \\
& & & & \\
Sin tratamiento & 2 & 0.16715 & 0.08357 & 0.01219 \\
Ozonación & 2 & 1.01134 & 0.50567 & 0.01830 \\
Ozono-UV & 2 & 1.51490 & 0.75745 & 0.01888 \\
\hline
\end{tabular}

ANÁLISIS DE VARIANZA

\begin{tabular}{lccccrr}
\hline \multicolumn{1}{c}{$\begin{array}{c}\text { Origen de las } \\
\text { variaciones }\end{array}$} & $\begin{array}{c}\text { Sumade } \\
\text { cuadrados }\end{array}$ & $\begin{array}{c}\text { Grados de } \\
\text { libertad }\end{array}$ & $\begin{array}{c}\text { Promedio de los } \\
\text { cuadrados }\end{array}$ & $F$ & Probabilidad & \multicolumn{1}{c}{$\begin{array}{c}\text { Valor } \\
\text { paŕtico }\end{array}$} \\
\hline Tratamientos & 0.04893 & 1 & 0.0489 & 217.2367 & 0.0046 & 18.513 \\
Soluciones acuosas & 0.46378 & 2 & 0.2319 & 1029.6131 & 0.0010 & 19 \\
Error & 0.00045 & 2 & 0.0002 & & & \\
& & & & & & \\
Total & 0.51315 & 5 & & & & \\
\hline
\end{tabular}

Se rechazan las hipótesis $\mathrm{H}_{\circ}$ y $\mathrm{H}_{1}$ ya que $\mathrm{F}>\mathrm{f}_{0}$. Entonces, el tipo del tratamiento y la solución usada si influyen la biodegradabilidad del 2,5-DCP y sus intermedios. 


\section{CAPÍTULO 5. RESULTADOS Y DISCUSIÓN}

\subsubsection{Prueba t para medias de dos muestras emparejadas -Biodegradabilidad de 2,5-DCP con tratamientos de POAs $\left(\mathrm{O}_{3}\right.$ y UV) en las soluciones ( 1 1)}

Para comparar cual es el mejor tratamiento se hace una comparación entre ozono y UV usando prueba t. Los resultados se muestran abajo.

$\mu_{1}$ : Media de biodegradabilidad de 2,5-DCP con tratamiento de ozono

$\mu_{2}$ : Media de biodegradabilidad de 2,5-DCP con tratamiento de ozono-UV

$$
\begin{array}{ll}
\text { Hipótesis para probar: } & H_{0}: \mu_{1}=\mu_{2} \\
& H_{a}: \mu_{1} \neq \mu_{2}
\end{array}
$$

\begin{tabular}{lrr}
\hline & Variable 1 & Variable 2 \\
\hline Media & 0.677440945 & 0.052624732 \\
Varianza & 0.000302058 & 0.00030993 \\
Observaciones & 3 & 3 \\
Coeficiente de correlación de & \\
Pearson & -0.285149968 & \\
Diferencia hipotética de las medias & 0 & \\
Grados de libertad & 2 & \\
Estadístico t & 38.58945655 \\
$P(T<=t)$ una cola & 0.000335425 & \\
Valor crítico de $t$ (una cola) & 2.91998558 \\
$P(T<=t)$ dos colas & 0.00067085 & \\
Valor crítico de t (dos colas) & 4.30265273 & \\
\hline
\end{tabular}

Según los resultados el tratamiento $\mathrm{O}_{3}-\mathrm{UV}$ da una mejor biodegradación del 2,5-DCP que el tratamiento con $\mathrm{O}_{3}$. 
REFERENCIAS

[1] E. F. Karamah, S. Bismo, L. Annasari y W. W. Purwanto, «Mass Transfer Study on MicroBubbles Ozonation in a Bubble Column,» Int. J. Chem. Eng. Res., 2, 243-252, 2010.

[2] R. Ramalho, «Teoría y práctica de la aireación en tratamientos de aguas residuales,» de ratamiento de Aguas Residuales, 2 ed. ed., 08029 Barcelona, Editorial Reverté, S.A., 1990, pp. 199-252.

[3] D. Azbel, Two-phase flows in chemical engineering., Cambridge University Press, 1981.

[4] P. Rollbusch, M. Becker, M. Ludwig, A. Bieberle, M. Grünewald, U. Hampel y R. Franke, «Experimental investigation of the influence of column scale, gas density,» Int. J. Multiphas. Flow, 75, 88-106, 2015.

[5] M. Bouaifi, G. Hébrard, D. Bastoul y M. Roustan, «A Comparative Study of Gas Hold-Up, Bubble size, Interfacial area and Mass Transfer Coefficients in Stirred Gas-Liquid reactors and Bubble Columns,» Chem. Eng. Process., 40, 97-111, 2001.

[6] G. Tchobanoglous, F. L. Burton y H. D. Stensel, Wastewater Engineering Treatment and Reuse/ Metcalf \& Eddy Inc., 4th Ed. ed., I. Metcalf \& Eddy, Ed., New York, NY 10020: McGraw Hill companies Inc., 2003.

[7] N. Kantarci, F. Borak y K. O. Ulgen, «Bubblecolumn reactors,» Process Biochem., 40, 2263-2283, 2005.

[8] E. Kadic y T. J. Heindel, «Bubble Column Bioreactors,» de An Introduction to Bioreactor Hydrodynamics and Gas-Liquid Mass Transfer, 1st ed. ed., Somerset, US, Wiley, 2014, pp. 123-168.

[9] M. D. Gurol y S. Nekouinaini, «Effect of Organic Substances on Mass Transfer in Bubble Aeration,» J. Water Pollut. Con. F., 57, 235-240, 1985.

[10] M. Roustan, J. Mallevialle, H. Roques y J. Jones, «Mass Transfer of Ozone to Water: A Fundamental study, Ozone Sci. Eng., 2, 337-344, 1981.

[11] R. N. Kumar y A. V. Vinod, "Oxygen Mass Transfer in Bubble Column Bioreactor," Period. Polytech. Chem. Eng., 58, 21-30, 2014.

[12] V. Linek, M. Kordac y T. Moucha, "Mechanism of mass transfer from bubbles in dispersions Part II: Mass transfer coefficients in stirred gas-liquid reactor and bubble column,» Chem. Eng. Process., 44, 121-130, 2005.

[13] R.-L. Cooke, «Water/Wastewater Distance Learning Website,» 21 Agosto 2000. [En línea]. Available: http://water.me.vccs.edu/courses/ENV149/ozonation.htm. [Último acceso: 10 Octubre 2013].

[14] Y. Qui, C. Kuo, M. E. Zappi y E. C. Fleming, «Ozonation of 2,6-, 3,4- and 3,5Dichlorophenol isomers within Aqueous Solutions,» J. Environ. Eng., 130, 408-416, 2004.

[15] J. C. Alexander y C. R. Ramírez-Cortina, «A Comparative Study: Degradation of 2,5Dichlorophenol in Wastewater and Distilled Water by Ozone and Ozone-UV, , Ozone Sci. Eng., 38 , 179-191, 2016.

[16] Y. Wang, P. Pai y J. Latchaw, «Effects of preozonation on the methanogenic toxicity of 2,5-DCP,» J. Water Pollut Control Fed., 61, Faltan páginas 1989. 
[17] $\mathrm{H}$. Eisenhauer, «Increased rate and efficiency of phenolic waste ozonization,» J. Water Poll. Control Fed., Falta el volumen 200-208, 1971.

[18] Y. Wang, «Methanogenic degradation of ozonation products of biorefractory or toxic aromatic compounds, » Water Res., 24, 185-190, 1990.

[19] Y. Qiu, M. E. Zappi, M. ASCE, C. Kuo y E. C. Fleming, «Kinetic and mechanisitic study of ozonation of three dichlorophenols in aqueous solutions, J. Environ Eng., 125, 441450, 1999.

[20] T. Poznyak y J. Vivero, «Degradation of aqueous phenol and chlorinated phenols by ozone,» Ozone Sci. \& Eng., 27, 447-458, 2005.

[21] Q. Ngo, L. Dao, E. Grigoriev y A. Petukhov, «The ozonation of extremely polluted petrochemical wastewater: Effect of catalysts, initial $\mathrm{pH}$, volumetric flow rate and concentration of ozone on oxidation rate,» J. Bio \& Env. Sci., 6, 587-598, 2015.

[22] N. Nilvebrant y $M$. Jansson, «Hydroxyl radical formation during hydrogen peroxide bleaching,» STFI-Packforsk, Stockholm, Sweden, 2005.

[23] M. D. Gurol y R. Vatistas, "Oxidation of Phenolic Compounds by Ozone and Ozone+UV Radiation: A Comparative Study,» Water Res., 21, 895-900, 1987.

[24] F. J. Benitez, J. Beltran-Heredia, J. L. Acero y F. Rubio, «Contribution of free radicals to chlorophenols decomposition by several advanced oxidation processes, " Chemosphere, 41, 1271-1277, 2000.

[25] H. Utsumi, S. Han y K. Ichikawa, «Enhancement of hydroxyl radical generation by phenol and their reaction intermediates during ozonation," Water Sci. Tech., 38 147-154, 1998.

[26] H. Utsumi, Y. Han y K. Ichikawa, «A kinetic study of 3-chlorophenol enhanced hydroxyl radical generation during ozonation,» Water Res., 37, 4924-4928, 2003.

[27] X. Huang, X. Li, B. Pan, H. Li, Y. Zhang y B. Xe, "Self enhanced ozonation of benzoic acid at acidic condition, » Water Res., 73, 9-16, 2015.

[28] APHA, AWWA y WEF, Standard Methods for the Examination of Water and Wastewater, 21st ed., Washington, D.C: America Public Health Association, 2005

[29] T. Poznyak, R. Tapia, J. Vivero y I. Chairez, «Effect of pH to the decomposition of aqueous phenosl mixture by ozone,» J. Mex. Chem. Soc., 50, 28-35, 2006.

[30] J. Wohlers, I. Koh, T. Wolfram y R. Wolfgang, «Application of air ionization device using an atmospheric pressure corona discharge process for water purification,» J. Water Air Soil Poll, 196, 101-114, 2009.

[31] E. Gilbert, «Biodegradability of ozonation products as a function of COD and DOC elimination by example of substituted aromatic substances,» Water Res., 21, 1273-1278, 1987.

[32] S. Contreras, M. Rodríguez, F. Al-Momani, C. Sans y S. Esplugas, "Contribution of the ozonation pre-treatment to the biodegradation of aqueous solutions of 2,4diclorophenol,» Water Res., 37, 3164-3171, 2003.

[33] S. Esplugas, P. L. Yue y M. I. Perez, «Degradation of 4-Chlorophenol by Photolytic oxidation,» Water Res., 28, 1323-1328, 1994.

[34] C. H. Kuo y C. H. Huang, «Aqueous phase ozonation of chlorophenols,» J. Hazard Mat., 41, 31-45, 1995. 
S. Contreras, J. Piatkowska, M. Rodríguez, C. Sans y S. Esplugas, «Biodegradability [35] improvement of aqueous 2,4-Dichlorophenol and Nitrobenzene Solutions by means of Single Ozonation,»

[36] R. F. Dantas, S. Contrearas, C. Sans y S. Esplugas, «Abatement of 4-Chlorophenol in Aqueous Phase by Ozonation Coupled with a sequencing Batch Biofilm Reactor (SBBR), 》 Ozone Sci. Eng., 30, 447-455, 2008.

[37] A. Karci, I. Arslan-Alaton, T. Olmez-Hanci y M. Bekbolet, "Transformation of 2,4dichlorophenol by H2O2/UV-C, Fenton and photo-Fenton processes: Oxidation products and toxicity evolution,» J. Photochemistry and photobiology A: Chemistry, 230, 65-73, 2012.

[38] M. A. Boncz, H. Bruning, W. H. Rulkens, E. J. R. Sudholter, G. H. Harmsen y J. W. Bijsterbosch, "Kinetic and Mechanistic aspects of the oxidation of chlorophenols by ozone,» Water Sci. Technol, 35, 65-72, 1997.

[39] E. Gilbert, "Chemical changes and reaction products in ozonization of organic water constituents,» de Oxidation techniques in drinking water treatment, Washington, DC, 1978.

[40] N.-C. Shang, Y.-H. Yu, Ma, Hqong-Wen, C.-H. Chang y M.-L. Liou, «Toxicity measurements in aqueous solution during ozonation of mono-chlorophenols,» J. Environ Manage, 78, 216-222, 2006.

[41] D. He, X. Guan, J. Ma, X. Yuan y C. Cui, «Influence of humic acids of differrent origins on the oxidation of phenol and chlorophenol by permanganate,» J. Hazard Mat., 182, 681-688, 2010.

[42] A. Mokrini, D. Oussi y S. Esplugas, "Oxidation of aromatic compounds with UV radiation/ozone/hydrogen peroxide,»Water Sci. Technol, 35, 95-102, 1997.

[43] Y. Ku, W.-J. Su y Y.-S. Shen, «Decomposition of phenols in aqueous solution by UV/O3 process,» Ozone Sci. Eng., 18, 443/460, 1996.

[44] M. Pera-Titus, V. García-Molina, M. A. Baños, J. Giménez y S. Esplugas, «Degradation of clorophenols by means of advanced oxidation processes: a general review., Appl Catal B: Environmental, 47, 219 - 256, 2004.

[45] S. Esplugas, J. Giménez, S. Contreras, E. Pascual y M. Rodríguez, "Comparison of different advance oxidation processes for phenol degradation,» Water Res., 36, 10341042, 2002.

[46] M. Trapido, A. Hirvonen, Y. Veressinina, J. Hentunen y R. Munter, «Ozonation, Ozone/UV and UV/H2O2 Degradation of Chlorophenols,» Ozone Sci. Eng., 19, 75-96, 1997.

[47] TOXNET, «TOXNET- Toxicology Data Network. (National Library of Medincine. National Institutes of Health),» 2008 2009. [En línea]. Available: http://toxnet.nlm.nih.gov. [Último acceso: 0210 2014].

[48] B. Gunawardana, N. Singhal y P. Swedlund, «Degradation of Chlorophenols by Zero Valent,» Environ. Eng. Res., 16, 187-203, 2011. 


\section{CAPÍTULO 5. RESULTADOS Y DISCUSIÓN}

[49] T. Merle, J. S. Pic, M. H. Manero, S. Mathé y H. Debellefontaine, «Influence of activated carbons on the kinetics and mechanisms of aromatic molecules ozonation,» Catal. Today, 151, 166-172, 2010.

[50] C.-R. Huang y H.-Y. Shu, «The reaction kinetics, decomposition pathways and intermediate formation of phenol in ozonation, UV/O3 and UV/H2O2 processes,» $\mathrm{J}$. Hazard Mat., vol. 41, pp. 47-64, 1995.

[51] D. J. W. Blum y R. E. Speece, «A database of chemical toxicity to environmental bacteria and its use in interspecies comparisons and correlations," J. Water Pollut. Control Fed., vol. 63, no 3, pp. 198-207, 1991.

[52] K. M. Basha, A. Rajendran y V. Thangavelu, «Recent advances in biodegradation of phenol- A review, Asian J. Exp. Biol. Sci., 2, 219-234, 2010.

[53] F. Kargi y E. Serkan, «Toxicity and batch biodegradation kinetics of 2,4-dichlorophenol by pure Pseudomonas putida culture,» Enzyme Microb. Tech., 35, 424-428, 2004.

[54] K. Bandyopadhyay, D. Das y B. R. Maiti, «Kinetics of phenol degradation using Pseudomonas putida MTCC 1194,» Bioproc. Eng., 18, 373-377, 1998.

[55] Y. Kaymaz, A. Babaoglu y N. K. Pazarlioglu, «Biodegradation kinetics of o-cresol by Pseudomonas putida DSM 548 (pJP4) and o-cresol removal in a batch-recirculation bioreactor system,» Electron. J. Biotechnol., 15, 1-10, 2012. 


\section{Capítulo 6. CONCLUSIONES}

Las conclusiones de esta tesis abarcan diferentes aspectos en cuanto a los procesos de oxidación avanzada estudiados, a las soluciones de 2,5-DCP en agua destilada y en agua residual, a los efectos de mineralización y de biodegradación, así como a la toxicidad de los compuestos intermedios que tienen lugar durante la oxidación, por lo cual las conclusiones se separan de acuerdo a los aspectos mencionados.

\section{Procesos de Oxidación Avanzada}

De acuerdo con los resultados experimentales se puede concluir que los procesos de oxidación avanzada con Ozono y Ozono-UV disminuyen la toxicidad del 2,5DCP y aumentan la biodegradabilidad en ambas soluciones acuosas, obteniéndose el mejor resultado en los experimentos con agua residual y con tratamiento de ozono-UV.

\section{Relación de consumo de ozono y remoción de DQO}

En los experimentos con agua residual, la misma cantidad de moles de ozono redujeron mayor cantidad de DQO que en los experimentos con agua destilada, lo cual indica que el agua residual da mejores resultados en la relación de ozono/DQO eliminada.

\section{Toxicidad}

Durante las pruebas de toxicidad con lodos activados del 2,5-DCP en solución con agua destilada y agua residual sin tratamiento previo, dieron como resultado una muy alta toxicidad para los M.O.; mientras que en las pruebas de los compuestos derivados de la oxidación con Ozono y Ozono-UV se observó una disminución de la toxicidad del 2,5-DCP, para ambas soluciones acuosas.

Por otra parte, la comparación entre los resultados que se obtuvieron con las pruebas de respirometría, mostraron que los productos finales formados en el tratamiento con ozono-UV fueron menos tóxicos a los M.O. que los formados con el tratamiento con ozono. 


\section{CAPÍTULO 6. CONCLUSIONES}

\section{Biodegradación}

No se detectó biodegradación del 2,5-DCP en solución con agua destilada sin tratamiento, sin embargo, después de los tratamientos con ozono y ozono-UV se incrementó la biodegradabilidad del 2,5-DCP. Las soluciones S2: con agua residual, fueron biodegradadas después de usar dosis de $630 \mathrm{mgO}_{3} / \mathrm{L}$ y 417 $\mathrm{mgO}_{3} / \mathrm{L}$ con tratamiento con ozono y ozono-UV, respectivamente.

Por otra parte, en las soluciones S1: con agua destilada sometidas a tratamiento con ozono y ozono-UV, sólo después de usar una dosis de ozono de $1154 \mathrm{mgO}_{3} / \mathrm{L}$ y $647 \mathrm{mgO}_{3} / \mathrm{L}$ respectivamente, resultaron biodegradadas. De acuerdo a los resultados, se puede concluir que los productos intermedios formados en el agua destilada son más resistentes a la biodegradación que los formados en el agua residual.

Además, se estableció una buena relación entre la biodegradabilidad y el estado de oxidación de la materia orgánica. La mejor biodegradabilidad se encontró cuando se presentó un aumento estadísticamente significativo en la oxidación de la materia orgánica contenida.

\section{Oxidación del 2,5-DCP}

Las pruebas de Cromatografía con HPLC mostraron que los procesos de ozonación y ozonación-UV oxidaron completamente el 2,5-DCP y se generaron compuestos intermedios biodegradables. Esto se confirmó con los valores obtenidos en la determinación de $\mathrm{DBO}_{5}$ y con la disminución del pH en los diferentes tratamientos para formar productos intermedios los cuales resultaron ser ácidos orgánicos.

\section{Cinética de Oxidación}

La velocidad de reacción de los dos procesos de oxidación estudiados, mostraron que la variación fue en el siguiente orden: $\mathrm{O}_{3}-\mathrm{UV}>\mathrm{O}_{3}$.

La evolución de la concentración de 2,5- DCP a través de la degradación sigue una cinética de primer orden con respecto a la concentración de los contaminantes. 


\section{CAPÍTULO 6. CONCLUSIONES}

Finalmente, el mejor resultado de los tratamientos fue con $\mathrm{O}_{3}-\mathrm{UV}$ en agua residual, en función de la remoción de DQO y COT.

\section{Compuestos Intermediarios formados}

Los siguientes compuestos: catecol, hidroquinona, 4-clorocatecol, ácido pentanoico, ácido acético, ácido propiónico 2,5-diclorohidroquinona, 3,6-dicloro1,2-benzendiol, ácido glicólico, fenol, fueron identificados mediante GC-MS como compuestos intermediarios preliminares y finales generados durante la oxidación del 2,5-DCP utilizando los diferentes procesos en ambas soluciones acuosas después de 60 min.

\section{Procesos biológicos}

Los resultados microbiológicos mostraron un mayor crecimiento de la bacteria Pseudomonas sp. en el biorreactor adaptado a fenol $(100 \mathrm{mg} / \mathrm{L})$ que en el blanco (sin tóxico). Las soluciones pretratadas que se oxidaron biológicamente en reactores discontinuos con agitación y reactores continuos, con biomasas R0, R1 y R3 presentaron las mejores remociones de $\mathrm{DQO}$ en los biorreactores alimentados con solución pretratada con ozono-UV. Los reactores sin adaptación (R0) y con adaptación a fenol (R3) tuvieron remociones de DQO similares, con lo cual se puede decir que el proceso biológico funcionó bien tanto con lodos adaptados como sin adaptar.

Al concluir este estudio se ha confirmado que con la aplicación de tratamientos de ozono y de ozono-UV, se logra degradar completamente el 2,5-DCP formándose productos intermedios que son menos tóxicos y más biodegradables que la solución original de 2,5-DCP, por lo tanto, se concluye que un pretratamiento con ozono o con ozono-UV, seguido de un tratamiento biológico con lodos activados, como es el caso de una planta de tratamiento de agua residual doméstica con lodos activados, son una buena opción para disminuir la toxicidad del 2,5-DCP a alta concentración y favorecer su biodegradabilidad. 


\section{TRABAJOS FUTUROS}

Con el fin de extender las investigaciones sobre la aplicación de tratamientos de los procesos de oxidación avanzada para disminuir la toxicidad y aumentar la biodegradabilidad del 2,5-DCP, se hacen las siguientes recomendaciones para futuros trabajos:

\section{Investigación básica (a escala laboratorio):}

- Determinar los productos intermedios y finales después del proceso biológico aerobio.

- Estudiar el efecto de los tratamientos con ozono y ozono-UV sobre el DCP en concentración variable con respecto a una concentración constante de material orgánico natural presente en un agua residual. Es decir, cuando la concentración del DCP es menos, mayor e igual a la concentración de material orgánico natural en un agua residual.

- Determinar los productos intermedios y finales después de los tratamientos con ozono y ozono-UV de la solución acuosa de DCP en agua residual.

- Estudiar la fitotoxicidad de los productos intermedios y finales durante el tratamiento con ozono y ozono-UV.

\section{Investigación aplicada:}

- Hacer estudios de los efluentes de industrias que contengan DCPs.

- Comprobar la viabilidad del tratamiento oxidado acoplado con un proceso biológico aerobio.

- Hacer un estudio económico y ambiental de los tratamientos de efluentes considerando el coste de operación, el ahorro y el impacto ambiental 
ANEXOS

ANEXOS 


\section{ANEXOS}

\section{ANEXO A}

ANEXO A-1. ESTÁNDARES DE 2,5-DCP EN AGUA DESTILADA (S1) Y EN AGUA RESIDUAL (S2)

Se realizó la calibración del cromatógrafo de HPLC con estándares de 2,5-DCP en agua destilada (0-100 ppm) y en agua residual (0-100 ppm) a un longitud de onda de $223 \mathrm{~nm}$. En la Figura A-0--1 y Figura A-0-2 se muestran las curvas de calibración de estos compuestos.

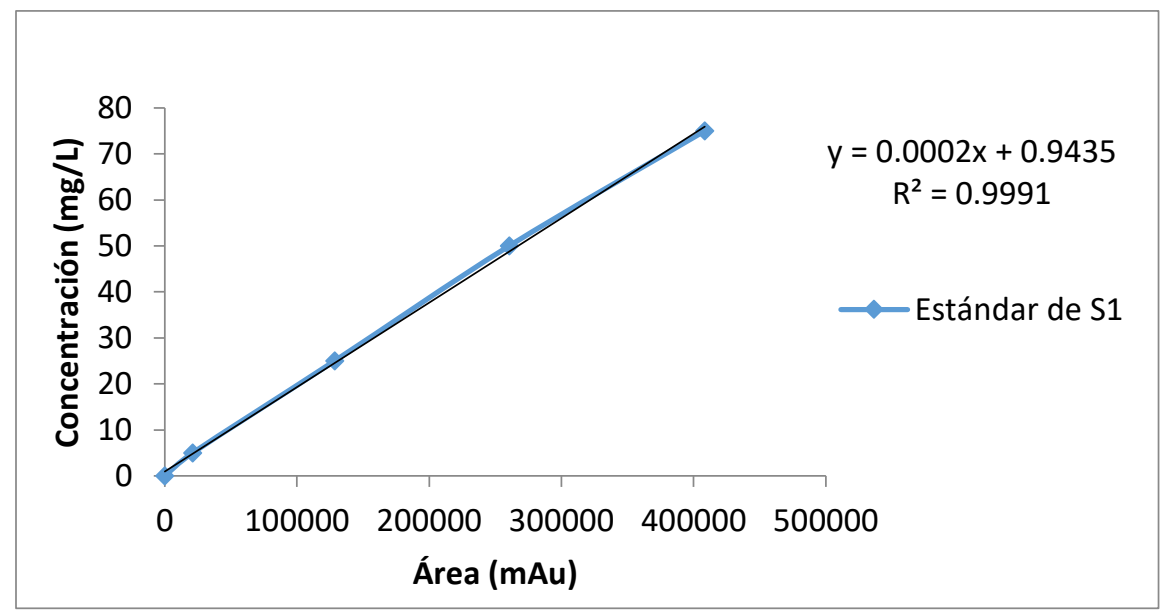

Figura A-0--1 Estándar de S1:2,5-DCP en agua destilada

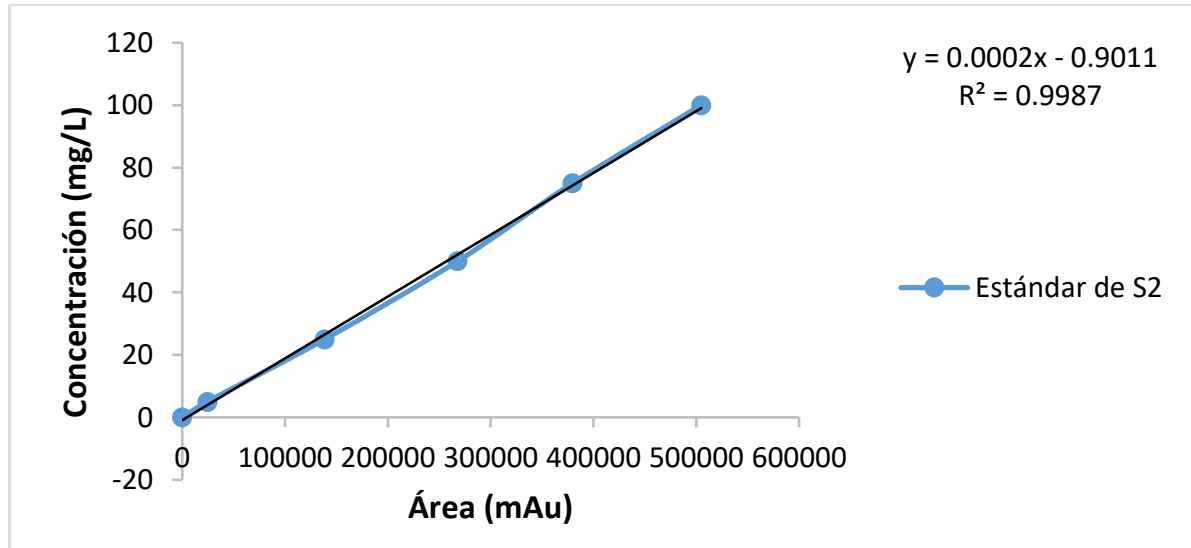

Figura A-0-2 Estándar de S2: 2,5-DCP en agua residual 


\section{ANEXOS}

ANEXO A-2. CROMATOGRAMAS OBTENIDOS POR HPLC DE 2,5-DCP TRATADO CON OZONO EN S1: CON AGUA DESTILADA Y A DIFERENTES TIEMPOS (OZONO APLICADO: $22 \mathrm{mgO} / \mathrm{min}$ )

a)

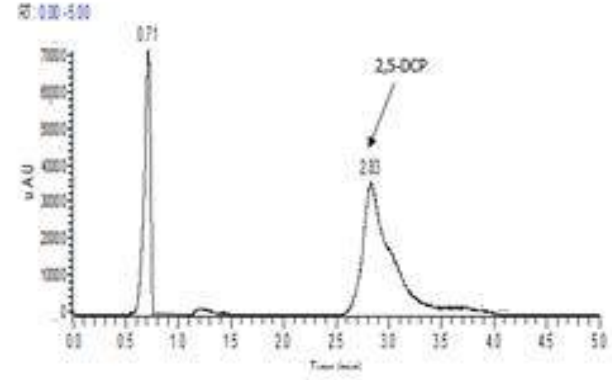

c)

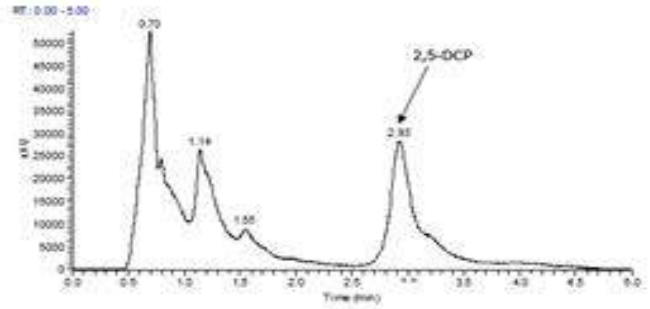

e)

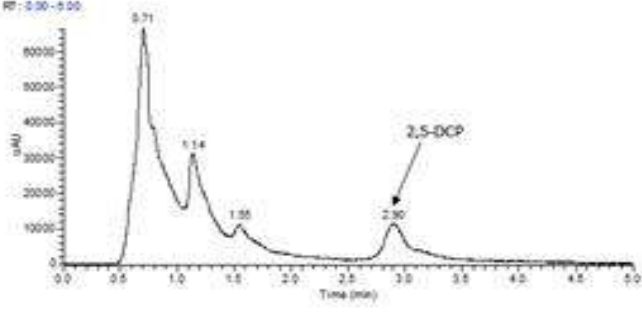

g)

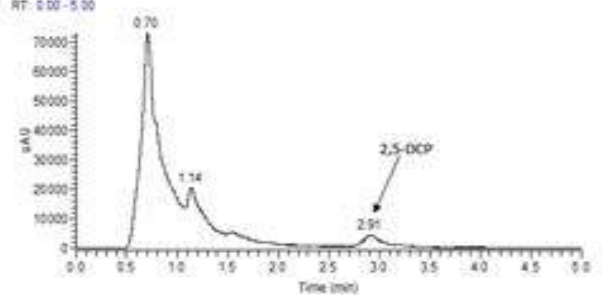

b)

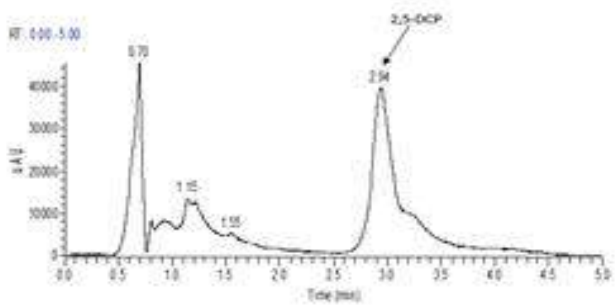

d)

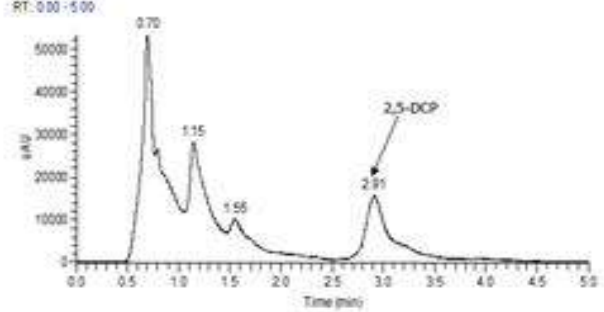

f)

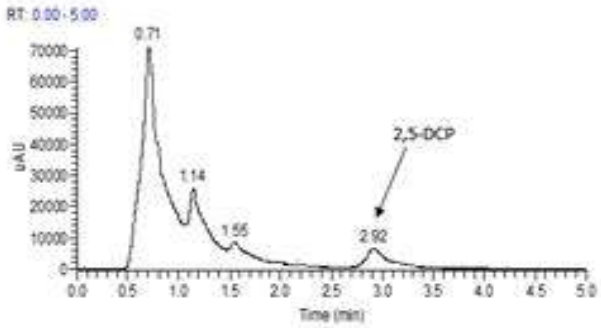

h)

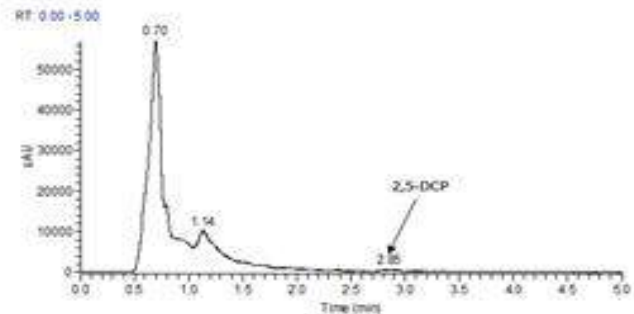

Figura A-0-3 Cromatograma obtenido por HPLC de 2,5-DCP en agua destilada tratado con ozono: (a) Tiempo = 0 min; (b) Tiempo = $5 \mathrm{~min}$; (c) Tiempo = $10 \mathrm{~min}$; (d) Tiempo = $20 \mathrm{~min}$;

(e) Tiempo = 30min; (f) Tiempo = 40min; (g) Tiempo = 50 $\mathrm{min}(\mathrm{h})$ Tiempo $=60 \mathrm{~min}$ 


\section{ANEXOS}

\section{ANEXO A-3. CROMATOGRAMAS OBTENIDOS POR HPLC DE 2,5-DCP TRATADO CON OZONO EN}

\section{S2: CON AGUA RESIDUAL Y A DIFERENTES TIEMPOS (OZONO APLICADO: 22 mgO $/ 3 / \mathrm{min}$ )}

a)

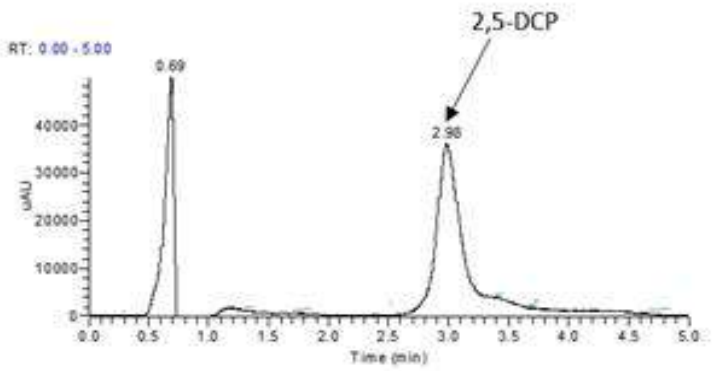

c)

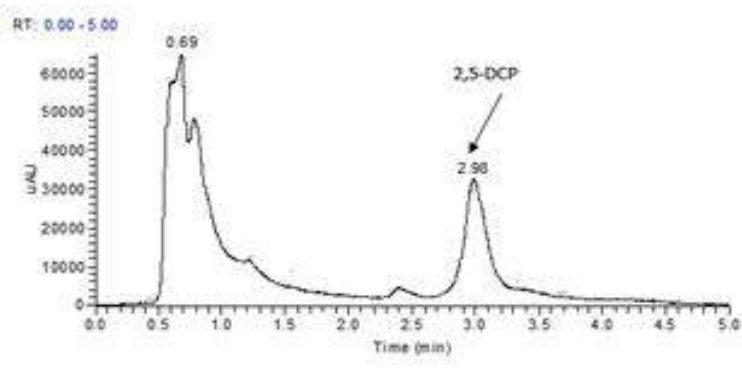

e)

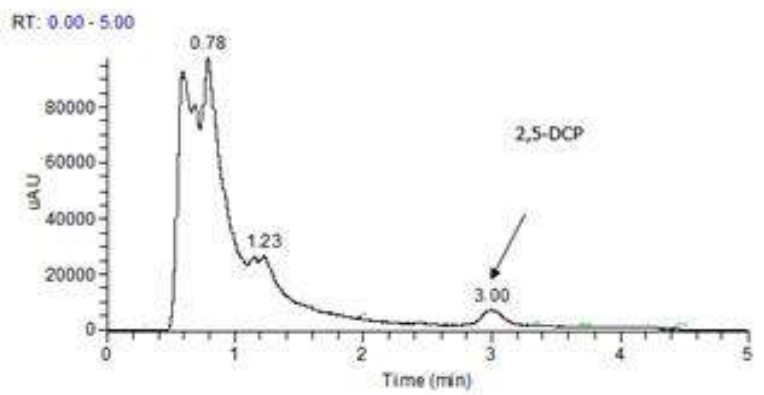

g)

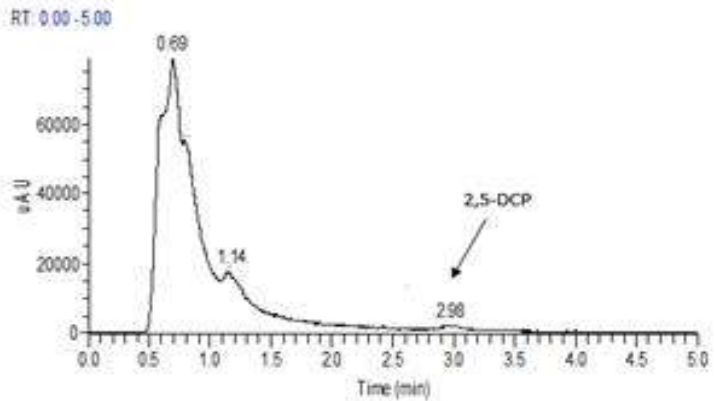

b)

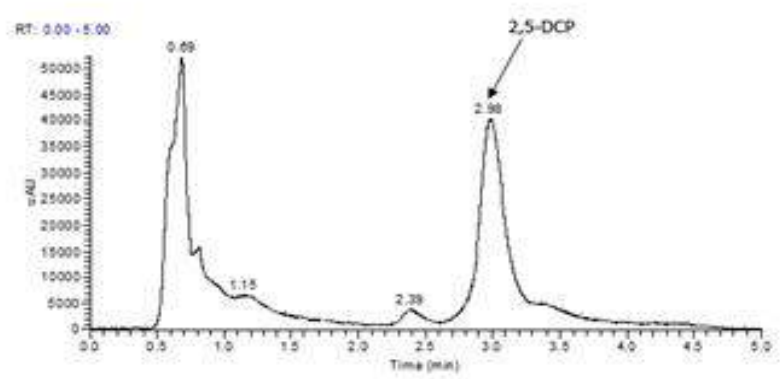

d)
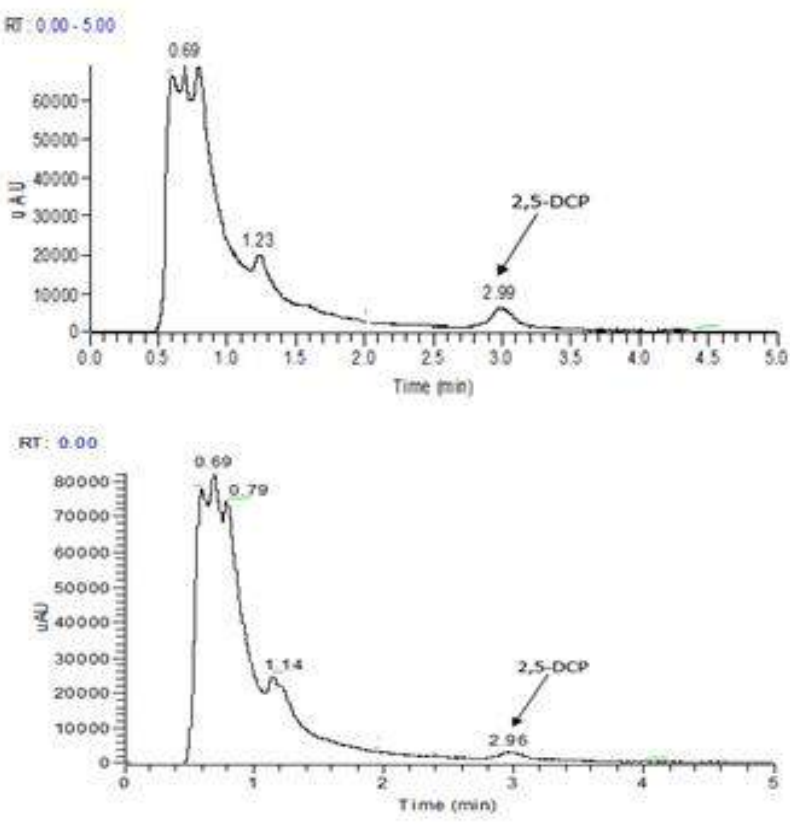

h)

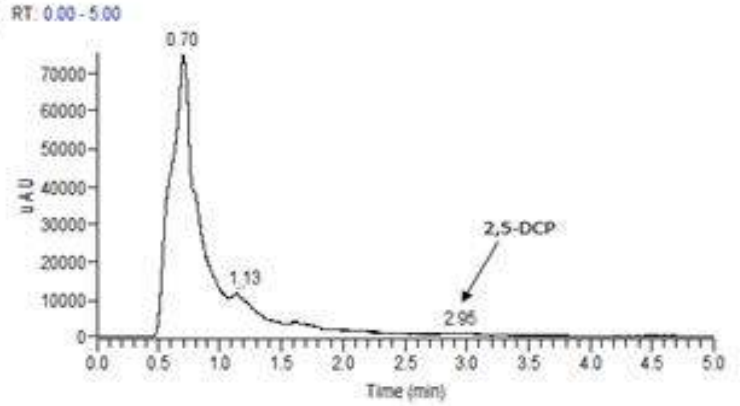

Figura A-0-4 Cromatograma obtenido por HPLC de 2,5-DCP en agua residual tratado con ozono: (a) Tiempo $=0 \mathrm{~min}$; (b) Tiempo $=5 \mathrm{~min}$; (c) Tiempo $=10 \mathrm{~min}$; (d) Tiempo $=20 \mathrm{~min}$;

(e) Tiempo = 30min; (f) Tiempo $=40 \mathrm{~min} ;(\mathrm{g})$ Tiempo $=50 \mathrm{~min}(\mathrm{~h})$ Tiempo $=60 \mathrm{~min}$ 


\section{ANEXOS}

ANEXO A-4. CROMATOGRAMAS OBTENIDOS POR HPLC DE 2,5-DCP TRATADO CON OZONO-UV

EN S1: CON AGUA DESTILADA Y A DIFERENTES TIEMPOS (OZONO APLICADO: $22 \mathrm{mgO}_{3} / \mathrm{min}$ )

a)

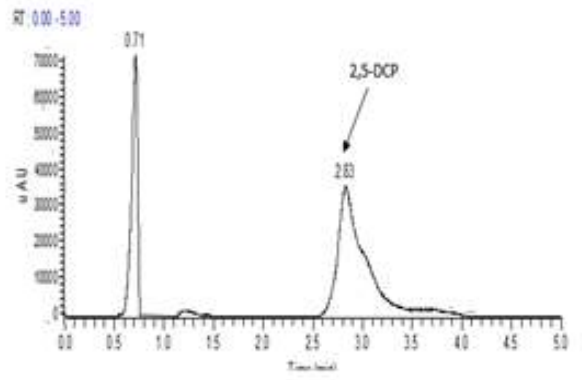

c)

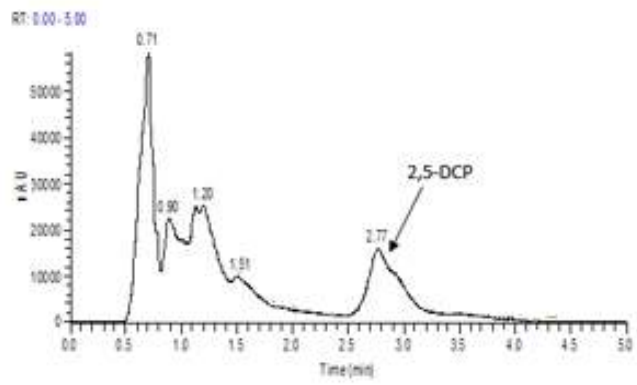

e)
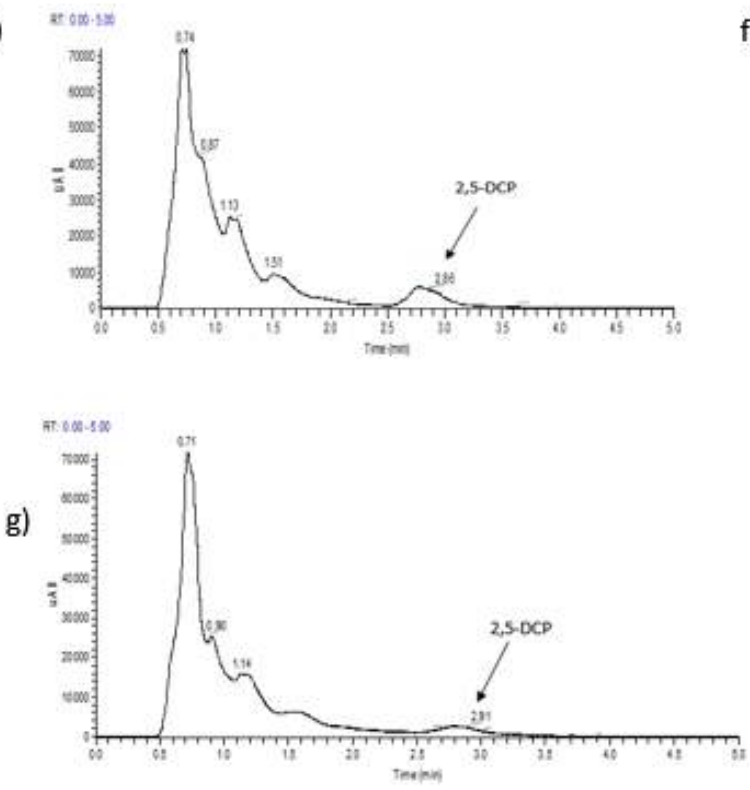

b)

d)
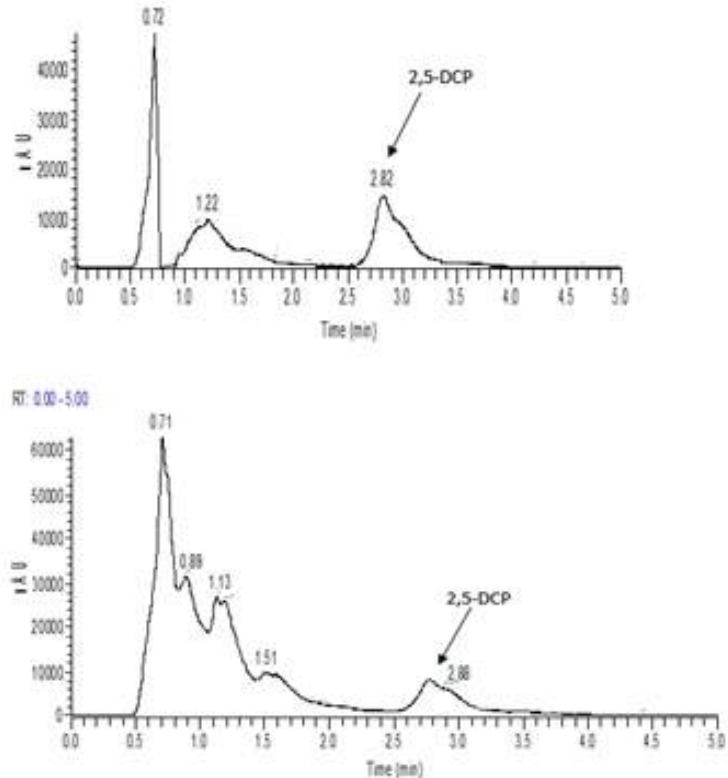

f)

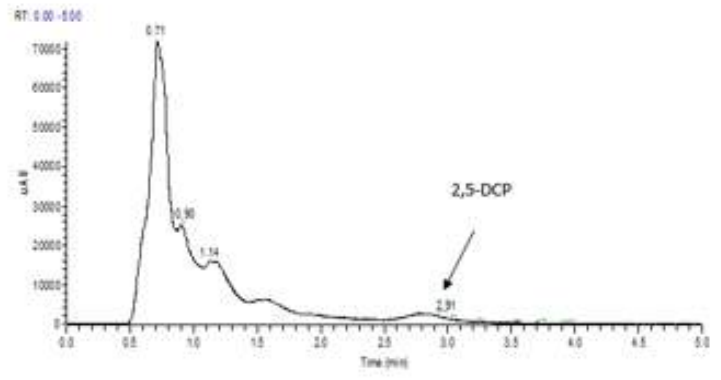

h)

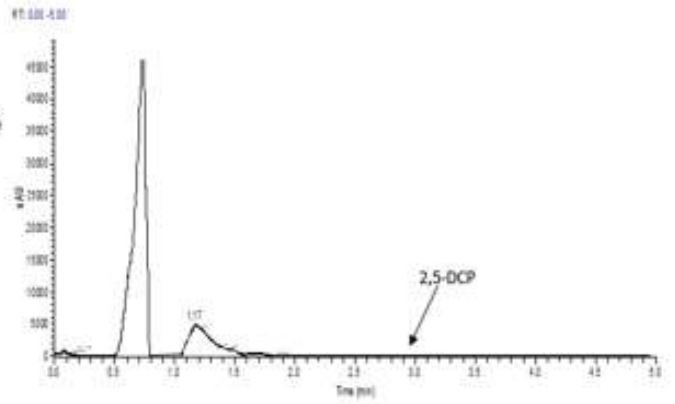

Figura A-0-5 Cromatograma obtenido por HPLC de 2,5-DCP en agua destilada tratado con $\mathrm{O}_{3}$-UV : (a)Tiempo $=0 \mathrm{~min}$; (b) Tiempo $=5 \mathrm{~min}$; (c) Tiempo $=10 \mathrm{~min}$; (d) Tiempo $=20 \mathrm{~min}$; (e) Tiempo $=30 \mathrm{~min} ;(\mathrm{f})$ Tiempo $=40 \mathrm{~min} ;(\mathrm{g})$ Tiempo $=50 \mathrm{~min}(\mathrm{~h})$ Tiempo $=60 \mathrm{~min}$ 


\section{ANEXOS}

ANEXO A-5. CROMATOGRAMAS OBTENIDOS POR HPLC DE 2,5-DCP TRATADO CON OZONO-UV EN S2: CON AGUA RESIDUAL Y A DIFERENTES TIEMPOS (OZONO APLICADO: 22 mgO $/ 3 / \mathrm{min}$ )

a)

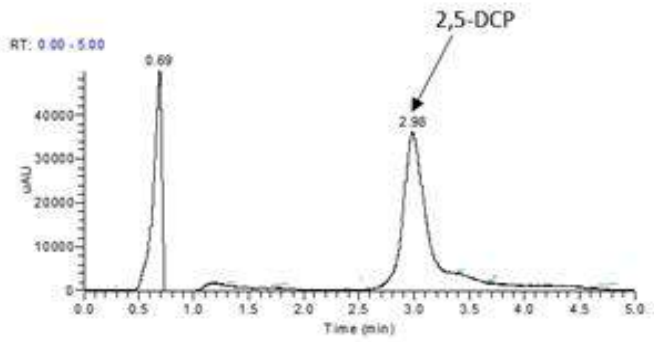

c)

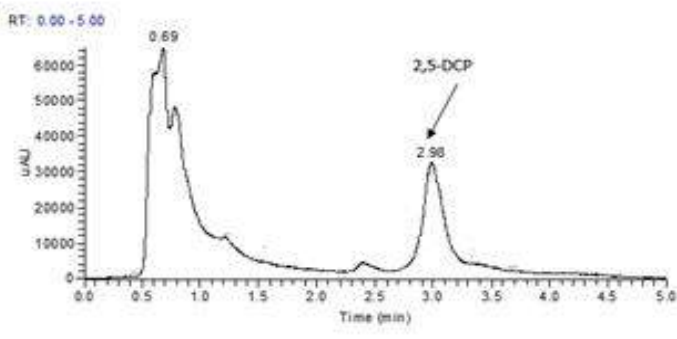

e)

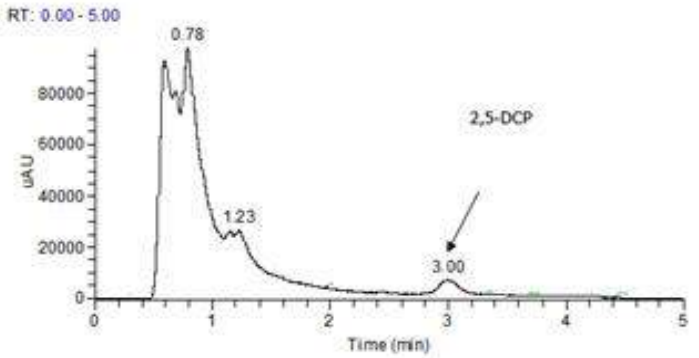

g)

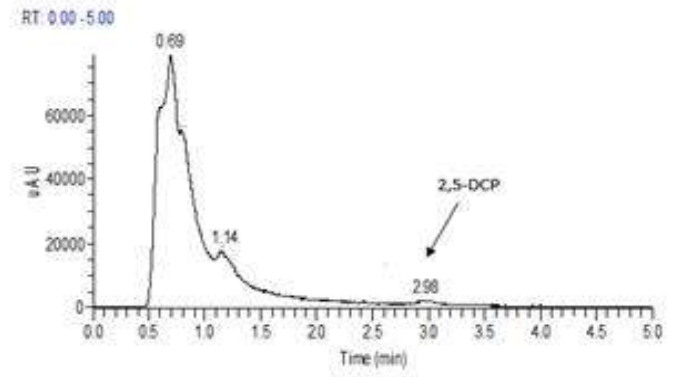

b)

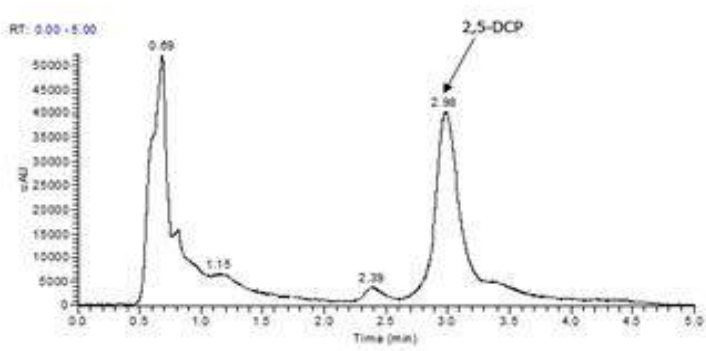

d)

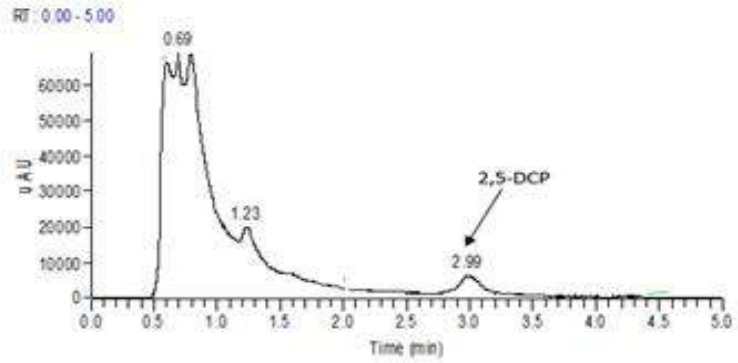

f)

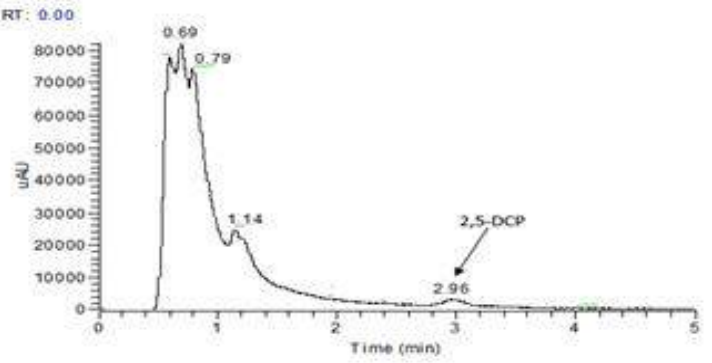

h)

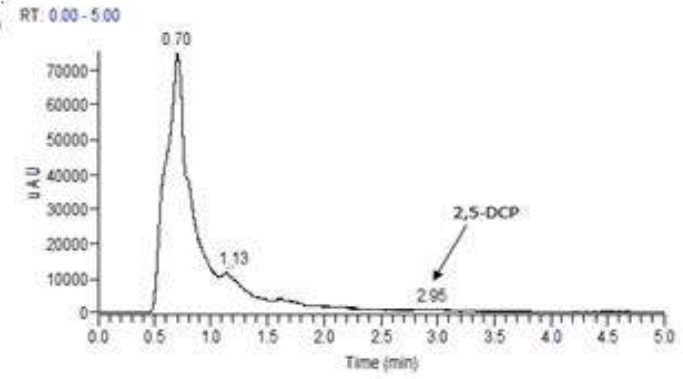

Figura A-0-6 Cromatograma obtenido por HPLC de 2,5-DCP en agua residual tratado con O3-UV: (a) Tiempo = 0 min; (b) Tiempo $=5$ min; (c) Tiempo = 10 min; (d) Tiempo = $20 \mathrm{~min}$; (e) Tiempo = 30min; (f) Tiempo = 40min; (g) Tiempo = 50min (h) Tiempo = $60 \mathrm{~min}$ 


\section{ANEXOS}

\section{ANEXO A-6. DATOS DE ENSAYOS DE LA DETERMINACIÓN DEL COEFICIENTE VOLUMÉTRICO DE TRANSFERENCIA DE OZONO EN EL REACTOR}

Tabla A-0-1 Datos de los ensayos

\begin{tabular}{|c|c|c|c|c|c|c|c|c|c|}
\hline Ensayo & $\begin{array}{c}\text { Tipo de } \\
\text { agua }\end{array}$ & $\begin{array}{l}\text { Flujo } \\
\text { (L/min) }\end{array}$ & $\begin{array}{c}\mathrm{T} \\
\left({ }^{\circ} \mathrm{C}\right)\end{array}$ & $\begin{array}{l}P_{\text {gas }} \\
\text { (psi) }\end{array}$ & $\begin{array}{c}V \\
(L)\end{array}$ & $\begin{array}{l}\text { Caída de } \\
\text { Presión } \\
\Delta \mathrm{P}(\mathrm{cmHg})\end{array}$ & $\begin{array}{c}\Delta \mathbf{h}_{\mathrm{T}}-\mathrm{ho} \\
\text { (cm) }\end{array}$ & $\begin{array}{c}\mathrm{h}_{\mathrm{o}} \\
(\mathrm{cm})\end{array}$ & $\begin{array}{c}C_{\text {sat }} \\
\mathrm{mg} / \mathrm{L}\end{array}$ \\
\hline 1 & $\begin{array}{l}\text { Agua } \\
\text { potable }\end{array}$ & 0.652 & 25 & 20 & 1.5 & 21 & 0.45 & 26 & 30.54 \\
\hline 2 & $\begin{array}{l}\text { Agua } \\
\text { desionizada }\end{array}$ & 0.5589 & 20 & 14.9 & 1.5 & 21 & 0.30 & 26 & 29.98 \\
\hline 3 & $\begin{array}{l}\text { Agua } \\
\text { desionizada }\end{array}$ & 0.606 & 20 & 14.9 & 1.5 & 21 & 0.40 & 26 & 30.6 \\
\hline 4 & $\begin{array}{l}\text { Agua } \\
\text { residual }\end{array}$ & 0.606 & 20 & 14.9 & 1.5 & 19 & 0.40 & 26 & 30.6 \\
\hline
\end{tabular}

Tabla A-0-2 Resultados de los ensayos

\begin{tabular}{|c|c|c|c|c|c|}
\hline \multirow{2}{*}{$\begin{array}{l}\text { Tiempo } \\
\text { (s) }\end{array}$} & Ensayo 1 & Ensayo 2 & \multirow{2}{*}{$\begin{array}{c}\text { Tiempo } \\
\text { (s) }\end{array}$} & Ensayo 3 & Ensayo4 \\
\hline & $\mathrm{Ln}(\mathrm{Cs}-\mathrm{CL})$ & $\mathrm{Ln}(\mathrm{Cs}-\mathrm{CL})$ & & $\mathrm{Ln}(\mathrm{Cs}-\mathrm{CL})$ & $\mathrm{Ln}(\mathrm{Cs}-\mathrm{CL})$ \\
\hline 0 & 3.4005 & 3.4005 & 0 & 3.4210 & 3.4210 \\
\hline 5 & 3.3607 & 3.3958 & 10 & 3.3830 & 3.3607 \\
\hline 10 & 3.2092 & 3.2741 & 20 & 3.2213 & 2.9392 \\
\hline 15 & 3.1544 & 3.1884 & 30 & 3.0106 & 2.4493 \\
\hline 20 & 2.9932 & 3.1254 & 40 & 2.8702 & 2.2783 \\
\hline 25 & 2.7862 & 3.0378 & 50 & 2.4857 & 2.2225 \\
\hline 30 & 2.5518 & 2.8870 & 60 & 2.4310 & 1.9559 \\
\hline 35 & 2.3437 & 2.7498 & 70 & 2.2061 & 1.7029 \\
\hline 40 & 2.2214 & 2.6210 & 80 & 1.1878 & 1.3913 \\
\hline 45 & 2.0042 & 2.5055 & 90 & 0.9203 & 1.0919 \\
\hline 50 & 1.8132 & 2.3721 & 100 & 0.5068 & 0.6678 \\
\hline 55 & 1.7120 & 2.2996 & 110 & 0.3436 & 0.3001 \\
\hline 60 & 1.5728 & 2.1114 & 120 & 0.1906 & 0.1398 \\
\hline 65 & 1.2865 & 2.1114 & & & \\
\hline 70 & 1.1632 & 1.9286 & & & \\
\hline 75 & 1.0647 & 1.7544 & & & \\
\hline 80 & 0.8065 & 1.5851 & & & \\
\hline 85 & 0.6678 & 1.4183 & & & \\
\hline 90 & 0.1906 & 1.2641 & & & \\
\hline
\end{tabular}




\section{ANEXOS}

\section{ANEXO A-7. DATOS DE ENSAYOS DE LA DETERMINACIÓN DE LA DEMANDA QUÍMICA DE OXÍGENO SOLUBLES EN LOS REACTORES ADAPTADOS}

Tabla A-0-3 Demanda química de oxígeno solubles en los reactores

\begin{tabular}{|c|c|c|c|c|c|}
\hline $\begin{array}{c}\text { Cambios en el } \\
\text { reactor }\end{array}$ & $\begin{array}{c}\text { Tiempo } \\
\text { (día) }\end{array}$ & $\mathrm{R} 1$ & $\mathrm{R} 2$ & $\mathrm{R} 3$ & $\mathrm{R} 4$ \\
\cline { 3 - 6 } & $\mathrm{DQOs}(\mathrm{mg} / \mathrm{L})$ & $\mathrm{DQOs}(\mathrm{mg} / \mathrm{L})$ & $\mathrm{DQOs}(\mathrm{mg} / \mathrm{L})$ & $\mathrm{DQOs}(\mathrm{mg} / \mathrm{L})$ \\
\hline $\begin{array}{c}\text { Añade solución } \\
\text { fresca }\end{array}$ & 20 & 179 & 260 & 90 & 189 \\
\hline Sin cambio & 24 & 139 & 0 & 27 & 12 \\
\hline $\begin{array}{c}\text { Añade solución } \\
\text { fresca }\end{array}$ & 27 & 269 & 37 & 77 & 59 \\
\hline Sin cambio & 30 & 41 & 0 & 19 & 0 \\
\hline $\begin{array}{c}\text { Añade solución } \\
\text { fresca }\end{array}$ & 35 & 50 & 60 & 13 & 59 \\
\hline Sin cambio & 37 & 30 & 10 & 68 & 23 \\
\hline $\begin{array}{c}\text { Añade solución } \\
\text { fresca }\end{array}$ & 40 & 20 & 20 & 40 & 75 \\
\hline Sin cambio & 43 & 3 & 9 & 26 & 29 \\
\hline $\begin{array}{c}\text { Añade solución } \\
\text { fresca }\end{array}$ & 50 & 112 & 65 & 16 & 40 \\
\hline Sin cambio & 57 & 56 & 49 & 1 & 20 \\
\hline $\begin{array}{c}\text { Añade solución } \\
\text { fresca }\end{array}$ & 65 & 97 & 29 & 8 & 59 \\
\hline Sin cambio & 70 & 68 & 5 & 0 & 54 \\
\hline
\end{tabular}


ANEXOS

ANEXO B.

ANEXO B.1 PARTICIPACIÓN EN CONGRESO

1. J. C. Alexander and C. R. Ramírez-Cortina. (2015, junio). A Comparative Study: Degradation of 2,5-dichlorophenol in Wastewater and Distilled Water by Ozone and Ozone-UV. Presentación Oral- IOA World Congress 2015 (Barcelona, Spain).

2. J. C. Alexander and C. R. Ramírez-Cortina. (2014, diciembre). Evaluación de los tratamientos de 2,5.diclorofenol con ozono y ozono-UV en agua residual como un pretratamiento para un proceso biológico. Presentación CartelColoquio del Posgrado en Ciencias e Ingeniería (UAM, Azcopotzalco).

3. J. C. Alexander. (2015, junio). Tratamiento de Agua con Procesos de Oxidación Avanzada. Presentación Oral-Seminario Ambiental (UAM, Azcopotzalco).

4. J. C. Alexander, C. R. Ramírez-Cortina, Oscar González and Santiago Esplugas. (2013, septiembre). The Degradation and Mineralization of 2,5dichlorophenol by Advanced Oxidation Processes. Presentación Oral- IUVA and IOA World Congress 2013 (Las Vegas, USA).

5. J. C. Alexander, C. R. Ramírez-Cortina, Oscar González and Santiago Esplugas. (2013, septiembre). Biodegradability Enhancement of an aqueous solution of 2,5-dichlorophenol by Advanced Oxidation Processes. Presentación Oral- IUVA and IOA World Congress 2013 (Las Vegas, USA). 


\section{ANEXO C.}

ANEXO C.1 ARTICULOS PUBLICADO EN CONGRESOS

1. J. C. Alexander and C.R. Ramírez-Cortina. 2015. A Comparative Study: Degradation of 2,5-dichlorophenol in Wastewater and Distilled Water by Ozone and Ozone-UV. IOA World Congress 2015 (Barcelona, Spain), Proceedings.

2. J. C. Alexander, C. R. Ramírez-Cortina, Oscar González and Santiago Esplugas. 2013. The Degradation and Mineralization of 2,5-dichlorophenol by Advanced Oxidation Processes. IUVA and IOA World Congress 2013 (Las Vegas, USA), Proceedings.

3. J. C. Alexander, C. R. Ramírez-Cortina, Oscar González and Santiago Esplugas. 2013. Biodegradability Enhancement of an aqueous solution of 2,5-dichlorophenol by Advanced Oxidation Processes. IUVA and IOA World Congress 2013 (Las Vegas, USA), Proceedings 


\section{ANEXOS}

ANEXO C.2 ARTICULO PUBLICADO EN REVISTA 
Ozone: Science \& Engineering

The Journal of the International Ozone Association

ISSN: 0191-9512 (Print) 1547-6545 (Online) Journal homepage: http://www.tandfonline.com/loi/bose20

\title{
A Comparative Study: Degradation of 2,5- Dichlorophenol in Wastewater and Distilled Water by Ozone and Ozone-UV
}

\author{
Jacqueline C. Alexander \& Clementina R. Ramírez-Cortina
}

To cite this article: Jacqueline C. Alexander \& Clementina R. Ramírez-Cortina (2016) A Comparative Study: Degradation of 2,5-Dichlorophenol in Wastewater and Distilled Water by Ozone and Ozone-UV, Ozone: Science \& Engineering, 38:3, 181-193, DOI: 10.1080/01919512.2015.1113853

To link to this article: http://dx.doi.org/10.1080/01919512.2015.1113853

Accepted author version posted online: 16

Nov 2015.

Published online: 16 Nov 2015.

Submit your article to this journal [त

Џlll Article views: 122

View related articles ¿

View Crossmark data \lceil 


\title{
A Comparative Study: Degradation of 2,5-Dichlorophenol in Wastewater and Distilled Water by Ozone and Ozone-UV
}

\author{
Jacqueline C. Alexander and Clementina R. Ramírez-Cortina \\ Universidad Autónoma Metropolitana - Azcapotzalco, División de CBI, Posgrado en Ciencias e Ingeniería Ambientales, Azcapotzalco, CP \\ 02200, Mexico, D.F.
}

\section{ABSTRACT}

The effectiveness of ozone and ozone-UV processes on effluents containing chlorophenol was evaluated. Experiments were performed using $3.06 \mathrm{mM}$ of 2,5-dichlorophenol in distilled water and wastewater at $\mathrm{pH} 7$ with ozone dose of $37 \mathrm{mg} / \mathrm{L}$. An ozone dose of $1.2 \mathrm{~g} / \mathrm{h}$ was effective in completely degrading 2,5-dichlorophenol and reducing the toxicity of its by-products. Overall, ozone-UV process was more effective in the oxidation of 2,5-DCP. Ozone-UV treatment of wastewater showed the highest mineralization (53\%), dechlorination (100\%), COD removal (75\%), and biodegradability $\left(\mathrm{BOD}_{5} / \mathrm{COD}=0.85\right)$. The organic/inorganic matters in wastewater seem to have a positive effect on the oxidation of 2,5-DCP and supports the use of ozone and ozone-UV processes for industrial effluent treatment.

\section{ARTICLE HISTORY}

Received 18 May 2015

Accepted September 18

2015

\section{KEYWORDS}

Ozone; Biodegradation; Degradation;

Dichlorophenol; Oxidation and Wastewater Treatment; Ozone-UV; Toxicity

\section{Introduction}

Chlorophenols (CPs) are used extensively in the environment due to their various antimicrobial properties. They are used in wood preservation, pesticides, disinfectants, dyes, and as intermediates in production of pharmaceuticals (Benitez et al. 2001; Pera-Titus et al. 2004; Qiu et al. 2004). The chlorophenol of interest in this study is 2,5-dichlorophenol (2,5-DCP), the principal metabolite of 1,4-dichlorobenzene (Barlow and Johnson 2007). Both compounds are produced in quantities greater than 1,000 tons per year and are listed as High production volume chemicals by United States Environmental Protection Agency (USEPA) and Organization for Economic Co-operation and Development (OECD) (HSDB 2009; OECD 2004). 2,5-DCP has been detected in effluent of certain industrial wastewater and groundwater. Furthermore, it has also been determined as a potential ecological risk stressor in surface water (Zhong, Wang, and Xu 2012). Additionally, 2,5-DCP is not very biodegradable by conventional biological process using activated sludge due to its recalcitrant properties (Ingols, Gaffney, and Stevenson 1966).

2,5-dichlorophenol is not only problematic to the environment but also to human health. It is known as an endocrine disrupting chemical, and it has been associated with increased in obesity (Buser, Murray, and Scinicariello 2014), type 2 diabetes (Wei and Zhu 2015), and food allergies (Jerschow et al. 2012) in adults, teenagers, and children, as well as reduced birth weight in boys (Philippat et al. 2012). However, it is an unregulated phenol in many countries. Due to its refractory properties, 2,5-DCP can still be present in the effluent of treated and untreated wastewater being discharged into the ocean. There are many published studies on the degradation of chlorophenols, which are listed as priority pollutants by USEPA. The most studied phenolic compounds are pentachlorophenol, 2,4,6-trichlorophenol, 2,4-dichlorophenol, 2-chlorophenol, 4-chlorophenol, and phenol. These compounds may be treated with different oxidation processes such as: Ozone $\left(\mathrm{O}_{3}\right)$, Ozone-Ultraviolet radiation $\left(\mathrm{O}_{3}-\mathrm{UV}\right)$, Ultraviolet radiation-Hydrogen peroxide $\left(\mathrm{UV}-\mathrm{H}_{2} \mathrm{O}_{2}\right)$, $\mathrm{O}_{3}-\mathrm{UV}-\mathrm{H}_{2} \mathrm{O}_{2}$, Fenton, Photo-Fenton, Ultraviolet radiation-Titanium dioxide (UV-TiO 2 ), and $\mathrm{O}_{3}-\mathrm{TiO}_{2}$ (Gurol and Vatistas 1987; Benitez et al. 1999; Pera-Titus et al. 2004; Essam et al. 2007; Karci et al. 2012).

The degradation and formation of by- products from phenol compounds is dependent on the position of chlorine atoms and the type of oxidation treatment used (Kuo and Huang 1995; Song-hu and Xiao-hua 2005). However, there are only few published studies on the oxidative treatment of 2,5-DCP. Among these limited studies, Tang and Huang (1996) investigated

CONTACT Jacqueline C. Alexander al210386971@azc.uam.mx Eniversidad Autónoma Metropolitana - Azcapotzalco, División de CBI, Posgrado en Ciencias e Ingeniería Ambientales. San Pablo 180, Colonia Reynosa Tamaulipas, Delegación Azcapotzalco, CP 02200, Mexico, D.F.

Color versions for one or more of the figures in the article can be found online at www.tandfonline.com/BOSE. 
the effect of chlorine atoms position of chlorophenols on their dechlorination kinetics by Fenton's reagents. These authors found that chlorine atom at the meta position has a faster dechlorination rate constant than the chlorine atom at orto position in monochlorophenols. Moreover, the effect of the chlorine position on dechlorination of dichlorophenol was better observed at $\mathrm{H}_{2} \mathrm{O}_{2} / \mathrm{DCP}$ ratio of 20 . The dechlorination rate constant decreased as followed 2,5-DCP $>3,5-\mathrm{DCP}>2,3$ DCP $>2$ 2,6-DCP $>2,4$-DCP.

Meanwhile, Wang, Pai, and Latchaw (1989) studied the effect of ozonation pretreatment of 2,5-DCP under anaerobic conditions. The authors used varying concentrations $(100-600 \mathrm{mg} / \mathrm{L})$ of $2,5-\mathrm{DCP}$ at $\mathrm{pH} 3$ and pH 9 in distilled deionized water. They found that the ozonation products formed at basic $\mathrm{pH}$ were less toxic than the 2,5-DCP, in anaerobic toxicity assay. In addition, the ozonation products formed at basic $\mathrm{pH}$ were more biodegradables than those in the acidic $\mathrm{pH}$ (Wang 1990).

Qiu et al. (1999) did a kinetic and mechanistic study of ozonation of 2,3-DCP, 2,4-DCP, and 2,5-DCP [0.4 $\times$ $10^{-3}$ to $1 \times 10^{-3} \mathrm{M}$ ] in distilled water from $\mathrm{pH} 2.1$ to $\mathrm{pH}$ 5. In their study, the authors found that two moles of ozone were required for initial conversion of each mole of the DCP isomers. Also, the reaction between ozone and each DCP followed second-order kinetics, and first order kinetics with respect to the reactant. Moreover, ozone reacted more rapidly with DCP ions than with DCP molecules. Ozonation of 2,5-DCP was found to be the fastest among the three isomers studied. The authors suggested that the additional use of UV light might increase the degradation of DCP.

Finally, Wohlers et al. (2009) studied the use of air ionization in the degradation of pesticides including 2,5-DCP. The target compounds used were at initial concentration of $5 \mathrm{mg} / \mathrm{L}$ in bi-distilled water, with and without the addition of humic acid. The authors found that humic acid did not interfere with the degradation rate of the target compounds at low concentrations, but at high humic acids concentration $(\geq 15 \mathrm{mg} / \mathrm{L})$ the decomposition rate was slower. It appears that the competitive reaction of humic acid with oxidant could result in insufficient oxygen species in the aqueous solution.

To our knowledge, no detailed study has been published on the use of ozone-UV to degrade 2,5-DCP. Furthermore, there are no toxicity studies on the byproducts formed during oxidative treatment of 2,5DCP under aerobic conditions. This compound is increasingly associated with health problems, thus its removal from wastewater is vital. The objectives of this investigation were to compare the efficiencies of ozone and ozone-UV processes in distilled water and wastewater. To this end, the degradation and mineralization of 2,5-DCP (3.06 $\mathrm{mM})$ and its oxidation products were measured. Also, the biodegradability and acute toxicity of 2,5-DCP and its by-products were studied.

\section{Materials and methods}

\section{Experimental procedure}

This investigation was realized to evaluate the use of ozone and ozone-UV processes as a pretreatment of chlorophenol compounds on a laboratory scale. Researches have shown that advanced oxidation processes lead to increase in biodegradability of chlorophenols and reduce the overall toxicity to microorganisms (Contreras et al. 2003; Cesaro, Naddeo, and Beigiorno 2013). This makes their application beneficial prior to a conventional biological process (Contreras, at al., 2003; Dantas et al. 2008). This study used 2,5-DCP (3.06 $\mathrm{mM}$ ) to represent untreated effluent from industries with high phenolic compounds concentration (Ioannou, Li Puma, and Fatta-Kassinos 2015; Goel et al. 2010). Experiments were carried out at neutral $\mathrm{pH}$, as this was the $\mathrm{pH}$ of the wastewater after being spiked with 2,5-DCP. In addition, it was within the $\mathrm{pH}$ range of most wastewater ( $\mathrm{pH} 7-8)$, as mentioned in literature (Gilbert 1987). The maximum ozone/oxygen flowrate that was used in the reactor was approximately $0.6 \mathrm{~L} / \mathrm{min}$, to reduce foam formed during oxidation processes. This produced an ozone dose of approximately $22 \mathrm{mg} / \mathrm{min}$, which was maintained constant for all the tests.

The oxidation experiments were carried out in a bubble column glass reactor with a height of $58 \mathrm{~cm}$, an inner diameter of $8.5 \mathrm{~cm}$, and equipped with a finepore diffuser (pores diameter $=100 \mu \mathrm{m}$ ). During ozone-UV treatments, a Pen-Ray UV lamp (4 mW/ $\mathrm{cm}^{2}$ at a distance of $2.54 \mathrm{~cm}$ using UVX-25 radiometer) placed in quartz tube was positioned vertically, in the center of reactor, as shown in Figure 1. Ozone was produced by an ozone generator (Ozone Ecological Equipments) and was fed with dry oxygen gas $\left(\mathrm{O}_{2}>99.5 \%\right.$, Infra $)$ at a pressure of $15 \mathrm{psi}$ and temperature of $20-25^{\circ} \mathrm{C}$. The residual ozone in samples was measured using a Hanna Kit (HI 93757-01). The ozone concentration in off gas and inlet were measured using a 2\% Potassium Iodide solution according to standard Method E section 2350 (APHA, AWWA and WEF 2005). Each experiment was carried out at initial pH 7 and with an initial volume of $1.5 \mathrm{~L}$ of 2,5-DCP solution in distilled water (S1) and in wastewater (S2). Aliquots were withdrawn at predetermined time intervals for 


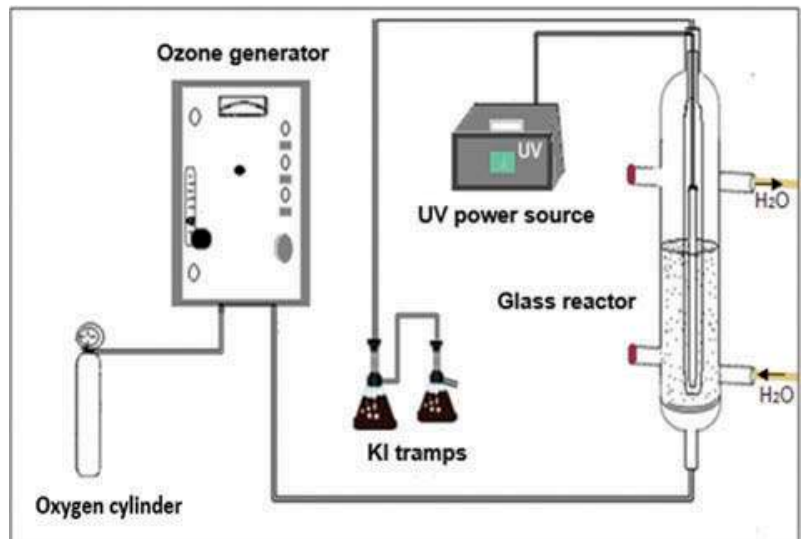

Figure 1. Schematic diagram of oxidation device.

Table 1. Physicochemical characteristics of wastewater.

\begin{tabular}{lc}
\hline Parameters (Units) & Values \\
\hline $\mathrm{pH}$ & 7.69 \\
$\mathrm{TSS}\left(\mathrm{mg} \mathrm{L}^{-1}\right)$ & 130 \\
$\mathrm{TDS}\left(\mathrm{mg} \mathrm{L}^{-1}\right)$ & 548 \\
Conductivity $\left(\mu \mathrm{s} \mathrm{cm}^{-1}\right)$ & 1048 \\
$\mathrm{TOC}\left(\mathrm{mg} \mathrm{L}^{-1}\right)$ & 115 \\
$\mathrm{BOD}\left(\mathrm{mg} \mathrm{L}^{-1}\right)$ & 198 \\
$\mathrm{COD}\left(\mathrm{mg} \mathrm{L}^{-1}\right)$ & 250 \\
Nitrates $\left(\mathrm{NO}_{3}^{-}-\mathrm{N}\right)\left(\mathrm{mg} \mathrm{L}^{-1}\right)$ & 10 \\
Phosphates $\left(\mathrm{PO}_{4}^{3-}\right)\left(\mathrm{mg} \mathrm{L}^{-1}\right)$ & 6 \\
$\mathrm{Cl}\left(\mathrm{mg} \mathrm{L}^{-1}\right)$ & 30 \\
Alkalinity (as mg L & 90 \\
\hline
\end{tabular}

Table 2. Initial values of 2,5-DCP (3.06 mM) in aqueous solutions.

\begin{tabular}{llll}
\hline & \multicolumn{1}{c}{$\mathrm{BOD}_{\mathrm{i}}$} & $\mathrm{COD}_{\mathrm{i}}$ & $\mathrm{TOC}_{\mathrm{i}}$ \\
\cline { 2 - 4 } Solution & $(\mathrm{mg} / \mathrm{L})$ & $(\mathrm{mg} / \mathrm{L})$ & $(\mathrm{mg} / \mathrm{L})$ \\
\hline S1: Distilled water & 10 & 627 & 233 \\
S2: Wastewater & 167.5 & 870 & 349 \\
\hline
\end{tabular}

analyses. Initial ozone concentration of approximately $37 \mathrm{mg} \mathrm{O}_{3} / \mathrm{L}$ was bubbled at an ozone-oxygen flowrate of $36 \mathrm{~L} / \mathrm{h}$ into the 2,5-DCP solutions $\mathrm{S} 1$ and $\mathrm{S} 2$ by finepore bubble diffuser at the bottom of the reactor.

\section{Materials}

2,5-dichlorophenol was purchased from Aldrich with purity $>98 \%$, and all other reagents used in this study were of analytic grade. Millipore water (Milli-Q Millipore system, with resistivity of $18 \mathrm{M} \Omega$. $\mathrm{cm}^{-1}$ ) was used to mix and dilute solutions. An aqueous solution ( $\mathrm{S} 1$ ), was prepared at initial concentration of $3.06 \mathrm{mM} 2,5-\mathrm{DCP}$ in distilled water. While, the aqueous solution (S2), was prepared at initial concentration of $3.06 \mathrm{mM} \mathrm{2,5-DCP}$ in wastewater. The wastewater was obtained from the influent of a Municipal wastewater treatment plant in
Azcapotzalco (Mexico City, Mexico). The solutions $\mathrm{S} 1$ and S2 were adjusted to $\mathrm{pH} 7$ using $0.1 \mathrm{~N} \mathrm{NaOH}$ and $0.1 \mathrm{~N} \mathrm{H}_{2} \mathrm{SO}_{4}$ solutions at the start of the experiment. The Municipal Wastewater was used in order to represent the condition of a real industrial wastewater containing 2,5-DCP at high concentration. Solution S1 was used as a control to monitor the degradation in 2,5-DCP without interference of contaminants present in the wastewater. Solution S2 was used to monitor the degradation with interference of contaminants that are normally present in wastewater. Table 1 shows the physicochemical characteristics of the wastewater used in this study. Table 2 shows the initial values of BOD, COD and TOC of the aqueous solutions after being spiked with 2,5-DCP $(3.06 \mathrm{mM})$.

\section{Analytic procedures}

Determination of biodegradability and degradation

The biodegradability of the samples was measured using $\mathrm{BOD}_{5} / \mathrm{COD}$ ratio. The biochemical oxygen demand (BOD) was measured using 5-Day BOD test under Method Section 5210 B of Standard Method (APHA, AWWA, and WEF 2005). The chemical oxygen demand (COD) was measured using closed reflux, under Colorimetric Method Section 5520 D of Standard Method (APHA, AWWA, and WEF 2005). Meanwhile, the degree of mineralization of 2,5-DCP was measured by Total Organic Carbon (TOC) using an Apollo 9000 TOC analyzer.

Identification of 2,5-DCP and its oxidation products HPLC procedure. The 2,5-DCP concentration was monitored by high performance liquid chromatography (HPLC) apparatus ACCELA. The analytical column used was a reverse-phase Hypersil GOLD ${ }^{\mathrm{TM}}$ with $50 \mathrm{~m}$ (length), $2.1 \mathrm{~mm}$ (internal diameter), and particle size of $1.9 \mu \mathrm{m}$. The mobile phase was a mixture of distilled water adjusted to $\mathrm{pH} 3$ with phosphoric acid and acetonitrile (50:50) at a rate of $0.2 \mathrm{~mL} / \mathrm{min}$. The wavelength used in the UV absorbance detector was $225 \mathrm{~nm}$, which corresponded to the maximum 2,5-DCP absorption. The data was analyzed using the XCALIBUR 2.1 software.

GC-MS procedure. The oxidation by-products formed during ozone and ozone-UV were identified using Agilent 7890 B gas chromatography (GC) equipped with an Agilent MSD 5975 mass spectrophotometer (MS), and Agilent 7693 injector Autosampler. The analytic column was a HP-5MS, $30 \mathrm{~m} \times 0.25 \mathrm{~mm}$ fused silica column with film 
thickness of $0.25 \mu \mathrm{m}$ (5\% phenyl)-95\% dimethylpolysiloxane stationary phase. The GC oven temperature was programmed from $60{ }^{\circ} \mathrm{C}$ for $2 \mathrm{~min}$, then increased via a ramp of $20{ }^{\circ} \mathrm{C} / \mathrm{min}$ to $130{ }^{\circ} \mathrm{C}$, then $15{ }^{\circ} \mathrm{C} / \mathrm{min}$ to $150^{\circ} \mathrm{C}$ and finally $10^{\circ} \mathrm{C} / \mathrm{min}$ to $300^{\circ}$ $\mathrm{C}$ for $2 \mathrm{~min}$; using helium as the carrier gas $(30 \mathrm{~cm}$. $\mathrm{s}^{-1}$ ). The MS was operated in full-scan mode from mass range 50-500 amu. SIM mode studies were obtained by monitoring single ion at $m / z=181$, $m / z=254$ and $m / z=290$. The inlet and MS transfer line temperatures were maintained at $250{ }^{\circ} \mathrm{C}$ and ion source temperature was $300{ }^{\circ} \mathrm{C}$. Sample injection $(1 \mu \mathrm{L})$ was performed in splitless mode using an automated injector for maximum sensitivity. MSD Chem Station data acquisition software (provided by Agilent) was used for GC-MS analysis. The mass spectra obtained were compared with the spectra database from NIST library, and the closest spectral match chosen. A mixture in dichloromethane containing the following compounds: catechol, hydroquinone, 4-chlorophenol, p-benzoquinone, 2,5-DCP and phenol was used to validate the library. All compound where accurately identified and the match ratios were greater than $90 \%$, showing the reliability of the library.

Preparation of GC-MS samples. Samples were prepared by two methods: 1) The Liquid-Liquid extraction by dichloromethane/hexane solvent. A $1-\mu \mathrm{L}$ volume of dichloromethane/hexane was added to a $0.5-\mu \mathrm{L}$ sample and then vortexed. The dichloromethane/hexane partition of the two immiscible liquid was extracted and transferred to a clean vial. To this vial, $1 \mu \mathrm{L}$ of dichloromethane/hexane was added, vortexed, and then a $1-\mu \mathrm{L}$ volume of sample was transferred to another vial for GC-MS analyses. 2) The solid phase extraction (SPE) was carried out using a reverse phase SPE LC-18 cartridge (SigmaAldrich). The samples from both methods were derivatized using a BF3-methanol kit $10 \%(\mathrm{w} / \mathrm{w})$ (Sigma-Aldrich). The samples were analyzed with and without derivatization (in triplicates).

\section{Analyses of $\mathrm{pH}$ and anions}

The $\mathrm{pH}$ was monitored using a Hanna HI $223 \mathrm{pH}$ bench meter. The anions chloride $\left(\mathrm{Cl}^{-}\right)$, nitrate $\left(\mathrm{NO}_{3}{ }^{-}-\mathrm{N}\right)$ and phosphate $\left(\mathrm{PO}_{4}{ }^{3-}\right)$ were measured using HANNA Kits HI 3815-0, HI 3874, and HI 3833 , respectively. These tests are based on the standard methods $4500 \mathrm{Cl}-\mathrm{C}$ (Mercuric nitrate titration), 4500- $\mathrm{NO}_{3}$-E (Cadmium Reduction), and 4500-P E (Ascorbic Acid Method), respectively (APHA, AWWA, and WEF 2005).

\section{Toxicity assays}

Toxicity tests for 2,5-DCP and its by-products were measured using "Activated Sludge, Respiration Inhibition Test." This method attempts to represent the conditions of a biological process and to provide information of inhibitory or stimulatory effects of a sample on microorganisms in activated sludge after a short exposure time (ISO 8192:2007). This test is based on measuring the respiration rate of the microbial inoculum in a synthetic sewage solution after 30-min contact time. The test utilizes controls and various concentrations of the test substance under identical conditions. The dissolve oxygen was measured using a dissolve oxygen meter (Hanna HI 2300). The inhibitory effect of the test substance at a given concentration is express as a percentage of the average respiration rates of two controls (OECD 2010; Yoshioka et al. 1986).

\section{Results and discussion}

\section{Changes in $\mathrm{pH}$}

In both solutions ( 1 1 and S2), an initial ozone dose of $1.3 \mathrm{~g} / \mathrm{h}$ was applied. The results showed that in solutions $\mathrm{S} 1$ the $\mathrm{pH}$ decreased rapidly from initial $\mathrm{pH} 7$ to pH 2.28 and $\mathrm{pH} 2.15$ at 60 min with ozone and ozoneUV processes, respectively. The reduction of the $\mathrm{pH}$ during the treatments could be due to the formation of acidic organic compounds (Qiu et al. 1999; Poznyak and Vivero 2005). In the case of solution S2, treatment with ozone and ozone-UV showed an increase in $\mathrm{pH}$ during the first $10 \mathrm{~min}$ from initial $\mathrm{pH} 7$ to 7.41 and 7.44 before decreasing to $\mathrm{pH} 3.01$ and 2.95 at $60 \mathrm{~min}$, respectively. This increase in the $\mathrm{pH}$ values during the oxidation of solutions S2 may be due to the presence of organic matters, carbonates, and hydroxides. These substances may increase alkalinity of solutions (Ngo et al. 2015; Nilvebrant and Jansson 2005).

\section{2,5-DCP removal and chloride release during oxidation treatments}

To evaluate the efficiency of the oxidation treatments $\left(\mathrm{O}_{3}\right.$ and $\mathrm{O}_{3}$-UV) in degradation of 2,5-DCP and its oxidation products, HPLC analyses were done. Figure 2(a) (solution S1) and Figure 2(b) (solution S2) show these HPLC chromatograms, before and after ozone-UV treatments. The concentration of 2,5-DCP in both solutions was measured by the area under the 2,5-DCP peak. The retention time of 2,5-DCP was approximately $3 \mathrm{~min}$. The results showed more peaks in the solutions with distilled water (S1) than in solutions with 

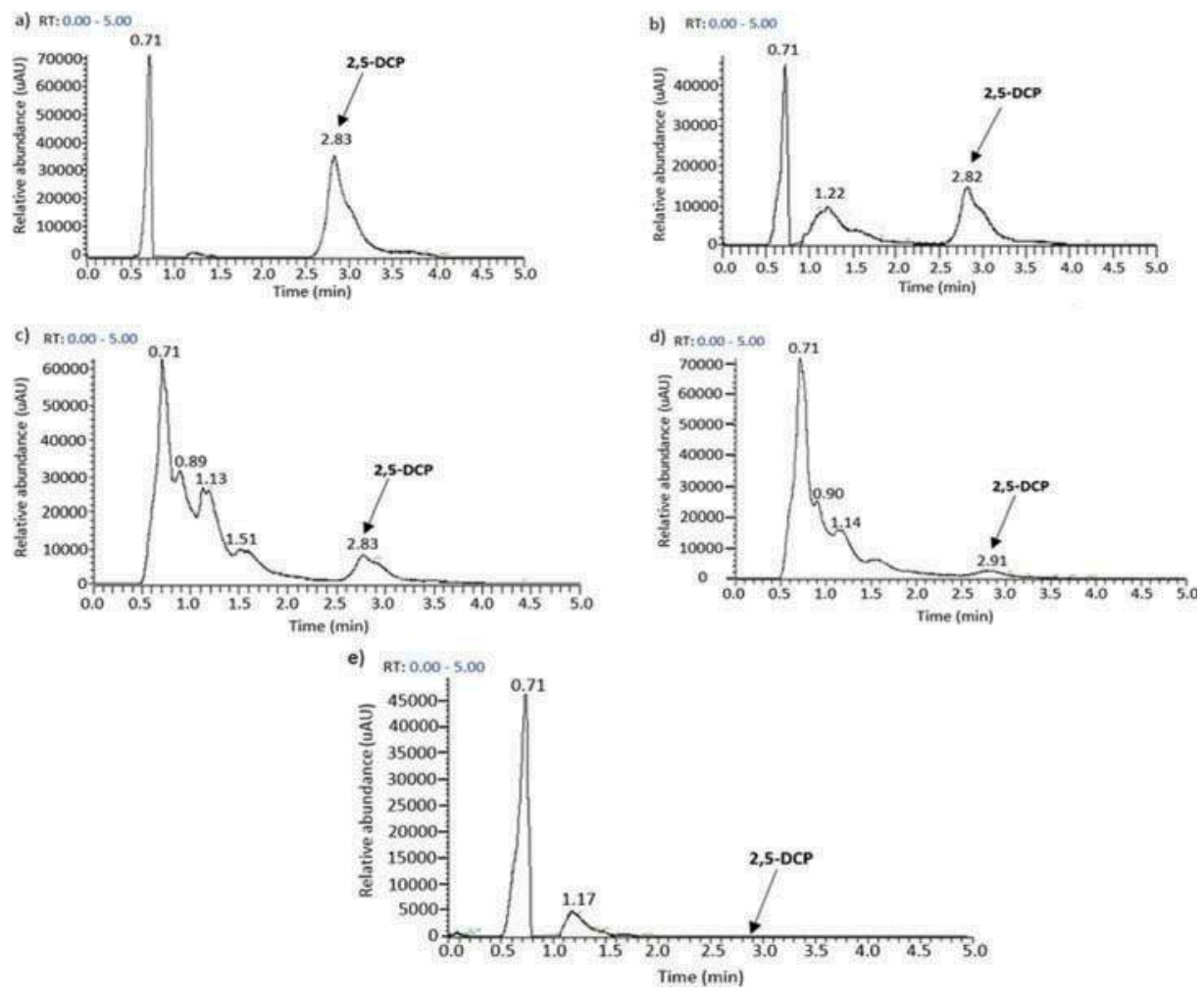

Figure 2a. HPLC chromatograms of 2,5-DCP in distilled water (S1:O3-UV) before and after ozone-UV treatments. At a) $t=0$ min; b) $\mathrm{t}=5 \mathrm{~min} ; \mathrm{c}) \mathrm{t}=20 \mathrm{~min} ; \mathrm{d}) \mathrm{t}=40 \mathrm{~min}$ and e) $\mathrm{t}=60 \mathrm{~min}$.
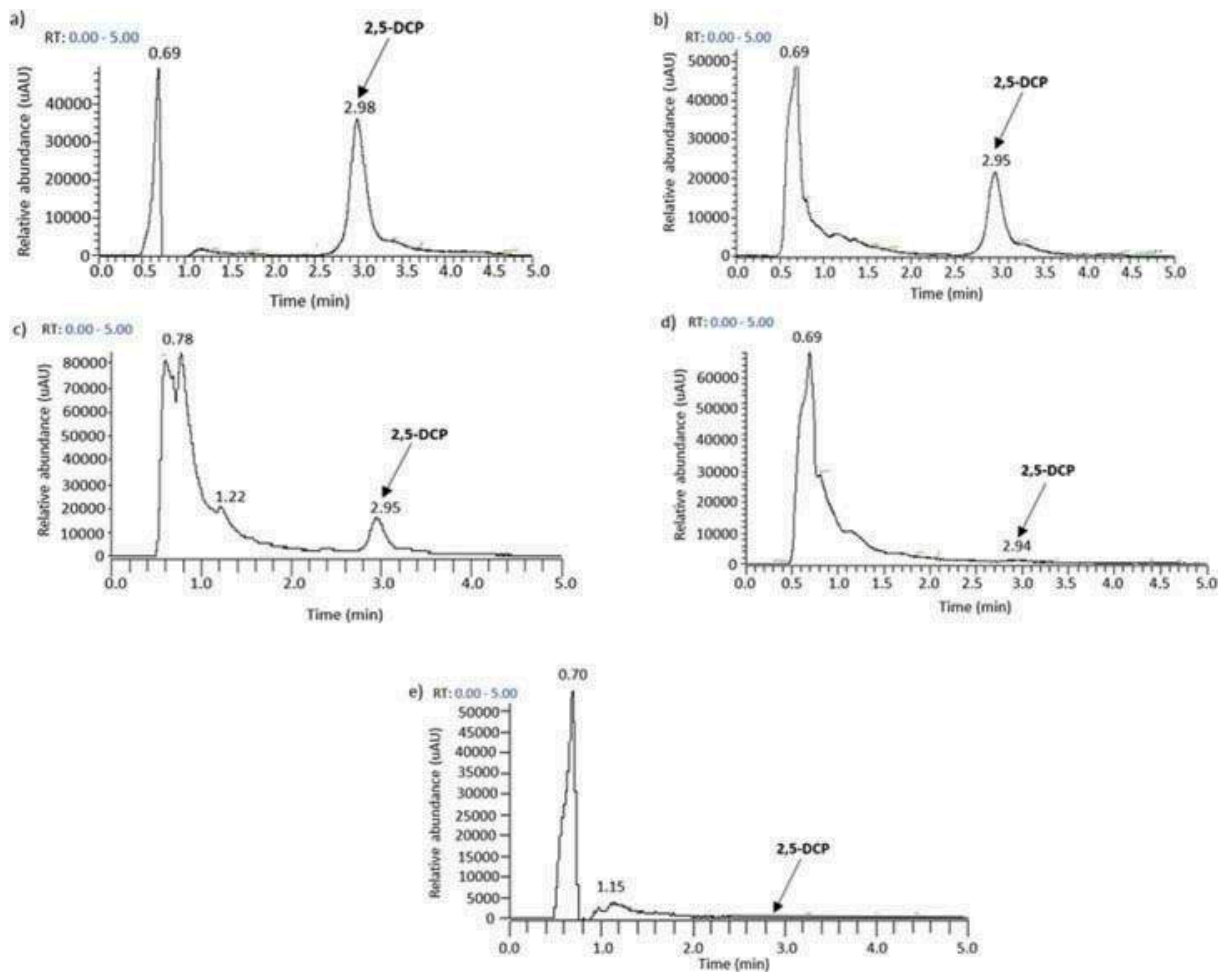

Figure 2b. HPLC chromatograms of 2,5-DCP in wastewater (S2:O3-UV) before and after ozone-UV treatments. At a) $t=0$ min; $b$ ) $\mathrm{t}=5 \mathrm{~min} ; \mathrm{c}) \mathrm{t}=20 \mathrm{~min} ; \mathrm{d}) \mathrm{t}=40 \mathrm{~min}$ and e) $\mathrm{t}=60 \mathrm{~min}$. 
A)

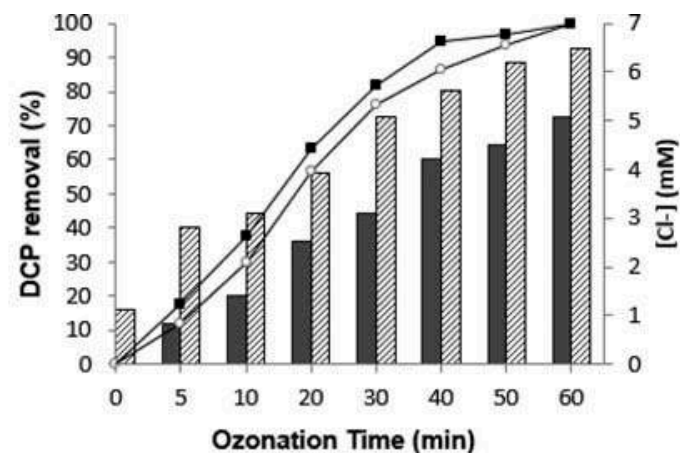

$[\mathrm{Cl}-]$ of $\mathrm{S} 1: \mathrm{O} 3$ - - DCP removal of $\mathrm{S} 1: 03$

B)

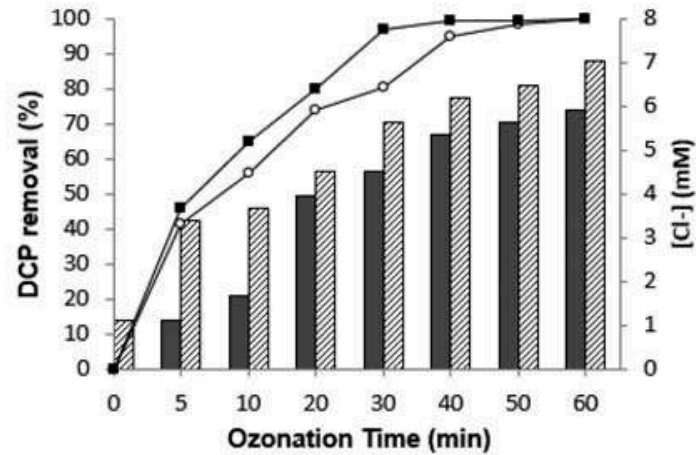

$[\mathrm{Cl}]$ of S1:O3-UV a-DCP removalof S1:O3-UV mims [Cl- $]$ of S2: O3-UV $\rightarrow-$ DCP removal of S2:O3-UV

Figure 3. 2,5-DCP degradation and chloride ion release vs. time for solutions S1 and S2 with treatments of A) ozonation and B) ozone-UV.

wastewater (S2). This may be due to the formation of more by-product or their presence in higher concentrations in the distilled water than in the wastewater at the time intervals shown. GC-MS studies confirmed the presence of more by-products and higher concentrations of chlorinated intermediates in the solutions S1 as compared to solution S2. The GC-MS studies showed that after 20-min ozone-UV treatment, 2,5-DCP, 4-Chloro-1,3Benzenediol, phenol, 4-Chloro-1,2-Benzenediol, 3chlorophenol, and pentanoic acid were found in solution S1 and S2. In addition, 2,5-dichloro-1,4Benzenediol, 3,6-Dichloro-benzene-1,2-diol, and catechol were found only in solution S1. Similar results were obtained during the ozonation of solutions S1 and S2. Most of these chlorinated by-products have been reported elsewhere (Poznyak and Vivero 2005; Qiu et al. 1999; Shang et al. 2006).

The formation of more hydroxyl radicals and the presence of organic/inorganic matter in wastewater could be the reason that Solution S2 had less chlorinated organic compounds in lower concentrations. Of relevance, Kuo and Huang (1999) and Poznyak and
Vivero (2005) found that phenolic solutions at basic $\mathrm{pH}$ produced less chlorinated compounds than those at acidic $\mathrm{pH}$. The authors were unable to find any GC-MS studies in the literature on the ozonation of chlorophenol in wastewater and in distilled water done under similar conditions, with which the results from this study could be compared.

Figure 3 shows the oxidation profile of the two aqueous solutions ( $\mathrm{S} 1$ and $\mathrm{S} 2$ ) during a) $\mathrm{O}_{3}$ and b) $\mathrm{O}_{3}$-UV treatments for 2,5-DCP degradation (\%) and dechlorination $(\mathrm{mM})$ plotted against time. The results show that treatments with ozone and ozone-UV were able to completely degrade $2,5-\mathrm{DCP}$ to oxidation byproducts after 60 and $40 \mathrm{~min}$, respectively. In Figure 3, it can be observed that the 2,5-DCP degradation and dechlorination proceeded simultaneously. The chloride ion concentration increases as 2,5-DCP concentration decreases, which is due to the release of the chlorine atoms bounded to DCP and the continuous degradation of chlorinated by-products formed during the oxidation treatments. Chloride ions were released within the first few minutes of ozonation and ozone-UV treatments of solutions S1 and S2. Similar results in the degradation of other DCP have been reported (Dantas et al. 2008; Karci et al. 2012). Complete dechlorination of solutions S1 and S2 was achieved after $60 \mathrm{~min}$ of ozone-UV treatments. In the case of ozonation processes, only $86 \%$ and $90 \%$ dechlorination was observed in solutions S1 and S2, respectively. These results were similar to those obtained by Qiu et al. (1999), who reported $87 \%$ chloride removal of 2,5-DCP in distilled water. Furthermore, both solutions (S1 and S2) did not achieve complete degradation of all chlorinated by-products after ozonation treatments for $60 \mathrm{~min}$.

The ozone consumption per mole of DCP removed beyond the initial oxidation of DCP was compared at $10 \mathrm{~min}$ for all samples. The results showed approximately 3 moles of ozone were consumed per mole of DCP degraded when $30 \%$ and $38 \%$ of DCP were removed during ozonation in S1 and S2, respectively. On the other hand, approximately 1.5 moles of ozone were consumed per mole of DCP degraded, when 56\% and $65 \%$ DCP were removed during ozone-UV processes in S1 and S2, respectively. The results of ozone consumption per mole of DCP removed are plotted against DCP removal as shown in Figure 4.

The results obtained with ozone-UV processes imply that DCP degradation (measured at $10 \mathrm{~min}$ ) was twice as fast as those with ozonation alone. It appears that more hydroxyl radicals were formed in solutions treated with ozone-UV than those with ozone alone. Qiu et al. (1999) found that 2 moles of ozone were required to remove 1 mole of initial DCP during ozonation in 


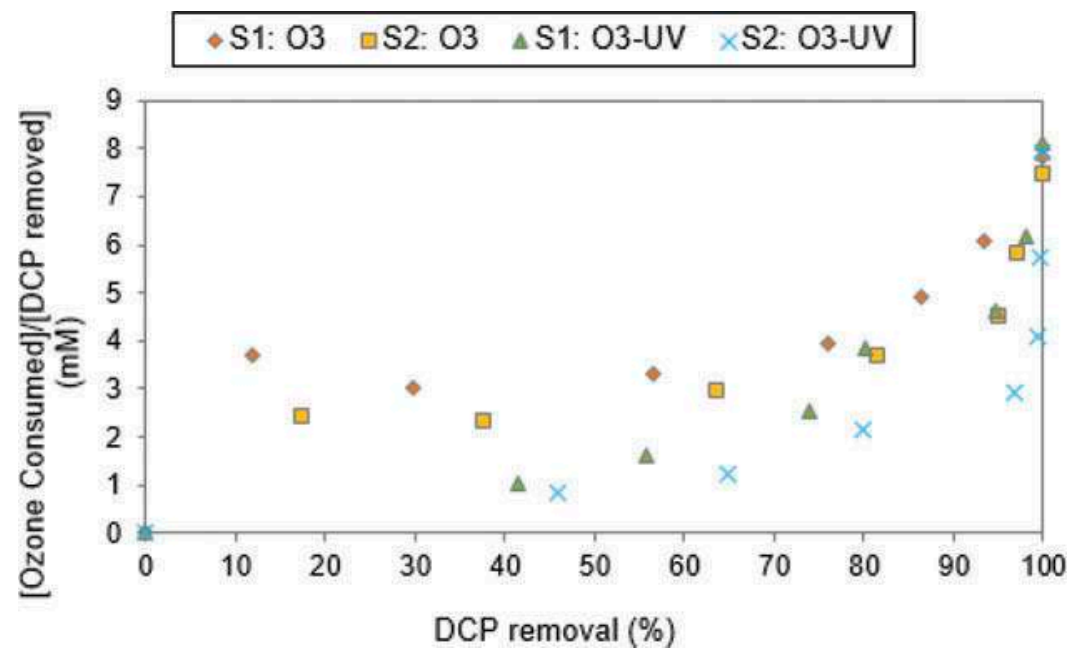

Figure 4. Ozone consumed per DCP removed $(\mathrm{mM})$ in function of DCP removed (\%) for 2,5-DCP in solutions S1: distilled water and S2: wastewater treated with $\mathrm{O}_{3}$ and $\mathrm{O}_{3}-\mathrm{UV}$.

distilled water. However, Gilbert (1978) reported that approximately 2-6 moles of ozone were required per mole of initial aromatic removed. Therefore, the ozone consumption results obtained in this study for ozonation are within the mentioned range.

Typically, the ozone consumption per mole of DCP removed increases with time as oxidation by-products formed have higher ozone demand and the formation of chloride ion in solution may act as radical scavenger (Gilbert 1978). However, in this study the ozonation by-products formed at $5 \mathrm{~min}$ had a higher ozone requirement than those formed at $10 \mathrm{~min}$. They required 19\% (S1) and 4\% (S2) more ozone consumption (per mole DCP removed) than by-products formed at $10 \mathrm{~min}$. This could be due to the higher concentration of some by-products such as phenol and 3-chlorophenol (detected in the GC-MS study) present in solutions ozonated for $5 \mathrm{~min}$. As these compounds are known for having higher ozone consumption requirements than DCP (Shang et al. 2005, Gilbert 1978).

Similar behavior was not observed in the ozone-UV treatments for either solution (S1 or S2). Moreover, the ozonation-UV oxidation by-products after $5 \mathrm{~min}$, which represent $42 \%$ and $46 \%$ DCP removal for solutions S1 and S2 respectively- had lower ozone demand than the 10 min ozone-UV by-products. This is because the solutions with ozone-UV treatments had higher DCP degradation (greater than $40 \%$ ) than the solutions treated with ozone (less than 20\% DCP removal).

The higher DCP degradation in solutions treated with ozone-UV could be due to the formation of hydroxyl radicals, which are more powerful oxidant than molecular ozone (Kuo and Huang 1999; Pera-
Titus et al. 2004). The combination of UV with ozone promotes the formation of hydroxyl radical concentration in solutions (Lamsal, Walsh, and Gagnon 2011). In addition, Esplugas et al. (2002) showed that direct photolysis contributed to partial degradation of DCP, due to the absorption of UV photons by aromatic compounds. In their study, using photolysis they achieved only a $24 \%$ degradation of phenol. Furthermore, Benitez et al. (2000) noted a decrease in the susceptibility of aromatic ring being attacked by UV photons as the number of chlorine atoms on the aromatic compound increased.

\section{COD and TOC removal using oxidation processes}

The results obtained showed that an applied ozone dose of $1.3 \mathrm{~g} / \mathrm{h}$, during the $\mathrm{O}_{3}$ and $\mathrm{O}_{3}$-UV treatments of 2,5-DCP in solutions S1 and S2 were not sufficient to achieve complete mineralization of 2,5-DCP. However, the results obtained in this work were fairly good, considering the high concentration of 2,5-DCP (3.06 mM) and the low doses of ozone applied. Figure 5 shows the maximum TOC removal achieved were $38 \%, 45 \%, 40 \%$ and $53 \%$ for

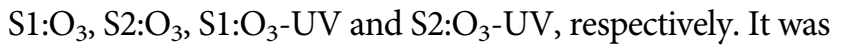
observed that TOC removal increases with ozone consumption. The highest TOC removal was achieved during $\mathrm{O}_{3}$-UV treatments, which shows that the UV photolysis process did have some influence on the ozonation process. This was demonstrated by an $8 \%$ increase in TOC removal with ozone-UV treatment of the wastewater (S2). Gurol and Vatistas (1987) and Kuo and Huang (1999) also reported much higher TOC removal in $\mathrm{O}_{3}$ - UV treatment than with ozone alone. 


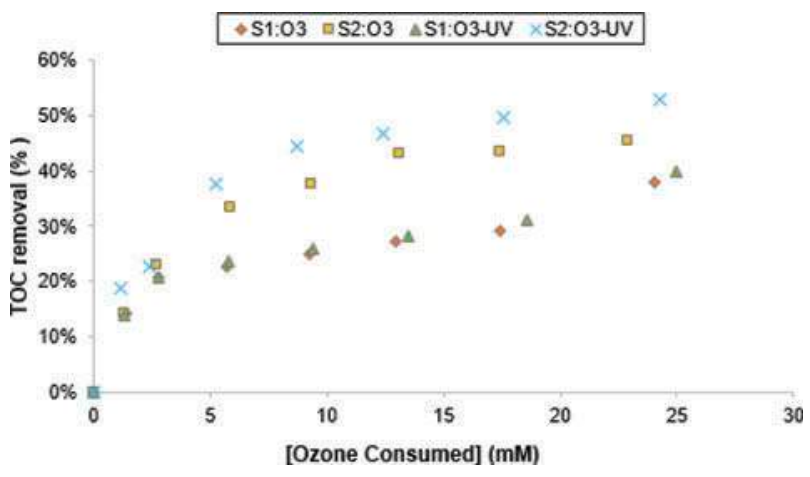

Figure 5. TOC removal (\%) vs ozone consumed (mM) for 2,5DCP in solutions S1: distilled water and S2: wastewater treated with $\mathrm{O}_{3}$ and $\mathrm{O}_{3}-\mathrm{UV}$.

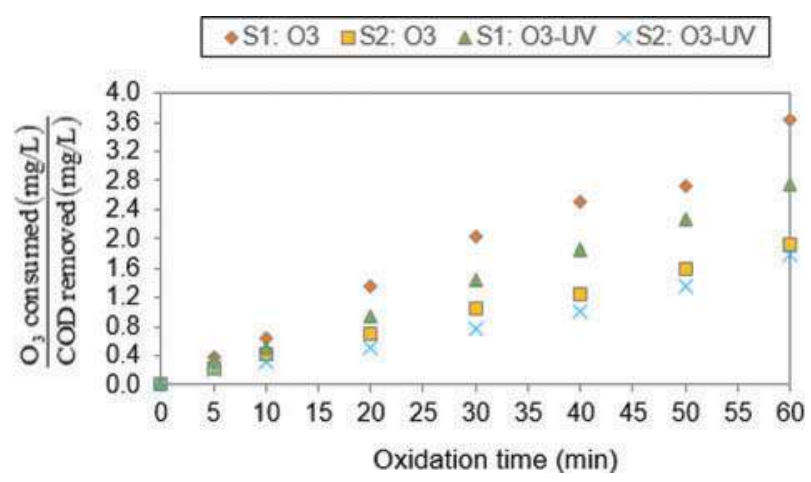

Figure 6. Ozone consumed per COD removed (mg/L) in function of oxidation time $(\mathrm{min})$ for 2,5-DCP in solutions S1: distilled water and S2: wastewater treated with $\mathrm{O}_{3}$ and $\mathrm{O}_{3}-\mathrm{UV}$.

The COD removal rate values were $59 \%, 66 \%, 70 \%$ and $75 \%$ at $60 \mathrm{~min}$ in $\mathrm{S} 1: \mathrm{O}_{3}, \mathrm{~S}_{2}: \mathrm{O}_{3}, \mathrm{~S}_{1}: \mathrm{O}_{3}-\mathrm{UV}$ and $\mathrm{S} 2$ : $\mathrm{O}_{3}$-UV, respectively. Figure 6 shows the ozone consumption per $\mathrm{mg} / \mathrm{L}$ of COD removed as a function of oxidation time. After $5 \mathrm{~min}$ of oxidation, approximately $0.38 \mathrm{mg} / \mathrm{L}$ and $0.23 \mathrm{mg} / \mathrm{L}$ of ozone were consumed per $\mathrm{mg} / \mathrm{L}$ of COD removed in solutions S1 and S2, respectively. Regarding the ozone-UV treatment, these values were $0.32 \mathrm{mg} / \mathrm{L}$ and $0.20 \mathrm{mg} / \mathrm{L}$ for solutions S1 and S2, respectively. However, after $60 \mathrm{~min}$ of oxidation, the ozone requirements per $\mathrm{mg} / \mathrm{L}$ of COD removed were approximately 9 times higher for the different oxidation processes. These results showed that the oxidation byproducts reacted at a slower rate than 2,5-DCP with the different oxidation treatments. Furthermore, lower ozone consumption was observed per mole of COD removed with the oxidation treatments in wastewater solution (S2). This can be due to the formation of more radicals and/or the presence of other substance(s) in wastewater (S2) that may act as promoters and thereby cause oxidation reactions to occur at faster rates than in distilled water (S1).

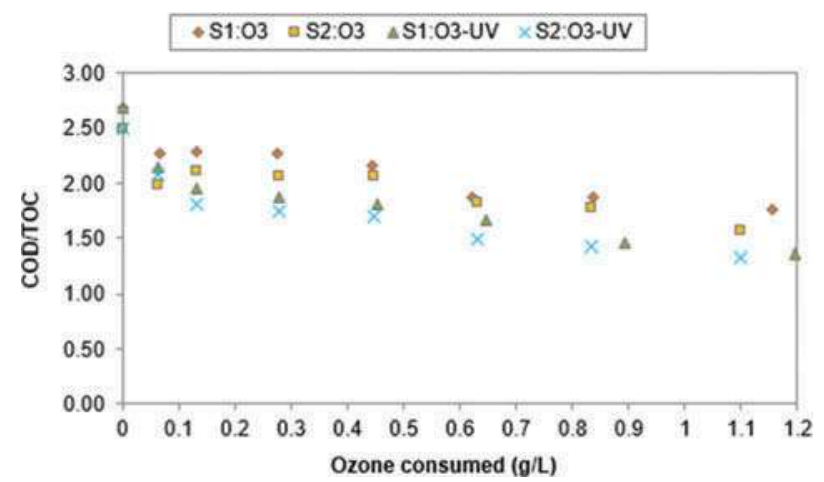

Figure 7. COD/TOC ratio as a function of ozone consumed for $\mathrm{O}_{3}$ and $\mathrm{O}_{3}$-UV treatments of 2,5-DCP in solutions $\mathrm{S} 1$ : distilled water and S2: wastewater.

To evaluate the degree of oxidation of 2,5-DCP and its oxidation products, the $\mathrm{COD} / \mathrm{TOC}$ ratio was calculated. Figure 7, shows the COD/TOC ratio as a function of ozone consumed during $\mathrm{O}_{3}$ and $\mathrm{O}_{3}$-UV treatments of 2,5-DCP. In solutions $\mathrm{S} 1$, the initial $\mathrm{COD} / \mathrm{TOC}$ ratio decreased from 2.6 to $1.76\left(\mathrm{O}_{3}\right)$ and $1.36\left(\mathrm{O}_{3}-\mathrm{UV}\right)$. However, in solutions S2, the initial COD/TOC ratio decreased from 2.5 to $1.57\left(\mathrm{O}_{3}\right)$ and $1.33\left(\mathrm{O}_{3}-\mathrm{UV}\right)$. These results imply higher degrees of oxidation with ozone-UV treatments than with ozone-only treatments.

\section{Ozone consumption}

Table 3 summarizes the results of ozone consumed per mole of TOC, DCP, and COD removed after $60 \mathrm{~min}$ of oxidation treatments with ozone and ozone-UV processes. These results show that at least 8 moles of ozone are required per mole of oxidation by-products removed. This is much higher than the 3 moles and 1.5 moles required for initial DCP degradation with ozone and ozone-UV processes, respectively. Oxidation by-products tend to react more slowly with ozone and hydroxyl radicals than their parent compound (Gilbert 1987).

A similar behavior was observed with respect to the ozone requirement per mole of TOC and COD removed. Approximately $0.26,0.15,0.22$, and 0.13 moles of ozone were consumed per mole of initial COD destroyed in solution $\mathrm{S}_{1}: \mathrm{O}_{3}, \mathrm{~S}_{2}: \mathrm{O}_{3}, \mathrm{~S} 1: \mathrm{O}_{3}-\mathrm{UV}$, and $\mathrm{S} 2: \mathrm{O}_{3}-\mathrm{UV}$, respectively. Initial ozone consumed per mole of TOC removed were $0.5,0.32,0.49$, and 0.21 moles with $\mathrm{S} 1: \mathrm{O}_{3}, \mathrm{~S} 2: \mathrm{O}_{3}, \mathrm{~S}_{1}: \mathrm{O}_{3}-\mathrm{UV}$, and $\mathrm{S} 2: \mathrm{O}_{3^{-}}$ $\mathrm{UV}$, respectively. The initial ozone required for the elimination of 1 mole of TOC and COD increases after $60 \mathrm{~min}$ of oxidation, as shown in the Table 3 . Furthermore, for solutions S1, approximately $4.2 \mathrm{mM}$ and $2.5 \mathrm{mM}$ of ozone for TOC elimination are needed to reduce to about $60 \%$ COD during $\mathrm{O}_{3}$ and $\mathrm{O}_{3}$-UV 
Table 3. Summary of the oxidation results of Solutions S1 and S2 after $60 \mathrm{~min}$ of ozone and ozone-UV treatments.

\begin{tabular}{|c|c|c|c|c|c|c|}
\hline Oxidation time (min) & Solutions & $\begin{array}{l}\text { Oxidation } \\
\text { treatment }\end{array}$ & $\mathrm{O}_{3}$ consumed $(\mathrm{mM})$ & $\begin{array}{l}\mathrm{O}_{3} \text { consumed }(\mathrm{mM}) \\
\text { TOCremoved }(\mathrm{mM})\end{array}$ & $\frac{\mathrm{O}_{3} \text { consumed }(\mathrm{mM})}{\text { CODremoved }(\mathrm{mM})}$ & $\frac{\mathrm{O}_{3} \text { consumed }(\mathrm{mM})}{\mathrm{DCPandbyproductsremoved}(\mathrm{mM})}$ \\
\hline 60 & $\begin{array}{l}\text { S1 } \\
\text { S2 } \\
\text { S1 } \\
\text { S2 }\end{array}$ & $\begin{array}{l}\text { ozone } \\
\text { ozone-UV }\end{array}$ & $\begin{array}{l}24.04 \\
22.92 \\
24.93 \\
24.25\end{array}$ & $\begin{array}{l}4.24 \\
1.73 \\
3.21 \\
1.58\end{array}$ & $\begin{array}{l}2.42 \\
1.28 \\
1.83 \\
1.19\end{array}$ & $\begin{array}{l}7.84 \\
7.47 \\
8.13 \\
7.90\end{array}$ \\
\hline
\end{tabular}

Table 4. Kinetic constants for the oxidation of 2,5-DCP and by-products.

\begin{tabular}{llcccc}
\hline & & & & \\
Aqueous Solution & Oxidation & $\mathrm{pH}$ & $\mathrm{k}(1 / \mathrm{min})$ & $\mathrm{t}^{2}$ & \\
\hline S1: Distilled Water & S1:03 & 7.05 & 0.0598 & 0.96 & \\
& S1: O3-UV & & 0.0949 & 0.92 & 72 \\
S2: Wastewater & S2:03 & & 0.0698 & 0.90 & 7 \\
& S2: O3-UV & & 0.1051 & 0.95 & 7 \\
\hline
\end{tabular}

processes, respectively. In the case of solutions $\mathrm{S} 2,1.1$ $\mathrm{mM}\left(\mathrm{O}_{3}\right)$ and $0.7 \mathrm{mM}\left(\mathrm{O}_{3}\right.$-UV) of ozone were required for $60 \%$ reduction in the COD value. These concentrations allow for the formation of reaction products that are easily biodegradable (COD removal $=60 \%$ ) (Gilbert 1987). Also, it was observed, with respect to ozone consumption, that by-products formed in wastewater (S2) consumed less ozone than those formed in distilled water (S1). In addition, ozone processes in solution S2 required about 1.5 times the amount of ozone than did ozone-UV treatments to form biodegradable products. Similar results were obtained in solution S1.

\section{Kinetic study of 2,5-DCP}

With regard to the reaction rate, the data was best fitted with pseudo-first-order model (Mokrini, Ousse, and Esplugas 1997). The kinetic constants, $k$ were calculated for the different oxidation processes in solutions $S 1$ and S2 as shown in Table 4. The calculated values for the oxidation processes behave similarly to those reported in the literature, where the reaction of DCP was faster with $\mathrm{O}_{3}$-UV than with $\mathrm{O}_{3}$ alone ( $\mathrm{Ku}$ et al. 1996; PeraTitus et al. 2004; Esplugas et al. 2002). Rate constant calculated by Trapido et al. (1997) for ozonation of 2,4DCP with concentration of $0.4 \mathrm{mM}$ was $9.76 \times 10^{-4} \mathrm{~s}^{-1}$ $\left(0.0586 \mathrm{~min}^{-1}\right)$, which is similar to the results obtained in this study for the ozonation treatment of 2,5-DCP in solutions S1 and S2. Qiu et al. (1999) in their study calculated rate constant of $58,000 \mathrm{M}^{-1} \mathrm{~s}^{-1}$ for DCP molecular and $2.6 \times 10^{9} \mathrm{M}^{-1} \mathrm{~s}^{-1}$ for DCP ion for ozone treatments of 2,5-DCP.

These constants are much faster than the values obtained in this study. However, the ratio of ozone dose to DCP was higher and the DCP concentration was much lower in their study than in this one. Taking in to consideration the high concentration of DCP used and the low ozone dosage applied, the rate constant calculated in this study are very promising. These results can be contributed to the reactor used; a bubble column equipped with fine-pore diffuser, and volumetric mass transfer $\left(\mathrm{k}_{\mathrm{L}} \mathrm{a}\right)$ of $1.58 \mathrm{~min}^{-1}$. The reactor was very efficient in mixing the ozone with DCP solutions because small spherical uniform bubbles were created. Moreover, the UV photolysis added to the ozone treatment accelerated the degradation of 2,5DCP and its by-products. The kinetic studies showed that the rate constants obtained for ozone-UV treatments were more than 1.5 times faster than the constants calculated for ozone treatments. This may be due to the high molar absorptivity of chlorophenols in the UV-region and the higher concentration of hydroxyl radicals in solutions.

\section{Biodegradability of 2,5-DCP and its by-products}

The biodegradability enhancement of 2,5-DCP and its oxidation products in solutions S1 and S2 treated with ozone and ozone-UV was evaluated. The COD and $\mathrm{BOD}_{5}$ analyses were carried out on all samples withdrawn before and after oxidation. Results obtained from these analyses were used to calculate the $\mathrm{BOD}_{5} /$ $\mathrm{COD}$ ratio. In general, the $\mathrm{BOD}_{5} / \mathrm{COD}$ results for the solutions in wastewater (S2) were higher than the $\mathrm{BOD}_{5} / \mathrm{COD}$ ratio for the solution in distilled water (S1). This is due to the natural organic matters present in the wastewater that gave higher initial BOD and COD results. The 2,5-DCP solutions: S1 and S2 were not biodegradable $\left(\mathrm{BOD}_{5} / \mathrm{COD}=0.02\right.$ and 0.19 , respectively) without oxidation treatment ( $t=0 \mathrm{~min}$ ). Ozone and ozone-UV treatments in solution S1, were able to achieve biodegradability $\left(\mathrm{BOD}_{5} / \mathrm{COD}=0.4\right)$ after oxidation for $60 \mathrm{~min}$ and $40 \mathrm{~min}$, respectively. On the other hand, ozone and ozone-UV treatments 
Table 5. Biodegradability of 2,5-DCP after oxidation (ozone and ozone-UV) in solution S1: distilled water and S2: wastewater.

\begin{tabular}{lcccc}
\hline \multirow{2}{*}{$\begin{array}{l}\text { Oxidation time } \\
\text { (min) }\end{array}$} & S1: O3 & S2: O3 & S1: O3-UV & S2: O3-UV \\
\cline { 2 - 5 } & BOD $_{5} /$ COD & BOD $_{5} /$ COD & BOD $_{5} /$ COD & BOD $_{5} /$ OOD $^{-}$ \\
\hline 0 & 0.02 & 0.19 & 0.02 & 0.19 \\
5 & 0.02 & 0.14 & 0.12 & 0.15 \\
10 & 0.07 & 0.20 & 0.18 & 0.25 \\
20 & 0.09 & 0.25 & 0.21 & 0.34 \\
30 & 0.13 & 0.35 & 0.27 & 0.50 \\
40 & 0.18 & 0.46 & 0.40 & 0.63 \\
50 & 0.26 & 0.50 & 0.47 & 0.72 \\
60 & 0.40 & 0.60 & 0.63 & 0.85 \\
\hline
\end{tabular}

Table 6. The Activated Sludge, Respiration Inhibition Test results of 2,5-DCP $(3.06 \mathrm{mM})$ and by-product treated with $\mathrm{O}_{3}$ and $\mathrm{O}_{3}$-UV in aqueous solutions of distilled water and wastewater.

\begin{tabular}{|c|c|c|c|c|c|}
\hline 2,5-DCP solutions & Treatment & Oxidation Time (min) & $\mathrm{EC}$ & Concentration $(\mathrm{mg} / \mathrm{L})$ & $\mathrm{R}^{2}$ \\
\hline S1: Distilled Water & Without Treatment & 0 & 50 & 50 & 0.9978 \\
\hline S2: Wastewater & Without Treatment & 0 & 50 & 57 & 0.9988 \\
\hline \multirow{3}{*}{ S1: Distilled Water } & Ozonation & 60 & 30 & 95 & 0.9945 \\
\hline & & 40 & 40 & 80 & 0.9988 \\
\hline & & 20 & 50 & 85 & 0.9987 \\
\hline \multirow[t]{3}{*}{ S2: Wastewater } & Ozonation & 60 & 30 & 110 & 0.9939 \\
\hline & & 40 & 40 & 100 & 0.9964 \\
\hline & & 20 & 50 & 95 & 0.9949 \\
\hline \multirow[t]{3}{*}{ S1: Distilled Water } & Ozone-UV & 60 & 30 & 121 & 0.9934 \\
\hline & & 40 & 40 & 110 & 0.9953 \\
\hline & & 20 & 50 & 105 & 0.9905 \\
\hline \multirow[t]{3}{*}{ S2: Wastewater } & Ozone-UV & 60 & 25 & 125 & 0.9980 \\
\hline & & 40 & 40 & 125 & 0.9976 \\
\hline & & 20 & 50 & 120 & 0.9903 \\
\hline
\end{tabular}

of solution S2 were biodegradable after oxidation for only $40 \mathrm{~min}$ and $30 \mathrm{~min}$, respectively (Table 5 ). These results show that an increase in ozone dose improve the biodegradability of $2,5-\mathrm{DCP}$. Since the $\mathrm{BOD}_{5} / \mathrm{COD}$ ratio for $2,5-\mathrm{DCP}(50 \mathrm{mg} / \mathrm{L})$ without treatment was nonbiodegradable, the enhancement in biodegradability can be attributed to the formation of oxidation products. It is expected that oxidation will degrade the 2,5 DCP compound into low molecular weight compounds (organic acid), which are less inhibitory to microorganism and hence easily biodegraded (Dantas et al. 2008).

\section{The changes in toxicity during oxidation treatments}

The activated sludge, respiration inhibition tests, were carried out on 2,5-DCP $(3.06 \mathrm{mM})$ in solutions S1 and S2 with and without oxidation treatments of ozone and ozone-UV at different time intervals $(0,20,40$ and $60 \mathrm{~min}$ ). Table 6 shows the results of the toxicity of the 2,5-DCP and its oxidation products toward the microbial inoculum of activated sludge used in this study. The inhibition of the studied compound and its by-products were measured in terms of effective concentration (EC). The value of $\mathrm{EC}_{50}$ represent the concentration of 2,5-DCP and its by-products that reduce the response of microbial population by half. The EC value for each test was obtained using probit analysis. All the tests in the study comply with the criteria and norms mentioned (Yoshioka et al. 1986). The differences between the controls in each test were less than $15 \%$, temperature was between $20-23{ }^{\circ} \mathrm{C}$, and final $\mathrm{pH}$ was maintained between $7-8$ for all tests. The results show that 2,5-DCP without treatment was very toxic to the microorganisms with $\mathrm{EC}_{50}$ values of 50 and 57 for solutions S1 and S2, respectively. These results were similar to those reported in literature for 2,5-DCP without treatments (Blum and Speece 1991; Ren, Asce, and Frymier 2003).

Treatments with ozone and ozone-UV processes for $40 \mathrm{~min}$ and $60 \mathrm{~min}$ were not sufficiently toxic to the microorganisms to permit the calculation of $\mathrm{EC}_{50}$. For these tests, the highest volume of oxidized solution used was $125 \mathrm{~mL}$. This proves that oxidation treatments were able to reduce the toxicity of DCP and its byproducts. In addition, it confirms that the oxidation byproducts formed were less toxic to the microorganisms than were the parent compound. Oxidation of CPs can produce intermediates that are more toxic than the parent compound to microorganisms in activated sludge (Shang et al. 2006). Hence, toxicity assays are critical for monitoring these by-products. The corresponding EC values were calculated for the studied 
compound in solutions S1 and S2. The lowest toxicity was obtained after $60 \mathrm{~min}$ of oxidation treatments. Toxicity decreased in the following order S1:O3 > S2: O3 > S1:O3-UV > S2:O3-UV. Table 6, showed the best results was obtained after 60 -min ozone-UV treatment in solution S2 (wastewater) with $\mathrm{EC}_{20}$ of $105 \mathrm{mg} / \mathrm{L}$.

The overall results obtained in this study are very promising and proved optimistic for future studies in wastewater of refractory compounds. Normally, laboratory studies are carried out using distilled water and synthetic water to avoid uncontrollable factors and negative interferences of natural organic and inorganic matters present in wastewater. However, in this study, it was shown that the presence of these organic and inorganic matters did not inhibit the oxidation effect on DCP. On the contrary, they had a positive effect, acting as conventional initiator or promoters of radical reactions. This allowed the oxidation reaction to occur much faster in the wastewater solution than in the distilled water solution for both ozone and ozone-UV treatments. It is unsure which substance or substances were acting as promoters or initiators in the oxidation treatments as this was not investigated in this work. In the few published studies on chlorophenols in synthetic wastewater, the concentrations have mostly been lower than the organic species present in the same wastewater ( $\mathrm{He}$ et al. 2010). This may have been one of the reasons for the inhibitory effect of the organic matter reported, as was found in the study by Wohlers et al. (2009). However, in this study the test content was much higher than the organic matter, which may be the reason there was no inhibitory effect observed. Moreover, the oxidation treatment of wastewater solutions (S2) yielded better results in 2,5-DCP degradation, TOC removal, and $\mathrm{COD}$ reduction per $\mathrm{mM}$ of ozone consumed in comparison with the distilled water solutions (S1). This was confirmed by the results obtained in this study.

\section{Conclusions}

This comparative study has confirmed that the application of ozone and ozone-UV treatments achieved complete degradation of 2,5-DCP to form new intermediates that were more biodegradable. In addition, oxidation by-products formed appear to be less toxic to the microorganisms present in activated sludge than the parent compound. The reaction rates of the two studied treatments in distilled water and wastewater were as followed: S2: Ozone $-\mathrm{UV}>\mathrm{S} 1$ : Ozone -UV > S2: Ozonation > S1:
Ozonation. All oxidation treatments were able to reduce the initial TOC and COD values. OzoneUV treatments of wastewater were able to remove $53 \%$ of TOC and $75 \%$ of COD after $60 \mathrm{~min}$ of oxidation using a consumed ozone dose of $24 \mathrm{mM}$.

The rate of degradation of the oxidation intermediates formed are slower than that of 2,5-dichlorophenol. The increase in chloride ion formation in the medium indicates the degradation of DCP with both oxidation processes. The enhanced degradation, biodegradability, and detoxification achieved for 2,5-DCP in wastewater, supports the potential use of ozone or ozone-UV treatments to improve the quality of effluent in industrial wastewater with high concentrations of dichlorophenol or other refractory chlorophenols.

\section{Nomenclature}

g Gram

mg Milligram

L Liter

min minute

h hour

s second

t Time

$\mathrm{cm} \quad$ centimeter

$\mathrm{mW}$ milliwatt

$\mu \mathrm{m} \quad$ micrometer

$\mathrm{mM}$ millimolar

$\mathrm{M} \Omega \quad$ Mega ohm

CPs Chlorophenols

DCP Dichlorophenol

S1 2,5-DCP solution in distilled water

S2 2,5-DCP solution in wastewater

BOD Biological oxygen demand

COD Chemical oxygen demand

amu Atomic mass unit

TOC Total organic carbon

TSS Total suspended solids

TDS Total dissolved solids

Cl- Chloride

$\mathrm{O}_{2} \quad$ Oxygen

$\mathrm{O}_{3} \quad$ Ozone

UV Ultraviolet

$\mathrm{TiO}_{2}$ Titanium dioxide

$\mathrm{H}_{2} \mathrm{O}_{2}$ Hydrogen peroxide

$\mathrm{NaOH}$ Sodium hydroxide

$\mathrm{H}_{2} \mathrm{SO}_{4}$ Sulfuric acid

$\mathrm{PO}_{4}{ }^{3-}$ Phoshate

$\mathrm{NO}_{3}{ }^{-}$Nitrate

GC-MS Gas chromatography-mass spectrometry

HPLC High performance liquid chromatography 


\section{kLa Volumetric mass transfer \\ k Rate constant \\ EC Effective concentration}

\section{Acknowledgments}

The authors would like to thank Dr. Luis Fernandez Linares and M.Sc. Sandra Garcia of UPIBI-National Polytechnic Institute and Dr. Victor Luna Pabello and M Sc. Luciano Hernandez Gomez of The Experimental Microbiology laboratory for their kind assistance.

\section{Funding}

Jacqueline C. Alexander will like to thank CONACYT for awarding her a scholarship to pursue her Ph.D. and for helping to fund this research project, and the Metropolitan Autonomous University for their financial assistance.

\section{References}

APHA, AWWA, and WEF. 2005. Standard Methods for the Examination of Water and Wastewater. 21st. Washington, D.C: America Public Health Association.

Barlow, J., and J. Johnson. 2007. "Breast Cancer and the Environment Research Centers Early Life Exposure to Phenols and Breast Cancer Risk in Later Year-Fact Sheet on Phenols." BCERC Community Outreach and Translation Cores, USA, pp. 9-20. Available at: http:// www.bcerc.org/COTCpubs/BCERC.FactSheets_all.pdf.

Benitez, F. J., J. Beltra-Heredia, J. L. Acero, and F. J. Rubio. 2001. "Oxidation of Several Chlorophenolic Derivatives by UV Irradiation and Hydroxyl Radicals.” Journal Chemical Technological Biotechnology 76:312-20. doi:10.1002/ jctb.384.

Benitez, F. J., J. Beltran-Heredia, J. L. Acero, and F. J. Rubio. 2000. "Contribution of Free Radicals to Chlorophenols Decomposition by Several Advanced Oxidation Processes." Chemosphere 41:1271-7. doi:10.1016/S00456535(99)00536-6.

Benitez, F. J., J. Beltrán-Heredia, J. L. Acero, and F. J. Rubio. 1999. "Chemical Decomposition of 2,4,6Trichlorophenol by Ozone, Fenton's Reagent and UV Radiation." Industrial Engineering Chemical Researcher 38:1341-9. doi:10.1021/ie980441f.

Blum, D., and R. Speece. 1991. "A Database of Chemical Toxicity to Environmental Bacteria and Its Use in Interspecies Comparisons and Correlations." Water Poll Control Federal 63:198-207.

Buser, M. C., H. E. Murray, and F. Scinicariello. 2014. "Association of Urinary Phenols with Increased Body Weight Measures and Obesity in Children and Adolescents." The Journal of Pediatrics 165 (4):744-9. doi:10.1016/j.jpeds.2014.06.039.

Cesaro, A., V. Naddeo, and V. Beigiorno. 2013. "Wastewater Treatment by Combination of Advanced Oxidation Processes and Conventional Biological Systems." Journal of Bioremediation \& Biodegradation 4:8.
Contreras, S., M. Rodríguez, F. Al-Momani, C. Sans, and S. Esplugas. 2003. "Contribution of the Ozonation PreTreatment to the Biodegradation of Aqueous Solutions of 2,4-Dichlorophenol." Water Research 37:3164-71. doi:10.1016/S0043-1354(03)00167-2.

Dantas, R. F., S. Contreras, C. Sans, and S. Esplugas. 2008. "Abatement of 4-Chlorophenol in Aqueous Phase by Ozonation Coupled with a Sequencing Batch Biofilm Reactor (SBBR)." Ozone: Science \& Engineering 30 (6):447-55. doi:10.1080/01919510802488037.

Esplugas, S., J. Giménez, S. Contreras, E. Pascual, and M. Rodríguez. 2002. "Comparison of Different Advanced Oxidation Processes for Phenol Degradation." Water Research 36:1034-42. doi:10.1016/S0043-1354(01)00301-3.

Essam, T., M. A. Amin, O. E. Tayeb, B. O. Mattiasson, and B. Guieysse. 2007. "Sequential Photochemical-Biological Degradation of Chlorophenols." Chemosphere 66:2201-9. doi:10.1016/j.chemosphere.2006.08.036.

Gilbert, E. 1978. "Chemical Changes and Reaction Products in Ozonization of Organic Water Constituents." In Oxidation Techniques in Drinking Water Treatment, edited by W. Kühn and H. Sontheimer, 232-70. Washington, DC: U.S. Environmental Protection Agency, Office of Drinking Water.

Gilbert, E. 1987. "Biodegradability of Ozonation Products as a Function of COD and DOC Elimination by Example of Substituted Aromatic Substances." Water Research 21 (10):1273-8. doi:10.1016/0043-1354(87)90180-1.

Goel, M., J.-M. Chovelon, C. Ferronato, T. R. Bayard, and T. R. Sreekrishnan. 2010. "The Remediation of Wastewater Containing 4-Chlorophenol Using Integrated Photocatalytic and Biological Treatment." Journal of Photochemistry and Photobiology B: Biology 98 (1):1-6. doi:10.1016/j.jphotobiol.2009.09.006.

Gurol, M. D., and R. Vatistas. 1987. "Oxidation of Phenolic Compounds by Ozone and Ozone+UV Radiation: A Comparative Study." Water Research 21 (8):895-900. doi:10.1016/S0043-1354(87)80006-4.

He, D., X. Guan, J. Ma, X. Yang, and C. Cui. 2010. "Influence of Humic Acids of Different Origins on Oxidation of Phenol and Chlorophenols by Permanganate." Journal of Hazardous Materials 182:681-8. doi:10.1016/j. jhazmat.2010.06.086.

HSDB. 08 20, 2009. "Bethesda (MD): National Library of Medicine (US)- Toxicology Data Network". Accessed March 10, 2015. http://toxnet.nlm.nih.gov/cgi-bin/sis/ search2/f?./temp/ DAdyZf:1

Ingols, R. S., P. E. Gaffney, and P. C. Stevenson. 1966. "Biological Activity of Halophenols." Journal Water Pollution Control Federal 38 (4):629-35.

Ioannou, L. A., G. Li Puma, and D. Fatta-Kassinos. 2015. "Treatment of Winery Wastewater by Physicochemical, Biological and Advanced Processes: A Review." Journal of Hazardous Materials 286:343-68. doi:10.1016/j. jhazmat.2014.12.043.

ISO8192. 2007. "International Organization for Standarization. Water Quality-Test for Inhibition of Oxygen Consumption by Activated Sludge for Carbonaceous and Ammonium Oxidation.” Geneva, Switzerland: International Organization for Standardization (ISO).

Jerschow, E., Parikh, P., McGinn, A. P., de Vos, G., Jariwala, S., Hudes, G., and Rosenstreich, D. 2012. Dichlorophenol- 
Containing Pesticides and Allergies: Results from the US National Health and Nutrition Examination Survey 2005-2006. Annals of Allergy, Asthma \& Immunology 109 (6):420-5. doi:10.1016/j.anai.2012.09.005.

Karci, A., I. Arslan-Alaton, T. Olmez-Hanci, and M. Bekbolet. 2012. "Transformation of 2,4-Dichlorophenol by $\mathrm{H} 2 \mathrm{O} 2 / \mathrm{UV}-\mathrm{C}$, Fenton and Photo-Fenton Processes: Oxidation Products and Toxicity Evolution." Journal of Photochemistry and Photobiology A: Chemistry 230:65-73. doi:10.1016/j.jphotochem.2012.01.003.

Kuo, C. H., and C. H. Huang. 1995. "Aqueous Phase Ozonation of Chlorophenols." Journal of Hazardous Materials 41:31-45. doi:10.1016/0304-3894(94)00096-Y.

Lamsal, R., M. E. Walsh, and G. A. Gagnon. 2011. "Comparison of Advanced Oxidation Processes for the Removal of Natural Organic Matter." Water Research 45:3263-9. doi:10.1016/j.watres.2011.03.038.

Mokrini, A., D. Ousse, and S. Esplugas. 1997. "Oxidation of Aromatic Compounds with UV Radiation/Ozone/ Hydrogen Peroxide." Water Science and Technology 35 (4):95-102. doi:10.1016/S0273-1223(97)00014-0.

Ngo, Q., L. Dao, E. Grigoriev, and A. Petukhov. 2015. “The Ozonation of Extremely Polluted Petrochemical Wastewater: Effect of Catalysts, Initial Ph, Volumetric Flow Rate and Concentration of Ozone on Oxidation Rate." Journal Bio \& Env Sciences 6 (1):587-98.

Nilvebrant, N., and M. B. Jansson. 2005. Hydroxyl Radical Formation during Hydrogen Peroxide Bleaching. Category 2, Cluster Research Program of Chemical Pulp-Fibre Line. Stockholm, Sweden: STFI-Packforsk.

OECD. Organisation for Economic Co-operation and Developmen. 2004. The 2004 OECD List of High Production Volume Chemicals. Paris, France: Environment Directorate organisation for economic co-operation and development.

OECD. 2010. Test No. 209: Activated Sludge, Respiration Inhibition Test (Carbon and Ammonium Oxidation), OECD Guidelines for the Testing of Chemicals, Section 2. Paris, France: OECD Publishing. doi: http://dx.doi.org/ 10.1787/9789264070080-en

Pera-Titus, M., V. García-Molina, M. A. Baños, J. Giménez, and S. Esplugas. 2004. "Degradation of Chlorophenols by Means of Advanced Oxidation Processes: A General Review." Applied Catalysis B: Environmental 47:219-56. doi:10.1016/j.apcatb.2003.09.010.

Philippat, C., et al. 2012. Exposure to Phthalates and Phenols during Pregnancy and Offspring Size at Birth. Environmental Health Perspectives 120 (3):464-70. doi:10.1289/ehp.1103634.

Poznyak, T., and J. Vivero. 2005. "Degradation of Aqueous Phenol and Chlorinated Phenols by Ozone." Ozone: Science \& Engineering 27 (6):447-58. doi:10.1080/ 01919510500351529.

Qiu, Y., C.-H. Kuo, M. E. Zappi, and E. C. Fleming. 2004. "Ozonation of 2,6-, 3,4- and 3,5-Dichlorophenol Isomers within Aqueous Solutions." Journal Environment Engineering $130 \quad$ (4):408-16. doi:10.1061/(ASCE)07339372(2004)130:4(408).
Qiu, Y., M. E. Zappi, A. S. C. E. Member, C. Kuo, and E. C. Fleming. 1999. "Kinetic and Mechanistic Study of Ozonation of Three Dichlorophenols in Aqueous Solutions." Journal Environment Engineering 125 (5):441-50. doi:10.1061/ (ASCE)0733-9372(1999)125:5(441).

Ren, S., M. Asce, and P. Frymier. 2003. “Toxicity Estimation of Phenolic Compounds by Bioluminescent Bacterium.” Journal Environment Engineering 129:328-35. doi:10.1061/(ASCE)0733-9372(2003)129:4(328).

Shang, N.-C., Y. Yue-Hwa, M. Hqong-Wen, C.-H. Chang, and M.-L. Liou. 2006. "Toxicity Measurements in Aqueous Solution during Ozonation of Mono-Chlorophenols." Journal of Environmental Management 78 (3):216-22. doi:10.1016/j.jenvman.2005.03.015.

Song-hu, Y., and L. Xiao-hua. 2005. "Comparison Treatment of Various Chlorophenols by Electro-Fenton Method: Relationship between Chlorine Content and Degradation." Journal of Hazardous Materials 118:85-92. doi:10.1016/j.jhazmat.2004.08.025.

Tang, W. Z., and C. P. Huang. 1996. "Effect of Chlorine Content of Chlorinated Phenols on Their Oxidation Kinetics by Fenton's Reagent." Chemosphere 33 (8):162135. doi:10.1016/0045-6535(96)00278-0.

Trapido, M., A. Hirvonen, Y. Veressinina, J. Hentunen, and R. Munter. 1997. "Ozonation, Ozone/UV and UV/ $\mathrm{H}_{2} \mathrm{O}_{2}$ Degradation of Chlorophenols.” Ozone: Science \& Engineering 19 (1):75-96. doi:10.1080/ 01919519708547319.

Wang, Y. 1990. "Methanogenic Degradation of Ozonation Products of Biorefractory or Toxic Aromatic Compounds." Water Research 24 (2):185-90. doi:10.1016/ 0043-1354(90)90101-B.

Wang, Y. T., P. C. Pai, and J. C. Latchaw. 1989. "Effects of Preozonation on the Methanogenic Toxicity of 2,5-DCP." Journal Water Pollution Control Federal 61:3.

Wei, Y., and J. Zhu. 2015. "Urinary Concentrations of 2,5-Dichlorophenol and Diabetes in US Adults." Journal of Exposure Science and Environmental Epidemiology 1-5. doi:10.1038/jes.2015.19.

Wohlers, J., I. Koh, T. Wolfram, and R. Wolfgang. 2009. "Application of an Air Ionization Device Using an Atmospheric Pressure Corona Discharge Process for Water Purification." Water, Air, and Soil Pollution 196:101-13. doi:10.1007/s11270-008-9760-6.

Yoshioka, Y., H. Nagase, Y. Ose, and T. Sato. 1986. "Evaluation of the Test Method "Activated Sludge, Respiration Inhibition Test" Proposed by the OECD." Ecotoxicology and Environmental Safety 12:206-12. doi:10.1016/0147-6513(86)90012-6.

Young, K., W.-J. Su, and Y.-S. Shen. 1996. "Decomposition of Phenols in Aqueous Solution by UV/O3 Process." Ozone Sciences \& Engineering 18:443/460.

Zhong, W., D. Wang, and X. Xu. 2012. "Phenol Removal Efficiencies of Sewage Treatment Processes and Ecological Risks Associated with Phenols in Effluents." Journal of Hazardous Materials $217 \quad$ (218):286-92. doi:10.1016/j. jhazmat.2012.03.026. 